\title{
INVESTIGATION ON MEMBRANE FOULING IN ULTRAFILTRATION OF LATEX SOLUTION
}

\author{
By \\ Amira Abdelrasoul \\ M.Sc., Chemical Engineering, Kuwait University, Kuwait, 2008 \\ B.Sc., Chemical Engineering, Alexandria University, Egypt, 2000
}

A dissertation presented to Ryerson University

\author{
in partial fulfillment of the \\ requirements for the degree of \\ Doctor of Philosophy \\ in the Program of \\ Chemical Engineering
}

Toronto, Ontario, Canada, 2015

(C)Amira Abdelrasoul 2015 


\begin{abstract}
AUTHOR'S DECLARATION
I hereby declare that I am the sole author of this dissertation. This is a true copy of the dissertation, including any required final revisions, as accepted by my examiners.

I authorize Ryerson University to lend this dissertation to other institutions or individuals for the purpose of scholarly research.

I further authorize Ryerson University to reproduce this dissertation by photocopying or by other means, in total or in part, at the request of other institutions or individuals for the purpose of scholarly research.

I understand that my dissertation may be made electronically available to the public.
\end{abstract}




\title{
INVESTIGATION ON MEMBRANE FOULING IN ULTRAFILTRATION OF LATEX SOLUTION
}

\author{
Amira Abdelrasoul \\ Doctor of Philosophy, Chemical Engineering, Ryerson University \\ Toronto, Canada, 2015
}

\begin{abstract}
The low-pressure membrane applications are considered to be the most effective and sustainable methods of addressing environmental problems in treating water and wastewater that meets or exceed stringent environmental standards. Nevertheless, membrane fouling is one of the primary operational concerns that is currently hindering a more widespread application of ultrafiltration (UF) with a variety of contaminants. Membrane fouling leads to higher operating costs, higher energy demand, reduced membrane life time, and increased cleaning frequency. As a consequence, an efficient and well-planned UF process is becoming a necessity for consistent and long-term monetary returns. Examining the source and mechanisms of foulant attachment to the membrane's surface is critical when it comes to the research of membrane fouling and its potential practical implementation. A mathematical model was developed in this study in order to predict the amount of fouling based on an analysis of particle attachments. This model was developed using both homogeneous and heterogeneous membranes, with a uniform and nonuniform pore sizes for the UF of simulated latex effluent with a wide range of particle size distribution. The objective of this mathematical model was to effectively identify and address the common shortcomings of previous fouling models, and to account for the existing chemical attachments in membrane fouling. The mathematical model resulting from this study was capable of accurately predicting the mass of fouling retained by the membrane and the increase in transmembrane pressure (TMP). In addition, predictive models of fouling attachments were derived and now form an extensive set of mathematical models necessary for the prediction of membrane fouling at a given operating condition, as well as, the various membrane surface charges.
\end{abstract}

Polycarbonate and Polysulfone flat membranes, with pore sizes of $0.05 \mu \mathrm{m}$ and a molecular weight cut off of 60,000 respectively, were used in the experimental designs under a constant feed flow rate and a cross-flow mode in UF of the simulated latex paint effluent. The TMP 
estimated from the model agreed with the experimentally measured values at different operating conditions, mostly within $5.0-8.0 \%$ error, and up to $13.0 \%$ error for the uniform, and nonuniform pore size membranes, respectively. Furthermore, different types of membranes with a variety of molecular weight cut-off (MWCO) values were tested so as to evaluate the accuracy of the models for a generalized application. In addition, a power consumption model, incorporating fouling attachment as well as chemical and physical factors in membrane fouling, was developed in order to ensure accurate prediction and scale-up. Innovative remediation techniques were likewise developed and applied in order to minimize membrane fouling, enhance the membrane performance, and save energy. Fouling remediation methodologies included the pre-treating of the latex effluent, so as to limit its fouling propensity by using different types of surfactants as cationic and anionic, in addition to the $\mathrm{pH}$ change. The antifouling properties of the membranes were improved through the implementation of the membrane $\mathrm{pH}$ treatment and anionic surfactant treatment. Increasing the ionic strength of latex effluent or enhancing the membrane surface hydrophilicity facilitated a significant increase in the cumulative permeate flux, a substantial decrease in the total mass of fouling, and a noticeable decrease in the specific power consumption. 


\section{ACKNOWLEDGEMENTS}

I would like to begin by expressing my sincere appreciation and profound gratitude to Dr. Huu Doan for his exceptional supervision, creative guidance, comprehensive attentive feedback, continuous support, and motivational encouragement. In the first year of my degree, he taught me in a professional way how to think independently and critically in my research direction and writing to achieve numerous publications. I would like also to extend my deep appreciation by thanking Dr. Ali Lohi for his valuable help with my research direction, worthy extensive feedback, productive brilliant discussions, invaluable encouragement and support. Working with Dr. Doan \& Dr. Lohi at Ryerson University was an extremely rewarding experience that has contributed to my work as an independent researcher, scholar, and educator. It has given me the real opportunity to learn directly from the kind of teachers and researchers that I aspire to become. Thanks so much for being wonderful and tremendous supervisors for me.

I would also like to extend my deepest gratitude to Dr. Chil-Hung Cheng for his guidance throughout my research, and valuable help in developing my learning processes at the graduate level.

I am also so grateful to have Dr. Xianshe Feng, Department of Chemical Engineering at the University of Waterloo, Dr. Ravi Ravindran, Department of Mechanical Engineering at Ryerson University Dr. Simant Upreti and Dr. Jiangning Wu, Department of Chemical Engineering at Ryerson University in the examining committee, and for taking the time to carefully review my dissertation and for their valuable comments.

I would like also to express my appreciation to Dr. Gideon Wolfaardt and Dr. Alex Dumitrache at the Confocal Laser Microscope Centre, Department of Chemistry and Biology at Ryerson University for their valuable help and guidance. I also want to acknowledge the help of Mr. Qiang Li, the Technical Officer of Scanning electron microscopy (SEM) imaging in the Department of Mechanical and Industrial Engineering at Ryerson University. Also, I would like to offer my appreciation to Dr. Dérick Rousseau, Dr. Renuka Gupta, and Dr. Muhammad Ali Naqvi at the Ryerson University Food Research Lab for their continuous help with my work on the particle size analyzer and Small-angle X-ray scattering (SAXS).

Furthermore, I would like to express my appreciation to all of the faculty members in the Department of Chemical Engineering at Ryerson University, especially, Dr. Simant Upreti, Dr. Farhad Ein-Mozaffari, Dr. Ginette Turcotte, Dr. Jiangning Wu, Dr. Ramdhane Dhib, and Dr. Dae Kun Hwang, for continued their support and encouraging influence during my learning journey at Ryerson University. I would also like to extend my gratitude to everyone at Department of Chemical Engineering at the Ryerson University, including, Mr. Ali Hemmati, Mr. Daniel Boothe, Mr. Tondar Tajrobehkar, Ms. Louise Lichacz, Ms. Alison MacLeod, Ms. Leah Rogan, and Ms. Isabella Fernandes, for the essential facilities and crucial assistance they have provided me throughout my $\mathrm{PhD}$ degree.

I would like also to acknowledge the Natural Science and Engineering Research Council of Canada (NSERC), Ontario Graduate Scholarship (OGS), Queen Elizabeth Scholarship (QEII GSST), and Ryerson Graduate Scholarship for the financial support.

At the personal level, I am indebted to all my family for their love and support.

Thank you for being an invaluable part of my doctoral degree! 


\section{TABLE OF CONTENTS}

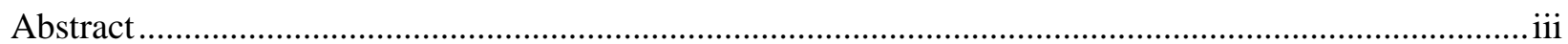

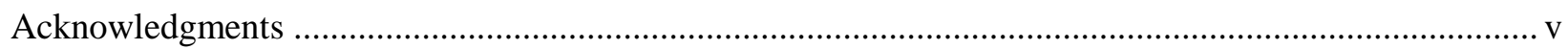

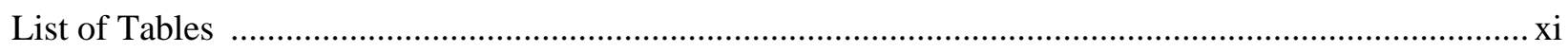

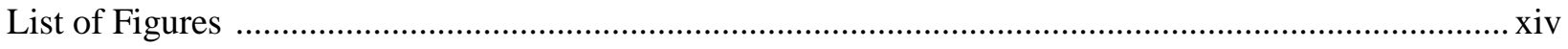

Nomenclature

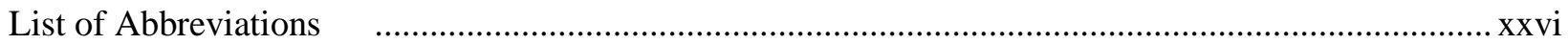

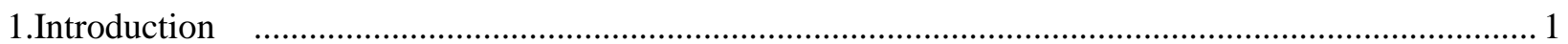

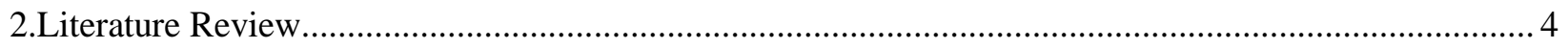

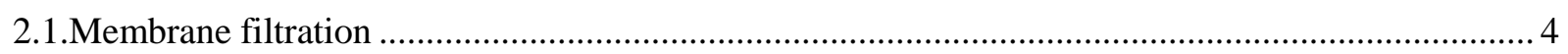

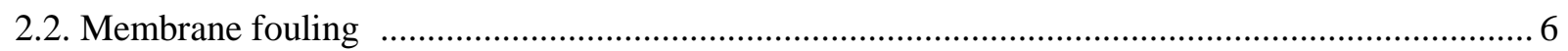

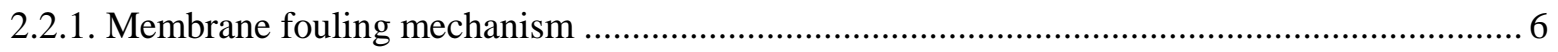

2.2.2. Concentration polarization and mass transfer theory …................................................... 7

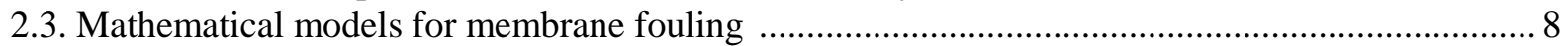

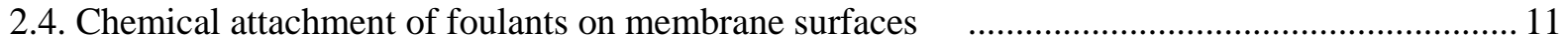

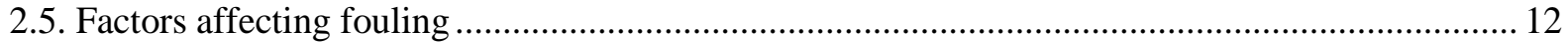

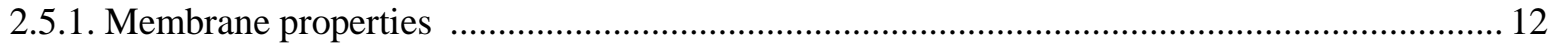

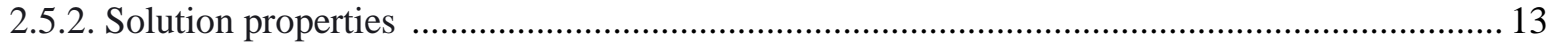

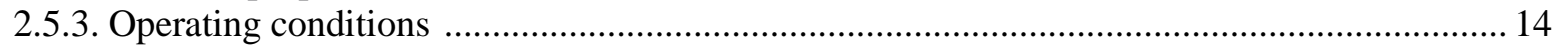

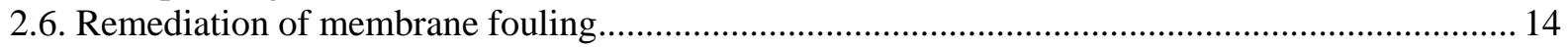

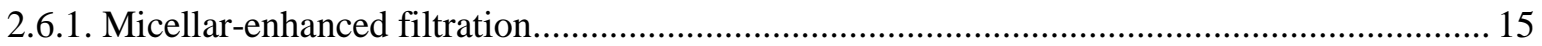

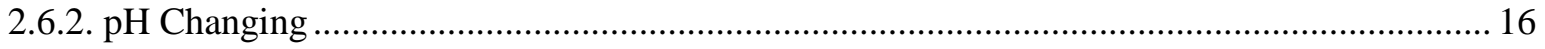

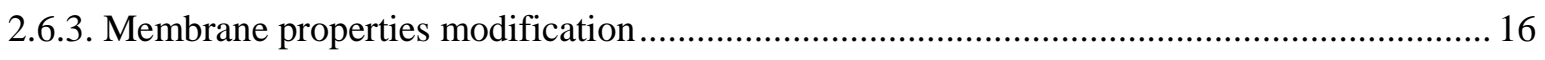

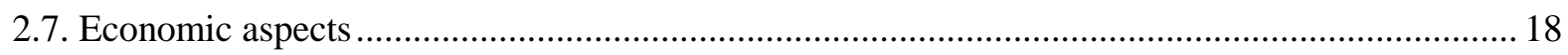

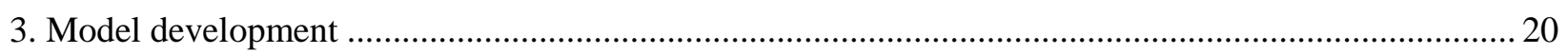

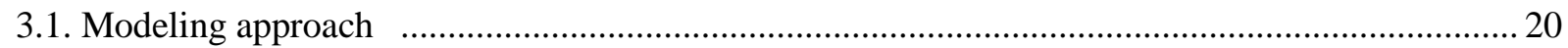

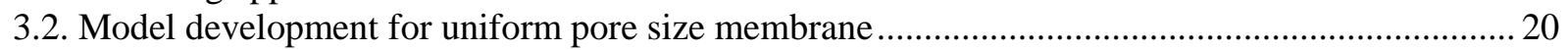

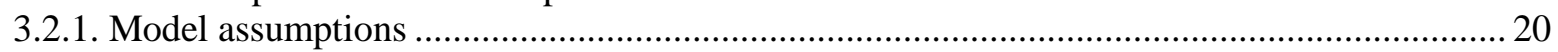

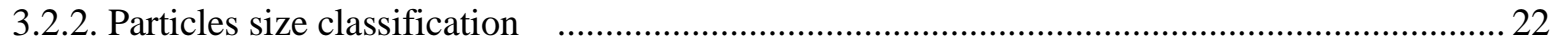

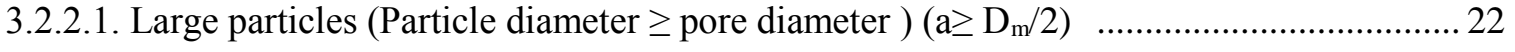

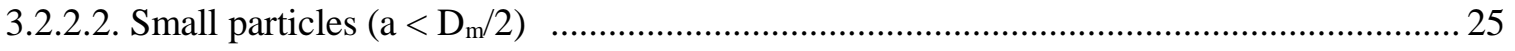

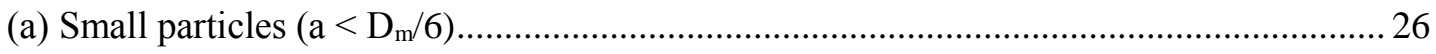

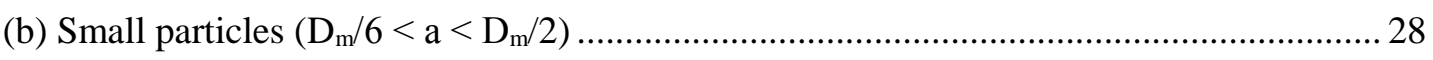

3.2.3. Cake layer formation 


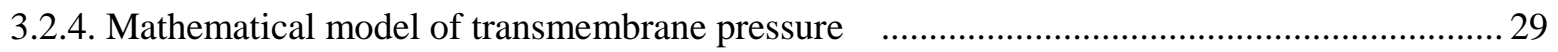

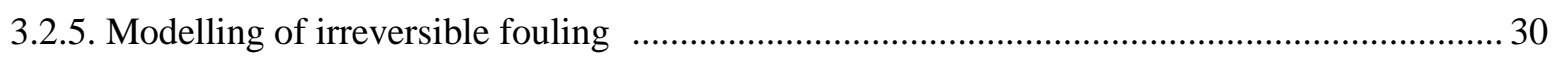

3.3. Modelling development for non-uniform pore size membrane ................................................. 31

3.3.1. Modelling development for non-uniform pore size membrane ........................................... 31

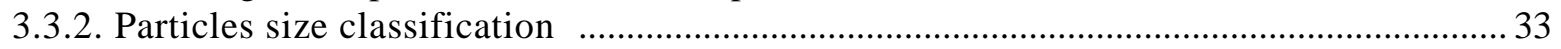

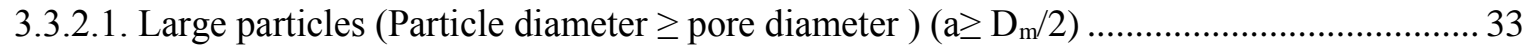

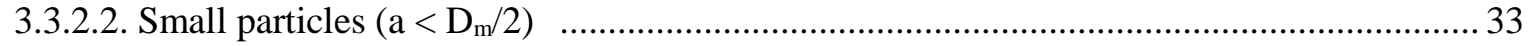

(a) Small particles $\left(a<D_{m} / 6\right)$

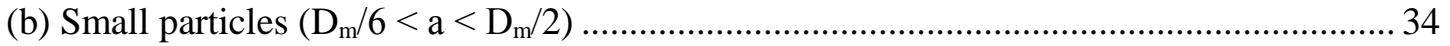

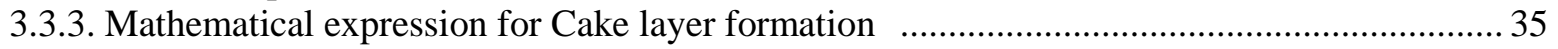

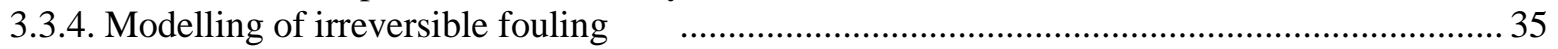

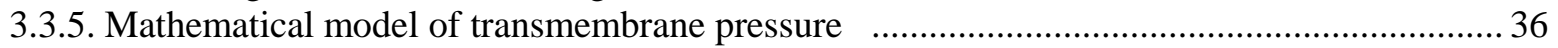

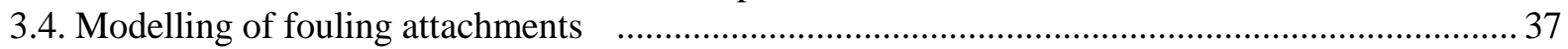

3.5. Attachment model development including sphericity of contaminant particles .......................... 37

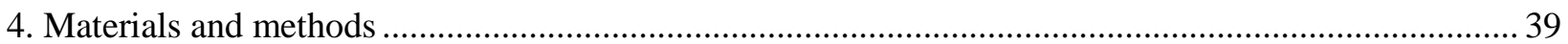

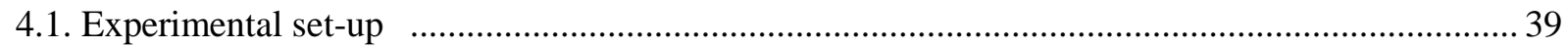

4.2. Ultrafiltration membranes

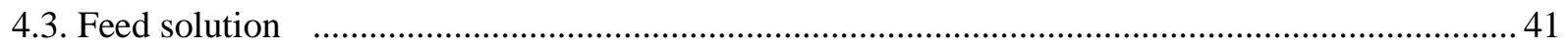

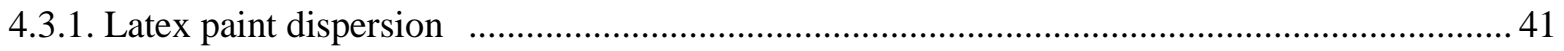

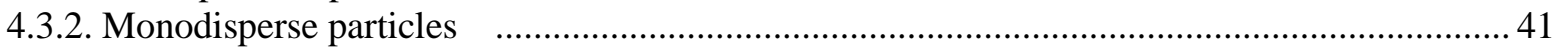

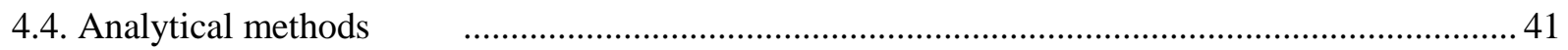

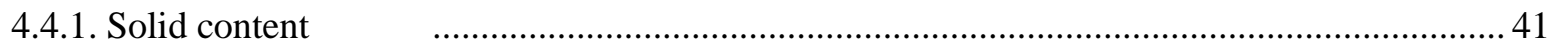

4.4.2. Particle size distribution of latex paint dispersion ........................................................... 41

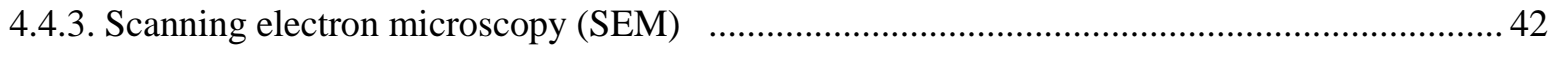

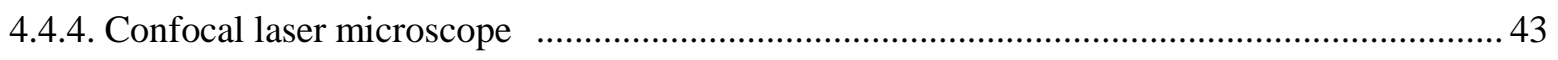

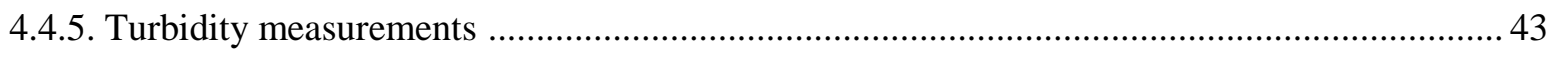

4.4.6 Membrane surface charge measurements (Zeta Potential $\zeta)$.............................................. 43

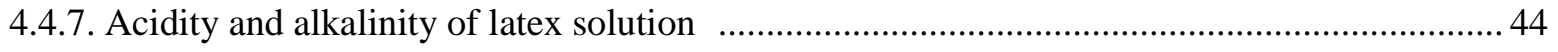

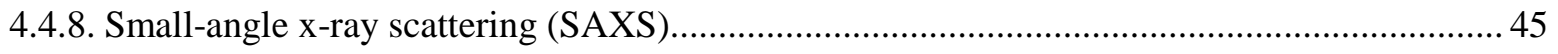

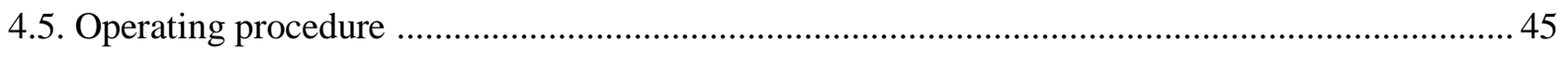

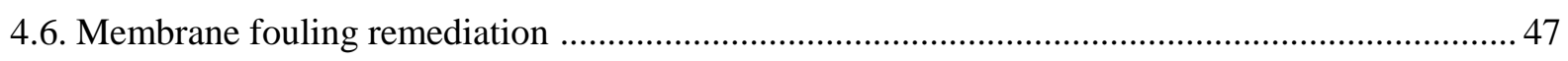

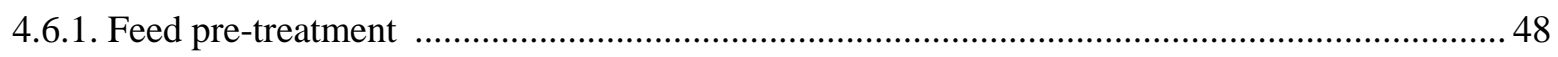

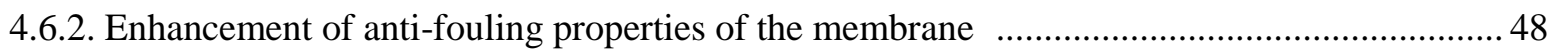

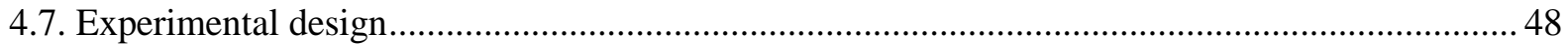

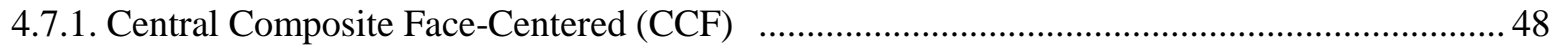

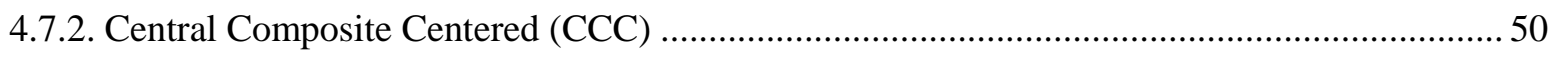

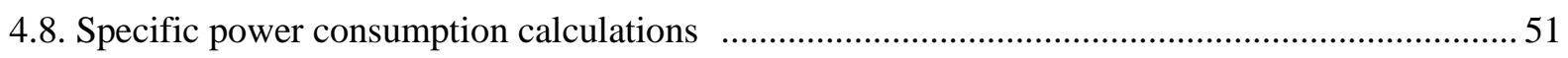

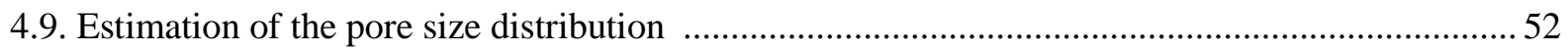

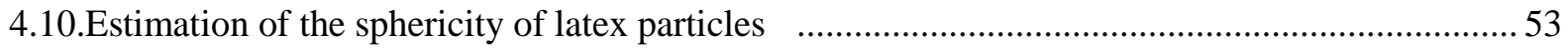


4.10.1. Calculating the sphericity for each particle size range in case of using Polysulfone membrane

4.10.2. Calculating the sphericity for each particle size range in case of using Polycarbonate membrane...

5.Results and discussion .57

5.1. Model prediction .57

5.2. Mathematical model validation. 61

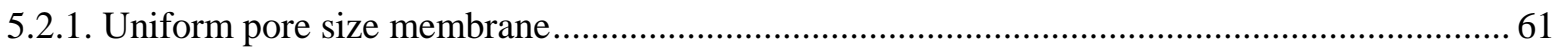

5.2.2. Model validation using heterogeneous membrane with non-uniform pore size ...................... 66

5.2.2.1. Fouling attachment with a non-homogenous pore size membrane ................................... 66

5.2.2.2. Validation of the mathematical model using monodisperse particles ............................. 69

5.2.2.3. Validation of the mathematical model using latex effluent ........................................... 71

5.3. Validation of the developed attachment model including the particle sphericity ........................ 73

5.3.1. Validation of the developed attachment model for homogeneous membrane ......................... 73

5.3.2. Validation of the developed attachment model for heterogeneous membrane ......................... 74

5.4. Effect of operating conditions on fouling attachments, cake layer, cumulative permeate flux, and

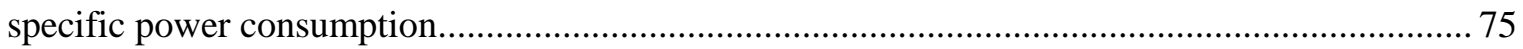

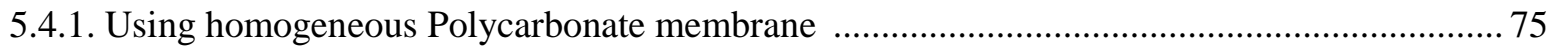

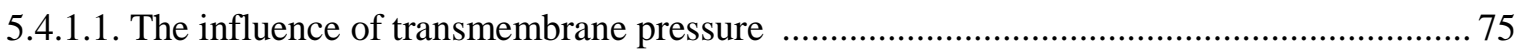

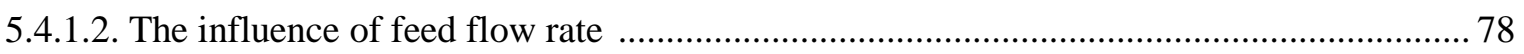

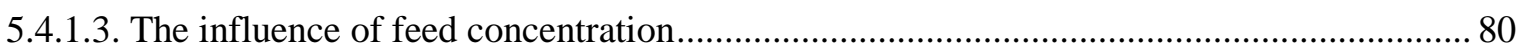

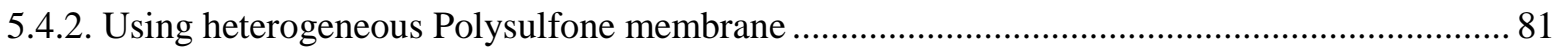

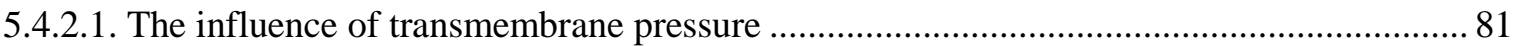

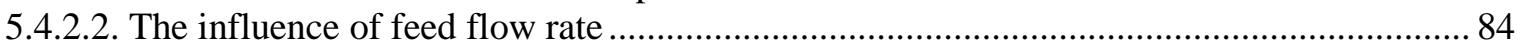

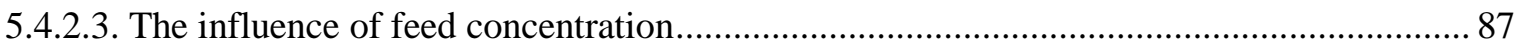

5.5. Effect of membrane pore size distribution on the ultrafiltration performance .............................. 90

5.6. Effect of the zeta potential of membrane surface on membrane fouling ..................................... 93

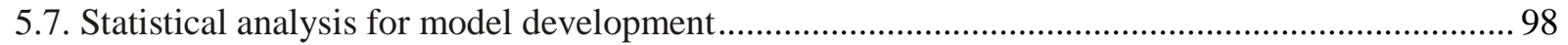

5.7.1. Fouling attachments models using homogeneous Polycarbonate membranes ....................... 98

5.7.2. Power consumption model for homogeneous Polycarbonate membranes ......................... 103

5.7.3. Fouling attachment models using heterogeneous Polysulfone membranes ......................... 105

5.7.3.1. Agreement between actual and predicted fouling attachments using PSU .................... 108

5.7.3.2. Validation of the fouling attachment models with different heterogeneous membranes 109

5.7.4. Fouling attachments models using heterogeneous hydrophilic and hydrophobic membranes

5.7.4.1. Validation of the attachment models with different heterogeneous membranes ..........116

5.7.4.2. Evaluation of the attachment models for hydrophobic heterogeneous membranes ........ 122

5.7.5.Power consumption model for heterogeneous membranes .............................................. 123

5.7.5.1. Validation of the power consumption model with different heterogeneous membranes 
5.7.5.2. Power consumption prediction for practical use in an industrial setting 133

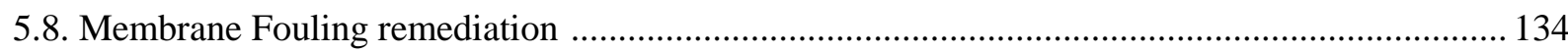

5.8.1. Feed pre-treatment by changing the $\mathrm{pH}$ of latex solution 134

5.8.1.1. Effect of $\mathrm{pH}$ on ionic strength of latex solution and membrane surface hydrophilicity of homogeneous Polycarbonate membrane.

5.8.1.2. Effect of $\mathrm{pH}$ change on membrane fouling and power consumption using a homogeneous Polycarbonate membrane

5.8.1.3. Effect of ionic valence on membrane fouling remediation usin Polycarbonate membrane

5.8.1.4. Effect of pre-treatment of simulated latex effluent by $\mathrm{pH}$ change on filtration using heterogeneous membranes 143

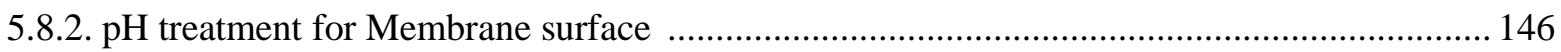

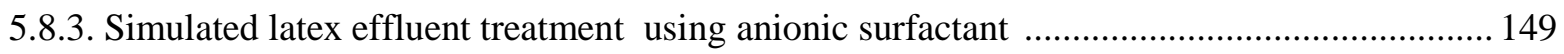

5.8.4. Membrane surface treatment using anionic surfactant .................................................... 152

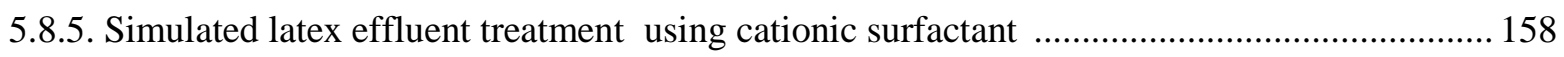

5.8.5.1 CTAB influence on membrane fouling using a homogeneous polycarbonate membrane

5.8.5.2. CTAB influence on membrane fouling using a heterogeneous PS membrane ............... 168

5.8.6.Effect of combined pretreatment of latex solution and membrane surface on ultrafiltration

performance

6. Conclusions and future work

6.1. Conclusions.

6.2. Future work.

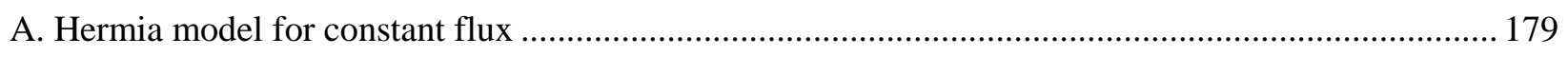

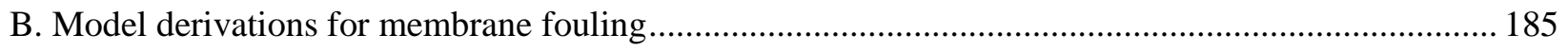

C. Model development for non-uniform pore size membranes …..................................................... 196

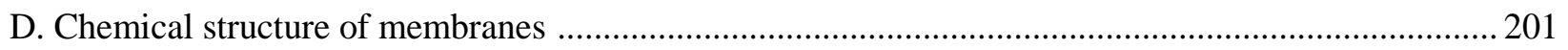

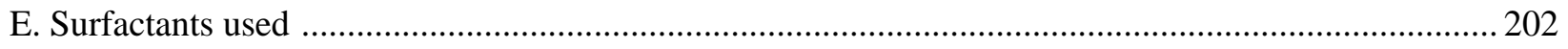

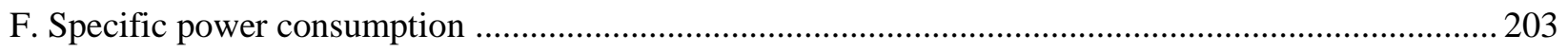

G. Pore size distribution of different non-uniform pore size membranes ............................................2 204

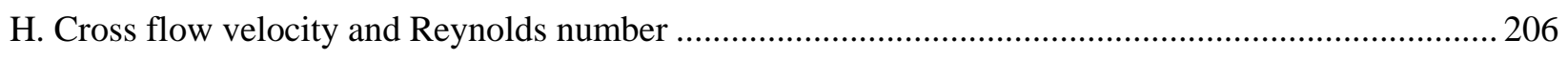

I. Stability of treated membrane surfaces after the ultrafiltration process …........................................ 207 
J. Experimental Reproducibility

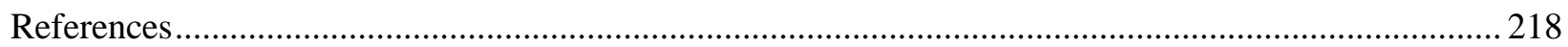




\section{LIST OF TABLES}

\begin{tabular}{|c|c|c|}
\hline No & Table Title & Page \\
\hline 2.1 & Comparison of different types of membranes & 4 \\
\hline 2.2 & Present worth Costs for a 36-mgd Plant with reducing fouling protocols & 19 \\
\hline 4.1 & Performance characteristics of GE uniform Polycarbonate membranes & 40 \\
\hline 4.2 & Process parameter levels & 49 \\
\hline 4.3 & $\begin{array}{l}\text { Process parameter levels in experiments with non-uniform pore size Polysulfone } \\
\text { membrane }\end{array}$ & 51 \\
\hline 5.1 & $\begin{array}{l}\text { Mass of particles retained by Polycarbonate membrane at different operational } \\
\text { conditions }\end{array}$ & 63 \\
\hline 5.2 & $\begin{array}{l}\text { Fouling probabilities predicted at different conditions and comparison of } \\
\text { predicted and experimental transmembrane pressure. }\end{array}$ & 64 \\
\hline 5.3 & $\begin{array}{l}\text { Model validation using Polycarbonate membrane and monondisperse particles } \\
(0.05 \mu \mathrm{m}) \text { at different operating conditions. }\end{array}$ & 66 \\
\hline 5.4 & $\begin{array}{l}\text { Model validation using Polysulfone heterogeneous membrane } \\
\text { monondisperse particles at different operating conditions }\end{array}$ & 70 \\
\hline 5.5 & $\begin{array}{l}\text { Model validation using polysulfone heterogeneous membrane at different } \\
\text { operating conditions using latex effluent }\end{array}$ & 72 \\
\hline 5.6 & $\begin{array}{l}\text { Validation of the attachment model, incorporating the particles sphericity, } \\
\text { applied to the homogeneous Polycarbonate membrane }\end{array}$ & 74 \\
\hline 5.7 & $\begin{array}{l}\text { Validation of the developed attachment model including the particle sphericity } \\
\text { using heterogeneous Polysulfone membranes }\end{array}$ & 75 \\
\hline 5.8 & $\begin{array}{l}\text { Effect of the zeta potential of Ultrafilic membrane at transmembrane pressure of } \\
25 \mathrm{psi} \text {, feed flow rate of } 4 \mathrm{LPM} \text {, feed concentration of } 1.3 \mathrm{~kg} / \mathrm{m}^{3} \text { on fouling } \\
\text { attachments, cumulative filtration volume, total mass of fouling, and the specific } \\
\text { power consumption }\end{array}$ & 96 \\
\hline 5.9 & $\begin{array}{l}\text { Experimental parameters and results based on the experimental design for the } \\
\text { fouling attachment probabilities using homogeneous Polycarbonate membrane }\end{array}$ & 99 \\
\hline 5.10 & Regression coefficients and probability values of statistical analysis & 101 \\
\hline 5.11 & $\begin{array}{l}\text { Agreement of fouling attachments prediction from regression correlations with } \\
\text { actual values for extra experiments out of the range of process parameters }\end{array}$ & 102 \\
\hline 5.12 & $\begin{array}{l}\text { Experimental parameters and results based on the experimental design for the } \\
\text { total mass of fouling and the specific power consumption }\end{array}$ & 103 \\
\hline 5.13 & Regression coefficients and probability values of statistical analysis & 105 \\
\hline 5.14 & $\begin{array}{l}\text { Experimental parameters and results based on the experimental design for the } \\
\text { fouling attachment probabilities }\end{array}$ & 106 \\
\hline 5.15 & Regression coefficients and probability values of statistical analysis & 108 \\
\hline 5.16 & $\begin{array}{l}\text { Agreement of the fouling attachments prediction from regression correlations } \\
\text { with actual values for extra experiments outside of the range of process } \\
\text { parameters }\end{array}$ & 109 \\
\hline
\end{tabular}




\begin{tabular}{|c|c|c|}
\hline 5.17 & $\begin{array}{l}\text { Agreement between the mass of fouling measured experimentally using } \\
\text { different membranes and the mass of fouling predicted using the fouling } \\
\text { attachments estimated from the predictive models }\end{array}$ & 110 \\
\hline 5.18 & $\begin{array}{l}\text { Agreement between the increase in transmembrane pressure measured } \\
\text { experimentally using different membranes and the increase in transmembrane } \\
\text { pressure predicted using the fouling attachments estimated from the predictive } \\
\text { models }\end{array}$ & 110 \\
\hline 5.19 & $\begin{array}{l}\text { xperimental parameters and results based on the experimental design for the } \\
\text { puling attachment probabilities using Polysulfone membrane }\end{array}$ & 113 \\
\hline 5.20 & $\begin{array}{l}\text { Regression coefficients and probability values of statistical analysis using } \\
\text { Polysulfone membrane }\end{array}$ & 115 \\
\hline 5.21 & $\begin{array}{l}\text { Comparison of the mass of fouling measured experimentally and the value } \\
\text { estimated from the predictive models for various membranes }\end{array}$ & 117 \\
\hline 5.22 & $\begin{array}{l}\text { Comparison of the increase in transmembrane pressure measured } \\
\text { experimentally and the value predicted from the predictive models for various } \\
\text { membranes }\end{array}$ & 118 \\
\hline 5.23 & $\begin{array}{l}\text { Comparison of the mass of fouling and the increase in transmembrane pressure } \\
\text { measured experimentally using PVDF hydrophobic membrane and the predicted } \\
\text { values using the fouling attachments estimated from the correlations with and } \\
\text { without the zeta potential influence }\end{array}$ & 122 \\
\hline 5.24 & $\begin{array}{l}\text { perimental parameters and results based on the experimental design for the } \\
\text { ss of fouling and the specific power consumption using Polysulfone } \\
\text { mbrane }\end{array}$ & 124 \\
\hline 5.25 & ents and nrobability & 125 \\
\hline 5.26 & $\begin{array}{l}\text { Power consumption calculated from experimental data and the predicted values } \\
\text { for Polysulfone membranes at different operating conditions and varying } \\
\text { membrane surface charges }\end{array}$ & 127 \\
\hline 5.27 & $\begin{array}{l}\text { Power consumption calculated from on the experimental data and predicted } \\
\text { values for various membranes at different operating conditions }\end{array}$ & 129 \\
\hline 5.28 & $\begin{array}{l}\text { Predicted power consumption using the arbitrarily input cumulative permeate } \\
\text { volume } V_{s} \text { and the power consumption calculated from the experimental } \\
\text { cumulative permeate volume for Polysulfone membranes }\end{array}$ & 133 \\
\hline 5.29 & $\begin{array}{l}\text { Comparison of total mass of fouling, volumetric permeate flux, cake height, and } \\
\text { the power consumption at different } \mathrm{pH} \text {. [TMP }=15 \mathrm{psia}],\left[\mathrm{Cf}=1.3 \mathrm{~kg} / \mathrm{m}^{3}\right] \text {, and } \\
25 \mathrm{~min}\end{array}$ & 140 \\
\hline 5.30 & $\begin{array}{l}\text { Comparison of the effect of the monovalent acid }(\mathrm{HCl}) \text { and the divalent acid } \\
\left(\mathrm{H}_{2} \mathrm{SO}_{4}\right) \text { at } \mathrm{pH} 3 \text { and } 5 \text { at transmembrane pressure } 15 \mathrm{psia}, 4 \mathrm{LPM} \text { and } 1.3 \mathrm{~kg} / \mathrm{m}^{3}\end{array}$ & 142 \\
\hline 5.31 & $\begin{array}{l}\text { Zeta potential of latex particles and latex solution conductivity at different LAS } \\
\text { concentrations, and the zeta potential of membrane surfaces after the } \\
\text { ultrafiltration process (After } 15 \text { minutes of LAS addition) }\end{array}$ & 150 \\
\hline 5.32 & $\begin{array}{l}\text { Zeta potential of latex particles and latex solution conductivity at various time } \\
\text { treatments at LAS concentration of } 0.0001 \mathrm{~g} / \mathrm{L} \text { and } 0.1 \mathrm{~g} / \mathrm{L}\end{array}$ & 151 \\
\hline 5.33 & $\begin{array}{l}\text { Fouling attachments, membrane fouling, increase in transmembrane pressure, } \\
\text { and irreversible fouling at different operating conditions using the untreated }\end{array}$ & 166 \\
\hline
\end{tabular}




\begin{tabular}{|c|l|c|} 
& latex solution and Polycarbonate membrane & \\
\hline 5.34 & $\begin{array}{l}\text { Fouling attachments, membrane fouling, increase in transmembrane pressure, } \\
\text { and irreversible fouling at different operating conditions using the treated latex } \\
\text { solution with CTAB at CMC and Polycarbonate membrane }\end{array}$ & 166 \\
\hline 5.35 & $\begin{array}{l}\text { Fouling attachments, membrane fouling, increase in transmembrane pressure, } \\
\text { and irreversible fouling at different operating conditions using Polysulfone } \\
\text { membrane and untreated and treated latex solutions }\end{array}$ & 169 \\
\hline 5.36 & $\begin{array}{l}\text { Results obtained from different remediation techniques using PVDF membranes } \\
\text { at the feed flow rate of 4 LPM, feed concentration of 0.78 kg/m }{ }^{3}, \text { and } \\
\text { transmembrane pressure of 15 psia }\end{array}$ & 170 \\
\hline A.1 & Values of k and n in the generalized Hermia model for constant flux & 184 \\
\hline E.1 & Surfactants tested for fouling remediation in ultrafiltration of latex solution & 202 \\
\hline H.1 & Cross flow velocity \& Reynolds Number of various feed flow rates & 206 \\
\hline J.1 & $\begin{array}{l}\text { Model validation errors for the Polycarbonate membrane at different operating } \\
\text { conditions using simulated latex effluent }\end{array}$ & 210 \\
\hline J.2 & $\begin{array}{l}\text { Model validation errors using Polysulfone heterogeneous membrane at different } \\
\text { operating conditions using latex effluent }\end{array}$ & 211 \\
\hline J.3 & $\begin{array}{l}\text { Validation errors of the Attachment Models with different Heterogeneous } \\
\text { Membranes }\end{array}$ & 212 \\
\hline J.4 & $\begin{array}{l}\text { Validation errors of the attachment model, incorporating the particles sphericity, } \\
\text { applied to the homogeneous Polycarbonate membrane }\end{array}$ & 214 \\
\hline J.5 & $\begin{array}{l}\text { Validation errors of the attachment model, incorporating the particles sphericity, } \\
\text { applied to the heterogeneous Polysulfone membrane }\end{array}$ & 216 \\
\hline
\end{tabular}




\section{LIST OF FIGURES}

\begin{tabular}{|c|c|c|}
\hline $\begin{array}{c}\text { Figure } \\
\text { no }\end{array}$ & Figure Title & Page \\
\hline 2.1 & Illustration of Dead-End and Cross-flow modes of Ultrafiltration & 5 \\
\hline 2.2 & A Schematic presentation of the three stages in flux decline & 6 \\
\hline 2.3 & $\begin{array}{l}\text { Illustration of the formation of a gel layer of colloidal material on the } \\
\text { surface of an ultrafiltration membrane by concentration polarization }\end{array}$ & 7 \\
\hline 2.4 & Schematic diagram of membrane fouling modes proposed by Hermia & 10 \\
\hline 2.5 & Interaction between 2 microscopic bodies 1 and 2 through medium & 12 \\
\hline 2.6 & (a) Hydrophilic membrane, (b) Hydrophobic membrane & 13 \\
\hline 2.7 & $\begin{array}{l}\text { Illustration of (A) Surfactant molecule (b) micelle composed of a number } \\
\text { of surfactant molecules. }\end{array}$ & 15 \\
\hline 3.1 & $\begin{array}{l}\text { A Diagram of UF Membrane Fouling by Colloidal Particles Larger than the } \\
\text { Membrane Pore Size. }\end{array}$ & 23 \\
\hline 3.2 & Irreversible cake fouling after backwash & 25 \\
\hline 3.3 & $\begin{array}{l}\text { A diagram of UF membrane fouling by particles smaller than the } \\
\text { membrane pore size. }\end{array}$ & 26 \\
\hline 3.4 & Schematic View of Cylindrical Membrane Pore & 27 \\
\hline 3.5 & $\begin{array}{l}\text { Illustration of all the mechanisms of particles attachments with non- } \\
\text { homogenous pore size distribution using ImageJ software }\end{array}$ & 32 \\
\hline 3.6 & Sphericity of particles & 38 \\
\hline 4.1 & Schematic diagram of experimental set & 40 \\
\hline 4.2 & Top view of membrane unit & 40 \\
\hline 4.3 & Particles size distribution of fees samples at different concentrations & 42 \\
\hline 4.4 & SEM image of clean Polycarbonate membrane $0.1 \mu \mathrm{m}$, gold-coated & 42 \\
\hline 4.5 & $\begin{array}{l}\text { Confocal laser microscope image of Polysulfone membrane layers after } \\
\text { ultrafiltration process using fluospheres carboxylate latex beads }\end{array}$ & 43 \\
\hline 4.6 & $\begin{array}{l}\text { The SEM images of membrane surface after ultrafiltration: (a) before the } \\
\text { cake layer was scratched off; (b) after the cake layer was scratched off for } \\
\text { the mass of fouling contributed to }\left(m_{p}\right) \text {; (c) after scratched off the cake } \\
\text { layer at a higher magnification of } 500\end{array}$ & 47 \\
\hline 4.7 & Area under the curve represents $\overline{\mathrm{TMP}}_{A V G}$ & 51 \\
\hline 4.8 & $\begin{array}{l}\text { Estimation of the pore size distribution of the polysulfone membrane } \\
\text { (a) SEM image 2D applied to the software } \\
\text { (b) SEM image of the exact pores obtained using the software }\end{array}$ & 52 \\
\hline 4.9 & The pore size distribution estimated using the software & 53 \\
\hline 4.10 & Estimation of the latex particles' sphericity using ImageJ software & 54 \\
\hline
\end{tabular}




\begin{tabular}{|c|c|c|}
\hline 4.11 & $\begin{array}{l}\text { The diameters of the smallest and largest circumscribed circles around latex } \\
\text { particle used for sphericity estimation }\end{array}$ & 54 \\
\hline 4.12 & $\begin{array}{l}\text { The particle size distribution of simulated latex effluent with a solid } \\
\text { concentration of } 1.3 \mathrm{~kg} / \mathrm{m}^{3}\end{array}$ & 55 \\
\hline 4.13 & $\begin{array}{l}\text { Sphericity of latex particles for each } d_{\text {mean }} \text { in filtration with Polysulfone } \\
\text { membrane }\end{array}$ & 55 \\
\hline 4.14 & $\begin{array}{l}\text { Sphericity of latex particles for each } \mathrm{d}_{\text {mean }} \text { in filtration with Polycarbonate } \\
\text { membrane }\end{array}$ & 56 \\
\hline 5.1 & Effect of depositional attachment probability on transmembrane pressure & 58 \\
\hline 5.2 & Effect of coagulation attachment probability on transmembrane pressure & 59 \\
\hline 5.3 & $\begin{array}{l}\text { Effect of depositional attachment probability on solid retained by } \\
\text { membrane at different feed solid concentrations }\end{array}$ & 60 \\
\hline 5.4 & $\begin{array}{l}\text { Effect of depositional fouling probability on solid retained by the } \\
\text { membrane at different volumetric permeate fluxes. }\end{array}$ & 60 \\
\hline 5.5 & $\begin{array}{l}\text { Effect of coagulation fouling probability on solid retained by membrane at } \\
\text { different feed solid concentrations. }\end{array}$ & 61 \\
\hline 5.6 & $\begin{array}{l}\text { SEM images of membrane (a) Blocked pore before backwash (b) Cleaned } \\
\text { pores after backwash }\end{array}$ & 63 \\
\hline 5.7 & $\begin{array}{l}\text { SEM images of membrane after ultrafiltration: (a) feed flow rate }=1 \mathrm{~L} / \mathrm{m} \text {; } \\
\text { (b) feed flow rate }=3 \mathrm{~L} / \mathrm{m} \text { [feed solid concentration }=1.3 \mathrm{~kg} / \mathrm{m}^{3} \text {, same } \\
\text { pressure and filtration time for both cases] }\end{array}$ & 65 \\
\hline 5.8 & SEM images of large particles attached to Polysulfone membrane pores & 66 \\
\hline 5.9 & SEM images of small particles attached to Polysulfone membrane pores & 67 \\
\hline 5.10 & $\begin{array}{l}\text { SEM image of latex particles contributing to the cake layer formation on } \\
\text { Polysulfone membrane }\end{array}$ & 68 \\
\hline 5.11 & SEM image of clean pores in Polysulfone membrane after ultrafiltration & 68 \\
\hline 5.12 & SEM image of particles attached to Polysulfone membrane surface & 69 \\
\hline 5.13 & $\begin{array}{l}\text { SEM images after ultrfiltration using monodisperse particles of } 0.05 \mu \mathrm{m} \text { (a) } \\
\text {, (b) using polysulfone membrane with non-uniform pore sizes, (c) using } \\
\text { polycarbonate membrane with uniform pore size of } 0.05 \mu \mathrm{m}\end{array}$ & 71 \\
\hline 5.14 & $\begin{array}{l}\text { SEM images of polysulfone membrane (a) Blocked pore before backwash } \\
\text { (b) Cleaned pores after backwash }\end{array}$ & 73 \\
\hline 5.15 & $\begin{array}{l}\text { Effect of initial transmembrane pressure at }[\mathrm{Q}=4 \mathrm{LPM}],\left[\mathrm{C}_{\mathrm{f}}=1.3 \mathrm{~kg} / \mathrm{m}^{3}\right] \\
{[\mathrm{pH}=7] \text { on }(\mathrm{a}) \text { Fouling attachment probabilities }\left(\alpha_{\mathrm{pp}}, \alpha_{\mathrm{pm}}\right) \text { and the }} \\
\text { volumetric permeate flux }\left(V_{s}\right) \text { (b) Mass of fouling and specific power } \\
\text { consumption. }\end{array}$ & 77 \\
\hline
\end{tabular}




\begin{tabular}{|c|c|c|}
\hline 5.16 & $\begin{array}{l}\text { SEM images of membrane after ultrafiltration }[\mathrm{Q}=4 \mathrm{LPM}],\left[\mathrm{C}_{\mathrm{f}}=1.3 \mathrm{~kg} / \mathrm{m}^{3}\right] \\
\text { (a) Cake height } 5.05 \mu \mathrm{m} \text { at pressure } 15 \text { psia (b) Cake height } 8.55 \mu \mathrm{m} \text { at } \\
\text { pressure } 35 \text { psia }\end{array}$ & 77 \\
\hline 5.17 & $\begin{array}{l}\text { SEM image of membrane after UF at } 45 \text { psia, } 4 \mathrm{LPM} \text { and } 1.3 \mathrm{~kg} / \mathrm{m}^{3} \\
\text { (Cake height } 7.9 \mu \mathrm{m})\end{array}$ & 77 \\
\hline 5.18 & $\begin{array}{l}\text { Effect of feed flow rate at [TMP }=15 \mathrm{psia}],\left[\mathrm{C}_{\mathrm{f}}=1.3 \mathrm{~kg} / \mathrm{m}^{3}\right] \text {, and }[\mathrm{pH}=7] \text { on } \\
\text { (a) fouling attachment probabilities }\left(\alpha_{\mathrm{pp}}, \alpha_{\mathrm{pm}}\right) \text { and the volumetric permeate } \\
\text { flux }\left(V_{s}\right) \text { (b) Mass of fouling and power consumption }\end{array}$ & 79 \\
\hline 5.19 & $\begin{array}{l}\text { SEM images of membrane after ultrafiltration }[\mathrm{P}=15 \mathrm{psia}],\left[\mathrm{C}_{\mathrm{f}}=1.3 \mathrm{~kg} / \mathrm{m}^{3}\right] \\
\text { (a) Cake height } 13.8 \mu \mathrm{m} \text { at feed flow rate } 1 \mathrm{LPM} \\
\text { (b) Cake height } 2.4 \mu \mathrm{m} \text { at feed flow rate } 6 \mathrm{LPM}\end{array}$ & 79 \\
\hline 5.20 & $\begin{array}{l}\text { Effect of feed concentration at }[\mathrm{Q}=1 \mathrm{LPM}],[\mathrm{TMP}=15 \mathrm{psia}] \text {, and }[\mathrm{pH}=7] \\
\text { on (a) Fouling attachment probabilities }\left(\alpha_{\mathrm{pp}}, \alpha_{\mathrm{pm}}\right) \text { and the volumetric } \\
\text { permeate flux }\left(V_{s}\right),(\mathrm{b}) \text { Mass of fouling and power consumption }\end{array}$ & 81 \\
\hline 5.21 & $\begin{array}{l}\text { SEM images of membrane after ultrafiltration }[\mathrm{Q}=1 \mathrm{LPM}],[\mathrm{P}=15 \mathrm{psia}] \\
\text { (a) Cake height } 4.3 \mu \mathrm{m} \text { at feed concentration } 0.78 \mathrm{~kg} / \mathrm{m}^{3} \\
\text { (b) Cake height } 18.5 \mu \mathrm{m} \text { at feed concentration } 1.82 \mathrm{~kg} / \mathrm{m}^{3}\end{array}$ & 81 \\
\hline 5.22 & $\begin{array}{l}\text { Effect of initial transmembrane pressure at }[\mathrm{Q}=4.00 \mathrm{LPM}] \text { and }\left[\mathrm{C}_{\mathrm{f}}=1.30\right. \\
\left.\mathrm{kg} / \mathrm{m}^{3}\right] \text { on }(\mathrm{a}) \text { fouling attachment probabilities }\left(\alpha_{\mathrm{pp}}, \alpha_{\mathrm{pm}}\right) \text { and the volumetric } \\
\text { permeate flux }\left(V_{s}\right)(\mathrm{b}) \text { the total Mass of fouling and specific power } \\
\text { consumption using untreated Polysulfone membranes with surface charge } \\
\text { of }-42.40 \mathrm{mV}\end{array}$ & 83 \\
\hline 5.23 & $\begin{array}{l}\text { SEM images of Polysulfone membrane after ultrafiltration at the feed flow } \\
\text { rate of } 4 \text { LPM , and feed concentration of } 1.3 \mathrm{~kg} / \mathrm{m}^{3} \text { at (a) transmembrane } \\
\text { pressure of } 35 \mathrm{psi} \text {; (b) transmembrane of } 45 \mathrm{psi}\end{array}$ & 84 \\
\hline 5.24 & $\begin{array}{l}\text { Effect of feed flow rate at }[\mathrm{TMP}=25.00 \mathrm{psia}] \text {, and }\left[\mathrm{C}_{\mathrm{f}}=1.30 \mathrm{~kg} / \mathrm{m}^{3}\right] \text { on (a) } \\
\text { fouling attachment probabilities }\left(\alpha_{\mathrm{pp}}, \alpha_{\mathrm{pm}}\right) \text { and the volumetric permeate flux } \\
\left(V_{s}\right) ;(\mathrm{b}) \text { the total Mass of fouling and power consumption using untreated } \\
\text { Polysulfone membranes with surface charge of }-42.40 \mathrm{mV}\end{array}$ & 86 \\
\hline 5.25 & $\begin{array}{l}\text { SEM images of Polysulfone membrane after ultrafiltration at } \\
\text { transmembrane pressure of } 25 \mathrm{psi} \text {, and feed concentration of } 1.3 \mathrm{~kg} / \mathrm{m}^{3} \text { (a) } \\
\text { Membrane surface at feed flow rate of } 7 \mathrm{LPM} \text {, (b) Cake layer at feed flow } \\
\text { rate of } 7 \mathrm{LPM} \text {, and (c) Cake layer at feed flow rate of } 1 \mathrm{LPM}\end{array}$ & 86 \\
\hline 5.26 & $\begin{array}{l}\text { Confocal laser microscope image of Polysulfone membrane layers after } \\
\text { ultrafiltration process using fluospheres carboxylate latex beads }\end{array}$ & 87 \\
\hline 5.27 & $\begin{array}{l}\text { Effect of feed concentration at }[\mathrm{Q}=4.00 \mathrm{LPM}] \text { and }[\mathrm{TMP}=25.00 \text { psia] on } \\
\text { (a) on the fouling attachment probabilities }\left(\alpha_{\mathrm{pp}}, \alpha_{\mathrm{pm}}\right) \text { and the volumetric } \\
\text { permeate flux }\left(V_{s}\right)(\mathrm{b}) \text { the total mass of fouling and the power consumption } \\
\text { using untreated Polysulfone membranes with surface charge of }-42.40 \mathrm{mV}\end{array}$ & 88 \\
\hline 5.28 & $\begin{array}{l}\text { SEM images of the membrane after ultrafiltration at [Q=4 LPM], [P=25 } \\
\text { psi]: (a) Membrane surface at feed concentration } 0.78 \mathrm{~kg} / \mathrm{m}^{3} ; \text { (b) Side view } \\
\text { of the cake height at feed concentration } 0.78 \mathrm{~kg} / \mathrm{m}^{3} ; \text { (c) Membrane surface } \\
\text { at feed concentration } 1.3 \mathrm{~kg} / \mathrm{m}^{3} ; \text { (d) Side view of the cake height at feed } \\
\text { concentration } 1.3 \mathrm{~kg} / \mathrm{m}^{3} ; \text { (e) Membrane surface at feed concentration } 1.82 \\
\mathrm{~kg} / \mathrm{m}^{3} \text {; (f) Side view of the cake height at feed concentration } 1.82 \mathrm{~kg} / \mathrm{m}^{3}\end{array}$ & 90 \\
\hline
\end{tabular}




\begin{tabular}{|c|c|c|}
\hline 5.29 & $\begin{array}{l}\text { Particle Size distribution of the permeate after the ultrafiltration of latex } \\
\text { solution }\left[\mathrm{C}_{\mathrm{f}}=1.3 \mathrm{~kg} / \mathrm{m} 3 \text {, and } \mathrm{Q}=4 \mathrm{LPM}\right] \text { at different transmembrane } \\
\text { pressure. }\end{array}$ & 91 \\
\hline 5.30 & $\begin{array}{l}\text { Particle Size distribution of the permeate after the ultrafiltration of latex } \\
\text { solution }\left[\mathrm{C}_{\mathrm{f}}=1.3 \mathrm{~kg} / \mathrm{m} 3 \text {, and } \mathrm{Q}=4 \mathrm{LPM}\right] \text { at different transmembrane } \\
\text { pressures. }\end{array}$ & 92 \\
\hline 5.31 & $\begin{array}{l}\text { Effect of the zeta potential of Polysulfone membrane surface at [25 psi], } \\
{[\mathrm{Q}=4.5 \mathrm{LPM}],\left[\mathrm{C}_{\mathrm{f}}=1.3 \mathrm{~kg} / \mathrm{m}^{3}\right] \text { on (a) Fouling attachment probabilities }\left(\alpha_{\mathrm{pp}} \text {, }\right.} \\
\left.\alpha_{\mathrm{pm}}\right) ;(\mathrm{b}) \text { Cumulative filtration volume per unit area }\left(V_{s}\right)\left[\mathrm{m}^{3} / \mathrm{m}^{2}\right] ;(\mathrm{c}) \text { Total } \\
\text { mass of fouling }\left(m_{t}\right)\left[\mathrm{kg} / \mathrm{m}^{2}\right] ; \text { and (d) Specific power consumption } \\
{\left[\mathrm{kW} . \mathrm{h} / \mathrm{m}^{3}\right]}\end{array}$ & 94 \\
\hline 5.32 & 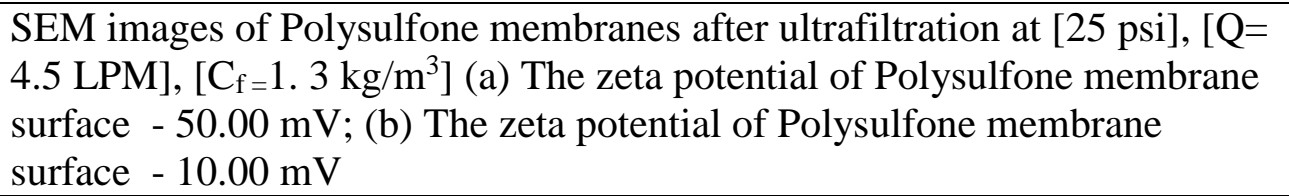 & 95 \\
\hline 5.33 & $\begin{array}{l}\text { SEM images of Ultrafilic membranes after ultrafiltration at [ } 25 \mathrm{psi}],[\mathrm{Q}= \\
4 \mathrm{LPM}],\left[\mathrm{C}_{\mathrm{f}}=1.3 \mathrm{~kg} / \mathrm{m}^{3}\right](\mathrm{a}) \text { Zeta potential of Ultrafilic membrane surface }= \\
-41.50 \mathrm{mV} \text {; (b) Zeta potential of Ultrafilic membrane surface }=-30.00 \mathrm{mV} \text {; } \\
\text { (c) Zeta potential of Ultrafilic membrane surface }=-15.00 \mathrm{mV}\end{array}$ & 96 \\
\hline 5.34 & $\begin{array}{l}\text { SEM images of Polysulfone membrane after ultrafiltration at } \\
\text { (a) PS [ } 25 \mathrm{psi}],[\mathrm{Q}=4.5 \mathrm{LPM}],\left[\mathrm{C}_{\mathrm{f}}=1.3 \mathrm{~kg} / \mathrm{m}^{3}\right],[-20.00 \mathrm{mV}] \text { (cross flow } \\
\text { velocity of } 46.8 \mathrm{~cm} / \mathrm{s} \text { ) } \\
\text { (b) PS [ } 25 \mathrm{psi}],[\mathrm{Q}=7.0 \mathrm{LPM}],\left[\mathrm{C}_{\mathrm{f}}=1.3 \mathrm{~kg} / \mathrm{m}^{3}\right],[-20.00 \mathrm{mV}](\text { cross flow } \\
\text { velocity of } 72.8 \mathrm{~cm} / \mathrm{s}(\mathrm{c}) \mathrm{PS}[25 \mathrm{psi}],[\mathrm{Q}=4.5 \mathrm{LPM}],\left[\mathrm{C}_{\mathrm{f}}=1.3 \mathrm{~kg} / \mathrm{m}^{3}\right],[- \\
50.00 \mathrm{mV}](\text { cross flow velocity of } 46.8 \mathrm{~cm} / \mathrm{s})\end{array}$ & 98 \\
\hline 5.35 & $\begin{array}{l}\text { Actaual and predicted fouling attachment probabilities agreement } \\
\text { (a) Coagulation attachment probability }\left(\alpha_{\mathrm{pp}}\right) \\
\text { (b) Depositional attachment probability }\left(\alpha_{\mathrm{pm}}\right)\end{array}$ & 102 \\
\hline 5.36 & $\begin{array}{l}\text { Actaual and predicted fouling attachment probabilities agreement (a) } \\
\text { Coagulation attachment probability }\left(\alpha_{\mathrm{pp}}\right) ; \text { (b) Depositional attachment } \\
\text { probability }\left(\alpha_{\mathrm{pm}}\right)\end{array}$ & 108 \\
\hline 5.37 & $\begin{array}{l}\text { Actual and predicted fouling attachment probabilities for hydrophobic } \\
\text { PVDF membrane at different operating conditions : (a) Depositional } \\
\text { attachment probability }\left(\alpha_{\mathrm{pm}}\right), \text { (b) Coagulation attachment probability }\left(\alpha_{\mathrm{pp}}\right)\end{array}$ & 112 \\
\hline 5.38 & $\begin{array}{l}\text { SEM images of membranes after ultrafiltration at }[\mathrm{Q}=4 \mathrm{LPM}],\left[\mathrm{C}_{\mathrm{f}}=0.78\right. \\
\left.\mathrm{kg} / \mathrm{m}^{3}\right] \text { : (a) Side view of the cake height of Polysulfone membrane at TMP } \\
\text { of } 25 \mathrm{psi} \text {, and zeta potential of }-42.40 \mathrm{mV} \text {; (b) Side view of the cake height } \\
\text { of PVDF membrane at TMP of } 15 \mathrm{psi} \text {, and zeta potential of }-2.50 \mathrm{mV}(\mathrm{c}) \\
\text { Membrane surface of Polysulfone membrane at TMP of } 25 \mathrm{psi} \text {, and zeta } \\
\text { potential of }-42.40 \mathrm{mV} \text {; (d) Membrane surface of PVDF membrane at TMP } \\
\text { of } 15 \mathrm{psi} \text {, and zeta potential of }-2.50 \mathrm{mV}\end{array}$ & 119 \\
\hline 5.39 & $\begin{array}{l}\text { SEM images of membrane surface after ultrafiltration at }[\mathrm{Q}=7 \mathrm{LPM}] \\
{[\mathrm{TMP}=15 \mathrm{psi}],\left[\mathrm{C}_{\mathrm{f}}=1.3 \mathrm{~kg} / \mathrm{m}^{3}\right] \text { (a) PVDF membrane at zeta potential of - }} \\
2.50 \mathrm{mV} \text {; (b) Ultrafilic membrane at at zeta potential of }-41.50 \mathrm{mV}\end{array}$ & 121 \\
\hline 5.40 & $\begin{array}{l}\text { SEM images of the Polysulfone membrane after ultrafiltration at }[\mathrm{P}=25.00 \\
\text { psia], }[\mathrm{Q}=7.00 \mathrm{LPM}],\left[\mathrm{C}_{\mathrm{f}}=1.30 \mathrm{~kg} / \mathrm{m}^{3}\right] \text { (a) with a membrane surface charge }\end{array}$ & 128 \\
\hline
\end{tabular}




\begin{tabular}{|c|c|c|}
\hline & $\mathrm{mV}$ & \\
\hline 5.41 & The pore size distribution (a) Cellulose Acetate (b) Polysulfone membrane & 130 \\
\hline 5.42 & $\begin{array}{l}\text { SEM images after ultrafiltration at [P=25.00 psia], [Q=4.00 LPM], } \\
{\left[\mathrm{C}_{\mathrm{f}}=1.30 \mathrm{~kg} / \mathrm{m}^{3}\right] \text { using (a) Membrane surface of Cellulose Acetate }} \\
\text { membrane with MWCO of } 20,000 ; \text { (b) Membrane surface of Polysulfone } \\
\text { membrane with MWCO of } 60,000 ; \text { (c) Side view of the cake height using } \\
\text { Cellulose Acetate membrane with MWCO of } 20,000 ; \text { (d) Side view of the } \\
\text { cake height of Polysulfone membrane with MWCO of } 60,000\end{array}$ & 130 \\
\hline 5.43 & The pore size distribution (a) Ultrafilic membrane and (b) PVDF membrane & 132 \\
\hline 5.44 & $\begin{array}{l}\text { SEM images after ultrafiltration at }[\mathrm{P}=15.00 \mathrm{psia}],[\mathrm{Q}=7.00 \mathrm{LPM}] \\
{\left[\mathrm{C}_{\mathrm{f}}=1.30 \mathrm{~kg} / \mathrm{m}^{3}\right] \text { using (a) PVDF membrane with zeta potential of }-2.50} \\
\mathrm{mV} ; \text { (b) Ultrafilic membrane with zeta potential of }-41.50 \mathrm{mV}\end{array}$ & 132 \\
\hline 5.45 & $\begin{array}{l}\text { The effect of } \mathrm{pH} \text { on (a) Conductivity of latex solution \& (b) Zeta potential } \\
\text { of latex particles and membrane surface. }\end{array}$ & 135 \\
\hline 5.46 & $\begin{array}{l}\text { Effect of } \mathrm{pH} \text { value at }[\mathrm{TMP}=15 \mathrm{psia}],\left[\mathrm{C}_{\mathrm{f}}=1.3 \mathrm{~kg} / \mathrm{m}^{3}\right] \&[\mathrm{Q}=4 \mathrm{LPM}] \\
\left(\mathrm{Using} 1 \mathrm{~N} \mathrm{NaOH} \& 0.1 \mathrm{~N} \mathrm{H}_{2} \mathrm{SO}_{4}\right) \text { on }(\mathrm{a}) \text { Fouling attachment probabilities } \\
\left(\alpha_{\mathrm{pp}}, \alpha_{\mathrm{pm}}\right) \text { and the volumetric permeate flux }\left(V_{s}\right)(\mathrm{b}) \text { Mass of fouling and } \\
\text { power consumption }\left[\mathrm{kWh} / \mathrm{m}^{3}\right]\end{array}$ & 137 \\
\hline 5.47 & $\begin{array}{l}\text { SEM images of membrane after ultrafiltration }[\mathrm{Q}=4 \mathrm{LPM}],\left[\mathrm{C}_{\mathrm{f}}=1.3\right. \\
\left.\mathrm{kg} / \mathrm{m}^{3}\right],[\mathrm{TMP}=15 \mathrm{psia}] \text { (a) Cake height }=5.05 \mu \mathrm{m} \text { at } \mathrm{pH}=7,(\mathrm{~b}) \text { Cake } \\
\text { height }=3.6 \mu \mathrm{m} \text { at } \mathrm{pH}=10 \text {, (c) Cake height }=1.85 \mu \mathrm{m} \text { at } \mathrm{pH}=12\end{array}$ & 137 \\
\hline 5.48 & $\begin{array}{l}\text { Effect of } \mathrm{pH} \text { value at }[\mathrm{TMP}=15 \mathrm{psia}],\left[\mathrm{C}_{\mathrm{f}}=1.3 \mathrm{~kg} / \mathrm{m}^{3}\right] \&[\mathrm{Q}=1 \mathrm{LPM}] \\
\left(\text { Using } 1 \mathrm{~N} \mathrm{NaOH} \& 0.1 \mathrm{~N} \mathrm{H}_{2} \mathrm{SO}_{4}\right) \text { on }(\mathrm{a}) \text { Fouling attachment probabilities } \\
\left(\alpha_{\mathrm{pp}}, \alpha_{\mathrm{pm}}\right) \text { and the volumetric permeate flux }\left(V_{s}\right)(\mathrm{b}) \text { Mass of fouling and } \\
\text { power consumption }\left[\mathrm{kWh} / \mathrm{m}^{3}\right]\end{array}$ & 138 \\
\hline 5.49 & $\begin{array}{l}\text { SEM images of membrane after ultrafiltration (a) Cake height } 13.8 \mu \mathrm{m} \text { at } \\
{[\mathrm{TMP}=15 \mathrm{psia}],\left[\mathrm{C}_{\mathrm{f}}=1.3 \mathrm{~kg} / \mathrm{m}^{3}\right],[\mathrm{Q}=1 \mathrm{LPM}] \& \mathrm{pH}=7 ;(\mathrm{b}) \text { Cake height } 6.1} \\
\mu \mathrm{m} \text { at }[\mathrm{TMP}=15 \mathrm{psia}],\left[\mathrm{C}_{\mathrm{C}}=1.3 \mathrm{~kg} / \mathrm{m}^{3}\right],[\mathrm{Q}=1 \mathrm{LPM}] \& \mathrm{pH}=1 ;(\mathrm{C}) \text { Cake } \\
\text { height } 2.3 \mu \mathrm{m} \text { at }[\mathrm{TMP}=15 \mathrm{psia}],\left[\mathrm{C}_{\mathrm{f}}=1.3 \mathrm{~kg} / \mathrm{m}^{3}\right],[\mathrm{Q}=1 \mathrm{LPM}] \& \mathrm{pH}=12 \\
\text { (d) Cake height } 2.4 \mu \mathrm{m} \text { at }[\mathrm{TMP}=15 \mathrm{psia}],\left[\mathrm{C}_{\mathrm{f}}=1.3 \mathrm{~kg} / \mathrm{m}^{3}\right],[\mathrm{Q}=6 \mathrm{LPM}] \& \\
\mathrm{pH}=7\end{array}$ & 139 \\
\hline 5.50 & $\begin{array}{l}\text { Effect of } \mathrm{pH} \text { value at }[\mathrm{TMP}=25 \mathrm{psia}],\left[\mathrm{C}_{\mathrm{f}}=1.3 \mathrm{~kg} / \mathrm{m}^{3}\right] \&[\mathrm{Q}=4 \mathrm{LPM}] \\
\left(\text { Using } 1 \mathrm{~N} \mathrm{NaOH} \& 0.1 \mathrm{~N} \mathrm{H}_{2} \mathrm{SO}_{4}\right) \text { on }(\mathrm{a}) \text { Fouling attachment probabilities } \\
\left(\alpha_{\mathrm{pp}}, \alpha_{\mathrm{pm}}\right) \text { and the volumetric permeate flux }\left(V_{s}\right)(\mathrm{b}) \text { Mass of fouling and } \\
\text { power consumption }\left[\mathrm{kWh} / \mathrm{m}^{3}\right]\end{array}$ & 141 \\
\hline 5.51 & $\begin{array}{l}\text { SEM images of membrane after ultrafiltration }[\mathrm{Q}=4 \mathrm{LPM}],\left[\mathrm{C}_{\mathrm{f}}=1.3\right. \\
\left.\mathrm{kg} / \mathrm{m}^{3}\right],[\mathrm{TMP}=25 \mathrm{psia}] \text { (a) Cake height } 6.65 \mu \mathrm{m} \text { at } \mathrm{pH}=7, \text { (b) Cake height } \\
5.30 \mu \mathrm{m} \text { at } \mathrm{pH}=10\end{array}$ & 141 \\
\hline 5.52 & $\begin{array}{l}\text { SEM images of membrane after ultrafiltration }[Q=4 \mathrm{LPM}],\left[\mathrm{C}_{\mathrm{f}}=1.3\right. \\
\left.\left.\mathrm{kg} / \mathrm{m}^{3}\right], \text { [ TMP }=15 \mathrm{psia}\right], \mathrm{pH}=3 \text { (a) Cake height }=6.35 \mu \mathrm{m} \text { using } 0.1 \mathrm{~N} \\
\mathrm{H}_{2} \mathrm{SO}_{4} \text { (b) Cake height }=7.65 \mu \mathrm{m} \text { using } 0.1 \mathrm{~N} \mathrm{HCl}\end{array}$ & 142 \\
\hline 5.53 & $\begin{array}{l}\text { Effect of } \mathrm{pH} \text { change of latex effluent on the zeta potential of latex particles } \\
\text { and the membrane surface through the ultrafiltration process }\end{array}$ & 144 \\
\hline 5.54 & SEM images of PVDF membrane surfaces after ultrafiltration at $[\mathrm{Q}=4$ & 145 \\
\hline
\end{tabular}




\begin{tabular}{|c|c|c|}
\hline & $\begin{array}{l}\mathrm{LPM}],\left[\mathrm{C}_{\mathrm{f}}=0.78 \mathrm{~kg} / \mathrm{m}^{3}\right],[15 \mathrm{psi}] \text { using latex solution (a) at } \mathrm{pH} \text { of } 7 \text { (b) at } \\
\mathrm{pH} \text { of } 11 .\end{array}$ & \\
\hline 5.55 & $\begin{array}{l}\text { Effect of the zeta potential of Polysulfone membrane surface at }[25 \mathrm{psi}] \\
{[\mathrm{Q}=4.5 \mathrm{LPM}],\left[\mathrm{C}_{\mathrm{f}}=1.3 \mathrm{~kg} / \mathrm{m}^{3}\right] \text { on }\left(\text { a) Fouling attachment probabilities }\left(\alpha_{\mathrm{pp}},\right.\right.} \\
\left.\alpha_{\mathrm{pm}}\right) ; \text { and cumulative filtration volume per unit area }\left(V_{s}\right)\left[\mathrm{m}^{3} / \mathrm{m}^{2}\right] ;(\mathrm{b}) \text { Total } \\
\text { mass of fouling }\left(m_{t}\right)\left[\mathrm{kg} / \mathrm{m}^{2}\right] \text {; and the specific power consumption } \\
{\left[\mathrm{kW} . \mathrm{h} / \mathrm{m}^{3}\right] .}\end{array}$ & 147 \\
\hline 5.56 & $\begin{array}{l}\text { SEM images of Polysulfone membranes after ultrafiltration at [ } 25 \mathrm{psi}],[\mathrm{Q}= \\
4.5 \mathrm{LPM}],\left[\mathrm{C}_{\mathrm{f}}=1.3 \mathrm{~kg} / \mathrm{m}^{3}\right] \text { at the zeta potential of (a) }-50.00 \mathrm{mV} ;(\mathrm{b})- \\
10.00 \mathrm{mV}\end{array}$ & 147 \\
\hline 5.57 & $\begin{array}{l}\text { SEM images of Ultrafilic membranes after ultrafiltration at [25 psi], [Q=4 } \\
\text { LPM }],\left[\mathrm{C}_{\mathrm{f}}=1.30 \mathrm{~kg} / \mathrm{m}^{3}\right] \text { at zeta potential of (a) }-41.50 \mathrm{mV} ; \text { (b) }-30.00 \mathrm{mV} \text {; } \\
\text { (c) }-15.00 \mathrm{mV} \text {. }\end{array}$ & 148 \\
\hline 5.58 & Micelle formation of anionic surfactant & 150 \\
\hline 5.59 & $\begin{array}{l}\text { Zeta potential of membrane surfaces after LAS treatment at a concentration } \\
\text { of (a) } 1 \times 10^{-4} \mathrm{~g} / \mathrm{L} \text { (b) } 0.1 \mathrm{~g} / \mathrm{L}\end{array}$ & 154 \\
\hline 5.60 & $\begin{array}{l}\text { Schematic of adsorption of Linear Alkyl Benzene Sulfonate (LAS) into the } \\
\text { membrane surface (a) hydrophilic membranes (b) hydrophobic membranes }\end{array}$ & 154 \\
\hline 5.61 & $\begin{array}{l}\text { SEM images of PVDF membrane surfaces after ultrafiltration at }[\mathrm{Q}=4 \\
\mathrm{LPM}],\left[\mathrm{C}_{\mathrm{f}}=0.78 \mathrm{~kg} / \mathrm{m}^{3}\right],[15 \mathrm{psi}]: \text { (a) at original zeta potential of }-2.50 \mathrm{mV} \\
\text { (b) at zeta potential of }-40.91 \mathrm{mV} \text { after } 20 \text { minutes treatment for the surface } \\
\text { charge using LAS with concentration of } 0.0001 \mathrm{~g} / \mathrm{L}\end{array}$ & 155 \\
\hline 5.62 & $\begin{array}{l}\text { SEM images of Ultrafilic membrane surfaces after ultrafiltration at }[\mathrm{Q}=1 \\
\mathrm{LPM}],\left[\mathrm{C}_{\mathrm{f}}=1.3 \mathrm{~kg} / \mathrm{m}^{3}\right],[35 \mathrm{psi}]: \text { (a) at original zeta potential of }-41.50 \mathrm{mV} \\
\text { (b) at zeta potential of }-50.67 \text { after } 15 \text { minutes treatment for the surface } \\
\text { charge using LAS with concentration of } 0.0001 \mathrm{~g} / \mathrm{L} \text {. }\end{array}$ & 156 \\
\hline 5.63 & PVDF membrane performance using different remediation techniques & 157 \\
\hline 5.64 & Polysulfone membrane performance using different remediation techniques & 157 \\
\hline 5.65 & $\begin{array}{l}\text { The particle size distribution of the treated latex solution with the } \\
\text { concentration of (a) } 0.78 \mathrm{~kg} / \mathrm{m}^{3} \text {, (b) } 1.3 \mathrm{~kg} / \mathrm{m}^{3} \text {, (c) } 1.82 \mathrm{~kg} / \mathrm{m}^{3}\end{array}$ & 159 \\
\hline 5.66 & $\begin{array}{l}\text { Micelles formed around negatively charged latex particles using cationic } \\
\text { surfactant }\end{array}$ & 159 \\
\hline 5.67 & $\begin{array}{l}\text { SEM of latex particles after the ultrafiltration process (a) without CTAB } \\
\text { addition at magnification of } 1000 \text {, (b) with CTAB pre-treatment at } \\
\text { magnification of } 300\end{array}$ & 160 \\
\hline 5.68 & $\begin{array}{l}\text { Particle size distribution of untreated and treated simulated latex effluent at } \\
\text { CMC of CTAB at different concentrations of the latex solution }\end{array}$ & 161 \\
\hline 5.69 & $\begin{array}{l}\text { Particle size distribution of untreated and treated simulated latex effluent at } \\
\text { CMC of CTAB at different treatment time }\end{array}$ & 161 \\
\hline 5.70 & $\begin{array}{l}\text { SEM images at magnification of } 500 \mathrm{of} \text { latex particles after ultrafiltration } \\
\text { process at the concentration of } 1.3 \mathrm{~kg} / \mathrm{m}^{3} \text {, feed flow rate of } 1 \mathrm{LPM} \text {, and } \\
\text { transmembrane pressure of } 35 \mathrm{psia} \text { using (a) untreated simulated latex } \\
\text { effluent (b) pretreated feed with CTAB at CMC concentration for } 10\end{array}$ & 161 \\
\hline
\end{tabular}




\begin{tabular}{|c|c|c|}
\hline & minutes & \\
\hline 5.71 & $\begin{array}{l}\text { Particle size distribution of untreated and treated simulated latex effluent at } \\
\text { CMC of CTAB at different agitation time periods. }\end{array}$ & 162 \\
\hline 5.72 & $\begin{array}{l}\text { Effects of interparticle interference and aggregation of small angle } \\
\text { scattering data for } 1.3 \mathrm{~kg} / \mathrm{m}^{3} \text { simulated latex effluent, with the addition of } \\
0.36 \mathrm{~g} / \mathrm{L} \text { CTAB (a) At minimal stirring (b) After } 1 \text { minute of stirring }\end{array}$ & 163 \\
\hline 5.73 & $\begin{array}{l}\text { SEM images of aggregated latex particles at the concentration of } 1.82 \\
\mathrm{~kg} / \mathrm{m}^{3} \text { after ultrfiltration process at the feed flow rate of } 1 \mathrm{LPM} \text {, } \\
\text { transmembrane pressure of } 25 \text { psia, and feed pretreatment of CTAB at } \\
\text { CMC concentration for } 10 \text { minutes as feed pre-treatment (a) with } 2 \text { minutes } \\
\text { of continuous stirring during the CTAB addition (b) with minimal agitation }\end{array}$ & 163 \\
\hline 5.74 & $\begin{array}{l}\text { Zeta potential of latex particles and various membrane surfaces at different } \\
\text { CTAB concentrations for } 10 \text { minute treatment }\end{array}$ & 164 \\
\hline 5.75 & $\begin{array}{l}\text { Zeta potential of latex particles and various membrane surfaces at different } \\
\text { CTAB concentrations for } 10 \text { minute treatment }\end{array}$ & 164 \\
\hline 5.76 & $\begin{array}{l}\text { Effects of CTAB addition at the concentration of CMC of } 0.36 \mathrm{~g} / \mathrm{L} \text { for each } \\
\text { experimental run using PC (a) The depositional attachment }\left(\alpha_{\mathrm{pm}}\right) ;(\mathrm{b}) \\
\text { mass of fouling contributed to pore blocking }\left(\mathrm{m}_{\mathrm{p}}\right)\end{array}$ & 167 \\
\hline 5.77 & $\begin{array}{l}\text { Effects of CTAB addition at the concentration of CMC of } 0.36 \mathrm{~g} / \mathrm{L} \text { for each } \\
\text { experimental run using PC (a) Cumulative permeate volume per unit area ; } \\
\text { (b) mass of irreversible fouling per unit area }\end{array}$ & 167 \\
\hline 5.78 & $\begin{array}{l}\text { Effect of CTAB addition at the concentration of CMC of } 0.36 \mathrm{~g} / \mathrm{L} \text { for each } \\
\text { experimental run using PSU (a) Total mass of fouling, (b) Cumulative } \\
\text { permeate volume per unit area }\end{array}$ & 169 \\
\hline C. 1 & SEM of Polysulfone non-uniform pore size membrane & 196 \\
\hline C. 2 & Effective pore length of the heterogeneous membrane & 196 \\
\hline G.1 & $\begin{array}{l}\text { SEM images of the membrane used for the validation of the models of } \\
\text { fouling attachments (a) Ultrafilic membrane; (b) Cellulose Acetate } \\
\text { membrane; and (c) PVDF membrane }\end{array}$ & 204 \\
\hline G.2 & $\begin{array}{l}\text { SEM image of the exact pores obtained using the software for the } \\
\text { estimation of the pore size distribution (a) Ultrafilic membrane; (b) } \\
\text { Cellulose Acetate membrane; and (c) PVDF membrane }\end{array}$ & 204 \\
\hline G.3 & $\begin{array}{l}\text { The pore size distribution (a) Ultrafilic membrane, (b) cellulose acetate } \\
\text { membrane, and (c) PVDF membrane }\end{array}$ & 205 \\
\hline I.1 & $\begin{array}{l}\text { The zeta potential of Polysulfone membrane surface before and after } \\
\text { ultrafiltration process }\end{array}$ & 207 \\
\hline J.1 & Normal distribution curve & 209 \\
\hline
\end{tabular}




\section{NOMENCLATURE}

\begin{tabular}{|c|c|}
\hline Symbol & Physical Meaning \\
\hline$a$ & Particle radius $[\mathrm{m}]$ \\
\hline$A_{t}$ & $\begin{array}{l}\text { Total uncovered membrane surface area at any filtration time } \\
\text { normalized to the total membrane surface area [dimensionless] }\end{array}$ \\
\hline$A_{\text {uncovered }}$ & Total uncovered membrane surface area at any filtration time $\left[\mathrm{m}^{2}\right]$ \\
\hline $\mathrm{A}_{\mathrm{o}}$ & Initial pore area of the membrane $\left[\mathrm{m}^{2}\right]$ \\
\hline$A_{w, 1}$ & $\begin{array}{l}\text { Total open area on the wall of one membrane pore after partially fouled } \\
\text { at } \mathrm{V} 1\left[\mathrm{~m}^{2}\right]\end{array}$ \\
\hline$B$ & Mass transfer coefficient $\left[\mathrm{m}^{-2}\right]$ \\
\hline$B_{i}$ & Mass transfer coefficient through the pore size $i\left[\mathrm{~m}^{-2}\right]$ \\
\hline $\mathrm{C}_{\mathrm{in}}$ & $\begin{array}{l}\text { The mean mass concentration of particles at the inlet of a membrane } \\
\text { pores }\left[\mathrm{kg} / \mathrm{m}^{3}\right]\end{array}$ \\
\hline $\mathrm{C}_{\mathrm{i}}$ & Concentration of the macromolecules in the boundary layer $\left[\mathrm{kg} / \mathrm{m}^{3}\right]$ \\
\hline$C_{i b}$ & Feed concentration or the bulk concentration $\left[\mathrm{kg} / \mathrm{m}^{3}\right]$ \\
\hline $\mathrm{C}_{\text {out }}$ & $\begin{array}{l}\text { The mean mass concentration of particles at the outlet of a membrane } \\
\text { pores }\left[\mathrm{kg} / \mathrm{m}^{3}\right]\end{array}$ \\
\hline$C_{f}$ & Concentration of solid particles in the feed water $\left[\mathrm{kg} / \mathrm{m}^{3}\right]$ \\
\hline $\mathrm{Cr}$ & Concentration of particles at any radius $\mathrm{r}\left[\mathrm{kg} / \mathrm{m}^{3}\right]$ \\
\hline $\mathrm{C}_{\mathrm{gel}}$ & Concentration of solute retained by membrane forms the gel $\left[\mathrm{kg} / \mathrm{m}^{3}\right]$ \\
\hline $\mathrm{C}_{\mathrm{p}}$ & Particle concentration at pore radius $\mathrm{r}\left[\mathrm{kg} / \mathrm{m}^{3}\right]$ \\
\hline $\mathrm{Ca}$ & Particle concentration in the membrane pore at axial direction $\left[\mathrm{kg} / \mathrm{m}^{3}\right]$ \\
\hline$C F$ & Confidence of the experimental data \\
\hline$D$ & Diffusion coefficient of colloidal particles $\left[\mathrm{m}^{2} / \mathrm{s}\right]$ \\
\hline$D_{i}$ & Diffusion coefficient of the macromolecule in the boundary layer $\left[\mathrm{m}^{2} / \mathrm{s}\right]$ \\
\hline $\mathrm{D}$ & The effective diffusion coefficient for transport through the pores $\left[\mathrm{m}^{2} / \mathrm{s}\right]$ \\
\hline$D_{p}$ & Diameter of particles $[\mathrm{m}]$ \\
\hline$D_{m}$ & Membrane pore diameter $[\mathrm{m}]$ \\
\hline$D_{m_{i}}$ & Membrane pore diameter of size $i[\mathrm{~m}]$ \\
\hline$d_{\text {mean }}$ & The mean particle size $[\mathrm{m}]$ \\
\hline$d_{p i}$ & The diameter of average particle size $i[\mathrm{~m}]$ \\
\hline$L_{m}$ & length of membrane pores $[\mathrm{m}]$ \\
\hline$J v$ & Convective flux \\
\hline$J$ & Permeate flux $\left[\mathrm{m}^{3} / \mathrm{m}^{2} . \mathrm{s}\right]$ \\
\hline$m_{p}$ & Mass of particles attaching to membrane pores in a unit membrane \\
\hline
\end{tabular}




\begin{tabular}{|c|c|}
\hline & surface area $\left[\mathrm{kg} / \mathrm{m}^{2}\right]$ \\
\hline$m_{p L}$ & $\begin{array}{l}\text { Mass of large particles attaching to membrane pores in a unit membrane } \\
\text { surface area }\left[\mathrm{kg} / \mathrm{m}^{2}\right]\end{array}$ \\
\hline$m_{p L_{i}}$ & $\begin{array}{l}\text { Mass of the particles larger than the pore of size } i \text { contribute to pore } \\
\text { blocking }\left[\mathrm{kg} / \mathrm{m}^{2}\right]\end{array}$ \\
\hline$m_{p s}$ & $\begin{array}{l}\text { Mass of small particles attaching to membrane pores in a unit } \\
\text { membrane surface area }\left[\mathrm{kg} / \mathrm{m}^{2}\right] \text { (pore diameter } / 6<\text { particle size }<\text { pore } \\
\text { diameter } / 2 \text { ) }\end{array}$ \\
\hline$m_{p S_{i}}$ & $\begin{array}{l}\text { Mass of small particles attaching to membrane pores of size } i \text { in a unit } \\
\text { membrane surface area }\left[\mathrm{kg} / \mathrm{m}^{2}\right]\left(D_{m_{i}} / 6<\text { particle size }<D_{m_{i}} / 2\right)\end{array}$ \\
\hline$m_{s}$ & $\begin{array}{l}\text { Mass of particles attaching to membrane surface in a unit membrane } \\
\text { surface area }\left[\mathrm{kg} / \mathrm{m}^{2}\right]\end{array}$ \\
\hline$m_{s S}$ & $\begin{array}{l}\text { Mass of small particles attaching to membrane surface in a unit } \\
\text { membrane surface area }\left[\mathrm{kg} / \mathrm{m}^{2}\right] \text { (pore diameter } 6<\text { particle size }<\text { pore } \\
\text { diameter } / 2 \text { ) }\end{array}$ \\
\hline$m_{s L}$ & $\begin{array}{l}\text { Mass of large particles attaching to membrane surface in a unit } \\
\text { membrane surface area }\left[\mathrm{kg} / \mathrm{m}^{2}\right]\end{array}$ \\
\hline$m_{p p}$ & $\begin{array}{l}\text { Mass of particles attaching to other particles on the membrane surface } \\
\text { normalized to a unit membrane surface area }\left[\mathrm{kg} / \mathrm{m}^{2}\right]\end{array}$ \\
\hline$m_{p p L}$ & $\begin{array}{l}\text { Mass of large particles attaching to other particles on the membrane } \\
\text { surface normalized to a unit membrane surface area }\left[\mathrm{kg} / \mathrm{m}^{2}\right]\end{array}$ \\
\hline$m_{p p S}$ & $\begin{array}{l}\text { Mass of small particles attaching to other particles on the membrane } \\
\text { surface normalized to a unit membrane surface area }\left[\mathrm{kg} / \mathrm{m}^{2}\right]\end{array}$ \\
\hline$m_{w}$ & $\begin{array}{l}\text { Mass of the particles attaching to the pore walls in all membrane pores } \\
\text { normalized to unit membrane surface area }\left[\mathrm{kg} / \mathrm{m}^{2}\right] \text { (particle size }<\text { pore } \\
\text { diameter } / 6 \text { ) }\end{array}$ \\
\hline$m_{w_{i}}$ & $\begin{array}{l}\text { Mass of the particles attaching to the pore walls of size } i \text { normalized to } \\
\text { unit membrane surface area }\left[\mathrm{kg} / \mathrm{m}^{2}\right]\left(\text { particle size }<D_{m_{i}} / 6\right)\end{array}$ \\
\hline$m_{f}$ & $\begin{array}{l}\text { Mass of particles that attach to membrane surfaces and cause fouling } \\
{[\mathrm{kg}]}\end{array}$ \\
\hline$m_{c}$ & $\begin{array}{l}\text { Total mass of particles in the cake layer per unit membrane surface area } \\
{\left[\mathrm{kg} / \mathrm{m}^{2}\right]}\end{array}$ \\
\hline$m_{\text {CIRR }}$ & $\begin{array}{l}\text { Total mass of particles in the irreversible cake layer per unit membrane } \\
\text { surface area }\left[\mathrm{kg} / \mathrm{m}^{2}\right]\end{array}$ \\
\hline$m_{C I R R L}$ & $\begin{array}{l}\text { Total mass of large particles in the irreversible cake layer per unit } \\
\text { membrane surface area }\left[\mathrm{kg} / \mathrm{m}^{2}\right]\end{array}$ \\
\hline$m_{C I R R S}$ & $\begin{array}{l}\text { Total mass of small particles in the irreversible cake layer per unit } \\
\text { membrane surface area }\left[\mathrm{kg} / \mathrm{m}^{2}\right] \text { (pore diameter } / 6<\text { particle size }<\text { pore } \\
\text { diameter } / 2 \text { ) }\end{array}$ \\
\hline$m_{I R R}$ & $\begin{array}{l}\text { Total mass of particles contribute to total irreversible fouling per unit } \\
\text { membrane surface area }\left[\mathrm{kg} / \mathrm{m}^{2}\right]\end{array}$ \\
\hline
\end{tabular}




\begin{tabular}{|c|c|}
\hline$m_{t}$ & $\begin{array}{l}\text { Total mass of particles introduced to the membrane per unit membrane } \\
\text { surface area }\left[\mathrm{kg} / \mathrm{m}^{2}\right]\end{array}$ \\
\hline$m_{d}$ & Mass of deposit per unit surface area of membrane $[\mathrm{kg} / \mathrm{m} 2]$ \\
\hline$N$ & $\begin{array}{l}\text { Total number of the non-uniform pore sizes determined in the pore size } \\
\text { distribution of the heterogeneous membranes }\end{array}$ \\
\hline$N_{m}$ & $\begin{array}{l}\text { Number denisty of membrane pores per a unit membrane surface area } \\
{\left[1 / \mathrm{m}^{2}\right]}\end{array}$ \\
\hline$\Delta P$ & Increase of transmembrane pressure $[\mathrm{psi}]$ \\
\hline$P^{\prime}$ & $\begin{array}{l}\text { The increase in transmembrane pressure during filtration normalized to } \\
\text { that of clean membranes [dimensionless] }\end{array}$ \\
\hline$P_{p}^{\prime}$ & $\begin{array}{l}\text { Increase of transmembrane pressure due to pore blocking } \\
\text { [dimensionless] }\end{array}$ \\
\hline$P^{\prime} p L$ & $\begin{array}{l}\text { Increase of transmembrane pressure due to pore blocking of large } \\
\text { particles [dimensionless] }\end{array}$ \\
\hline$P_{p S}^{\prime}$ & $\begin{array}{l}\text { Increase of transmembrane pressure due to pore blocking of small } \\
\text { particles [dimensionless] (pore diameter } / 6<\text { particle size }<\text { pore } \\
\text { diameter } / 2 \text { ) }\end{array}$ \\
\hline$P_{c}^{\prime}$ & Increase of transmembrane pressure due to cake layer [dimensionless] \\
\hline$P^{\prime}{ }_{C I R R}$ & $\begin{array}{l}\text { Increase of transmembrane pressure due to irreversible cake } \\
\text { [dimensionless] }\end{array}$ \\
\hline$P_{C I R R L}^{\prime}$ & $\begin{array}{l}\text { Increase of transmembrane pressure due to irreversible cake by large } \\
\text { particles [dimensionless] }\end{array}$ \\
\hline$P_{C I R R S}^{\prime}$ & $\begin{array}{l}\text { Increase of transmembrane pressure due to irreversible cake by small } \\
\text { particles [dimensionless] (pore diameter } / 6<\text { particle size }<\text { pore } \\
\text { diameter } / 2 \text { ) }\end{array}$ \\
\hline$P_{I R R}^{\prime}$ & $\begin{array}{l}\text { Increase of transmembrane pressure due to total irreversible fouling } \\
\text { [dimensionless] }\end{array}$ \\
\hline$P^{\prime} w$ & $\begin{array}{l}\text { Increase of transmembrane pressure due to small particles attached to } \\
\text { pore wall [dimensionless] (particle size }<\text { pore diameter } / 6 \text { ) }\end{array}$ \\
\hline P-value & Probability in statistical significance testing (ANOVA test) \\
\hline $\mathrm{Q}_{1}$ & Permeate flow rate in single pore $[\mathrm{L} / \mathrm{s}]$ \\
\hline $\mathrm{Q}$ & Feed flow rate [LPM] \\
\hline$Q_{i}$ & Permeate flow rate in single pore of size $i[\mathrm{~L} / \mathrm{s}]$ \\
\hline$R_{m}$ & Resistance due to the membrane $\left[\mathrm{m}^{-1}\right]$ \\
\hline$R_{c}$ & Resistance due to the cake $\left[\mathrm{m}^{-1}\right]$ \\
\hline$\hat{R} c$ & Specific cake resistance $[\mathrm{m} / \mathrm{kg}]$ \\
\hline$R_{T}$ & Total resistance \\
\hline$R$ & Radius of membrane pore $[\mathrm{m}]$ \\
\hline $\mathrm{R}^{2}$ & The percent of the variation of the response explained by the model \\
\hline$r$ & Average radius of membrane pores $[\mathrm{m}]$ \\
\hline$r_{p}$ & Membrane pore radius $[\mathrm{m}]$ \\
\hline
\end{tabular}




\begin{tabular}{|c|l|}
\hline $\mathrm{TMP}$ & Transmembrane pressure [psi] \\
\hline$\overline{\mathrm{TMP}}_{A V G}$ & $\begin{array}{l}\text { Time-averagedtransmembrane pressure throughout the filtration } \\
\text { duration [psi.min] }\end{array}$ \\
\hline $\mathrm{TMP}_{\mathrm{AVG}}$ & Average transmembane pressure throughout the filtration duration [psi] \\
\hline $\mathrm{V}$ & Cumulative volume passing through the membrane $\left[\mathrm{m}^{3}\right]$ \\
\hline$v$ & Cross flow velocity [cm/s] \\
\hline$V s$ & $\begin{array}{l}\text { Cumulative volume of the permeate normalized to membrane surface } \\
\text { area }\left[\mathrm{m}^{3} / \mathrm{m}^{2}\right]\end{array}$ \\
\hline$\overline{\mathrm{V}}_{S}$ & Cumulative permeate volume $\left[\mathrm{m}^{3}\right]$ \\
\hline$x_{i}$ & Number average percentage of the pore of size $i$ \\
\hline$X_{i}$ & The $\mathrm{i}^{\text {th }}$ independent factor \\
\hline $\mathrm{X}_{i}$ & The volume fraction of a particle size range $i$ \\
\hline$Y$ & The response factor of attachment probabilities $\left(\alpha_{\mathrm{pp}} \& \alpha_{\mathrm{pm}}\right)$ \\
\hline
\end{tabular}

\section{Greek Symbols}

\begin{tabular}{|c|c|}
\hline$\beta$ & Model coefficient \\
\hline$\beta_{s}$ & $\begin{array}{l}\text { Collision probability between particle and membrane surface } \\
\text { [dimensionless] }\end{array}$ \\
\hline$\beta_{p}$ & $\begin{array}{l}\text { Collision probability between particle and membrane pore } \\
\text { [dimensionless] }\end{array}$ \\
\hline$\beta_{p p}$ & $\begin{array}{l}\text { Collision probability between particle and another particle } \\
\text { [dimensionless] }\end{array}$ \\
\hline$\sigma_{\mathrm{L}}$ & $\begin{array}{l}\text { projected area of a unit mass of the large particles (Particle } \\
\text { diameter } \geq \text { pore diameter) on membrane surface }\left[\mathrm{m}^{2} / \mathrm{kg}\right]\end{array}$ \\
\hline$\sigma_{\mathrm{S}}$ & $\begin{array}{l}\text { projected area of a unit mass of the small particles on membrane } \\
\text { surface }\left[\mathrm{m}^{2} / \mathrm{kg}\right](\text { pore diameter } / 6<\text { particle size }<\text { pore diameter } / 2)\end{array}$ \\
\hline$\sigma \mathrm{xs}$ & $\begin{array}{l}\text { projected area of a unit mass of the very small particles on } \\
\text { membrane surface }\left[\mathrm{m}^{2} / \mathrm{kg}\right](\text { particle size }<\text { pore diameter } / 6)\end{array}$ \\
\hline$\zeta$ & Surface zeta potential $[\mathrm{mV}]$ \\
\hline$\rho$ & Particle density $\left[\mathrm{kg} / \mathrm{m}^{3}\right]$ \\
\hline$\rho_{\mathrm{m}}$ & The density of membrane materials $\left[\mathrm{kg} / \mathrm{m}^{3}\right]$ \\
\hline$\varepsilon_{\mathrm{s}}$ & Membrane surface porosity [dimensionless] \\
\hline$\mu$ & Solution viscosity $[\mathrm{kg} / \mathrm{m} . \mathrm{s}]$ \\
\hline$\tau$ & Tortuosity of the membrane [dimensionless] \\
\hline$\delta$ & Boundary layer thickness. \\
\hline$\delta^{\prime}$ & The thickness of the adsorption layer [m] \\
\hline$\delta_{\mathrm{c}}$ & $\begin{array}{l}\text { The constrictivity parameter, which is the ratio of the diameter of the } \\
\text { diffusing particle to the pore diameter [dimensionless] }\end{array}$ \\
\hline
\end{tabular}




\begin{tabular}{|c|c|}
\hline$\Psi$ & Sphericity of latex particles [dimensionless] \\
\hline$\alpha_{\mathrm{pm}}$ & $\begin{array}{l}\text { The attachment probabilities between a particle and the membrane } \\
\text { [dimensionless] }\end{array}$ \\
\hline$\alpha_{\mathrm{pp}}$ & The attachment probabilities between two particles [dimensionless] \\
\hline
\end{tabular}

\section{Subscript}

\begin{tabular}{|c|l|}
\hline$A V G$ & Average \\
\hline$c$ & Cake layer \\
\hline Calc. & Calculated \\
\hline Exp. & Experimental \\
\hline$f$ & Feed solution \\
\hline$I R R$ & Irreversible fouling \\
\hline$L$ & Large particles (Particle diameter $\geq$ pore diameter) \\
\hline$m$ & Memberane \\
\hline$p$ & Pore blocking \\
\hline$S$ & Small particles (pore diameter $/ 6<$ particle size $<$ pore diameter $/ 2)$ \\
\hline$t$ & Total \\
\hline$W$ & Pore wall \\
\hline$X S$ & Very small particles (particle size $<$ pore diameter $/ 6)$ \\
\hline
\end{tabular}




\section{List of Abbreviations}

\begin{tabular}{|c|l|}
\hline Abbreviation & \multicolumn{1}{|c|}{ Meaning } \\
\hline CMC & critical micelle concentration \\
\hline CTAB & Trimethylammonium bromide \\
\hline DLVO & The Derjaguin and Landau, Verwey and Overbeek \\
\hline Gpd & gallon per day \\
\hline GFD & Gallons per square foot per day \\
\hline LAS & Linear alkyl benzene sulfonate standard \\
\hline LDPE & Low density polyethylene \\
\hline LL & Lauroyl Lysine \\
\hline LLDPE & Linear low density polyethylene \\
\hline LPM & Liter per minute \\
\hline MF & Micro-filtration \\
\hline MGD & million gallon per day \\
\hline MWCO & Molecular weight cut-off \\
\hline NOM & Natural organic matters \\
\hline PC & Polycarbonates \\
\hline PES & Polyethersulfone \\
\hline PS & Polysulfone \\
\hline PVDF & Polyvinylidene difluoride \\
\hline RIS & Resistance in series model \\
\hline SDS & Sodium dodecyl sulphate \\
\hline STDEV & Standard deviation \\
\hline TMP & Transmembrane pressure \\
\hline TSS & Total soluble solids \\
\hline UF & Ultra-filtration \\
\hline & \\
\hline
\end{tabular}




\section{Chapter 1 INTRODUCTION}

Ultrafiltration (UF) for wastewater treatment can no longer be considered an emerging technology. It has been implemented in both industrial and municipal wastewater treatment facilities. In fact, the use of low-pressure membrane systems has experienced an exponential growth over the past few years due to their ability to deliver drinking water and treated wastewater that meet or exceed stringent quality standards. During the manufacturing of paint products, the cleaning of reactors and mixing basins generates a large amount of wastewater. Paint effluents typically have high levels of biological oxygen demand (i.e., BOD of greater than $580 \mathrm{mg} / \mathrm{L}$ ), chemical oxygen demand (COD, greater than $5500 \mathrm{mg} / \mathrm{L}$ ), and a high level of suspended solids and turbidity (Dey et al., 2004). One of the benefits of treating water-based paint effluent by UF over other processes, such as the electrochemical oxidation (Körbahti and Aktaş, 2007) or Fenton oxidation (Kurt et al., 2006), is the potential to reclaim the retained solids in the paint effluent for recycling purposes and to reuse the permeate liquid as process or cleaning water (Dey et al., 2004). However, one of the major factors hindering a more widespread application of UF is the permeate flux decline with filtration time. This phenomenon is commonly known as membrane fouling, which refers to the blockage of membrane pores through the combination of sieving and adsorption of particulates and compounds into the membrane surface or within the membrane pores during a filtration process (Javacek and Bouchet, 1993; Kennedy, 2008). Fouling leads to the significantly higher operating costs, higher energy demands, reduced membrane lifetime and increased cleaning frequency.

For a typical seawater desalination plant, the cost of the membrane unit is approximately $20-25 \%$ of the total capital cost. Usually about $10 \%$ of the membrane is replaced annually in order to maintain the targeted product quality and production quantity (Al-Amoudi and Lovitt, 2007). Permeate flux and transmembrane pressure (TMP) are the best indicators of membrane fouling. Membrane fouling leads to a significant increase in the hydraulic resistance, manifested as a permeate flux decline or a TMP increase when the process is operated under constant-TMP or constant-flux conditions, respectively. In a system where the permeate flux is maintained by increasing TMP, the energy required to achieve filtration increases, resulting in a higher power consumption. For a plant with a $100 \mathrm{~m}^{3} /$ day capacity the energy consumption is more than $10 \mathrm{KWh} / \mathrm{m}^{3}$; however, it can be reduced to 3.5 $\mathrm{KWh} / \mathrm{m}^{3}$ if the fouling is controlled (Avlonitis et al., 2003). Various reported research 
projects on this subject indicate that the implementation of different fouling remediation techniques results in a significant reduction in the power consumption in the filtration process (Al-Amoudi and Lovitt, 2007; Hu and Stuckey, 2006; Winzeler and Belfort, 1993). One of the studies showed that the total energy consumed for 40 minutes filtration was from 86.14 to $107.57 \mathrm{KJ}$ at 3 bars, while the energy consumed in membrane cleaning ranged from 87.08 to $107 \mathrm{~kJ}$ for 50-100 minutes at different operational pressures (Bahnasawy and Shenana, 2010). In addition, over a long period of time, membrane operation is not totally reversible by back-washing (Kosvintsev et al., 2004). This results in increased operational costs, and makes UF a less economically feasible solution for some of the industrial applications. All of these factors and their correlation to various economic aspects make membrane fouling research a priority.

Some mechanisms involved in membrane fouling have been proposed. However, no theoretical model is yet available that can accurately predict ultrafiltration performance without requiring experimental data for estimating some of the model's parameters. Instead, empirical and semi-empirical models are mostly used (Vela et al., 2008). In addition, effects of the operating parameters are yet to be fully understood. The Hermia model predicts the decline of permeate flux with the ultimate flux of zero, for dead-end filtration (Hermia, 1982). In cross-flow filtration, membrane fouling is strongly affected by the shear flow, hence, the ultimate flux would be finite (non-zero) (Davis, 1992; Song, 1998). Nevertheless, the Hermia model has been successfully applied to cross-flow membrane filtration in a number of research studies (Hwang et al., 2007; Salahi et al., 2010). In addition, the effects of operating parameters on membrane fouling vary significantly among different systems. Other models developed and reported are thus also empirical and semi-empirical. Among those, the more popular ones are the resistance-in-series model and the concentration polarization model (Viadero et al., 1999; Bruijn et al., 2005; Ho and Zydney, 2002). These models are system-specific, and are thus their uses are limited when it comes to process generalization and scale-up. One-dimensional and two-dimensional models for the permeate flux in a tubular membrane, derived from equations of continuity and motion were also reported in scientific literature (Paris et al., 2002; Song, 1998). Consequently, in most cases empirical and semi-empirical models are used in the UF design. In addition, mono-dispersed suspensions (solutions with single-size particles) were implemented in many research studies. Arguably, this imposes a practical limitation on the extent to which the research results can be applied to the real-life cases involving wastewaters, and specifically, wastewaters where the suspended solids have a wide range of particle size distribution. 
The key question underlying membrane fouling and its practical applicability in ultrafiltration is the cause of foulant attachment to the membrane's surface. The two major forces contributing to the foulant attachment are the dispersion interaction force and the polar interaction force (Israelachvili, 1992). Foulants that remain attached to the membrane surfaces are most likely caused by the balance of the van der Waals attraction force, and the electrostatic repulsion force between particles and the membrane's surface due to the surface charges. Van Oss proposed the concepts of apolar and polar interactions in order to classify and effectively predict the interactions in an aqueous medium, based on the Derjaguin, Landau, Verwey, and Overbeek (DLVO) theory (Gregory, 2005). The strength of chemical attachment depends on the dispersion interaction (apolar), as well as, predominantly, on the polar interaction. The latter can be either attractive or repulsive, depending on the hydrophilicity of the two interacting surfaces (Gregory, 2005; Israelachvili, 1992). These interactions elucidate the advantages of altering the particle-to-membrane or particle-toparticle attachments by manipulating the zeta potential of the membrane surface or the ionic strength of the solution, as an effective fouling remediation technique and allow for a lower membrane fouling propensity.

Owing to this, the primary objectives of the present study were to:

- Investigate the mechanism of membrane fouling in ultrafiltration of latex paint with a wide range of particle size distribution with non-uniform pore size membranes.

- Develop, simulate, and validate a novel mechanistic mathematical model capable of offering an accurate estimation of the mass of fouling and the increase in the transmembrane pressure, applicable for both homogeneous and heterogeneous membranes with uniform and non-uniform pore size membranes, respectively.

- Obtain predictive models that would allow for accurate estimation of the fouling attachments, at a given operating condition, as well as, at a specific surface charge of the membrane surface.

- Investigate the various effects of the operating conditions and membrane surface zeta potential on fouling attachments, total mass of fouling, cake height, cumulative permeate flux, and specific power consumption in ultrafiltration of latex solution.

- Develop a set of innovative membrane fouling remediation techniques capable of enhancing the ultrafiltration performance and reducing power consumption. 


\section{Chapter 2 \\ LITERATURE REVIEW}

\subsection{Membrane filtration}

Membrane filtration is a process that separates solid constituents of a solution, and is based on the correlation between the sizes of the solid particles to the pore size of the membranes, as illustrated in Table 2.1 (Tchobanoglous et al., 2003).

Table 2.1: Comparison of different types of membranes (Tchobanoglous et al., 2003)

\begin{tabular}{|c|c|c|c|}
\hline Process & $\begin{array}{c}\text { Structure } \\
(\text { Pore size) }\end{array}$ & $\begin{array}{c}\text { Typical operating } \\
\text { range }(\boldsymbol{\mu m})\end{array}$ & $\begin{array}{c}\text { Typical constituents } \\
\text { removed }\end{array}$ \\
\hline Micro-filtration & $\begin{array}{c}\text { Macropore } \\
(>50 \mathrm{~nm})\end{array}$ & $0.08-2.0$ & $\begin{array}{c}\text { TTS, turbidity, some } \\
\text { bacteria and viruses }\end{array}$ \\
\hline Ultra-filtration & $\begin{array}{c}\text { Mesopores } \\
(2-50 \mathrm{~nm})\end{array}$ & $0.005-0.2$ & $\begin{array}{c}\text { Macromolecules, most } \\
\text { bacteria, some viruses }\end{array}$ \\
\hline Nano-filtration & $\begin{array}{c}\text { Micropores } \\
(<2 \mathrm{~nm})\end{array}$ & $0.001-0.01$ & $\begin{array}{c}\text { small molecules, most } \\
\text { viruses }\end{array}$ \\
\hline Reverse Osmosis & $\begin{array}{c}\text { Dense } \\
(<2 \mathrm{~nm})\end{array}$ & $0.0001-0.001$ & $\begin{array}{c}\text { Very small molecules, } \\
\text { metallic and ions }\end{array}$ \\
\hline
\end{tabular}

There are two main modes of membrane filtration, as illustrated in Figure 2.1. The first one is dead-end mode, where the feed is directed perpendicularly to the membrane's surface allowing for the separation of particles larger than the membrane pore size from the permeate stream. In this case, building up of the solid cake layer requires an increase in pressure on the feed side so as to achieve the desired permeate flow rate. The second mode is cross flow, where the feed flows parallel to the membrane's surface. In this mode, separation across the membrane occurs due to the pressure driving force, causing the clean solvent to pass through the membrane as a permeate stream; and hence, the retentate concentration increases. It was reported by Teuler and Glucina that the energy consumption of a cross-flow system is about $5 \mathrm{~kW} \cdot \mathrm{h} / \mathrm{m}^{3}$ permeate. Alternatively at the same operating conditions, for a dead-end filtration the energy consumption is only 0.1 to $0.2 \mathrm{~kW} . \mathrm{h} / \mathrm{m}^{3}$ permeates (Teuler and Glucina, 2003) 


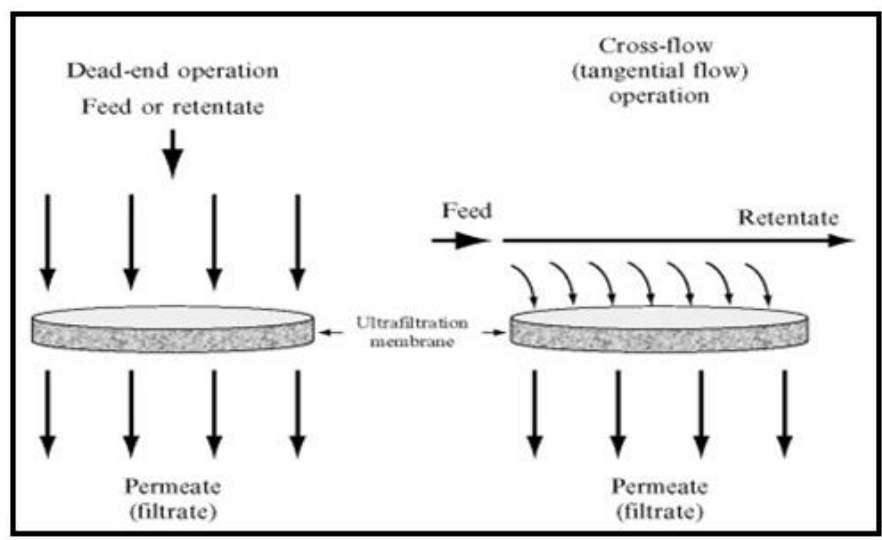

Figure 2.1: Illustration of Dead-End and Cross-flow modes of Ultrafiltration (Li et al., 2008)

Membranes are manufactured from either polymeric or ceramic materials. Polymeric membranes can be divided into two classes, namely, hydrophobic and hydrophilic. Hydrophilic polymers, such as: cellulose and its derivatives, Polysulfone (PS), polyethersulfone (PES), and polycarbonates (PC), have been used widely for the manufacturing UF membranes. Hydrophilic membranes tend to have less fouling than hydrophobic ones. For the fabrication of ceramic membranes, alumina, zirconia, titania, and glass are widely used. They are also known as inorganic membranes. Inorganic membranes remain remarkably stable at high temperature (over $100{ }^{\circ} \mathrm{C}$ ) and at extreme $\mathrm{pH}$, but they are brittle (Li et al., 2008). There are many configurations of membrane modules: tubular hollow fiber, plate and frame, spiral wound and rod (Russell, 2006). The most common one is tubular or flat sheet module. According to the American Water Works Association Research Foundation (AWWARF) survey in 2002, the capital cost for low pressure membrane system is in the range of $\$ 0.18-\$ 0.23 /$ gallon per day (gpd) and is expected to become even lower in the coming decades with values closer to \$ $0.15-\$ 0.20 /$ gpd (Lozier and Jacangelo, 2002; Mohanty and Purkait, 2012).

Membrane systems are operated under either constant flow rate with variable pressure or constant transmembrane pressure. To maintain a constant permeate flux for a membrane undergoing fouling an increase in transmembrane pressure is necessary. In constant-pressure systems, the permeate flux decreases with filtration time due to membrane fouling. In industrial applications, membrane process is usually operated under a constant permeate flow rate mode since most industrial processes are continuous. However, this can be very difficult to achieve and maintain for prolonged periods of time because of membrane fouling. 


\subsection{Membrane fouling}

Fouling refers to the build-up of solid compounds on the membrane's surface or within its pores, which leads to the reduction in the permeate flux at constant pressure. The rate of membrane fouling depends on the membrane module configuration, the mode of operation, the membrane material, operational conditions and the feed composition.

\subsubsection{Membrane fouling mechanism}

A typical flux-time curve of ultrafiltration (UF), as shown in Figure 2.2, starts with (I) a rapid initial drop of the permeate flux, (II) followed by a longer period of gradual flux decrease, and (III) ended with a steady-state flux.

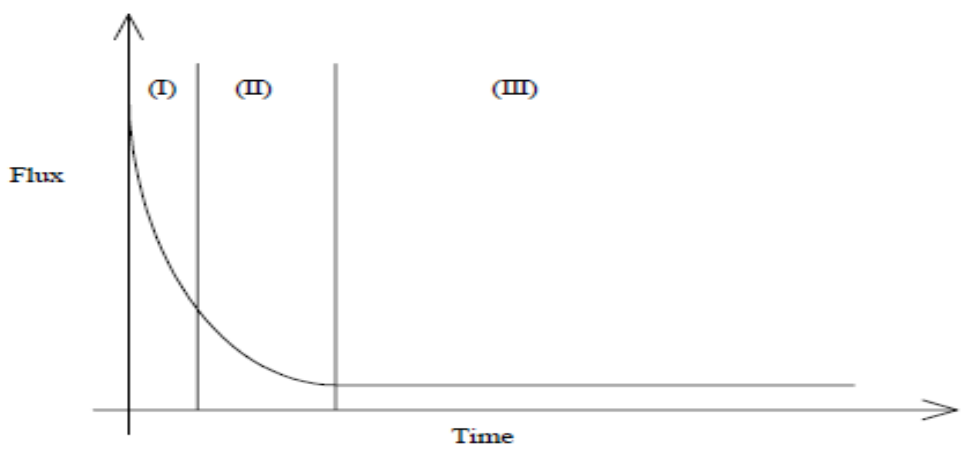

Figure 2.2: A Schematic presentation of the three stages in flux decline ( $\mathrm{Li}$ et al., 2008)

Flux decline in membrane filtration is a result of the increase in the membrane resistance by the membrane pore blockage and the formation of a cake layer on the membrane surface. The pore blocking increases the membrane resistance while the cake formation creates an additional layer of resistance to the permeate flow. Pore blocking and cake formation can be considered as two essential mechanisms of the membrane fouling.

The rapid initial drop of the permeate flux can be attributed to quick blocking of membrane pores. The maximal permeate flux always occurs at the beginning of filtration because membrane pores are clean and widely open at that moment. Flux declines as membrane pores are being blocked by retained particles. The degree of pore blockage depends on the shape and relative size of particles and pores. The blockage is generally more complete when the particles and pores are similar in both shape and size (Belfort and Zydney, 1994; Hermia, 1982; Javacek and Bouchet, 1993). Pore blocking is a quick process compared with cake formation since less than one layer of particles is sufficient to achieve the full blocking (Granger et al., 1985; Javacek and Bouchet, 1993). 
Further flux decline after pore blockage is due to the formation and growth of a cake layer on the membrane surface. The cake layer is formed on the membrane surface as the amount of retained particles increases. The cake layer creates an additional resistance to the permeate flow and the resistance of the cake layer increases with the growth of cake layer thickness. Consequently, the permeate flux continues decreasing with time.

\subsubsection{Concentration polarization and mass transfer theory}

Concentration polarization is caused by the build-up of inorganic species at the membrane-liquid interface, and resulting in a region of higher concentration if compared to the overall bulk. Concentration polarization leads to the reduction in permeate flux due to the formation of gel layer (Benitez et al., 2009).

As illustrated in Figure 2.3, at steady state with a well-established gel layer, the solute mass transfer by the convective flux, $J_{v}$, within the laminar boundary layer is balanced by the diffusive flux of the retained solute in the opposite direction, as expressed below:

$J_{V} c_{i}=D_{i} \frac{d c_{i}}{d x}$

Equation (2.1)

where $D_{i}$ is the diffusion coefficient of the macromolecule in the boundary layer, $\frac{d c_{i}}{d x}$ is the concentration gradient in $\mathrm{x}$ direction. Integration of Equation (2.1) gives the equation for the permeate flux as below (Song and Elimelech, 1995).

$J_{V}=\frac{D_{i}}{\delta} \ln \frac{C_{g e l}}{C_{i b}}$

Equation (2.2)

where $c_{i b}$ is the feed concentration or the bulk concentration, $c_{g e l}$ is the concentration of solute at the insoluble gel layer-feed solution interface and $\delta$ is the boundary layer thickness.

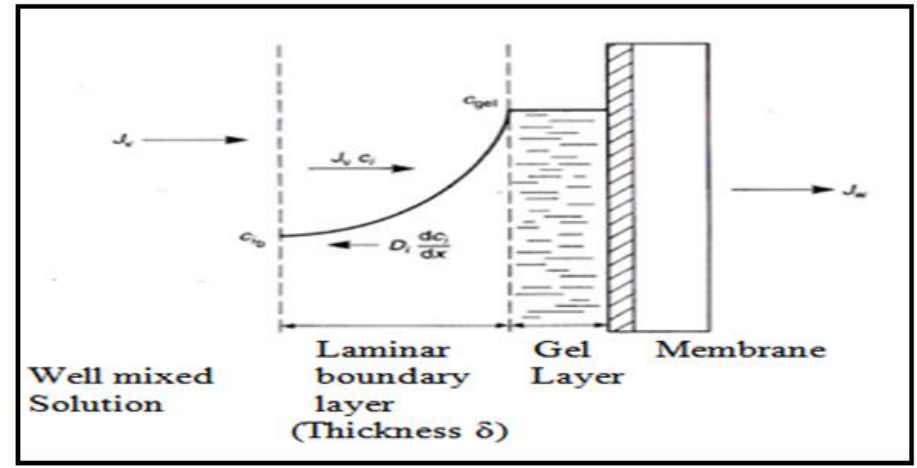

Figure 2.3: Illustration of the formation of a gel layer of colloidal material on the surface of an ultrafiltration membrane by concentration polarization (Um et al., 2001) 


\subsection{Mathematical models for membrane fouling}

Pursuant to the understanding of different roles of aquatic components in membrane fouling, different mathematical models have been developed to describe the membrane fouling. There are many empirical models found in literature (Mendret et al., 2010; Ahmad et al., 2006; Bhattacharjee and Datta, 2003). However, empirical models usually require extensive pilot and full scale tests in order to obtain the required constants to predict the permeate flux. In most cases these constants also have little physical meanings. These models also offer limited insight into the mechanism of fouling. Among those, the more popular one is the resistance-in-series model. The permeate flux $J,\left[\mathrm{~m}^{3} / \mathrm{m}^{2} . \mathrm{s}\right]$ is expressed as below:

$J=\frac{\Delta \mathrm{P}}{\mu\left(R_{m}+R_{c}\right)}$

Equation (2.3)

where $\Delta P[\mathrm{~Pa}]$ is transmembrane pressure, $\mu[\mathrm{Pa} . \mathrm{s}]$ is the solution viscosity and $R m\left[\mathrm{~m}^{-1}\right]$ is the hydrodynamic resistance of clean membrane. The hydrodynamic resistance of cake layer $R c\left[\mathrm{~m}^{-1}\right]$ is defined as:

$R_{c}=\hat{R}_{c} \cdot m_{d}$

Equation (2.4)

where $\hat{R}_{c}[\mathrm{~m} / \mathrm{kg}]$ is the specific cake resistance of the cake layer on the membrane surface and $m_{d}\left[\mathrm{~kg} / \mathrm{m}^{2}\right]$ is the mass of deposit per unit surface area of membrane (Chellam et al., 1998; Kim and Hoek, 2002; Zhang and Song, 2000). However, the model does not explain the mechanisms of fouling, but only indicates the proportionality between the increase in hydrodynamic resistance and the mass of deposit on the membrane as filtration proceeds. The values of $\hat{R}_{c}$ vary from $10^{10}$ to $10^{16} \mathrm{~m} / \mathrm{kg}$ for different aquatic substances (Endo and Alonso, 2001). The resistance-in-series model has been used frequently to analyze membrane fouling phenomenon. Although it is easy to apply, one should be cautious in the use of this model as it doesn't consider pore blocking mechanism (Song and Elimelech, 1995; Viadero et al., 1999).

Kosvintsev et al. developed a model to describe membrane fouling by physical sieving of particles larger than membrane pore sizes (Kosvintsev et al., 2002). According to their analysis, membrane fouling by cake filtration does not start right after the onset of filtration, and the fouling is rather dominated by pore blocking until the membrane surface is covered by particles. This model describes the permeate volume as a function of permeate time, dominated by pore blocking at constant pressure as follows:

$$
\mathrm{V}=\frac{1}{\gamma n \beta} \ln \left(1+\beta t^{*}\right)
$$


where $\mathrm{V}$ is the permeate volume $\left[\mathrm{cm}^{3}\right], \beta$ it is the ratio of the membrane area fouled with particles to the area of clean pores. $n$ represents the number of particles per unit volume of the feed, $\gamma$ is the ratio of the pores area to the total membrane area and $t^{*} i s$ the dimensionless filtration time $=\gamma n \int_{0}^{t} \frac{d V}{d t} t$. More details of the model are presented in the authors' recent work (Bruijn et al., 2005; Kosvintsev et al., 2004). This model was limited to pore blocking fouling and the effect of cake layer on the permeate volume was not considered.

Zydney et al. combined two fouling mechanisms, pore blockage and cake formation, to describe fouling of low pressure membranes by proteins and humic acids (Ho and Zydney, 2002 ; Srebnik, 2003; Yuan et al., 2002). Again, this model is established by assuming that the fouling is caused primarily by large particles, aggregates of proteins and humic acids. The mathematical development is based on constant pressure operation and varying flux, and it can be written as below:

$\frac{\mathrm{J}}{\mathrm{J}_{\mathrm{o}}}=\exp \left(-\frac{\mathrm{K}_{\mathrm{b}} \Delta \mathrm{P} \mathrm{C}_{\mathrm{b}}}{\mu R_{m}} \mathrm{t}\right)+\frac{R_{m}}{R_{m}+R_{C}}\left[1-\exp \left(-\frac{\mathrm{K}_{\mathrm{b}} \Delta \mathrm{P} \mathrm{C}_{\mathrm{b}}}{\mu R_{m}} \mathrm{t}\right)\right]$

Equation (2.6)

where $\mathbf{J}$ and $\mathbf{J}_{0}\left[\mathrm{~m}^{3} / \mathrm{s}\right]$ are the permeate flux at a given time and the initial flux through the unfouled membrane respectively, $\mathrm{K}_{\mathrm{b}}\left[\mathrm{m}^{2} / \mathrm{kg}\right]$, a pore blockage parameter, which is equal to the blocked membrane area per unit mass of aggregates convected to the membrane. This parameter can be evaluated experimentally. $C_{b}\left[\mathrm{~kg} / \mathrm{m}^{3}\right]$ is the bulk concentration of large aggregates, $R_{m}[1 / \mathrm{m}]$ is the clean membrane resistance, $R_{c}$ is cake layer resistance $[1 / \mathrm{m}], \mu$ is the solution viscosity and $\Delta \mathrm{P}$ is the transmembrane pressure [Pa]. Both resistances can be evaluated experimentally. The right-hand side of the equation has two terms that are related to pore blocking and cake formation, respectively. The first term (pore blocking) dominates the early stage of fouling, and the second term (cake filtration) governs fouling at longer times. The impact of solution chemistry on membrane fouling and the chemical attachment between paticles, however, not included in the model.

In comparison to the aforementioned models, adsorptive fouling of membranes by particles smaller than membrane pore sizes is incorporated in the following model. The impact of the adsorption layer on the permeability of membranes can be estimated using a modified form of Hagen-Poiseulle capillary filtration model (Srebnik, 2003) from Equation 2.7 .

$$
\frac{J}{J_{o}}=\left[1-\frac{\delta \prime}{r_{p}}\right]^{4}
$$


where $J$ and $J_{0}\left(\mathrm{~m}^{3} / \mathrm{m}^{2}\right.$. s) are the permeate flux after the formation of the adsorptive fouling layer and the initial flux, respectively. Under a given transmembrane pressure, $\delta^{\prime}(\mathrm{m})$ is the thickness of the adsorption layer that can be measured experimentally and $r_{p}(m)$ is the membrane pore radius. The major difficulty in applying the adsorptive fouling model to filtration of natural surface waters lies in the complex nature of aquatic Natural organic matters (NOM). In other words, the value of $\delta^{\prime}$ is not easy to obtain either theoretically or experimentally. This problem is further complicated by the heterogeneity of membrane surface properties.

Hermia developed four empirical models for four basic types of fouling: complete blocking, intermediate blocking, standard blocking, and cake layer formation (Hermia, 1982). Each mode of fouling depends on the size of particles and whether they are either larger or smaller than the membrane pore size. In the complete blocking mode, the particles larger than the pore size are adsorbed onto the membrane's surface. In intermediate blocking, the particles of similar size to that of the pore cause an obstruction of the pores. Typically, it is assumed that the particles are chemically adsorbed into the surface, and the new particles arriving to the membrane are blocked by the already adsorbed particles. Standard blocking involves adsorption of small particles (smaller than the pore size) into the membrane pore walls, resulting in some restriction for the permeate flow going through the pores. The final mode of fouling is the formation of a cake layer due to a build-up of particles on the membrane's surface. Particles involved in the formation of the cake layer may be larger or smaller than the membrane pore size (Bowen et al., 1995; Hwang and Lin, 2002). Schematic diagrams of the four fouling modes are presented in Figure 2.4.

(a)

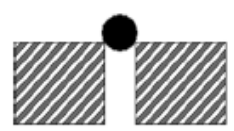

(c)
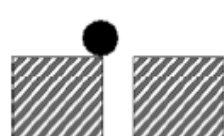

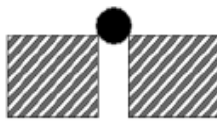

(b)

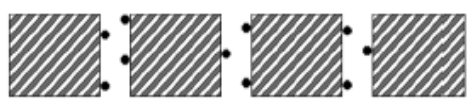

(d)
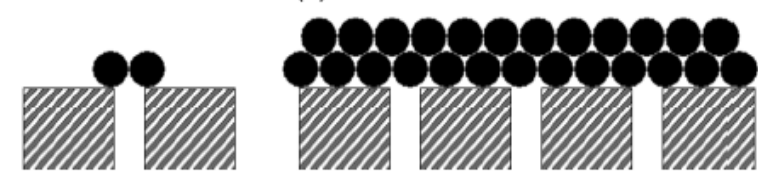

Figure 2.4: Schematic diagram of membrane fouling modes proposed by Hermia: (a) complete pore blocking; (b) internal pore blocking (standard pore blocking); (c) intermediate pore blocking; (d) cake filtration (Vela et al., 2008) 
The basic expression for Hermia for constant flux is:

$\frac{d P^{\prime}}{d m_{f}^{\prime}}=\mathrm{k} P^{\prime n}$

Equation (2.8)

where $\mathrm{P}^{\prime}$ is the increase in TMP, $m_{f}^{\prime}$ is the mass of particles that attach to the membrane surface, $\mathrm{k}$ and $\mathrm{n}$ are constants depending on the type of fouling. k equals to $\frac{\hat{\mathrm{R}} c}{R_{m}}$ and $\frac{2}{L_{m} \rho}$ for cake formation and standard pore blocking, respectively, while $\mathrm{k}$ is simply equal to the projected area of a particle on the membrane surface $(\sigma)$ for both intermediate and complete blocking models. $\hat{R} c$ and $R_{m}$ are the specific cake resistance $[\mathrm{m} / \mathrm{kg}]$ and the membrane resistance $[1 / \mathrm{m}]$, respectively. $L_{m}$ is the length of cylindrical membrane pore and $\rho$ is the particles density. Values for $n$ are $0,1,3 / 2$ and 2 for cake formation, intermediate blocking, standard blocking and complete blocking, respectively. Overall, the Hermia model does not adequately consider all of the chemical aspects involved in fouling, however it does provide a useful preliminary evaluation of the efficacy of different types of particle attachments on fouling once it occurs (Appendix A).

\subsection{Chemical attachment of foulants on membrane surfaces}

The major forces contributing to the attachments are dispersion interaction force and polar interaction force (Israelachvili, 1992). Foulants staying together on membrane surfaces are most likely due to the balance of the van der Waals attractive force and the electrostatic repulsion between particles and the membrane surface due to the surface charges.

To represent the dispersion interaction, the Hamaker constant can be used. It is an indicator of the strength of van der Waals interactions forces between macroscopic bodies through a third medium, as presented in Figure 2.5.Typical values of the Hamaker constant are in the range of $10^{-19}-10^{-21} \mathrm{~J}$. It can be estimated using the Lifshitz theory of macroscopic van der Waals interaction forces (Israelachvili, 1992). Van Oss postulated the concepts of apolar and polar interactions to classify and predict the interactions in an aqueous medium, based on the DLVO theory (Israelachvili, 1992; Gregory, 2005) . The apolar interaction is mainly dispersion interaction. On the other hand, the polar interaction is the interaction between Lewis acid-base pairs in the system, including the two interacting entities and surrounding water molecules. These interactions are useful in explaining the advantage of hydrophilizing the membrane surface to reduce the irreversible attachment of particles and other fouling materials on membrane surface (Carroll et al., 2002; Hester and Mayes, 2002; Liu et al., 2003; Taniguchi, 2003; Wavhal and Fisher, 2003; Yu et al., 2005). The 
strength of chemical attachment depends not only on the dispersion interaction (apolar), but also, or even more predominantly, on the polar interactions. The latter can be either attractive or repulsive dependent on the hydrophilicity of the two interacting surfaces. All aforementioned chemical attachment mechanisms are based on the assumption that the interacting surfaces have homogeneous surface properties, and thus can be characterized using some global parameters, such as: charge density, hydrophobicity, and the Hamaker constant. However, this may not be realistic because particles could have heterogeneous surfaces. Different parts of the surface have different affinities to the membrane.

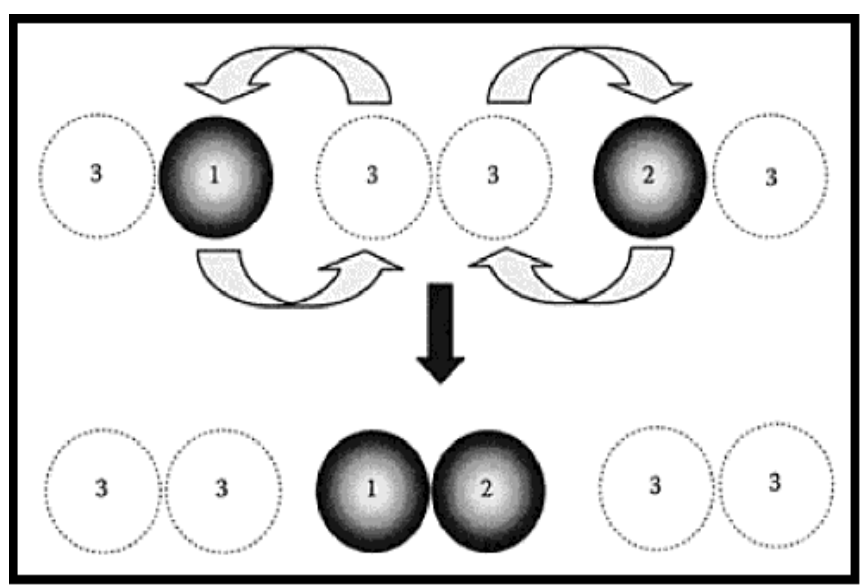

Figure 2.5: Interaction between 2 microscopic bodies 1 and 2 through medium (Israelachvili, 1992)

\subsection{Factors affecting fouling}

There are a number of key factors affecting fouling. The membrane properties play a critical role in membrane fouling, especially, properties such as pore size, hydrophobicity, pore size distribution, and membrane material. The solution properties are likewise essential in determining how fouling formation occurs. Some of the aspects that can affect fouling and relate to the solution are $\mathrm{pH}$, solid concentration, particle size, and physical and chemical characteristics of particles. Finally, the operating conditions, such as, temperature, flow rate, and pressure, are all contributing factors to fouling formation.

\subsubsection{Membrane Properties}

In an aqueous environment a membrane can be attractive or repulsive to water. The composition of the membrane and its corresponding surface chemistry determine its interaction with water, thus affecting its wettability. The wettability of the membrane can be determined by measuring the contact angle between the membrane surface and a droplet of water, as shown in Figure 2.6. Hydrophilic membranes are characterized by the presence of 
active groups that have the ability to form hydrogen-bonds with water and so water droplets spread out on the membrane surface as can be seen in Figure (2.6.a). Hydrophobic membranes have the opposite interaction to water compared to hydrophilic membranes as they have little or no tendency to absorb water and water tends to bead on their surfaces (i.e. discrete droplets) as shown in Figure (2.6.b). Hydrophobic membranes possess low wettability due to the lack of active groups in their surface for the formation of hydrogenbonds with water. This tends to enhance fouling. Usually, greater charge density on a membrane surface is associated with greater membrane hydrophilicity. Hydrophilic membranes are thus often used for water treatment and wastewater recovery to reduce fouling.

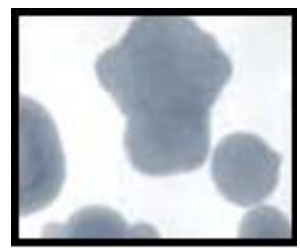

(a)

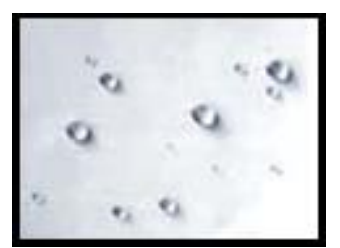

(b)

Figure 2.6: (a) Hydrophilic membrane, (b) Hydrophobic membrane (Al-Amoudi and Lovitt, 2007)

Membrane morphology also has a considerable effect on fouling as pore size, pore size distribution and pore geometry, especially at the surface of the membrane. These determine the predominant fouling mechanisms such as pore blocking and cake formation as previously discussed in Section 2.2.1.

\subsubsection{Solution Properties}

The properties of the feed solution also significantly influence membrane fouling. Some of the important feed properties are solid (particle) concentration, particle properties, $\mathrm{pH}$ and ionic strength. Generally, an increase in the feed concentration results in a decline in the permeate flux. This is due to the increase in membrane fouling rate. Particles can cause fouling by pore blocking, pore narrowing or cake formation, dependent on the particle sizes. In a filtration process, the particle sizes in the feed often cover a wide range. The presence of fine as well as coarse particles results in a lower cake porosity as the fine particles can slide between the large ones, filling the interstices (Vyas, 2000). The range of the particle size distribution plays a major role in the selective deposition. In addition to the particle size, the particle shape affects the porosity of the cake formed on the membrane surface. In general, the lower the particle sphericity, the greater is the porosity (Vyas, 2000). 
Some other factors, such as: $\mathrm{pH}$, ionic strength, and electric charges of particles, are also important. The $\mathrm{pH}$ and ionic strength of the feed affect the charge on the membrane, the charge on the particles, conformation and stability of the particles, and there by adhesiveness of particles/molecules and the size of the cake.

\subsubsection{Operating Conditions}

The effect of temperature on the permeate flux was investigated and found that at higher temperatures, the permeate flux increased, indicating a lower degree of fouling. Changing the feed temperature from $20^{\circ} \mathrm{C}$ to $40^{\circ} \mathrm{C}$ led to an increase in the permeate flux up to $60 \%$ (Salahi et al., 2010).

The effect of the cross-flow velocity on the permeate flux has been studied for a wide variety of feed solutions. It is believed that increasing the cross-flow velocity positively affects the permeate flux (Salahi et al., 2000). Larger cross-flow velocity leads to a reduction of aggregation of the feed solids in the gel layer, essentially due to increasing diffusion of these components back towards the bulk, leading to an overall reduction in the effect of concentration polarization.

The transmembrane pressure (TMP) between the feed side and the permeate stream greatly affects the permeation rate. At a higher TMP, the force of the fluid flowing towards the membrane is increased, leading to a higher permeate flux. As the applied pressure is increased, the resulting higher flux leads to the increase in the concentration polarization at the membrane surface. If the pressure is increased further to a critical pressure, concentration polarization becomes large enough for the accumulation of solutes at the membrane surface to form a gel layer. Once the gel layer has formed, further increase in the applied pressure does not lead to further increase in the permeate flux above this critical value. The gel layer thickness and the density of the retained material at the membrane surface, however, increases. This limits the permeate flux through the membrane. It was reported that no fouling was experimentally observed when the process was operated under this critical flux.

\subsection{Remediation of membrane fouling}

Fouling remediation can be done through the pre-treatment of the feed with surfactants so as to limit its fouling propensity and allow for the micellar-enhanced filtration, change $\mathrm{pH}$ of the feed, improvement of antifouling properties of the membrane, and optimization of operating conditions. 


\subsubsection{Micellar-Enhanced filtration}

Micellar enhanced ultrafiltration is an emerging technique that is used to improve the performance of a filtration process by adding a surfactant to the feed in order to promote the entrapment of foulants in the micelles formed by the surfactant. Surfactants are molecules that contain a hydrophobic tail (usually long chain hydrocarbon) and a hydrophilic head, as shown in Figure (2.7.a). Above a specific concentration surfactant molecules come together to form clusters or micelles as illustrated in figure (2.7.b). This concentration is termed the critical micelle concentration (CMC) and differs depending on the specific surfactant being implemented.

Surfactants can be generally categorized by the charge of the hydrophilic portion of the molecule as: anionic (negatively charged), cationic (positively charged), non-anionic (neither positively nor negatively charged), and zwitterionic (both negatively and negatively charged). The formation of micelles increases the particle size, allowing for the use of membranes with larger pore sizes while maintaining the same feed. Some surfactants also interfere with hydrophobic interactions between foulants and membranes (Byhlin and Jonsson, 2002).

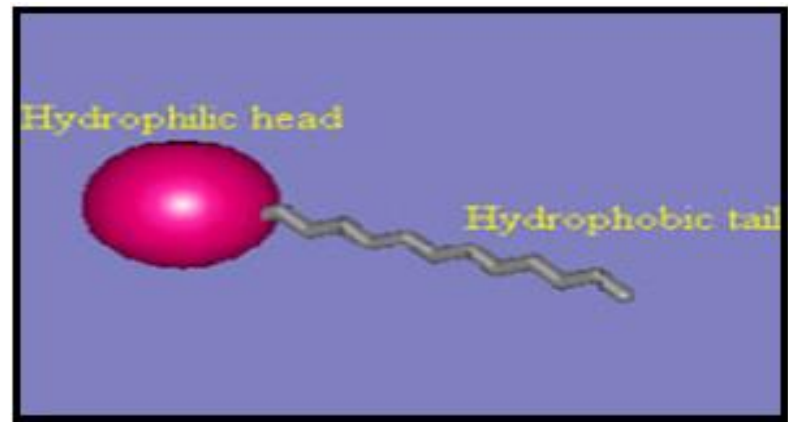

(a)

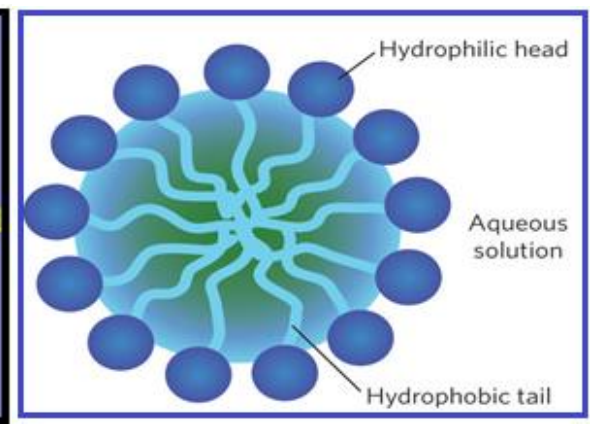

(b)

Figure 2.7: Illustration of (A) Surfactant molecule (b) micelle composed of a number of surfactant molecules.

Bedasie et al., 2010, reported that adding cationic surfactants, like Cetyl trimethylammonium bromide (CTAB), resulted in an improved ultrafiltration of the latex paint wastewater, while the permeate flux increased up to 134\% (Bedasie et al., 2010).

Mikulasek (Mikultiek and Cakl, 1994) reported that addition of 5\% wt. /wt. of an anionic surfactant (Disponil AES 60, Henkel, Germany) to a latex solution was the most effective way of enhancing latex ionic strength since a pre-treatment prior to microfiltration resulted in nearly four times higher permeate flux. Influences of surfactants on membrane fouling are mostly governed by the surfactant molecular structure and the hydrophilicity of the membrane surface. 


\subsubsection{Effects of change in $\mathrm{pH}$ of the feed on membrane fouling}

The ionic strength of the feed solution significantly alters the membrane surface properties and interactions of colloidal foulants, thus affecting the fouling potential ( Singh and Song, 2005; Binks and Horozov, 2006). For hydrophilic membranes, membrane fouling decreased when the ionic strength of the feed solution was amplified through the increase of the solution $\mathrm{pH}$. This was attributed to the augmentation of the electrostatic repulsion forces between the foulants and the membrane surface, due to the increased negative charge on the membrane surface (Childress and Elimelesh, 1996; Chun et al., 2002; Deshrnukh and Childress, 2001; Elimelech et al., 2010; Faibish et al., 1998; Jones and O'Melia,2000; Mika et al., 2006; Nal and Yonggang, 2012).

It was reported that polyacrylic acid was usually very well rejected by an ultrafiltration membrane at $\mathrm{pH}$ of 5 and above, but was completely permeable through the same membrane at $\mathrm{pH}$ of 3 and lower. This change in rejection behaviour was related to the alteration of the configuration of the polyacid. In a solution at $\mathrm{pH}$ of 5 or higher acrylic acid was ionized. In the ionized form, the negatively charged carboxyl groups along with the polymer backbone repelled each other, hence, the polymer coil was extended considerably and made relatively inflexible. In this form, the molecule couldn't readily permeate small pores in an ultrafiltration membrane. At $\mathrm{pH}$ of 3 or lower, the carboxyl groups along the poly acrylic acid polymer backbone were all protonated. The resulting neutral molecule was significantly more flexible and could pass through the membrane's pores (Li et al., 2008). Moreover, the $\mathrm{pH}$ of the solution affects the membrane surface properties. At low $\mathrm{pH}$, the hydrophilic membrane becomes less negatively charged, resulting in more attraction with the latex. However, at a high $\mathrm{pH}$, the negative charge of the membrane as well as the ionic strength of the latex particles increase, resulting in a higher repulsion force between particles and the membrane surface. Owing to this, the membrane fouling decreases and permeates flux increases (Childress and Elimelesh, 1996).

\subsubsection{Membrane properties modification}

The enhancement of the hydrophilicity of membranes can help reducing membrane fouling (Chang et al., 2008; Gullinkala and Escobar, 2008; Hua et al., 2008). Various techniques can be used to increase the membrane surface hydrophilicity. In comparison to other surface modification techniques, such as: plasma treatment, irradiation with gammarays, corona discharge, ion beam treatment and UV radiation, ozonation is an inexpensive method which allows for simple and relatively effective operation (Wang et al., 2000). 
Moreover, ozonation offers a uniform surface modification even in cases with complicated shapes (Yuan, Y. Et al., 2002). When polymers are exposed to ozone, active peroxide groups are introduced onto the surface. These active peroxide groups are capable of initiating graft polymerization of vinyl monomers with hydrophilic groups. The hydrophilicity of the polymer surfaces is thus improved (Gatenholm et al., 1997). Ozonation can be conducted in either gaseous phase or aqueous phase. Notably, aqueous ozonation facilitates the rapid decomposition of molecular ozone and the formation of free radicals which are stronger oxidants than ozone itself. Oxidation by molecular ozone is defined as direct oxidation as in a gaseous ozonation while oxidation by radicals formed from the ozone's reaction with water is defined as indirect oxidation (Hoigne and Bader, 1976).

It was reported that in surface hydrophilicity modification of polypropylene, low density polyethylene, and high density polyethylene membranes, the generation of peroxide increased with ozonation time and applied ozone dose regardless of whether the ozonation was conducted in aqueous phase or in gaseous phase (Gu et al., 2012; Patel et al., 2012). It was determined that for hydrophilicity improvement, aqueous ozonation was noticeably more effective than gaseous ozonation while catalytic ozonation was the most effective one (Gu et al., 2012; Gu et al., 2009; Patel et al., 2012). The above conclusion was supplemented by the results of lower measured contact angles, the surface characterization with new peaks occurring at $1716 \mathrm{~cm}^{-1}$ by FTIR and the increased intensity of the peak with the applied ozone dose. This peak corresponds to aliphatic aldehydes, carboxylic acids, and aliphatic ketones (Patel et al., 2012). Results of filtration tests likewise showed that the protein adsorption on the membrane was reduced more for the aqueous phase ozonated membrane. Moreover, peroxide generation was very stable, featuring a reduction in the peroxide amount after 30 days of only around 3\%. $\mathrm{pH}$ is an essential parameter in aqueous ozonation because ozone self-decomposition in water depends on the $\mathrm{pH}$. It was found that the concentration of peroxides decreased gradually with an increase in pH (Patel et al., 2012).

Hydrophilization of the membrane's surface can also be conducted by pre-coating the membrane with a nonionic surfactant. This method is highly effective and reliable in practical application because of its simple operation. With hydrophilization treatment, the ultrafiltration of antifoam rejection was improved significantly, and hence, the permeate flux was almost doubled (Noble and Stern, 1995). Keesom investigated polycarbonate membrane surface modification by adsorption of ionic surfactants on the membrane surface (Keesom et al., 1988). The authors reported that by adding Sodium dodecyl sulfate (SDS), even at very low concentrations at $\mathrm{pH}$ of 7 or higher, the zeta potential of membrane surface is negatively 
increased up to $-25 \mathrm{mV}$. Increasing the membrane surface charge results in permeates flux being doubled and the flux decline rate with time decreased.

\subsection{Economic Aspects}

The use of membrane systems has experienced an exponential growth over the last 5 years due to their capacity to deliver drinking water and wastewater that meet stringent industry compliance standards. The average annual growth rate of UF is $9.7 \%$ from $\$ 458$ million in 2002 to $\$ 727$ million in 2007. The global market of UF was raised to more than $\$ 3$ billion in 2010 (Wang et al., 2011). Lower UF costs are spurred by increased competition, higher demand that regulate the economic policies in manufacturing, and more efficient process operation methods (Mohanty and Purkait, 2012). According to the American Water Works Association Research Foundation AWWARF survey in 2002, the capital cost for low-pressure membrane system is currently in the range of $\$ 0.18-\$ 0.23 /$ gallon per day (gpd) and is expected to lower to \$0.15-\$0.20/gpd in coming decades (Lozier and Jacangelo, 2002; Mohanty and Purkait, 2012). This means that the majority of cost reduction methods incited by the competitive market environment have already been realized in the past few years. Further reduction in cost would largely come from either the development of high flux, low fouling membranes, or the incorporation of more efficient ways to operate both of these factors in membrane systems. The membrane can be considered as the core of a desalination plant where the cost of membrane unit is about $20-25 \%$ of the total capital cost (Al-Amoudi and Lovitt, 2007).

With the introduction of membrane fouling reducing strategies, significant savings can be achieved with respect to membrane and replacement costs. To compare the costs of a membrane plant with and without fouling control, consider the following case for a 36-Mgd (million gallons of water processed daily) at a wastewater plant in Table (2.2) (Caothien and O'Connell, 2002). This case study analysis was based on a 20 -year life cycle of the plant equipment, membrane replacement period of 10 years, and a $6 \%$ interest rate. Operating the membranes at enhanced flux capacities resulted in 30\% savings of the original projected costs. The raised energy costs for pumping/heating and chemicals (operating cost) were minor in comparison to the savings in membrane capital and replacement costs (Caothien and O'Connell, 2002). 
Table 2.2: Present worth Costs for a 36-mgd Plant with reducing fouling protocols

\begin{tabular}{|c|c|c|c|c|}
\hline & $\begin{array}{c}\text { Yearly } \\
\text { Operating } \\
\text { Cost }\end{array}$ & $\begin{array}{c}\text { System } \\
\text { Capital Cost }\end{array}$ & $\begin{array}{l}\text { Membrane } \\
\text { replacement } \\
\text { cost }\end{array}$ & $\begin{array}{c}\text { Total Project } \\
\text { Cost }\end{array}$ \\
\hline 40 GFD & $\$ 248,000$ & $\$ 10,800,000$ & $\$ 4,400,000$ & $\$ 18,000,000$ \\
\hline $\begin{array}{l}75 \text { GFD flux } \\
\text { enhancement }\end{array}$ & $\$ 255,000$ & $\$ 7,100,000$ & $\$ 2,600,000$ & $\$ 12,600,000$ \\
\hline Saving & $(\$ 7,000)$ & $\$ 3,700,000$ & $\$ 1,800,000$ & $\$ 5,400,000$ \\
\hline \multicolumn{4}{|c|}{ GFD : Gallons per square foot per day } & Saving $30 \%$ \\
\hline
\end{tabular}

It was also reported that for a wastewater treatment plant with a capacity of 100 $\mathrm{m}^{3} /$ day, the energy consumption is more than $10 \mathrm{KWh} / \mathrm{m}^{3}$ that can be reduced to $3.5 \mathrm{KWh} / \mathrm{m}^{3}$ if fouling is effectively controlled (Avlonitis, 2003; Colic, 2007)

These economics of wastewater treatment emphasize the necessity to prioritize membrane fouling research. Economic and innovation potential that exists in membrane research needs to be explored further through the development of novel techniques for the reduction and prevention of membrane fouling, and minimizing the overall operating costs based on chemical consumption, energy consumption, cleaning frequency, and membrane life time. 


\section{CHAPTER 3 MODEL DEVELOPMENT}

In this study a novel mechanistic model of membrane fouling was developed for homogeneous and heterogeneous membranes. The derivations of the model equations are illustrated in details in Appendix (B).

\subsection{Modeling Approach}

One of the research objectives is to develop a model that is capable of assessing the effect of physiochemical/chemical attachment potentials on ultrafiltration membrane fouling by latex. As indicated in this chapter some appropriate assumptions on physical and chemical properties of ultrafiltration membranes are made in order to establish a simple but useful mathematical model for an in-depth understanding of the fouling phenomenon.

\subsection{Model development for uniform pore size membrane}

Membrane fouling refers to the blockage of membrane pores through the combination of sieving and adsorption of the particles into the membrane surface or within the membrane pores during the ultrafiltration process, followed by a cake layer formation. Fouling is primarily ascribed to the existence of favorable chemical attachments among foulant entities (coagulation attachment) and between foulants and membrane surfaces (depositional attachment). The attachment probabilities are dependent not only on the properties of the foulants and the membranes, but also on the solution chemistry and the operating conditions. In the present study, a mathematical model was developed to predict the amount of fouling based on analyses of particle attachments in ultrafiltration of a latex paint solution. The mathematical model was combined with Hermia model to further develop models for transmembrane pressure prediction.

\subsubsection{Model Assumptions}

It is assumed that the entire surface of the polycarbonate ultrafiltration membrane has homogeneous chemical properties, and hence, the attachment probability between the membrane and a particle $\left(\alpha_{\mathrm{pm}}\right)$ is the same everywhere on the membrane. Likewise, it is also assumed that the particle-to-particle attachment probability $\left(\alpha_{\mathrm{pp}}\right)$ is uniform throughout the filtration system. Also, latex particles are assumed to be nondeformable, spherical particles possessing uniform surface properties. The sizes of latex particles and membrane pores are regarded as the primary factor in determining the occurrence of surface fouling (cake layer formation or pore blocking) and adsorptive internal 
plugging. The radius of a latex particle (represented as a) could be either greater or smaller than the membrane pore radius $\left(D_{m} / 2\right)$ since the simulated latex paint wastewater has a wide particle size distribution. Therefore, due to the poly-dispersed nature of the latex paint solution, the models were developed for different particle size ranges with respect to the membrane pore diameter. For cross-flow filtration, the collision and attachment of particles to particles and/or particles to membrane occur in the flow boundary layer (Romero and Davis, 1999). Not all collisions result in attachments as indicated by the probability of attachment less than 1 . The projected area of a unit mass of the particles on membrane surface, $\sigma\left[\mathrm{m}^{2} / \mathrm{kg}\right]$ is calculated as:

$\sigma=\frac{0.75}{\rho a}$

Equation (3.1)

where $\rho$ is the particle density $\left[\mathrm{kg} / \mathrm{m}^{3}\right]$.

On the other hand, the structure of UF membranes is simplified as homogenous porous bodies with uniform circular cylindrical pores. The diameter of the pores, $D_{m}[\mathrm{~m}]$, is related to the mean pore size of the commercial membrane used in the study as determined in solute rejection tests. The length of membrane pores is $L_{m}[\mathrm{~m}]$, the number density of membrane pores is $N_{m}\left[1 / \mathrm{m}^{2}\right]$. And the surface porosity of the membrane is $\varepsilon_{\mathrm{s}}$ [dimensionless].

The attachment potentials between a latex particle and the ultrafiltration membrane and between two latex particles denoted as $\alpha_{\mathrm{pm}}$ and $\alpha_{\mathrm{pp}}$, respectively are defined as:

$\alpha_{\mathrm{pm}}[$ dimensionless $]=\frac{\text { Rate at which particles attach on membrane surface }}{\text { Rate at which partilces collide with membrane surface }}$

$\alpha_{\mathrm{pp}}[$ dimensionless $]=\frac{\text { Rate at which particles attach to each other }}{\text { Rate at which partilces collide with each other }}$

These two attachment probabilities are the key parameters of the model. It is assumed that the entire surface of the membrane has homogeneous chemical properties and therefore the attachment probability between the membrane and a particle $\left(\alpha_{\mathrm{pm}}\right)$ is the same everywhere inside and outside the membrane pores, including solid surface and pore openings. Likewise, it is also assumed that the attachment probability $\left(\alpha_{\mathrm{pp}}\right)$ is uniform for particles in the feed water or between a particle in the feed stream and a particle attached on the membrane surface. 
In order to develop a model based on the process of membrane fouling, fouling is considered having three consecutive steps: collision, attachment and reduction of permeability. The developed model was based on the modified Hermia model for a constant flux as illustrated in Appendix (A). The latex particle distribution will be divided by its size to contribute to the fouling modes.

\subsubsection{Particles Size Classification}

\subsubsection{Large particles (Particle diameter $\geq$ pore diameter) $\left(a \geq D_{m} / 2\right)$}

The reduction of membrane permeability is dominated by pore blockage and the cake layer formation if the fouling is caused by particles larger than the pore size. Apparently from Figure (3.1), particles cannot penetrate into membrane pores as a result of size exclusion. Particle 1 is delivered to a membrane pore by the flow. This particle stays at the pore entrance if the hydrodynamic drag force exerted on the particle by the flow cannot overcome the interaction between the particle and the membrane. The particles gradually cover the surface and reduce the available open pores for incoming particles to attach with. Hence, the incoming particles have less probability to attach to the pores, but more probability to have particle-particle attachment as particle 3 which can be flushed away from the membrane surface by the reversed drag force during hydraulic backwashing of the membrane. Therefore, the fouling caused by this particle is hydraulically reversible. On the other hand, for particle 1 if the chemical attachment of this particle to other particles is less than the chemical attachment of this particle to the membrane surface, the pore blockage will be more predominate and less likely to be hydraulically reversible. In comparison, particle 2 is intercepted by the membrane surface and becomes part of the cake layer as it does not directly reduce the area of the pore entrance beneath. However, it is likely to remain on the membrane surface during hydraulic backwashing if particle-membrane attachment is strong enough to overcome the drag force of the backwash flow. Particle 4 is also attached to the membrane surface as particle 2. However, due to the difference in coagulation affinity, particle 4 becomes an effective collector to capture incoming particles that pass around it. The particle-particle attachment between particle 3 and particle 4 could then occur. Particle 3 then participates in the formation of a cake layer. 


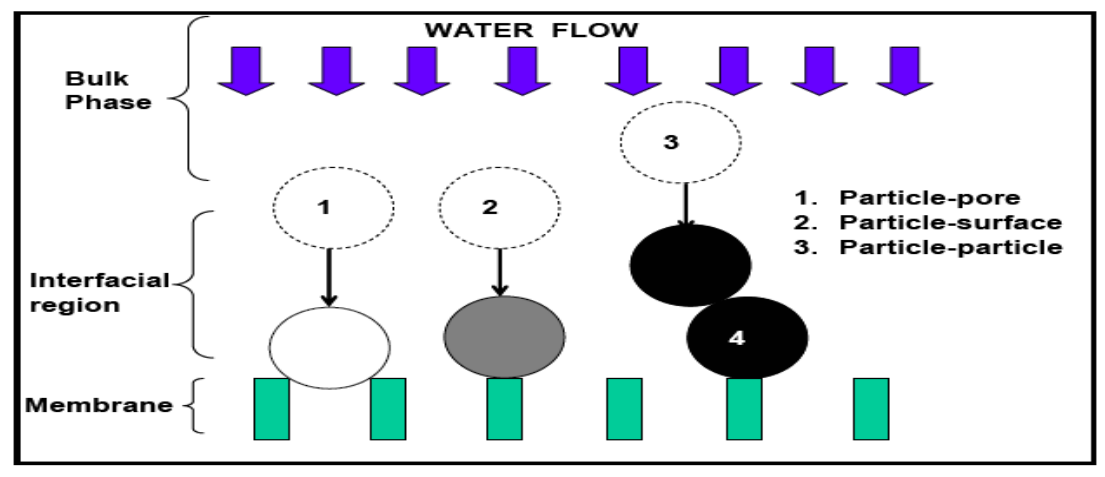

Figure 3.1: A Diagram of UF membrane fouling by colloidal particles larger than the membrane pore size.

Three types of collisions can happen on membrane outside surfaces: collision between a particle and the membrane solid surface as particles $(2,4)$, collision between a particle and another particle attached on the membrane solid surface as particle (3), and collision between a particle and the membrane pore as particle (1). Among all three modes of collision namely particle-to-pore, particle-to-surface and particle-to-particle, the collision probabilities are complementary, and hence, the summation of those collision probabilities is equal to unity:

$\beta_{s}+\beta_{p}+\beta_{p p}=1$

Equation (3.2)

where $\beta_{s}, \beta_{p}$, and $\beta_{\mathrm{pp}}$ [dimensionless] are the collision probabilities between a particle and the membrane surface, a membrane pore, and another particle, respectively. The particleparticle collision probability $\beta_{p p}$ is proportional to the ratio of the membrane surface area effectively covered by particles to that of the entire membrane. The change of the uncovered membrane surface area can be expressed as:

$d A_{t}=-4^{\alpha p p} \sigma A_{t} \mathrm{~d} m_{t}$

Equation (3.3)

where $A_{t}$ [dimensionless] is the total uncovered or open membrane surface area at a given filtration time normalized to the total membrane surface area, $\left[A_{t}=\left(\mathrm{A}_{\text {uncovered }} / \mathrm{A}_{\mathrm{o}}\right)\right.$, $A_{o}$ is the total membrane surface area,$\sigma\left[\mathrm{m}^{2} / \mathrm{kg}\right]$ is the projected area of a unit mass of the particles on membrane surface, and $m_{t}\left[\mathrm{~kg} / \mathrm{m}^{2}\right]$ is the total mass of particles introduced to the membrane per unit membrane surface area, which is equal to $C_{\mathrm{f}} V_{\mathrm{s}}, V_{\mathrm{s}}$ is the cumulative permeate flux $\left[\mathrm{m}^{3} / \mathrm{m}^{2}\right]$ and $C_{\mathrm{f}}\left[\mathrm{kg} / \mathrm{m}^{3}\right]$ is the solid concentration in the feed. The term $\left(4^{\alpha_{p p}}\right)$ reflects the fact that a particle already landed on the open area of a membrane can collide with incoming particles moving into a circular area up to 4 times of the projected area of the particle; therefore, the effective loss of open area equals $\left(4^{\alpha_{p p}}\right) \sigma \mathrm{d} m_{t}$. $\alpha_{\mathrm{pp}}$ [dimensionless] is the particle-to-particle attachment probability and ranges between zero and unity. When $\alpha_{\mathrm{pp}}$ equals zero, the effective loss of open membrane area decreases to 
$\sigma d m_{t}$, indicating that incoming particles can "slide" off the surface of the attached particle after collision and arrive at the uncovered membrane surface. Comparatively, if $\alpha_{\mathrm{pp}}$ increases to unity, the particles collide to each others have more affinity to coagulation attachment (particle-particle attachment); therefore, incoming particles moving in an area of $4 \sigma d m_{t}$ and will attach to the attached particle and prevent the open membrane areas underneath them from being reached by other incoming particles.

Integration of Equation (3.3), using the initial condition: $A_{t}=1$ when $m_{t}=0$, gives:

$$
A_{t}=\exp \left(-4^{\alpha p} \sigma \mathrm{m}_{\mathrm{t}}\right)
$$

The collision probabilities for the fouled membrane can thus be written as follows:

$\beta_{p p}=1-\exp \left(-4^{\alpha_{p p}} \sigma m_{t}\right)$

Equation (3.5)

For the collision probability between a particle and a pore on a clean membrane, it is simply the surface porosity $\left(\varepsilon_{\mathrm{s}}\right)$ of the membrane times the uncovered area of the membrane.

$\beta_{p}=\varepsilon_{\mathrm{s}} \exp \left(-4^{\alpha p} \sigma m_{t}\right)$

Equation (3.6)

The sum of the three collision probabilities is equal to unity. Therefore, the particle-tosurface collision probability can be written as:

$\beta_{s}=\left(1-\varepsilon_{\mathrm{s}}\right) \exp \left(-4^{\alpha p p} \sigma m_{t}\right)$

Equation (3.7)

Correspondingly, the specific mass of large particles that block membrane pores $\left(m_{\mathrm{p}}\right)\left[\mathrm{kg} / \mathrm{m}^{2}\right]$ $d m_{p}=\alpha_{\mathrm{pm}} \beta_{p} \mathrm{dm}_{\mathrm{t}}$

Equation (3.8)

where $\beta_{p}$ refers to the collision probability between a particle and the membrane pores, and $\mathrm{m}_{\mathrm{t}}\left[\mathrm{kg} / \mathrm{m}^{2}\right]$ is the total mass of particles delivered to a unit membrane surface area. Combining Equation (3.6) into Equation (3.8) and solving the differential equation to get the mass of large particles contributes to the pore blocking as follow:

$m_{p L}=\frac{\alpha_{\mathrm{pm}} \varepsilon_{\mathrm{S}}}{4^{\alpha} \mathrm{pp} \sigma_{\mathrm{L}}}\left[1-\exp \left(-4^{\alpha p p} \sigma_{\mathrm{L}} m_{t}\right)\right]$

Equation(3.9)

In order to predict the amount of particles participated in hydraulically irreversible fouling, the type of particle attachment in the cake layer has to be considered. Some particles directly attach to the membrane surface, and their mass per unit membrane area is defined as $m_{s}\left[\mathrm{~kg} / \mathrm{m}^{2}\right]$. The mass of particles attaching to other particles on the membrane surface is defined as $m_{p p}\left[\mathrm{~kg} / \mathrm{m}^{2}\right]$, as illustrated in Figure (3.2)

$$
\begin{aligned}
& d m_{s}=\alpha_{\mathrm{pm}} \beta_{s} \mathrm{~d} m_{t} \\
& m_{s L}=\frac{\alpha_{\mathrm{pm}}\left(1-\varepsilon_{\mathrm{s}}\right)}{4^{\alpha \mathrm{pp}} \sigma_{\mathrm{L}}}\left[1-\exp \left(-4^{\alpha_{\mathrm{pp}}} \sigma_{\mathrm{L}} m_{t}\right)\right] \\
& d m_{p p}=\alpha_{\mathrm{pp}} \beta_{p p} d m_{t} \\
& m_{p p L}=\alpha_{\mathrm{pp}} m_{t}-\frac{\alpha_{p p}}{4^{\alpha \mathrm{pp}} \sigma_{\mathrm{L}}}\left[1-\exp \left(-4^{\alpha_{\mathrm{pp}}} \sigma_{\mathrm{L}} m_{t}\right)\right]
\end{aligned}
$$




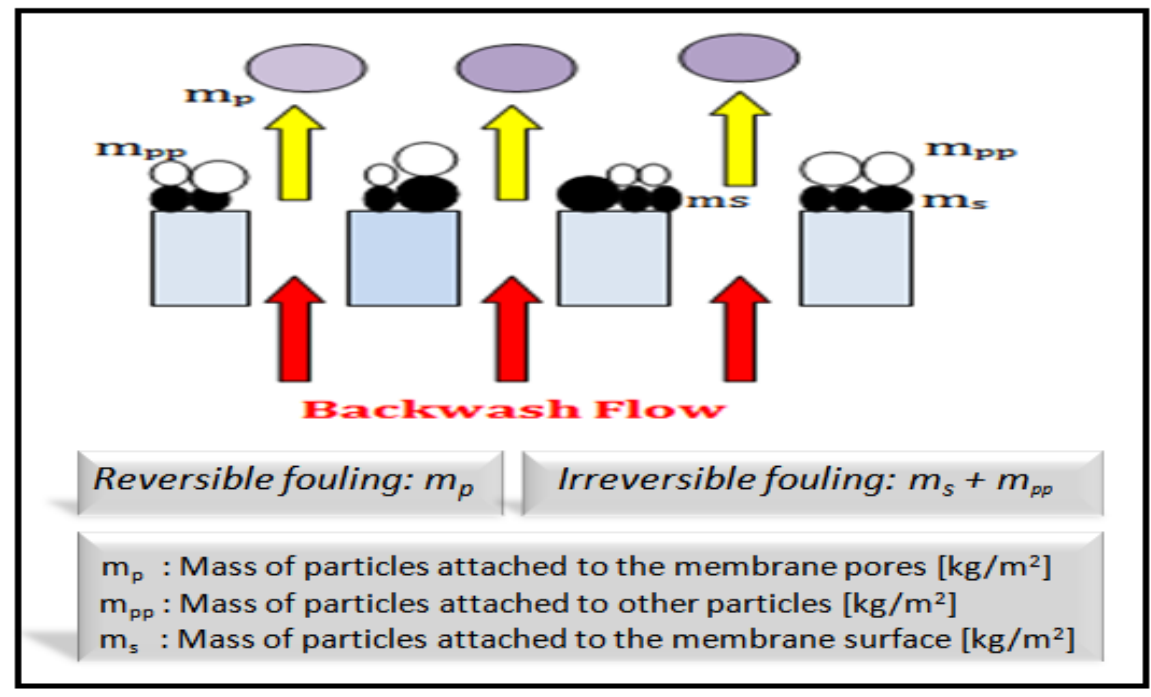

Figure 3.2: Irreversible cake fouling after backwash

The amount of solid particles participated in irreversible fouling is:

$m_{c I R R L}=m_{s L}+m_{p p L}=\alpha_{\mathrm{pp}} m_{t}+\frac{\alpha_{\mathrm{pm}}\left(1-\varepsilon_{\mathrm{s}}\right)-\alpha_{\mathrm{pp}}}{4^{\alpha \mathrm{pp}} \sigma_{\mathrm{L}}}\left[1-\exp \left(-4^{\alpha_{\mathrm{pp}}} \sigma_{\mathrm{L}} m_{t}\right)\right]$

Equation (3.14)

\subsubsection{Small particles $\left(a<D_{m} / 2\right)$}

Particles that are smaller than the membrane pore size could attach to the membrane surface and contribute to the cake formation. Also, some small particles could penetrate clean membrane pores. Figure (3.3) depicts the fouling of UF membrane caused by colloidal particles smaller than its pore size. When the membrane is clean, the absence of a physical sieving effect gives particle 1 the opportunity to penetrate through the membrane pore. If the particle-membrane attachment is unfavorable, this particle goes directly through the membrane. Comparatively, particle 3 collides and attaches to the internal wall of the membrane pore, and hence, it creates the restriction to other small particles to move through the membrane pore. This also decreases the effective pore size of the membrane, resulting in an increase in the hydraulic resistance to the permeate flow through the pore, i.e. a decrease in the permeability of the membrane. Particle 3 represents the particles with radius less than $1 / 6$ of the pore diameter $\left(\mathrm{a}<D_{m} / 6\right.$ or $\frac{D_{p}}{D_{m}}<1 / 3$ ) for standard pore blocking. In this small size range the particles would attach to the pore wall since the attachment force would be higher than the drag force (Spinette and Charles, 2008). This type of particle attachment contributes to irreversible fouling. Another effect of pore constriction is shown with particle 5. In this case, the penetration of particle 6 through the membrane is prohibited because the physical size of the pore is now less than that of the particle. This happens when the radius of 
the particle is in a critical range of $1 / 6$ - 1/2 of pore diameter (Spinette and Charles, 2008). Meanwhile, particle 2 and particle 4 collide and attach with the outside surface of the membrane, similar to the large particles. Destabilized small particles are more likely to form aggregates before they reach the membrane surface. This scenario is presented as a cluster of particles 7. The aggregate of multiple small particles contributes to dense cake layer and results in an increase in the cake layer resistance. Consequently, small particles cause more fouling than large particles.

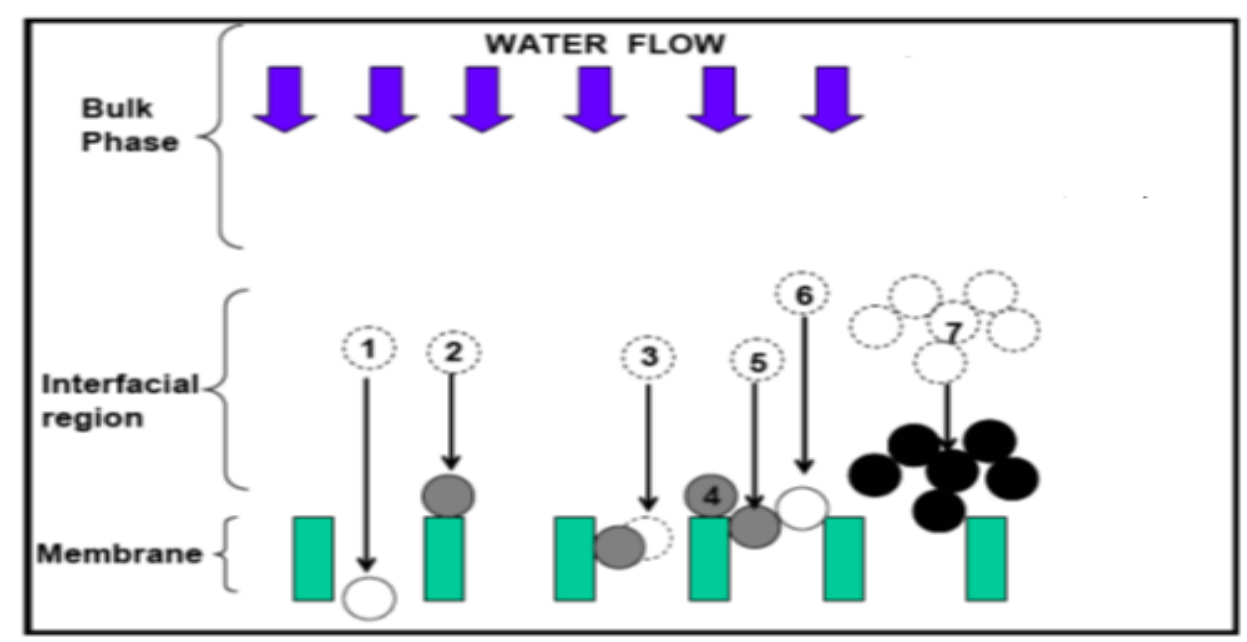

Figure 3.3: A diagram of UF membrane fouling by particles smaller than the membrane pore size.

\section{a. Small particles $\left(a<D_{m} / 6\right)$ (standard pore blocking)}

For very small particles with a $<\mathrm{D}_{\mathrm{m}} / 6$, the particles tend to attach to the pore wall since the shear force would be lower than the attractive force between the particles and the pore wall (Spinette and Charles, 2008). To assess the collision and attachment of small particles on pore walls, as particle 3 shown in Figure 3.3, the convective transport of small particles inside cylindrical tubes in radial and axial directions under steady state conditions can be considered (Figure 3.4). 


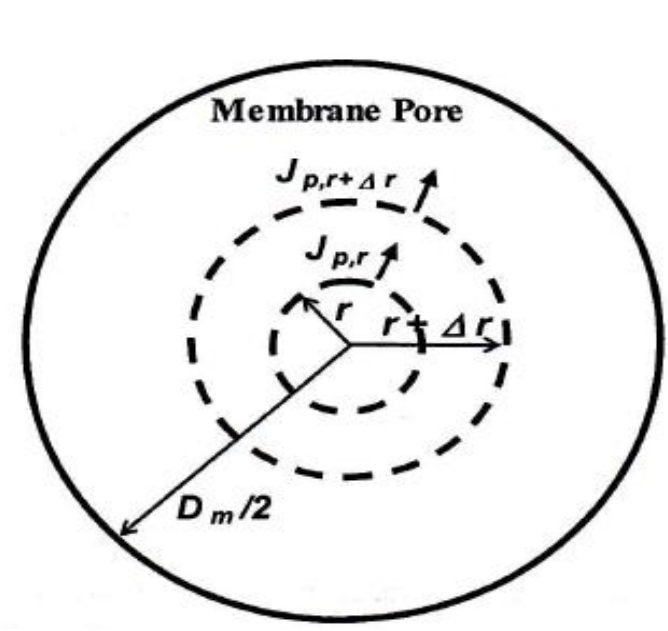

( a )

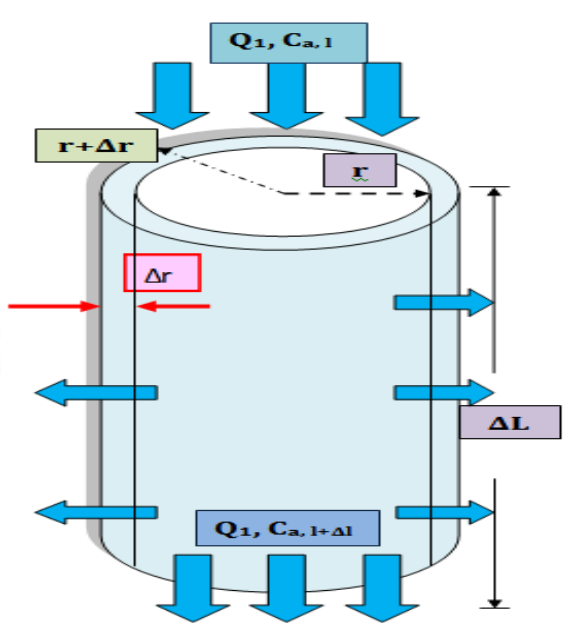

(b)

Figure 3.4: Schematic View of Cylindrical Membrane Pore

First, a mass balance equation can be established for a ring-like slice of cylindrical shell in the straight pore channel as shown in Figure 3.4 (a):

$J_{p, r+\Delta r}\left[2 \pi(\mathrm{r}+\Delta \mathrm{r}) L_{m}\right]-J_{p, r}\left(2 \pi \mathrm{r} L_{m}\right)=0$

where $J_{p}\left[\mathrm{~kg} / \mathrm{m}^{2} \mathrm{~s}\right]$ is the particle flux in the radial direction, $\mathrm{L}_{\mathrm{m}}[\mathrm{m}]$ is length of the membrane pore and $r[\mathrm{~m}]$ is the radius.

Fick's first law can be applied in the radial direction:

$J_{p}=-\mathrm{D} \frac{d C_{p}}{d r}$

where $\mathrm{D}\left[\mathrm{m}^{2} / \mathrm{s}\right]$ is the diffusion coefficient of colloidal particles, and $\mathrm{C}_{\mathrm{p}}\left[\mathrm{kg} / \mathrm{m}^{3}\right]$ is the particle concentration.

By arranging and solving equations as shown in Appendix (B), the particle flux at the pore wall is as follows:

$$
J_{p, D m / 2}=\frac{2 C_{a} \mathrm{D}}{D_{m} \ln \left(\frac{D_{m}}{2 a}\right)}
$$

From mass balance in axial direction as shown in Figure (3.4b), the concentration of the solid in the axial direction can be expressed as (Appendix B):

$\frac{C_{\text {out }}}{C_{\text {in }}}=\exp \left[-\frac{2 \alpha_{\mathrm{pm}} \mathrm{D}}{\mathrm{Q}_{1} \mathrm{D}_{\mathrm{m}} \ln \left(\frac{\mathrm{D}_{\mathrm{m}}}{2 \mathrm{a}}\right)}\left(\pi D_{m} \mathrm{~L}_{\mathrm{m}}\right)\right]$

The equation shows that the term $\left(\pi D_{m} L_{m}\right)$ on the RHS is indeed the total area of pore wall. If the membrane pore is partially fouled due to particle attachment onto the pore wall, equation (3.18) need to be modified. 
$\frac{\mathrm{C}_{\text {out }}}{\mathrm{C}_{\text {in }}}=\exp \left[-\frac{2 \alpha_{\mathrm{pm}} \mathrm{DAw}, 1}{\mathrm{D}_{\mathrm{m}} \mathrm{Q}_{1} \ln \left(\frac{\mathrm{Dm}_{\mathrm{m}}}{2 \mathrm{a}}\right)}\right]=\exp \left(-\alpha_{\mathrm{pm}} \mathrm{B} A_{w, 1}\right)$

where $C_{\text {in }}$ and $C_{\text {out }}$ are the mean particle concentrations at the inlet (feedwater $C_{f}$ ) and outlet of the membrane pore (permeate), $\mathrm{D}\left[\mathrm{m}^{2} / \mathrm{S}\right]$ is the diffusion coefficient of latex particles in water, $\mathrm{Q}_{1}[\mathrm{~L} / \mathrm{s}]$ is the permeate flow rate, $\mathrm{D}_{\mathrm{m}}[\mathrm{m}]$ is the membrane pore diameter, a is latex particle radius, $\mathrm{B}\left[\mathrm{m}^{-2}\right]$ is a mass transfer coefficient clustering all parameters in the exponential term on the RHS of the equation except $\alpha_{\mathrm{pm}}$ and the variable $A_{w, 1, \text {; }}$ and $A_{w, 1}$ is the available surface area of the pore wall when the permeate volume reaches $V_{1}$ which can be calculated from Equation 3.20.

$A_{w, l}=\frac{1}{\alpha_{p m} B} \ln \left[1+\exp \left(\pi D_{m} L_{m} B \alpha_{p m}-\sigma_{\mathrm{xs}} \alpha_{\mathrm{pm}} \mathrm{B} \mathrm{C}_{\mathrm{in}} V_{l}\right)\right]$

Equation (3.20)

where $V_{l}=\frac{V_{S}}{N_{m}}$

Equation (3.21)

Mass of particles attached to the pore wall can be calculated from equation (3.22)

$m_{w}=\frac{N_{m}}{\sigma_{\mathrm{xs}} \alpha_{\mathrm{pm}} B}\left\{\pi D_{m} L_{m} B \alpha_{\mathrm{pm}^{-}} \ln \left[1+\exp \left(\pi D_{m} L_{m} B \alpha_{\mathrm{pm}}-\frac{\sigma_{\mathrm{xs}} \alpha_{\mathrm{pm}} B}{N_{m}} C_{f} V_{s}\right)\right]\right\}$

Equation (3.22)

where $m_{w}\left[\mathrm{~kg} / \mathrm{m}^{2}\right]$ is the mass of the particles attached to the pore walls in all membrane pores normalized to a unit membrane surface area, $V s\left[\mathrm{~m}^{3} / \mathrm{m}^{2}\right]$ is the cumulative volume of permeate filtered through a unit surface area of the membrane, $L_{m}$ is the length of the membrane pore, and $N_{m}\left[\mathrm{~m}^{-2}\right]$ is the pore density in the membrane. $B\left[\mathrm{~m}^{-2}\right]$ is a mass transfer coefficient and defined as:

$B=\frac{2 \mathrm{D}}{D_{m} \mathrm{Q}_{1} \ln \left(\frac{D_{m}}{2 \mathrm{a}}\right)}$

where $\mathrm{D}$ is the diffusion coefficient of latex particles in water, $\mathrm{Q}_{1}$ is the permeate flow rate in a membrane pore, $D_{m}$ is the membrane pore diameter and a is the latex particle radius.

\section{b. Small particles $\left(\mathrm{D}_{\mathrm{m}} / 6<\mathrm{a}<\mathrm{D}_{\mathrm{m}} / \mathbf{2}\right)$}

Small particles within this critical range (such as particle 5 and 6 in Figure 3.3) would block the internal membrane pores. Also, the absence of the particle-to-particle attachment can be considered inside the pores; i.e. $\alpha_{\mathrm{pp}}=0$

$d m_{p}=\alpha_{\mathrm{pm}} \beta_{p} \mathrm{dm}_{\mathrm{t}}$

$m_{p S}=\frac{\alpha_{\mathrm{pm}} \varepsilon_{\mathrm{s}}}{\sigma_{\mathrm{s}}}\left[1-\exp \left(-\sigma_{\mathrm{s}} m_{t}\right)\right]$

Equation (3.25) 
Similar to the derivation approach for large particles, the amount of small particles attached to the membrane surface and contributed to the cake layer can be expressed as:

$$
\begin{aligned}
& m_{s S}=\frac{\alpha_{\mathrm{pm}}\left(1-\varepsilon_{\mathrm{S}}\right)}{4^{\alpha \mathrm{pp}} \sigma_{\mathrm{S}}}\left[1-\exp \left(-4^{\alpha \mathrm{pp}} \sigma_{\mathrm{S}} m_{t}\right)\right] \\
& m_{p p S}=\alpha_{\mathrm{pp}} m_{t}-\frac{\alpha_{\mathrm{pp}}}{4^{\alpha \mathrm{pp}} \sigma_{\mathrm{S}}}\left[1-\exp \left(-4^{\alpha}{ }_{\mathrm{pp}} \sigma_{\mathrm{S}} m_{t}\right)\right] \\
& m_{C \text { IRR } S}=m_{S S}+m_{p p S}=\alpha_{\mathrm{pp}} m_{t}+\frac{\alpha_{\mathrm{pm}}\left(1-\varepsilon_{\mathrm{S}}\right)-\alpha_{\mathrm{pp}}}{4^{\alpha \mathrm{pp}} \sigma_{\mathrm{S}}}\left[1-\exp \left(-4^{\alpha \mathrm{pp}} \sigma_{\mathrm{S}} m_{t}\right)\right]
\end{aligned}
$$

\subsubsection{Cake layer formation}

The mass of the total cake layer, $m_{\mathrm{c}}\left[\mathrm{kg} / \mathrm{m}^{2}\right]$, can be expressed as:

$$
\begin{array}{lr}
m_{c}=\alpha_{\mathrm{pp}} m_{t}-m_{p L^{-}} m_{p S}-m_{w} & \text { Equation (3.29) } \\
m_{c}=\alpha_{\mathrm{pp}} C_{f} V_{s}-\frac{\alpha_{\mathrm{pm}} \varepsilon_{\mathrm{s}}}{4^{\alpha \mathrm{pp}} \sigma_{\mathrm{L}}}\left[1-\exp \left(-4^{\alpha \mathrm{pp}} \sigma_{\mathrm{L}} C_{f} V_{s}\right)\right]-\frac{\alpha_{\mathrm{pm}} \varepsilon_{\mathrm{s}}}{\sigma_{\mathrm{s}}}\left[1-\exp \left(-\sigma_{\mathrm{s}} m_{t}\right)\right]-\frac{N_{m}}{\sigma_{\mathrm{xs}} \alpha_{\mathrm{pm}} B}\{\pi \\
\left.D_{m} L_{m} B \alpha_{\mathrm{pm}}-\ln \left[1+\exp \left(\pi D_{m} L_{m} B \alpha_{\mathrm{pm}}-\frac{\sigma_{\mathrm{xs}} \alpha_{\mathrm{pm}} B}{N_{m}} C_{f} V_{s}\right)\right]\right\} & \text { Equation (3.30) }
\end{array}
$$

Moreover, the mass of fouling contributed to cake layer formation resulted from the particles attached to the membrane surface, and the particles contributed to cake build up due to particle-to-particle attachement.

$$
m_{c}=\alpha_{\mathrm{pp}} C f V S+\left\{\frac{\alpha_{\mathrm{pm}}\left(1-\varepsilon_{\mathrm{S}}\right)-\alpha_{\mathrm{pp}}}{4^{\alpha} \mathrm{pp}}\left[\frac{\left[1-\exp \left(-4^{\alpha} \mathrm{pp}_{\sigma_{\mathrm{L}}} m_{t}\right)\right.}{\sigma_{\mathrm{L}}}+\frac{\left[1-\exp \left(-4^{\alpha} \mathrm{pp}_{\sigma_{\mathrm{S}}} \mathrm{m}_{\mathrm{t}}\right)\right.}{\sigma_{\mathrm{s}}}\right]\right\}
$$

Equation (3.31)

\subsubsection{Mathematical model for transmembrane pressure}

The reduction of membrane permeability results in the increase of transmembrane pressure $\left(P^{\prime}\right) . P^{\prime}$ is defined as the ratio of TMP at a given time during filtration to the initial TMP of a clean membrane. $P^{\prime}$ is a function of the mass of particles retained by the membrane, as illustrated in Appendix (A). For the transmembrane pressure increases due to large and small particles participated in pore blocking, the equation can be rewritten as:

$$
\begin{aligned}
& \frac{d P^{\prime}}{d m_{p}}=\sigma P^{\prime 2} \quad \text { (complete pore blocking) } \\
& P_{p L}^{\prime}=\frac{1}{1-\frac{\alpha_{\mathrm{pm}} \varepsilon_{\mathrm{S}}}{4^{\alpha \mathrm{pp}}\left[1-\exp \left(-4^{\alpha} \mathrm{pp}_{\sigma_{\mathrm{L}}} \mathrm{C}_{\mathrm{f}} V_{S}\right)\right]}} \\
& P_{p S}^{\prime}=\frac{1}{1-\alpha_{\mathrm{pm}} \varepsilon_{\mathrm{S}}\left[1-\exp \left(-\sigma_{\mathrm{S}} \mathrm{C}_{\mathrm{f}} V_{S}\right)\right]}
\end{aligned}
$$

Transmembrane pressure changes, due to very small particles attached to the membrane pore wall, can be expressed as: 
$\frac{d P^{\prime}}{d m_{w}}=\left(\frac{2}{L_{m} \rho}\right) P^{\prime 3 / 2} \quad$ (standard pore blocking)

Equation (3.35)

$P_{w}^{\prime}=\frac{1}{\left\{1-\frac{N_{m}}{\sigma_{\mathrm{xs}} \rho \alpha_{\mathrm{pm}} B L_{m}}\left\{\pi D m L m B \alpha_{\mathrm{pm}}-\ln \left[1+\exp \left(\pi D m L m B \alpha_{\mathrm{pm}}-\frac{\sigma_{\mathrm{xs}} \alpha_{\mathrm{pm}} B}{N_{m}} C f V s\right)\right]\right\}\right\}^{2}}$

Equation (3.36)

The increase in transmembrane pressure due to cake layer formation can be written as:

$\frac{d P^{\prime}}{d m_{c}}=\frac{\hat{R}_{c}}{R_{m}} \quad$ (Cake layer formation)

Equation (3.37)

Where $\mathrm{R}_{\mathrm{m}}\left[\mathrm{m}^{-1}\right]$ is hydraulic resistance of clean membranes and $\hat{R}_{c}[\mathrm{~m} / \mathrm{kg}]$ is Specific cake resistance (both are measured experimentally)

$P_{c}^{\prime}=1+\frac{\hat{R}_{c}}{R_{m}}\left\{\mathrm{C}_{\mathrm{f}} V_{s}-\frac{\alpha_{\mathrm{pm}} \varepsilon_{\mathrm{s}}}{4^{\alpha_{\mathrm{pp}}} \sigma_{\mathrm{L}}}\left[1-\exp \left(-4^{\alpha \mathrm{pp}} \sigma_{\mathrm{L}} \mathrm{m}_{\mathrm{t}}\right)\right]-\frac{\alpha_{\mathrm{pm}} \varepsilon_{\mathrm{S}}}{\sigma_{\mathrm{s}}}\left[1-\exp \left(-\sigma_{\mathrm{s}} m_{\mathrm{t}}\right)\right]-\frac{N_{m}}{\sigma_{\mathrm{xs}} \alpha_{\mathrm{pm}} B}\left\{\pi D_{m}\right.\right.$

$\left.L_{m} B \alpha_{\mathrm{pm}^{-}} \ln \left[1+\exp \left(\pi D_{m} L_{m} B \alpha_{\mathrm{pm}}-\frac{\sigma_{\mathrm{xs}} \alpha_{\mathrm{pm}} \mathrm{B}}{N_{m}} C_{f} V_{s}\right)\right]\right\}$

Equation (3.38)

The increase in the total transmembrane membrane pressure during a filtration process can be calculated from the summation of equations 3.33, 3.34, 3.36 and 3.38.

\subsubsection{Modelling of irreversible fouling}

The total mass of irreversible fouling can be calculated from the following equation:

$$
\begin{array}{lr}
m_{I R R}=m_{c I R R L}+m_{c I R R S}+m_{w} & \text { Equation (3.39) } \\
m_{I R R}=\alpha_{\mathrm{pp}} m_{t}+\left\{\frac{\alpha_{\mathrm{pm}}\left(1-\varepsilon_{\mathrm{s}}\right)-\alpha_{\mathrm{pp}}}{4^{\alpha \mathrm{pp}}}\left[\frac{\left[1-\exp \left(-4^{\alpha \mathrm{pp}} \sigma_{\mathrm{L}} m_{t}\right)\right.}{\sigma_{\mathrm{L}}}+\frac{\left[1-\exp \left(-4^{\alpha} \mathrm{pp}_{\mathrm{s}_{\mathrm{s}}} \mathrm{m}_{\mathrm{t}}\right.\right.}{\sigma_{\mathrm{s}}}\right]\right\}+\frac{N_{m}}{\sigma_{\mathrm{xs}} \alpha_{\mathrm{pm}} B} \\
\left\{\pi D_{m} L_{m} B \alpha_{\mathrm{pm}}-\ln \left[1+\exp \left(\pi D_{m} L_{m} B \alpha_{\mathrm{pm}}-\frac{\sigma_{\mathrm{xs}} \alpha_{\mathrm{pm}} B}{N_{m}} C_{f} V_{s}\right)\right]\right\} & \text { Equation (3.40) }
\end{array}
$$

After backwashing, the transmembrane pressure increased, as compared to that with the clean membrane, when the membrane was placed back to the filtration cycle again. This is due to particles remaining in the membrane after backwashing. Those remaining particles contribute to the irreversible fouling, including the irreversible cake and the irreversible fouling on the membrane pore wall. The increase in the transmembrane pressure after backwash $\left(P_{\text {IRR }}\right)$ can be calculated from equation (3.42)

$$
\begin{aligned}
& P_{\text {IRR }}=P^{\prime} c_{I R R L}+P^{\prime} c_{I R R S}+P_{w}^{\prime} \\
& \dot{P}_{I R R}=1+\frac{\hat{\mathrm{R}} c}{R_{m}}\left\{\alpha_{\mathrm{pp}} m_{t}+\left(\frac{\alpha_{\mathrm{pm}}\left(1-\varepsilon_{\mathrm{s}}\right)-\alpha_{\mathrm{pp}}}{4^{\alpha \mathrm{pp}}}\left[\frac{\left[1-\exp \left(-4^{\alpha \mathrm{pp}} \sigma_{\mathrm{L}} m_{t}\right)\right.}{\sigma_{\mathrm{L}}}+\frac{\left[1-\exp \left(-4^{\alpha} \mathrm{pp}_{\mathrm{s}_{\mathrm{s}}} \mathrm{m}_{\mathrm{t}}\right)\right.}{\sigma_{\mathrm{s}}}\right]\right)\right\} \\
& +\frac{1}{\left\{1-\frac{N_{m}}{\sigma_{\mathrm{Xs}} \rho \alpha_{\mathrm{pm}} B L m}\left\{\pi D m L m B \alpha_{\mathrm{pm}}-\ln \left[1+\exp \left(\pi D m L m B \alpha_{\mathrm{pm}}-\frac{\sigma_{\mathrm{Xs}} \alpha_{\mathrm{pm}} B}{N_{m}} C f V s\right)\right]\right\}\right\}^{2}}
\end{aligned}
$$


Based on the particle size distribution of latex paint and the pore size distribution of the heterogeneous membrane used in this study, the fouling probabilities $\alpha_{\mathrm{pp}}$ and $\alpha_{\mathrm{pm}}$, were calculated using the model equations. Equation (3.43) and (3.44) for total mass of fouling contributed to pore blocking $\left(m_{p}\right)$ and the total mass of fouling contributed to cake layer $\left(m_{c}\right)$, were then solved for $\alpha_{\mathrm{pp}}$ and $\alpha_{\mathrm{pm}}$ using $m_{p}$ and $m_{c}$ measured experimentally as described in Section (4.5). Eventually, these predicted fouling attachment probabilities were used to calculate the total increase of transmembrane pressure, which were validated by comparing them with experimentally measure values.

$$
\begin{aligned}
& m_{p}=\frac{\alpha_{\mathrm{pm}} \varepsilon_{\mathrm{s}}}{4^{\alpha}{ }_{\mathrm{pp}} \sigma_{\mathrm{L}}}\left[1-\exp \left(-4^{\alpha \mathrm{pp}} \sigma_{\mathrm{L}} \mathrm{m}_{\mathrm{t}}\right)\right]+\frac{\alpha_{\mathrm{pm}} \varepsilon_{\mathrm{s}}}{\sigma_{\mathrm{s}}}\left[1-\exp \left(-\sigma_{\mathrm{s}} m_{t}\right)\right]+\frac{N_{m}}{\sigma_{\mathrm{xs}} \alpha_{\mathrm{pm}} B}\left\{\pi D_{m} L_{m} B\right. \\
& \alpha_{\mathrm{pm}}-\ln \left[1+\exp \left(\pi D_{m} L_{m} B \alpha_{\mathrm{pm}}-\frac{\sigma_{\mathrm{xs}} \alpha_{\mathrm{pm}} B}{N_{m}} C_{f} V_{s}\right)\right] \\
& m_{c}=\alpha_{\mathrm{pp}} C f V s+\left\{\frac{\alpha_{\mathrm{pm}}\left(1-\varepsilon_{\mathrm{s}}\right)-\alpha_{\mathrm{pp}}}{4^{\alpha \mathrm{pp}}}\left[\frac{\left[1-\exp \left(-4^{\alpha \mathrm{pp}} \sigma_{\mathrm{L}} m_{t}\right)\right.}{\sigma_{\mathrm{L}}}+\frac{\left[1-\exp \left(-4^{\alpha}{ }_{\mathrm{pp}} \sigma_{\mathrm{s}} \mathrm{m}_{\mathrm{t}}\right)\right.}{\sigma_{\mathrm{s}}}\right]\right\}
\end{aligned}
$$

Equation (3.44)

\subsection{Model development for non-uniform pore size membrane}

In this study, a mechanistic model was developed and generalized for the applications with non-uniform pore size membranes, based on the fouling potential of the particles of different sizes with different pore sizes.

\subsubsection{Simulation of the particles attachments with non-homogenous pore size distribution}

The size of the latex particles and membrane pores were regarded as the primary factor in determining the occurrence of surface fouling (cake layer formation or pore blocking) and adsorptive internal plugging. The heterogeneous membranes have pore size distribution of $(N)$ non-uniform pore sizes. Notably, the individual pores are not aligned in a straight manner, and thus cause the flow to take a non-linear path with the length of the path greater than the path equal to the membrane thickness. Consequently, the tortuosity of the membrane will be included in the model expressions. Figure (3.5) illustrates the examples of all possible mechanisms involved in particle attachments with non-homogenous pore membrane using ImageJ software [ImageJ 1.46r, National Institutes Of Health, USA]. These attachments are further discussed in Section 5.2.2.1 using SEM images of the membrane surface after ultrafiltration of the latex effluent. All possible attachments of each particle size are applied in the mathematical model for each pore size range. Eventually, the average percentage $\left(x_{i}\right)$ of each pore $\operatorname{size}(i)$ estimated by the software will be used in the model's calculations. 


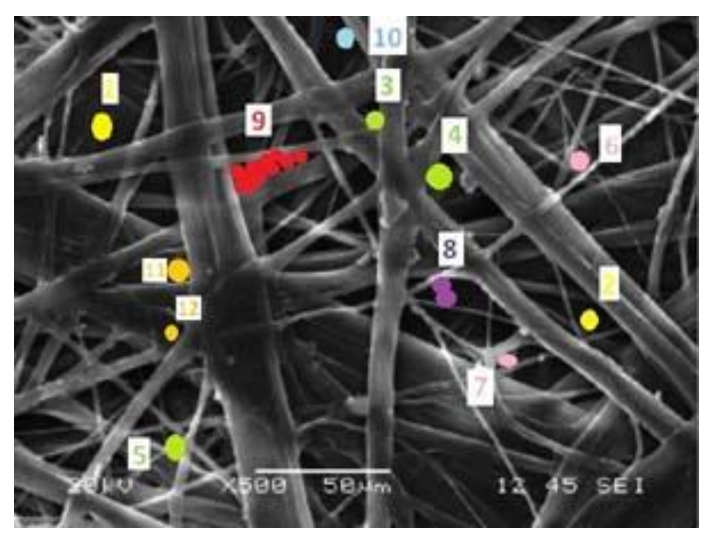

\section{Figure 3.5: Illustration of all the mechanisms of particles attachments with non- homogenous pore size distribution using ImageJ software}

Undoubtedly, at the beginning of the ultrafiltration process with clean membrane pores, the particles smaller than the pore size can penetrate the membrane, as long as the particle-membrane attachment is unfavorable such as with particles 1 and 2 . As the process continues, particles gradually cover the surface and reduce the number of open pores available for the incoming particles, due to the depositional attachment $\left(\alpha_{\mathrm{pm}}\right)$ between the particle and membrane surface. Thus, the incoming particles have a lower probability of attachment to the pore surface, but a higher probability of having particle-to-particle attachments due to the coagulation attachment $\left(\alpha_{\mathrm{pp}}\right)$. Large particles $\left(\mathrm{a} \geq D_{m} / 2\right)$, the ratio of the latex particle size to that of the pore through which it is passing is equal or larger than one, where a $[\mathrm{m}]$ is the particle radius and $D_{m}[\mathrm{~m}]$ is the diameter of the membrane pore, could have a size similar to the membrane pore size, like particles 6 and 7, or larger like particles 3, 4, and 5. These large particles attach to the pore entrances and block the flow through these pores. In addition, particles that are smaller than the membrane pore size (a $<D_{m} / 2$ ), the ratio of the latex particle size to that of the pore through which it is passing is less than one, can also get attached to the membrane surface and contribute to cake formation or go through clean membrane pores. Particles with radius less than $1 / 6$ of the pore diameter (a $<D_{m} / 6$ or $\frac{D_{p}}{D_{m}}<1 / 3$ ), the ratio of the latex particle size to that of the pore through which it is passing is less than one third, may collide with and get attached to the internal wall of the membrane pore (as particle 10), creating a potential restriction for the other small particles attempting to move through the membrane pore. As these particles continue to decrease the pore size of the membrane, they contribute to an increase of the hydraulic resistance to the permeate flow through the pore, in other words, they cause a decrease in the permeability of the membrane. Another effect of pore constriction is illustrated with particle 8 . In the case of 
this particle size $\left(D_{m} / 6<\mathrm{a}<D_{m} / 2\right)$, the ratio of the latex particle size to that of the pore through which it is passing is more than one third and less than 1, two particles can collide and block the membrane pore, thus effectually prohibiting the penetration of other particles through the membrane. Destabilized small particles are also more likely to form aggregates before they reach the membrane surface. This scenario is presented as a cluster of particles 9 . The accumulation of multiple small particles contributes to the formation of the dense cake layer, resulting in an increase of the cake layer resistance. On the other hand, particles such as 11 or 12 do not block the pores when attached to the membrane surface, and have less impact on the passage of the permeate flow through the membrane. However, particles 11 and 12 still contribute to the cake layer formation.

\subsubsection{Particles size classification}

\subsubsection{Large particles (particle size $\geq$ pore diameter) $\left(\mathrm{a} \geq D_{m} / 2\right)$}

Based on the equation derived for the uniform pore size membrane and intended for calculating the mass of fouling contributed to pore blocking by larger sized particle, the equation was developed for non-uniform pore size membranes. For each average pore size $(i=1$ to $N$ ), the mass of the particles larger than the pore of size $i$ contributes to the pore blocking $\left(m_{p L_{i}}\right)\left[\mathrm{kg} / \mathrm{m}^{2}\right]$ and can be calculated from Equation (3.45)

$m_{p L_{i}}=\frac{\alpha_{p m} \varepsilon_{\mathrm{s}}}{4^{\alpha} p p_{\sigma_{\mathrm{L}}}}\left[1-\exp \left(-4^{\alpha}{ }^{\alpha p} \sigma_{\mathrm{L}} C_{f} V_{s}\right)\right]$

where $\sigma_{\mathrm{L}}\left[\mathrm{m}^{2} / \mathrm{kg}\right]$ is the projected area of a unit mass of the large particles on membrane surface, $V_{\mathrm{s}}$ is the cumulative permeate flux $\left[\mathrm{m}^{3} / \mathrm{m}^{2}\right], C_{\mathrm{f}}\left[\mathrm{kg} / \mathrm{m}^{3}\right]$ is the solid concentration in the feed, and $\varepsilon_{s}$ [dimensionless] is the membrane porosity.Correspondingly, the specific mass of large particles that block the membrane pores $\left(m_{p L}\right)\left[\mathrm{kg} / \mathrm{m}^{2}\right]$ can be calculated from Equation (3.46).

$m_{p L}=\sum_{i=1}^{N} x_{i} m_{p L_{i}}$ Equation (3.46)

where $x_{i}$ is the percentage of the pore of size $i$, and $N$ is the number of the non-uniform pore sizes determined in the pore size distribution of the heterogeneous membranes.

\subsubsection{Small particles $\left(\mathrm{a}<D_{m} / 2\right)$}

\section{a. Very small particles $\left(a<D_{m} / 6\right)$ (standard pore blocking)}

The convective transport of small particles in the pores, in radial and axial directions under a steady state condition, was considered in order to assess the collision and attachment of small particles on the pore walls, as was noted in Section (3.1.2.2). The equation was developed for non-uniform pore size membranes and the mass of particles attached to the pore wall of size $i$ can be calculated from the equation (3.47) 
$m_{w_{i}}=\frac{N_{m}}{\sigma_{\mathrm{xs}} \alpha_{\mathrm{pm}} B_{i}}\left\{\frac{\pi D_{m_{i}} L_{m} B_{i} \alpha_{\mathrm{pm}}}{\tau}-\ln \left[1+\exp \left(\frac{\pi D_{m_{i}} L_{m} B_{i} \alpha_{\mathrm{pm}}}{\tau}-\frac{\sigma_{\mathrm{xs}} \alpha_{\mathrm{pm}} B_{i}}{N_{m}} C_{f} V_{s}\right)\right]\right\}$

Equation (3.47)

where $L_{m}[\mathrm{~m}]$ is the length of the membrane pore, $N_{m}$ is the density of pores per a unit membrane surface area, $D_{m_{i}}[\mathrm{~m}]$ is the membrane pore diameter of size $i, \sigma_{\mathrm{xs}}\left[\mathrm{m}^{2} / \mathrm{kg}\right]$ is the projected area of a unit mass of the very small particles on the membrane surface $(a<$ $D_{m} / 6$ ), and $\tau$ is the tortuosity of the membrane (defined as ratio between the membrane thickness $\left(L_{m}\right)$ and the actual path that the small particles follows through the membrane pore The tortuosity in our study was estimated using Hagen Poiseuille Equation (Cuperus, 1991) and using the experimental data of the permeate flux of water collected at different transmembrane pressures as expressed in Equation (3.48)

$J=\frac{\pi N_{m} r^{4} P}{8 \mu \tau L_{m}}$

where $J\left[\mathrm{~m}^{3} / \mathrm{m}^{2} . \mathrm{S}\right]$ is the permeate flux, $\mathrm{r}[\mathrm{m}]$ is the mean average radius of membrane pores calculated using the pore size distribution, $P\left[\mathrm{~N} / \mathrm{m}^{2}\right]$ is the transmembrane pressure, and $\mu[\mathrm{N}$ $\left.\mathrm{S} / \mathrm{m}^{2}\right]$ is the water viscosity. Besides, $B_{i}\left[\mathrm{~m}^{-2}\right]$ is a mass transfer coefficient and defined as:

$B_{i}=\frac{2 \mathrm{D}}{D_{m_{i}} Q_{i} \ln \left(\frac{D_{m_{i}}}{2 \mathrm{a}}\right)}$

where $\mathrm{D}$ is the diffusion coefficient of latex particles in water, $Q_{i}$ is the permeate flow rate in a membrane pore of size $i$, and a [m] is the particle radius. Accordingly, the total mass of particles attached to the membrane wall $m_{w}\left[\mathrm{~kg} / \mathrm{m}^{2}\right]$ can be calculated from Equation (3.50). In this case, the particles attached to the pores' wall contribute to the irreversible fouling as described in Section (3.1.2.2).

$m_{w}=\sum_{i=1}^{N} x_{i} m_{w_{i}}$

Equation (3.50)

\section{b. Models for small particles $\left(D_{m} / 6<\mathrm{a}<D_{m} / 2\right)$}

Within this critical range, smaller particles would effectually block the internal membrane pores. Notably, the particle-to-particle attachment can be considered negligible inside the pores; i.e. $\alpha_{\mathrm{pp}}=0$. The mass of the small particles contributing to the blocking of the pores of size $i\left(m_{p s_{i}}\right)\left[\mathrm{kg} / \mathrm{m}^{2}\right]$ is calculated from Equation (3.51), while the total mass of small particles contributing to pore blocking $m_{p S}\left[\mathrm{~kg} / \mathrm{m}^{2}\right]$ is calculated from Equation (3.52), as the model was developed for non-uniform pore size membrane.

$m_{p s_{i}}=\frac{\alpha_{\mathrm{pm}} \varepsilon_{\mathrm{s}}}{\sigma_{\mathrm{s}}}\left[1-\exp \left(-\sigma_{\mathrm{s}} C_{f} V_{s}\right)\right]$

Equation (3.51)

$m_{p S}=\sum_{i=1}^{N} x_{i} m_{p s_{i}}$

Equation (3.52) 
where $\sigma_{\mathrm{s}}\left[\mathrm{m}^{2} / \mathrm{kg}\right]$ is the projected area of a unit mass of the small particles on the membrane surface (pore diameter $/ 6<$ particle radius $<$ pore diameter $/ 2$ ).

\subsubsection{Mathematical expression for cake layer}

Mass of particles contributing to the cake layer could be calculated by subtracting the mass of particles from all sizes contributing to pore blocking, from the total mass of particles in the feed with the potential for particle-to-particle attachment. The mass of the particles participating in the cake layer formation, $m_{\mathrm{c}}\left[\mathrm{kg} / \mathrm{m}^{2}\right]$, can be expressed as:

$$
\begin{array}{ll}
m_{c}=\alpha_{\mathrm{pp}} C_{f} V_{s^{-}}\left\{\sum_{i=1}^{N} x_{i} m_{p L_{i}}-\sum_{i=1}^{N} x_{i} m_{p S_{i}}-\sum_{i=1}^{N} x_{i} m_{w_{i}}\right\} & \text { Equation (3.53) } \\
m_{c}=\alpha_{\mathrm{pp}} C_{f} V_{s}-\left\{\sum_{i=1}^{N} x_{i}\left\{\frac{\alpha_{p m} \varepsilon_{\mathrm{s}}}{4^{\alpha} p p_{\sigma_{\mathrm{L}}}}\left[1-\exp \left(-4^{\alpha}{ }^{\alpha p} \sigma_{\mathrm{L}} C_{f} V_{s}\right)\right]\right\}+\sum_{i=1}^{N} x_{i}\left\{\frac{N_{m}}{\sigma_{\mathrm{xs}} \alpha_{\mathrm{pm}} B_{i}}\right.\right. \\
\left.\left\{\frac{\pi D_{m_{i}} L_{m} B_{i} \alpha_{\mathrm{pm}}}{\tau}-\ln \left[1+\exp \left(\frac{\pi D_{m_{i}} L_{m} B_{i} \alpha_{\mathrm{pm}}}{\tau}-\frac{\sigma_{\mathrm{xs}} \alpha_{\mathrm{pm}} B_{i}}{N_{m}} C_{f} V s\right)\right]\right\}\right\}+\sum_{i=1}^{N} x_{i}\left\{\frac{\alpha_{\mathrm{pm}} \varepsilon_{\mathrm{s}}}{\sigma_{\mathrm{s}}}[1-\right.
\end{array}
$$$$
\left.\left.\left.\exp \left(-\sigma_{\mathrm{s}} C_{f} V_{s}\right)\right]\right\}\right\}
$$

The mass of particles contributed to cake layer formation can be expressed as the mass of particles attached to membrane surface in addition to the mass of particles contributed to cake build up, as presented in Equation (3.55).

$m_{c}=\alpha_{\mathrm{pp}} C_{f} V_{S}+\left\{\frac{\alpha_{\mathrm{pm}}\left(1-\varepsilon_{\mathrm{S}}\right)-\alpha_{\mathrm{pp}}}{4^{\alpha \mathrm{pp}}}\left[\frac{\left[1-\exp \left(-4^{\alpha} \mathrm{pp}_{\sigma_{\mathrm{L}}} C_{f} V_{S}\right)\right.}{\sigma_{\mathrm{L}}}+\frac{\left[1-\exp \left(-4^{\alpha} \mathrm{pp}_{\sigma_{\mathrm{S}}} C_{f} V_{S}\right)\right.}{\sigma_{\mathrm{s}}}\right]\right\}$

Equation (3.55)

\subsubsection{Modeling of irreversible fouling}

The type of particle attachment in the cake layer must be accounted for in order to accurately predict the quantity of the particles participating in the hydraulically irreversible fouling. In most cases, some of the particles get attached directly to the membrane's surface. The mass per unit membrane area of these particles can be ascribed as $m_{s}\left[\mathrm{~kg} / \mathrm{m}^{2}\right]$ and can be calculated from Equation (3.56).

$m_{s}=\frac{\alpha_{\mathrm{pm}}\left(1-\varepsilon_{s}\right)}{4^{\alpha p p} \sigma}\left[1-\exp \left(-4^{\alpha} p p \sigma C_{f} V_{S}\right)\right]$

Equation (3.56)

In addition, the mass of the particles getting attached to other particles already situated on the membrane surface was outlined in the previous section for uniform pore size membrane and defined as $m_{p p}\left[\mathrm{~kg} / \mathrm{m}^{2}\right]$, and is presented in Equation (3.57). Furthermore, the particles attached to the pore wall $m_{w}$ also contribute to the irreversible membrane fouling, as discussed in Section (3.1.2.2).

$m_{p p}=\alpha_{\mathrm{pp}} C_{f} V_{s}-\frac{\alpha_{p p}}{4^{\alpha} p p_{\sigma}}\left[1-\exp \left(-4^{\alpha} p p \sigma C_{f} V_{s}\right)\right]$

Equation (3.57)

Hence, the total mass of irreversible cake layer is expressed in the following equation 
$m_{c I R R}=\alpha_{\mathrm{pp}} C_{f} V_{s}+\left\{\left[1-\exp \left(-4^{\alpha} p p \sigma C_{f} V_{s}\right)\right]\left(\frac{\alpha_{\mathrm{pm}}\left(1-\varepsilon_{\mathrm{s}}\right)-\alpha_{p p}}{4^{\alpha} p p_{\sigma}}\right)\right\}$

Equation (3.58)

As a consequence, the total mass of irreversible fouling can be calculated using the following equations:

$m_{I R R}=m_{c I R R}+m_{w}$

Equation (3.59)

$m_{I R R}=\alpha_{\mathrm{pp}} C_{f} V_{s}+\left\{\left[1-\exp \left(-4^{\alpha_{p p}} \sigma C_{f} V_{s}\right)\right]\left(\frac{\alpha_{\mathrm{pm}}\left(1-\varepsilon_{\mathrm{s}}\right)-\alpha_{p p}}{4^{\alpha p p} p_{\sigma}}\right)\right\}+\sum_{i=1}^{N} x_{i} m_{w_{i}}$

Equation (3.60)

\subsubsection{Mathematical model for transmembrane pressure}

The mathematical model was combined with Hermia model in order to expand the models specifically for the transmembrane pressure prediction, as demonstrated in our previous section for uniform pore size membranes. The reduction of the membrane permeability, predominantly as a consequence of pore blockage and cake layer formation, results in an increase of the relative transmembrane pressure $\left(P^{\prime}\right) . P^{\prime}$ is defined as the increase of transmembrane pressure TMP during the filtration process normalized with respect to clean membranes [dimensionless]. $P$ ' is a function of the particle mass retained by the membrane. The increase of transmembrane pressure, due to the large and small particles participating in the pore blocking, can be calculated using Equations (3.61) and (3.62), respectively.

$P_{p L}^{\prime}=\frac{1}{1-\sigma_{\mathrm{L}} \sum_{i=1}^{N} x_{i} m_{p L_{i}}}$

$P_{p S}^{\prime}=\frac{1}{1-\sigma_{\mathrm{S}} \sum_{i=1}^{N} x_{i} m_{p s_{i}}}$

The change of transmembrane pressure, due to very small particles getting attached to the membrane pore wall, can be expressed as:

$P_{w}^{\prime}=\frac{1}{\left(1-\frac{\sum_{i=1}^{N} x_{i} m_{w_{i}}}{\rho L_{m}}\right)^{2}}$

The increase of transmembrane pressure due to the cake layer formation can be written as:

$P_{c}^{\prime}=1+\frac{\hat{\mathrm{R}}_{C}}{R_{m}}\left[\alpha_{\mathrm{pp}} C_{f} V_{s}-\left(\sum_{i=1}^{N} x_{i} m_{p L_{i}}-\sum_{i=1}^{N} x_{i} m_{p S_{i}}-\sum_{i=1}^{N} x_{i} m_{w_{i}}\right)\right]$

Equation (3.64)

Accordingly, the increase of total transmembrane membrane pressure during a filtration process can be calculated from Equation (3.65)

$P^{\prime}=1+\frac{1}{1-\sigma_{\mathrm{L}} \sum_{i=1}^{N} x_{i} m_{p L_{i}}}+\frac{1}{1-\sigma_{\mathrm{S}} \sum_{i=1}^{N} x_{i} m_{p S_{i}}}+\frac{1}{\left(1-\frac{\sum_{i=1}^{N} x_{i} m_{w_{i}}}{\rho L_{m}}\right) 2}+\frac{\hat{\mathrm{R}}_{\hat{\mathrm{R}} c}}{R_{m}}\left[\alpha_{\mathrm{pp}} C_{f} V_{s}-\right.$
$\left.\left(\sum_{i=1}^{N} x_{i} m_{p L_{i}}-\sum_{i=1}^{N} x_{i} m_{p S_{i}}-\sum_{i=1}^{N} x_{i} m_{w_{i}}\right)\right]$

Equation (3.65) 
In fact, after the backwash process, the minimum transmembrane pressure required for the permeate to pass through the membrane is increased in comparison to the transmembrane pressure occurring with the clean membrane. This could be attributed to the accumulation of the irreversible fouling particles, including the irreversible cake layer and the irreversible fouling on the membrane pore wall. Owing to this, the increase of transmembrane pressure after backwash $\left(P_{\text {IRR }}\right)$ can be calculated from Equation (3.67)

$\dot{P}_{\text {IRR }}=P^{\prime} c_{I R R}+P_{W}^{\prime}$

Equation (3.66)

$P_{I R R}^{\prime}=1+\frac{\hat{\mathrm{R}} c}{R_{m}}\left\{\alpha_{\mathrm{pp}} C_{f} V_{S}+\left(\left[1-\exp \left(-4^{\alpha} p p \sigma C_{f} V_{S}\right)\right]\left(\frac{\alpha_{\mathrm{pm}}\left(1-\varepsilon_{\mathrm{S}}\right)-\alpha_{p p}}{4^{\alpha} p p_{\sigma}}\right)\right)\right\}+\frac{1}{\left(1-\frac{\sum_{i=1}^{N} x_{i} m_{w_{i}}}{\rho L_{m}}\right)^{2}}$

Equation (3.67)

Based on the particle size distribution of latex paint and the pore size distribution of the heterogeneous membrane used in this study, the fouling probabilities $\alpha_{\mathrm{pp}}$ and $\alpha_{\mathrm{pm}}$, were calculated using the model equations. Equation (3.68) and Equation (3.55) for the total mass of fouling contributed to pore blocking $\left(m_{p}\right)$ and the total mass of fouling contributed to cake formation $\left(m_{c}\right)$, were then solved for $\alpha_{\mathrm{pp}}$ and $\alpha_{\mathrm{pm}}$ using $m_{p}$ and $m_{c}$ measured experimentally as described in Section (4.5). Eventually, these predicted fouling attachment probabilities were used to calculate the increase of transmembrane pressure from Equation (3.65), which were validated by comparing them with experimentally measure values.

$m_{p}=\sum_{i=1}^{N} x_{i}\left\{\frac{\alpha_{p m} \varepsilon_{\mathrm{s}}}{4^{\alpha} p p_{\sigma_{\mathrm{L}}}}\left[1-\exp \left(-4^{\alpha_{p p}} \sigma_{\mathrm{L}} C_{f} V_{s}\right)\right]\right\}+\sum_{i=1}^{N} x_{i}\left\{\frac{N_{m}}{\sigma_{\mathrm{xs}} \alpha_{\mathrm{pm}} B_{i}}\left\{\frac{\pi D_{m_{i}} L_{m} B_{i} \alpha_{\mathrm{pm}}}{\tau}-\ln [1+\exp \right.\right.$
$\left.\left.\left.\left(\frac{\pi D_{m_{i}} L_{m} B_{i} \alpha_{\mathrm{pm}}}{\tau}-\frac{\sigma_{\mathrm{xS}} \alpha_{\mathrm{pm}} B_{i}}{N_{m}} C_{f} V_{s}\right)\right]\right\}\right\}+\sum_{i=1}^{N} x_{i}\left\{\frac{\alpha_{\mathrm{pm}} \varepsilon_{\mathrm{S}}}{\sigma_{\mathrm{s}}}\left[1-\exp \left(-\sigma_{\mathrm{s}} C_{f} V_{s}\right)\right]\right\} \quad$ Equation (3.68)

\subsection{Modeling of fouling attachments}

Predictive models for an accurate estimation of fouling attachments at a given operating condition were developed and validated for homogeneous and heterogeneous membranes of different types and with a variety of MWCO values, as illustrated in Section (5.6.1,5.6.3,5.6.4).The fouling model and the fouling attachment correlations found in the present study form a comprehensive set of predictive models, applicable to both hydrophilic and hydrophobic membranes in a variety of materials with different molecular weight cut off (MWCO) values.

\subsection{Attachment model development including sphericity of contaminant particles}

In this study a mechanistic model was developed and generalized for application with uniform and non-uniform pore size membranes, based on the fouling potential of the different 
particle sizes and featuring a variety of pore sizes. Due to the fact that the contaminated particle sizes may be larger or smaller than each pore size within the overall range of the membrane, the size of the latex particles and membrane pores were regarded as the primary factors in determining the occurrence of surface fouling (cake layer formation or pore blocking) and adsorptive internal plugging. Furthermore, the sphericity value of the particles $(\psi)$, defined as the ratio of the surface area of a sphere of the same volume as the given particle to the surface area of the particle, would have a significant effect on the fouling phenomenon for each of the tested pore sizes, as shown in Figure 3.6. Therefore, the model was developed to include the sphereicty of latex particles while evaluating its effectiveness in the model prediction. As a consequence, the fouling attachment model accounts for most of the characteristic variables that influence fouling phenomenon, such as, the membrane surface charge $(\zeta)$, the membrane pores tortuosity $(\tau)$, and the sphericity of contaminated particles $(\psi)$.

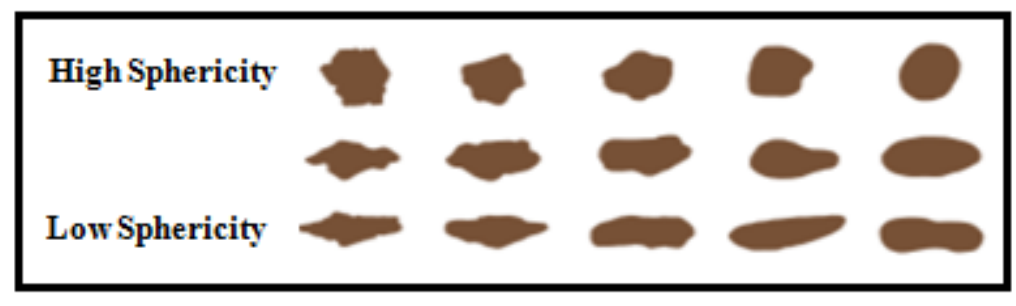

Figure 3.6 : Sphericity of particles

For the developed model equations, the projected area of a unit mass of the particles on membrane surface, $\sigma\left[\mathrm{m}^{2} / \mathrm{kg}\right]$ is calculated as:

$\sigma_{\mathrm{L}}=\frac{0.75}{\rho \psi_{L} a}$

$\sigma_{S}=\frac{0.75}{\rho \psi_{S} a}$

Equation (3.70)

$\sigma \mathrm{XS}=\frac{0.75}{\rho \Psi_{X S} a}$

Equation (3.71)

where $\rho$ is the particle density $\left[\mathrm{kg} / \mathrm{m}^{3}\right] . \Psi_{L}, \Psi_{S}$, and $\Psi_{X S}$ are the average sphericities of the latex particles in the large, small, and very small range, respectively. The estimation of the latex particles' sphericity using ImageJ software was discussed in Section 4.10. The validation of the developed attachment model including the particle sphericity for homogeneous and heterogeneous membranes was examined in Section 5.3. 


\section{CHAPTER 4 MATERiAls AND MeTHOdS}

In this chapter, details of the experimental setup designed for the ultrafiltration process of latex paint effluent, procedure, materials, and analytical methods are summarized.

\subsection{Experimental set-up}

A schematic diagram of the experimental setup is shown in Figure 4.1. It includes a $1.0 \mathrm{hp}$ feed pump and a flow meter (Model F-400N, Blue White Industries Ltd., USA, $\pm 5 \%$ ) ranging from 1.0 to $7.0 \mathrm{~L} / \mathrm{min}$. The liquid feed pressure is monitored using a pressure transducer (Model V82/V182/V782, George Fischer, USA). Three pressure sensors (0-100 psi) (Model Omega PX303-100G5V, $\pm 0.25 \%$ ) connected to the data acquisition system to measure the pressure in the filtration unit and to evaluate the pressure influence on cake layer thickness. The permeate stream is continuously measured gravimetrically using an electronic balance, $\pm 0.1 \mathrm{~g}$ (Model Adventurer Pro AV2101, Ohaus Corporation, New Jersey, USA). Both the pressure transducers and the electronic balance are connected to a data acquisition system. The membrane filtration unit is constructed of two acrylic plates held together by nuts and bolts. The gap between the two plates for the liquid flow was $2 \mathrm{~mm}$. O-rings were used to seal the two plates of the unit. There were 2 rectangular slits; one on each end of the unit, for the feed inlet and the reject outlet. The membrane sheet area was $28 \mathrm{~cm} \mathrm{x} 8 \mathrm{~cm}$ that was supported by a porous stainless steel disc, as shown in Figure 4.2.

\subsection{Ultrafiltration membranes}

Polycarbonate membrane filters with uniform nominal pore size of $0.01 \mu \mathrm{m}, 0.05 \mu \mathrm{m}$ and $0.1 \mu \mathrm{m}$ (GE water \& Process Technologies) were used as homogeneous membranes for the experimental work. These membranes are hydrophilic with narrow pore size distributions which were manufactured using track etching. Table 4.1 shows the membrane characteristics. The membrane filters were available in large sheets, $300 \mathrm{~mm} \times 3000 \mathrm{~mm}$ is size, which were easily cut to the desired shape and dimensions. Polycarbonate Chemical Structure illustrated in Appendix (D).

Furthermore, Polysulfone membrane with MWCO of 60,000 and with the chemical structure of $\left[\mathrm{OC}_{6} \mathrm{H}_{4} \mathrm{OC}_{6} \mathrm{H}_{4} \mathrm{SO}_{2} \mathrm{C}_{6} \mathrm{H}_{4}\right]_{n}$ (GE Water \& Process Technologies), Ultrafilic membrane with MWCO of 100,000 and with the chemical structure of $\left(\mathrm{C}_{3} \mathrm{H}_{3} \mathrm{~N}\right)_{\mathrm{n}}$ (GE Water

\& Process Technologies), Cellulose Acetate with MWCO of 20,000 and with the 
chemical structure of $\left[\mathrm{C}_{6} \mathrm{H}_{7} \mathrm{O}_{2}(\mathrm{OH})_{3}\right]_{\mathrm{n}}$ (GE Water \& Process Technologies), and Polyvinylidene Difluoride (PVDF) membrane with MWCO of 100,000 and with the chemical structure of $\left(\mathrm{C}_{2} \mathrm{H}_{2} \mathrm{~F}_{2}\right)_{\mathrm{n}}$ (Koch Membrane Systems) were used as heterogeneous non-uniform pore size membranes.

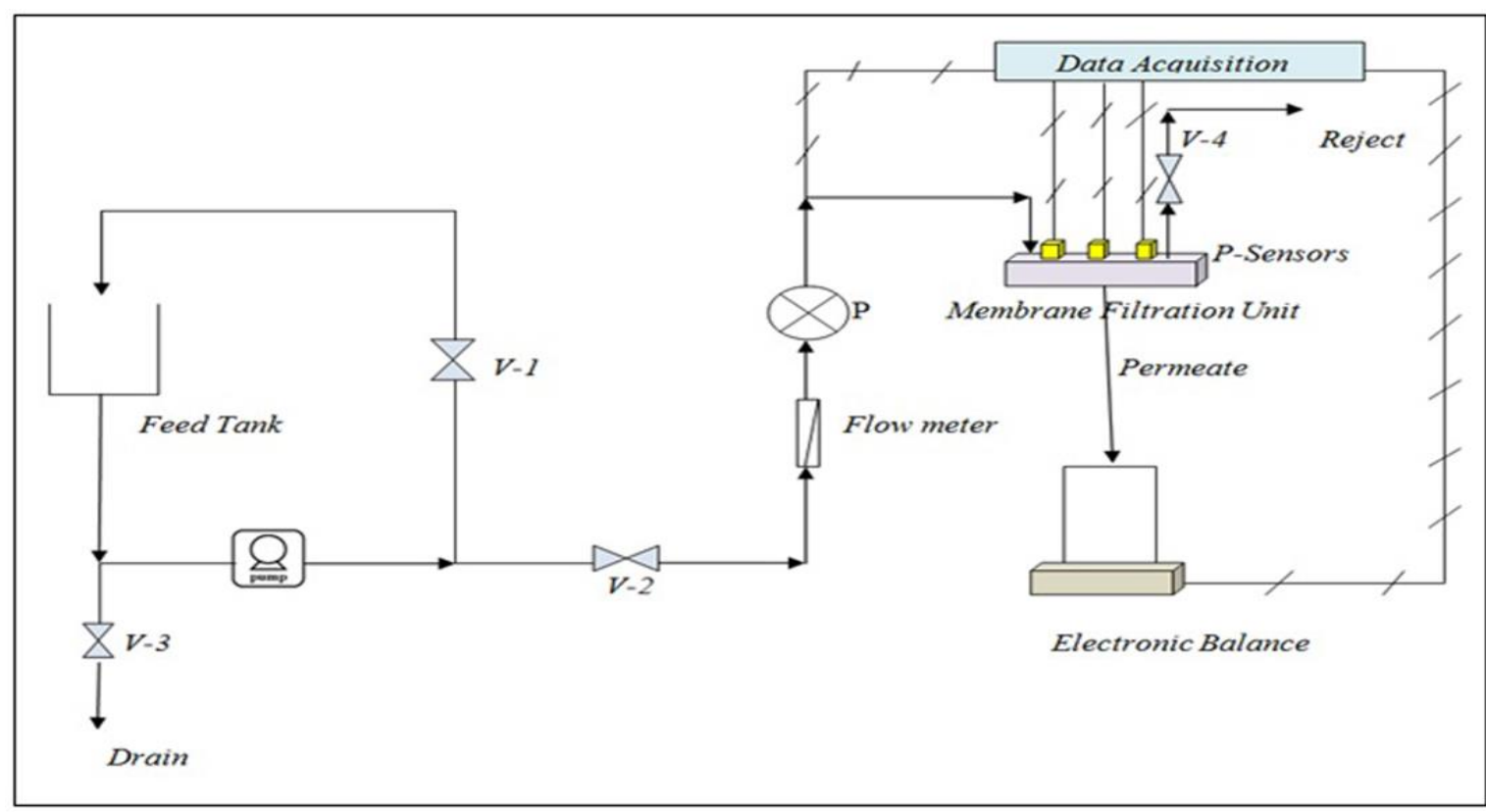

Figure 4.1: Schematic diagram of experimental set

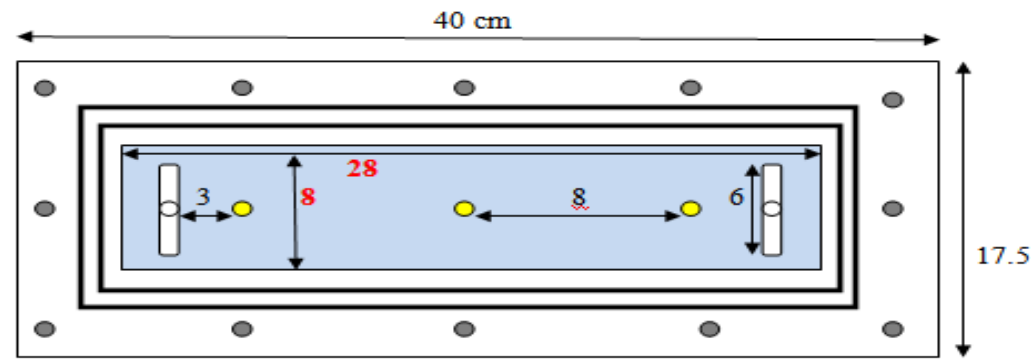

Figure 4.2: Top view of the membrane unit (All dimensions are symmetric and in $\mathrm{cm}$ )

Table 4.1: Performance characteristics of GE uniform Polycarbonate membranes

\begin{tabular}{|c|c|c|c|c|}
\hline $\begin{array}{l}\text { Pore } \\
\text { size }^{(a)} \\
\mu \mathrm{m}\end{array}$ & $\begin{array}{c}\text { Pore } \\
\text { Density } \\
(\text { b) } \\
\left(\text { pore } / \mathrm{cm}^{2}\right)\end{array}$ & $\begin{array}{c}\text { Nominal } \\
\text { weight } \\
\left(\mathrm{mg} / \mathrm{cm}^{2}\right)\end{array}$ & $\begin{array}{l}\text { Nominal } \\
\text { Thickness } \\
\text { (c) } \mu \mathrm{m}\end{array}$ & $\begin{array}{l}\text { Typical flow } \\
\text { rate }^{\text {(d) }} \\
\mathrm{mL} / \mathrm{min} / \mathrm{cm}^{2}\end{array}$ \\
\hline 0.1 & $4 \times 10^{8}$ & 0.7 & 6 & 2.5 \\
\hline 0.05 & $6 \times 10^{8}$ & 0.7 & 6 & 0.4 \\
\hline 0.01 & $6 \times 10^{8}$ & 0.7 & 6 & 0.1 \\
\hline
\end{tabular}

Notes:
(a) Tolerance $+0 \%,-20 \%$
(b) Tolerance $\pm 15 \%$
(c) Tolerance $\pm 10 \%$
(d) Initial flow rates measured using pre-filtered water at 10 Psi 


\subsection{Feed solution}

\subsubsection{Latex paint dispersion}

In large tank, a measured volume of latex paint (Type: Glidden Easyflow Interior Latex Paint, White, Flat) will be added to distilled water at different feed solid concentrations. Vinyl acrylic latex $\left[\mathrm{CH}_{2} \mathrm{CHCOOCH}_{2} \mathrm{CH}\right]_{\mathrm{n}}$ is used as the binder. However, the exact composition of the paint is proprietary. Latex paint $\mathrm{pH}$ is 9 and density is $1.34 \mathrm{~kg} / \mathrm{L}$. The volume of latex paint used varied with the solid concentration required using the analytical method for solid content. As an example, in order to obtain a feed solid concentration of $0.13 \%, 2.5 \mathrm{ml}$ of latex paint is added to each liter of distilled water used. Lastly, during the experiments, distilled water was used for the preparation of the feed. A simulated latex effluent with a $\mathrm{pH}$ value of 7 was used. The zeta potential of latex particles at $\mathrm{pH}$ of 7 was approximately $-26.61 \mathrm{mV}$.

\subsubsection{Monodisperse particles}

Monodisperse polystyrene nano-spheres of size $50 \mathrm{~nm}$ and $100 \mathrm{~nm}$ (MicrospheresNanospheres Company, New York, USA) was used for model validation of non-uniform pore size membranes at different concentrations.

\subsection{Analytical methods}

\subsubsection{Solid content}

A measured mass of each feed sample was transferred to a metal dish that was placed in an oven at $105^{\circ} \mathrm{C}$ for more than a week. The mass of each dish was periodically measured using an electronic balance (Mettler Toledo Model AB 54-S Fact, Switzerland, $\pm 0.1 \mathrm{mg}$ ), approximately every three days, until there was no change. From the measured masses of the solution and the solid in the metal dish, the solid content of the paint solution was determined.

\subsubsection{Particle size distribution of latex paint dispersion}

The particle size distribution of the latex paint solution was determined using a particle size analyzer (Model 2000 -Malvern Mastersizer) which had a range of 0.02 to 2000 microns. The particle size distribution of the latex feed solution ranges from 0.03 microns (30 nanometers) to 800 microns, as illustrated in Figure 4.3. The concentration of samples didn't affect the particle size distribution obtained. For the accuracy of the measurement, three identical measurements were performed at each feed concentration. In addition, the particle size distribution of the collected permeate was measured three times for each of the samples so as to ensure the accuracy of measurments. 


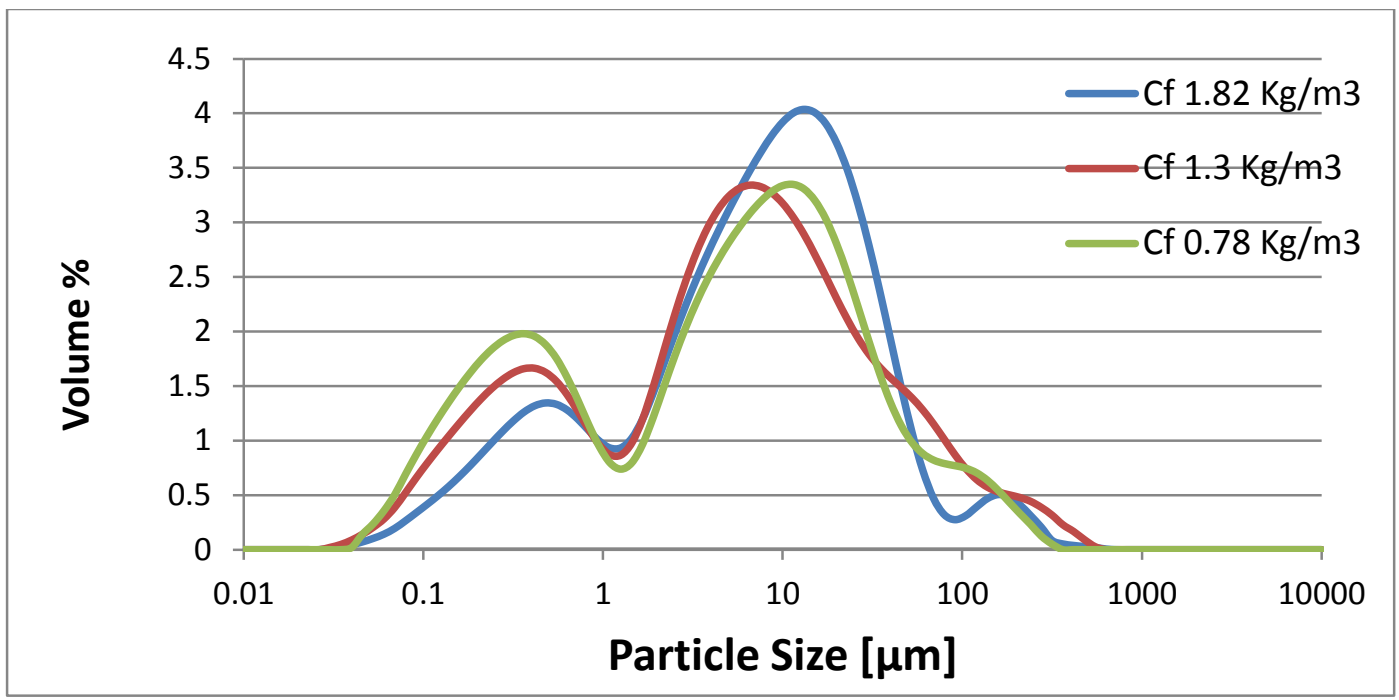

Figure 4.3: Particles size distribution of feed samples at different concentrations

\subsubsection{Scanning electron microscopy (SEM) imaging}

To obtain surface images of the membrane before and after filtration, a scanning electron microscope (Model JEOL, JSM-6380 LV, Oxford Instrument, U.K.) was used. A clean membrane sample was coated with a thin layer of gold particles to improve the resolution of the images. Figure 4.4 (a) shows that the surface of the Polycarbonate homogenous membrane had a high pore density, but the pores were arranged in a random distribution. Figure 4.4 (b) zooms into an area of the membrane surface. From this image, it can be seen that the pores are predominantly circular (or cylindrical) in nature. Measuring of the dimensions of the pore openings showed that the majority of the pore sizes were about $0.1 \mu \mathrm{m}$.

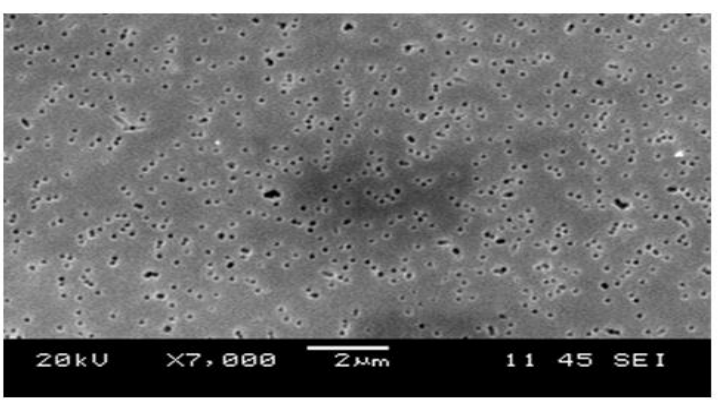

(a)

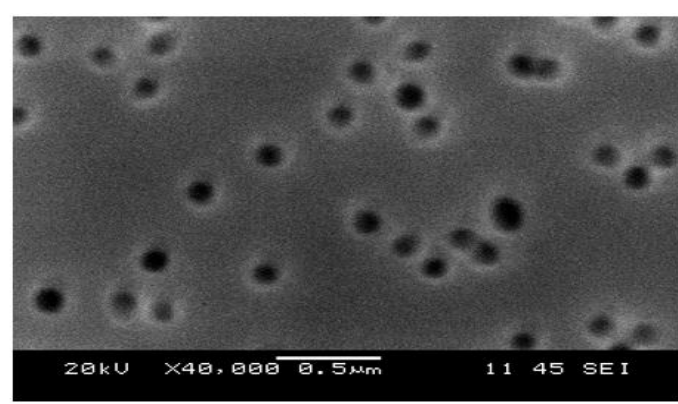

(b)

Figure 4.4: SEM image of clean Polycarbonate membrane $0.1 \mu \mathrm{m}$, gold-coated 


\subsubsection{Confocal laser microscope imaging}

To provide an evidence of particles attachments in membrane pores, surface images of the membrane after filtration were obtained using Confocal Microscope ( Eclipse 90i , Nikon Instruments Inc., USA). Fluospheres Carboxylate Modified Microspheres (latex beads) of Orange Fluorescent with the size of 0.1 microns and zeta potential of $-56 \mathrm{mV}$ were used. The images were analyzed using NIS-Elements Microscope Imaging software (NIS-Elements AR 3.1 Microscope Imaging Software, Nikon Instruments Inc., USA). Figure 4.5. presented the attachments of Fluospheres Carboxylate microspheres latex beads inside the membrane layers.

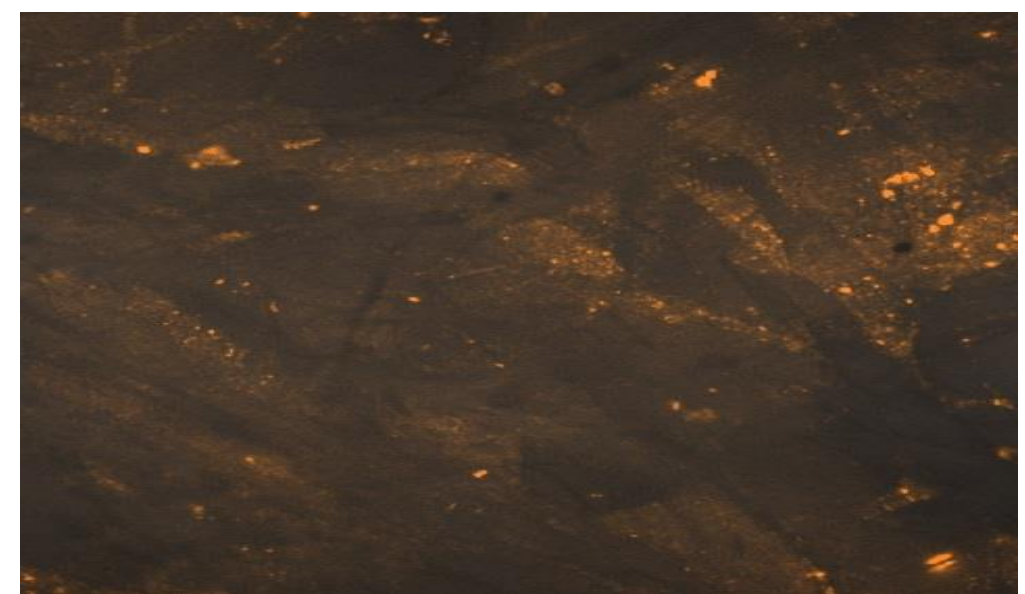

Figure 4.5: Confocal laser microscope image of Polysulfone membrane layers after ultrafiltration process using fluospheres carboxylate latex beads

\subsubsection{Turbidity measurements}

The turbidity of permeate was measured for each of the experimental runs using the Turbidimeter (La Motte 2020 we TurbidimeterTurbidimeter, USA, $\pm 2 \%$ ). Turbidity is a measure of how clear the water is. High turbidity means that there are a lot of particles suspended in the water and light cannot get through. The allowable turbidity in drinking water cannot be higher than 1.0 nephelometric turbidity units (NTU).

\subsubsection{Membrane surface charge measurements (zeta potential $\zeta$ )}

The zeta potentials of latex particles and the membrane surface were measured using a zeta potential analyzer (Zetasizer Nano Series, Malvern Instruments Ltd., UK, $\pm 0.01 \mathrm{mV}$ ). The zeta potentials of the untreated membranes used in the present study were $-36.67 \mathrm{mV},-42.40$ $\mathrm{mV}, \quad-41.50 \mathrm{mV},-2.50 \mathrm{mV}$, and $-33.90 \mathrm{mV}$ for polycarbonates, polysulfone, ultrafilic, PVDF, and cellulose acetate membranes, respectively. 
The membrane surface charge was adjusted using a soaking solution in an MPT-2 autotitrator of the zeta potential analyzer (ZetasizerNano Series, Malvern Instruments Ltd, UK, $\pm 0.01 \mathrm{MV}$ ). The acidity or the alkalinity of the soaking solution was adjusted by using $0.1 \mathrm{~N}$ $\mathrm{H}_{2} \mathrm{SO}_{4}$ or $0.1 \mathrm{~N} \mathrm{NaOH}$. The membrane sheets were immersed in the solutions for 2 hours since this period was optimal for the adsorption of the $\mathrm{OH}^{-}$or $\mathrm{H}^{+}$group on the membrane surface after the preliminary experiments. This time was estimated based on the preliminary experiments for the stability of the surface charge after the ultrafiltration process, as shown in Appendix (I). Polysulfone membrane zeta potentials of $-10.00 \mathrm{mV},-20.00 \mathrm{mV},-30.00 \mathrm{mV},-40.00 \mathrm{mV}$, and $50.00 \mathrm{mV}$, were respectively obtained after immersing in soaking solutions at $\mathrm{pH}$ values of 2.4, 4.1, 5.7, 6.8, and 10.9. The Ultrafilic membrane with zeta potentials of $-15.00 \mathrm{mV}$ and -30.00 $\mathrm{mV}$ were obtained at $\mathrm{pH}$ values of 2.8 , and 6 , respectively. Moreover, the zeta potential of the back surface of the membrane sheet was measured after each ultrafiltration run to check the stability of the surface charge of treated membranes. For the experiments of treated membrane surface, a simulated latex effluent with a $\mathrm{pH}$ of 7 was used in all runs. In order to ensure the accuracy of the zeta potential measurement, three identical measurements were performed. This will be discussed in details in Section 5.2. The zeta potential of latex particles at a solution $\mathrm{pH}$ of 7 was approximately $-26.61 \mathrm{mV}$.

In the case of membrane surface charge treatment using an anionic surfactant, the flat membrane sheets were immersed in Linear Alkyl Benzene Sulfonate (LAS), having the chemical structure as $\left[\left(\mathrm{CH}_{3}\right)_{2}\left(\mathrm{CH}_{2}\right)_{9} \mathrm{CHC}_{6} \mathrm{H}_{4}-\mathrm{SO}_{3} \mathrm{Na}\right]$, at different concentrations and varied treatment times. The critical micelle concentration (CMC) of LAS is $0.1 \mathrm{~g} / \mathrm{L}$. LAS was also added at different concentrations to the simulated latex effluent in order to investigate its effect on the ionic strength of the latex solution and the zeta potential of latex particles.

\subsubsection{Acidity and alkalinity of latex solution}

The latex solution $\mathrm{pH}$ was adjusted with the aids of a $\mathrm{pH}$ transmitter (Mettlertoledo $\mathrm{pH}$ Transmitters 2100e, Mettler Toledo, Germany, $<0.02 \mathrm{pH}$ ). The solution acidity was increased using $0.1 \mathrm{~N} \mathrm{H}_{2} \mathrm{SO}_{4}$ or $0.1 \mathrm{~N} \mathrm{HCl}$ in order to investigate the effects of the divalent and monovalent acids on the membrane fouling attachments. Similarly, $0.1 \mathrm{~N} \mathrm{NaOH}$ was used to increase the alkalinity of the latex solution. Experiments were carried out in the $\mathrm{pH}$ value range between 3 and 12 . The conductivity of the latex solution $[\mathrm{mS} / \mathrm{cm}]$ was measured at each $\mathrm{pH}$ value using a 
conductivity meter (Model 4063 Traceable ${ }^{\circledR}$ Portable Conductivity Meter, Control Company, USA, $\pm 0.3 \%)$.

\subsubsection{Small-angle X-ray scattering (SAXS)}

The aggregation and the shape of the particles was confirmed by Small-angle X-ray scattering (SAXS) (Bruker Daltonics Ltd., East Milton, ON, CANADA). The elastic scattering of X-rays (wavelength $0.1-0.2 \mathrm{~nm}$ ) by the latex solution samples was recorded at very low angles (typically $0.1-10^{\circ}$ ). SAXS was capable of delivering key structural information on macromolecules.

\subsection{Operating procedure}

In a feed tank, a measured volume of latex paint (Type: Glidden Easyflow Interior Latex Paint, White, Flat) was mixed with distilled water to get a solution at a specific feed solid concentration. Vinyl acrylic latex is used as the binder in the paint. However, the exact composition of the paint is proprietary. Latex solution $\mathrm{pH}$ was at 9.0, and the density was 1.34 $\mathrm{kg} / \mathrm{L}$. The volume of latex paint used varied with the solid concentration required. For example, in order to obtain a feed solid concentration of $0.13 \%$ by weight, $2.5 \mathrm{ml}$ of latex paint was used for each liter of solution.

The temperature of the solution was kept at room temperature. Flow rates ranging from 1.0 to $4.0 \mathrm{~L} / \mathrm{min}$ were used in experiments. Operating pressures from 3.0 to $5.0 \mathrm{psi}$ for the $0.1 \mu \mathrm{m}$ membrane and from 5.0 to 12 psi for the $0.05 \mu \mathrm{m}$ membrane were used with varied feed solid concentrations of $0.78 \mathrm{~kg} / \mathrm{m}^{3}, 1.3 \mathrm{~kg} / \mathrm{m}^{3}$ and $1.82 \mathrm{~kg} / \mathrm{m}^{3}$. Experiments using clean distilled water as the feed were also performed. Mass of latex particles retained by the membrane was measured to predict the fouling probabilities. The predicted transmembrane pressures were validated using experimentally measured values.

For each experimental run, a membrane sheet was placed in the membrane filtration unit. The feed tank was filled with a latex paint solution at a specific solid concentration. The solution was mixed in the tank via the recycle line by fully opening valve V-1. At the start of the experimental run, the feed valve, $\mathrm{V}-2$, and the reject valve, $\mathrm{V}-4$, were opened slowly in order to set the pressure and the flow rate to appropriate values. If a high pressure was necessary, the reject valve, $\mathrm{V}-4$, were opened less than the valve setting for lower operating pressures at the same feed flow rate while the feed valve, $\mathrm{V}-2$, was opened slightly more. The reject stream is not 
returned to the feed tank so to have a continuous steady state filtration process with a specific feed concentration. Measurements of the pressure of the feed stream entering the filtration unit were displayed on a computer monitor and recorded at one-second intervals. The permeate stream was collected on an electronic balance that was also connected to the data acquisition for accurate and automatic recording of the permeate mass collected over time.

The run time was kept constant for all experiments to investigate the influence of the operating conditions on the mass of particles retained by the membrane, the permeate flux and the fouling attachments. Furthermore, cross flow backwash experiments were performed for model validation and restore membrane fluxes at different conditions.

The total mass of fouling $\left(m_{t}\right)$ is the difference in weight of the membrane before and after filtration. For measuring the mass of particles contributing to cake layer $\left(m_{c}\right)$, the cake was scratched off under the microscope, so as to keep the membranes pores blocked with the particles contributing to the pore blocking. The scratched off solid portion was then weighted in order to determine the amount of cake layer. The blocked pores of the membrane were checked using SEM. The mass of particles contributing to pore blocking $\left(m_{p}\right)$, is the difference between the weight of the membrane before filtration (clean membrane) and the weight after the cake layer was scratched off. The mass of particles $\left(m_{t}, m_{c}\right.$ and $\left.m_{p}\right)$ was measured using an electronic balance (Mettler Toledo Model AB 54-S Fact, Switzerland, $\pm 0.1 \mathrm{mg}$ ). Figure 4.6 (a) presents SEM images of the membrane surface after the ultrafiltration of the latex solution, and before the cake layer was scratched off, which represent the total mass of solids $\left(m_{t}\right)$. The SEM image of the membrane surface after the cake layer was scratched off for the measurments of $m_{c}$ and $m_{p}$, as shown in Figure 4.6 (b). As clarified by a higher magnification in Figure 4.6 (c), the particles blocked the membrane pores and were trapped inside the membrane matrix.

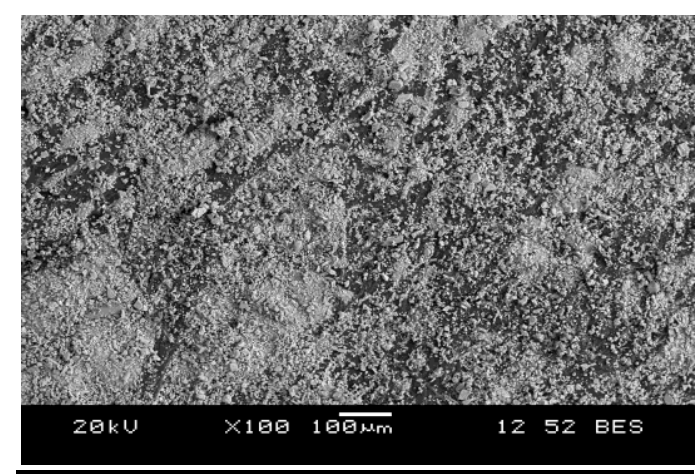

(a)

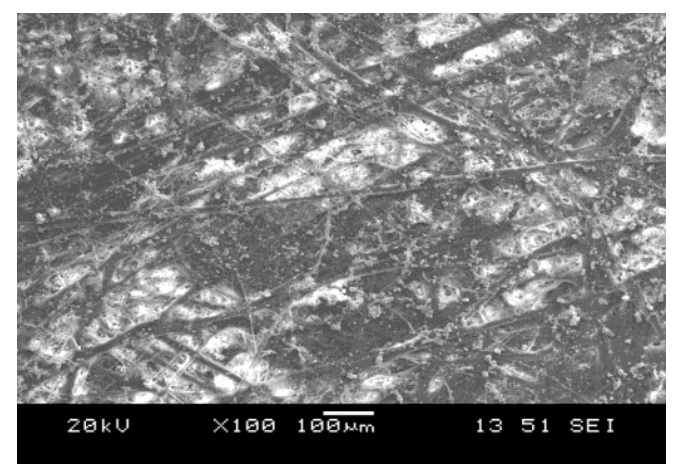

(b) 


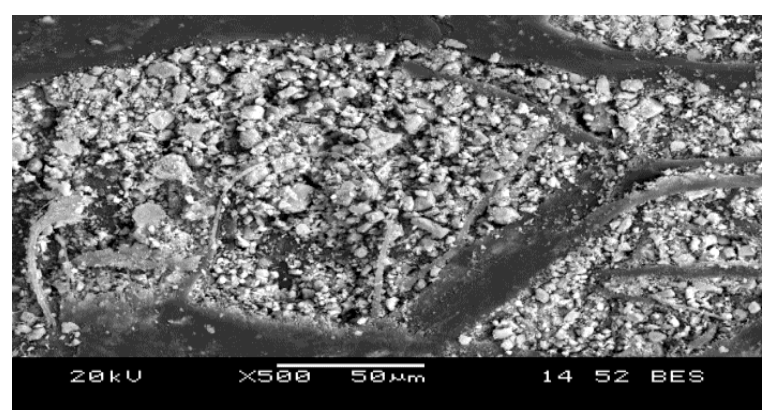

(c)

Figure 4.6: The SEM images of membrane surface after ultrafiltration: (a) before the cake layer was scratched off; (b) after the cake layer was scratched off for the mass of fouling contributed to $\left(m_{p}\right)$; (c) after scratched off the cake layer at a higher magnification of 500

\subsection{Membrane fouling remediation}

Experimental work was extended for fouling remediation using different techniques by improving the antifouling properties of the membrane and pre-treating the feed to limit its fouling propensity. The goal was to minimize membrane fouling of latex effluent by altering the membrane surface charge or the ionic strength of the simulated latex effluent either through the $\mathrm{pH}$ change or using anionic surfactants. The influence of the ionic strength, via varying of the solution $\mathrm{pH}$ or adding anionic surfactant, on the fouling attachments, the total mass of fouling, cumulative permeate volume per unit area, and the specific power consumption was investigated. The impact of membrane surface treatment on improving the anti-fouling properties of the membrane, membrane fouling remediation, and decreasing the specific power consumption was also studied. In addition, the effect of cationic surfactant on the latex particle size distribution was investigated at different concentrations, various treatment times, and diverse agitation duration. The effects of cationic surfactant on the zeta potential of latex particles and membrane surfaces were also investigated. In addition the effect of cationic surfactant on fouling attachments, total mass of fouling, cumulative permeate volume per unit is, and the specific power consumption was also investigated. Preliminary experiments were performed to check the optimum mixing time, duration, and surfactant concentration to get the largest particles size distribution after aggregation using cationic surfactant or the optimum membrane and latex particles surface charge using anionic surfactant. This optimum mixing time, duration, and surfactant concentration were used during the ultrafiltration process. 


\subsubsection{Feed pre-treatment}

The $\mathrm{pH}$ of simulated latex effluent was varied to investigate the effects of the solution $\mathrm{pH}$ over a range from 3-12 on particle-particle attachment and particle-membrane attachment since those attachment potentials strongly affect the volumetric permeate flux, the total mass of fouling, and the specific power consumption. Furthermore, cationic and anionic surfactants were used to control membrane fouling and minimize the specific power consumption.

As part of the current research study, dodecylamine cationic surfactant was also tested. Dodecylamine has a melting point of $27-30^{\circ} \mathrm{C}$ and thus cannot be used at room temperature. This condition effectually leads to significantly higher power consumption. As a consequence, Cetyl trimethyl ammonium bromide was found to be a more appropriate cationic, since it remains liquid at room temperature. Cetyl trimethyl ammonium bromide (CTAB) $\left[\mathrm{C}_{19} \mathrm{H}_{42} \mathrm{BrN}\right]$, a cationic surfactant, was added to the latex solution in order to investigate its effect on the latex particle size distribution, the zeta potential of latex particles, and the zeta potential of the membrane surface at various concentrations and different treatment times. The reported CMC of CTAB is 0.00092M (Murkerjee and Mysels, 1971) or approximately $0.36 \mathrm{~g} / \mathrm{L}$. Another cationic surfactant, Dodecylamine, was also tested (Surfactants details illustrated in Appendix E)

Anionic surfactant might increase the ionic strength of the solution and the zeta potential (surface charge) of the latex particles and the membrane surface. These charges would result in the increasing of the repulsion force between latex particles and the membrane surface, hence, increase the permeate flux and reduce membrane fouling. The selected anionic surfactant was Linear Alkyl Benzene Sulfonate Standard LAS.

\subsubsection{Enhancement of anti-fouling properties of the membrane}

The membrane surface negativity was enhanced to increase the repulsion force between the latex particles and the membranes, as described in Section 4.4.6.

\subsection{Experimental design}

\subsubsection{Central Composite Face-Centered CCF}

The Central Composite Face-Centered CCF Response Surface Method (RSM) was selected as the experimental design method (Montgomery, 1997). Fouling attachment probabilities ( $\alpha_{\mathrm{pp}}$ and $\alpha_{\mathrm{pm}}$ ), total mass of fouling, and the specific power consumption were the main responses. The main operational process parameters investigated for the membrane 
ultrafiltration process are the transmembrane pressure, feed flow rate, and feed concentration. The temperature of the solution was kept at room temperature $\left(22-24^{\circ} \mathrm{C}\right)$. Operation time for each experiment was kept constant for each of the experimental runs in order to investigate the influence of the operating conditions on mass of particles retained by membrane, permeate flux, fouling probabilities, and cake height. The ranges of the operating conditions are shown in Table 4.2 .

Table 4.2: Process parameter levels

\begin{tabular}{|c|c|c|c|c|}
\hline \multirow{2}{*}{ Factor } & \multirow{2}{*}{ Variable } & \multicolumn{2}{|c|}{ Range } & \multirow{2}{*}{ Unit } \\
\cline { 3 - 4 } & & Low & High & \multirow{2}{*}{} \\
\cline { 3 - 4 } & & $\mathbf{( - 1 )}$ & $\mathbf{( + 1 )}$ & \\
\hline $\mathrm{A}$ & Transmembrane Pressure & 15 & 35 & $\mathrm{psi}$ \\
\hline $\mathrm{B}$ & Feed Flow rate & 1 & 7 & $\mathrm{LPM}$ \\
\hline $\mathrm{C}$ & Feed concentration & 0.78 & 1.82 & $\mathrm{~kg} / \mathrm{m}^{3}$ \\
\hline
\end{tabular}

Twenty experiments were performed and their results were then analyzed using multiregression. For the minimization of error, six replicated experiments at zero code for each process parameter were performed in randomized order. Statistical software (Stat-Ease, Version 8.0 Stat-Ease Inc., USA) was used to determine the best-fitting model by regression and stepwise elimination. The coefficients for the complete model were evaluated by regression analysis and tested for their respective significance. The significance of the coefficients was then assessed by an F-test, and the insignificant coefficients were promptly excluded. The p-value was used to set the level of confidence for the F-test. The model's adequacy and efficacy were then evaluated by the coefficients of determination $\left(\mathrm{R}^{2}\right)$ and the analysis of variances (ANOVA). Stat-Ease software was further used to identify the process parameters for the ultrafiltration fouling of latex solution that have minimum fouling attachment probabilities. The quadratic and linear regression models can be expressed as Equations (4.1) and (4.2) below:

$$
\begin{array}{ll}
Y=\beta_{k o}+\sum_{i=1}^{3} \beta_{k i} x_{i}+\sum_{i=1}^{3} \beta_{k i i} x_{i}^{2}+\sum_{i=1}^{3} \sum_{j=i+1}^{3} \beta_{k i j} x_{i} x_{j} & \text { Equation (4.1) } \\
Y=\beta_{k o}+\sum_{i=1}^{3} \beta_{k i} x_{i} & \text { Equation (4.2) }
\end{array}
$$

where $Y$ is the response factor of attachment probabilities $\left(\alpha_{\mathrm{pp}} \& \alpha_{\mathrm{pm}}\right), x_{\mathrm{i}}$ the $\mathrm{i}^{\text {th }}$ independent factor, $\beta_{k o}$ the intercept, $\beta_{k i}$ the first-order model coefficients, $\beta_{k i i}$ the quadratic coefficients for the factor $\mathrm{i}$, and $\beta_{k i j}$ is the linear model coefficient for the interaction between factors $\mathrm{i}$ and $\mathrm{j}$. 


\subsubsection{Central Composite Centered (CCC)}

For model development, it was crucial to introduce the surface charge as zeta potential ( $\zeta)$ of the membrane surface into our predictive model so as to be generalized for both hydrophilic and hydrophobic membranes. Therefore, in a part of the current study the investigated operational process parameters were: transmembrane pressure, feed flow rate, feed concentration, and the zeta potential of Polysulfone membrane surface. The solution temperature was maintained constant at room temperature $\left(22-24{ }^{\circ} \mathrm{C}\right)$. Throughout this study, the ultrafiltration time for each experiment was kept constant (25 minutes), in order to analyze the impact of the operating conditions and the surface charge on fouling attachments probabilities in the experimental design. As a sequence, the influence on the total mass of fouling, cumulative filtration volume per unit area, and specific power consumption could be accurately investigated. In this study, the Central Composite Centered (CCC) Response Surface Method (RSM) was selected as the experimental design method. The coagulation and the depositional attachments are the main responses. The four process parameters of the study include: transmembrane pressure, feed flow rate, feed concentration, and zeta potential of the membrane surface. Table 4.3 presents coded and actual levels of the process parameters. To maintain a high level of accuracy, each process parameter features five levels with four parameter interactions. A total of thirty (30) experiments were performed and their results were then rigorously analyzed using multi-regression. Zero code represents the average range value for each process parameter. In order to minimize the error margin, six replicated experiments at zero code for each process parameter were performed in random order. To determine the best-fitting model of the process of regression and stepwise elimination, statistical software (Stat-Ease, Version 8.0 Stat-Ease Inc., USA) was applied. Next, the coefficients for a full model were assessed through regression analysis, and then tested for their significance. The F-test was implemented to assess the significance of the coefficients, after which the insignificant coefficients were excluded accordingly. P-value analysis was used to set the level of confidence for the F-test. The coefficients of determination $\left(\mathrm{R}^{2}\right)$ and the analysis of variances (ANOVA) were used to evaluate the model fitting. 
Table 4.3: Process parameter levels in experiments with non-uniform pore size Polysulfone membrane

\begin{tabular}{|c|c|c|c|c|c|c|c|}
\hline \multirow[b]{2}{*}{ Factor } & \multirow[b]{2}{*}{ Variable } & \multicolumn{5}{|c|}{ Range } & \multirow[b]{2}{*}{ Unit } \\
\hline & & $(-2)$ & $(-1)$ & $\mathbf{0}$ & $(+1)$ & $(+2)$ & \\
\hline A & $\begin{array}{c}\text { Initial } \\
\text { Transmembrane } \\
\text { Pressure } \\
\end{array}$ & 5 & 15 & 25 & 35 & 45 & Psi \\
\hline $\mathrm{B}$ & Feed Flow Rate & 1.5 & 3.0 & 4.5 & 6.0 & 7.5 & LPM \\
\hline $\mathrm{C}$ & $\begin{array}{c}\text { Feed } \\
\text { Concentration }\end{array}$ & 0.26 & 0.78 & 1.30 & 1.82 & 2.34 & $\mathrm{~kg} / \mathrm{m}^{3}$ \\
\hline D & $\begin{array}{l}\text { Zeta Potential } \\
\text { of membrane } \\
\text { surface }\end{array}$ & -50.00 & -40.00 & -30.00 & -20.00 & -10.00 & $\mathrm{mV}$ \\
\hline
\end{tabular}

\subsection{Specific power consumption calculations}

During the filtration process, the resistance to the permeate flow can be increased due to the pore blockage and the cake layer formation, resulting in the membrane fouling. Hence, the permeate flux noticeably declines with filtration time. A higher permeate flux can be attained by augmenting the transmembrane pressure, which in turn causes a higher energy consumption. The specific power consumption per unit volume of filtrate was calculated using Equation (4.3). Equation (4.3) is illustrated in details in Appendix (F).

Specific power consumption $\left[\frac{k W h}{m^{3}}\right]=1.916 \times 10^{-6} \times \frac{\overline{\mathrm{TMP}}_{A V G} * \mathrm{Q}}{{\overline{\mathrm{V}_{S}}}}$

Equation (4.3)

where $\overline{\mathrm{TMP}}_{A V G}$ is the time-averaged transmembrane pressure throughout the filtration duration. $\overline{\mathrm{TMP}}_{A V G}$ [psi.min] can be calculated based on the area under the curve, as shown in Figure 4.7. Q $[\mathrm{LPM}]$ is the feed flow rate, and $\overline{\mathrm{V}}_{S}\left[\mathrm{~m}^{3}\right]$ is the cumulative permeate volume.

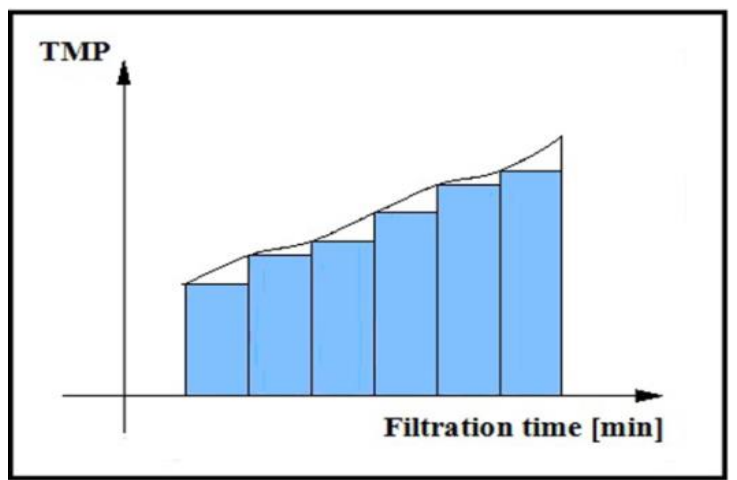

Figure 4.7: Area under the curve represents $\overline{\mathrm{TMP}}_{A V G}$ [psi.min] 


\subsection{Estimation of the pore size distribution}

The non-uniform pore size distribution of the Polysulfone membrane was estimated using the ImageJ software. Figure 4.8 (a) presents an SEM image of the clean Polysulforne membrane. The membrane consists of multiple layers featuring pores in a non-straight (non-linear) alignment. The ImageJ software viewer identifies the pores by using volume rendering for displaying image volumes and transferring pixels in such a way that darker pixels are more transparent than lighter pixels. The images are displayed as multiOrthoslice. The technique behind converting the images using ImageJ software was explained in details in a recent study on this subject (Schmid et al., 2010). The specific pores were selected, as demonstrated in Figure 4.8 (b), and the exact pore sizes were determined with the help of the software based on spherical approximation technique. The pore size intervals were allocated by the software. In order to ensure accurate representation of the membrane pore size distribution, several SEM images were taken at random locations on the membrane surface. Also, each SEM image was analyzed three times using the software in a randomized order. The resulting analysis indicated that the pore size distribution for each SEM image was identical, which provided the evidence necessary to validate the applicability of the software to measurements of pore sizes and pore size distribution. The resulting pore size distribution was represented using 10 pore size distributions as shown in Figure 4.9. Pore size distribution of other heterogeneous membranes estimated from ImageJ software is illustrated in Appendix (G).

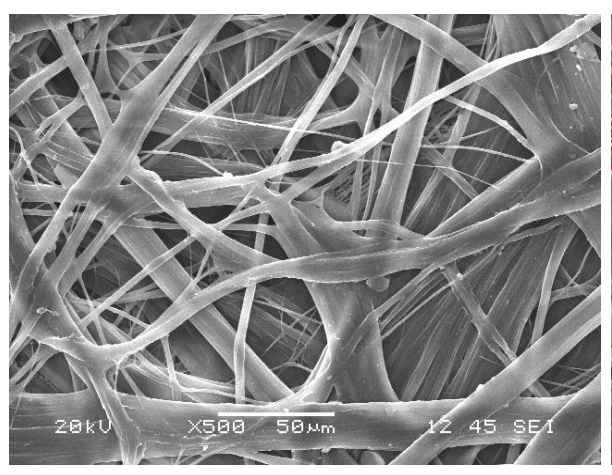

(a)

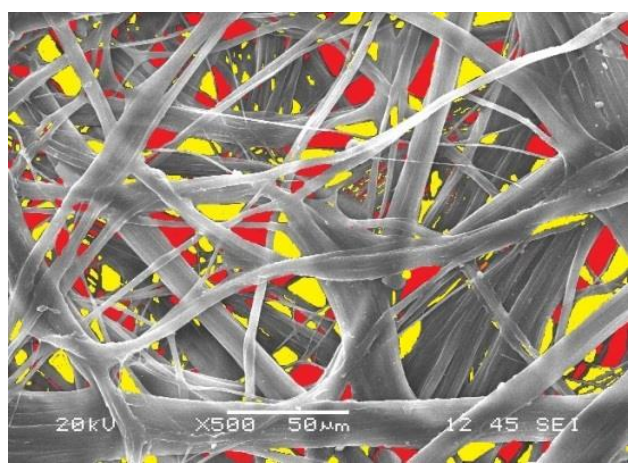

(b)

Figure 4.8: Estimation of the pore size distribution of the polysulfone membrane: (a) SEM image applied to the software

(b) SEM image of the exact pores obtained using the software 


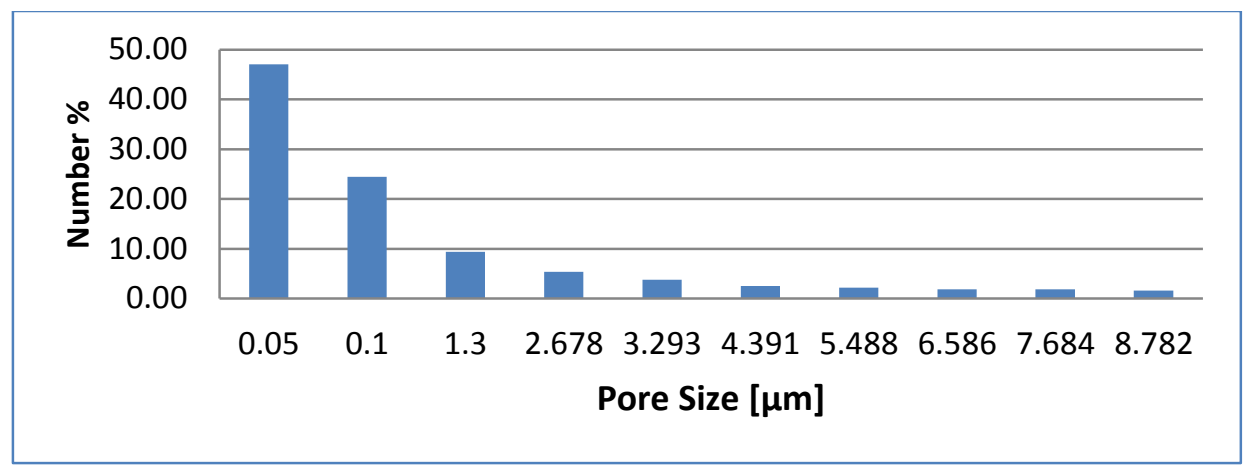

Figure 4.9: The pore size distribution of Polysulfone estimated using the software

\subsection{Estimation of the sphericity of latex particles}

The sphericity of the latex was estimated using the ImageJ software. Figure 4.10 (a) presents an SEM image of latex particles on the membrane. The particles were selected, as demonstrated in Figure 4.10 (b), and the exact charcterstic diameters were determined with the help of the software and based on the SEM magnification scale, as illustrated in Figure 4.10 (c). The particle size intervals were allocated by the software, and the sphericity of the particles was estimated using the ratio of the diameters of the smallest and largest circumscribed circles around latex particle (Rodriguez et at., 2012), as shown in Figure 4.11. In order to ensure accurate representation of the sphericity measurements, several SEM images of latex particles, approximately 30 images, were taken so as to cover the whole range of particle size distribution. Also, each SEM image was carefully analysed three separate times in a randomized order with the help of the software. The analysis indicated that the measurements of average sphericity for each particle size range were identical, which provided the necessary evidence for the validation of the software.

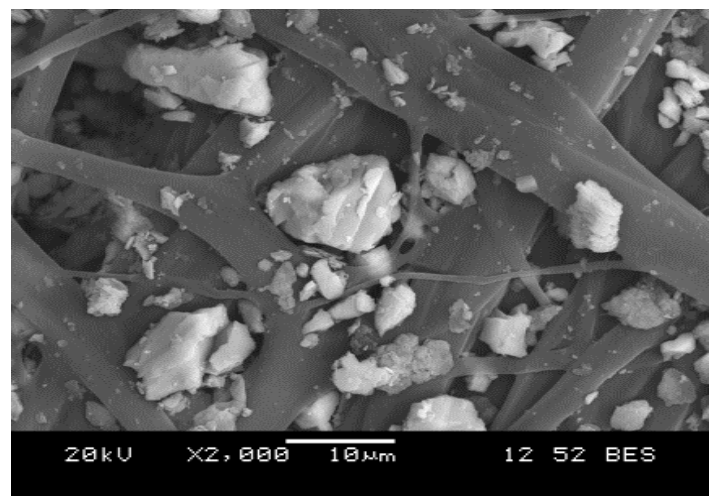

(a) 


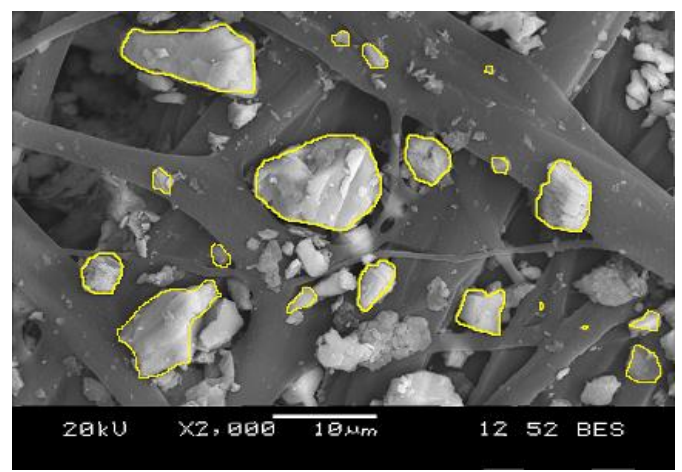

(b)

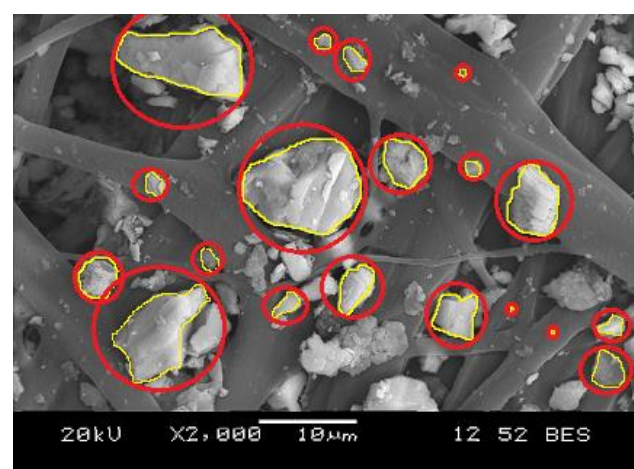

(c)

Figure 4.10 : Estimation of the latex particles' sphericity using ImageJ software
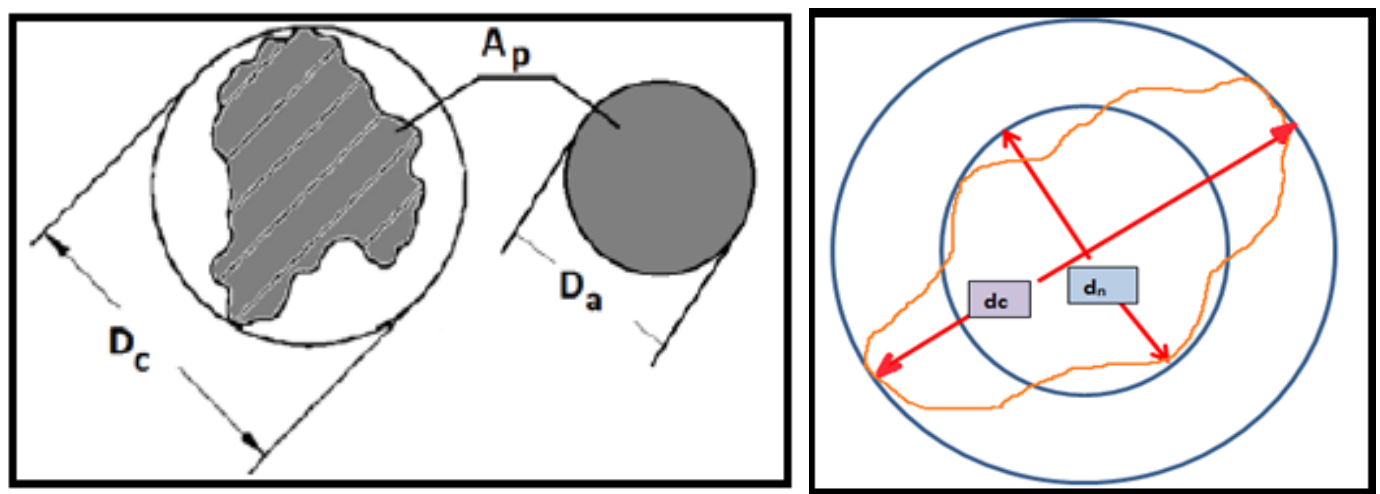

Figure 4.11: The diameters of the smallest and largest circumscribed circles around latex particle used for sphericity estimation

\subsubsection{Calculating the sphericity for each particle size range in case of using Polysulfone membrane}

As previously discussed, the attachment model was developed based on the fouling potential of the different sizes particles and a range of pore sizes. The sizes of contaminated particles may be larger or smaller than each membrane pore size range. Therefore, for each pore size of the $(N)$ pore size distribution, as portrayed in Figure 4.9, the particles will be divided according to whether they are large particles, small particles, or very small particles. The mean particle size $d_{\text {mean }}$ was calculated for the particle size distribution of simulated latex effluent with a solid concentration of $1.3 \mathrm{~kg} / \mathrm{m}^{3}$, as shown in Figure 4.12 . The mean particle size $\mathrm{d}_{\text {mean }}$ was calculated using the Equation (4.4) (Lambert et al., 1967; Akbari et al., 2011). For the sphericity of the particle size ranges needed for the model calculations, the particle size ranges were selected based on the pore size distribution of the membrane for the particle size classification. The sphericity of each $d_{\text {mean }}$ range was shown in Figure 4.13. 
$d_{\text {mean }}=\frac{1}{\sum_{i} \frac{X_{i}}{d_{p i}}}$

Equation (4.4)

where $d_{p i}$ is the diameter of particle size $i$, and $X_{i}$ is the volume fraction of a particle size $i$.

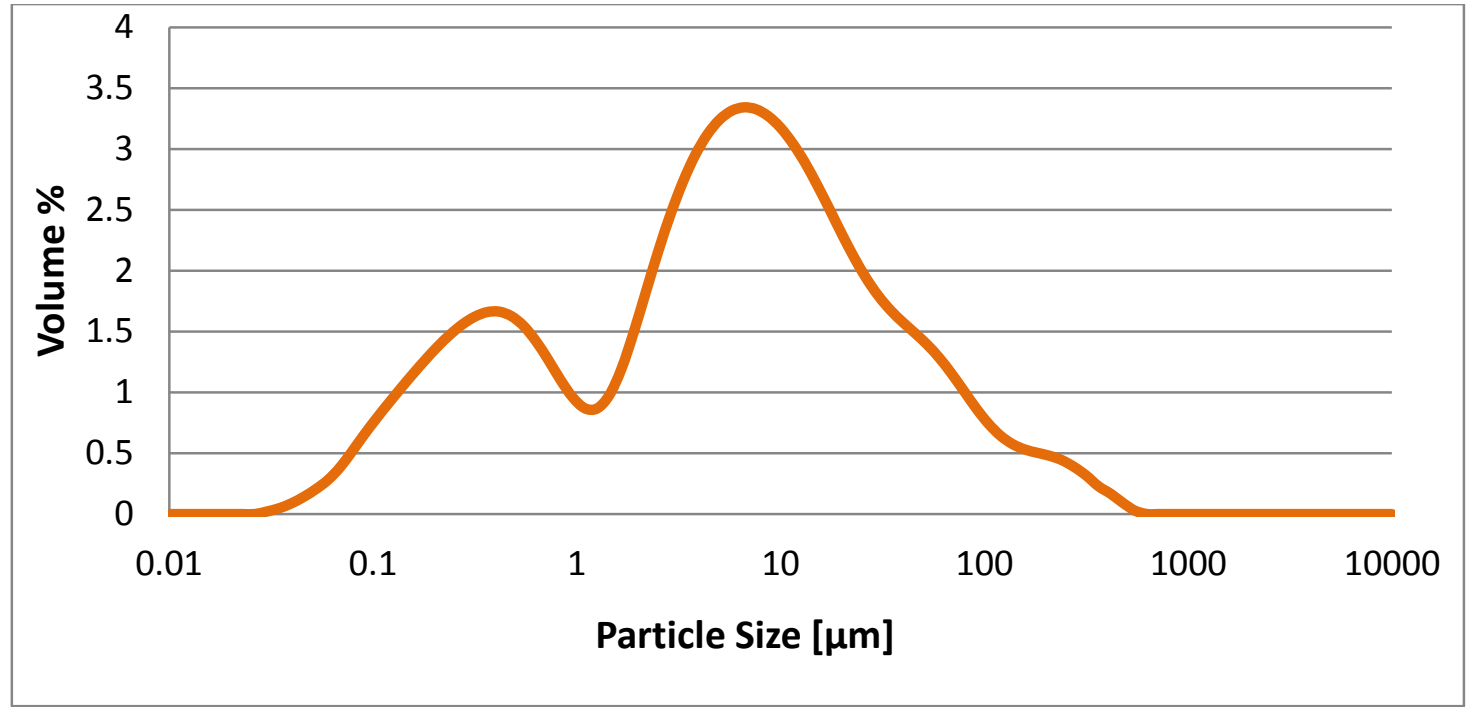

Figure 4.12: The particle size distribution of simulated latex effluent with a solid concentration of $1.3 \mathrm{~kg} / \mathrm{m}^{3}$

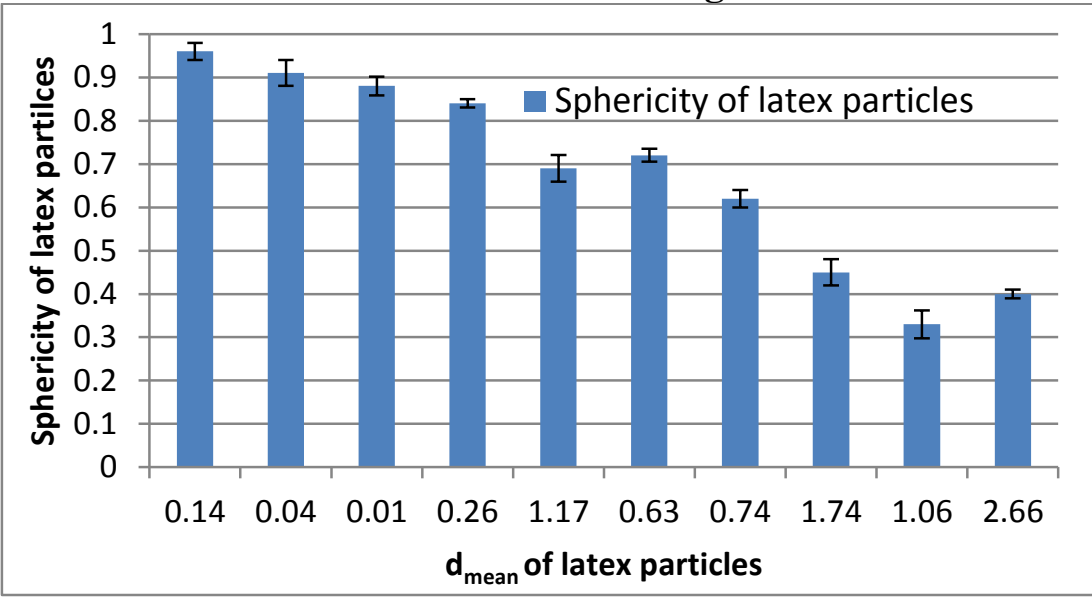

Figure 4.13: Sphericity of latex particles for each $d_{\text {mean }}$ in filtration with Polysulfone membrane

\subsubsection{Calculating the sphericity for each particle size range in case of using Polycarbonate} membrane

Similarly, in order to use the sphericity in the attachment model for homogeneous pore sizes, the particle size was divided according to whether it is larger or smaller than $0.05 \mu \mathrm{m}$ pore size, as illustrated in Figure 4.14. 


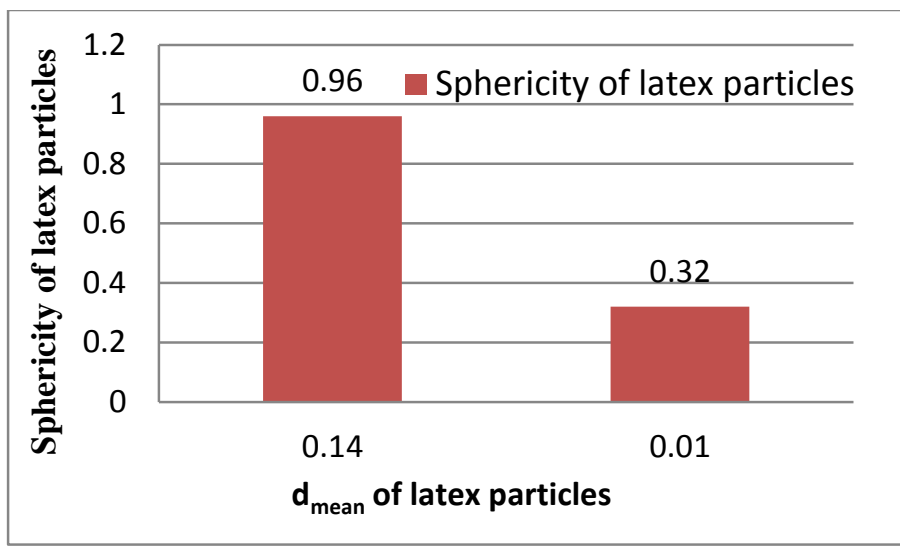

Figure 4.14: Sphericity of latex particles for each dmean in filtration with Polycarbonate membrane 


\section{Chapter 5 RESULTS AND DISCUSSION}

\subsection{Model Prediction}

Model simulation results indicate that the depositional (particle-to-membrane) attachment is primarily responsible for reversible and irreversible membrane fouling. Irreversible fouling is the mass of particles still attached to the membrane after backwash. It is the combination of individual portions that can be calculated from equations (3.14) and (3.22) for the amounts of large and small particles contributing to irreversible fouling, respectively, plus equation (3.28) for the amount of very small particles irreversibly attached to the membrane wall. Reversible fouling is the mass of particles blocked the membrane pores, which can be removed during backwash. Reversible fouling can be calculated from equations (3.9) and (3.26) for the amounts of large and small particles contributing to pore blocking, respectively. As shown in Figure 5.1, increases in the particle-to-membrane surface attachment probability, $\alpha_{\mathrm{pm}}$, result in higher transmembrane pressures. This might be due to the increase in the mass of particles participated in pore blocking and attached to the membrane surface, $m_{s}$, which is considered hydraulically irreversible after backwash in the mathematical model. Correspondingly, irreversible fouling increased substantially as indicated by the increase in the transmembrane pressure due to pore blocking. From the perspective of chemical attachment, hydraulically irreversible fouling occurs when the attachment interaction between the particles and the membrane surface are strong enough to overcome by hydrodynamic forces generated during hydraulic backwash. However, depositional attachment leading to the cake formation has insignificant effect on the transmembrane pressure. 


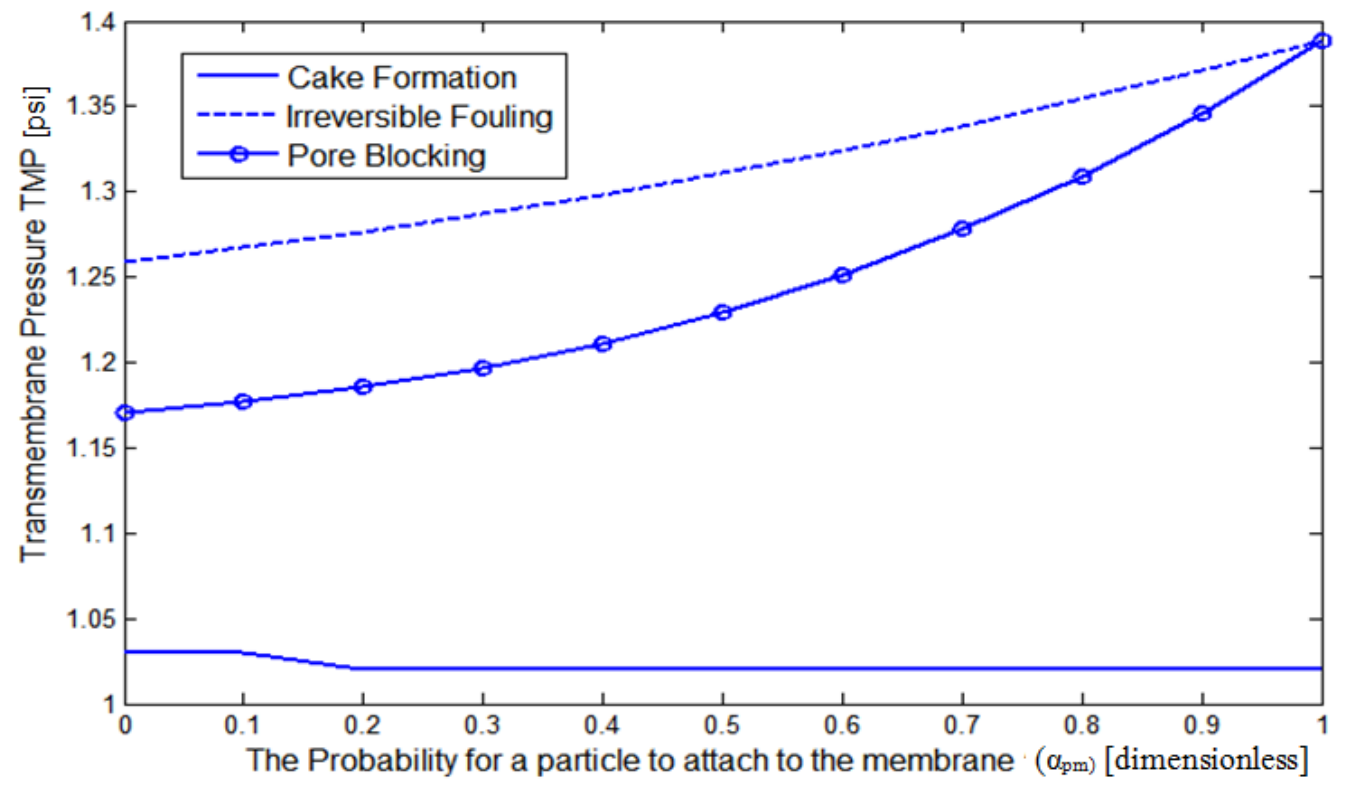

Figure 5.1: Effect of depositional attachment probability on transmembrane pressure

On the other hand, the particles instability with respect to coagulation (particle-to-particle attachment) has a competitive effect to the depositional attachment and usually results in a decrease of the total irreversible fouling. Figure 5.2 shows that the transmembrane pressure TMP due to the cake layer formation increases with the increasing of particle-to-particle probability $\left(\alpha_{\mathrm{pp}}\right)$. Coagulation forms bigger particle aggregates that reduce the probability of standard pore blocking. Therefore, the total amount of irreversible fouling decreased because the cake layer could be hydraulically backwashed. Consequently, TMP due to irreversible fouling decreased. Also, it can be noticed that the particle-particle attachment probability has an insignificant effect on the increase of the transmembrane pressure due to pore blocking. 


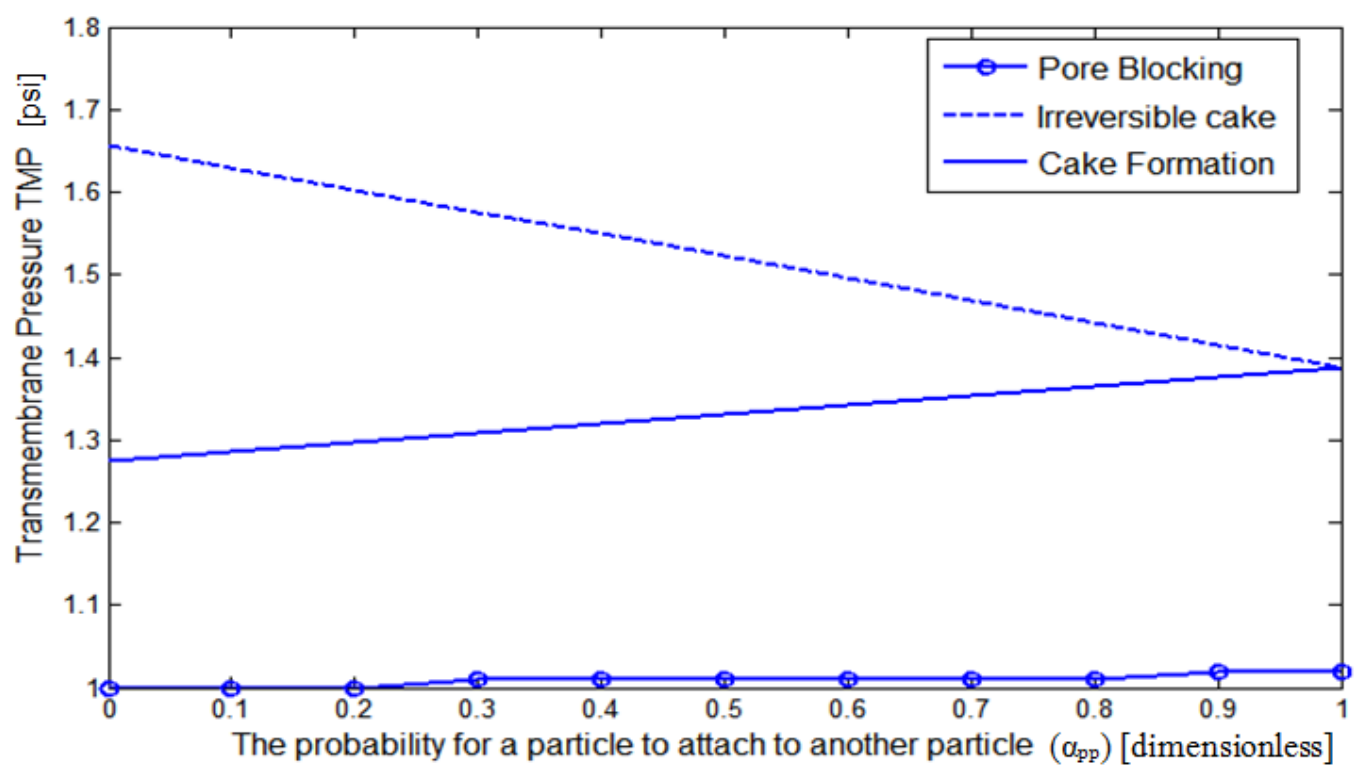

Figure 5.2: Effect of coagulation attachment probability on transmembrane pressure

The effect of depositional fouling probability (the particle-to-membrane probability, $\alpha_{\mathrm{pm}}$ ) on the mass of particles attached to membrane pores, which contributed to pore blocking, was also simulated. The mass of particles attached to the membrane increases with the depositional fouling probability, as shown in Figure 5.3. This indicates that the particles have a higher tendency to attach to the membrane than other particles. Also, increases in the feed solid concentration result in higher amounts of particles retained by the membrane due to pore blocking since more solid particles are introduced to the membrane surface. Similarly, as can be seen in Figure 5.4, the total mass retained by the membrane increases with the depositional probability, $\alpha_{\mathrm{pm}}$, and the permeate flux. Again, more mass would be retained by the membrane at a higher volumetric permeate flux because more solid particles would be brought to the pores, and hence, the chance of pore blocking increases. 


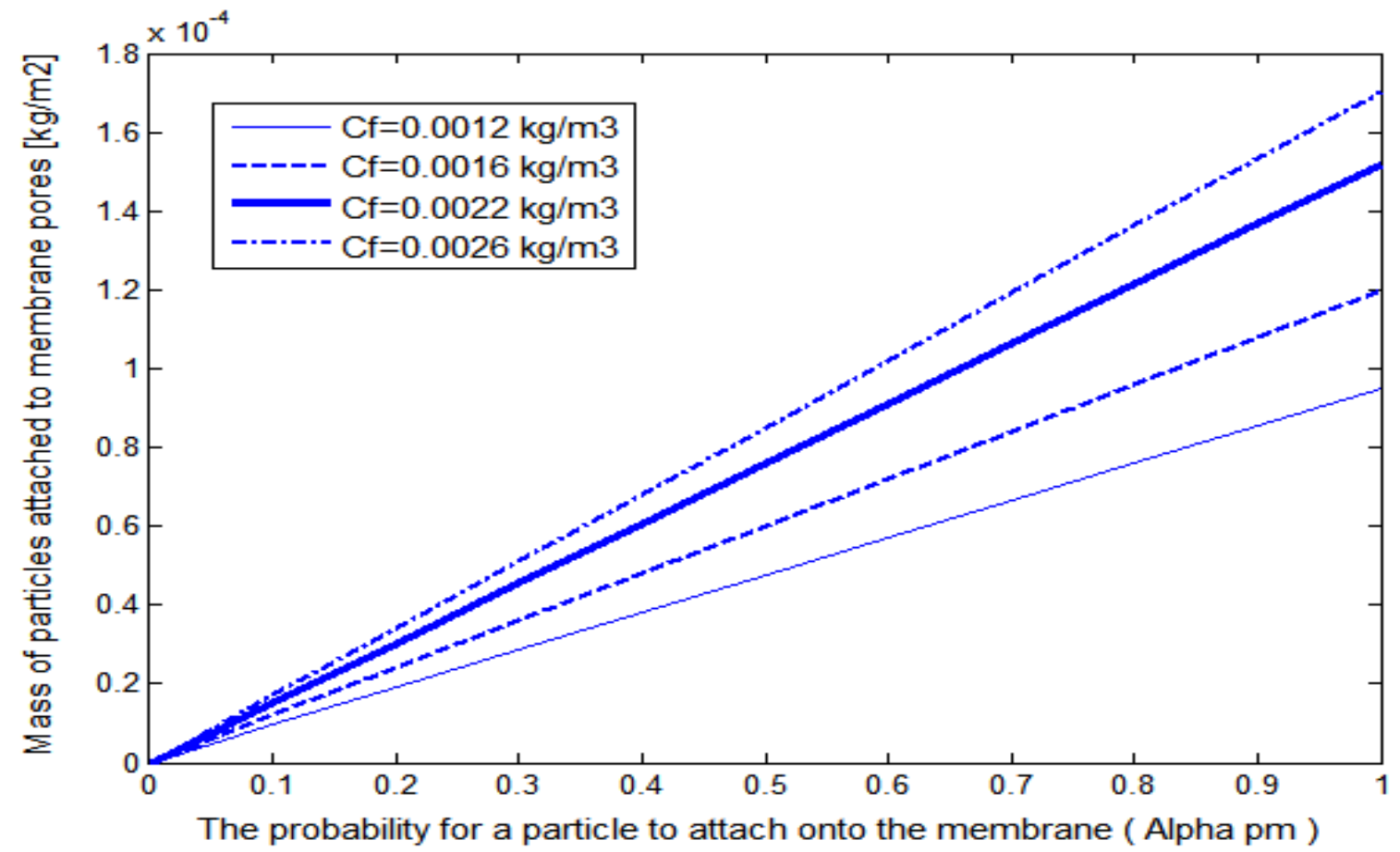

Figure 5.3: Effect of depositional attachment probability on solid retained by membrane at different feed solid concentrations

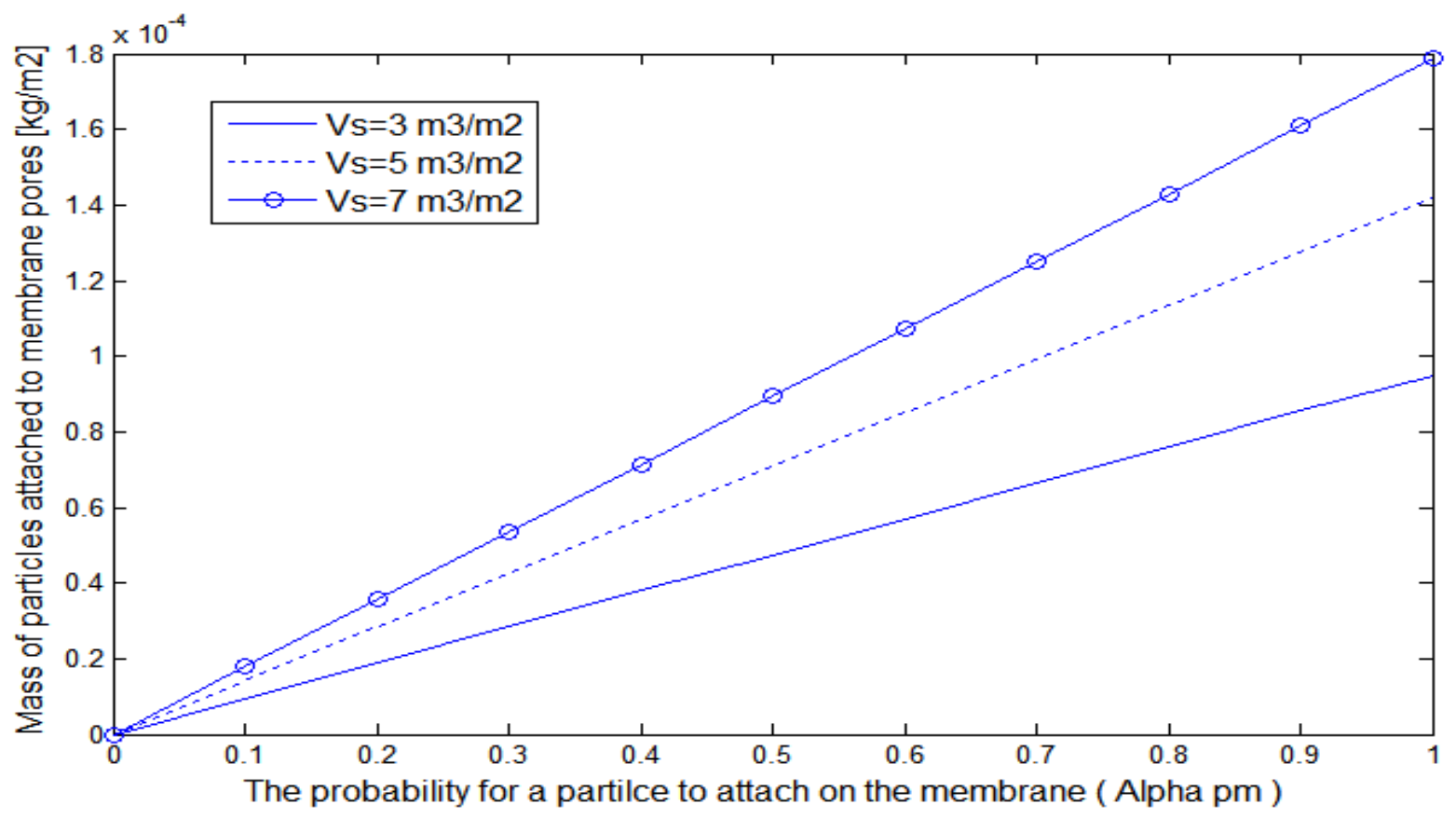

Figure 5.4: Effect of depositional fouling probability on solid retained by the membrane at different volumetric permeate fluxes. 
Figure 5.5 presents the effect of the coagulation fouling probability, $\alpha_{\mathrm{pp}}$, on the mass of solid retained by the membrane at different feed solid concentrations. Increases in the particle-toparticle attachment (coagulation) probability lead to higher amounts of particles participating in the cake formation as previously shown in Figure 5.2. On the other hand, the mass of particles contributing to pore blocking decreases with the coagulation probability, as can be seen in Figure 5.5. At a higher particle-to-particle attachment probability, particles in liquid tend to attach to particles already deposited on the membrane surface, and hence, the cake formation would be further facilitated. Consequently, less solid particles would be available to participate in pore blocking.

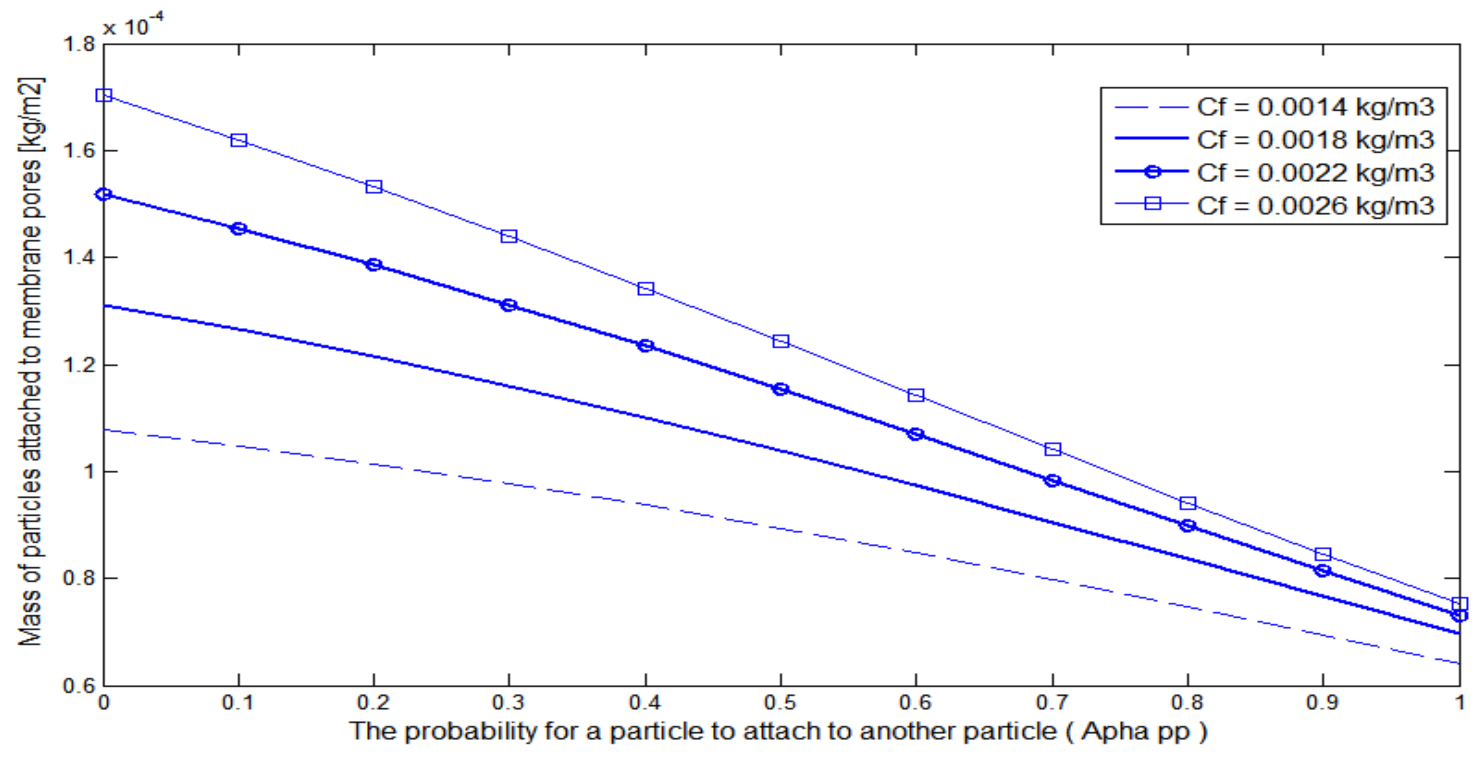

Figure 5.5: Effect of coagulation fouling probability on solid retained by membrane at different feed solid concentrations.

\subsection{Mathematical model validation}

\subsubsection{Uniform pore size membrane}

Each parameter of the mathematical models was tested to evaluate the effect of changing the membrane properties, feed flow rate, volumetric permeate flux, pressure and feed concentration on the parameters. Table 5.1 shows the experimental results of the total mass of particles retained by the polycarbonate membrane, the mass of particles contributing to pore blocking, the mass of particles contributing to the cake layer, the volumetric permeate flux and the transmembrane pressure obtained at different operational conditions. For the total mass of fouling $\left(\mathrm{m}_{\mathrm{t}}\right)$, it's the difference in the weight of the membrane before and after filtration. For the 
mass of particles contributing to the cake layer $\left(\mathrm{m}_{\mathrm{c}}\right)$, the cake layer was removed (scratched off) slowly and carefully under an optical microscope so to keep the membranes pores blocked with the particles contributing to pore blocking. The scratched off solid was then weighed to determine the amount of the cake layer. The blocked pores of the membrane were checked using SEM. For the mass of particles contributing to pore blocking $\left(\mathrm{m}_{\mathrm{p}}\right)$, it's the difference in the weight of the membrane before filtration (clean membrane) and after scratching off the cake layer.

Time was kept constant for all experimental runs with the $0.1 \mu \mathrm{m}$ membrane with same initial feed concentration to investigate the influence of the operating conditions on the amount of particles retained by the membrane, the permeate flux and the fouling probability. All experiments were carried out at the operating conditions above the critical flux as fouling was observed in all experiments. It can be seen in Table 5.1 that the volumetric permeate flux and the mass of particles retained by the membrane increased with the feed flow rate and pressure. For the membrane with a pore size of $0.05 \mu \mathrm{m}$, higher feed flow rate and pressure were required to obtain a volumetric permeate flux similar to that of the membrane with a pore size of $0.1 \mu \mathrm{m}$. For example, at a volumetric permeate flux of $0.007 \mathrm{~m}^{3} / \mathrm{m}^{2}$ with the $0.1 \mu \mathrm{m}$ membrane, the required pressure and feed flow rate were $3.0 \mathrm{psi}$ and $1.0 \mathrm{~L} / \mathrm{min}$, respectively. However, in order to achieve a similar permeate flux with the $0.05 \mu \mathrm{m}$ membrane, the required pressure and the feed flow rate were more than 2 times of those for the $0.1 \mu \mathrm{m}$ membrane. In addition, increases in the feed concentration resulted in increases in the amounts of particles contributing to the pore blocking and the cake layer; hence, the total mass of the particles retained by the membrane increased, almost 1 to 1 ratio. When the feed flow rate and pressure were increased from 1$3 \mathrm{~L} / \mathrm{min}$ and 3-5 psi, the volumetric permeate flux and the total mass of fouling particles increased almost 10 times from 0.007 to $0.064 \mathrm{~m}^{3} / \mathrm{m}^{2}$ and 0.1202 to $1.11 \mathrm{~g}$, respectively. At higher permeate flows, more solid particles were brought to the membrane, resulting in higher mass of retained particles. With a smaller membrane pore size $0.05 \mu \mathrm{m}$ under the same operating conditions (the feed flowrate $\mathrm{Q}=2 \mathrm{LPM}$ and pressure $\mathrm{P}=4 \mathrm{psi}$ ), the volumetric permeate flux decreased from $0.04 \mathrm{~m}^{3} / \mathrm{m}^{2}$ to $0.0189 \mathrm{~m}^{3} / \mathrm{m}^{2}$, resulting in a reduction of the mass of fouling retained by membrane from $0.652 \mathrm{~g}$ to $0.378 \mathrm{~g}$ due to lower attachment probabilities. 
Table 5.1: Mass of particles retained by Polycarbonate membrane at different operational conditions

\begin{tabular}{|c|c|c|c|c|c|c|c|c|}
\hline \multirow{2}{*}{$\underset{[L / \mathrm{min}]}{Q}$} & \multirow{2}{*}{$\begin{array}{c}\text { Initial P } \\
{[\mathrm{psi}]}\end{array}$} & \multirow{2}{*}{$\begin{array}{l}\text { membrane } \\
\text { pore size }[\mu]\end{array}$} & \multirow{2}{*}{$\begin{array}{c}\mathrm{C}_{\mathrm{f}} \\
{\left[\mathrm{kg} / \mathrm{m}^{3}\right]}\end{array}$} & \multirow{2}{*}{$\begin{array}{c}V s \\
{\left[\mathrm{~m}^{3} / \mathrm{m}^{2}\right]}\end{array}$} & \multirow{2}{*}{$\begin{array}{c}\text { Increase } \\
\text { in TMP } \\
\text { Exp }\end{array}$} & \multicolumn{3}{|c|}{ Experimental Results } \\
\hline & & & & & & $m_{t}[\mathrm{~g}]$ & $m_{p}[g]$ & $m_{c}[\mathrm{~g}]$ \\
\hline 1 & 3 & 0.1 & 1.3 & 0.007 & 7 & 0.1202 & 0.0036 & 0.117 \\
\hline 2 & 4 & 0.1 & 1.3 & 0.04 & 20 & 0.652 & 0.0162 & 0.642 \\
\hline 3 & 5 & 0.1 & 1.3 & 0.064 & 29 & 1.11 & 0.0274 & 1.083 \\
\hline 1 & 4 & 0.1 & 1.82 & 0.007 & 8 & 0.175 & 0.004 & 0.171 \\
\hline 1 & 3 & 0.1 & 1.3 & 0.007 & 7 & 0.1202 & 0.0036 & 0.117 \\
\hline 1 & 2 & 0.1 & 0.78 & 0.007 & 6 & 0.0773 & 0.0018 & 0.076 \\
\hline 4 & 11 & 0.05 & 1.3 & 0.007 & 5 & 0.1201 & 0.0012 & 0.119 \\
\hline 2 & 4 & 0.05 & 1.3 & 0.0189 & 10 & 0.378 & 0.0029 & 0.375 \\
\hline
\end{tabular}

The experimentally measured mass of particles retained by the polycarbonate membrane,

which contributed to the pore blocking, $m_{p}$, or the cake layer, $m_{c}$, were used in the model to predict the fouling probabilities, $\alpha_{\mathrm{pp}}$ and $\alpha_{\mathrm{pm}}$, as shown in Table 5.2. The estimated attachment probabilities were then used to determine the increase in the transmembrane pressure. The transmembrane pressures predicted from the mathematical models are within $\pm 5.3-7.7 \%$ error of the experimental values for $0.1 \mu \mathrm{m}$ and $0.05 \mu \mathrm{m}$ membranes. The estimated values appear to be always less than the experimental values. This might be due to the fact that in the present study, membrane fouling was treated as the interactions of suspended particles and membranes with uniform pore size distribution and structure, for the purpose of simplicity. Therefore, the potential impact of system heterogeneity was overlooked. This will be further investigated in the near future.

For backwashing at flow rates from 2-4 LPM, mass of irreversible fouling predicted from the model agrees with the total amount of solid fouling experimentally measured within $10 \%$ error. Figure 5.6. presents SEM images of membrane pores before and after backwash. The larger and dark spots in Figure 5.6 (b) indicate clean and opened pores after backwashing.

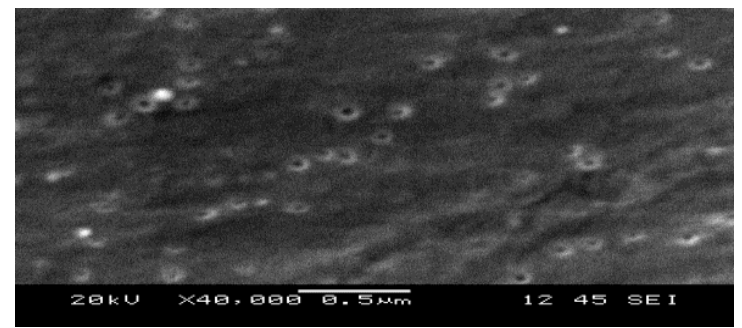

(a)

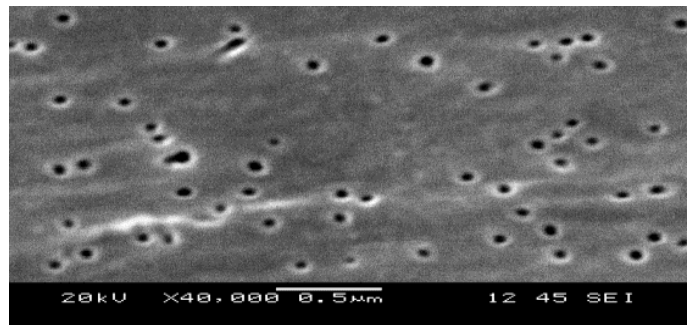

(b)

Figure 5.6: SEM images of Polycarbonate membrane (a) Blocked pore before backwash (b) Cleaned pores after backwash 
Table 5.2: Fouling probabilities predicted at different conditions and comparison of predicted and experimental transmembrane pressure.

\begin{tabular}{|c|c|c|c|c|c|c|c|c|c|c|}
\hline \multirow{2}{*}{$\begin{array}{l}\text { Pore } \\
\text { size } \\
{[\mu \mathrm{m}]}\end{array}$} & \multirow{2}{*}{$\begin{array}{c}\mathrm{C}_{\mathrm{f}} \\
{\left[\mathrm{kg} / \mathrm{m}^{3}\right]}\end{array}$} & \multirow{2}{*}{$\underset{[L / \mathrm{min}]}{\mathrm{Q}}$} & \multirow{2}{*}{$\begin{array}{c}V s \\
{\left[\mathrm{~m}^{3} / \mathrm{m}^{2}\right]}\end{array}$} & \multirow{2}{*}{$\begin{array}{c}m_{p} \operatorname{Exp} \\
{[\mathrm{g}]}\end{array}$} & \multirow[b]{2}{*}{$m_{c} \operatorname{Exp}[\mathrm{g}]$} & \multirow{2}{*}{$\begin{array}{c}\alpha_{\mathrm{pp}} \\
\text { Predicted }\end{array}$} & \multirow{2}{*}{$\begin{array}{c}\alpha_{\mathrm{pm}} \\
\text { Predicted }\end{array}$} & \multirow{2}{*}{$\begin{array}{l}\text { Increase in } \\
\text { TMP } \\
\text { Calculated }\end{array}$} & \multirow{2}{*}{$\begin{array}{c}\text { Increase in } \\
\text { TMP } \\
\text { Exp }\end{array}$} & \multirow{2}{*}{$\begin{array}{c}\text { Error \% } \\
*(\text { Error } / \\
\text { Exp })^{*} 100 \\
\end{array}$} \\
\hline & & & & & & & & & & \\
\hline 0.1 & 1.3 & 1 & 0.007 & 0.0036 & 0.117 & 1.00 & 0.10 & 6.63 & 7 & -5.3 \\
\hline 0.1 & 1.3 & 2 & 0.04 & 0.0162 & 0.642 & 0.80 & 0.77 & 18.69 & 20 & -6.6 \\
\hline 0.1 & 1.3 & 3 & 0.064 & 0.0274 & 1.082 & 0.70 & 0.82 & 27.47 & 29 & -5.3 \\
\hline 0.1 & 1.82 & 1 & 0.007 & 0.004 & 0.171 & 0.90 & 0.90 & 7.58 & 8 & -5.2 \\
\hline 0.1 & 1.3 & 1 & 0.007 & 0.0036 & 0.117 & 1.00 & 0.10 & 6.63 & 7 & -5.3 \\
\hline 0.1 & 0.78 & 1 & 0.007 & 0.0018 & 0.075 & 0.50 & 0.85 & 5.54 & 6 & -7.7 \\
\hline 0.05 & 1.3 & 4 & 0.007 & 0.0012 & 0.119 & 0.60 & 0.30 & 4.7 & 5 & -6.0 \\
\hline 0.05 & 1.3 & 2 & 0.0189 & 0.0029 & 0.375 & 0.50 & 0.72 & 9.23 & 10 & -7.7 \\
\hline
\end{tabular}

*Error $=($ Estimated value - Experimental value $)$

TMP calculated using the Equations 3.33, 3.34,3.36 and 3.38, and the predicted fouling probabilities based on the range of particle size distribution in the feed sample

As shown Table 5.2, when the feed flow rate was increased from $1.0 \mathrm{~L} / \mathrm{min}$ to $3.0 \mathrm{~L} / \mathrm{min}$, the particle-to-particle attachment probability decreased from 1.0 to 0.7 while the depositional attachment (particle-to-membrane) probability increased from 0.10 to 0.82 . Particle-tomembrane attachment probability $\left(\alpha_{\mathrm{pm}}\right)$ varied more drastically with the feed flow rate, as compared to $\alpha_{\mathrm{pp}}$. A higher feed flow rate provided a higher shear rate applied on the particles at the cake layer, resulting in a higher amount of particles washed away from the cake layer. Consequently, the resultant particle-to-particle attachment probability $\left(\alpha_{\mathrm{pp}}\right)$ decreased. On the other hand, the permeate flux increased with the feed flowrate. As a result, more particles were brought into contact with the membrane, leading to a higher particle-to-membrane attachment probability $\left(\alpha_{\mathrm{pm}}\right)$. However, both depositional attachment probability $\left(\alpha_{\mathrm{pm}}\right)$ and coagulation attachment probability $\left(\alpha_{\mathrm{pp}}\right)$ decreased with decreases in the feed solid concentration. It is evident that at a lower solid concentration, the number of particles in the feed stream was lower. Therefore, chance for particle-to-particle and particle-to-membrane collision and attachment would be lower; and hence, the depositional attachment probability $\left(\alpha_{\mathrm{pm}}\right)$ and coagulation attachment probability $\left(\alpha_{\mathrm{pp}}\right)$ were lower. The effect of the feed solid concentration is more prominent on $\alpha_{\mathrm{pp}}$. This might be due to the fact that at a higher solid concentration, more suspended particles present in liquid enhanced collision and attachment between particles, resulting in a higher $\alpha_{\mathrm{pp}}$ while the volumetric permeate flux $V_{s}$ had a stronger effect on $\alpha_{\mathrm{pm}}$. 
Figure 5.7 presents SEM images of membrane after ultrafiltration to illustrate the effect of the feed flow rate on the cake build-up. Figure 5.7 (a) was obtained with a sample at a feed flow rate of $1.0 \mathrm{~L} / \mathrm{min}$, showing a thick cake (average thickness of about $6.2 \mu \mathrm{m}$ ). The thickness of the membrane is about $6 \mu \mathrm{m}$. Figure 5.7 (b) shows that the cake thickness decreased to about $2.7 \mu \mathrm{m}$ when the feed flow rate was increased to $3.0 \mathrm{~L} / \mathrm{min}$. The liquid cross flow over the membrane can be considered as continuous washing of the cake layer. At a higher feed flowrate, a higher shear rate applied on the particles deposited at the cake layer; hence, more particles were washed away, resulting in a thinner cake layer. In addition, as the feed flow rate was increased, the concentration polarization effect decreased. Therefore, the accumulated particles on the membrane surface returned back to the bulk fluid and the concentration polarization effect diminished. The osmotic pressure thus decreased, resulting in an increase in the permeation flux.

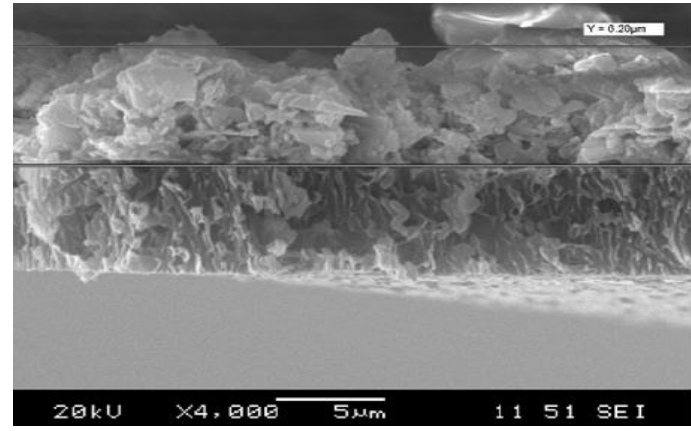

(a)

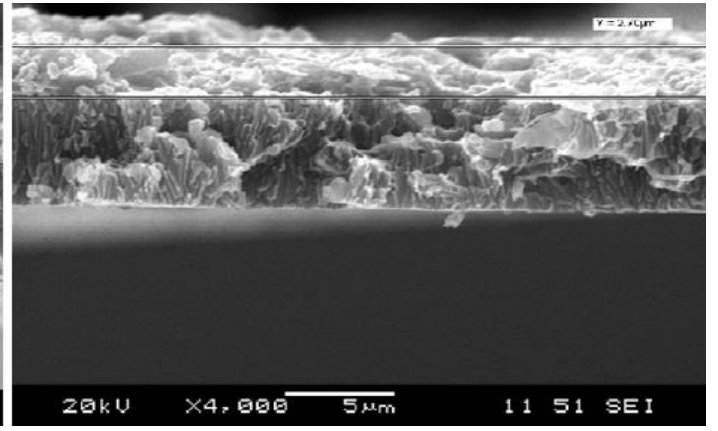

(b)

Figure 5.7: SEM images of Polycarbonate membrane after ultrafiltration: (a) feed flow rate $=1 \mathrm{~L} / \mathbf{m}$;

(b) feed flow rate $=3 \mathrm{~L} / \mathrm{m}$ [feed solid concentration $=1.3 \mathrm{~kg} / \mathrm{m}^{3}$, same pressure and filtration time for both cases]

The model was also validated using mondisperse particles and Polycarbonate homogeneous membranes with the uniform pore size of $0.05 \mu \mathrm{m}$ at different operating conditions, as presented in Table 5.3. The monodisperse particles of $0.05 \mu \mathrm{m}$ contributed as large particles to the membrane pores (Particle diameter $\geq$ pore diameter), as the particle size was equal the pore size. This model for predicting the increase in transmembrane pressure agreed with the increase in transmembrane pressure obtained experimentally and measured within \pm 2.2 to $11.6 \%$ error. 
Table 5.3. Model validation using Polycarbonate membrane and monondisperse particles $(0.05 \mu \mathrm{m})$ at different operating conditions.

\begin{tabular}{|c|c|c|c|c|c|c|c|c|c|c|c|c|c|}
\hline \multirow{2}{*}{$\begin{array}{c}\text { Monodisperse } \\
\text { Particles Size } \\
{[\mu \mathrm{m}]}\end{array}$} & \multirow{2}{*}{$\underset{\text { [LPM] }}{\mathbf{Q}}$} & \multirow{2}{*}{$\begin{array}{c}\text { Initial } \\
\text { TMP } \\
\text { [psi] }\end{array}$} & \multirow{2}{*}{$\begin{array}{c}C_{f} \\
{\left[\mathrm{~kg} / \mathrm{m}^{3}\right]}\end{array}$} & \multirow{2}{*}{$\begin{array}{c}V s \\
{\left[\mathrm{~m}^{3} / \mathrm{m}^{2}\right]}\end{array}$} & \multirow{2}{*}{$\begin{array}{l}\text { End } \\
\text { TMP } \\
\text { [psi] }\end{array}$} & \multicolumn{3}{|c|}{ Experimental Results } & \multirow{2}{*}{$\begin{array}{c}\boldsymbol{\alpha}_{\mathrm{pp}} \\
\text { Predicted }\end{array}$} & \multirow{2}{*}{$\begin{array}{c}\alpha_{\mathrm{pm}} \\
\text { Predicted }\end{array}$} & \multirow{2}{*}{$\begin{array}{c}\boldsymbol{P}^{\prime} \\
\text { Calculated }\end{array}$} & \multirow{2}{*}{$\begin{array}{c}\text { Experimental } \\
P^{\prime}\end{array}$} & \multirow{2}{*}{\begin{tabular}{|c|} 
Error \% \\
$\begin{array}{r}*(\text { Error / } \\
\text { Exp) })^{*} 100\end{array}$
\end{tabular}} \\
\hline & & & & & & $m_{t}[g]$ & $m_{p}[g]$ & $m_{c}[g]$ & & & & & \\
\hline 0.05 & 4 & 15 & 0.086 & 0.044 & 16 & 0.0784 & 0.0078 & 0.0706 & 0.85 & 0.6 & 1.022 & 1 & 2.20 \\
\hline 0.05 & 4 & 35 & 0.084 & 0.054 & 36.5 & 0.0892 & 0.0098 & 0.0794 & 0.93 & 0.69 & 1.674 & 1.5 & 11.60 \\
\hline 0.05 & 1 & 25 & 0.083 & 0.05 & 26.2 & 0.0801 & 0.0160 & 0.0641 & 0.87 & 0.5 & 1.33 & 1.2 & 10.83 \\
\hline 0.05 & 6 & 25 & 0.08 & 0.061 & 26 & 0.0517 & 0.0155 & 0.0362 & 0.74 & 0.42 & 1.1 & 1 & 10.00 \\
\hline
\end{tabular}

\subsubsection{Model validation using heterogeneous membrane with non-uniform pore size}

\subsubsection{Fouling attachment with a non-homogenous pore size membrane}

It was necessary to validate the simulation of particle attachments with non-homogenous pore size distribution (Section 3.3.1), so as to provide the evidence that would support the mathematical model based on particle attachments. In order to have a clear set of SEM images of the attachments between particles and Polysulfone membrane pores, latex solution was used at a low concentration of $0.1 \mathrm{~kg} / \mathrm{m}^{3}(0.2 \mathrm{ml}$ per liter). Figure 5.8 represents all of the possible attachments between the large particles (particle diameter $\geq$ pore diameter) and the membrane pores. Particles larger than the pore size, as Particles 3, 4 and 5 in Figure 1, were circled in the SEM image in Figure 6. On the other hand, the particle blocking the membrane pore is indicated with a square around it in Figure 5.8, due to its exact pore-size, similar to Particles 6 and 7 in Figure 3.5.

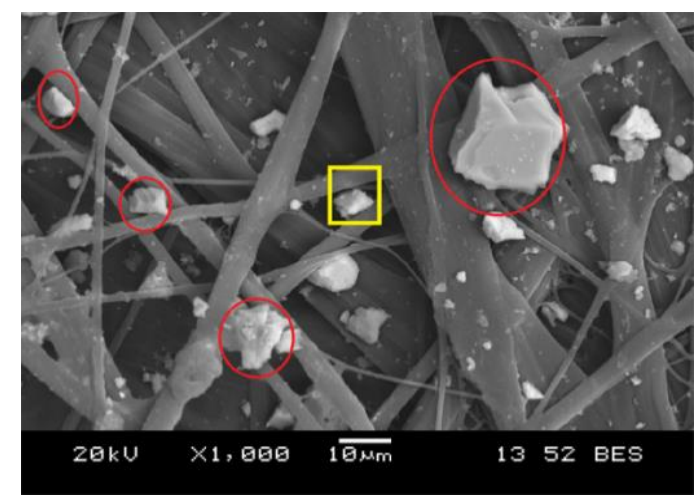

Figure 5.8: SEM images of large particles attached to Polysulfone membrane pores 
Figure 5.9 (a) demonstrates the blockage of the membrane pores with two parties $\left(D_{m} / 6<\right.$ $\mathrm{a}<D_{m} / 2$ ) and thus provides the evidence of the presence of Particle 8 in the simulation (Figure 1). Figure 5.9 (b) represents the attachments of the tiny particles $\left(\mathrm{a}<D_{m} / 6\right)$, like Particle 10 in Figure 1. Figure 5.9 (c) represents the clusters of small particles inside the membrane pores, like Particle (9), in the simulation (Figure 3.5).

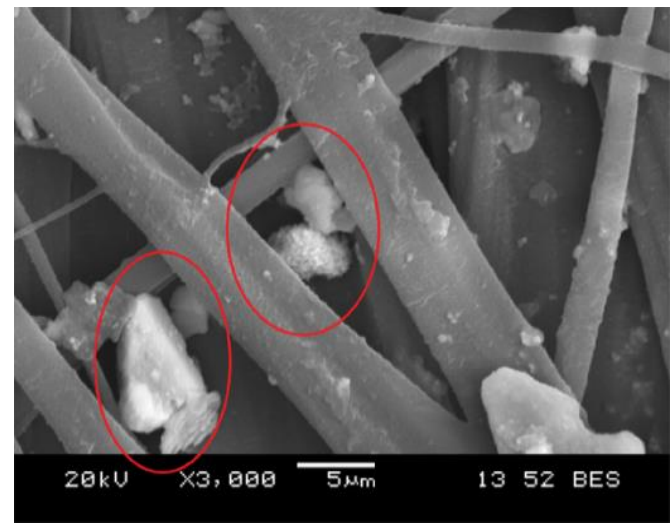

(a)

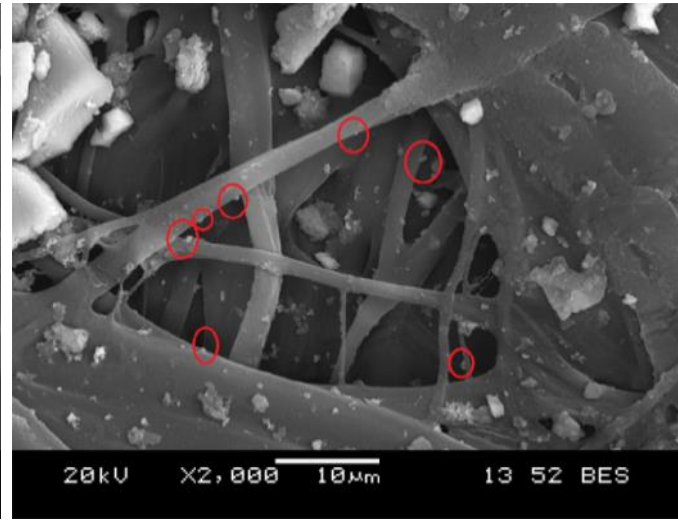

(b)

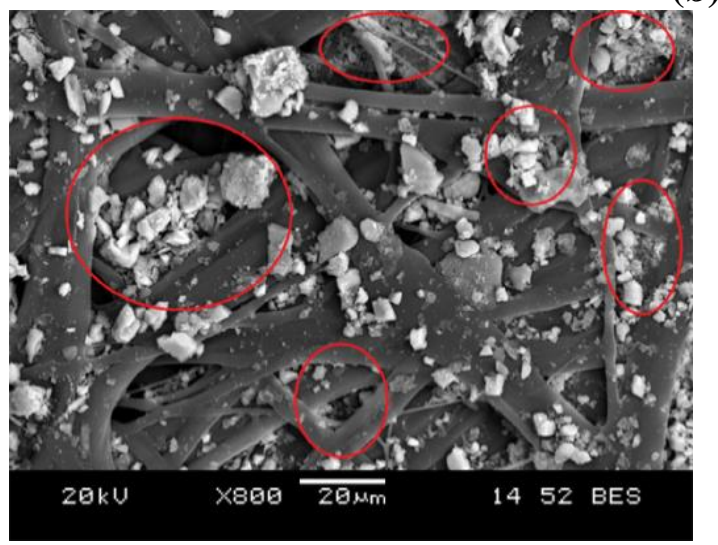

(c)

Figure 5.9: SEM images of small particles attached to Polysulfone membrane pores

As the consequence of particles attachments to the membrane, the particles begun to accumulate and, as such, contributed to the cake layer formation, shown in Figure 5.10. Nevertheless, the heterogeneous Polysulfone membranes retained some clean pores after ultrafiltration, despite the other pores being completely blocked with latex particles as shown in Figure 5.11. These clean pores allowed small particles to penetrate as represented with Particles 1, 2 in Figure 3.5 (zero rejection). 

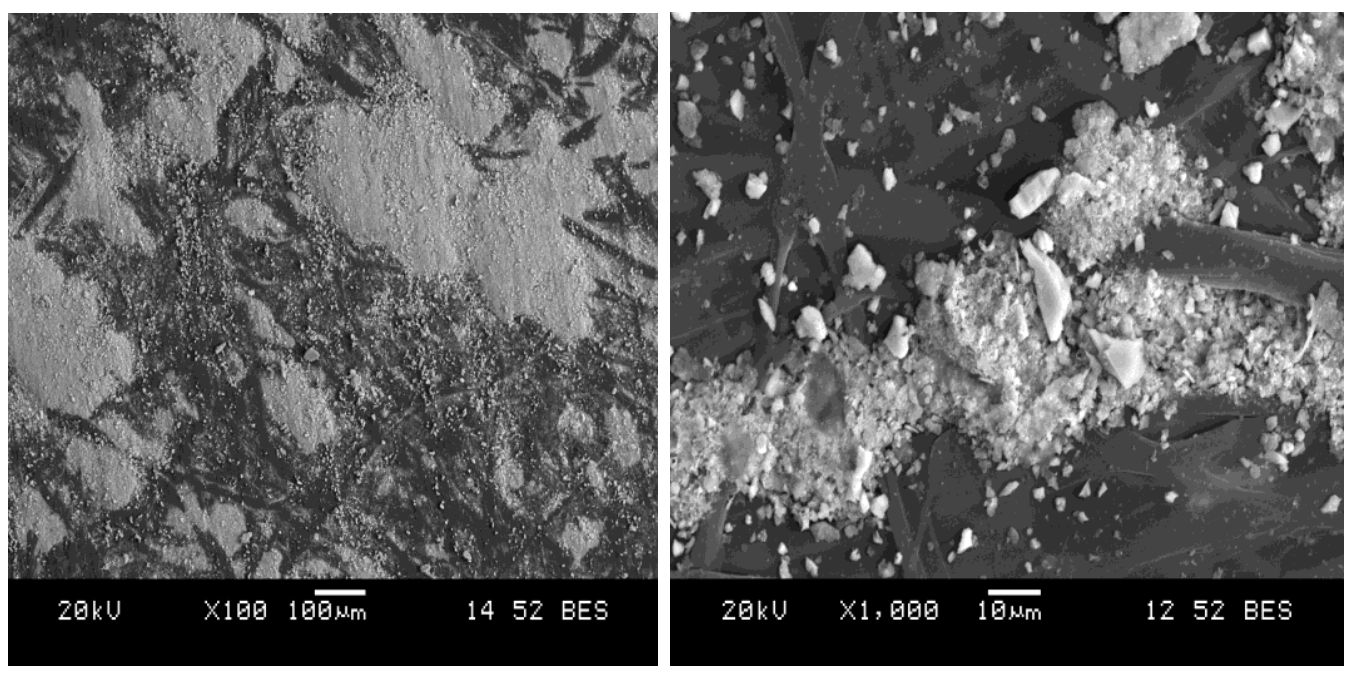

Figure 5.10: SEM image of latex particles contributing to the cake layer formation on Polysulfone membrane

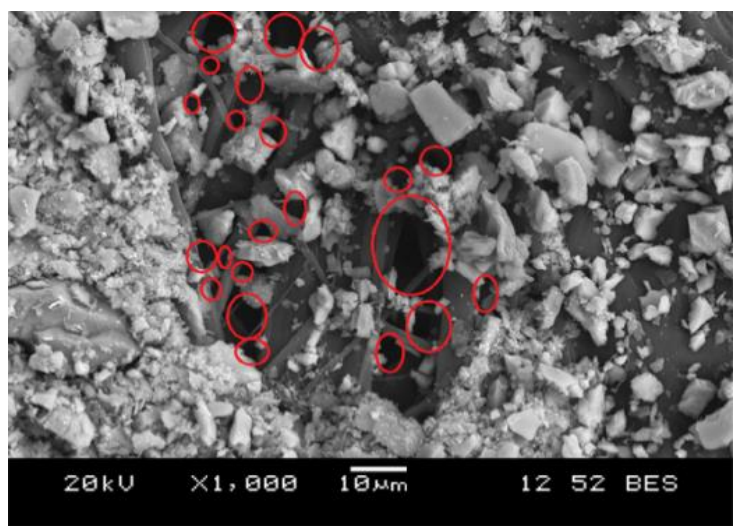

Figure 5.11: SEM image of clean pores in Polysulfone membrane after ultrafiltration

Arguably, particles had a higher chance for particle-to-membrane collision and attachment with heterogeneous membranes, due to the presence of multilayer within the membrane tissues. Figure 5.12 illustrates the attachments of some small particles that have passed the first layer of the membrane and then settled on the membrane tissue. For that reason, the pore size distribution was solely determined based on the real dark pores in the SEM image obtained using the software. In fact, the particles attached to the membrane surface (non-zero rejection) have contributed to the cake layer and the hydraulically irreversible fouling after backwash. 

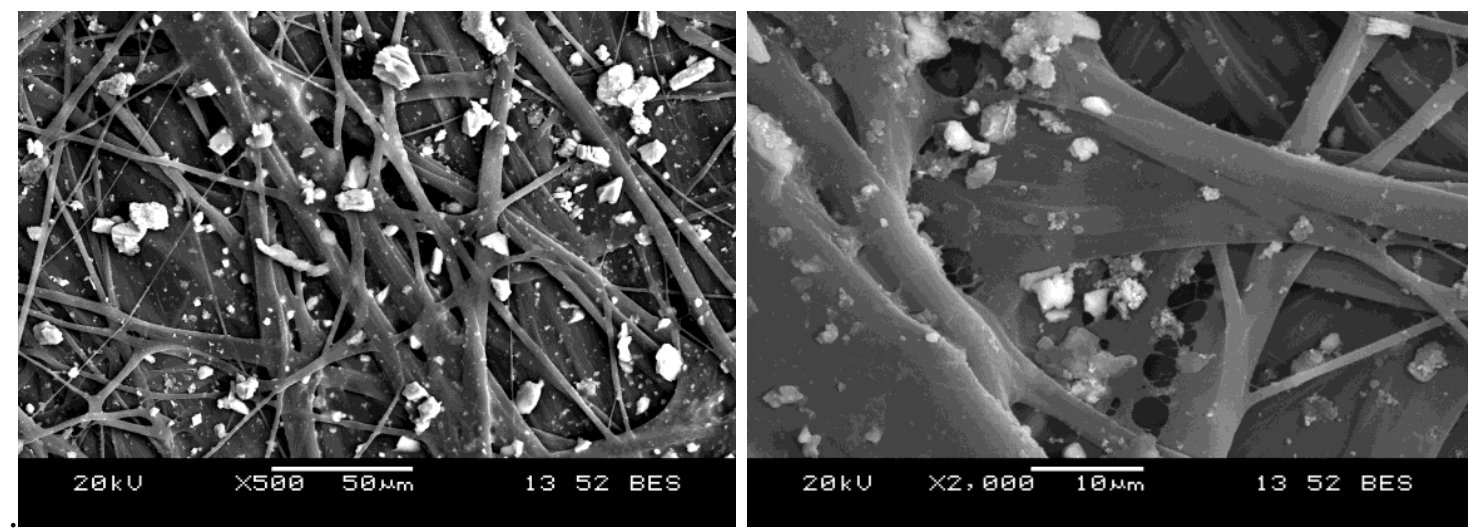

Figure 5.12: SEM image of particles attached to Polysulfone membrane surface

\subsubsection{Validation of the mathematical model using monodisperse particles}

The monodisperse particles (50 and $100 \mathrm{~mm}$ ) at low concentration ranging from 0.09 $0.107 \mathrm{~kg} / \mathrm{m}^{3}$ were used to validate this model. Ultrafiltration process was performed under a constant feed flow rate and a constant time of 60 minutes using Polysulfone membrane. It was observed that the particles contributed only to the pore blocking, due to the low concentration of the monodisperse particles. Table 5.4 represents a precise agreement between the predicted increase in the transmembrane pressure and the experimental one at various operating conditions. During the model validation, the pressure sensor readings were used with the accuracy of \pm $0.25 \%$. The increase in the transmembrane pressure $P^{\prime}$ was calculated using Equation 3.65. The error was $\pm 3.4-8 \%$ and \pm 3.3 - $10 \%$, using 0.05 and $0.1 \mu \mathrm{m}$ monodisperse particles, respectively. The experimental data for the masses of fouling or the volumetric permeate fluxes using 0.05 and $0.1 \mu \mathrm{m}$ had an insignificant difference. This could be attributed to the fact that the heterogeneous membrane had a wide range of pore size distribution. Hence, monodisperse particles contributed as large particles for some small pores, smaller particles for some large pores, and as tiny particles for other pores in the membrane. As a consequence, the monodisperse particles (with a single particle size) allowed us to validate every aspect of the model individually and thus ensure reliability and accuracy of the model. Figure 5.13 (a) presents the SEM images of polysulfone membrane surface after the ultrafiltration process using the monodisperse particles of $0.05 \mu \mathrm{m}$. The monodisperse particles with a single particle size have contributed to pore blocking, since the pore sizes are similar or are of smaller than particle size. On the other hand, monodisperse particles are considered to be a smaller particles when the pore sizes are larger than the particle size. As a result, the particles had the chance to go through the 
clean pores, or have contributed to pore blocking with particle-to-particle attachment featuring one or more particle as aggregation. In addition, the monodisperse particles get attached to the wall of the pore when the particle radius is estimated to be less than the pore diameter/6. Moreover, monodisperse particles attached to the membrane surface contribute to the cake formation. Figure 5.13 (b) illustrates that the particles got settled and attached to the internal membrane pores, while the cake layer had an insignificant increase in thickness due to the low concentration. In order to have a clear comparison of the single size particle attachment mechanisms between the homogenous (i.e., uniform pore size distribution) and the heterogeneous membranes (i.e., non-uniform pore size distribution) an ultrafiltration process of mondisperse particles of $0.05 \mu \mathrm{m}$ using polycarbonate with uniform pore size of $0.05 \mu \mathrm{m}$ was performed. Figure 5.13 (c) illustrates that the single size particles only contributed in pore blocking or cake formation.

Table 5.4: Model validation using polysulfone heterogeneous membrane and monondisperse particles at different operating conditions.

\begin{tabular}{|c|c|c|c|c|c|c|c|c|c|c|}
\hline $\begin{array}{c}\text { Monodisperse } \\
\text { Particles Size } \\
{[\mu \mathrm{m}]}\end{array}$ & $\begin{array}{c}\mathbf{Q} \\
{[\text { LPM] }}\end{array}$ & $\begin{array}{c}\text { Initial } \\
\text { TMP } \\
\text { [psi] }\end{array}$ & $\begin{array}{c}C_{f} \\
{\left[\mathrm{~kg} / \mathrm{m}^{3}\right]}\end{array}$ & $\begin{array}{c}V s \\
{\left[\mathrm{~m}^{3} / \mathrm{m}^{2}\right]}\end{array}$ & $\begin{array}{l}\text { End } \\
\text { TMP } \\
\text { [psi] }\end{array}$ & $\begin{array}{c}\alpha_{\mathrm{pp}} \\
\text { Predicted }\end{array}$ & $\begin{array}{c}\alpha_{\mathrm{pm}} \\
\text { Predicted }\end{array}$ & $\begin{array}{l}\text { Increase in } \\
\text { TMP } \\
\text { Calculated }\end{array}$ & $\begin{array}{c}\text { Exp. } \\
\text { Increase } \\
\text { in TMP }\end{array}$ & $\begin{array}{c}{ }^{*} \text { Error } \\
\%\end{array}$ \\
\hline 0.05 & 4 & 15 & 0.107 & 0.0391 & 16.00 & 0.20 & 0.76 & 1.08 & 1.0 & 8.0 \\
\hline 0.05 & 4 & 35 & 0.100 & 0.0421 & 36.30 & 0.24 & 0.81 & 1.20 & 1.3 & -7.7 \\
\hline 0.05 & 1 & 25 & 0.096 & 0.0346 & 26.00 & 0.30 & 0.80 & 1.06 & 1.0 & 5.5 \\
\hline 0.05 & 6 & 25 & 0.090 & 0.0542 & 26.00 & 0.24 & 0.71 & 1.03 & 1.0 & 3.4 \\
\hline 0.1 & 4 & 15 & 0.107 & 0.0385 & 16.00 & 0.30 & 0.78 & 1.08 & 1.0 & 7.8 \\
\hline 0.1 & 4 & 35 & 0.101 & 0.0447 & 36.50 & 0.35 & 0.83 & 1.65 & 1.5 & 10.0 \\
\hline 0.1 & 1 & 25 & 0.097 & 0.0363 & 26.00 & 0.22 & 0.75 & 1.07 & 1.0 & 6.7 \\
\hline 0.1 & 6 & 25 & 0.091 & 0.0518 & 26.00 & 0.18 & 0.68 & 1.03 & 1.0 & 3.3 \\
\hline
\end{tabular}

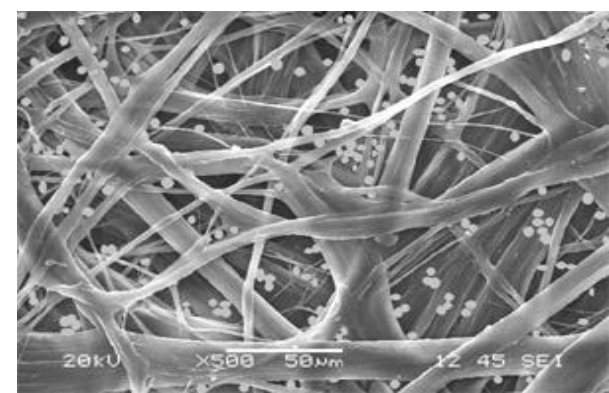

(a)

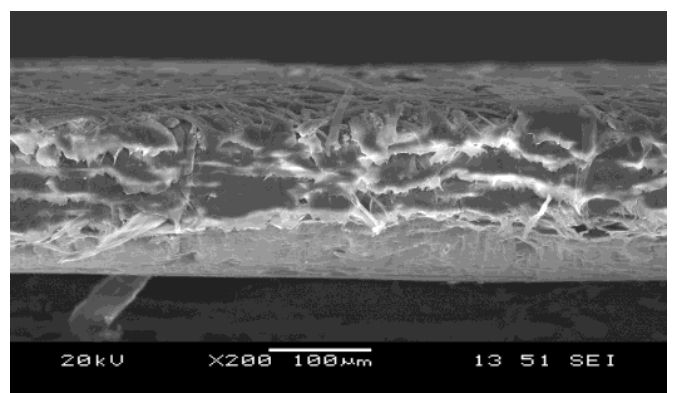

(b) 


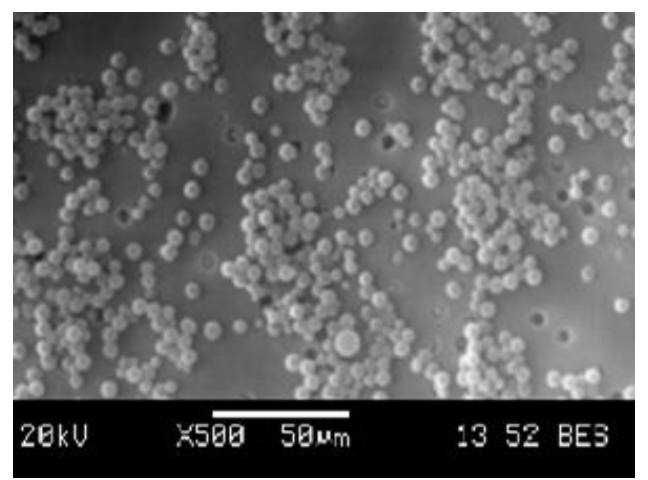

(c)

Figure 5.13: SEM images after ultrfiltration using monodisperse particles of $0.05 \mu \mathrm{m}$ (a) , (b) using polysulfone membrane with non-uniform pore sizes, (c) using polycarbonate membrane with uniform pore size of $0.05 \mu \mathrm{m}$

\subsubsection{Validation of the mathematical model using simulated latex effluent}

The fouling attachment probabilities were calculated based on several particle size ranges classified in accordance with the pore size distribution of the membrane. Latex particle distribution had a range of 0.03 to $800 \mu \mathrm{m}$ and was applied to each pore size $D_{m_{i}}$ ( $i$ to $N$ ). For each range of particle sizes, the average particle size was used for the calculation of the projected area of the particles on the membrane surface. Eventually, the percentage of each average pore size was used in the model calculations. Table 5.5 shows the experimental results of the total mass of the particles retained by Polysulfone membrane, the mass of the particles contributing to pore blocking, the mass of the particles contributing to the cake layer, the volumetric permeate flux, and the increase in the transmembrane pressure obtained at different operational conditions. Time was kept constant (25 minutes) for all experimental runs in order to accurately determine the influence of the operating conditions on the amount of particles retained by the membrane, the permeate flux, and the fouling attachment probabilities.

The transmembrane pressures predicted from the mathematical models using latex effluent were within $\pm 9.7-12.4 \%$ error of the experimental values for the polysulfone membrane. This might be occurring due to the fact that in the present study, membrane fouling was treated as an interaction between suspended particles with a wide range of particle size distribution and membranes featuring non-uniform pore size distribution. Notably, the estimated values appear to be always greater than the experimental values. This may be attributed to the complexity of the model calculations and its predisposition to treat each particle size with each pore size, a dynamic that may be executed somewhat differently during the modeling, from the 
real fouling phenomenon. The mass of fouling contributing to the pore blocking $\left(m_{p}\right)$ was representing $67 \%$ more than the mass of fouling contributed to cake formations in all experiments. This is due to the nature of the non-uniform pore size Polysulfone membrane, which allows the particles to be settled deep inside the pores' tissue.

Table 5.5: Model validation using Polysulfone heterogeneous membrane at different operating conditions using latex effluent.

\begin{tabular}{|c|c|c|c|c|c|c|c|c|c|c|c|c|}
\hline \multirow{2}{*}{$\begin{array}{c}Q \\
\text { [LPM] }\end{array}$} & \multirow{2}{*}{$\begin{array}{c}\text { Initial } \\
\text { TMP } \\
\text { [psi] }\end{array}$} & \multirow{2}{*}{$\begin{array}{c}\mathrm{C}_{\mathrm{f}} \\
{\left[\mathrm{kg} / \mathrm{m}^{3}\right]}\end{array}$} & \multirow{2}{*}{$V s\left[\mathrm{~m}^{3} / \mathrm{m}^{2}\right]$} & \multirow{2}{*}{$\begin{array}{l}\text { End TMP } \\
\text { [psi] }\end{array}$} & \multicolumn{3}{|c|}{ Experimental Results } & \multirow{2}{*}{$\begin{array}{c}\alpha_{\mathrm{pp}} \\
\text { Predicted }\end{array}$} & \multirow{2}{*}{$\begin{array}{c}\alpha_{\mathrm{pm}} \\
\text { Predicted }\end{array}$} & \multirow{2}{*}{$\begin{array}{c}P^{\prime} \\
\text { Calculated }\end{array}$} & \multirow{2}{*}{$\begin{array}{c}\text { Experiment } \\
\text { al } P^{\prime}\end{array}$} & \multirow{2}{*}{ *Error \% } \\
\hline & & & & & $m_{t}[\mathrm{~g}]$ & $m_{p}[\mathrm{~g}]$ & $m_{c}[\mathrm{~g}]$ & & & & & \\
\hline 4 & 25 & 0.78 & 0.014196 & 28 & 0.2464 & 0.2464 & 0 & 0.34 & 0.83 & 3.32 & 3 & 10.7 \\
\hline 4 & 25 & 1.3 & 0.011429 & 30.5 & 0.3024 & 0.257 & 0.0454 & 0.78 & 0.87 & 6.14 & 5.5 & 11.6 \\
\hline 4 & 25 & 1.82 & 0.009241 & 32 & 0.37408 & 0.2731 & 0.10098 & 0.81 & 0.89 & 7.77 & 7 & 11.0 \\
\hline 4 & 15 & 1.3 & 0.008906 & 18.5 & 0.25536 & 0.198 & 0.05736 & 0.54 & 0.67 & 3.88 & 3.5 & 10.9 \\
\hline 4 & 35 & 1.3 & 0.013839 & 42.5 & 0.39872 & 0.288 & 0.11072 & 0.82 & 0.91 & 8.23 & 7.5 & 9.7 \\
\hline 1 & 25 & 1.3 & 0.006357 & 33 & 0.4368 & 0.3201 & 0.1167 & 0.83 & 0.9 & 8.99 & 8 & 12.4 \\
\hline
\end{tabular}

$* \%$ Error $=100 *($ Estimated value - Experimental value $) /($ experimental value $)$

The results obtained in Table 5.5 indicate that an increase in transmembrane pressure from 15 to 35 psi leads to an increase in the particle-to-particle $\left(\alpha_{\mathrm{pp}}\right)$ and the particle-tomembrane $\left(\alpha_{\mathrm{pm}}\right)$ attachment probabilities, from 0.54 to 0.82 and 0.67 to 0.91 , respectively. Higher fouling attachment probabilities resulted in an increase in the total mass of fouling from $0.2554 \mathrm{~kg} / \mathrm{m}^{2}$ to $0.3987 \mathrm{~kg} / \mathrm{m}^{2}$. This contributed to a higher pressure that caused an increase in the permeate flow through the membrane which brought more particles to the membrane's surface. Hence, the chances for the particle-to-particle and particle-to-membrane collision and attachment were increased, effectively causing higher attachment probabilities. Moreover, it was observed that the depositional attachment probability $\alpha_{\mathrm{pm}}$ had higher values than the coagulation attachment probability $\alpha_{\mathrm{pp}}$. This indicates that the transmembrane pressure might have more impact on the pore blocking and the membrane-to-particle attachment than the cake layer build up. A substantial reduction in particle-to-particle attachment probability $\left(\alpha_{\mathrm{pp}}\right)$ was expected with a higher flow rate (4 LPM), due to the greater shear rate applied on the particles at the cake layer. Nevertheless, particle-to-particle attachment probability $\left(\alpha_{\mathrm{pp}}\right)$ had an insignificant reduction from 0.83 to 0.78 at 1 LPM and 4 LPM, respectively. Arguably, this is due to the nature of the heterogeneous membrane, which results in more particles attaching to each other inside the membrane matrix and trapped deeply within it. On the other hand, at a higher flow rate, the cumulative permeate flux $\left(V_{s}\right)$ had a noticeable increase from 0.00636 to $0.01143 \mathrm{~m}^{3} / \mathrm{m}^{2}$. 
For backwashing flow rates of 2-4 LPM, the model prediction of the mass of the irreversible fouling agreed with the total solid of irreversible fouling experimentally measured within $\pm 7-8.5 \%$ error while the increase in transmembrane pressure predicted from the model agreed with the experimental values within $\pm 10.1-12.8 \%$ error. Figure 5.14 represents SEM images of Polysulfone membrane after the backwash at a flow rate of 3 LPM. The dark spots indicate the cleaned and opened pores after backwashing.

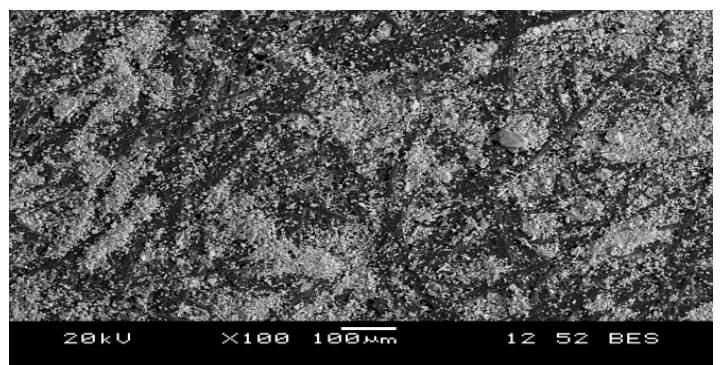

(a)

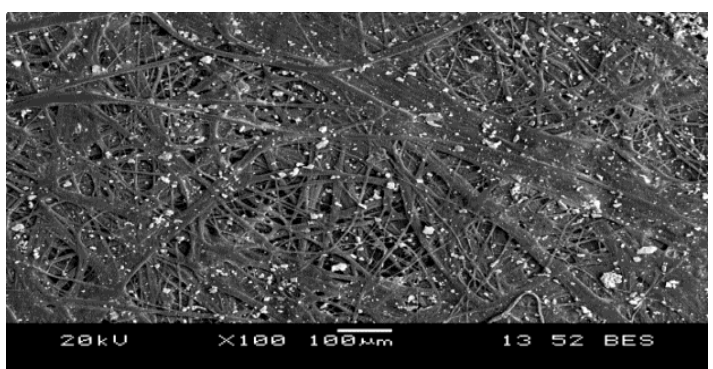

(b)

Figure 5.14: SEM images of polysulfone membrane (a) Blocked pore before backwash (b) Cleaned pores after backwash

\subsection{Validation of the developed attachment model including the particle sphericity}

\subsubsection{Validation of the developed attachment model for homogeneous membrane}

It was essential to validate the model developed for homogenous membranes, including the particle sphericity using Polycarbonate homogeneous membrane. As shown in Table 5.6, Polycarbonate membranes with the pore size of 0.1 and $0.05 \mu \mathrm{m}$ were used for the validation at a variety of operating conditions. The obtained experimental results were compared the predicted values of the total mass of fouling and the increase in transmembrane pressure using the attachment model with and without the particle sphericity. For the transmembrane pressure using the membrane with the average pore size of $0.1 \mu \mathrm{m}$, the average error was between the experimental and predicted values was $6.0 \%$ when the model did not include the sphericity of the particles. On the other hand, the error was reduced to $4.5 \%$ when the model included the spericty of the particles. Similarly, for the $0.05 \mu \mathrm{m}$ membrane, the average error was between the experimental transmembrane pressure and predicted values was $6.9 \%$ when the model did not include the sphericity of the particles. On the other hand, the error was reduced to $4.2 \%$ when the model included the spericty of the particles. In addition, the predicted total mass of particles agreed with the experimental mass of fouling when utilizing Polycarbonate membrane with the pore size of $0.1 \mu \mathrm{m}$ by $11.8 \%$, and $8.3 \%$ using the attachment model of fouling without and 
with the sphericity of the particles parameters, respectively. The predicted total mass of particles agreed with the experimental mass of fouling using Polycarbonate membrane with the pore size of $0.05 \mu \mathrm{m}$ by $11.8 \%$, and $7.5 \%$ using the attachment model of fouling without and with the sphericity of the particles, respectively. This indicates that fouling of a homogenous membrane with uniform pore size and straight pores would be significantly affected by the shape and sphericity of the particles.

Table 5.6: Validation of the attachment model, incorporating the particles sphericity, applied to the homogeneous Polycarbonate membrane

\begin{tabular}{|c|c|c|c|c|c|c|c|c|c|c|c|c|c|c|c|c|}
\hline \multirow[b]{2}{*}{$\begin{array}{c}\text { Pore size } \\
{[\mu \mathrm{m}]}\end{array}$} & \multirow[b]{2}{*}{$\begin{array}{l}\text { Initial } \\
\text { TMP } \\
\text { [psi] }\end{array}$} & \multirow[b]{2}{*}{$\begin{array}{c}\mathrm{C}_{\mathrm{f}} \\
{\left[\mathrm{kg} / \mathrm{m}^{3}\right]}\end{array}$} & \multirow[b]{2}{*}{$\begin{array}{c}\mathrm{Q} \\
{[\mathrm{LPM}]}\end{array}$} & \multirow[b]{2}{*}{$\begin{array}{c}V s \\
{\left[\mathrm{~m}^{3} / \mathrm{m}^{2}\right]}\end{array}$} & \multirow[b]{2}{*}{$\begin{array}{c}\alpha_{\mathrm{pp}} \\
\text { Predicted }\end{array}$} & \multirow[b]{2}{*}{$\begin{array}{c}\alpha_{\mathrm{pm}} \\
\text { Predicted }\end{array}$} & \multirow[b]{2}{*}{$\begin{array}{l}\mathrm{m}_{\mathrm{t}} \operatorname{Exp} \\
{\left[\mathrm{kg} / \mathrm{m}^{2}\right]}\end{array}$} & \multirow[b]{2}{*}{\begin{tabular}{|c} 
Exp \\
Increase \\
in TMP
\end{tabular}} & \multicolumn{4}{|c|}{ Model prediction } & \multicolumn{4}{|c|}{ Model included sphericity } \\
\hline & & & & & & & & & \begin{tabular}{|c|} 
Increase \\
in TMP \\
Predicted
\end{tabular} & $\begin{array}{c}* \text { Error } \\
\% \\
\text { TMP }\end{array}$ & $\begin{array}{c}m_{t} \\
{\left[\mathrm{~kg} / \mathrm{m}^{2}\right]} \\
\text { Predicted }\end{array}$ & $\begin{array}{c}\text { *Error } \\
\% \\
m_{t}\end{array}$ & $\begin{array}{c}\text { Increase } \\
\text { in TMP } \\
\text { Predicted }\end{array}$ & $\begin{array}{l}* \text { Error } \\
\% \\
\text { TMP }\end{array}$ & $\begin{array}{c}m_{t} \\
{\left[\mathrm{~kg} / \mathrm{m}^{2}\right]} \\
\text { Predicted }\end{array}$ & $\begin{array}{c}* \text { Error } \\
\% \\
m_{t}\end{array}$ \\
\hline 0.1 & 3 & 1.3 & 1 & 0.007 & 1 & 0.1 & 0.1206 & 7 & 6.63 & -5.3 & 0.109 & -9.6 & 6.73 & -3.9 & 0.112 & -7.1 \\
\hline 0.1 & 4 & 1.3 & 2 & 0.04 & 0.8 & 0.77 & 0.0294 & 20 & 18.69 & -6.6 & 0.026 & -11.5 & 18.99 & -5.1 & 0.027 & -8.1 \\
\hline 0.1 & 5 & 1.3 & 3 & 0.064 & 0.7 & 0.82 & 0.0495 & 29 & 27.47 & -5.3 & 0.055 & 11.1 & 27.97 & -3.6 & 0.052 & 5.0 \\
\hline 0.1 & 4 & 1.82 & 1 & 0.007 & 0.9 & 0.9 & 0.0078 & 8 & 7.58 & -5.2 & 0.0069 & -11.7 & 7.68 & -4.0 & 0.0071 & -9.1 \\
\hline 0.1 & 2 & 0.78 & 1 & 0.007 & 0.5 & 0.85 & 0.0034 & 6 & 5.54 & -7.7 & 0.0029 & -15.4 & 5.66 & -5.7 & 0.003 & -12.5 \\
\hline 0.05 & 11 & 1.3 & 4 & 0.007 & 0.6 & 0.3 & 0.0054 & 5 & 4.7 & -6 & 0.006 & 11.8 & 4.81 & -3.8 & 0.0057 & 6.2 \\
\hline 0.05 & 4 & 1.3 & 2 & 0.0189 & 0.5 & 0.72 & 0.0169 & 10 & 9.23 & -7.7 & 0.0149 & -11.7 & 9.55 & -4.5 & 0.0154 & -8.7 \\
\hline
\end{tabular}

\subsubsection{Validation of the developed attachment model for heterogeneous membrane}

As showcased in Table 5.7, the Polysulfone membrane was used to validate the attachment model for heterogeneous membranes, including the respective sphericity values at different operating conditions. The attachment model prediction for the increase in transmembrane pressure corresponds with the experimental results, with the average errors of $10.0 \%$ and $9.9 \%$, when the model excluded and included the sphericity of the particles, respectively. In addition, the predicted total mass of particles agreed with the experimental data for Polysulfone membranes by $10.2 \%$, and $10.4 \%$, using the attachment model of fouling without and with the particle sphericity, respectively. This can be attributed to the nature of nonuniform pore size membranes. Furthermore, the pores of Polysulfone membranes are not aligned straight. As a consequence, the particles sphericity was ineffective in the model based on heterogeneous membranes. Therefore, it can be concluded that the spericity of the particles had a significant effect only on the homogenous attachment model. 
Table 5.7 : Validation of the developed attachment model including the particle sphericity using heterogeneous Polysulfone membranes

\begin{tabular}{|c|c|c|c|c|c|c|c|c|c|c|c|c|c|c|c|}
\hline \multirow[b]{2}{*}{$\begin{array}{l}\text { Initial } \\
\text { TMP } \\
\text { [psi] }\end{array}$} & \multirow[b]{2}{*}{$\begin{array}{c}\mathrm{C}_{\mathrm{f}} \\
{\left[\mathrm{kg} / \mathrm{m}^{3}\right]}\end{array}$} & \multirow[b]{2}{*}{$\begin{array}{c}\mathrm{Q} \\
{[\mathrm{LPM}]}\end{array}$} & \multirow[b]{2}{*}{$\begin{array}{c}V s \\
{\left[\mathrm{~m}^{3} / \mathrm{m}^{2}\right]}\end{array}$} & \multirow[b]{2}{*}{$\begin{array}{c}\alpha_{\mathrm{pp}} \\
\text { Predicted }\end{array}$} & \multirow[b]{2}{*}{$\begin{array}{c}\alpha_{\mathrm{pm}} \\
\text { Predicted }\end{array}$} & \multirow[b]{2}{*}{$\begin{array}{l}\mathrm{m}_{\mathrm{t}} \operatorname{Exp} \\
{\left[\mathrm{kg} / \mathrm{m}^{2}\right]}\end{array}$} & \multirow[b]{2}{*}{$\begin{array}{c}\text { Exp } \\
\text { Increase } \\
\text { in TMP }\end{array}$} & \multicolumn{4}{|c|}{ Model prediction } & \multicolumn{4}{|c|}{ Model included sphericity } \\
\hline & & & & & & & & $\begin{array}{c}\text { Increase } \\
\text { in TMP } \\
\text { Predicted }\end{array}$ & $\begin{array}{l}\text { *Error } \\
\% \\
\text { TMP }\end{array}$ & $\begin{array}{c}m_{t} \\
{\left[\mathrm{~kg} / \mathrm{m}^{2}\right]} \\
\text { Predicted }\end{array}$ & $\begin{array}{c}* \text { Error } \\
\% \\
m_{t}\end{array}$ & $\begin{array}{c}\text { Increase } \\
\text { in TMP } \\
\text { Predicted }\end{array}$ & $\begin{array}{l}\text { *Error } \\
\% \\
\text { TMP }\end{array}$ & $\begin{array}{c}m_{t} \\
{\left[\mathrm{~kg} / \mathrm{m}^{2}\right]} \\
\text { Predicted }\end{array}$ & $\begin{array}{c}\text { *Error } \\
\% \\
m_{t}\end{array}$ \\
\hline 25 & 0.78 & 4 & 0.0142 & 0.34 & 0.83 & 0.0110 & 3 & 3.32 & 10.7 & 0.0096 & -12.7 & 3.29 & 9.7 & 0.0095 & -13.6 \\
\hline 25 & 1.30 & 4 & 0.0114 & 0.78 & 0.87 & 0.0135 & 5.5 & 6.14 & 11.6 & 0.0146 & 8.1 & 6.15 & 11.8 & 0.0145 & 7.4 \\
\hline 25 & 1.82 & 4 & 0.0092 & 0.81 & 0.89 & 0.0167 & 7 & 7.77 & 11.0 & 0.0187 & 12.0 & 7.75 & 10.7 & 0.0187 & 12.0 \\
\hline 15 & 1.30 & 4 & 0.0089 & 0.54 & 0.67 & 0.0114 & 3.5 & 3.18 & -9.1 & 0.0103 & -9.7 & 3.18 & -9.1 & 0.0104 & -8.8 \\
\hline 35 & 1.30 & 4 & 0.0138 & 0.82 & 0.91 & 0.0178 & 7.5 & 8.23 & 9.7 & 0.0195 & 9.6 & 8.25 & 10.0 & 0.0197 & 10.7 \\
\hline 25 & 1.30 & 1 & 0.0064 & 0.83 & 0.90 & 0.0195 & 8 & 7.35 & -8.1 & 0.0177 & -9.2 & 7.34 & -8.3 & 0.0176 & -9.7 \\
\hline
\end{tabular}

\subsection{Effect of operating conditions on fouling attachments, cake layer, cumulative permeate flux, and specific power consumption}

One of the objectives of the present study was to investigate the impact of operating conditions on fouling attachment probabilities, the total mass of fouling, the cake height, the cumulative permeate volume, and the specific power consumption. Results obtained show that the transmembrane pressure (TMP), feed flow rate and feed concentration had a significant effect on the mass of fouling, membrane performance and power consumption, as demonstrated in this section. In addition, the objective was to compare the impact of the same operating conditions on the membrane fouling using membranes with uniform and non-uniform pore sizes.

\subsubsection{Using homogeneous Polycarbonate membrane}

\subsubsection{The influence of transmembrane pressure}

At a feed flow rate of $4.0 \mathrm{~L} / \mathrm{min}$ and a feed concentration of $1.3 \mathrm{~kg} / \mathrm{m}^{3}$, increasing the transmembrane pressure from 15 to 45 psi lead to increases in the particle-to-particle $\left(\alpha_{\mathrm{pp}}\right)$ and the particle-to-membrane $\left(\alpha_{\mathrm{pm}}\right)$ attachment potentials from 0.4 to 0.76 and 0.55 to 0.8 , respectively. Higher fouling attachment probabilities resulted in an increase in the total mass of fouling from $0.0104 \mathrm{~kg} / \mathrm{m}^{2}$ to $0.0145 \mathrm{~kg} / \mathrm{m}^{2}$. As shown in Figure 5.15 (a), when the pressure was raised from 15 to $35 \mathrm{psi}$, the fouling attachment probabilities increased from 0.4 to 0.75 and from 0.5 to 0.8 for coagulation attachment probability $\left(\alpha_{\mathrm{pp}}\right)$ and depositional attachment probability $\left(\alpha_{\mathrm{pm}}\right)$, respectively. However, further increase in pressure did not affect $\alpha_{\mathrm{pp}}$ and $\alpha_{\mathrm{pm}}$ significantly. When the transmembrane pressure increased from 15 to 35 psi, the volumetric permeate flux and the mass of fouling increased from $0.0125 \mathrm{~m}^{3} / \mathrm{m}^{2}$ to $0.0178 \mathrm{~m}^{3} / \mathrm{m}^{2}$ and from $0.0104 \mathrm{~kg} / \mathrm{m}^{2}$ to $0.0142 \mathrm{~kg} / \mathrm{m}^{2}$, respectively. Higher permeate flow through the membrane brought more particles 
to the membrane's surface. Hence, chances for the particle-to-particle and particle-to-membrane collision and attachment have increased, resulting in a higher attachment probabilities. Notably, increasing the pressure from 35 to 45 psi resulted in an insignificant change in the volumetric permeate flux $\left(V_{s}\right.$ ) from $0.0178 \mathrm{~m}^{3} / \mathrm{m}^{2}$ to $0.0179 \mathrm{~m}^{3} / \mathrm{m}^{2}$. The reason for the minimal increase lies in the fact that the transmembrane pressure higher than the critical pressure has an insignificant effect on the permeate flux or the total mass of fouling retained by the membrane. Thus, the fouling attachments probabilities values leveled off to a relatively constant value. Moreover, Figure 5.15 shows that the depositional attachment probability $\alpha_{\mathrm{pm}}$ had higher values than the coagulation attachment probability $\alpha_{\mathrm{pp}}$. This indicates that the transmembrane pressure might have more impact on the pore blocking and the membrane-to-particle attachment than the cake layer build up. Higher fouling attachment probabilities resulted in an increase in the total mass of fouling from $0.0104 \mathrm{~kg} / \mathrm{m}^{2}$ to $0.0145 \mathrm{~kg} / \mathrm{m}^{2}$ as shown in Figure 5.15 (b). The specific power consumption also increased from 10.17 to $21.02 \mathrm{kWh} / \mathrm{m}^{3}$. The error bars presented in the figures of this study, represent the confidence intervals of $95 \%$, as calculated in Appendix (J).

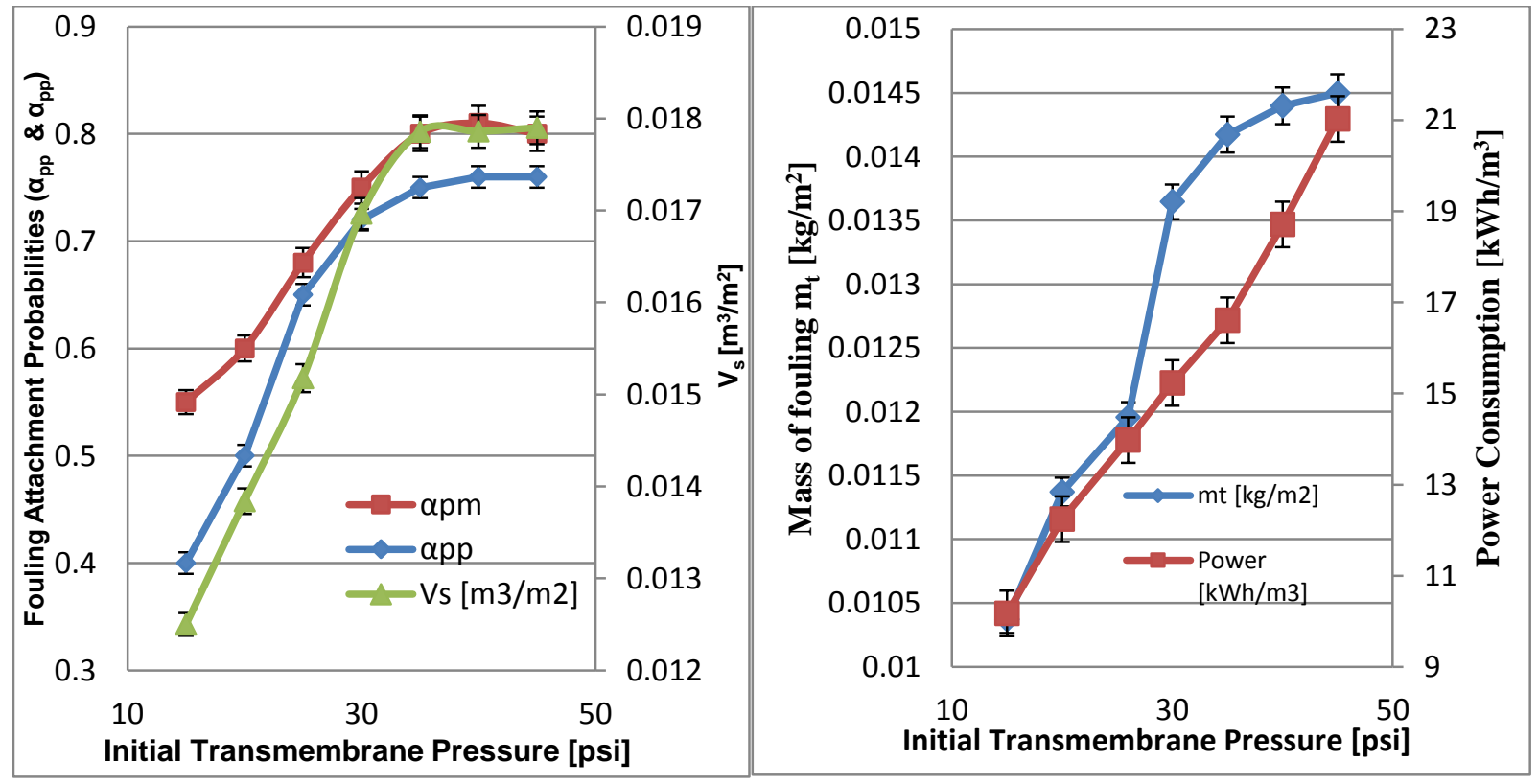

(a)

(b)

Figure 5.15: Effect of initial transmembrane pressure at $[Q=4 \mathrm{LPM}],\left[\mathrm{C}_{\mathrm{f}}=1.3 \mathrm{~kg} / \mathrm{m}^{3}\right]$, [pH=7] on (a) Fouling attachment probabilities $\left(\alpha_{\mathrm{pp}}, \alpha_{\mathrm{pm}}\right)$ and the volumetric permeate flux $\left(V_{s}\right)$ (b) Mass of fouling and specific power consumption. 
Figure 5.16 presents the SEM images of the membrane after the ultrafiltration experiment at different pressures, and at a fixed feed flow rate, filtration time and feed concentration, illustrating the effect of pressure on the cake build-up. Figure 5.16 (a) was obtained from a sample at a pressure of $15 \mathrm{psi}$, showing a thick cake sample (average thickness of about 5.05 $\mu \mathrm{m})$. Figure 5.16 (b) shows that the cake thickness increased to about $8.55 \mu \mathrm{m}$ when the pressure was increased to $35 \mathrm{psi}$. Arguably, at the transmembrane pressure of 35 psi (critical pressure at feed flow rate $4 \mathrm{LPM}$ and feed concentration $1.3 \mathrm{~kg} / \mathrm{m}^{3}$ ), the concentration polarization might attain a sufficient level for the retained solutes at the membrane surface to reach the gel concentration. Once a gel layer has formed, further increase in the applied pressure does not lead to the increase in the volumetric permeate flux above the one attained at critical pressure value. However, higher pressure causes the formed cake layer on membrane surface to be compressed. As shown in Figure 5.17 the cake layer becomes compressed to $7.9 \mu \mathrm{m}$ at 45 psi.

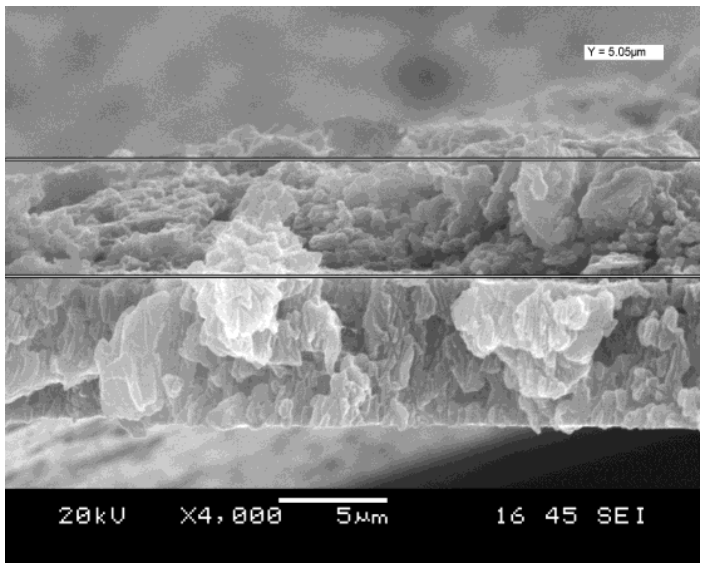

(a)

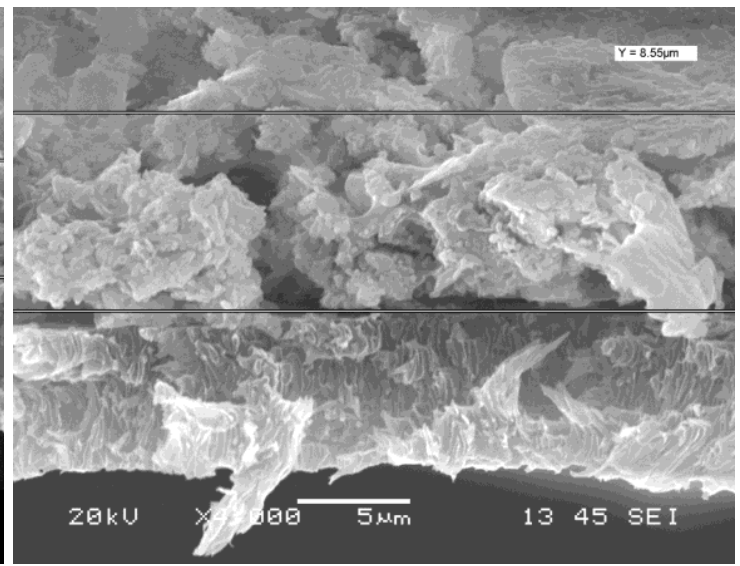

(b)

Figure 5.16: SEM images of membrane after ultrafiltration $[Q=4 \mathrm{LPM}],\left[\mathrm{C}_{\mathrm{f}}=1.3 \mathrm{~kg} / \mathrm{m}^{3}\right]$ (a) Cake height $5.05 \mu \mathrm{m}$ at pressure 15 psi (b) Cake height $8.55 \mu \mathrm{m}$ at pressure 35 psi

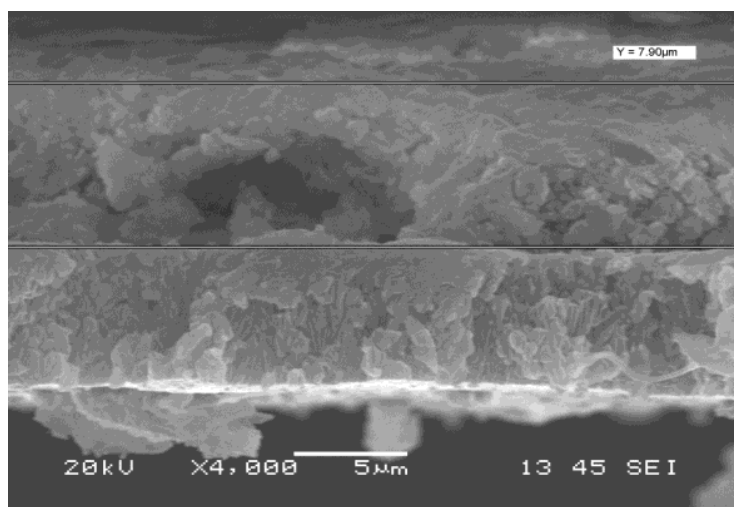

Figure 5.17: SEM image of membrane after UF at $45 \mathrm{psi}, 4 \mathrm{LPM}$ and $1.3 \mathrm{~kg} / \mathrm{m}^{3}$ (Cake height $7.9 \mu \mathrm{m}$ ) 


\subsubsection{The influence of feed flow rate}

Figure 5.18 depicts the effect of the feed flow rate on the fouling attachments, cumulative permeate flux, total mass of fouling, and the specific power consumption at $15 \mathrm{psi}$ and feed concentration at $1.3 \mathrm{~kg} / \mathrm{m}^{3}$. It was observed that the particle-to-particle attachment probability $\left(\alpha_{\mathrm{pp}}\right)$ was significantly reduced from 0.86 at $1 \mathrm{LPM}$ (cross flow velocity of $10.4 \mathrm{~cm} / \mathrm{s}$ ) to 0.19 at 6 LPM (cross flow velocity of $62.5 \mathrm{~cm} / \mathrm{s}$ ), while the particle-to-membrane attachment probability $\left(\alpha_{\mathrm{pm}}\right)$ decreased from 0.82 to 0.49 . The probable cause for this substantial reduction in $\alpha_{\mathrm{pp}}$ with the feed flow rate is that at a higher flow rate, a higher shear rate is applied on the particles at the cake layer. Consequently, a higher number of particles were washed away from the cake layer. In particular, as the feed flow rate was increased to $3.0 \mathrm{LPM}$, there was a stiff decrease in $\alpha_{\mathrm{pp}}$, which, arguably, marks the critical flow rate for membrane fouling in this system. On the other hand, at higher flow rate, the cumulative permeate flux $\left(V_{s}\right)$ increased from 0.0076 to 0.014 $\mathrm{m}^{3} / \mathrm{m}^{2}$. As a result, more particles were brought into contact with the membrane, leading to an increase in collisions and attachments between particles and membrane surface. Consequently, $\alpha_{\mathrm{pm}}$ decreased at a lower rate as compared with that of $\alpha_{\mathrm{pp}}$. As shown in Figure 5.18 (a), $\alpha_{\mathrm{pp}}$ and $\alpha_{\mathrm{pm}}$ approach maximum values at flow rate less than 1.0 LPM. It was also observed that as the fouling attachment probabilities decreased, the mass of particles retained by the membrane dropped from $0.0162 \mathrm{~kg} / \mathrm{m}^{2}$ at a feed low rate of $1 \mathrm{LPM}$ to $0.00838 \mathrm{~kg} / \mathrm{m}^{2}$ at $6 \mathrm{LPM}$. Particles accumulated on the membrane surface would be washed back to the bulk fluid more at higher flow rates; and thus, the concentration polarization effect diminished. This, in turn, caused the osmotic pressure to decrease, permeation flux to increase, and the solid retained and cake height to decrease. Due to the reduction of the total mass of fouling by increasing the feed flow rate from 1 to 6 LPM, the transmembrane pressure over the duration of the filtration process only increased by $1 \mathrm{psi}$, compared to an increase of 5 psi at 1 LPM. Although the total mass of fouling was decreased, with the increase in the flow rate from 1 to 6 LPM, the power consumption per unit volume increased from 4.47 to $13.1 \mathrm{~kW} . \mathrm{h} / \mathrm{m}^{3}$ as illustrated in Figure 5.18 (b). This aligned with the specific power consumption as directly proportional to the feed flow rate in Equation (4). Specifically, this indicates that the increasing of the flow rate 6 times results in a 3 times increasing of the power consumption. This, in turn, implies that the remediation of the fouling is greatly required to reduce the total mass of fouling in lower flow rates, increase the 
volumetric permeate flux, and, at the same time, reduce the power consumption per unit volume of filtrate.

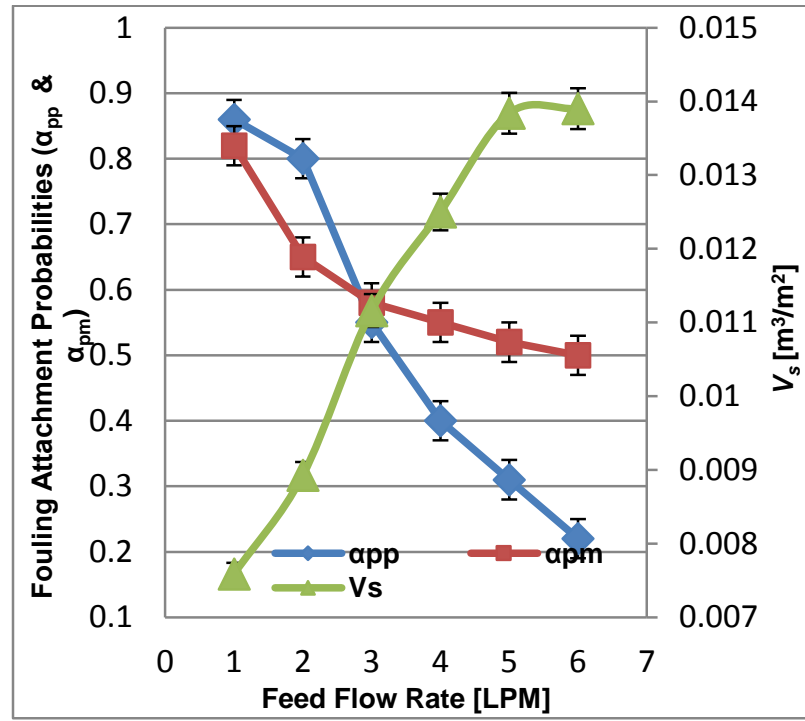

(a)

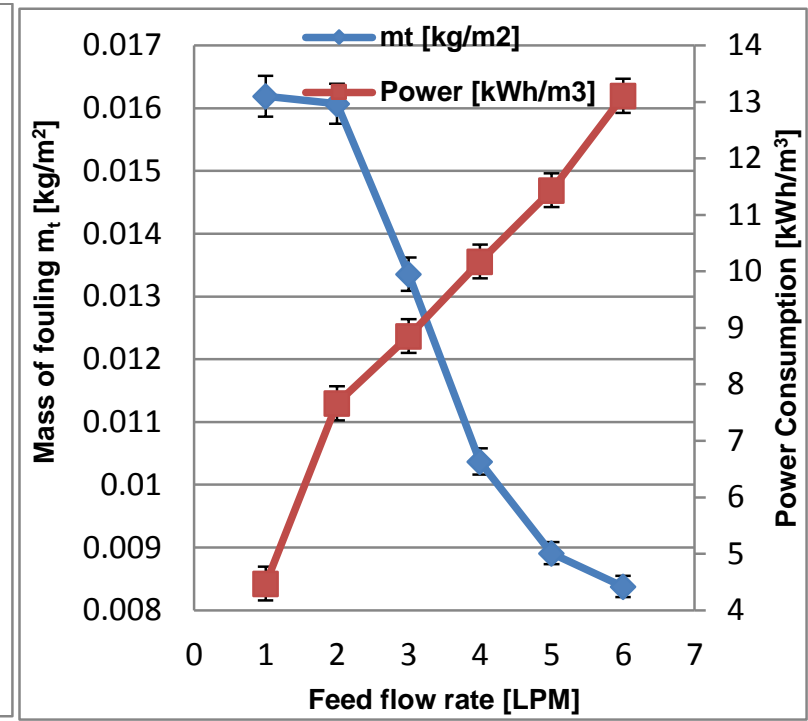

(b)

Figure 5.18: Effect of feed flow rate at $[\mathrm{TMP}=15 \mathrm{psi}],\left[\mathrm{C}_{\mathrm{f}}=1.3 \mathrm{~kg} / \mathrm{m}^{3}\right]$, and $[\mathrm{pH}=7]$ on (a) fouling attachment probabilities $\left(\alpha_{\mathrm{pp}}, \alpha_{\mathrm{pm}}\right)$ and the volumetric permeate flux $\left(V_{s}\right)$ (b) Mass of fouling and power consumption

Figure 5.19 presents the SEM images of the membrane after ultrafiltration at different feed flow rates (fixed pressure, filtration time, and feed concentration). Figure 5.19 (a) was obtained from a sample at a feed flow rate of $1.0 \mathrm{~L} / \mathrm{min}$, showing the cake thickness of about $13.8 \mu \mathrm{m}$. Figure 5.19 (b) shows that the cake thickness decreased to about $2.4 \mu \mathrm{m}$ at the feed flow rate of $6.0 \mathrm{~L} / \mathrm{min}$. The cross-flow of the feed can be considered as a continuous washing of the cake layer, and hence, the resultant particle-to-particle attachment $\left(\alpha_{\mathrm{pp}}\right)$ decreased from 0.86 at 1 LPM to 0.19 at 6 LPM.

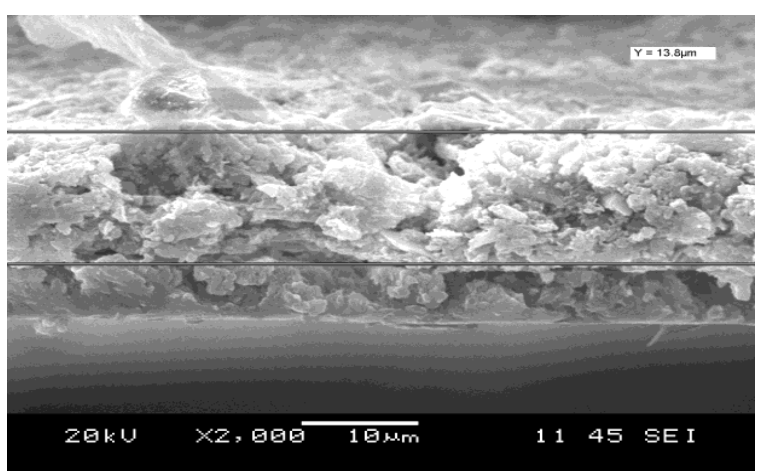

(a)

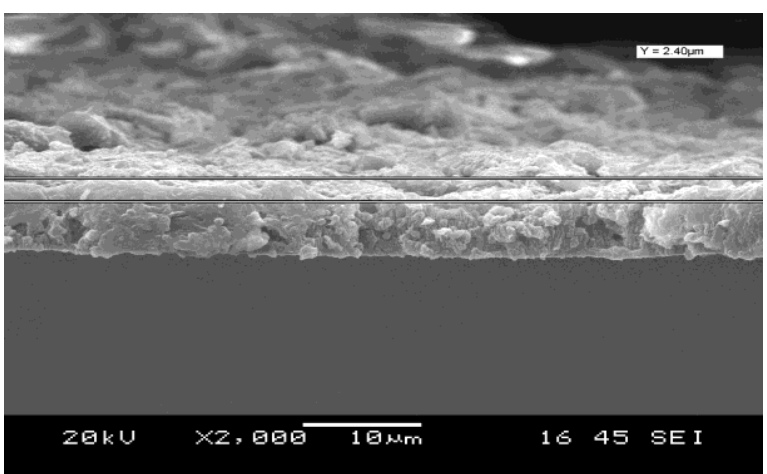

(b)

Figure 5.19: SEM images of membrane after ultrafiltration $[P=15 \mathrm{psi}],\left[C_{\mathrm{f}}=1.3 \mathrm{~kg} / \mathrm{m}^{3}\right]$ (a) Cake height $13.8 \mu \mathrm{m}$ at feed flow rate 1 LPM, (b) Cake height $2.4 \mu \mathrm{m}$ at feed flow rate 6 LPM 


\subsubsection{The influence of feed concentration}

Figure 5.20 shows the effect of the feed concentration on the fouling attachment probabilities, cumulative permeate flux, total mass of fouling and the specific power consumption at a feed flow rate of $1 \mathrm{~L} / \mathrm{min}$ and 15 psi. Increasing the feed concentration from $0.78 \mathrm{~kg} / \mathrm{m}^{3}$ to $1.82 \mathrm{~kg} / \mathrm{m}^{3}$ resulted in a significant increase in the coagulation attachment probability, $\alpha_{\mathrm{pp}}$, and a significant decrease in the depositional attachment probability, $\alpha_{\mathrm{pm}}$. The particle-to-particle attachment, $\alpha_{\mathrm{pp}}$, increased from 0.3 to 0.9 , while the particle-to-membrane attachment, $\alpha_{\mathrm{pm}}$, decreased from 0.95 to 0.6 . Increasing the feed concentration resulted in a higher chance of particle-to-particle collision and attachment. As a consequence, the coagulation attachment probability and cake layer build up are enhanced. It was also observed that the total mass of fouling was increased from $0.0088 \mathrm{~kg} / \mathrm{m}^{2}$ to $0.0133 \mathrm{~kg} / \mathrm{m}^{2}$ when the concentration increased from $0.78 \mathrm{~kg} / \mathrm{m}^{3}$ to $1.82 \mathrm{~kg} / \mathrm{m}^{3}$, as expected. On the other hand, increasing the feed concentration lead to decreases in the volumetric permeate flux $\left(V_{s}\right)$ from $0.011 \mathrm{~m}^{3} / \mathrm{m}^{2}$ to 0.007 $\mathrm{m}^{3} / \mathrm{m}^{2}$. A reduced permeate flow through the membrane pores resulting in a lower chance of particle-to-membrane collision and attachment. The depositional attachment probability, $\alpha_{\mathrm{pm}}$, thus decreased from 0.95 to 0.6. Moreover, as Figure 5.21 illustrates, the feed concentration had a significant effect on the cake layer thickness. The cake thickness increased from $4.3 \mu \mathrm{m}$ to $18.5 \mu \mathrm{m}$ when the feed concentration was increased from $0.78 \mathrm{~kg} / \mathrm{m}^{3}$ to $1.82 \mathrm{~kg} / \mathrm{m}^{3}$. Therefore, it can be concluded that the particle-to-particle attachment probability $\left(\alpha_{\mathrm{pp}}\right)$ was the predominant factor responsible for the cake formation, even though the particle-to-membrane attachment $\left(\alpha_{\mathrm{pm}}\right)$ was decreased with the increase in the feed concentration. Figure 5.20 (b) indicates that the total mass of fouling increased from $0.0088 \mathrm{~kg} / \mathrm{m}^{2}$ to $0.0188 \mathrm{~kg} / \mathrm{m}^{2}$ when the concentration wasincreased from $0.78 \mathrm{~kg} / \mathrm{m}^{3}$ to $1.82 \mathrm{~kg} / \mathrm{m}^{3}$, as expected.Consequently, increase in transmembrane pressure over the duration of filtration was elevated from 2 psi to 5 psi to overcome the higher resistance to the permeate flow; hence, the specific power consumption was also almost doubled from $2.8 \mathrm{kWh} / \mathrm{m}^{3}$ to $4.8 \mathrm{kWh} / \mathrm{m}^{3}$. 


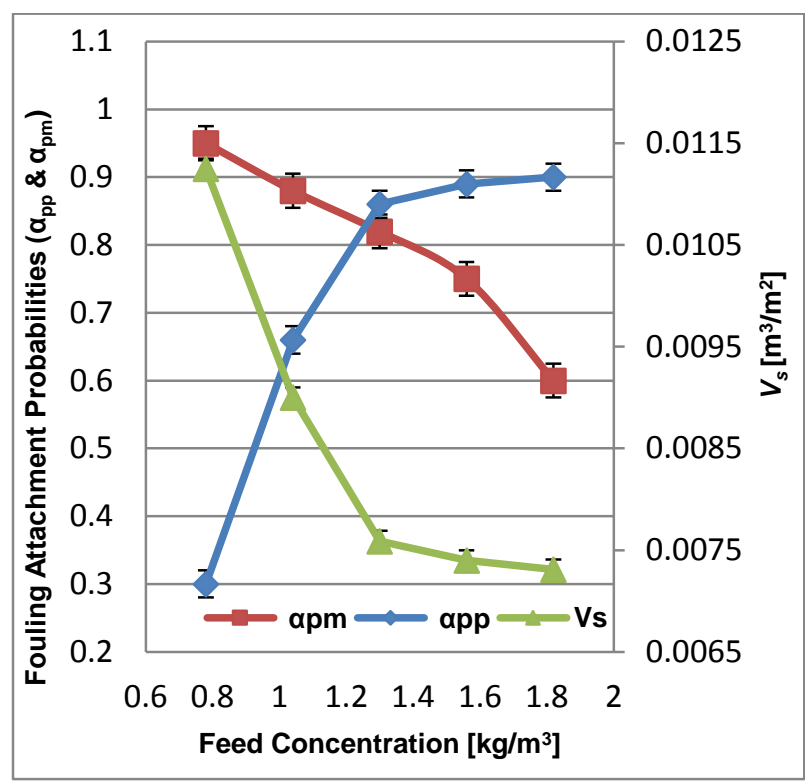

(a)

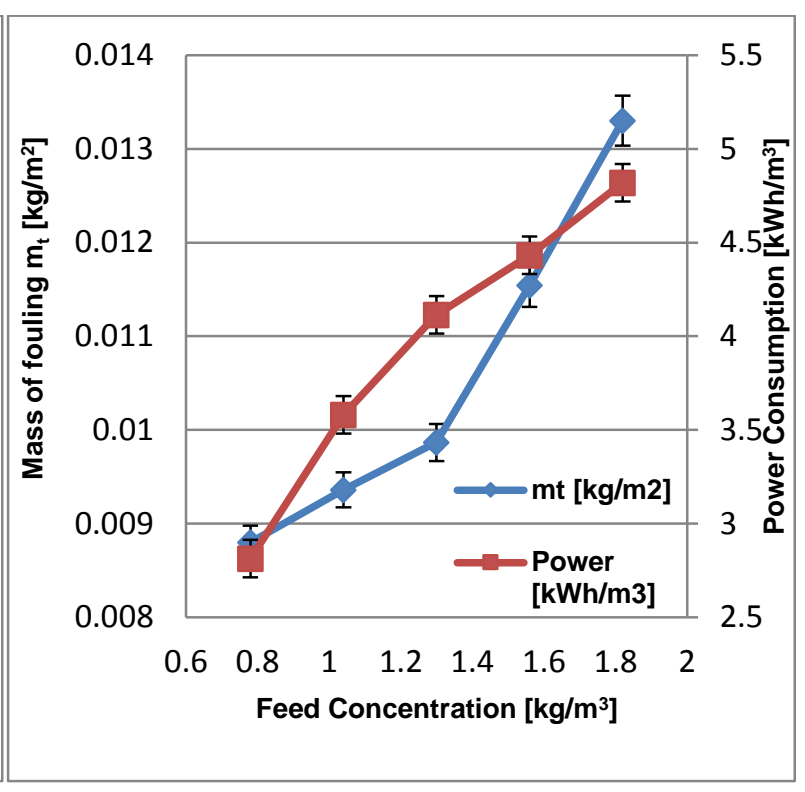

(b)

Figure 5.20: Effect of feed concentration at $[\mathrm{Q}=1 \mathrm{LPM}],[\mathrm{TMP}=15 \mathrm{psi}$, and [pH=7] on (a) Fouling attachment probabilities $\left(\alpha_{\mathrm{pp}}, \alpha_{\mathrm{pm}}\right)$ and the volumetric permeate flux $\left(V_{s}\right)$, (b) Mass of fouling and power consumption

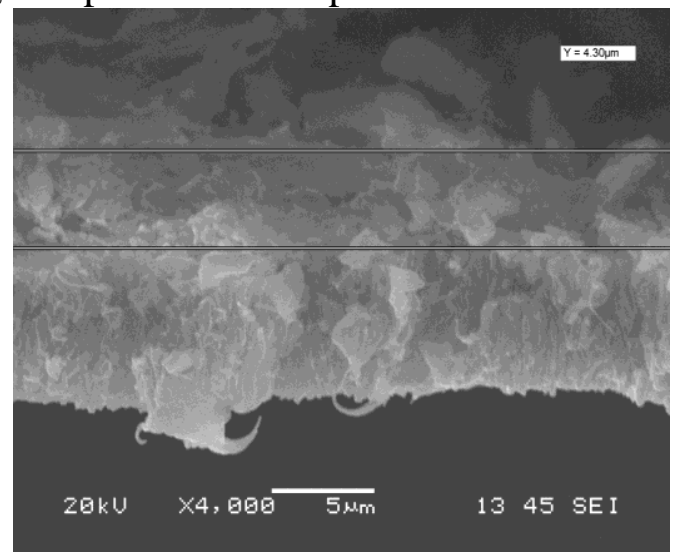

(a)

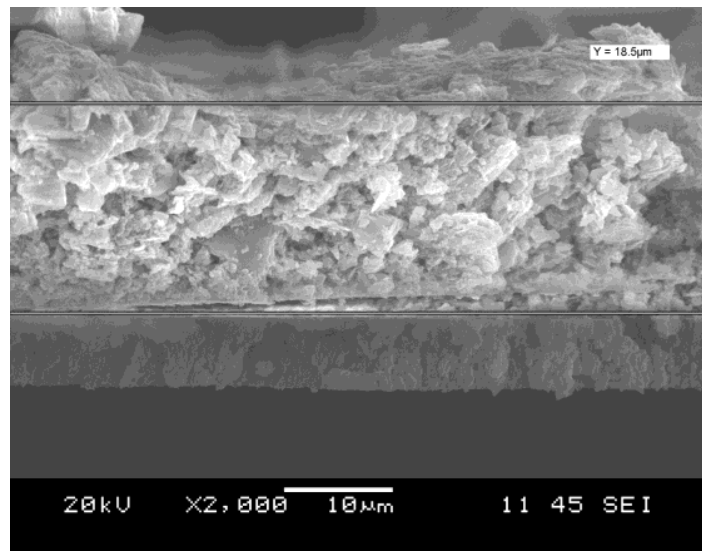

(b)

Figure 5.21: SEM images of membrane after ultrafiltration $[Q=1 \mathrm{LPM}],[\mathrm{P}=15 \mathrm{psi}]$

(a) Cake height $4.3 \mu \mathrm{m}$ at feed concentration $0.78 \mathrm{~kg} / \mathrm{m}^{3}$

(b) Cake height $18.5 \mu \mathrm{m}$ at feed concentration $1.82 \mathrm{~kg} / \mathrm{m}^{3}$

\subsubsection{Using heterogeneous Polysulfone membrane}

\subsubsection{The influence of transmembrane pressure}

At a feed flow rate of $4.0 \mathrm{~L} / \mathrm{min}$ and a feed concentration of $1.3 \mathrm{~kg} / \mathrm{m}^{3}$, the increase of transmembrane pressure from 15 to 45 psi leads to an increase in the particle-to-particle $\left(\alpha_{\mathrm{pp}}\right)$ and the particle-to-membrane $\left(\alpha_{\mathrm{pm}}\right)$ attachment probabilities, from 0.54 to 0.82 and 0.67 to 0.91 , respectively. The resulting higher fouling attachment probabilities, in turn, caused an increase in 
the total mass of fouling from $0.011 \mathrm{~kg} / \mathrm{m}^{2}$ to $0.018 \mathrm{~kg} / \mathrm{m}^{2}$. The fouling attachments and the mass of fouling obtained with heterogeneous Polysulfone membranes were higher than those obtained at a similar transmembrane pressure using the homogenous Polycarbonate membranes with uniform pore size, as illustrated in Section (5.3.1.1). Arguably, particles had a higher chance for particle-to-membrane collision and attachment with Polysulfone heterogeneous membranes due to the presence of multilayers within the membrane. Thus, a higher coagulation attachment can be attributed to the fact that more particles attached to each other in the membrane matrix and trapped deeply within it. Therefore, at the same operating conditions, the total mass of fouling was higher and the permeate flux was lower in the case of heterogeneous Polysulfone membrane, in comparison to the homogenous Polycarbonate membrane. As shown in Figure 5.22 (a), when the pressure was raised from 15 to $30 \mathrm{psi}$, the fouling attachment probability $\left(\alpha_{\mathrm{pp}}\right)$ and depositional attachment probability $\left(\alpha_{\mathrm{pm}}\right)$ increased from 0.54 to 0.8 and from 0.67 to 0.9 , respectively. However, further increase in pressure did not affect $\alpha_{\mathrm{pp}}$ and $\alpha_{\mathrm{pm}}$ significantly. When the transmembrane pressure increased from 15 to $30 \mathrm{psi}$, the volumetric permeate flux and the mass of fouling increased from $0.0089 \mathrm{~m}^{3} / \mathrm{m}^{2}$ to $0.0125 \mathrm{~m}^{3} / \mathrm{m}^{2}$ and from $0.011 \mathrm{~kg} / \mathrm{m}^{2}$ to $0.016 \mathrm{~kg} / \mathrm{m}^{2}$, respectively. Higher permeate flow through the membrane brought more particles to the membrane's surface. Hence, the chances for the particle-to-particle and particle-to-membrane collision and attachment increased, resulting in higher attachment probabilities. Notably, increasing the pressure from 35 to 45 psi resulted in an insignificant change in the volumetric permeate flux $\left(V_{s}\right)$ from $0.01384 \mathrm{~m}^{3} / \mathrm{m}^{2}$ to $0.01386 \mathrm{~m}^{3} / \mathrm{m}^{2}$. Arguably, at the transmembrane pressure of 35 psi (critical pressure at feed flow rate of 4 LPM and feed concentration of 1.3 $\mathrm{kg} / \mathrm{m}^{3}$ ), the concentration polarization might attain a sufficiently high level for the retained solutes at the membrane's surface to reach the gel concentration. Once a gel layer has formed, further increase in the applied pressure does not lead to the increase in the volumetric permeate flux above the one attained at the critical pressure value. As a result, the fouling attachment probability values tend to level off at a relatively constant specific value. It was also observed that the cake layer was compacted at transmembrane pressure of $45 \mathrm{psi}$, as shown in Figure 5.23 (b) , when compared to Figure 5.23 (a) which illustrating the process of ultrafiltration at transmembrane pressure of 35 psi. Notably, this corresponds with the previously demonstrated fact that the transmembrane pressure increase influences the cake and its permeability, porosity, and shape characteristics (Hamachi and Peuchot, 1999). Moreover, Figure 5.22 (a) shows that 
the depositional attachment probability $\alpha_{\mathrm{pm}}$ has higher values than the coagulation attachment probability $\alpha_{\mathrm{pp}}$. This indicates that the transmembrane pressure might have significantly more impact on the pore blocking inside the membrane matrix and the membrane-to-particle attachment than the cake layer build up. A similar observation was made in our previous work with homogenous Polycarbonate membrane. This increase in the total mass of fouling, in turn, caused an increase in the transmembrane pressure through the ultrafiltration process from 3.00 to $6.00 \mathrm{psi}$, and raised the specific power consumption from 1.59 to $3.25 \mathrm{~kW} . \mathrm{h} / \mathrm{m}^{3}$, as presented in Figure 5.22 (b).

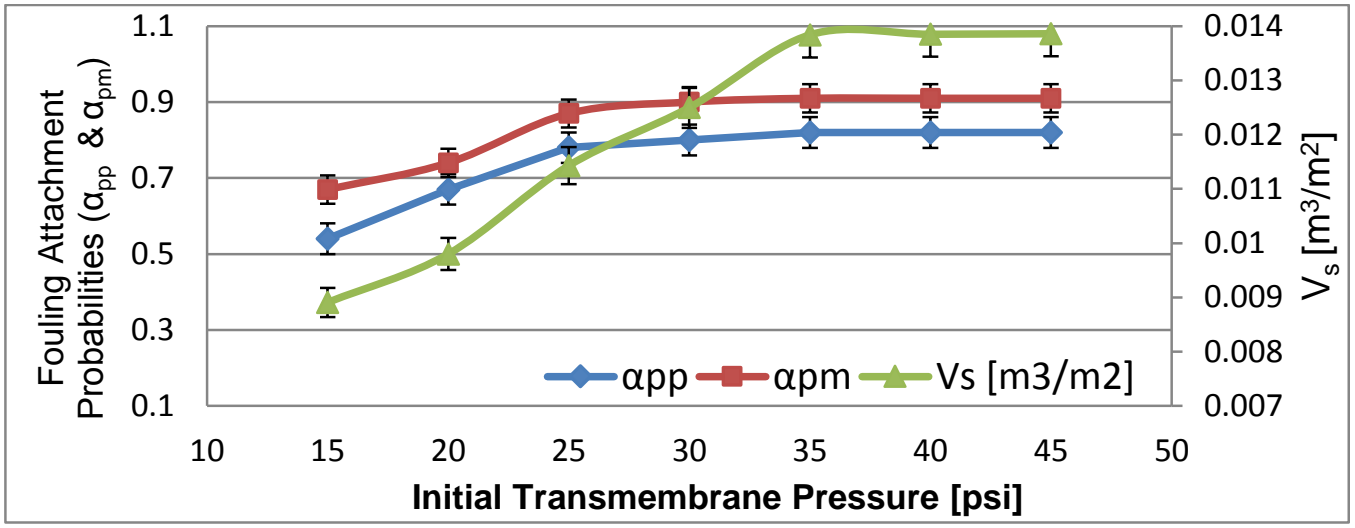

(a)

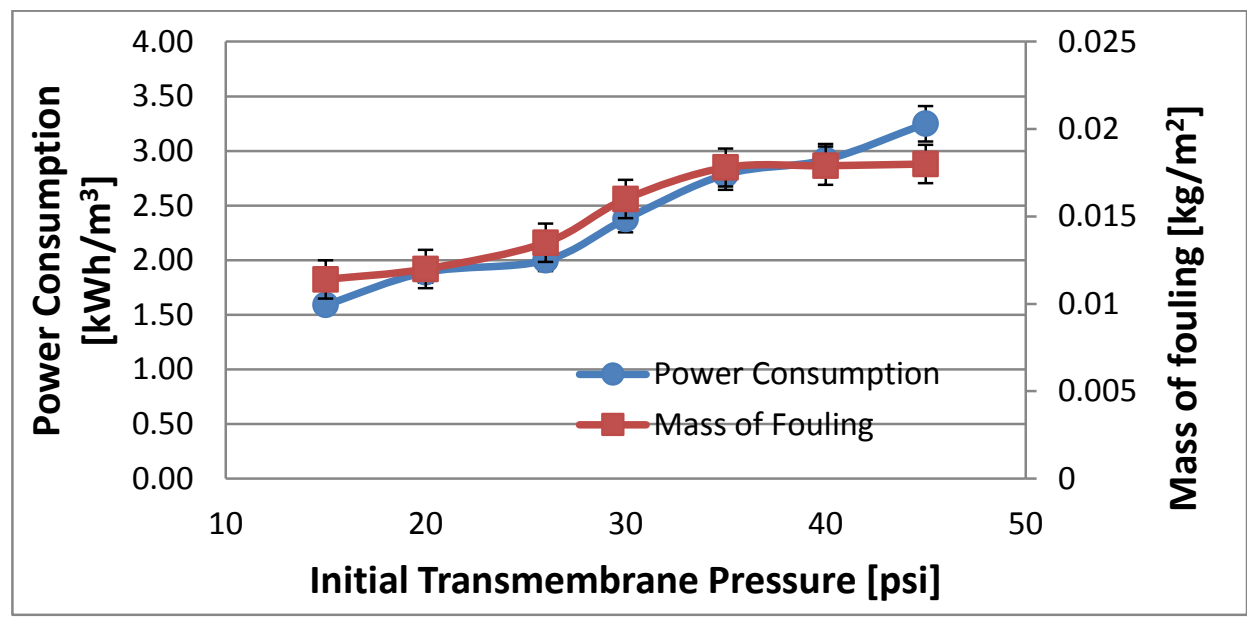

(b)

Figure 5.22: Effect of initial transmembrane pressure at $[Q=4.00 \mathrm{LPM}]$ and $\left[\mathrm{C}_{\mathrm{f}}=1.30\right.$ $\mathrm{kg} / \mathrm{m}^{3}$ ] on (a) fouling attachment probabilities $\left(\alpha_{\mathrm{pp}}, \alpha_{\mathrm{pm}}\right)$ and the volumetric permeate flux ( $V_{s}$ ) (b) the total Mass of fouling and specific power consumption using untreated Polysulfone membranes with surface charge of $\mathbf{- 4 2 . 4 0 ~} \mathbf{m V}$ 


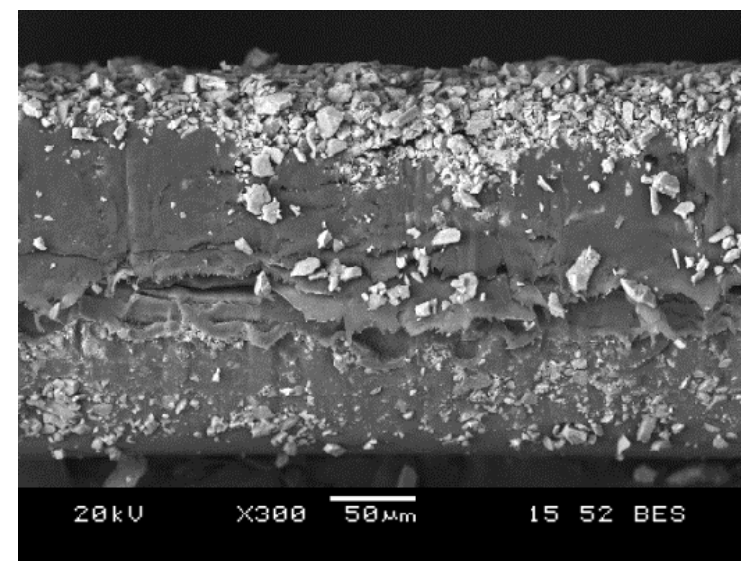

(a)

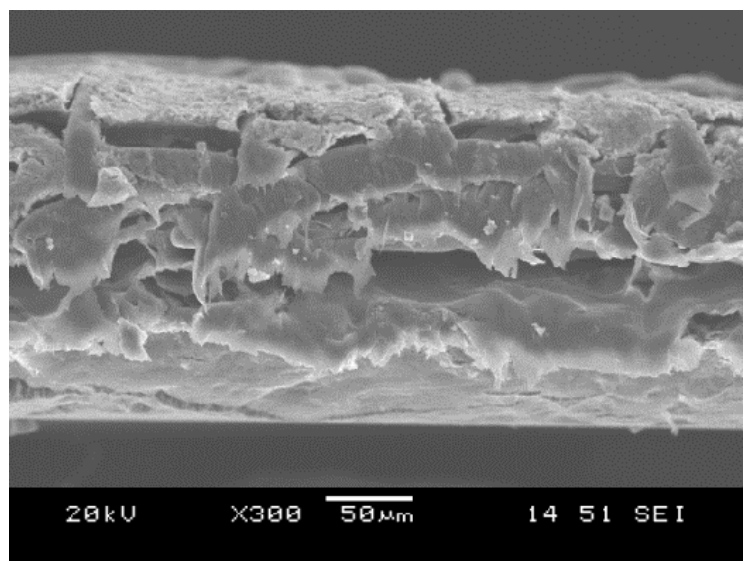

(b)

Figure 5.23: SEM images of Polysulfone membrane after ultrafiltration at the feed flow rate of $4 \mathrm{LPM}$, and feed concentration of $1.3 \mathrm{~kg} / \mathrm{m}^{3}$ at (a) transmembrane pressure of 35 psi; (b) transmembrane of 45 psi

\subsubsection{The influence of feed flow rate}

Figure 5.24 depicts the effect of the feed flow rate on the fouling attachment probability, cumulative permeate flux, the total mass of fouling and the specific power consumption at $25 \mathrm{psi}$ and feed concentration of $1.3 \mathrm{~kg} / \mathrm{m}^{3}$. A substantial decrease in particle-to-particle $\left(\alpha_{\mathrm{pp}}\right)$ and particle-to-membrane $\left(\alpha_{\mathrm{pm}}\right)$ attachments with increasing the flow rate was expected due to the higher shear rate to wash away the particles, as in the case of the homogenous Polycarbonate membrane discussed in Section 5.3.1.2. However, the results obtained in the present study show otherwise the increase of the feed flow rate caused a slight reduction in the particle-to-particle attachment $\left(\alpha_{\mathrm{pp}}\right)$ from 0.83 at 1 LPM (cross flow velocity of $10.4 \mathrm{~cm} / \mathrm{s}$ ) to 0.7 at 7 LPM (cross flow velocity of $72.8 \mathrm{~cm} / \mathrm{s}$ ). This may be attributed to the structure of Polysulfone membrane, specifically, even at the highest flow rate of 7 LPM used in this study; the particles were still attaching to each other and contributing to the multiple cake layers inside the matrix of the membrane, as shown in Figure 5.25 (a) and Figure 5.25 (b). Figure 5.26 provides evidence of the manner in which the nature of the heterogeneous membranes allowed the foulants to be deposited inside the membrane's layers.

Furthermore, higher thransmembrane pressure of 25 psi caused insignificant decrease of fouling attachments with heterogeneous Polysulfone membrane, when compared to the results obtained with a polycarbonate membrane at transmembrane of 15 psi (Section 5.3.1.2). On the other hand, at higher flow rate, the cumulative permeate flux $\left(V_{s}\right)$ increased from 0.006 to 0.014 $\mathrm{m}^{3} / \mathrm{m}^{2}$. As a result, more particles came into contact with membrane, leading to an increase in 
collisions and attachments between particles and the membrane's surface. Accordingly the particle-to-membrane attachment probability $\left(\alpha_{\mathrm{pm}}\right)$ decreased only from 0.9 to 0.82 at $1 \mathrm{LPM}$ and 7 LPM, respectively. It was observed that as the fouling attachment probabilities decreased, the mass of particles retained by the membrane dropped from $0.0195 \mathrm{~kg} / \mathrm{m}^{2}$ at a feed low rate of 1 LPM to $0.0088 \mathrm{~kg} / \mathrm{m}^{2}$ at $7 \mathrm{LPM}$, as shown in Figure 5.24 (b). The decrease in the total mass of fouling resulted in a smaller increase in the transmembrane pressure through the ultrafiltration duration from 7.00 to 2.00 psi. However, the power consumption per unit volume was raised from 0.85 to $3.33 \mathrm{~kW} . \mathrm{h} / \mathrm{m}^{3}$ as illustrated in Figure 5.24 (b). This trend agrees with Equation (4.3) where the specific power consumption is directly proportional to the feed flow rate. It is worth noting that in the case of the Polysulfone membranes it is difficult to measure the cake height accurately, due to its heterogeneous multilayered surface, as demonstrated in Figures 5.25 (b) and 5.25 (c). Figures 5.25 (a) and 5.25 (b) demonstrates that the higher shear force at 7 LPM washed away most of the particles located on the top surface while other particles were still retained deeply inside the membrane's matrix.

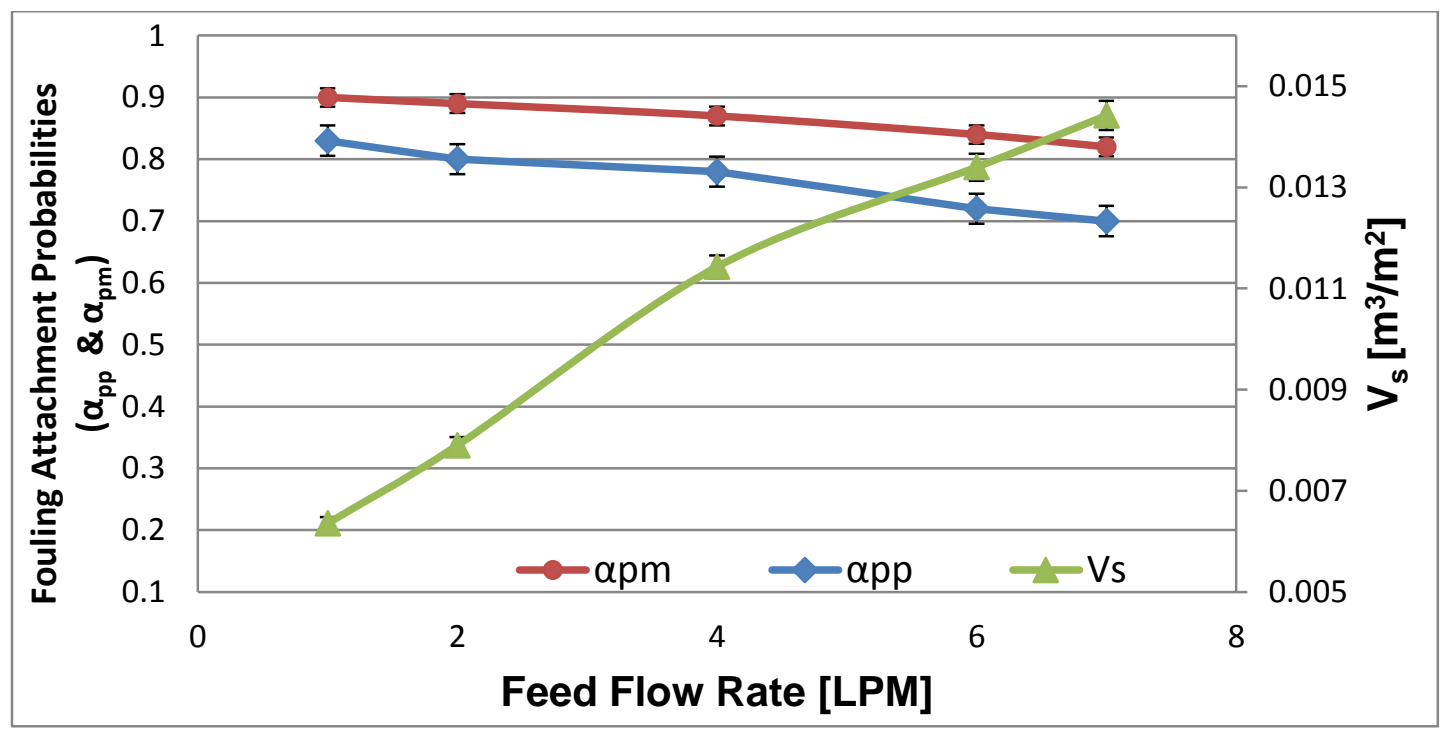

(a) 


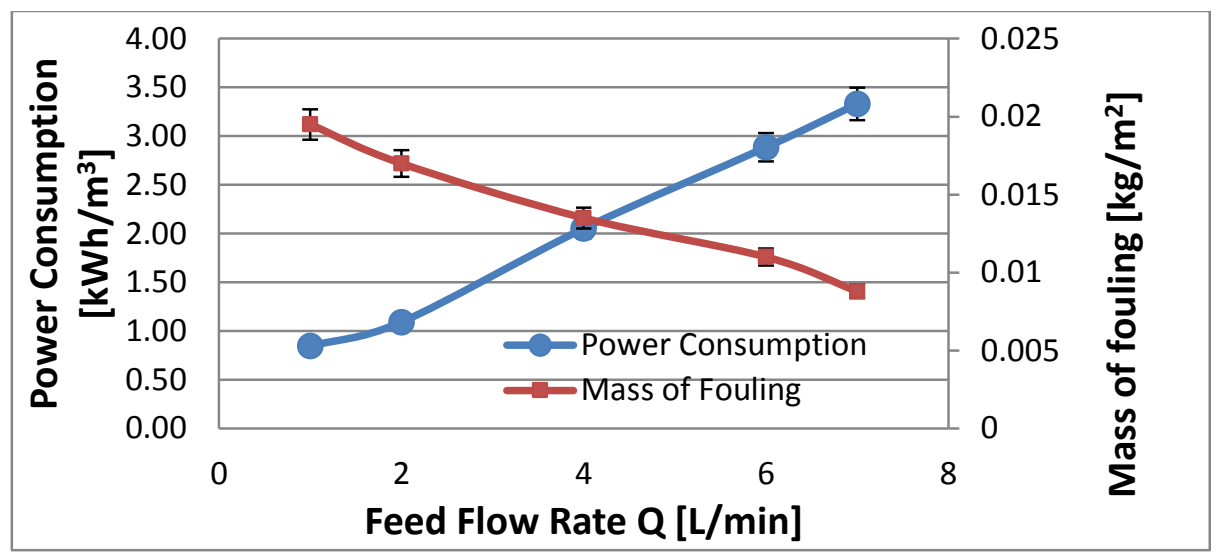

(b)

Figure 5.24: Effect of feed flow rate at $[T M P=25.00 \mathrm{psi}]$, and $\left[\mathrm{C}_{\mathrm{f}}=1.30 \mathrm{~kg} / \mathrm{m}^{3}\right]$ on (a) fouling attachment probabilities $\left(\alpha_{\mathrm{pp}}, \alpha_{\mathrm{pm}}\right)$ and the volumetric permeate flux $\left(V_{s}\right)$; (b) the total Mass of fouling and power consumption using untreated Polysulfone membranes with surface charge of $\mathbf{- 4 2 . 4 0 ~} \mathbf{m V}$

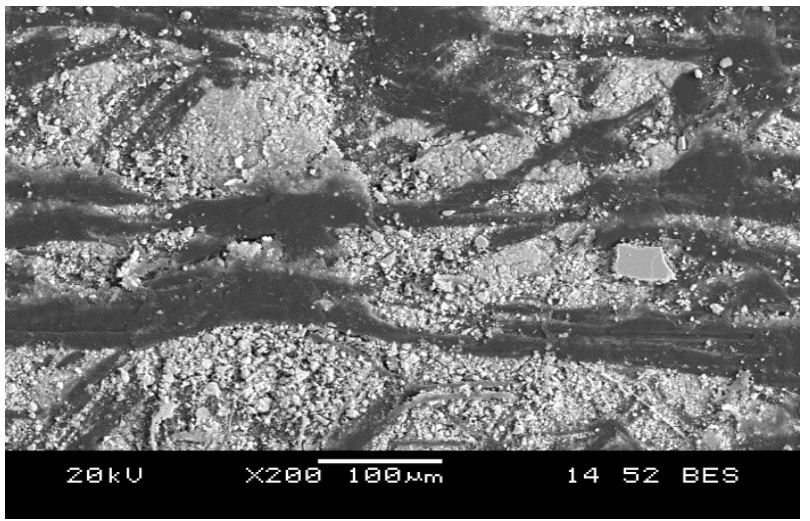

(a)

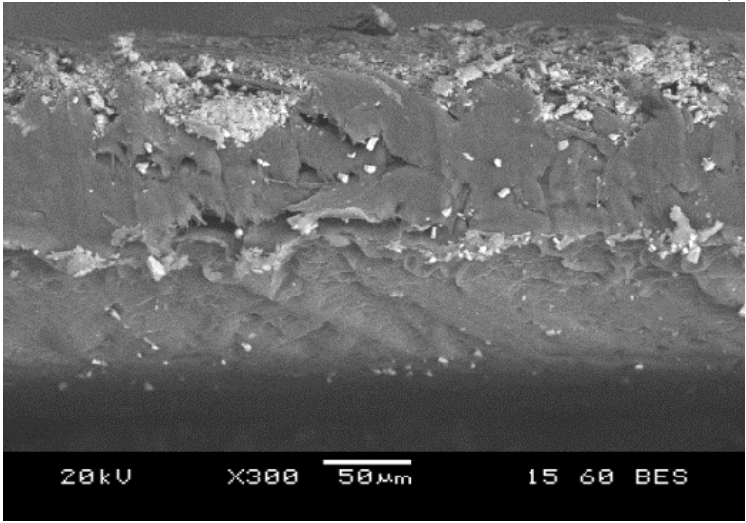

(b)

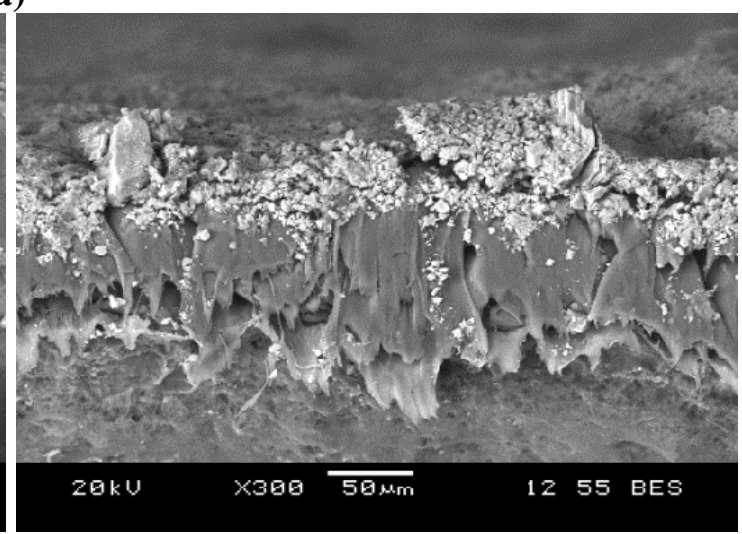

(c)

Figure 5.25: SEM images of Polysulfone membrane after ultrafiltration at transmembrane pressure of $25 \mathrm{psi}$, and feed concentration of $1.3 \mathrm{~kg} / \mathrm{m}^{3}$ (a) Membrane surface at feed flow rate of 7

LPM, (b) Cake layer at feed flow rate of 7 LPM, and (c) Cake layer at feed flow rate of 1 LPM 


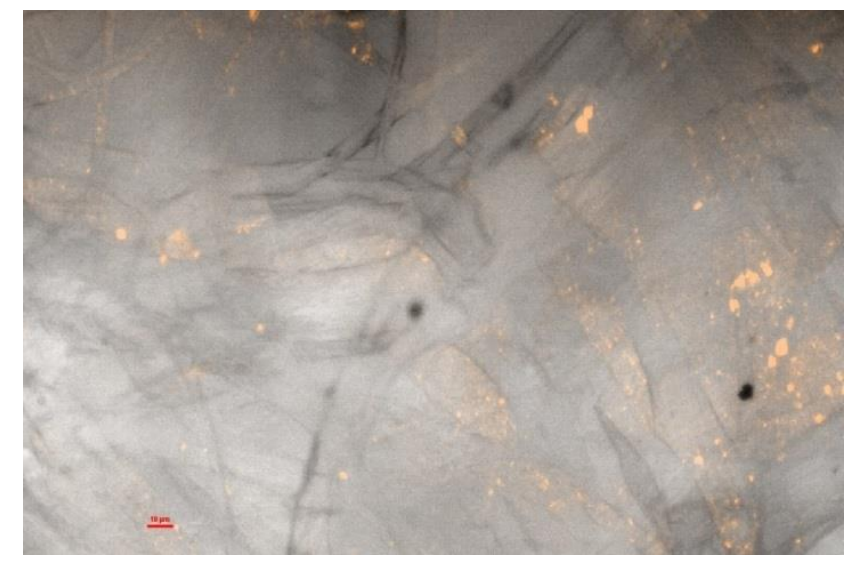

Figure 5.26: Confocal laser microscope image of deposited particles inside the Polysulfone membrane layers after ultrafiltration process using fluospheres carboxylate latex beads

\subsubsection{The influence of feed concentration}

The effects of feed concentration on the fouling attachment probabilities and the permeate flux with a Polysulfone heterogeneous membrane at a feed flow rate of $4 \mathrm{~L} / \mathrm{min}$ and a transmembrane pressure of 25 psi were presented in Figure 5.27 (a). Increasing the feed concentration from $0.78 \mathrm{~kg} / \mathrm{m}^{3}$ to $1.82 \mathrm{~kg} / \mathrm{m}^{3}$ led to a significant increase in the coagulation attachment probability, $\alpha_{\mathrm{pp}}$, from 0.34 to 0.81 and a slight increase in the depositional attachment probability, $\alpha_{\mathrm{pm}}$, from 0.83 to 0.89 . Increasing the feed concentration resulted in a higher chance of particle-to-particle collision and the coagulation attachment probability and cake layer build up were enhanced. It was also observed that the total mass of fouling increased from $0.011 \mathrm{~kg} / \mathrm{m}^{2}$ to $0.017 \mathrm{~kg} / \mathrm{m}^{2}$ when the concentration was increased from $0.78 \mathrm{~kg} / \mathrm{m}^{3}$ to $1.82 \mathrm{~kg} / \mathrm{m}^{3}$, as anticipated. As shown in Figure 5.27 (a), particle-to-particle attachment values leveled off to a relatively constant value at the concentration of $1.3 \mathrm{~kg} / \mathrm{m}^{3}$. At this concentration, a significant amount of particles might have been present to facilitate the maximum possible particle collision and attachment. On the other hand, increasing the feed concentration led to a decreases in the volumetric permeate flux $\left(V_{s}\right)$ from $0.0142 \mathrm{~m}^{3} / \mathrm{m}^{2}$ to $0.00924 \mathrm{~m}^{3} / \mathrm{m}^{2}$. A reduced permeate flow through the membrane pores would decrease particle-to-membrane collision and attachment hence, the depositional attachment probability, $\alpha_{\mathrm{pm}}$, would decrease as observed with homogeneous Polycarbonate membranes as reported in Section 5.3.1.3. Nevertheless, the opposite trend was observed with the Polysulfone membrane used in the present study. This could be attributed to the structure of the Polysulfone membrane which allows the particles to settle inside the membrane matrix and thus facilitated more particle-to-membrane attachments 
with increases in solid concentration. The increase of transmembrane pressure over the duration of the filtration process was also raised from 3.00 to 7.00 psi. As a consequence, the specific power consumption increased from $1.50 \mathrm{~kW} \cdot \mathrm{h} / \mathrm{m}^{3}$ to $8.00 \mathrm{~kW} . \mathrm{h} / \mathrm{m}^{3}$, as depicted at Figure 5.27 (b). Notably, increasing the feed concentration from $1.30 \mathrm{~kg} / \mathrm{m}^{3}$ to $1.82 \mathrm{~kg} / \mathrm{m}^{3}$ led a noticeable decrease in the volumetric permeate flux $\left(V_{s}\right)$ from $0.0114 \mathrm{~m}^{3} / \mathrm{m}^{2}$ to $0.00924 \mathrm{~m}^{3} / \mathrm{m}^{2}$. Consequently, a more significant increase in the power consumption occurred at the concentrations above $1.30 \mathrm{~kg} / \mathrm{m}^{3}$, as shown in Figure 5.27 (b).

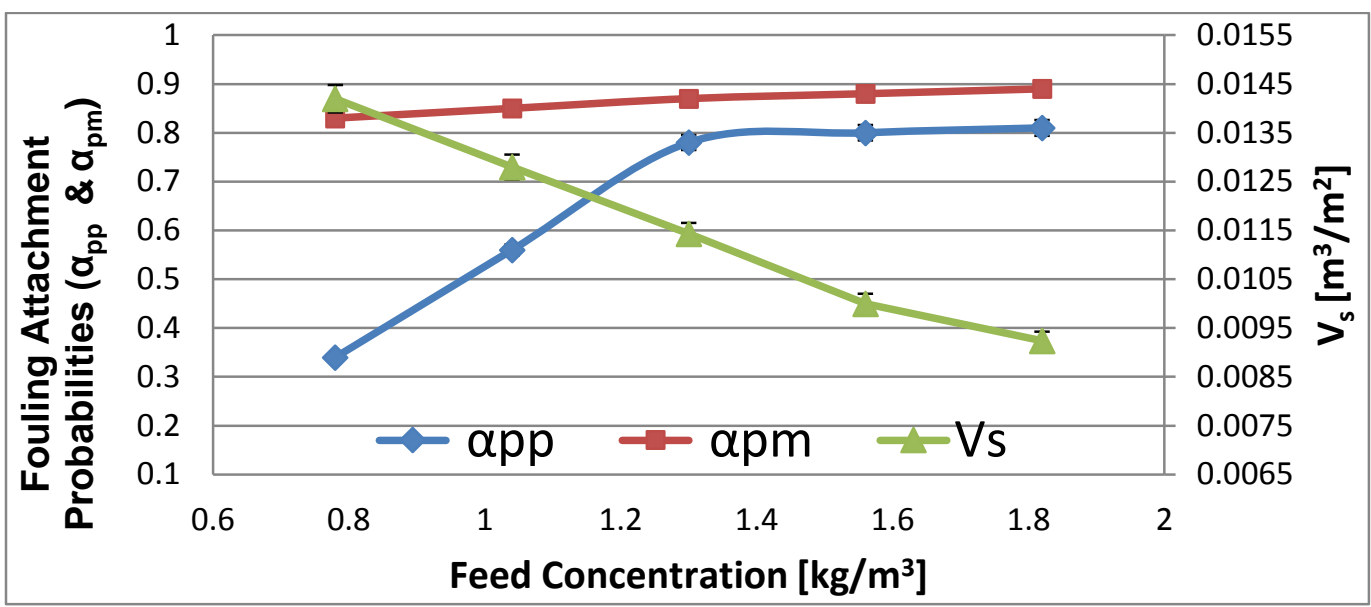

(a)

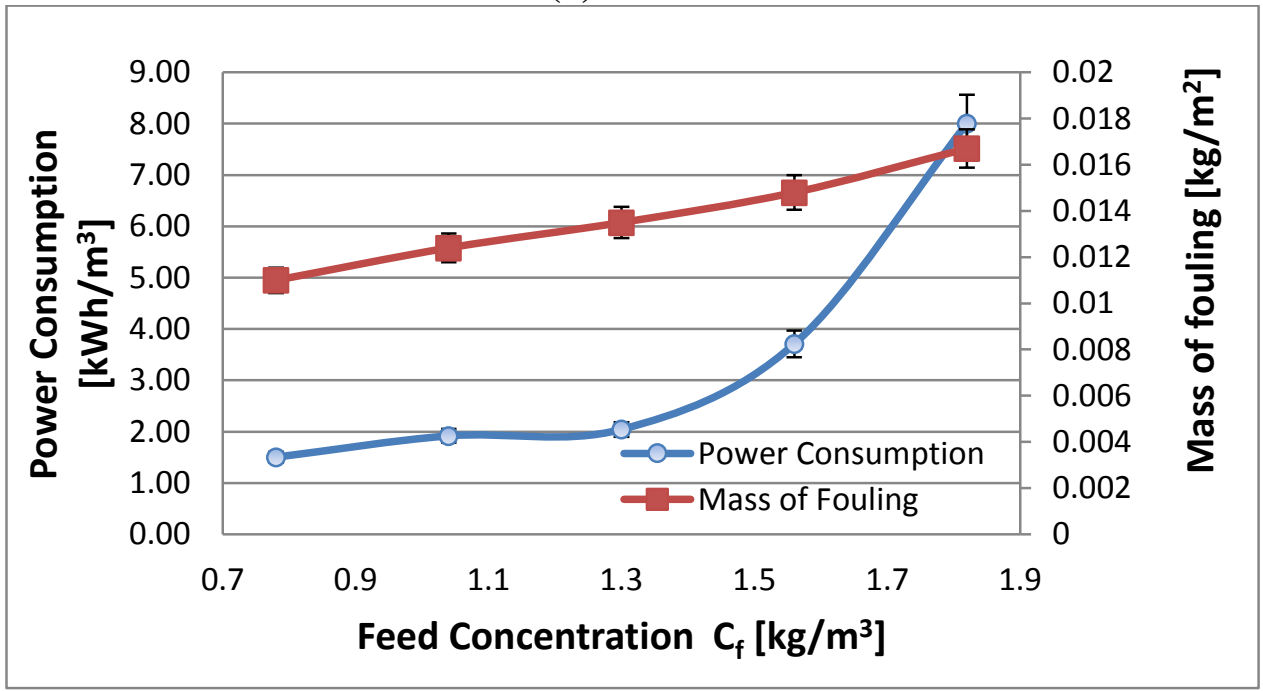

(b)

Figure 5.27 : Effect of feed concentration at $[Q=4.00 \mathrm{LPM}]$ and $[\mathrm{TMP}=25.00 \mathrm{psi}]$ on (a) on the fouling attachment probabilities $\left(\alpha_{\mathrm{pp}}, \alpha_{\mathrm{pm}}\right)$ and the volumetric permeate flux ( $\left.V_{s}\right)($ b) the total mass of fouling and the power consumption using untreated Polysulfone membranes with surface charge of $\mathbf{- 4 2 . 4 0 ~} \mathbf{m V}$

Figure 5.28 illustrates the membrane surface after the ultrafiltration of latex solutions at different feed concentrations, while maintaining all other operating conditions at the same 
conditions (25 psi transmembrane pressure, 4 LPM feed flow rate, and 25 minutes). Figure 5.28 (a), (c), (e) represents SEM image of the membrane surface after the ultrafiltration at feed concentrations of $0.78,1.3$, and $1.82 \mathrm{~kg} / \mathrm{m}^{3}$, respectively. As shown in Figure 5.28 (a), at a low concentration some of the particles attached to the membrane pores due to the depositional attachment $\left(\alpha_{\mathrm{pm}}\right)$, some of the particles aggregated due to the coagulation attachment $\left(\alpha_{\mathrm{pp}}\right)$, and some pores remained clean due to the smaller particles passing through these pores unrestricted. As a result, the presence of clean pores at low feed concentration leads to a higher volumetric permeate flux of $0.0142 \mathrm{~m}^{3} / \mathrm{m}^{2}$, compared with $0.00924 \mathrm{~m}^{3} / \mathrm{m}^{2}$ at $1.82 \mathrm{~kg} / \mathrm{m}^{3}$. Arguably, at this concentration the particles attached to the membrane pores and settled inside the membrane matrix do not in fact contribute in the cake layer formation, as shown in Figure 5.28 (b). Increasing the feed concentration, from $0.78 \mathrm{~kg} / \mathrm{m}^{3}$ to $1.3 \mathrm{~kg} / \mathrm{m}^{3}$, results in a considerable augmentation in the mass of particles contributing to the pore blocking, represented in Figure 5.28 (d). A further increase in the feed concentration, causes an even higher occurrence of the particle-to-particle collision and attachment. As a consequence, the coagulation attachment probability and cake layer build-up are enhanced. For instance, at a feed concentration of 1.82 $\mathrm{kg} / \mathrm{m}^{3}$, the particle-to-particle attachment $\left(\alpha_{\mathrm{pp}}\right)$ increased to 0.8 , and hence, the resulting mass of particles contributing to the cake formation $\left(m_{c}\right)$ increased to $0.101 \mathrm{~g}$. Consequently, the cake height increased, as illustrated in Figure 5.28 (f), if compared to the cake height in Figure 5.28 (d). It was also observed that the total mass of fouling was increased from $0.011 \mathrm{~kg} / \mathrm{m}^{2}$ to 0.017 $\mathrm{kg} / \mathrm{m}^{2}$ when the concentration increased from $0.78 \mathrm{~kg} / \mathrm{m}^{3}$ to $1.82 \mathrm{~kg} / \mathrm{m}^{3}$, in accordance with the estimation. Figure 5.28 shows that the mass of fouling contributing to the pore blocking is much higher than the mass of fouling contributing to the cake layer. The cause for this resides in the polysulfone membranes characterized by multi layers of tissues with non-uniform pore size distribution. 


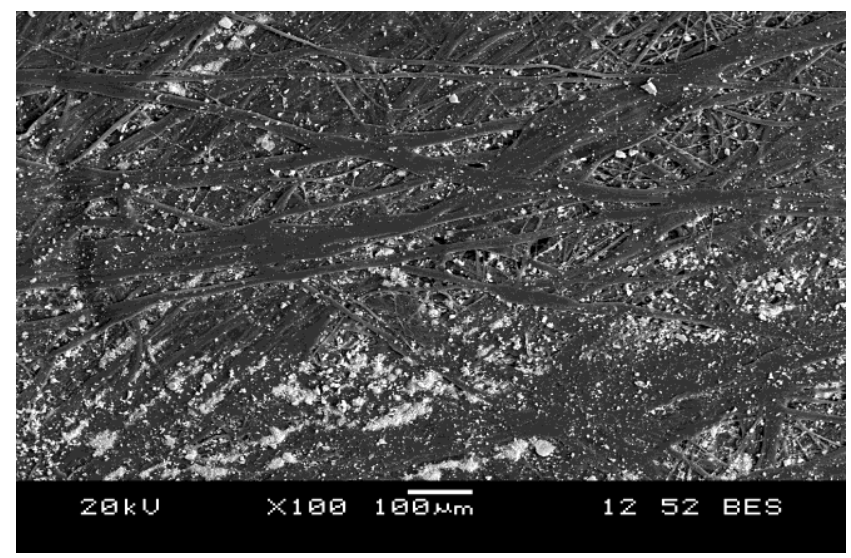

(a)

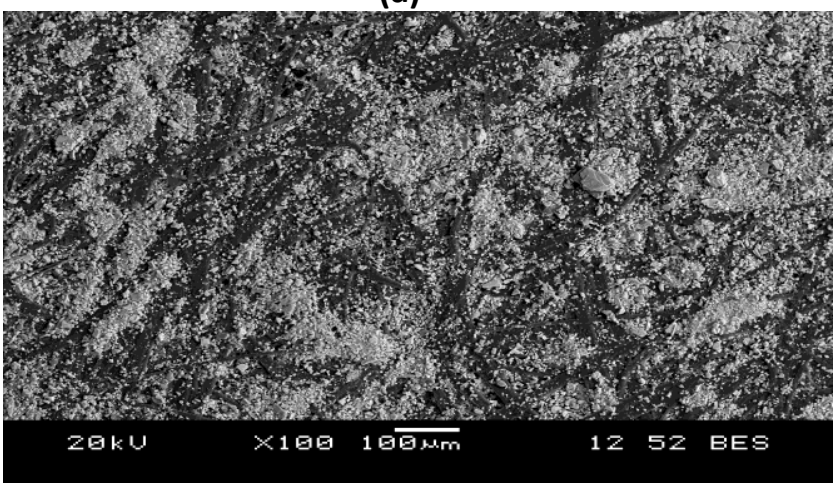

(c)

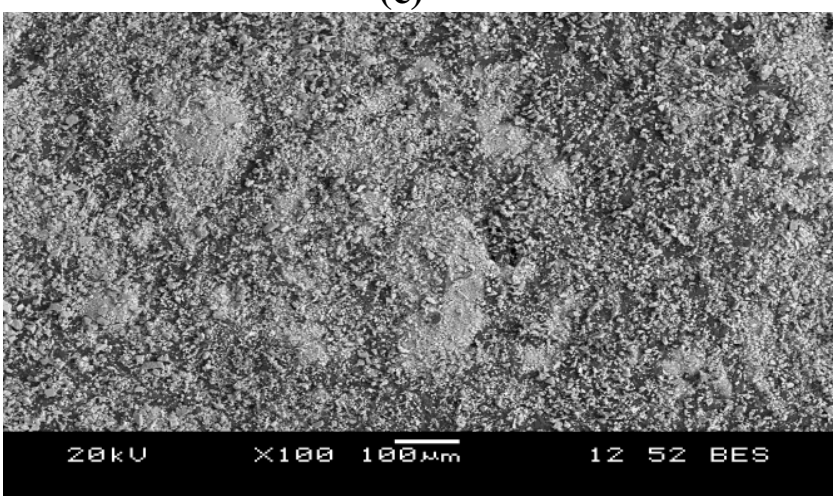

(e)

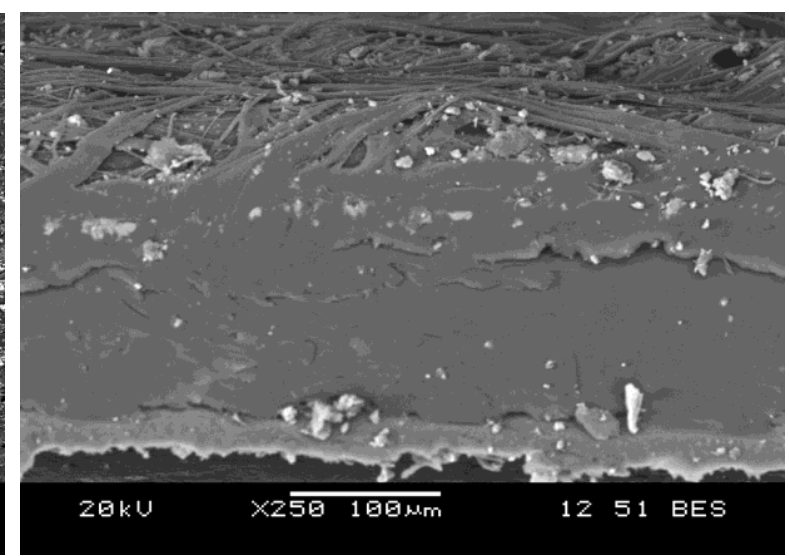

(b)

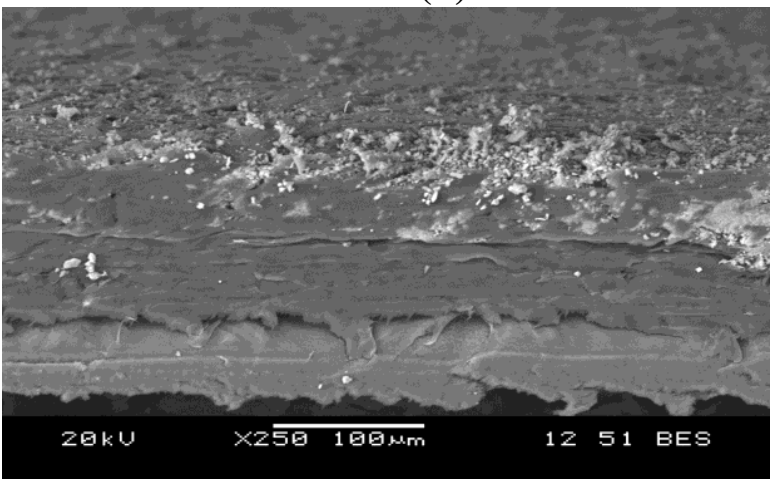

(d)

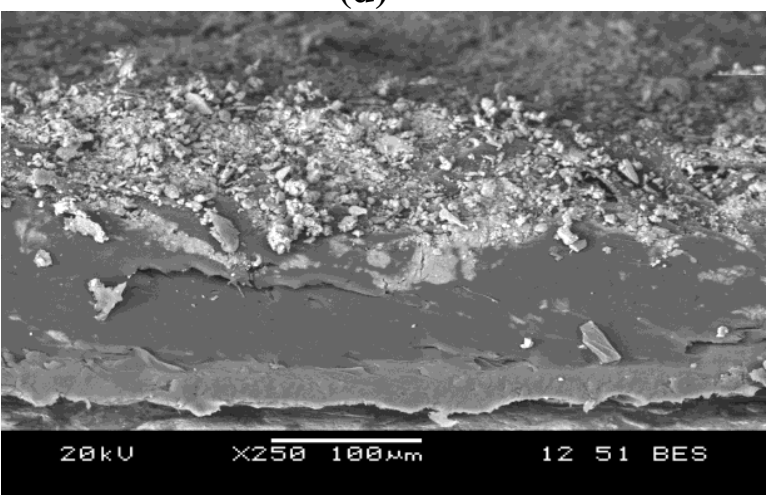

(f)

Figure 5.28: SEM images of the membrane after ultrafiltration at $[Q=4 \mathrm{LPM}],[\mathrm{P}=25 \mathrm{psi}]$ : (a) Membrane surface at feed concentration $0.78 \mathrm{~kg} / \mathrm{m}^{3}$; (b) Side view of the cake height at feed concentration $0.78 \mathrm{~kg} / \mathrm{m}^{3}$; (c) Membrane surface at feed concentration $1.3 \mathrm{~kg} / \mathrm{m}^{3}$; (d) Side view of the cake height at feed concentration $1.3 \mathrm{~kg} / \mathrm{m}^{3}$; (e) Membrane surface at feed concentration $1.82 \mathrm{~kg} / \mathrm{m}^{3}$; (f) Side view of the cake height at feed concentration $1.82 \mathrm{~kg} / \mathrm{m}^{3}$

\subsection{Effect of membrane pore size distribution on the ultrafiltration performance}

The collected water from the permeate had an average turbidity of 125 NTU for the ultrafiltration of latex solution with a poylsufone membrane including a wide range of pore size distribution, which results in the small particles (less than the pore size) to pass through the 
pores. The particle size distribution of the permeate was measured in order to evaluate the ultrafiltration performance using heterogeneous membranes. It was determined that the latex particles up to the range of $7.58 \mu \mathrm{m}$ could pass through the membrane during the filtration process. This was caused by the presence of different pore sizes up to $8.782 \mu \mathrm{m}$, as presented in Figure 4.10. Figure 5.29 depicts the particle size distribution of the permeate after the ultrafiltration of latex solution, at the feed concentration of $1.3 \mathrm{~kg} / \mathrm{m}^{3}$ and the feed flow rate of 4 LPM at various levels of transmembrane pressure. The particle size distribution of the latex in the permeate showed a higher percentage of particles at the transmembrane pressure of $35 \mathrm{psi}$, if compared to the percentage of particles present in the permeate at the transmembrane pressure of 15 psi. This can be attributed to the fact that the higher transmembrane pressure forced the smaller particles to go through the membrane pores.

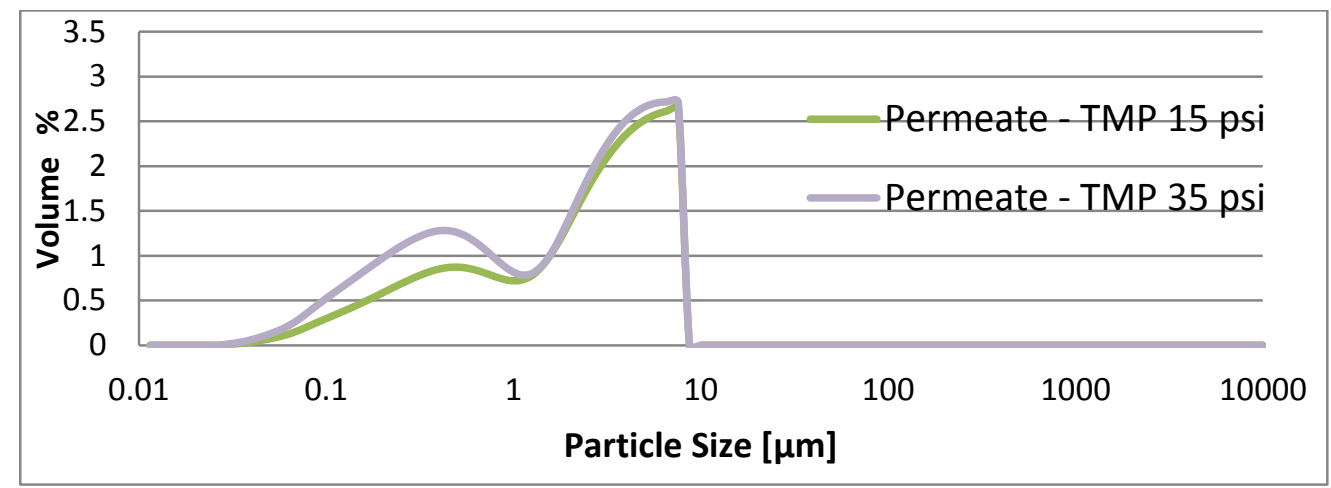

Figure 5.29: Particle Size distribution of the permeate after the ultrafiltration of latex solution $\left[C_{f}=1.3 \mathrm{~kg} / \mathrm{m3}\right.$, and $\left.Q=4 \mathrm{LPM}\right]$ at different transmembrane pressure.

The cellulose acetate membrane with a MWCO of 20,000 demonstrates a high performance ultrafiltration process, which results in a clear water with turbidity of zero. The reason is $80 \%$ of the pore size distribution of cellulose acetate membrane is 0.01 microns. Arguably, all heterogeneous membranes with small MWCO values, such as the one present in the cellulose acetate membranes, would show similar performance of the ultrafiltration process as the homogenous polycarbonate membranes of homogenous pore size at different operating conditions. On the other hand, the performance of the ultrafiltration process using ultrafilic and PVDF membranes with MWCO of 100,000 depends on the membrane pressure used. At a transmembrane pressure of $15 \mathrm{psi}$, the ultrafiltration process showed the highest performance quality using the ultrafilic and PVDF membranes. However, at a higher transmembrane pressure of 25 and 35psi, the water collected from the permeate using the ultrafilic membrane had an 
average turbidity of 90 and 191 NTU, respectively. Meanwhile, the turbidity of the permeate using the PVDF was 125 and 184 NTU at a transmembrane pressure of 25 and 35 psi, respectively. These membranes included a wide range of pore size distribution, which resulted in the small particles (less than the pore size) passing unrestricted through the pores. The particle size distribution of the permeate was measured in order to accurately evaluate the ultrafiltration performance using the non-uniform pore size membranes with MWCO of 100,000 . It was determined that the latex particles, up to the range of 15.13 and $17.37 \mu \mathrm{m}$, could in fact pass through the membrane during the filtration process implementing the ultrafilic and PVDF membranes, with the respective ranges. This was caused by the presence of different pore sizes, up to the range of 15.49 and $18.425 \mu \mathrm{m}$, in the ultrafilic and PVDF membranes respectively. Figure 5.30 depicts the particle size distribution of the permeate after the ultrafiltration of the latex solution using both of these membranes, at the feed concentration of $1.3 \mathrm{~kg} / \mathrm{m}^{3}$, and the feed flow rate of 4 LPM at different transmembrane pressure levels. The particle size distribution of the latex in the permeate showed a higher percentage of particles present in the permeate at the transmembrane pressure of $35 \mathrm{psi}$, in comparison to the percentage of particles at the transmembrane pressure of 25 psi. Admittedly, this could be attributed to the fact that the higher transmembrane pressure forced the smaller particles to pass through the membrane's pores unobstructed.

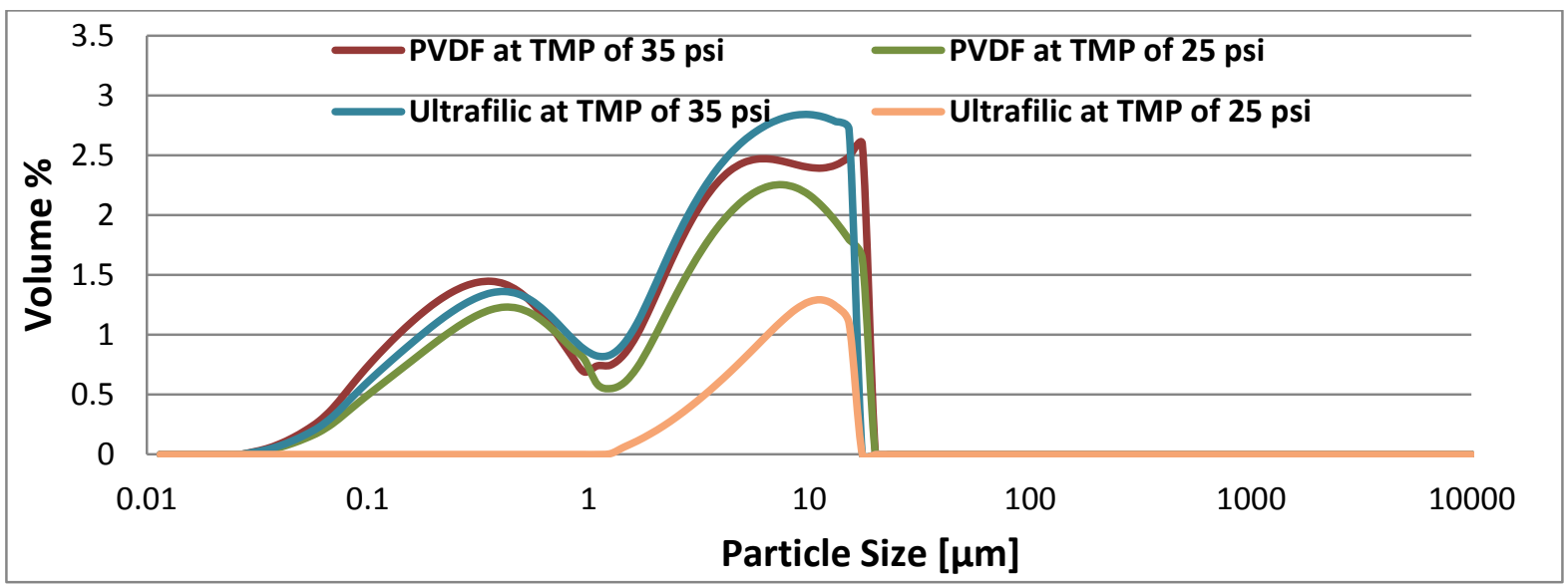

Figure 5.30: Particle Size distribution of the permeate after the ultrafiltration of latex solution $\left[C_{f}=1.3 \mathrm{~kg} / \mathrm{m3}\right.$, and $\left.Q=4 \mathrm{LPM}\right]$ at different transmembrane pressures. 


\subsection{Effect of the zeta potential of membrane surface on membrane fouling}

The effect of the zeta potential of the membrane surface on fouling attachments, the total mass of fouling, permeate flux, and specific power concerns was investigated. Under the operating conditions of $25 \mathrm{psi}, 4.5 \mathrm{LPM}, 1.3 \mathrm{~kg} / \mathrm{m}^{3}$, and after increasing the zeta potential of the membrane surface, the surface charge became increasingly negative, from -10.00 to $-50.00 \mathrm{mV}$ (5 times), resulted in reduction of depositional attachment $\left(\alpha_{\mathrm{pm}}\right)$ by $65 \%$, from 0.99 to 0.35 , as shown in Figure 5.31 (a). This could be attributed to the increased hydrophilicity of the membrane, which was created upon introducing more negative charges on the membrane surface; hence, the electrostatic attraction force between the latex particles and the membrane surface was significantly decreased. The zeta potential of latex particles at $\mathrm{pH}$ of 7 is approximately $-26.61 \mathrm{mV}$. The particle-to-membrane attachment was thus significantly reduced because the repulsion forces between latex particles and the higher negativity membrane surface increased. On the other hand, increasing the zeta potential negativity of the membrane surface 5 times resulted in an insignificant decrease of the coagulation attachment $\left(\alpha_{\mathrm{pp}}\right)$ by $5.3 \%$ from 0.75 to 0.71 , as shown in Figure 5.31 (a). The decrease in the depositional attachment $\left(\alpha_{\mathrm{pm}}\right)$ caused a significant increase in the cumulative filtration volume per unit area from 0.015 to $0.123 \mathrm{~m}^{3} / \mathrm{m}^{2}$, an augmentation of about10 times, as shown in Figure 5.31 (b). This could be attributed to the significant reduction in the depositional attachment that resulted in less particle attachment to the membrane pores, i.e. less pore blockage to the filtrate passage through the membrane. Moreover, as a consequence of the depositional attachment reduction, the total mass of fouling diminished by $61 \%$, from 0.018 to $0.007 \mathrm{~kg} / \mathrm{m}^{2}$, as illustrated in Figure 5.31 (c). Decreasing the total mass of fouling resulted in a lower rate of the transmembrane pressure increase during the filtration process. Accordingly, the specific power consumption was noticeably decreased by $92.5 \%$, from 24.83 to $1.86 \mathrm{~kW} . \mathrm{h} / \mathrm{m} 3$, as presented in Figure 5.31 (d). From these observations a conclusion can be drawn that the depositional attachment is the predominant factor in membrane fouling. In addition, altering the particle-to-membrane attachment $\left(\alpha_{\mathrm{pm}}\right)$ by manipulating the zeta potential of the membrane surface could be an essential process in fouling remediation. 


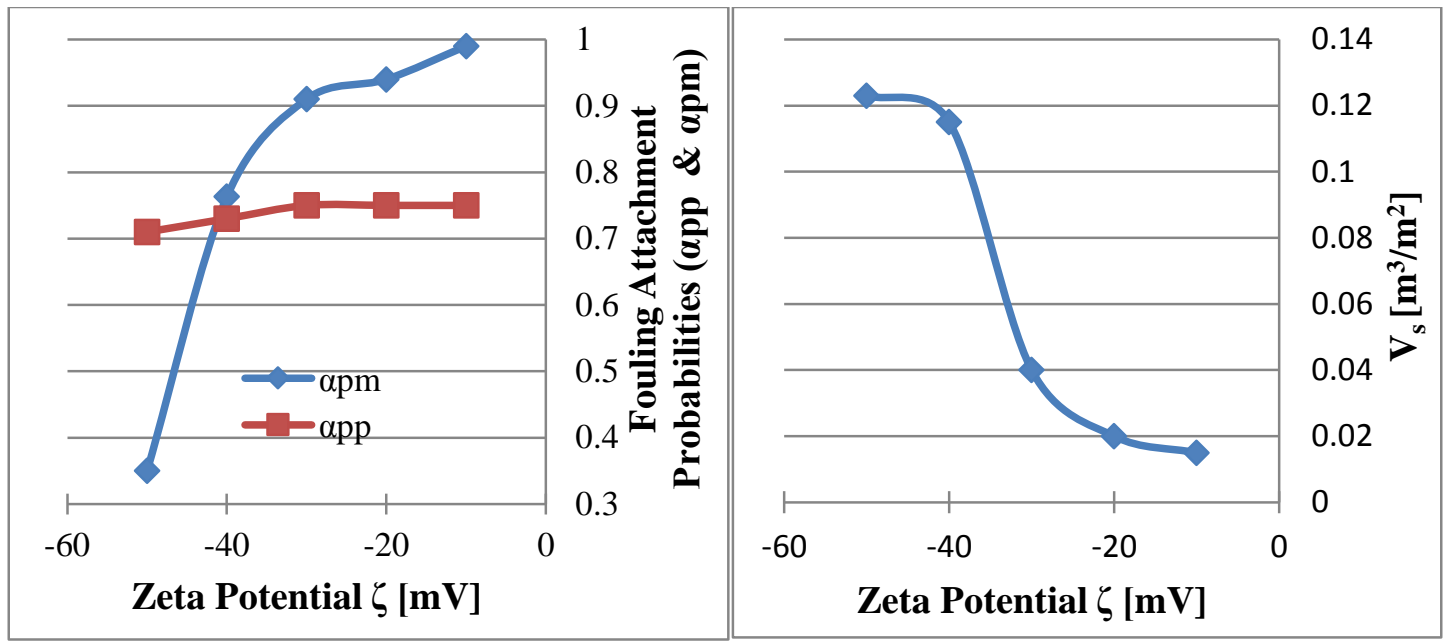

(a)

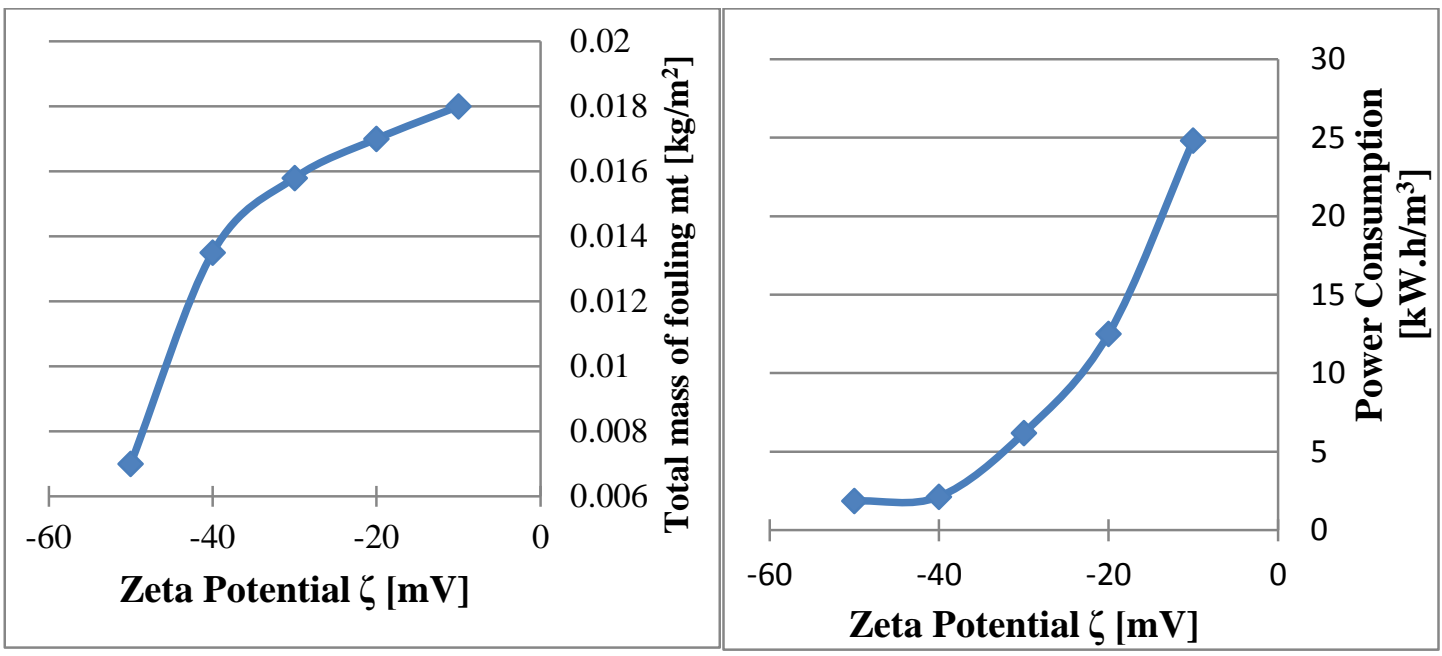

(c)

(d)

Figure 5.31: Effect of the zeta potential of Polysulfone membrane surface at [25 psi], [Q= 4.5 LPM], $\left[C_{\mathrm{f}}=1.3 \mathrm{~kg} / \mathrm{m}^{3}\right]$ on (a) Fouling attachment probabilities $\left(\alpha_{\mathrm{pp}}, \alpha_{\mathrm{pm}}\right)$; (b) Cumulative filtration volume per unit area $\left(V_{s}\right)\left[\mathrm{m}^{3} / \mathrm{m}^{2}\right] ;(c)$ Total mass of fouling $\left(m_{t}\right)\left[\mathrm{kg} / \mathrm{m}^{2}\right]$; and (d) Specific power consumption $\left[\mathbf{k W} \cdot \mathbf{h} / \mathrm{m}^{3}\right]$

Figure 5.32 (a) presents SEM image of Polysulfone membrane with the zeta potential of $-50.00 \mathrm{mV}$ after ultrafiltration at a transmembrane pressure of $25 \mathrm{psi}$, a feed flow rate of 4.5 LPM, and a feed concentration of $1.3 \mathrm{~kg} / \mathrm{m}^{3}$. Alternatively, Figure 5.32 (b) presents an SEM image of Polysulfone membrane with the zeta potential of $-10.00 \mathrm{mV}$ after ultrafiltration at the same operating conditions. In SEM images, the white latex particles blocked the membrane pores and deposited between membrane fiber. As shown in Figure 5.32 (a), the lower depositional attachment caused a decrease in the total mass of fouling, due to the reduced chances for particles to participate in particle-to-membrane attachment. 


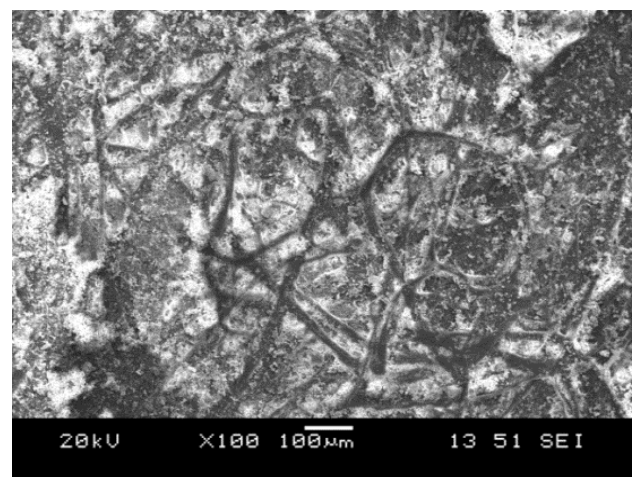

(a)

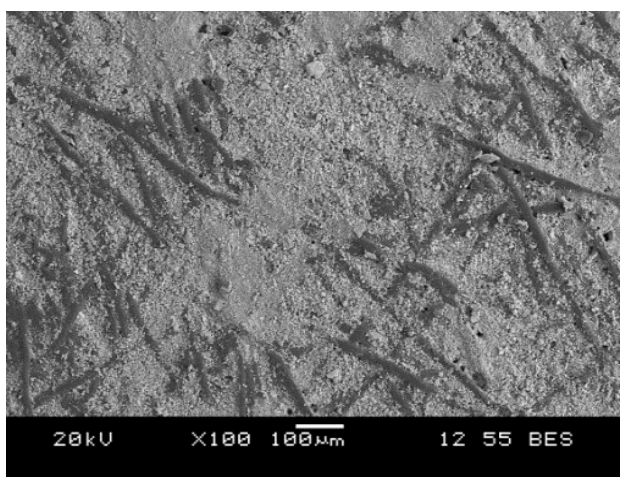

(b)

Figure 5.32: SEM images of Polysulfone membranes after ultrafiltration at $[25 \mathrm{psi}],[\mathrm{Q}=4.5$ LPM], $\left[C_{f}=1.3 \mathrm{~kg} / \mathrm{m}^{3}\right.$ ] (a) The zeta potential of Polysulfone membrane surface $-50.00 \mathrm{mV}$; (b) The zeta potential of Polysulfone membrane surface $-\mathbf{1 0 . 0 0} \mathbf{~ m V}$.

It was likewise critical to investigate the effects of increasing the membrane hydrophilicity of different heterogeneous membranes other than Polysulfone. For this reason, the effect of the zeta potential of the Ultrafilic membrane surface on membrane fouling was investigated at a transmembrane pressure of 25 psi, a feed flow rate of 4 LPM, and a feed concentration of $1.3 \mathrm{~kg} / \mathrm{m}^{3}$, as presented in Table 5.8. Reducing the negativity of the surface charge of Ultrafilic membrane from the original zeta potential value of $-41.50 \mathrm{mV}$ to $-30.00 \mathrm{mV}$ resulted in a decreased repulsion force between the membrane surface and latex particles, which in turn caused the depositional attachment $\left(\alpha_{\mathrm{pm}}\right)$ to increase from 0.70 to 0.85 . Higher $\alpha_{\mathrm{pm}}$ led to more particle attachment to the membrane surface, resulting in a higher pore blockage, a decrease in the cumulative filtration volume per unit area from 0.123 to $0.115 \mathrm{~m}^{3} / \mathrm{m}^{2}$, an increase in the mass of fouling from 0.025 to $0.03 \mathrm{~kg} / \mathrm{m}^{2}$, and the power consumption escalation from 1.82 to $1.93 \mathrm{~kW} . \mathrm{h} / \mathrm{m}^{3}$. Further decrease in the surface negativity from $-30.00 \mathrm{mV}$ to $-15.00 \mathrm{mV}$, caused a further increase in the depositional attachment from 0.85 to 0.96 . Consequently, the cumulative filtration volume per unit area decreased from 0.115 to $0.03 \mathrm{~m}^{3} / \mathrm{m}^{2}$, while the mass of fouling increased from 0.03 to $0.05 \mathrm{~kg} / \mathrm{m}^{2}$. Raising the total mass of fouling caused the increase in the transmembrane pressure to raise at a higher rate through the filtration process, and this allowed the power consumption to increase from 1.93 to $7.5 \mathrm{~kW} \cdot \mathrm{h} / \mathrm{m}^{3}$. It should be noted that the coagulation attachment $\left(\alpha_{\mathrm{pp}}\right)$ was $0.76,0.76$, and 0.77 using Ultrafilic membranes with the zeta potentials of $-41.50 \mathrm{mV},-30.00 \mathrm{mV}$, and $-15.00 \mathrm{mV}$, respectively. Figure 5.33 (a), Figure 5.33 (b), and Figure 5.33 (c) showcase the SEM images for Ultrafilic membrane after ultrafiltration at a transmembrane pressure of $25 \mathrm{psi}$, a feed flow rate of 4 LPM, and a feed concentration of 1.3 
$\mathrm{kg} / \mathrm{m}^{3}$, at the zeta potentials of $-41.50 \mathrm{mV},-30.00 \mathrm{mV}$, and $-15.00 \mathrm{mV}$, respectively. Figure 5.33 (b) illustrates that decreasing the negativity of the surface charge of Ultrafilic membrane resulted in a smaller number of clean pores, greater number of particle attachments to the membrane surface, and a higher chance of particle-to-particle collisions and attachments, if compared to Figure 5.33 (a). A further decrease in the surface negativity caused extensive particle deposition on the membrane surface, and thus an even higher chance for the particles to contribute to the coagulation attachment and cake formation, as shown in Figure 5.33 (c).

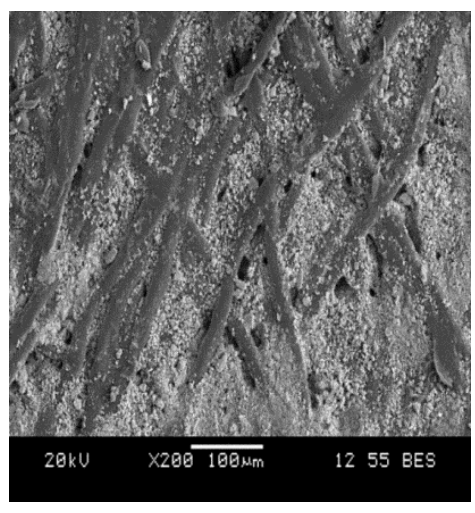

(a)

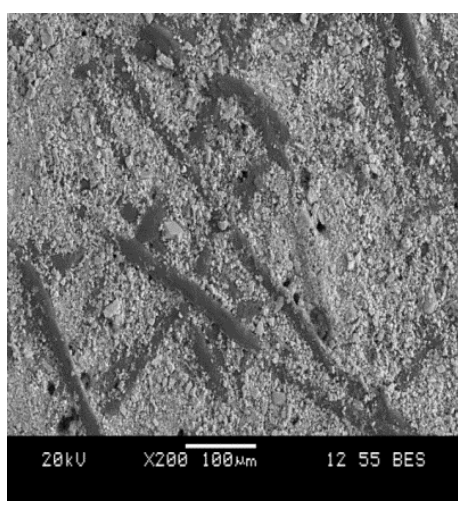

(b)

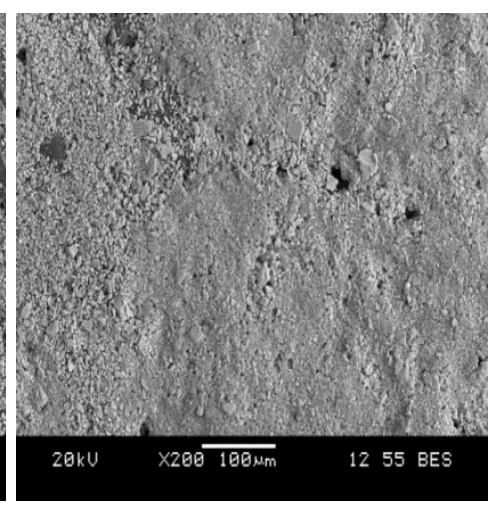

(c)

Figure 5.33: SEM images of Ultrafilic membranes after ultrafiltration at [25 psi], [Q= 4LPM], $\left[C_{f}=1.3 \mathrm{~kg} / \mathrm{m}^{3}\right]$ (a) Zeta potential of Ultrafilic membrane surface = $-41.50 \mathrm{mV}$; (b) Zeta potential of Ultrafilic membrane surface $=\mathbf{- 3 0 . 0 0} \mathbf{~ m V}$; (c) Zeta potential of Ultrafilic

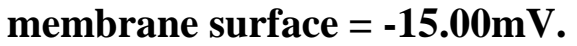

Table 5.8: Effect of the zeta potential of Ultrafilic membrane at transmembrane pressure of 25 psi, feed flow rate of $4 \mathrm{LPM}$, feed concentration of $1.3 \mathrm{~kg} / \mathrm{m}^{3}$ on fouling attachments, cumulative filtration volume, total mass of fouling, and the specific power consumption

\begin{tabular}{|c|c|c|c|c|c|}
\hline $\begin{array}{c}\text { Zeta } \\
\text { Potential } \\
{[\mathrm{mV}]}\end{array}$ & \multicolumn{2}{|l|}{ Fouling Attachments } & $\begin{array}{c}\text { Cumulative } \\
\text { Filtration } \\
\text { volume per unit } \\
\text { area }\left[\mathrm{m}^{3} / \mathrm{m}^{2}\right]\end{array}$ & $\begin{array}{c}\text { The Mass } \\
\text { of Fouling } \\
{\left[\mathrm{kg} / \mathrm{m}^{2}\right]}\end{array}$ & $\begin{array}{c}\text { Specific } \\
\text { Power } \\
\text { Consumption } \\
{\left[\mathrm{kW} . \mathrm{h} / \mathrm{m}^{3}\right]}\end{array}$ \\
\hline-41.50 & 0.7 & 0.76 & 0.123 & 0.025 & 1.82 \\
\hline-30.00 & 0.85 & 0.76 & 0.115 & 0.03 & 1.93 \\
\hline-15.00 & 0.96 & 0.77 & 0.03 & 0.05 & 7.5 \\
\hline
\end{tabular}

For Polysulfone membrane, the difference between the effect of raising the feed flow rate and the effect of increasing the zeta potential of membrane surface on membrane fouling was also investigated. At a transmembrane pressure of $25 \mathrm{psi}$, a feed concentration of $1.3 \mathrm{~kg} / \mathrm{m}^{3}$, and a zeta potential of $-20.00 \mathrm{mV}$, increasing the feed flow rate from 4.5 LPM to 7 LPM resulted in a 
reduced coagulation attachment from 0.75 to 0.55 . At the higher flow rate, the cross-flow of the feed can be considered as a continuous washing of the cake layer, causing a decrease in particleto-particle attachment $\left(\alpha_{\mathrm{pp}}\right)$. Figure 5.34 (b) indicates a lower cake height at a cross flow velocity of $72.8 \mathrm{~cm} / \mathrm{s}$ (7 LPM), if compared to Figure 5.34 (a) at a cross flow velocity of 46.8 $\mathrm{cm} / \mathrm{s}$ (4.5 LPM). It is worth noting that in the case of the Polysulfone membranes it is difficult to measure the cake height accurately due to its heterogeneous multilayered surface. Increasing the feed flow rate resulted in a $41.2 \%$ reduction in the total mass of fouling from $0.017 \mathrm{~kg} / \mathrm{m}^{2}$ to 0.01 $\mathrm{kg} / \mathrm{m}^{2}$, owing only to the diminishing of the cake layer. As the depositional attachment $\left(\alpha_{\mathrm{pm}}\right)$ only decreased from 0.94 to 0.89 , due to the accumulation of particles trapped inside the membrane tissue, which contributed to the multiple cake layers inside the matrix of the membrane. Moreover, Increasing the feed flow rate caused an increase in the cumulative filtration volume per unit area from 0.02 to $0.025 \mathrm{~m}^{3} / \mathrm{m}^{2}(25 \%)$. Despite the fact that the total mass of fouling was decreased by $41.2 \%$, thus reduction in transmembrane pressure through the ultrafiltration process from 6.5 to 4 psi, the power consumption per unit volume still increased by $21.7 \%$ from $12.5 \mathrm{~kW} \cdot \mathrm{h} / \mathrm{m}^{3}$ to $15.2 \mathrm{~kW} \cdot \mathrm{h} / \mathrm{m}^{3}$. An analysis of these relationships suggests that there is an alignment with the specific power consumption as it is directly proportional to the feed flow rate from the Equation (4.3). This proportional correlation entails that the remediation of the fouling is necessary for the reduction of the total mass of fouling in lower flow rates, increase of the cumulative filtration volume per unit area, and a reduction of the power consumption per unit volume of filtrate.

On the other hand, at the transmembrane pressure of 25 psi, feed concentration of 1.3 $\mathrm{kg} / \mathrm{m}^{3}$, and feed flow rate of 4.5 LPM, increasing the surface zeta potential from $-20.00 \mathrm{mV}$ to $50.00 \mathrm{mV}$ resulted in a lesser attraction force between the particles and the membrane surface. This caused the depositional attachment $\left(\alpha_{\mathrm{pm}}\right)$ to noticeably decrease by $62.76 \%$, from 0.94 to 0.35 , leading to a smaller number of particles trapped inside the matrix, as presented in Figure 5.34 (c). The cumulative filtration volume per unit area escalated more than 5 times from 0.02 $\mathrm{m}^{3} / \mathrm{m}^{2}$ to $0.123 \mathrm{~m}^{3} / \mathrm{m}^{2}$, and the total mass of fouling decreased by $58.8 \%$, from $0.017 \mathrm{~kg} / \mathrm{m}^{2}$ to $0.007 \mathrm{~kg} / \mathrm{m}^{2}$. Decreasing the total mass of fouling resulted in a lower increment in the transmembrane pressure through the ultrafiltration process from 6.5 to 1.5 psi. Accordingly, the specific power consumption was significantly reduced by $85.1 \%$, from $12.5 \mathrm{~kW} . \mathrm{h} / \mathrm{m}^{3}$ to 1.8 $\mathrm{kW} \cdot \mathrm{h} / \mathrm{m}^{3}$. The coagulation attachment probability had only slightly lessened from 0.75 to 0.72 . 
Due to a smaller number of particles attached to the membrane surface, chances of collision and attachment of particles on the membrane surface with other particles would be lower, as shown in Figure 5.34 (c).

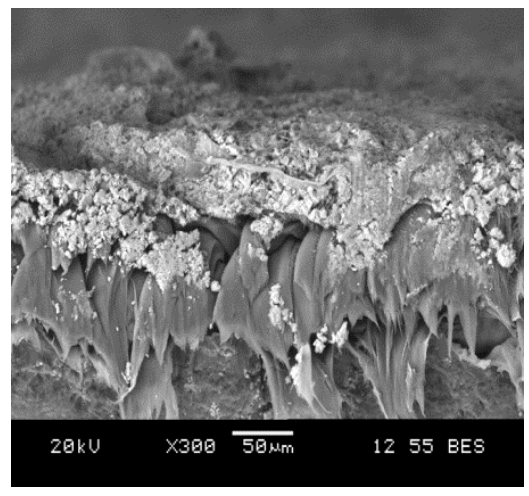

(a)

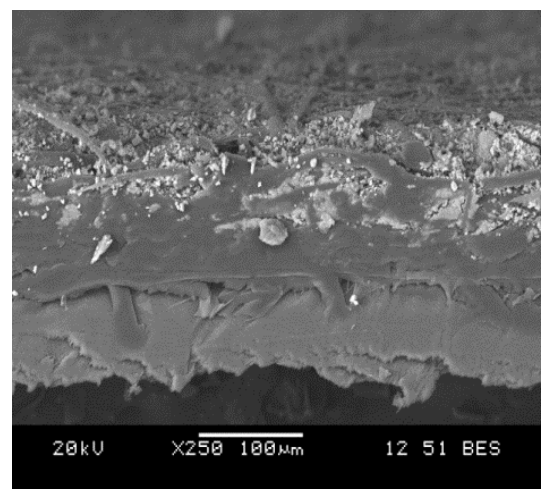

(b)

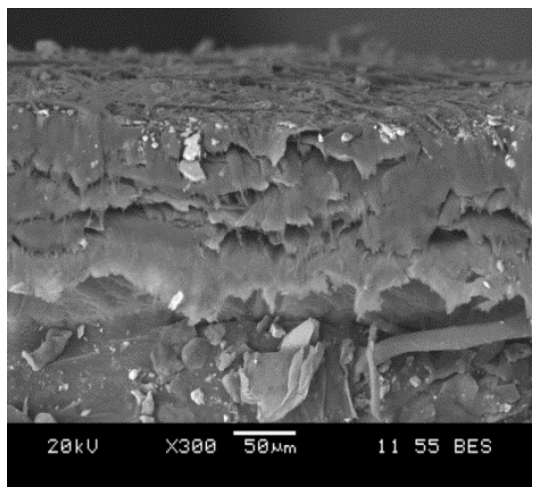

(c)

Figure 5.34: SEM images of Polysulfone membrane after ultrafiltration at

(a) PS [25 psi], [Q=4.5 LPM], [C $\left.=1.3 \mathrm{~kg} / \mathrm{m}^{3}\right],[-20.00 \mathrm{mV}]$ (cross flow velocity of $46.8 \mathrm{~cm} / \mathrm{s}$ )

(b) PS [25 psi], [Q= 7.0 LPM], [Cf $\left.=1.3 \mathrm{~kg} / \mathrm{m}^{3}\right],[-20.00 \mathrm{mV}]$ (cross flow velocity of $72.8 \mathrm{~cm} / \mathrm{s}$ )

(c) PS [25 psi], [Q= 4.5 LPM], [C $\left.\mathrm{f}=1.3 \mathrm{~kg} / \mathrm{m}^{3}\right],[-50.00 \mathrm{mV}]($ cross flow velocity of $46.8 \mathrm{~cm} / \mathrm{s})$

\subsection{Statistical analysis for model development}

The Response Surface Methodology (RSM) was used to design experiments that provided sufficient data to establish correlations for the prediction of the attachment fouling probabilities at a given operational condition. These correlations can be then used by our previous mathematical model to make a complete set of predictive models. The predicted fouling attachment probabilities from the correlations could be used to calculate the total mass of fouling retained by the membrane, irreversible fouling after backwash, increase in transmembrane pressure through the filtration process, and the increase in transmembrane pressure due to irreversible fouling.

\subsubsection{Fouling Attachments models using homogeneous Polycarbonate membranes}

The process parameters include transmembrane pressure, feed flow rate, and feed concentration. In this study, the Central Composite Face-Centered CCF Response Surface Method (RSM) was selected as the experimental design method. Twenty experiments were performed and the fouling attachment probabilities $\left(\alpha_{\mathrm{pp}}\right.$ and $\left.\alpha_{\mathrm{pm}}\right)$ were calculated for each experimental run, as shown in Table 5.9. The results were analyzed using multi-regression so as to identify the effects of the process parameters on the membrane fouling in ultrafiltration 
of a latex solution. Moreover, the process parameters were examined in order to identify the optimum conditions that would allow for the minimum fouling attachment probabilities. The analysis of the results indicated that the fouling attachment probabilities directly depend on the operating conditions being implemented. Depositional attachment probability $\alpha_{\mathrm{pm}}$ and the coagulation fouling probabilities $\alpha_{\mathrm{pp}}$ vary between the ranges of 0.3 to 0.98 and 0.15 to 0.95 , respectively. The mean value of the depositional attachment probability is 0.67 , while the mean value of the coagulation attachment probability is 0.58 .

TABLE 5.9: Experimental parameters and results based on the experimental design for the fouling attachment probabilities using homogeneous Polycarbonate membrane

\begin{tabular}{|c|c|c|c|c|c|c|c|c|}
\hline \multirow[b]{2}{*}{$\begin{array}{l}\text { Exp } \\
\text { No. }\end{array}$} & \multicolumn{6}{|c|}{ Independent Variables } & \multirow[b]{2}{*}{$\begin{array}{c}\alpha_{p p} \\
\text { [dimensionless] }\end{array}$} & \multirow[b]{2}{*}{$\begin{array}{c}\alpha_{p m} \\
\text { [dimensionless] }\end{array}$} \\
\hline & $\begin{array}{c}\text { Pressure } \\
\text { P [psi] }\end{array}$ & $\begin{array}{l}\text { Coded } \\
\text { Factor } \\
\text { of } P\end{array}$ & $\begin{array}{l}\text { Feed } \\
\text { Flow } \\
\text { rate Q } \\
\text { [LPM] }\end{array}$ & $\begin{array}{c}\text { Coded } \\
\text { Factor } \\
\text { of } Q\end{array}$ & $\begin{array}{c}\text { Feed } \\
\text { Concentration } \\
\mathrm{C}_{\mathrm{f}}\left[\mathrm{kg} / \mathrm{m}^{3}\right]\end{array}$ & $\begin{array}{l}\text { Coded } \\
\text { Factor } \\
\text { of } C_{f}\end{array}$ & & \\
\hline 1 & 15 & -1 & 1 & -1 & 0.78 & -1 & 0.3 & 0.95 \\
\hline 2 & 35 & 1 & 1 & -1 & 0.78 & -1 & 0.5 & 0.98 \\
\hline 3 & 15 & -1 & 7 & 1 & 0.78 & -1 & 0.15 & 0.6 \\
\hline 4 & 35 & 1 & 7 & 1 & 0.78 & -1 & 0.4 & 0.73 \\
\hline 5 & 15 & -1 & 1 & -1 & 1.82 & 1 & 0.9 & 0.6 \\
\hline 6 & 35 & 1 & 1 & -1 & 1.82 & 1 & 0.95 & 0.79 \\
\hline 7 & 15 & -1 & 7 & 1 & 1.82 & 1 & 0.3 & 0.3 \\
\hline 8 & 35 & 1 & 7 & 1 & 1.82 & 1 & 0.6 & 0.5 \\
\hline 9 & 15 & -1 & 4 & 0 & 1.3 & 0 & 0.4 & 0.55 \\
\hline 10 & 35 & 1 & 4 & 0 & 1.3 & 0 & 0.75 & 0.8 \\
\hline 11 & 25 & 0 & 1 & -1 & 1.3 & 0 & 0.76 & 0.82 \\
\hline 12 & 25 & 0 & 7 & 1 & 1.3 & 0 & 0.51 & 0.48 \\
\hline 13 & 25 & 0 & 4 & 0 & 0.78 & -1 & 0.4 & 0.78 \\
\hline 14 & 25 & 0 & 4 & 0 & 1.82 & 1 & 0.76 & 0.5 \\
\hline 15 & 25 & 0 & 4 & 0 & 1.3 & 0 & 0.65 & 0.68 \\
\hline 16 & 25 & 0 & 4 & 0 & 1.3 & 0 & 0.64 & 0.69 \\
\hline 17 & 25 & 0 & 4 & 0 & 1.3 & 0 & 0.66 & 0.67 \\
\hline 18 & 25 & 0 & 4 & 0 & 1.3 & 0 & 0.64 & 0.67 \\
\hline 19 & 25 & 0 & 4 & 0 & 1.3 & 0 & 0.66 & 0.68 \\
\hline 20 & 25 & 0 & 4 & 0 & 1.3 & 0 & 0.65 & 0.68 \\
\hline
\end{tabular}


Based on the ANOVA analysis, quadratic and linear models best fitted the experimental data for $\alpha_{\mathrm{pp}}$ and $\alpha_{\mathrm{pm}}$. The models for $\alpha_{\mathrm{pm}}$ and $\alpha_{\mathrm{pp}}$ are given in Equation (5.1) and Equation (5.2), respectively. Equations (5.1a) \& (5.2a) are used to predict the fouling attachments using the feed flow rate, while Equations (5.1b) \& (5.2b) are used to predict the fouling attachments using the cross flow velocity. In addition, the goodness of fit was determined by evaluating the coefficients of determination $\left(\mathrm{R}^{2}\right) . \mathrm{R}^{2}$ was $96 \%$ for the quadratic and linear models. In fact, $\mathrm{R}^{2}$ of $96 \%$ indicated that the models can adequately predict the relationships between the selected parameters.

$$
\begin{aligned}
\alpha_{\mathrm{pm}}= & 1.014+0.008 \times \mathrm{A}-0.051 \times \mathrm{B}-0.25962 \times \mathrm{C} \\
\alpha_{\mathrm{pm}}= & 1.014+0.008 \times \mathrm{A}-0.0049 \times \mathrm{D}-0.25962 \times \mathrm{C} \\
\alpha_{\mathrm{pp}}= & -0.94833+0.043034 \times \mathrm{A}-0.000606061 \times \mathrm{B}+1.21732 \times \mathrm{C} \\
& +0.00125 \times \mathrm{A} \times \mathrm{B}-0.00240385 \times \mathrm{A} \times \mathrm{C}-0.05609 \times \mathrm{B} \times \mathrm{C} \\
& -0.000668182 \times \mathrm{A}^{2}-0.000757576 \times \mathrm{B}^{2}-0.22862 \times \mathrm{C}^{2} \\
\alpha_{\mathrm{pp}}= & -0.94833+0.043034 \times \mathrm{A}-5.82 \times 10^{-5} \times \mathrm{D}+1.21732 \times \mathrm{C} \\
& +0.00012 \times \mathrm{A} \times \mathrm{D}-0.00240385 \times \mathrm{A} \times \mathrm{C}-0.0054 \times \mathrm{D} \times \mathrm{C} \\
& -0.000668182 \times \mathrm{A}^{2}-6.97 \times 10^{-6} \times \mathrm{D}^{2}-0.22862 \times \mathrm{C}^{2}
\end{aligned}
$$

where fouling attachment probabilities are functions of transmembrane pressure (A) [psia], feed flow rate (B) $[\mathrm{LPM}]$, cross flow velocity (D) $[\mathrm{cm} / \mathrm{s}]$, and feed concentration (C) $\left[\mathrm{kg} / \mathrm{m}^{3}\right]$. A positive sign implies that increasing the factor improves the effect and vice versa. The sign of the quadratic term coefficient indicates that the curve is concave downward when it has a negative sign and concave upward when it has a positive sign. To assess their validity the generated results were then analyzed by the ANOVA as presented in Table 5.10. The p-value is the probability value used to set the level of confidence for the F-test and to ascertain the significance of each of the coefficients. The p-value should be less than or equal to 0.05 to be significant (Calatayud et al., 2010; Yuliwati et al., 2012). According to regression coefficients and probability values (P-value) shown in Table 5.8, the linear terms were all functionally significant for both fouling attachment probabilities. Thus, it can be concluded from Equation (5.1a) that in order to minimize the depositional attachment probability $\left(\alpha_{\mathrm{pm}}\right)$ the pressure should be decreased while the feed flow rate and feed concentration should be increased. The 
interactions of the transmembrane pressure-feed flow rate $(\mathrm{AB})$ and the feed flow rate-feed concentration $(\mathrm{BC})$ are also significant for particle-to-particle attachment $\left(\alpha_{\mathrm{pp}}\right)$. Indeed, higher particle-to-particle attachment was achieved at higher transmembrane pressure-feed flow rate interaction $(\mathrm{AB})$. On the other hand, at higher feed flow rate-feed concentration interaction $(\mathrm{BC})$ the coagulation attachment was decreased.

Table 5.10: Regression coefficients and probability values of statistical analysis

\begin{tabular}{|c|c|c|c|c|c|}
\hline $\begin{array}{l}\text { Coded } \\
\text { Factor }\end{array}$ & Factor & $\begin{array}{c}\text { Coefficient for } \\
\alpha_{p p}\end{array}$ & p-value & $\begin{array}{c}\text { Coefficient for } \\
\alpha_{\mathrm{pm}}\end{array}$ & p-value \\
\hline$A$ & Pressure & +0.043034 & $<0.0001$ & +0.008 & $<0.0001$ \\
\hline B & Feed Flow rate & -0.000606061 & $<0.0001$ & -0.051 & $<0.0001$ \\
\hline $\mathrm{C}$ & Feed Concentration & +1.21732 & $<0.0001$ & -0.25962 & $<0.0001$ \\
\hline$A * B$ & $\begin{array}{l}\text { Pressure } * \text { Feed Flow } \\
\text { rate }\end{array}$ & +0.00125 & 0.0231 & & \\
\hline$A^{*} C$ & $\begin{array}{l}\text { Pressure } * \text { Feed } \\
\text { Concentration }\end{array}$ & -0.00240385 & 0.3926 & & \\
\hline$B^{*} \mathrm{C}$ & $\begin{array}{l}\text { Feed Flow rate } * \text { Feed } \\
\text { Concentration }\end{array}$ & -0.05609 & $<0.0001$ & & \\
\hline$A^{2}$ & Pressure $^{2}$ & -0.000668182 & 0.0188 & & \\
\hline $\mathrm{B}^{2}$ & Feed Flowrate $^{2}$ & -0.000757576 & 0.7809 & & \\
\hline $\mathrm{C}^{2}$ & Feed Concentration $^{2}$ & -0.22862 & 0.0269 & & \\
\hline
\end{tabular}

Values of "p-value" less than 0.05 indicate model terms are significant.

In this case of $\alpha_{\mathrm{pp}}$ : $\mathrm{A}, \mathrm{B}, \mathrm{C}, \mathrm{AB}, \mathrm{BC}, \mathrm{A}^{2}, \mathrm{C}^{2}$ are significant model terms.

In the case of $\alpha_{\mathrm{pm}}: \mathrm{A}, \mathrm{B}, \mathrm{C}$ are significant model terms.

Fouling attachment probabilities estimated from the generated models in Equation 5.1a \& 5.2a were then compared to the actual values of attachment probabilites ( $\alpha_{\mathrm{pp}}$ and $\left.\alpha_{\mathrm{pm}}\right)$. This validation to ascertain the reliability and accuracy of the generated models at a range of process parameters. The actual values of fouling attachemnt probabilities calculated from Equations 3.43 \& 3.44 using the exprimental values of $\mathrm{m}_{\mathrm{c}} \& \mathrm{~m}_{\mathrm{p}}$ for each ultrafiltration run same operating conditions. Figure 5.35 indicates a good agreement of the values of attachemnt probabilities $\left(\alpha_{\mathrm{pp}}\right.$ and $\alpha_{\mathrm{pm}}$ ) predicted from the correlations (Equations 5.1a and 5.2a) and the actual values estimated from the mechanistic model and experimental data. 


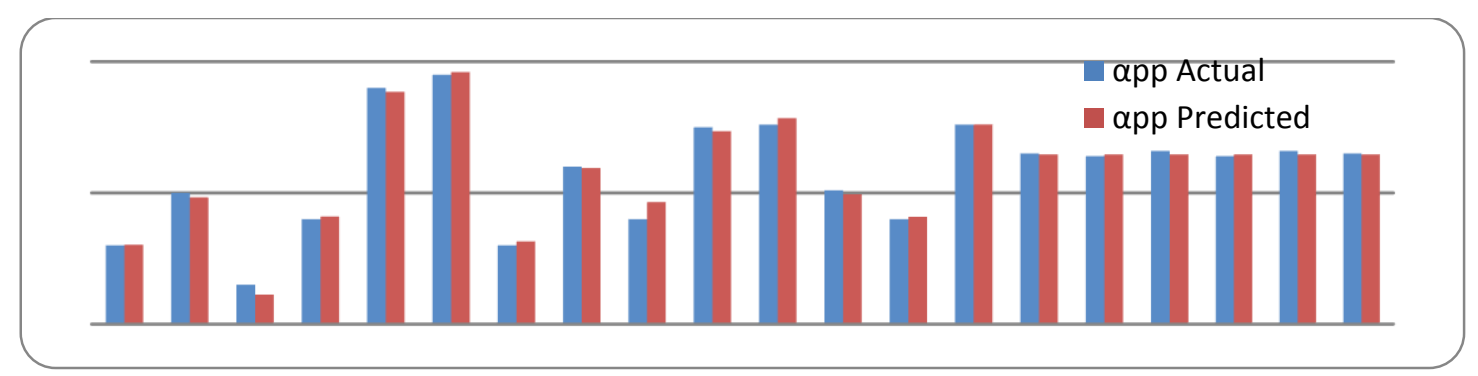

(a)

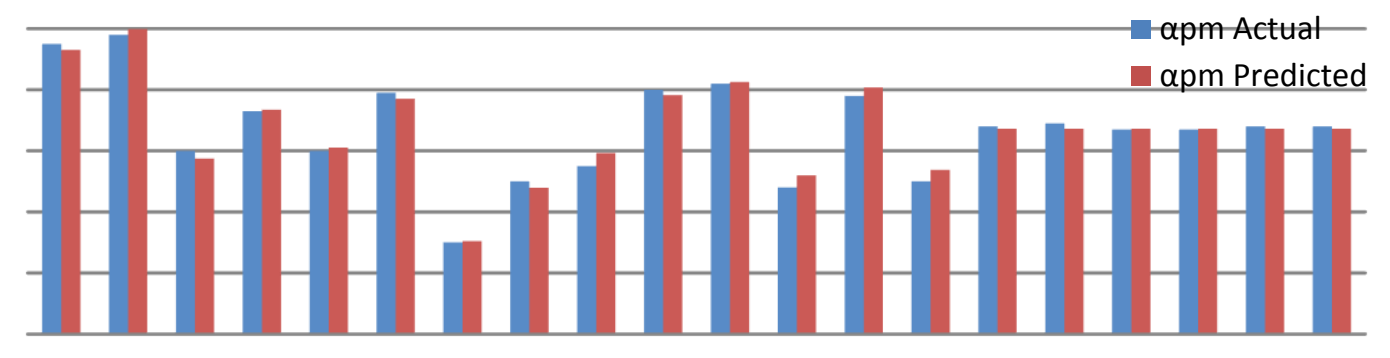

(b)

Figure 5.35 : Actual and predicted fouling attachment probabilities agreement

(a) Coagulation attachment probability $\left(\alpha_{p p}\right)$

(b) Depositional attachment probability $\left(\alpha_{\mathrm{pm}}\right)$

Moreover, additional experiments were performed with process parameters outside of the original range used in the RSM experimental design. In these experiments, the fouling attachment probabilities $\alpha_{\mathrm{pp}}$ and $\alpha_{\mathrm{pm}}$ were calculated using Equations (3.43) and (3.44) and then compared to $\alpha_{\mathrm{pp}}$ and $\alpha_{\mathrm{pm}}$ predicted using Equations (5.1a) and (5.2a). Table (5.11) presents a good agreement between fouling attachments predicted from regression correlations with actual values at different operating conditions. The depositional attachment probability predicted using Equation (5.1a) is within 2 - $4 \%$ error of the actual values. However, the coagulation attachment probability predicted from Equation (5.2a) are within $9 \%$ error of actual values.

Table 5.11: Agreement of fouling attachments prediction from regression correlations with actual values for extra experiments out of the range of process parameters

\begin{tabular}{|c|c|c|c|c|c|c|c|c|}
\hline $\mathrm{P}[\mathrm{psi}]$ & $\begin{array}{c}\mathrm{Q} \\
{[\mathrm{LPM}]}\end{array}$ & $\begin{array}{c}\mathrm{C}_{\mathrm{f}} \\
{\left[\mathrm{kg} / \mathrm{m}^{3}\right]}\end{array}$ & $\alpha_{\mathrm{pp}}$ & $\alpha_{\mathrm{pm}}$ & $\begin{array}{c}\alpha_{\mathrm{pp}} \\
\text { Predicted }\end{array}$ & $\begin{array}{c}\alpha_{\mathrm{pm}} \\
\text { Predicted }\end{array}$ & $\begin{array}{c}\% \text { Error } \\
{\left[\alpha_{\mathrm{pp}}\right]}\end{array}$ & $\begin{array}{c}\% \text { Error } \\
{\left[\alpha_{\mathrm{pm}}\right]}\end{array}$ \\
\hline 10 & 4 & 1.3 & 0.32 & 0.54 & 0.32 & 0.55 & 0.0 & 2.3 \\
\hline 40 & 4 & 1.3 & 0.76 & 0.81 & 0.67 & 0.79 & -7.9 & -2.2 \\
\hline 45 & 4 & 1.3 & 0.76 & 0.8 & 0.61 & 0.83 & -9.2 & 4.1 \\
\hline 15 & 1 & 0.7 & 0.24 & 0.95 & 0.24 & 0.93 & 0.0 & -2.1 \\
\hline
\end{tabular}

$\alpha_{\mathrm{pp}}$ and $\alpha_{\mathrm{pm}}$ were calculated using Equation (5.2a) and (5.1a) and the experimental values of $\mathrm{m}_{\mathrm{p}}$ and $\mathrm{m}_{\mathrm{c}}$ $\alpha_{\mathrm{pp}}$ and $\alpha_{\mathrm{pm}}$ predicted using Equations (3.43) and (3.44)

Error $=[($ Estimated value - Actual value $) /$ Actual value $] * 100$ 
The process parameters were then analyzed to identify the optimum conditions for a minimum fouling probability within the range of process parameters implemented in this study. For the depositional attachment $\alpha_{\mathrm{pm}}$, the minimum value achieved is 0.2961 at $16.32 \mathrm{psi}, 6.88$ LPM and $1.78 \mathrm{~kg} / \mathrm{m}^{3}$. The minimum value of 0.134 for particle-to-particle attachment (coagulation potential) was achieved at $15.33 \mathrm{psi}, 6.87 \mathrm{LPM}$ and $0.8 \mathrm{~kg} / \mathrm{m}^{3}$. These optimal conditions indicated that the minimum response of both fouling attachment probabilities could be obtained at the minimum transmembrane pressure, medium feed concentration, and maximum feed flow rate of the range of process parameters used in the present study.

\subsubsection{Power consumption model for homogeneous Polycarbonate membranes}

Table 5.10 presents coded and actual levels of the process parameters. The coded values are designated as -1 (low), 0 (medium), and 1 (high). Central Composite Face-Centred CCF Response Surface Method (RSM) was selected as the experimental design method. The total mass of fouling was measured for each experimental run, and the specific power consumption was calculated, as shown in Table 5.12 using Equation 4.3. The total mass of fouling and the power consumed per unit volume of permeate varied in the ranges of 0.0048 to $0.024 \mathrm{~kg} / \mathrm{m}^{2}$ and 2.81 to $37.97 \mathrm{kWh} / \mathrm{m}^{3}$, respectively.

Table 5.12: Experimental parameters and results based on the experimental design for the total mass of fouling and the specific power consumption

\begin{tabular}{|c|c|c|c|c|c|c|c|}
\hline \multirow[b]{2}{*}{$\begin{array}{l}\text { Exp } \\
\text { No. }\end{array}$} & \multirow[b]{2}{*}{$\begin{array}{c}\text { Initial } \\
\text { TMP } \\
\text { [psi] }\end{array}$} & \multirow[b]{2}{*}{$\begin{array}{c}\text { TMP }_{\text {AVG }} * \\
{[p s i]}\end{array}$} & \multirow[b]{2}{*}{$\begin{array}{l}\text { Final } \\
\text { TMP } \\
\text { [psi] }\end{array}$} & \multicolumn{2}{|c|}{ Independent Variables } & \multirow[b]{2}{*}{$\underset{\left[\mathbf{k g} / \mathbf{m}^{2}\right]}{\mathbf{m}_{\mathbf{t}}}$} & \multirow{2}{*}{$\begin{array}{c}\text { Power } \\
\text { consumed } \\
\mathbf{k W} \cdot \mathbf{h} / \mathbf{m}^{3}\end{array}$} \\
\hline & & & & $\begin{array}{l}\text { Feed } \\
\text { Flow } \\
\text { rate Q } \\
{[\text { LPM] }}\end{array}$ & $\begin{array}{c}\text { Feed } \\
\text { Concentration } \\
\mathrm{C}_{\mathrm{f}}\left[\mathrm{kg} / \mathrm{m}^{3}\right]\end{array}$ & & \\
\hline 1 & $15(-1)$ & 15 & 17 & $1(-1)$ & $0.78(-1)$ & 0.0088 & 2.81 \\
\hline 2 & $35(1)$ & 35 & 40 & $1(-1)$ & $0.78(-1)$ & 0.013 & 5.74 \\
\hline 3 & $15(-1)$ & 15 & 16 & $7(1)$ & $0.78(-1)$ & 0.0048 & 14.74 \\
\hline 4 & $35(1)$ & 35 & 39 & $7(1)$ & $0.78(-1)$ & 0.012 & 28.46 \\
\hline 5 & $15(-1)$ & 16.47 & 20 & $1(-1)$ & $1.82(1)$ & 0.018 & 4.82 \\
\hline 6 & $35(1)$ & 35.27 & 42 & $1(-1)$ & $1.82(1)$ & 0.019 & 8.66 \\
\hline 7 & $15(-1)$ & 16.27 & 21 & $7(1)$ & $1.82(1)$ & 0.0155 & 25.98 \\
\hline 8 & $35(1)$ & 35 & 43 & $7(1)$ & $1.82(1)$ & 0.023 & 37.97 \\
\hline 9 & $15(-1)$ & 15 & 18 & $4(0)$ & $1.3(0)$ & 0.01 & 10.17 \\
\hline
\end{tabular}




\begin{tabular}{|c|c|c|c|c|c|c|c|}
10 & $35(1)$ & 35 & 41 & $4(0)$ & $1.3(0)$ & 0.015 & 16.61 \\
\hline 11 & $25(0)$ & 25 & 32 & $1(-1)$ & $1.3(0)$ & 0.0195 & 5.34 \\
\hline 12 & $25(0)$ & 25 & 27 & $7(1)$ & $1.3(0)$ & 0.0082 & 19.64 \\
\hline 13 & $25(0)$ & 25 & 27 & $4(0)$ & $0.78(-1)$ & 0.0076 & 12.01 \\
\hline 14 & $25(0)$ & 26.8 & 33 & $4(0)$ & $1.82(1)$ & 0.024 & 17.23 \\
\hline 15 & $25(0)$ & 25.5 & 29 & $4(0)$ & $1.3(0)$ & 0.012 & 13.98 \\
\hline 16 & $25(0)$ & 25 & 29 & $4(0)$ & $1.3(0)$ & 0.0117 & 13.77 \\
\hline 17 & $25(0)$ & 25 & 29 & $4(0)$ & $1.3(0)$ & 0.0118 & 13.61 \\
\hline 18 & $25(0)$ & 25 & 29 & $4(0)$ & $1.3(0)$ & 0.012 & 13.84 \\
\hline 19 & $25(0)$ & 25 & 29 & $4(0)$ & $1.3(0)$ & 0.0121 & 13.66 \\
\hline 20 & $25(0)$ & 25 & 29 & $4(0)$ & $1.3(0)$ & 0.0119 & 13.51 \\
\hline
\end{tabular}

The results were analyzed using multi-regression so as to identify the effects of the process parameters on the total mass of fouling and the specific power consumption in ultrafiltration of a latex solution. Moreover, the process parameters were examined in order to identify the optimum conditions that would allow for the minimum mass of fouling and power consumption. Based on the ANOVA analysis, linear models best fitted the experimental data for the total mass of fouling and the specific power consumption. The ANOVA result is presented in Table 5.13. The p-value is the probability value used to set the level of confidence for the F-test and to ascertain the significance of each of the coefficients. According to regression coefficients and probability values ( $\mathrm{p}$-value), as shown in Table (5.13), the linear terms were all functionally significant for the total mass of fouling and the specific power consumption. The models for the total mass of fouling and the specific power consumption are given in Equation (5.3) and Equation (5.4), respectively. In addition, the goodness of fit was determined by evaluating the coefficients of determination $\left(\mathrm{R}^{2}\right)$. $\mathrm{R}^{2}$ was 0.97 for the linear models.

Total mass of fouling $\left(\mathrm{m}_{\mathrm{t}}\right)\left[\mathrm{kg} / \mathrm{m}^{2}\right]=-0.00499+0.000299 \times \mathrm{A}-0.0003267 \times \mathrm{B}+0.00929 \times \mathrm{C}$

(Equation 5.3a)

Total mass of fouling $\left(\mathrm{m}_{\mathrm{t}}\right)\left[\mathrm{kg} / \mathrm{m}^{2}\right]=-0.00499+0.000299 \times \mathrm{A}-3.135 \times 10^{-5} \times \mathrm{D}+0.00929 \times \mathrm{C}$ (Equation 5.3b) 
Specific Power Consumption $\left[\mathrm{kWh} / \mathrm{m}^{3}\right]=-16.2412+0.3978 \times \mathrm{A}+3.3427 \times \mathrm{B}+5.777 \times \mathrm{C}$

(Equation 5.4a)

Specific Power Consumption $\left[\mathrm{kWh} / \mathrm{m}^{3}\right]=-16.2412+0.3978 \times \mathrm{A}+0.32079 \times \mathrm{D}+5.777 \times \mathrm{C}$

(Equation 5.4b)

where the total mass of fouling $\left(\mathrm{m}_{\mathrm{t}}\right)$ and the specific power consumption are function of average transmembrane pressure $\mathrm{TMP}_{\mathrm{AVG}}(\mathrm{A})$ [psi], feed flow rate (B) [LPM], cross flow velocity (D) $[\mathrm{cm} / \mathrm{s}]$, and feed concentration $(\mathrm{C})\left[\mathrm{kg} / \mathrm{m}^{3}\right]$. The linear models were compatible with the results. As illustrated in Equation (5.3a), in order to minimize the total mass of fouling, the transmembrane pressure and feed concentration should be decreased while the feed flow rate should be increased. On the other hand, to minimize the specific power consumption, the transmembrane pressure, feed flow rate and feed concentration should be decreased. Furthermore the average transmembrane pressure $\mathrm{TMP}_{\mathrm{AVG}}$ [psi] can be estimated so as to predict the specific power consumption from Equation (5.4a) using the initial transmembrane pressure, variation of transmembrane pressure $\left(P^{\prime}\right)$ with time estimated from the mechanistic model and the filtration time.

Table 5.13: Regression coefficients and probability values of statistical analysis

\begin{tabular}{|c|l|c|c|c|c|}
\hline $\begin{array}{c}\text { Coded } \\
\text { Factor }\end{array}$ & Actual Factor & $\begin{array}{c}\text { Coefficient for } \\
\boldsymbol{m}_{\boldsymbol{t}}\left[\mathbf{k g} / \mathbf{m}^{2}\right]\end{array}$ & $\mathbf{p}$-value & $\begin{array}{c}\text { Coefficient for } \\
\text { specific power } \\
\text { consumption } \\
{\left[\mathbf{k W h} / \mathbf{m}^{3}\right]}\end{array}$ & $\begin{array}{c}\mathbf{p}- \\
\text { value }\end{array}$ \\
\hline $\mathrm{A}$ & $\mathrm{TMP}_{\text {AVG }}[\mathrm{psi}]$ & +0.000299 & 0.0044 & +0.39780 & 0.0005 \\
\hline $\mathrm{B}$ & Feed Flow rate $[\mathrm{LPM}]$ & -0.000326667 & 0.0005 & +3.34267 & $<0.000$ \\
\hline $\mathrm{C}$ & Feed Concentration $\left[\mathrm{kg} / \mathrm{m}^{3}\right]$ & +0.00928846 & $<0.0001$ & +5.77692 & 0.0045 \\
\hline
\end{tabular}

Values of "p-value "less than 0.05 indicate model terms are significant.

In case of total mass of fouling and specific power consumption models: A, B, C are significant model terms.

\subsubsection{Fouling attachment models using heterogeneous Polysulfone membranes}

In the current study, the Central Composite Face-Centered (CCF) Response Surface Method (RSM) was selected as the optimal experimental design method. Twenty experiments were performed and the fouling attachment probabilities $\left(\alpha_{\mathrm{pp}}\right.$ and $\left.\alpha_{\mathrm{pm}}\right)$ were calculated for each of the experimental runs, as shown in Table 5.14. For the minimization of errors, six replicated experiments at zero code for each process parameter were performed in randomized order. 
Depositional attachment probability $\alpha_{\mathrm{pm}}$ and the coagulation fouling probabilities $\alpha_{\mathrm{pp}}$ vary between the ranges of 0.35 to 0.97 and 0.27 to 0.92 , respectively.

TABLE 5.14: Experimental parameters and results based on the experimental design for the fouling attachment probabilities

\begin{tabular}{|c|c|c|c|c|c|c|c|c|}
\hline \multirow[b]{3}{*}{$\begin{array}{l}\text { Exp. } \\
\text { No. }\end{array}$} & \multicolumn{6}{|c|}{ Independent Variables } & \multirow[b]{3}{*}{$\begin{array}{c}\alpha_{\mathrm{pp}} \\
\text { [dimensionless] }\end{array}$} & \multirow[b]{3}{*}{$\begin{array}{c}\alpha_{p m} \\
\text { [dimensionless }\end{array}$} \\
\hline & (A) & \multirow[b]{2}{*}{$\begin{array}{l}\text { Coded } \\
\text { Factor } \\
\text { of } P\end{array}$} & (B) & \multirow[b]{2}{*}{$\begin{array}{l}\text { Coded } \\
\text { Factor } \\
\text { of } Q\end{array}$} & (C) & \multirow[b]{2}{*}{$\begin{array}{l}\text { Coded } \\
\text { Factor } \\
\text { of } C_{f}\end{array}$} & & \\
\hline & $\begin{array}{c}\text { Pressure } \\
\mathrm{P} \text { [psi] }\end{array}$ & & $\begin{array}{c}\text { Feed } \\
\text { Flow rate } \\
\text { Q [LPM] }\end{array}$ & & $\begin{array}{c}\text { Feed } \\
\text { Concentration } \\
\mathrm{C}_{\mathrm{f}}\left[\mathrm{kg} / \mathrm{m}^{3}\right]\end{array}$ & & & \\
\hline 1 & 15 & -1 & 1 & -1 & 0.78 & -1 & 0.62 & 0.81 \\
\hline 2 & 35 & 1 & 1 & -1 & 0.78 & -1 & 0.78 & 0.9 \\
\hline 3 & 15 & -1 & 7 & 1 & 0.78 & -1 & 0.27 & 0.35 \\
\hline 4 & 35 & 1 & 7 & 1 & 0.78 & -1 & 0.55 & 0.42 \\
\hline 5 & 15 & -1 & 1 & -1 & 1.82 & 1 & 0.92 & 0.97 \\
\hline 6 & 35 & 1 & 1 & -1 & 1.82 & 1 & 0.92 & 0.95 \\
\hline 7 & 15 & -1 & 7 & 1 & 1.82 & 1 & 0.52 & 0.72 \\
\hline 8 & 35 & 1 & 7 & 1 & 1.82 & 1 & 0.89 & 0.8 \\
\hline 9 & 15 & -1 & 4 & 0 & 1.3 & 0 & 0.54 & 0.67 \\
\hline 10 & 35 & 1 & 4 & 0 & 1.3 & 0 & 0.82 & 0.91 \\
\hline 11 & 25 & 0 & 1 & -1 & 1.3 & 0 & 0.83 & 0.9 \\
\hline 12 & 25 & 0 & 7 & 1 & 1.3 & 0 & 0.7 & 0.82 \\
\hline 13 & 25 & 0 & 4 & 0 & 0.78 & -1 & 0.34 & 0.83 \\
\hline 14 & 25 & 0 & 4 & 0 & 1.82 & 1 & 0.81 & 0.89 \\
\hline 15 & 25 & 0 & 4 & 0 & 1.3 & 0 & 0.78 & 0.87 \\
\hline 16 & 25 & 0 & 4 & 0 & 1.3 & 0 & 0.77 & 0.87 \\
\hline 17 & 25 & 0 & 4 & 0 & 1.3 & 0 & 0.77 & 0.88 \\
\hline 18 & 25 & 0 & 4 & 0 & 1.3 & 0 & 0.78 & 0.86 \\
\hline 19 & 25 & 0 & 4 & 0 & 1.3 & 0 & 0.78 & 0.87 \\
\hline 20 & 25 & 0 & 4 & 0 & 1.3 & 0 & 0.79 & 0.87 \\
\hline
\end{tabular}

Based on the ANOVA analysis, the experimental data of the fouling attachment ( $\alpha_{\mathrm{pp}}$ and $\left.\alpha_{\mathrm{pm}}\right)$ fitted the linear model well, using multi regression. The models for the depositional attachment $\left(\alpha_{\mathrm{pm}}\right)$ and coagulation attachment $\left(\alpha_{\mathrm{pp}}\right)$ are given in Equation (5.5) and Equation (5.6) with the coefficients of determination $\left(\mathrm{R}^{2}\right)$ of $95 \%$ and $93 \%$, respectively. 
$\alpha_{\mathrm{pm}}=+0.48+0.0056 \times \mathrm{A}-0.078 \times \mathrm{B}+0.38 \times \mathrm{C}$

Equation (5.5a)

$\alpha_{\mathrm{pm}}=+0.48+0.0056 \times \mathrm{A}-0.007485 \times \mathrm{D}+0.38 \times \mathrm{C}$

Equation (5.5b)

$\alpha_{\mathrm{pp}}=+0.30+0.025 \times \mathrm{A}-0.069 \times \mathrm{B}+0.082 \times \mathrm{C}$

Equation (5.6a)

$\alpha_{\mathrm{pp}}=+0.30+0.025 \times \mathrm{A}-0.006622 \times \mathrm{D}+0.082 \times \mathrm{C}$

Equation (5.6b)

where A, B, C and D represent the transmembrane pressure [psi], the feed flow rate [LPM], the feed solid concentration $\left[\mathrm{kg} / \mathrm{m}^{3}\right]$, and cross flow velocity $[\mathrm{cm} / \mathrm{s}]$, respectively. The interactions between the operating conditions had an insignificant effect on the fouling attachment using the Polysulfone heterogeneous membrane. Recalling that the interactions between the transmembrane pressure-feed flow rate $(\mathrm{AB})$ and the feed flow rate-feed concentration (BC) had a significant impact on the particle-to-particle attachment $\left(\alpha_{\mathrm{pp}}\right)$ using the Polycarbonate homogenous membrane.

In order to assess the validity of the model coefficients, the results were then analysed using ANOVA, as presented in Table 5.15. The p-value is the probability value used to set the level of confidence for the F-test, and to ascertain the significance of each coefficient. According to the regression coefficients and probability values (p-value) shown in Table 5.15, the linear terms were all functionally significant for both of the fouling attachment probabilities at the 95 $\%$ level of confidence. From Equations (5.5a) and (5.6a), in order to minimize the attachments probabilities $\left(\alpha_{\mathrm{pm}} \& \alpha_{\mathrm{pp}}\right)$ using the Polysulfone heterogeneous membranes, the transmembrane pressure and the feed concentration should be decreased while the feed flow rate should be increased. However, in order to minimize the depositional attachment probability $\left(\alpha_{\mathrm{pm}}\right)$ in the case of the Polycarbonate homogenous membrane, the transmembrane pressure should be decreased while the feed flow rate and feed concentration should be increased. These optimized conditions indicate that the minimum value for both of the fouling attachment probabilities could be obtained at the minimum transmembrane pressure, minimum feed concentration, and maximum feed flow rate within the range of process parameters used in the present study. At a transmembrane pressure of $15 \mathrm{psi}$, feed flow rate of 7 LPM, and the feed concentration of 0.78 $\mathrm{kg} / \mathrm{m}^{3}$, the particle-to-particle and the particle-to-membrane attachments approach the minimum values of 0.27 and 0.35 , respectively. 
Table 5.15: Regression coefficients and probability values of statistical analysis

\begin{tabular}{|c|l|c|c|c|c|}
\hline $\begin{array}{c}\text { Coded } \\
\text { Factor }\end{array}$ & \multicolumn{1}{|c|}{ Factor } & $\begin{array}{c}\text { Coefficient } \\
\text { for } \alpha_{\mathrm{pm}}\end{array}$ & p-value & $\begin{array}{c}\text { Coefficient } \\
\text { for } \alpha_{\mathrm{pp}}\end{array}$ & p-value \\
\hline A & Pressure & 0.0056 & 0.0419 & 0.025 & $<0.0001$ \\
\hline B & Feed Flow rate & -0.078 & 0.0394 & -0.069 & 0.0499 \\
\hline C & Feed Concentration & 0.38 & $<0.0001$ & 0.082 & 0.009 \\
\hline
\end{tabular}

Note: 1. Values of "p-value "less than 0.05 indicate model terms are significant.

2. In the case of $\alpha_{\mathrm{pp}} \& \alpha_{\mathrm{pm}}: \mathrm{A}, \mathrm{B}, \mathrm{C}$ are significant model terms.

\subsubsection{Agreement between actual and predicted fouling attachments using PSU}

Fouling attachment probabilities estimated from the models in Equation 5.5a \& 5.6a were also compared to the actual values of fouling attachments probabilities $\left(\alpha_{\mathrm{pm}}\right.$ and $\left.\alpha_{\mathrm{pp}}\right)$. This validation to ascertain the reliability and accuracy of the generated models, while functioning within a wide range of process parameters. The actual values of the fouling attachment probabilities were calculated based on Equations $3.55 \& 3.68$ using the experimental values of $m_{c} \& m_{P}$ for each of the ultrafiltration runs conducted under the same operating conditions. Figure (5.36) indicates a strong correspondence between the predicted values and the actual values of $\alpha_{\mathrm{pp}}$ and $\alpha_{\mathrm{pm}}$.

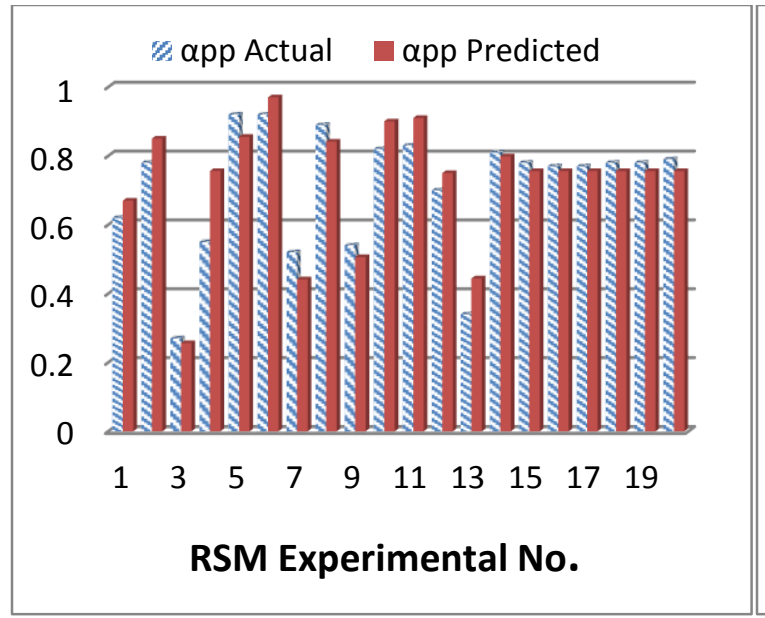

(a)

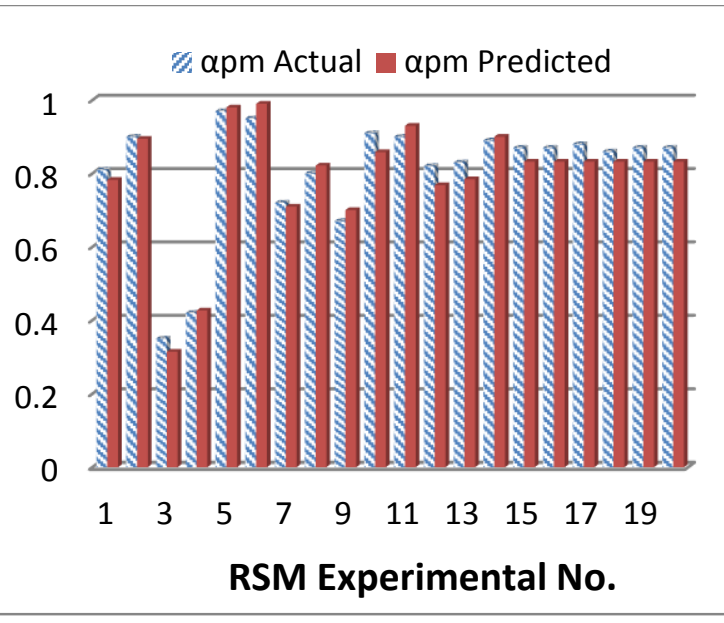

(b)

Figure 5.36: Actual and predicted fouling attachment probabilities agreement (a) Coagulation attachment probability $\left(\alpha_{\mathrm{pp}}\right)$; (b) Depositional attachment probability $\left(\alpha_{\mathrm{pm}}\right)$

Moreover, additional experiments were performed using the process parameters slightly outside of the range originally used in the RSM experimental design (one parameter at a time). In these experiments the fouling attachment probabilities $\alpha_{\mathrm{pp}}$ and $\alpha_{\mathrm{pm}}$ were calculated using Equations (3.55) and (3.68) and then compared to $\alpha_{\mathrm{pm}}$ and $\alpha_{\mathrm{pp}}$ predicted from Equations (5.5a) 
and (5.6a). The results are presented in Table (5.16). Depositional attachment probability predicted from Equation (5.5a) and the coagulation attachment probability predicted from Equation (5.6a) are within \pm 3.6 to $10.0 \%$ and \pm 4.8 to $8.7 \%$ error of the actual values, respectively.

Table 5.16: Agreement of the fouling attachments prediction from regression correlations with actual values for extra experiments outside of the range of process parameters

\begin{tabular}{|c|c|c|c|c|c|c|c|c|}
\hline $\mathbf{P}[\mathrm{psi}]$ & $\begin{array}{c}\mathbf{Q} \\
{[\mathrm{LPM}]}\end{array}$ & $\begin{array}{c}\boldsymbol{C}_{f} \\
{\left[\mathrm{~kg} / \mathrm{m}^{\mathbf{3}}\right]}\end{array}$ & $\boldsymbol{\alpha}_{\mathrm{pp}}$ & $\boldsymbol{\alpha}_{\mathrm{pm}}$ & $\begin{array}{c}\boldsymbol{\alpha}_{\mathrm{pp}} \\
\text { Predicted }\end{array}$ & $\begin{array}{c}\boldsymbol{\alpha}_{\mathrm{pm}} \\
\text { Predicted }\end{array}$ & $\begin{array}{c}\text { \% Error } \\
{\left[\boldsymbol{\alpha}_{\mathrm{pp}}\right]}\end{array}$ & $\begin{array}{c}\% \text { Error } \\
{\left[\boldsymbol{\alpha}_{\mathrm{pm}}\right]}\end{array}$ \\
\hline 10 & 4.0 & 1.3 & 0.40 & 0.66 & 0.38 & 0.72 & -4.8 & 8.7 \\
\hline 15 & 0.5 & 1.3 & 0.70 & 0.90 & 0.75 & 0.99 & 6.7 & 10.0 \\
\hline 15 & 1.0 & 0.7 & 0.61 & 0.78 & 0.66 & 0.75 & 8.7 & -3.6 \\
\hline
\end{tabular}

Note: $1 . \alpha_{\mathrm{pm}}$ and $\alpha_{\mathrm{pp}}$ were calculated using Equation (3.68) and (3.55) and the experimental values of $\mathrm{m}_{\mathrm{p}}$ and $\mathrm{m}_{\mathrm{c}}$

2. $\alpha_{\mathrm{pm}}$ and $\alpha_{\mathrm{pp}}$ predicted using Equations (5.5a) and (5.6a)

3 . Error $=[($ Estimated value - Actual value $) /$ Actual value $] * 100$

\subsubsection{Validation of the fouling attachment models with different heterogeneous membranes}

As part of this study, it was crucial to examine the predictive capability of the complete set of the models, the mechanistic models and the correlations for $\alpha_{\mathrm{pm}}$ and $\alpha_{\mathrm{pp}}$, applied to different operating conditions, and various heterogeneous membranes of different materials and different MWCO values, so as to ensure the reliability and accuracy of the developed correlations for $\alpha_{\mathrm{pm}}$ and $\alpha_{\mathrm{pp}}$. Ultrafilic and PVDF membranes with a MWCO of 100,000, and Cellulose acetate with a MWCO of 20,000, were tested for this purpose.

The pore size distribution had a significant effect on the mass of fouling retained by the membrane, and the increase in transmembrane pressure, as shown in Tables 5.17 and 5.18, respectively. The cellulose acetate membrane with a MWCO of 20,000 had 0.01 microns as 80 $\%$ of the pore size distribution, which resulted in the least experimental values of the mass of fouling and the increase in transmembrane pressure. Increasing the pore size in case of Ultrafilic and PVDF membranes with MWCO of 100,000 resulted in more flow through the membrane pores. Hence, the chances for the particle-to-particle and particle-to-membrane collision and attachment increased. Consequently, the mass of fouling and the increase in transmembrane pressure increased, at same operating conditions, as illustrated in Tables 5.17 and 5.18, respectively. 
Furthermore, Tables 5.17 and 5.18 present the comparison between the predicted and the experimental values of the mass of fouling and the increase in transmembrane pressure at different operating conditions using the Ultrafilic, cellulose acetate, PVDF, and Polysulfone membranes. The fouling attachments $\left(\alpha_{\mathrm{pm}}\right.$ and $\left.\alpha_{\mathrm{pp}}\right)$ were estimated using the developed correlations in Equations (5.5a) and (5.6a). In addition to the physical properties of each membrane, these fouling attachments were then used in Equations (3.55) and (3.68) to predict the total mass of fouling retained by the membrane's surface, and in Equation (3.65) to predict the increase in transmembrane pressure.

Table 5.17: Agreement between the mass of fouling measured experimentally using different membranes and the mass of fouling predicted using the fouling attachments estimated from the predictive models

\begin{tabular}{|c|c|c|c|c|c|c|c|c|c|c|c|c|c|c|c|c|c|}
\hline \multirow{3}{*}{$\begin{array}{l}\text { Exp } \\
\text { No. }\end{array}$} & \multirow{2}{*}{\multicolumn{3}{|c|}{$\begin{array}{l}\text { Operating } \\
\text { Conditions }\end{array}$}} & \multirow{2}{*}{\multicolumn{2}{|c|}{ Predective Models }} & \multicolumn{3}{|c|}{ Ultrafilic } & \multicolumn{3}{|c|}{ CA } & \multicolumn{3}{|c|}{ PVDF } & \multicolumn{3}{|c|}{ PS } \\
\hline & & & & & & \multirow{2}{*}{$\begin{array}{c}\text { Pred.* } \\
m_{t} \\
{\left[\mathrm{~kg} / \mathrm{m}^{2}\right]}\end{array}$} & \multirow{2}{*}{$\begin{array}{c}\operatorname{Exp} \\
m_{t} \\
{\left[\mathrm{~kg} / \mathrm{m}^{2}\right]}\end{array}$} & \multirow{2}{*}{$\begin{array}{c}\text { Error } \\
\%\end{array}$} & \multirow{2}{*}{$\begin{array}{c}\text { Pred.* } \\
m_{t} \\
{\left[\mathrm{~kg} / \mathrm{m}^{2}\right]}\end{array}$} & \multirow{2}{*}{$\begin{array}{c}\text { Exp } \\
m_{t} \\
{\left[\mathrm{~kg} / \mathrm{m}^{2}\right]}\end{array}$} & \multirow{2}{*}{$\begin{array}{c}\text { Error } \\
\%\end{array}$} & \multirow{2}{*}{$\begin{array}{c}\text { Pred.* } \\
m_{t} \\
{\left[\mathrm{~kg} / \mathrm{m}^{2}\right]}\end{array}$} & \multirow{2}{*}{$\begin{array}{c}\operatorname{Exp} \\
m_{t} \\
{\left[\mathrm{~kg} / \mathrm{m}^{2}\right]}\end{array}$} & \multirow{2}{*}{$\begin{array}{c}\text { Error } \\
\%\end{array}$} & \multirow{2}{*}{$\begin{array}{c}\text { Pred.* } \\
m_{t} \\
{\left[\mathrm{~kg} / \mathrm{m}^{2}\right]}\end{array}$} & \multirow{2}{*}{$\begin{array}{c}\operatorname{Exp} \\
m_{t} \\
{\left[\mathrm{~kg} / \mathrm{m}^{2}\right]}\end{array}$} & \multirow{2}{*}{$\begin{array}{c}\text { Error } \\
\%\end{array}$} \\
\hline & $\begin{array}{c}P \\
{[p s i]}\end{array}$ & $\underset{[\text { LPM] }}{\mathrm{Q}}$ & $\begin{array}{c}\mathrm{C}_{\mathrm{f}} \\
{\left[\mathrm{kg} / \mathrm{m}^{3}\right]}\end{array}$ & Eqn (5) & Eqn (6) & & & & & & & & & & & & \\
\hline 1 & 15 & 1 & 0.78 & 0.78 & 0.67 & 0.0067 & 0.0061 & 9.8 & 0.002 & 0.0019 & 8.1 & 0.009 & 0.014 & -33.3 & 0.0029 & 0.0031 & -6.5 \\
\hline 2 & 15 & 7 & 0.78 & 0.31 & 0.26 & 0.0049 & 0.0054 & -9.3 & 0.0014 & 0.0015 & -6.7 & 0.0081 & 0.011 & -26.4 & 0.0026 & 0.0025 & 2.2 \\
\hline 3 & 25 & 4 & 1.3 & 0.80 & 0.76 & 0.0219 & 0.025 & -12.4 & 0.006 & 0.0065 & -7.7 & 0.033 & 0.05 & -34.0 & 0.015 & 0.0135 & 11.1 \\
\hline 4 & 35 & 7 & 1.82 & 0.82 & 0.84 & 0.0324 & 0.03 & 8.0 & 0.008 & 0.0075 & 6.7 & 0.0218 & 0.04 & -45.5 & 0.0135 & 0.015 & -10.0 \\
\hline
\end{tabular}

* Predicted $m_{t}$ was calculated using Equation (3.55) plus Equation (3.68) using the estimated fouling attachments $\alpha_{\mathrm{pm}} \& \alpha_{\mathrm{pp}}$ from Equations (5.5a) and (5.6a).

Table 5.18: Agreement between the increase in transmembrane pressure measured experimentally using different membranes and the increase in transmembrane pressure predicted using the fouling attachments estimated from the predictive models

\begin{tabular}{|c|c|c|c|c|c|c|c|c|c|c|c|c|c|c|c|c|c|}
\hline \multirow{3}{*}{$\begin{array}{l}\text { Exp } \\
\text { No. }\end{array}$} & \multirow{2}{*}{\multicolumn{3}{|c|}{$\begin{array}{l}\text { Operating } \\
\text { Conditions }\end{array}$}} & \multirow{2}{*}{\multicolumn{2}{|c|}{ Predective Models }} & \multicolumn{3}{|c|}{ Ultrafilic } & \multicolumn{3}{|c|}{ CA } & \multicolumn{3}{|c|}{ PVDF } & \multicolumn{3}{|c|}{ PS } \\
\hline & & & & & & \multirow[b]{2}{*}{$\begin{array}{c}\text { Pred.* } \\
P^{\prime}\end{array}$} & \multirow[b]{2}{*}{$\begin{array}{c}\text { Exp. } \\
P^{\prime}\end{array}$} & \multirow[b]{2}{*}{$\begin{array}{c}\text { Error } \\
\%\end{array}$} & \multirow[b]{2}{*}{$\begin{array}{c}\text { Pred.* } \\
P^{\prime}\end{array}$} & \multirow[b]{2}{*}{$\begin{array}{c}\text { Exp. } \\
P^{\prime}\end{array}$} & \multirow[b]{2}{*}{$\begin{array}{c}\text { Error } \\
\%\end{array}$} & \multirow[b]{2}{*}{$\begin{array}{c}\text { Pred.* } \\
P^{\prime}\end{array}$} & \multirow[b]{2}{*}{$\begin{array}{c}\text { Exp. } \\
P^{\prime}\end{array}$} & \multirow[b]{2}{*}{$\begin{array}{c}\text { Error } \\
\%\end{array}$} & \multirow[b]{2}{*}{$\begin{array}{c}\text { Pred.* } \\
P^{\prime}\end{array}$} & \multirow[b]{2}{*}{$\begin{array}{c}\text { Exp. } \\
P^{\prime}\end{array}$} & \multirow[b]{2}{*}{$\begin{array}{c}\text { Error } \\
\%\end{array}$} \\
\hline & $\begin{array}{c}\mathrm{P} \\
\text { [psi] }\end{array}$ & $\begin{array}{c}\mathrm{Q} \\
{[\text { LPM] }}\end{array}$ & $\begin{array}{c}\mathrm{C}_{\mathrm{f}} \\
{\left[\mathrm{kg} / \mathrm{m}^{3}\right]}\end{array}$ & Eqn (5) & Eqn (6) & & & & & & & & & & & & \\
\hline 1 & 15 & 1 & 0.78 & 0.78 & 0.67 & 1.41 & 1.5 & -6.0 & 0.56 & 0.5 & 12.0 & 3.57 & 5 & -28.6 & 1.12 & 1 & 12.0 \\
\hline 2 & 15 & 7 & 0.78 & 0.31 & 0.26 & 1.13 & 1 & 13.0 & 0.46 & 0.5 & -8.0 & 2.18 & 4 & -45.5 & 0.465 & 0.5 & -7.0 \\
\hline 3 & 25 & 4 & 1.3 & 0.80 & 0.76 & 9.1 & 8 & 13.8 & 1.33 & 1.5 & -11.3 & 6.11 & 10 & -38.9 & 4.73 & 5 & -5.4 \\
\hline 4 & 35 & 7 & 1.82 & 0.82 & 0.84 & 8.1 & 8.5 & -4.7 & 2.12 & 2 & 6.0 & 5.89 & 9 & -34.6 & 6.43 & 6 & 7.2 \\
\hline
\end{tabular}

* Predicted $P^{\prime}$ was calculated using Equation (3.65) using the estimated fouling attachments $\alpha_{\mathrm{pm}} \& \alpha_{\mathrm{pp}}$ from Equations (5.5a) and (5.6a).

As shown in Table 5.17, the mass of fouling measured experimentally corresponds to the mass of fouling predicted using the fouling attachments predictive models from Equations (5.5a) and (5.6a), with error range of $8.0-12.4 \%, 6.7-8.1 \%$, and $2.2-11.1 \%$ for the Ultrafilic, cellulose acetate, and Polysulfone, respectively. Arguably, these error ranges could be caused by the 
complexity of the model's calculation, which considers each particle size with each pore size, a dynamic that may be executed somewhat differently during the modeling, from the real fouling phenomenon. However, a high error range of 26.4-45.5\% between the mass of fouling predicted using the estimated fouling attachment and the experimental value was observed in case of PVDF membrane. In terms of the increase in the transmembrane pressure, as shown in Table 5.18, the experimental values corresponded with the values predicted by Equation (3.65) using the fouling attachments predicted from Equation (5.5a) and Equation (5.6a), with the error range of $\pm 4.7-13.8 \%, \pm 6.0-12.0 \%$, and $\pm 5.4-12.0 \%$ for Ultrafilic, cellulose acetate, and Polysulfone, respectively. Nevertheless, a very high error range of 28.6- $45.5 \%$ was obtained with PVDF membrane.

To investigate the nature of the high error, it was necessary to calculate the fouling attachments ( $\alpha_{\mathrm{pp}}$ and $\alpha_{\mathrm{pm}}$ ) from Equations (3.55) and (3.68), using $m_{c}$ and $m_{p}$ values measured experimentally, for the ultrafiltration experiments specifically using the PVDF membrane. Figure 5.37 presents the correlation between the fouling attachment estimated from Equation (5.5a) and Equation (5.6a), and the fouling attachments from Equations (3.55) and (3.68), using $m_{c}$ and $m_{p}$ values measured experimentally. Notably, the depositional attachment estimated from the predicted model (Equation (5.5a)) does not agree with the actual value, as can be seen in Figure 5.37 (a). All the estimated values are less than the actual ones, with an error range of 14.0 to 54.0 $\%$. It is relevant to note that the zeta potential of the latex particles is approximately $-26.61 \mathrm{mV}$. This would result in a lower repulsive force with the PVDF membrane, which has the zeta potential of $-2.5 \mathrm{mV}$, as compared with other hydrophilic membranes with higher negative charges. The actual depositional attachments thereby were greater than the ones predicted by the model due to the much higher attraction forces between the latex particles and the membrane surface. Consequently, the experimental values for the mass of fouling and the increase in transmembrane pressure are higher than the estimated values. The depositional attachment model was obtained based on the experimental data of hydrophilic Polysulfone membrane with zeta potential of $-42.4 \mathrm{mV}$. Therefore, the depositional attachment (particle-to-membrane) estimated from Equation (5.5a) can only be used for hydrophilic membranes with high negative charges. On the other hand, the coagulation attachment estimated from Equation (5.6) agrees well with the experimental values, even with the hydrophobic PVDF membrane, as shown in Figure 5.37 
(b), since the hydrophilicity of the membrane would not have any effect on the particle-toparticle attachment.

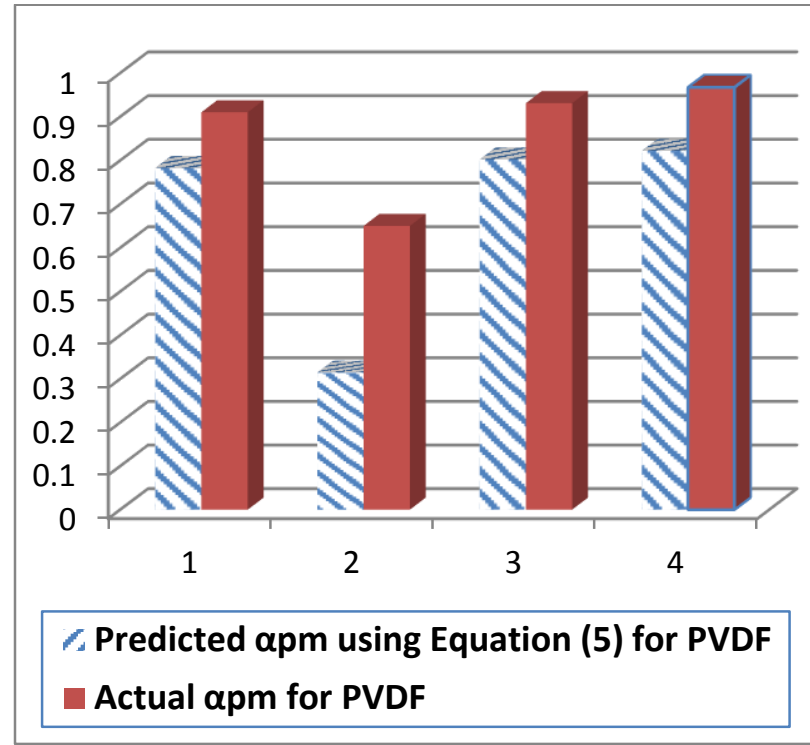

(a)

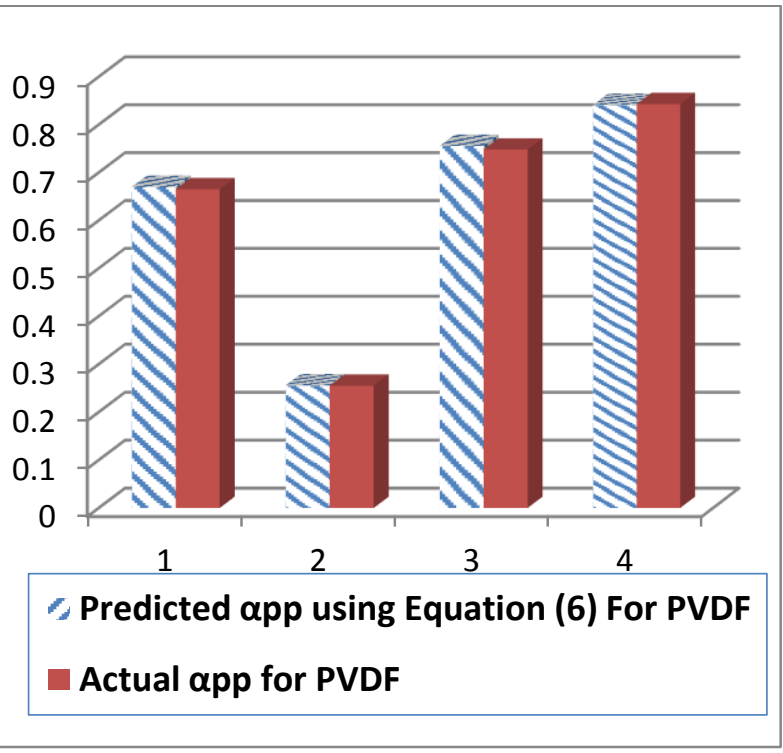

(b)

Figure 5.37: Actual and predicted fouling attachment probabilities for hydrophobic PVDF membrane at different operating conditions : (a) Depositional attachment probability $\left(\alpha_{\mathrm{pm}}\right)$ , (b) Coagulation attachment probability $\left(\alpha_{\mathrm{pp}}\right)$

Thus, according to this model, the estimated depositional attachment values can only be used for hydrophilic membranes with high negative charges. This indicates that the zeta potential of the membrane surface must be considered to be the predominant factor in ultrafiltation membrane fouling. As a result, it was crucial to introduce the surface charge as zeta potential $(\zeta)$ of the membrane surface into our predictive model so as to be generalized for both hydrophilic and hydrophobic membranes.

\subsubsection{Fouling attachments models using heterogeneous hydrophilic and hydrophobic membranes}

According to the results of the Section 5.6.3, the model will not be sufficient for a comprehensive understanding of the fouling potential of the latex solution using hydrophilic and hydrophobic membranes. The model development is necessary for the elucidation of the underlying factors affecting membrane fouling and fouling attachments through the particle-toparticle and particle-to-membrane attachments. In the current study the Central Composite 
Centered (CCC) Response Surface Method (RSM) was selected as the optimal experimental design method. A total of thirty experiments was performed and the fouling attachment probabilities $\left(\alpha_{\mathrm{pp}}\right.$ and $\left.\alpha_{\mathrm{pm}}\right)$ were calculated for each of the experimental runs, as shown in Table 5.19. The depositional attachment probability $\alpha_{\mathrm{pm}}$ and the coagulation fouling probabilities $\left(\alpha_{\mathrm{pp}}\right)$ vary between the ranges of 0.35 to 0.99 and 0.22 to 0.98 , respectively.

TABLE 5.19: Experimental parameters and results based on the experimental design for the fouling attachment probabilities using Polysulfone membrane

\begin{tabular}{|c|c|c|c|c|c|c|c|c|c|c|}
\hline $\begin{array}{c}\text { Run } \\
\#\end{array}$ & $\begin{array}{l}\text { TMP } \\
\text { [psi] }\end{array}$ & $\begin{array}{c}\text { Coded } \\
\text { Factor } \\
\text { of } P\end{array}$ & $\begin{array}{c}\mathrm{Q} \\
{[\mathrm{LPM}]}\end{array}$ & $\begin{array}{c}\text { Coded } \\
\text { Factor } \\
\text { of } Q\end{array}$ & $\begin{array}{c}\mathrm{C}_{\mathrm{f}} \\
{\left[\mathrm{kg} / \mathrm{m}^{3}\right]}\end{array}$ & $\begin{array}{c}\text { Coded } \\
\text { Factor } \\
\text { of } C_{f}\end{array}$ & $\begin{array}{c}\text { Initial } \\
\zeta \\
{[\mathrm{mV}]}\end{array}$ & $\begin{array}{c}\text { Coded } \\
\text { Factor } \\
\text { of } \zeta\end{array}$ & $\begin{array}{c}\alpha_{\mathrm{pm}} \\
\text { [dimensionless] }\end{array}$ & $\begin{array}{c}\alpha_{p p} \\
\text { [dimensionless] }\end{array}$ \\
\hline 1 & 35 & 1 & 6.0 & 1 & 1.82 & 1 & -20 & 1 & 0.92 & 0.91 \\
\hline 2 & 15 & -1 & 6.0 & 1 & 0.78 & -1 & -20 & 1 & 0.60 & 0.58 \\
\hline 3 & 35 & 1 & 3.0 & -1 & 0.78 & -1 & -20 & 1 & 0.91 & 0.94 \\
\hline 4 & 25 & 0 & 4.5 & 0 & 0.26 & -2 & -30 & 0 & 0.78 & 0.22 \\
\hline 5 & 15 & -1 & 3.0 & -1 & 1.82 & 1 & -40 & -1 & 0.75 & 0.63 \\
\hline 6 & 25 & 0 & 4.5 & 0 & 1.30 & 0 & -30 & 0 & 0.93 & 0.74 \\
\hline 7 & 35 & 1 & 6.0 & 1 & 0.78 & -1 & -20 & 1 & 0.86 & 0.82 \\
\hline 8 & 35 & 1 & 6.0 & 1 & 0.78 & -1 & -40 & -1 & 0.60 & 0.80 \\
\hline 9 & 25 & 0 & 4.5 & 0 & 1.30 & 0 & -30 & 0 & 0.91 & 0.75 \\
\hline 10 & 15 & -1 & 6.0 & 1 & 1.82 & 1 & -40 & -1 & 0.63 & 0.45 \\
\hline 11 & 45 & 2 & 4.5 & 0 & 1.30 & 0 & -30 & 0 & 0.96 & 0.78 \\
\hline 12 & 25 & 0 & 7.5 & 2 & 1.30 & 0 & -30 & 0 & 0.84 & 0.68 \\
\hline 13 & 25 & 0 & 4.5 & 0 & 1.30 & 0 & -30 & 0 & 0.92 & 0.74 \\
\hline 14 & 15 & -1 & 6.0 & 1 & 1.82 & 1 & -20 & 1 & 0.62 & 0.61 \\
\hline 15 & 25 & 0 & 4.5 & 0 & 2.34 & 2 & -30 & 0 & 0.97 & 0.98 \\
\hline 16 & 35 & 1 & 3.0 & -1 & 1.82 & 1 & -40 & -1 & 0.91 & 0.92 \\
\hline 17 & 25 & 0 & 4.5 & 0 & 1.30 & 0 & -30 & 0 & 0.92 & 0.74 \\
\hline 18 & 25 & 0 & 1.5 & -2 & 1.30 & 0 & -30 & 0 & 0.96 & 0.80 \\
\hline 19 & 15 & -1 & 3.0 & -1 & 0.78 & -1 & -20 & 1 & 0.92 & 0.54 \\
\hline 20 & 35 & 1 & 3.0 & -1 & 0.78 & -1 & -40 & -1 & 0.75 & 0.90 \\
\hline 21 & 15 & -1 & 3.0 & -1 & 0.78 & -1 & -40 & -1 & 0.68 & 0.53 \\
\hline 22 & 35 & 1 & 6.0 & 1 & 1.82 & 1 & -40 & -1 & 0.88 & 0.91 \\
\hline 23 & 35 & 1 & 3.0 & -1 & 1.82 & 1 & -20 & 1 & 0.96 & 0.97 \\
\hline 24 & 25 & 0 & 4.5 & 0 & 1.30 & 0 & -10 & 2 & 0.99 & 0.75 \\
\hline 25 & 15 & -1 & 3.0 & -1 & 1.82 & 1 & -20 & 1 & 0.93 & 0.89 \\
\hline 26 & 25 & 0 & 4.5 & 0 & 1.30 & 0 & -50 & -2 & 0.35 & 0.71 \\
\hline
\end{tabular}




\begin{tabular}{|l|c|c|c|c|c|c|c|c|c|c|}
27 & 15 & -1 & 6.0 & 1 & 0.78 & -1 & -40 & -1 & 0.45 & 0.32 \\
\hline 28 & 25 & 0 & 4.5 & 0 & 1.30 & 0 & -30 & 0 & 0.94 & 0.73 \\
\hline 29 & 25 & 0 & 4.5 & 0 & 1.30 & 0 & -30 & 0 & 0.91 & 0.74 \\
\hline 30 & 5 & -2 & 4.5 & 0 & 1.30 & 0 & -30 & 0 & 0.71 & 0.50 \\
\hline
\end{tabular}

Based on the ANOVA analysis and the multi regression method, the experimental data of the fouling attachments $\left(\alpha_{\mathrm{pp}}\right.$ and $\left.\alpha_{\mathrm{pm}}\right)$ were found to accurately correspond with the linear model. Equation (5.7) and Equation (5.8) provide specific models for the depositional attachment $\left(\alpha_{\mathrm{pm}}\right)$ and the coagulational attachment $\left(\alpha_{\mathrm{pp}}\right)$, with the coefficients of determination $\left(\mathrm{R}^{2}\right)$ of $95 \%$ and $97 \%$, respectively. Notably, the fouling attachment using the Polysulfone heterogeneous membranes was not significantly affected by the interaction between the operating conditions.

$$
\begin{aligned}
& \alpha_{\mathrm{pm}}=+0.22+0.0528 \times \mathrm{TMP}[\mathrm{psi}]-0.0112 \times \mathrm{Q}[\mathrm{LPM}]+0.0804 \times \mathrm{C}_{\mathrm{f}}\left[\mathrm{kg} / \mathrm{m}^{3}\right]+\begin{array}{r}
0.025 \times \zeta[\mathrm{mV}] \\
\text { Equation }(5.7 \mathrm{a})
\end{array} \\
& \alpha_{\mathrm{pm}}=+0.22+0.0528 \times \mathrm{TMP}[\mathrm{psi}]-0.001075 \times v[\mathrm{~cm} / \mathrm{s}]+0.0804 \times \mathrm{C}_{\mathrm{f}}\left[\mathrm{kg} / \mathrm{m}^{3}\right]+0.025 \times \zeta[\mathrm{mV}]
\end{aligned}
$$

Equation (5.7b)

$$
\begin{array}{r}
\alpha_{\mathrm{pp}}=+0.30+0.025 \times \mathrm{TMP}[\mathrm{psi}]-0.069 \times \mathrm{Q}[\mathrm{LPM}]+0.082 \times \mathrm{C}_{\mathrm{f}}\left[\mathrm{kg} / \mathrm{m}^{3}\right]+1 \times 10^{-7} \times \zeta[\mathrm{mV}] \\
\quad \text { Equation }(5.8 \mathrm{a}) \\
\alpha_{\mathrm{pp}}=+0.30+0.025 \times \mathrm{TMP}[\mathrm{psi}]-0.006622 \times v[\mathrm{~cm} / \mathrm{s}]+0.082 \times \mathrm{C}_{\mathrm{f}}\left[\mathrm{kg} / \mathrm{m}^{3}\right]+1 \times 10^{-7} \times \zeta[\mathrm{mV}]
\end{array}
$$

Equation (5.8b)

The validity of the model coefficients was determined by an ANOVA analysis of the results, as presented in Table 5.20. The p-value indicates the probability value used to set the level of confidence for the F-test, as well as, to ascertain the importance of each coefficient. According to the regression coefficients and probability values (p-value) shown in Table 5.20, the operating conditions (transmembrane pressure, feed flow rate, and feed concentration) are significantly correlated to both fouling attachments. However, the charge on the membrane surface as represented by the zeta potential value was found to be only significant for the depositional fouling attachment. The zeta potential did not have a substantial effect on the coagulation attachment (particle-to particle attachment), as confirmed by the experimental data and presented in Section 5.5. On the other hand, increasing the zeta potential of the membrane surface, by lowering the negatively charged value, resulted in an increased depositional attachment. Therefore, in order to reduce membrane fouling, the zeta potential should be decreased by raising the negativity of the surface charge. 
Table 5.20: Regression coefficients and probability values of statistical analysis using Polysulfone membrane

\begin{tabular}{|c|l|c|c|c|c|}
\hline $\begin{array}{c}\text { Coded } \\
\text { Factor }\end{array}$ & \multicolumn{1}{|c|}{ Factor } & $\begin{array}{c}\text { Coefficient } \\
\text { for } \alpha_{\mathrm{pm}}\end{array}$ & p-value & $\begin{array}{c}\text { Coefficient } \\
\text { for } \alpha_{\mathrm{pp}}\end{array}$ & p-value \\
\hline TMP & Pressure & 0.0528 & 0.0003 & 0.025 & $<0.0001$ \\
\hline $\mathrm{Q}$ & Feed Flow rate & -0.0112 & 0.001 & -0.069 & 0.0337 \\
\hline $\mathrm{C}_{\mathrm{f}}$ & Feed Concentration & 0.0804 & 0.0049 & 0.082 & 0.0001 \\
\hline $\mathrm{Z}$ & Zeta potential & 0.025 & $<0.0001$ & $1 \times 10^{-7}$ & 0.1006 \\
\hline
\end{tabular}

Notes:

1. Values of "p-value "less than 0.05 indicate model terms are significant.

2. In the case of $\alpha_{\mathrm{pm}}$ : TMP $, \mathrm{Q}, \mathrm{C}_{\mathrm{f}}$, and $\zeta$ are significant model terms.

3. In the case of $\alpha_{\mathrm{pp}}$ : TMP, $\mathrm{Q}$, and $\mathrm{C}_{\mathrm{f}}$ are significant model terms.

The influence of the transmembrane pressure, feed flow rate, and feed concentration on the fouling attachment is shown in Table 5.19. For example, experimental runs ( $20 \& 21)$ and (23 \& 25) reflect the effect of the transmembrane pressure, while experimental runs (12 \& 13) and $(17 \& 18)$ indicate the influence of the feed flow rate, while experimental runs ( $13 \& 15)$ showcase the effects of feed concentration. Either increasing the transmembrane pressure, or raising the feed concentrations, resulted in an increase in both fouling attachments. On the other hand, an increase in the feed flow rate caused both fouling attachments to decrease. Regression coefficients in Equation 5.7a and Equation 5.8a reflect the extent of the impact of each operating condition on $\alpha_{\mathrm{pm}} \& \alpha_{\mathrm{pp}}$ (Table 5.19). The transmembrane pressure had more impact on the depositional attachment, while the feed flow rate and the feed concentration have more influence on the coagulation attachment, emphasizing and re-confirming the experimental results obtained in Section 5.3.2. Accordingly, at constant operating conditions and featuring the same membrane surface charge so as to minimize the attachment probabilities $\left(\alpha_{\mathrm{pm}} \& \alpha_{\mathrm{pp}}\right)$ using the Polysulfone heterogeneous membranes, the transmembrane pressure and the feed concentration are expected to decrease while the feed flow rate should increase.

Table 5.19 (runs number 7 and 8) shows that at a transmembrane pressure of $35 \mathrm{psi}$, feed flow rate of $6 \mathrm{LPM}$, and feed concentration of $0.78 \mathrm{~kg} / \mathrm{m}^{3}$, and once the surface negativity of Polysulfone membrane increased by $100 \%$ from $-20.00 \mathrm{mV}$ to $-40.00 \mathrm{mV}$, the particle-to-particle attachment only decreased by $2.4 \%$, from 0.82 to 0.80 . Moreover, as indicated in Table 5.19 (run numbers 26 and 28), at a transmembrane pressure of 25 psi, feed flow rate of 4.5 LPM, feed concentration of $1.3 \mathrm{~kg} / \mathrm{m}^{3}$, and once the surface negativity of Polysulfone membrane decreased by $40 \%$ from $-50.00 \mathrm{mV}$ to $-30.00 \mathrm{mV}$, the particle -to-particle attachment was slightly raised by 
$2.8 \%$ from 0.71 to 0.73 . These results suggest that the coagulation attachment is independent of the membrane hydrophilicty. The optimized conditions indicate that the minimum response for both of the fouling attachment probabilities could be obtained at the minimum transmembrane pressure, minimum feed concentration, maximum feed flow rate, and highest negative charge on the membrane surface, within the range of process parameters used in the present study.

\subsubsection{Validation of the attachment models with different heterogeneous membranes}

This study intended to examine the predictive capability of a complete set of models, including the mechanistic models and the correlations for $\alpha_{\mathrm{pm}}$ and $\alpha_{\mathrm{pp}}$, for a variety of operating conditions with various heterogeneous membranes featuring different materials, MWCO values, and surface charges. This analysis was conducted in order to verify the accuracy and reliability of the developed correlations for $\alpha_{\mathrm{pm}}$ and $\alpha_{\mathrm{pp}}$. Ultrafilic and PVDF membranes with a MWCO of 100,000, and Cellulose acetate membranes with a MWCO of 20,000, were specifically tested for this purpose. Table 5.21 reflects the agreement between the mass of fouling measured experimentally and the value predicted from the mechanistic models using the fouling attachments estimated by the correlations for $\alpha_{\mathrm{pm}}$ and $\alpha_{\mathrm{pp}}$. For Polysulfone membrane, the validation experiments were performed over a range of operating conditions rather than the ones used in the experimental design. The mass of fouling measured experimentally corresponded to the value predicted through the fouling attachment predictive models, with the error range of 2.59.1\% (Run number 1 to 8 ) and 4.0-14.3\% (Run number 9 to 11) for hydrophilic and hydrophobic PVDF membranes, respectively. Admittedly, the complexity of the model's calculation could be the responsible of this error. As the model considers each particle size with each pore size, while the real fouling phenomenon features an alternative dynamic that may be executed somewhat differently. 
Table 5.21: Comparison of the mass of fouling measured experimentally and the value estimated from the predictive models for various membranes

\begin{tabular}{|c|c|c|c|c|c|c|c|c|c|c|}
\hline $\begin{array}{c}\text { Run } \\
\#\end{array}$ & $\begin{array}{c}\text { Membrane } \\
\text { Material }\end{array}$ & $\begin{array}{l}\text { TMP } \\
\text { [psi] }\end{array}$ & $\begin{array}{c}\mathrm{Q} \\
\text { [LPM] }\end{array}$ & $\begin{array}{c}C_{f} \\
{\left[\mathrm{~kg} / \mathrm{m}^{3}\right]}\end{array}$ & $\zeta[\mathrm{mV}]$ & $\begin{array}{c}\alpha_{\mathrm{pm}} \\
\text { [dimensionless] } \\
\text { Predicted }\end{array}$ & $\begin{array}{c}\alpha_{\mathrm{pp}} \\
\text { [dimensionless] } \\
\text { Predicted }\end{array}$ & $\left|\begin{array}{c}\text { Pred.* } \\
m_{t} \\
{\left[\mathrm{~kg} / \mathrm{m}^{2}\right]}\end{array}\right|$ & $\begin{array}{l}\operatorname{Exp} m_{t} \\
{\left[\mathrm{~kg} / \mathrm{m}^{2}\right]}\end{array}$ & $\begin{array}{c}\text { Error } \\
\%\end{array}$ \\
\hline 1 & Polysulfone & 25 & 7.5 & 1.30 & -25.00 & 0.94 & 0.51 & 0.0123 & 0.0120 & 2.5 \\
\hline 2 & Polysulfone & 15 & 4.0 & 1.30 & -10.00 & 0.82 & 0.51 & 0.0155 & 0.0167 & -7.2 \\
\hline 3 & Polysulfone & 25 & 4.0 & 0.78 & -42.40 & 0.34 & 0.83 & 0.0120 & 0.0110 & 9.1 \\
\hline 4 & Polysulfone & 15 & 6.0 & 1.82 & -15.00 & 0.72 & 0.41 & 0.0143 & 0.0155 & -7.7 \\
\hline 5 & Polysulfone & 25 & 4.5 & 1.30 & -28.00 & 0.89 & 0.72 & 0.0155 & 0.0158 & -1.6 \\
\hline 6 & $\begin{array}{c}\text { cellulose } \\
\text { acetate }\end{array}$ & 25 & 4.5 & 1.30 & -33.90 & 0.75 & 0.72 & 0.0064 & 0.0061 & 4.9 \\
\hline 7 & Ultrafilic & 25 & 4.5 & 2.34 & -41.50 & 0.64 & 0.81 & 0.0294 & 0.0285 & 3.2 \\
\hline 8 & Ultrafilic & 15 & 7.0 & 1.30 & -41.50 & 0.19 & 0.29 & 0.0080 & 0.0086 & -7.0 \\
\hline 9 & PVDF & 15 & 4.0 & 0.78 & -2.50 & 0.97 & 0.46 & 0.0120 & 0.0125 & -4.0 \\
\hline 10 & PVDF & 15 & 7.0 & 1.30 & -2.50 & 0.98 & 0.30 & 0.0123 & 0.0134 & -8.2 \\
\hline 11 & PVDF & 20 & 4.0 & 0.26 & -2.50 & 0.99 & 0.57 & 0.09 & 0.105 & -14.3 \\
\hline
\end{tabular}

Note: 1. Predicted $* m_{t}$ was calculated using Equation (3.55) plus Equation (3.68) using the estimated fouling attachments $\alpha_{\mathrm{pm}} \&$ $\alpha_{\mathrm{pp}}$ from Equations (5.7a) and (5.8a).

2. The zeta potential of Polysulfone membrane was adjusted using the $\mathrm{pH}$ treatment, as discussed in Section (4.4.6)

As presented in Table 5.22, in the case of the increase in transmembrane pressure, the experimental values correlated with the values estimated using the fouling attachments predictive models, with error ranges of 7.5-10.0\% (Run number 1 to 8), and 3.4-12.3\% (Run number 9 to 11) for hydrophilic and hydrophobic membranes, respectively. Hence, the model prediction of the mass of fouling and the increase in transmembrane pressure agreed quite well with the experimental values for both hydrophilic and hydrophobic membranes. 
Table 5.22: Comparison of the increase in transmembrane pressure measured experimentally and the value calculated from the predictive models for various membranes

\begin{tabular}{|c|c|c|c|c|c|c|c|c|c|c|}
\hline $\begin{array}{c}\text { Run } \\
\#\end{array}$ & $\begin{array}{c}\text { Membrane } \\
\text { Material }\end{array}$ & $\begin{array}{c}\text { TMP } \\
{[\mathrm{psi}]}\end{array}$ & $\begin{array}{c}\mathrm{Q} \\
{[\mathrm{LPM}]}\end{array}$ & $\begin{array}{c}\mathrm{C}_{\mathrm{f}} \\
{\left[\mathrm{kg} / \mathrm{m}^{3}\right]}\end{array}$ & $\zeta[\mathrm{mV}]$ & $\begin{array}{c}\alpha_{\mathrm{pm}} \\
\text { [dimensionless] } \\
\text { Predicted }\end{array}$ & $\begin{array}{c}\alpha_{\mathrm{pp}} \\
\text { [dimensionless] } \\
\text { Predicted }\end{array}$ & $\begin{array}{c}\text { Pred. } \\
\text { Increase } \\
\text { in TMP }\end{array}$ & $\begin{array}{c}\text { Exp. } \\
\text { Increase } \\
\text { in TMP }\end{array}$ & $\begin{array}{c}\text { Error } \\
\%\end{array}$ \\
\hline 1 & Polysulfone & 25 & 7.5 & 1.30 & -25.00 & 0.94 & 0.51 & 3.70 & 4.0 & -7.5 \\
\hline 2 & Polysulfone & 15 & 4.0 & 1.30 & -10.00 & 0.82 & 0.51 & 5.95 & 6.5 & -8.5 \\
\hline 3 & Polysulfone & 25 & 4.0 & 0.78 & -42.40 & 0.34 & 0.83 & 3.77 & 3.5 & 7.7 \\
\hline 4 & Polysulfone & 15 & 6.0 & 1.82 & -15.00 & 0.72 & 0.41 & 6.45 & 6.0 & 7.5 \\
\hline 5 & Polysulfone & 25 & 4.5 & 1.30 & -28.00 & 0.89 & 0.72 & 5.46 & 6.0 & -9.0 \\
\hline 6 & $\begin{array}{c}\text { cellulose } \\
\text { acetate }\end{array}$ & 25 & 4.5 & 1.30 & -33.90 & 0.75 & 0.72 & 1.62 & 1.5 & 8.0 \\
\hline 7 & Ultrafilic & 25 & 4.5 & 2.34 & -41.50 & 0.64 & 0.81 & 10.78 & 10.0 & 7.8 \\
\hline 8 & Ultrafilic & 15 & 7.0 & 1.30 & -41.50 & 0.19 & 0.29 & 2.20 & 2.0 & 10.0 \\
\hline 9 & PVDF & 15 & 4.0 & 0.78 & -2.50 & 0.97 & 0.46 & 4.37 & 4.0 & 9.3 \\
\hline 10 & PVDF & 15 & 7.0 & 1.30 & -2.50 & 0.98 & 0.30 & 4.83 & 5.0 & -3.4 \\
\hline 11 & PVDF & 20 & 4.0 & 0.26 & -2.50 & 0.99 & 0.57 & 3.51 & 4.0 & -12.3 \\
\hline
\end{tabular}

Note: Predicted* increase in the TMP was calculated using Equation (3.65) for $P^{\prime}$, using the estimated fouling attachments $\alpha_{\mathrm{pm}}$ $\& \alpha_{\mathrm{pp}}$ from Equations (5.7a) and (6.8a).

Equation (5.7a) and Equation (5.8a) illustrate that based on the regression coefficient, of the independent variables, the transmembrane pressure had more impact on fouling attachment than the zeta potential of the membrane. However, the results obtained at the validation runs number 3 and 9, in Tables 5.21 and 5.22, suggest that the hydrophobic PVDF membrane with the zeta potential of $-2.50 \mathrm{mV}$ demonstrated a higher fouling capability at a lower transmembrane pressure than the hydrophilic Polysulfone membrane with the zeta potential of $-42.40 \mathrm{mV}$. At the feed flow rate of $4 \mathrm{LPM}$ and the feed concentration of $0.78 \mathrm{~kg} / \mathrm{m}^{3}$, the total mass of fouling was $0.011 \mathrm{~kg} / \mathrm{m}^{2}$, and $0.0125 \mathrm{~kg} / \mathrm{m}^{2}$ after the ultrafiltration process was performed using hydrophilic Polysulfone, and hydrophobic PVDF membranes at 25 psi, and 15 psi, respectively, as shown in Figure 5.38. The specific power consumption was $14.5 \mathrm{~kW} . \mathrm{h} / \mathrm{m}^{3}$ for the Polysulfone membrane, and $15.4 \mathrm{~kW} . \mathrm{h} / \mathrm{m}^{3}$ for PVDF membranes. This could be attributed to the pore size distribution which had a significant effect on the mass of fouling retained by the membrane and caused the increase in transmembrane pressure, as shown in Table 5.21 and Table 5.22. Increasing the pore size in case of PVDF membranes with MWCO of 100,000 resulted in greater flow through the membrane pores, if compared to Polysulfone membrane of MWCO of 60,000. As a result, the chances for particle-to-particle and particle-to-membrane collisions and attachment increased. 
Following the growing particle attachment, the total mass of fouling increased at a lower transmembrane pressure, as reflected by the SEM images in Figure 5.38 (b) and 5.38 (d), as compared to Figure 5.38 (a) and 5.38 (c). Moreover, the higher negative charge of Polysulfone membrane generated a higher level of repulsion between the particles and the membrane surface, and bringing about lower depositional attachment $\left(\alpha_{\mathrm{pm}}\right)$ of 0.34 , as compared to 0.97 for the PVDF hydrophobic membrane. On the other hand, the coagulation attachment $\left(\alpha_{\mathrm{pp}}\right)$ had higher value in case of polysulfone membrane due to the impact of the higher transmembrane pressure on particle-to-particle attachment. From this a conclusion can be drawn that the pore size enhances the influence of membrane hydrophilicity more than the impact of the applied transmembrane pressure at same feed flow rate and under the same feed concentration.

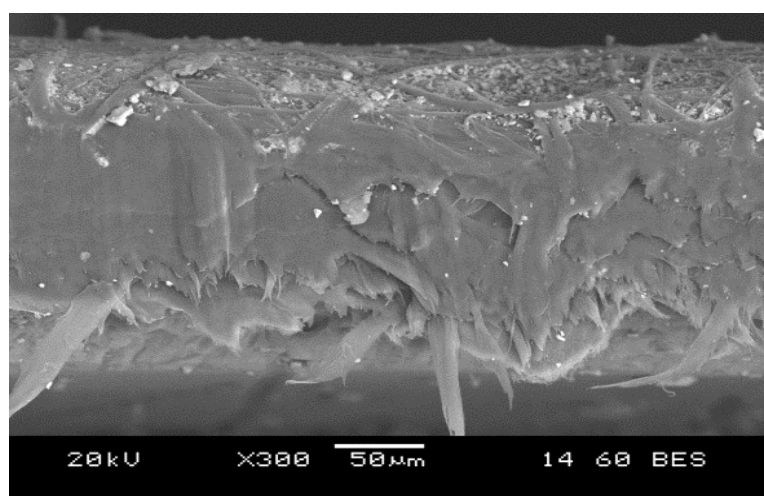

(a)

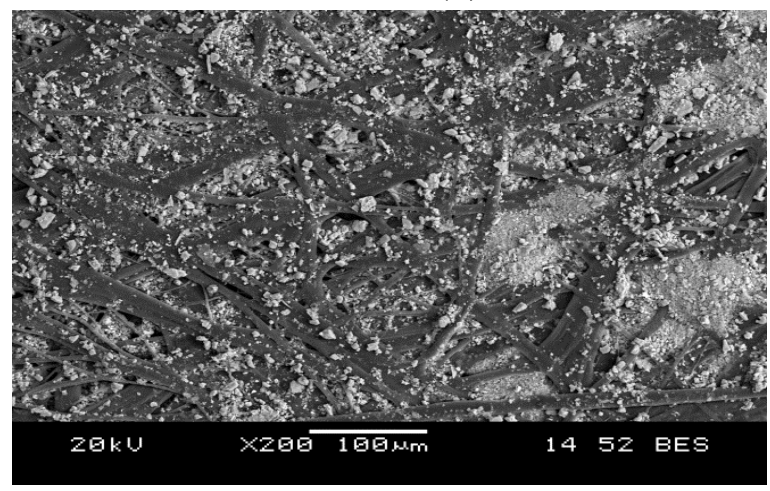

(c)

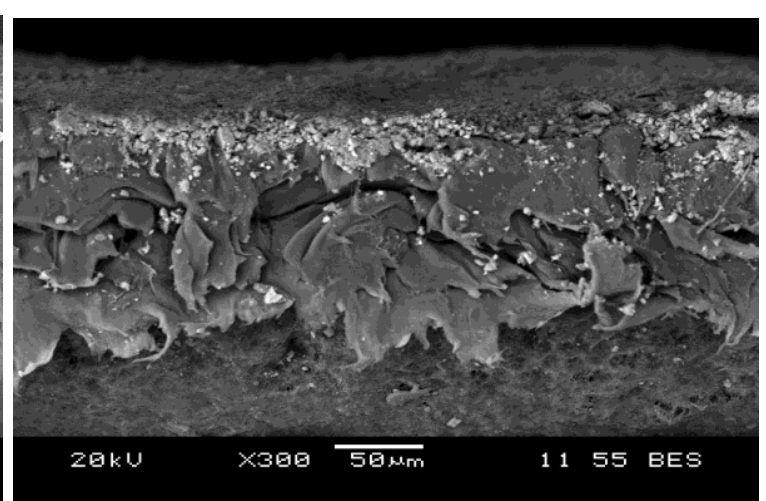

(b)

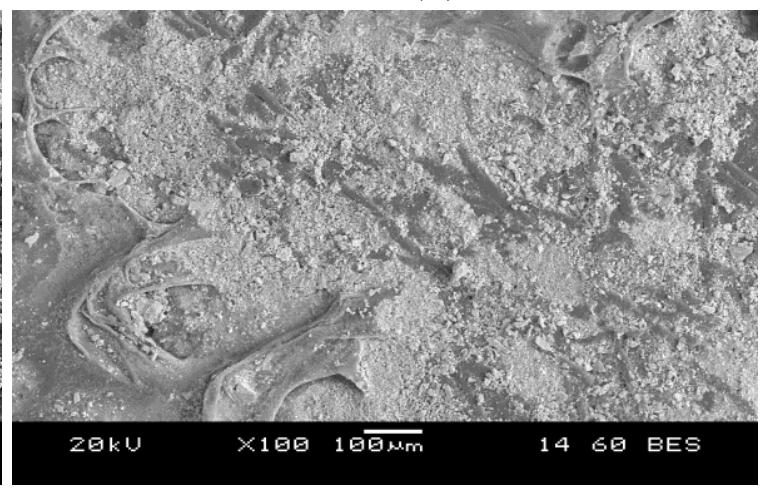

(d)

Figure 5.38: SEM images of membranes after ultrafiltration at $[Q=4 \mathrm{LPM}],\left[\mathrm{C}_{\mathrm{f}}=0.78 \mathrm{~kg} / \mathrm{m}^{3}\right]$ : (a) Side view of the cake height of Polysulfone membrane at TMP of 25 psi, and zeta potential of $\mathbf{- 4 2 . 4 0}$ $\mathrm{mV}$; (b) Side view of the cake height of PVDF membrane at TMP of 15 psi, and zeta potential of $2.50 \mathrm{mV}$ (c) Membrane surface of Polysulfone membrane at TMP of 25 psi, and zeta potential of $42.40 \mathrm{mV}$; (d) Membrane surface of PVDF membrane at TMP of 15 psi, and zeta potential of -2.50 mV 
Equation 5.7a presented that the zeta potential would have a stronger effect on the depositional attachment $\left(\alpha_{\mathrm{pm}}\right)$ than the feed flow rate, while the feed flow rate could be considered the predominant factor in the coagulation attachment $\left(\alpha_{\mathrm{pp}}\right)$ change, as presented in Equation 5.8a. Both equations generated from data with Polysulfone membrane and indeed the case for other heterogeneous membranes used in the present study. At transmembrane pressure of $15 \mathrm{psi}$ and a feed concentration of $1.3 \mathrm{~kg} / \mathrm{m}^{3}$, the depositional attachment using Polysulfone membrane at feed flow rate of 4 LPM was 0.82 , compared to 0.98 for PVDF membrane at 7 LPM, as shown in Table 5.19 (Run 2 and 10). This can be attributed to the ultrafiltration process which is performed using a treated Polysulfone membrane with the zeta potential of $-10.00 \mathrm{mV}$, and as a result, causing less attraction force between latex particles and the membrane surface, especially if compared to PVDF membrane with the original zeta potential of $-2.50 \mathrm{mV}$. This indicates that at a higher feed flow rate the depositional attachment does not decrease as expected due to the influence of the membrane surface charge. Correlations such as this further confirm that the zeta potential has a greater impact on the depostitioanl attachment than the feed flow rate. On the other hand, the coagulation attachment $\left(\alpha_{\mathrm{pp}}\right)$ was found to be 0.51 and 0.3 using hydrophilic Polysulfone membrane at 4 LPM and hydrophobic PVDF membrane at 7 LPM, respectively. This indicates that the fact the feed flow rate had a significant effect on the particle-to-particle attachment, while the coagulation membrane was functioning independently of the membrane surface charge. PVDF with MWCO of 100,000 allows greater flow through the membrane pores, if compared to the Polysulfone membrane of MWCO of 60,000, which resulted in higher chances for particle collisions and attachment. Furthermore, PVDF has a hydrophobic nature with zeta potential $-2.5 \mathrm{mV}$, which increases the chances for greater deposition and higher particle-to-membrane attachment, if compared to Polysulfone membrane with zeta potential of $10 \mathrm{MV}$, as shown in Table 5.21. However, the total mass of fouling was higher in the case of Polysulfone membrane than PVDF, as presented in Table 5.21. This can be attributed to the influence of feed flow rate which reduced the particle-to-particle attachment and the cake layer.

The effect of hydrophilicty of different membranes materials with the same MWCO on fouling attachments, the total mass of fouling, and the increase in the transmembrane pressure was also investigated. At a transmembrane pressure of 15 psi, feed flow rate of 7 LPM, and a feed concentration of $1.3 \mathrm{~kg} / \mathrm{m}^{3}$, using Ultrafilic and PVDF membranes of the same MWCO of 100,000 . Due to the hydrophilicity of untreated Ultrafilic membrane with a zeta potential of - 
$41.50 \mathrm{mV}$, a depositional attachment of 0.19 was obtained, compared to 0.98 with the hydrophobic PVDF membrane with a zeta potential of $-2.50 \mathrm{mV}$. It is relevant to note that the coagulation attachment (particle-to-particle) was similar for both hydrophilic and hydrophobic membranes $(0.29,0.30)$, as shown in Table 5.21. The experimental mass of fouling was 0.0086 $\mathrm{kg} / \mathrm{m}^{2}$ and $0.0134 \mathrm{~kg} / \mathrm{m}^{2}$ for Ultrafilic and PVDF membranes, respectively. The transmembrane pressure increased at a higher rate of 5 psi through the ultrafiltration process with the hydrophobic PVDF membrane due to the greater total mass of fouling, in comparison to 2 psi for the hydrophilic Ultrafilic membrane (Table 5.22). Figure 5.39 presents the SEM images of the membrane surface of Ultrafilic and PVDF membranes at different surface charges after the ultrafiltration process. The hydrophilic Ultrafilic membrane has cleaner pores and a lower total mass of fouling as shown in Figure 5.39 (b), compared to the hydrophobic PVDF membrane in Figure 5.39 (a) at same operating conditions and same MWCO.

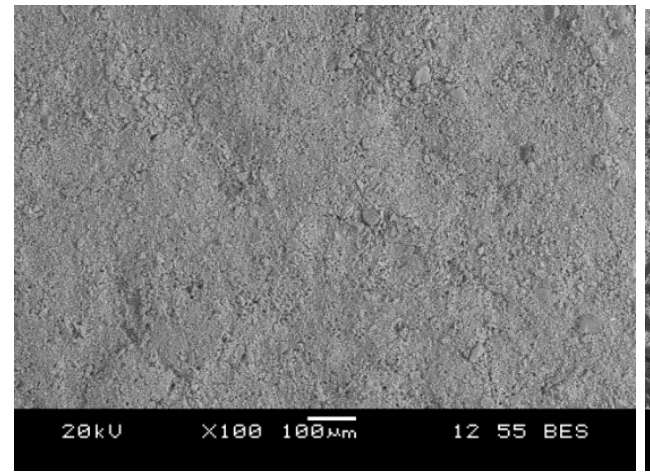

(a)

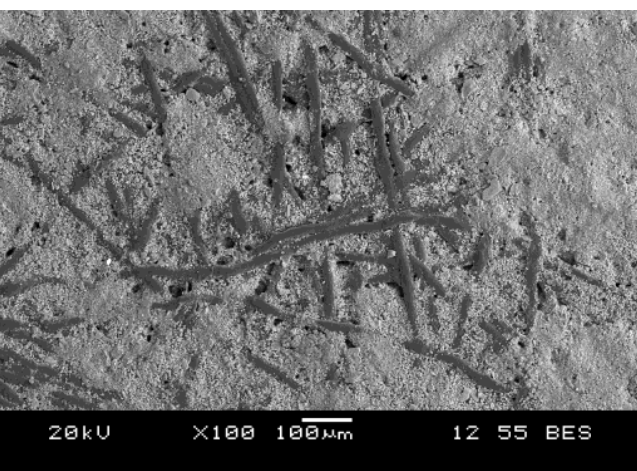

(b)

Figure 5.39: SEM images of membrane surface after ultrafiltration at $[Q=7 \quad L P M],[T M P=15$ psi], $\left[C_{\mathrm{f}}=1.3 \mathrm{~kg} / \mathrm{m}^{3}\right]$ (a) PVDF membrane at zeta potential of $-2.50 \mathrm{mV}$; (b) Ultrafilic membrane at at zeta potential of $-41.50 \mathrm{mV}$

Moreover, the experimental run number 3 which performed at low feed concentration of $0.78 \mathrm{~kg} / \mathrm{m}^{3}$, a transmembrane pressure of $25 \mathrm{psi}$, and feed flow rate of $4 \mathrm{LPM}$, presented in Table 5.21\&5.22, was also performed for 15 minutes and 45 minutes to examine the reliability of the correlations obtained in this study. The results indicated that the mass of fouling predicted from the mechanistic models using the fouling attachments estimated by Equations 5 and 6 were in agreement with the measured experimentally value with the error of $11 \%$, and $14.5 \%$ for 15 minutes, and 45 minutes, respectively. While the predicted increase in transmembrane agreed with the experimental values with the error of $12.2 \%$, and 14.715 minutes, and 45 minutes, respectively. 


\subsubsection{Evaluation of the attachment models for hydrophobic heterogeneous membranes}

As shown in Table 5.23, for the hydrophobic PVDF membrane, the estimated mass of fouling and the increase in the transmembrane pressure using Equations 5.5a and 5.6a (attachment models excluding the zeta potential) have noticeably higher error ranges of $26.7 \%$ to $43.3 \%$ and $25.0 \%$ to $41.8 \%$, respectively. It was attributed to the fact that the depositional attachment model was obtained from the experimental data using hydrophilic Polysulfone membrane with zeta potential of $-42.40 \mathrm{mV}$. However, PVDF membrane is a hydrophobic membrane with a zeta potential of $-2.50 \mathrm{mV}$, which would have a relatively higher attraction force with the latex particles with a zeta potential of $-26.61 \mathrm{mV}$, as compared with other hydrophilic membranes carrying more negative charges. On the other hand, the attachment models presented in Equation 5.7a and 5.8a (including the zeta potential) yielded good agreement between predicted values and experimental data even for the PVDF hydrophobic membranes as demonstrated in Table 5.23. The mass of fouling predicted by the models developed in the present study had a significantly lower error range of 7.8 to $14.3 \%$, as compared to the range of 26.7 to $43.3 \%$ using Equations 5.5a and 5.6a that do not include the effect of the zeta potential of the membrane surface on fouling. Likewise, the increase in the transmembrane pressure error was found within the range of 8.9 to $12.3 \%$, as compared to 25 to $41.8 \%$. Hence, the depositional correlation including the zeta potential is applicable for both hydrophilic and hydrophobic membranes.

Table 5.23: Comparison of the mass of fouling and the increase in transmembrane pressure measured experimentally using PVDF hydrophobic membrane and the predicted values using the fouling attachments estimated from the correlations with and without the zeta potential influence

\begin{tabular}{|c|c|c|c|c|c|c|c|c|c|c|c|c|c|c|c|c|c|}
\hline \multirow{2}{*}{$\begin{array}{l}\text { Exp } \\
\text { No. }\end{array}$} & \multicolumn{3}{|c|}{ Operating Conditions } & \multicolumn{2}{|c|}{ Experimental } & \multirow{2}{*}{$\begin{array}{c}\alpha_{p m} \\
\text { using } \\
\text { Eqn (7) }\end{array}$} & \multirow{2}{*}{$\begin{array}{c}\alpha_{p p} \\
\text { using } \\
\text { Eqn (8) }\end{array}$} & \multirow{2}{*}{$\begin{array}{l}\text { Pred. } \\
{ }^{* *} m_{t} \\
{[\mathrm{~kg} / \mathrm{m} 2]}\end{array}$} & \multirow{2}{*}{$\begin{array}{c}\text { Error } \\
\%\end{array}$} & \multirow{2}{*}{$\begin{array}{l}\text { Pred. } \\
* * P^{\prime}\end{array}$} & \multirow{2}{*}{$\begin{array}{c}\text { Error } \\
\%\end{array}$} & \multirow{2}{*}{$\begin{array}{c}\alpha_{p m} \\
\text { using } \\
\text { Eqn (5) }\end{array}$} & \multirow{2}{*}{$\begin{array}{c}\alpha_{p p} \\
\text { using } \\
\text { Eqn (6) }\end{array}$} & \multirow{2}{*}{$\begin{array}{c}\text { Pred.* } \\
m_{t} \\
{[\mathrm{~kg} / \mathrm{m} 2]}\end{array}$} & \multirow{2}{*}{$\begin{array}{c}\text { Error } \\
\%\end{array}$} & \multirow{2}{*}{$\begin{array}{c}\text { Pred.* } \\
P^{\prime}\end{array}$} & \multirow{2}{*}{$\begin{array}{c}\text { Errol } \\
\%\end{array}$} \\
\hline & $\begin{array}{c}P \\
{[p s i]}\end{array}$ & $\begin{array}{c}\mathrm{Q} \\
\text { [LPM] }\end{array}$ & $\begin{array}{c}\mathrm{C}_{\mathrm{f}} \\
{\left[\mathrm{kg} / \mathrm{m}^{3}\right]}\end{array}$ & $\begin{array}{c}m_{t} \\
{\left[\mathrm{~kg} / \mathrm{m}^{2}\right]}\end{array}$ & $P^{\prime}$ & & & & & & & & & & & & \\
\hline 1 & 15 & 4.0 & 0.78 & 0.012 & 7.5 & 0.55 & 0.46 & 0.009 & -26.7 & 2.88 & -36.0 & 0.97 & 0.46 & 0.011 & -8.3 & 4.1 & -8.9 \\
\hline 2 & 15 & 7.0 & 1.30 & 0.0141 & 5.5 & 0.51 & 0.29 & 0.009 & -37.6 & 3.2 & -41.8 & 0.98 & 0.3 & 0.013 & -7.8 & 4.98 & -9.5 \\
\hline 3 & 20 & 4 & 0.26 & 0.105 & 4 & 0.38 & 0.55 & 0.009 & -43.33 & 3 & -25.0 & 0.99 & 0.57 & 0.09 & -14.3 & 3.51 & -12.3 \\
\hline
\end{tabular}

Notes:

1. Predicted* $m_{t}$ was calculated using Equation (3.55) plus Equation (3.68) using the estimated fouling attachments $\alpha_{\mathrm{pm}} \&$ $\alpha_{\mathrm{pp}}$ from Equations(5.7a) and (5.8a), while Predicted $* * m_{t}$ was calculated using Equation (3.55) plus Equation (3.68) using the estimated fouling attachments $\alpha_{\mathrm{pm}} \& \alpha_{\mathrm{pp}}$ from Equations(5.5a) and (5.6a)

2. Predicted $* P^{\prime}$ was calculated using Equation (3.65) using the estimated fouling attachments $\alpha_{\mathrm{pm}} \& \alpha_{\mathrm{pp}}$ from Equations(5.7a) and (5.8a), while Predicted $* * P^{\prime}$ was calculated using Equation (3.65) using the estimated fouling attachments $\alpha_{\mathrm{pm}} \& \alpha_{\mathrm{pp}}$ from Equations(5.5a) and (5.6a). 


\subsubsection{Power consumption model for heterogeneous membranes}

Power consumption models have the potential to predict the power consumption trends, and to provide accurate predictions of the power consumption for larger-scale ultrafiltration systems. While there is a variety of power consumption data available for analysing and modelling (Jurado et al., 1994; Knops and Futselaar, 1992; Suman et al., 2012), there are no adequate predictive models for an accurate estimation of the power consumption in ultrafiltration of latex effluent using different types of heterogeneous membranes of various materials, with a variety of MWCO values at a required performance level. This could be attributed to the fact that the increase in transmembrane pressure through the filtration is dependent on the mass of fouling. As a consequence, the average transmembrane pressure through the filtration process will vary with fouling attachments and the morphological characterization of the membrane Therefore, analyses and modeling of the experimental data reported in the literature would be system specific and generally insufficient for an accurate prediction. They would also have some limitation in terms of process generalization and scale-up. Furthermore, it was determined that operation conditions, latex solution chemistry, and surface charge have a significant impact on fouling attachments, the total mass of fouling, and the cake height as demonstrated in previous publications. As a consequence, the average transmembrane pressure over a period of filtration process varies in each case. Thus, it's more accurate to predict the power consumption based on the variation of the transmembrane pressure throughout the filtration process. Therefore, the goal was to enable accurate prediction of the specific power consumption in the ultrafiltration process of simulated latex effluent using heterogeneous membranes at a given feed flow rate, initial transmembrane pressure, feed concentration, and membrane surface charge for a required cumulative permeate volume per unit area. The increase in the transmembrane pressure will be predicted based on the morphological characterization of the membrane as well as the fouling attachments. The models were validated using different types of heterogeneous membranes. The Central Composite Face-Centered (CCF) Response Surface Method (RSM) was selected as the optimal experimental design method. Within the framework of the study a total of twenty experiments was performed, and the specific power consumption was accurately calculated for each of the experimental runs, as indicated in Table 5.24. The results indicate that the specific power consumption varied between the ranges of $0.85 \mathrm{~kW} . \mathrm{h} / \mathrm{m}^{3}$ to $8.00 \mathrm{~kW} \cdot \mathrm{h} / \mathrm{m}^{3}$. 
Table 5.24: Experimental parameters and results based on the experimental design for the mass of fouling and the specific power consumption using Polysulfone membrane

\begin{tabular}{|c|c|c|c|c|c|c|c|}
\hline \multirow[b]{2}{*}{$\begin{array}{l}\text { Exp } \\
\text { No. }\end{array}$} & \multicolumn{3}{|c|}{ TMP } & \multicolumn{2}{|c|}{$\begin{array}{c}\text { Independent } \\
\text { Variables }\end{array}$} & \multirow[b]{2}{*}{$\begin{array}{c}\mathbf{m}_{\mathbf{t}} \\
{\left[\mathrm{kg} / \mathrm{m}^{2}\right]}\end{array}$} & \multirow[b]{2}{*}{$\begin{array}{c}\text { Power } \\
\text { consumed } \\
{\left[\mathbf{k W} . \mathbf{h} / \mathbf{m}^{3}\right]}\end{array}$} \\
\hline & $\begin{array}{c}\text { Initial } \\
\text { TMP [psi] }\end{array}$ & $\begin{array}{l}\text { TMPPAvG* } \\
\text { [psi] }\end{array}$ & $\begin{array}{l}\text { Final } \\
\text { TMP } \\
\text { [psi] }\end{array}$ & $\begin{array}{c}\text { Feed Flow } \\
\text { rate } Q \\
{[\text { LPM] }}\end{array}$ & $\begin{array}{c}\text { Feed } \\
\text { Concentrati } \\
\text { on } C_{f} \\
{\left[\mathbf{k g} / \mathbf{m}^{3}\right]}\end{array}$ & & \\
\hline 1 & $15.00(-1)$ & 15.50 & 16.00 & $1.00(-1)$ & $0.78(-1)$ & 0.0031 & 1.65 \\
\hline 2 & 35.00 (1) & 35.60 & 36.50 & $1.00(-1)$ & $0.78(-1)$ & 0.0052 & 2.64 \\
\hline 3 & $15.00(-1)$ & 15.20 & 15.50 & $7.00(1)$ & $0.78(-1)$ & 0.0025 & 1.92 \\
\hline 4 & $35.00(1)$ & 36.20 & 37.00 & $7.00(1)$ & $0.78(-1)$ & 0.008 & 3.58 \\
\hline 5 & $15.00(-1)$ & 15.60 & 16.00 & $1.00(-1)$ & $1.82(1)$ & 0.0044 & 3.44 \\
\hline 6 & $35.00(1)$ & 36.00 & 37.00 & $1.00(-1)$ & $1.82(1)$ & 0.008 & 4.28 \\
\hline 7 & $15.00(-1)$ & 16.50 & 18.00 & 7.00 (1) & $1.82(1)$ & 0.0093 & 4.55 \\
\hline 8 & $35.00(1)$ & 38.20 & 41.00 & 7.00 (1) & $1.82(1)$ & 0.015 & 7.67 \\
\hline 9 & $15.00(-1)$ & 16.70 & 18.00 & $4.00(0)$ & $1.30(0)$ & 0.0114 & 1.59 \\
\hline 10 & 35.00 (1) & 38.20 & 41.00 & $4.00(0)$ & $1.30(0)$ & 0.0178 & 3.25 \\
\hline 11 & $25.00(0)$ & 28.60 & 32.00 & $1.00(-1)$ & $1.30(0)$ & 0.0195 & 0.85 \\
\hline 12 & $25.00(0)$ & 26.10 & 27.00 & 7.00 (1) & $1.30(0)$ & 0.0088 & 3.33 \\
\hline 13 & $25.00(0)$ & 26.00 & 27.00 & $4.00(0)$ & $0.78(-1)$ & 0.011 & 1.50 \\
\hline 14 & $25.00(0)$ & 26.80 & 31.00 & $4.00(0)$ & $1.82(1)$ & 0.0167 & 8.00 \\
\hline 15 & $25.00(0)$ & 25.50 & 30.00 & $4.00(0)$ & $1.30(0)$ & 0.0135 & 2.04 \\
\hline 16 & $25.00(0)$ & 27.90 & 30.00 & $4.00(0)$ & $1.30(0)$ & 0.0135 & 2.03 \\
\hline 17 & $25.00(0)$ & 27.80 & 30.00 & $4.00(0)$ & $1.30(0)$ & 0.0135 & 1.98 \\
\hline 18 & $25.00(0)$ & 27.90 & 30.00 & $4.00(0)$ & $1.30(0)$ & 0.0135 & 1.99 \\
\hline 19 & $25.00(0)$ & 27.90 & 30.00 & $4.00(0)$ & $1.30(0)$ & 0.0135 & 2.04 \\
\hline 20 & $25.00(0)$ & 27.80 & 30.00 & $4.00(0)$ & $1.30(0)$ & 0.0135 & 1.98 \\
\hline
\end{tabular}

$* \mathrm{TMP}_{\mathrm{AVG}}[\mathrm{psi}]=\overline{\mathrm{TMP}}_{A V G}\left[\mathrm{psi}\right.$. min] $/$ Filtration time [min], $\overline{\mathrm{TMP}}_{A V G}[\mathrm{psi}$. min] calcualted as mentioned in section 3

Based on the ANOVA analysis and the multi regression method, the experimental data of specific power consumption was found to accurately correspond with the linear model. Equation (5.9) presented the numerical model with the coefficients of determination $\left(\mathrm{R}^{2}\right)$ of 0.96 . Notably, specific power consumption value occurring during the use of the Polysulfone heterogeneous membranes was not significantly affected by the various interactions between the operating conditions.

The Specific Power Consumption $=-1.7280+0.1880 \times \mathrm{TMP}_{\mathrm{AVG}}+0.1872 \times \mathrm{Q}+0.4900 \times C_{f}$ 
Equation (5.9a)

The Specific Power Consumption $=-1.7280+0.1880 \times \mathrm{TMP}_{\mathrm{AVG}}+0.0179655 \times v+0.4900 \times C_{f}$

Equation (5.9b)

where the specific power consumption was function of average transmembrane pressure $\left(\mathrm{TMP}_{\mathrm{AVG}}\right)[\mathrm{psi}]$, feed flow rate $(\mathrm{Q})[\mathrm{LPM}]$, cross flow velocity $(v)[\mathrm{cm} / \mathrm{s}]$, and feed concentration

$\left(C_{f}\right)\left[\mathrm{kg} / \mathrm{m}^{3}\right]$. In order to assess their validity, the generated results were then analyzed by the ANOVA and are presented in Table 5.25. The p-value indicates the probability value used to set the level of confidence for the F-test, as well as, to ascertain the importance of each coefficient. According to the regression coefficients and probability values (p-value) shown in Table 5.25, the operating conditions (Initial transmembrane pressure, feed flow rate, and feed concentration) noticeably affected the calculated power consumption.

Table 5.25: Regression coefficients and probability values of statistical analysis

\begin{tabular}{|c|l|c|c|}
\hline $\begin{array}{c}\text { Coded } \\
\text { Factor }\end{array}$ & \multicolumn{1}{|c|}{ Factor } & $\begin{array}{c}\text { Coefficient for } \\
\text { specific power } \\
\text { consumption } \\
{\left[\mathbf{k W . h} / \mathbf{m}^{3}\right]}\end{array}$ & p-value \\
\hline $\mathrm{TMP}_{\mathrm{AVG}}$ & $\begin{array}{l}\text { Average transmembrane pressure } \\
\text { through the filtration process }[\mathrm{psi}]\end{array}$ & 0.1880 & $<0.0001$ \\
\hline $\mathrm{Q}$ & Feed Flow rate $[\mathrm{LPM}]$ & 0.1872 & 0.0042 \\
\hline$C_{f}$ & Feed Concentration $\left[\mathrm{kg} / \mathrm{m}^{3}\right]$ & 0.4900 & $<0.0001$ \\
\hline
\end{tabular}

Values of "p-value "less than 0.05 indicate model terms are significant.

In case of the specific power consumption model: $\mathrm{TMP}_{\mathrm{AVG}}, \mathrm{Q}, C_{f}$ are significant model terms.

The average transmembrane pressure $\mathrm{TMP}_{\mathrm{AVG}}[\mathrm{psi}$ ] can be calculated using the initial transmembrane pressure, the increase of transmembrane pressure $\left(P^{\prime}\right)$ with time estimated from Equation (3.65) and filtration time. Then, it can be used to predict the specific power consumption from Equation (5.9). The increase in the transmembrane pressure can be estimated from the morphological characterization of the membrane and the fouling attachments, as indicated in Equation (3.65). The fouling attachments, in turn, can be estimated from Equation (5.7) and Equation (5.8).

Regression coefficients in Equation 5.9a reflect the extent of the impact of each operating condition on the power consumption, as described in Table 5.24. The feed concentration had more effect on the power consumption than the initial transmembrane pressure and the feed flow rate, emphasizing and re-confirming the results obtained in our previous work based on the use 
of Polycarbonate membranes with uniform pore size. Notably, the average transmembrane pressure had a significant effect on the specific power consumption, which reflects the importance of accurately predicting the increase in transmembrane pressure for various membrane properties, characterization, surface charges, and operating conditions.

\subsubsection{Validation of the power consumption model with different heterogeneous membranes}

This study intended to examine the predictive capability of the specific power consumption model using the complete set of models, including the mechanistic models tracking the increase in transmembrane pressure (Equation 3.65) and the models of fouling attachments. The models were tested for a variety of operating conditions with multiple heterogeneous membranes of different materials, MWCO values, and surface charges. At the same operating condition and the same surface charge, the power consumption would vary dependent on the characteristic properties of each membrane, such as: the membrane surface porosity, the pore size distribution, the number density of membrane pores per unit membrane surface area, the thickness of the membrane, and the tortuosity of the membrane pores structure since all those parameters were included in the model for the increase in transmembrane pressure. This was further considered with respect to the particle size distribution of the simulated latex effluent.

Table 5.26 reflects some level of agreement between the specific power consumption calculated based on the experimental values and the value predicted by the numerical model for the specific power consumption using the estimated fouling attachments and the increase in the transmembrane pressure. The first step in this process was to predict the depositional and coagulational attachments from Equations 5.7a and 5.8a using the initial transmembrane pressure, feed flow rate, feed concentration, and membrane surface charge values. The second step was to estimate the transmembrane pressure from Equation 3, using the predicted fouling attachment, the morphological characterization of the membrane (such as: the membrane surface porosity, the pore size distribution, the number density of membrane pores per unit membrane surface area, the thickness of the membrane, and the tortuosity of the membrane pores), the cumulative permeate volume per unit area, feed concentration, the particle's projected area, and the cake resistance values. The increase in transmembrane pressure was then in turn used to calculate the average transmembrane pressure throughout the filtration process, which finally was used to estimate the specific power consumption using Equation 5.9. As shown in Table 
5.26 the validation experiments were performed over a range of operating conditions rather than the ones used in the original experimental design and at a different surface charge of the Polysulfone membrane. The specific power consumption calculated from Equation (4.3) using the experimental values agree fairly well with the value predicted from the numerical model, with an error range of $\pm 6.7-18.9 \%$ for Polysulfone membrane over varied membrane surface charges from $-15.00 \mathrm{mV}$ to $-42.40 \mathrm{mV}$. Admittedly, the complexity of the mechanistic model could be the responsible for this error range. The mechanistic model of the increase in transmembrane pressure considers the attachments of each particle size with respect to each pore size range while the real fouling phenomenon features an alternative dynamic that may be executed somewhat differently. The model only approximates the pore size distribution ranges, but it does not reflect the exact pore size distribution. Consequently, the predicted increase in transmembrane pressure agreed with the experimental values with \pm 6.7 to $12.0 \%$. In addition, the experimental error in obtaining the experimental data would augment this deviation further to some extent since the experimental error embedded in the data that was used in the model development.

Table 5.26: Power consumption calculated from experimental data and the predicted values for Polysulfone membranes at different operating conditions and varying membrane surface charges

\begin{tabular}{|c|c|c|c|c|c|c|c|c|c|c|c|c|}
\hline \multirow[b]{2}{*}{$\begin{array}{l}\text { Exp } \\
\text { No. }\end{array}$} & \multicolumn{3}{|c|}{ Operating Conditions } & \multirow[b]{2}{*}{$\zeta[\mathrm{mV}]$} & \multirow[b]{2}{*}{$\begin{array}{r}\text { Exp. } \\
P^{\prime}\end{array}$} & \multirow{2}{*}{$\begin{array}{c}\text { The specific } \\
\text { power } \\
\text { consumption } \\
{\left[\mathrm{kW} \cdot \mathrm{h} / \mathrm{m}^{3}\right]}\end{array}$} & \multicolumn{2}{|c|}{ Predective Models } & \multirow[b]{2}{*}{$\begin{array}{l}\text { Pred. }{ }^{*} P^{\prime} \\
\text { (Eqn 3) }\end{array}$} & \multirow[b]{2}{*}{$\begin{array}{c}\text { Error \% } \\
\qquad P^{\prime}\end{array}$} & \multirow{2}{*}{$\begin{array}{c}\text { Predicted } \\
\text { specific } \\
\text { power } \\
\text { consumption } \\
{\left[\mathrm{kW} \cdot \mathrm{h} / \mathrm{m}^{3}\right]}\end{array}$} & \multirow[b]{2}{*}{ Error \% } \\
\hline & $\begin{array}{l}\text { TMP } \\
\text { [psi] }\end{array}$ & {$\left[\begin{array}{c}\mathrm{Q} \\
{[\mathrm{LPM}]}\end{array}\right.$} & $\begin{array}{c}C_{f} \\
{\left[\mathrm{~kg} / \mathrm{m}^{3}\right]}\end{array}$ & & & & Eqn (7) & Eqn (8) & & & & \\
\hline 1 & 15.00 & 1.00 & 0.78 & -42.40 & 1.00 & 1.65 & 0.78 & 0.67 & 1.12 & 12.0 & 1.85 & 12.0 \\
\hline 2 & 15.00 & 7.00 & 0.78 & -42.40 & 0.50 & 1.92 & 0.31 & 0.26 & 0.465 & -7.0 & 2.22 & 15.7 \\
\hline 3 & 25.00 & 4.00 & 1.82 & -42.40 & 7.00 & 8.00 & 0.89 & 0.81 & 7.50 & 7.1 & 6.49 & -18.9 \\
\hline 4 & 35.00 & 7.00 & 1.82 & -42.40 & 6.00 & 7.67 & 0.80 & 0.89 & 6.40 & 6.7 & 8 & 6.7 \\
\hline 5 & 25.00 & 7.00 & 1.30 & -25.00 & 4.00 & 8.89 & 0.94 & 0.51 & 3.70 & -7.5 & 7.74 & -12.9 \\
\hline 7 & 30.00 & 5.00 & 1.82 & -15.00 & 6.00 & 9.51 & 0.98 & 0.85 & 6.45 & 7.5 & 7.71 & -18.9 \\
\hline 8 & 25.00 & 4.50 & 1.30 & -28.00 & 6.00 & 6.19 & 0.89 & 0.72 & 5.46 & -9.0 & 5.58 & -9.9 \\
\hline
\end{tabular}

At a transmembrane pressure of $25.00 \mathrm{psi}$, a feed flow rate of $7.00 \mathrm{LPM}$, and a feed concentration of $1.30 \mathrm{~kg} / \mathrm{m}^{3}$, Table 5.24 run 12, and Table 5.24 run 5 respectively show the results obtained using Polysulfone membranes with surface charge of $-42.40 \mathrm{mV}$ and $-25.00 \mathrm{mV}$ . The increase in transmembrane pressure was $2.00 \mathrm{psi}$ and $4.00 \mathrm{psi}$ in the case of Polysulfone membrane with surface charges of $-42.40 \mathrm{mV}$ and $-25.00 \mathrm{mV}$, respectively. This was due to the higher attraction force between the latex particles and the membrane surface which caused a 
higher depositional attachment of 0.94 for Polysulfone membrane with surface charge of -25.00 $\mathrm{mV}$, as compared to 0.82 for Polysulfone membrane with surface charge of $-42.40 \mathrm{mV}$. The larger depositional attachment led to a higher total mass of fouling of $0.012 \mathrm{~kg} / \mathrm{m}^{2}$, as compared to $0.0088 \mathrm{~kg} / \mathrm{m}^{2}$. Evidence of this effect of the surface charge on the amount of fouling can be seen in SEM images shown in Figure 5.40. Furthermore, a lower cumulative permeate volume per unit area of $0.042 \mathrm{~m}^{3} / \mathrm{m}^{2}$ was obtained with the Polysulfone membrane with a lower surface charge of $-25.00 \mathrm{mV}$. While for the Polysulfone membrane with a hydrophilic surface (zeta potential of $-42.40 \mathrm{mV}$ ), the cumulative permeate volume per unit area was $0.113 \mathrm{~m}^{3} / \mathrm{m}^{2}$. As a consequence, the specific power consumption was $3.33 \mathrm{~kW} \cdot \mathrm{h} / \mathrm{m}^{3}$ and $8.89 \mathrm{~kW} \cdot \mathrm{h} / \mathrm{m}^{3}$ for Polysulfone membranes with surface charges of $-42.40 \mathrm{mV}$ and $-25.00 \mathrm{mV}$ respectively. This is expected since the cumulative permeate volume is inversely proportional to the specific power consumption, as indicated by Equation (4.3). It should be noted that the model incorporates surface charge influence on the depositional attachment in addition to the cumulative permeate volume per unit area, which makes the model predicts the power consumption accurately.

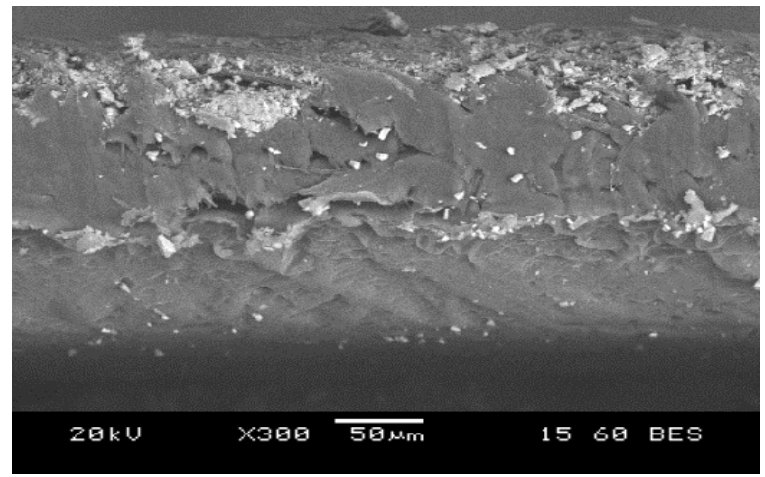

(a)

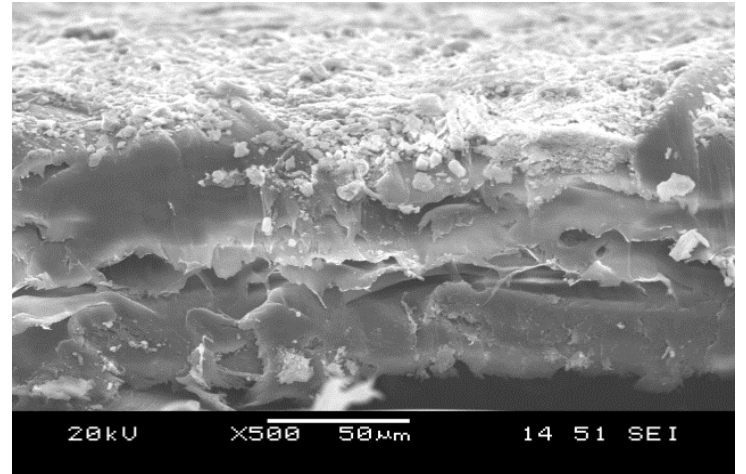

(b)

Figure 5.40: SEM images of the Polysulfone membrane after ultrafiltration at $[\mathrm{P}=25.00$ psi],

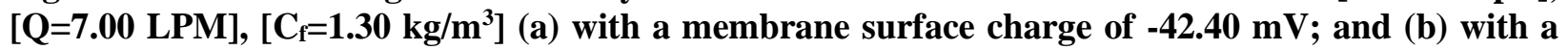
membrane surface charge of $\mathbf{- 2 5 . 0 0} \mathbf{~ m V}$

In addition, Ultrafilic and PVDF membranes with a MWCO of 100,000, and Cellulose acetate membranes with a MWCO of 20,000, were specifically tested for this purpose. Table 5.27 shows the predicted power consumption using various membranes at different operating conditions agreed with the power consumption calculated from the experimental values with an error range of 6.0 to $19.1 \%$. Furthermore, the predicted increase in transmembrane pressure agreed with the experimental value within the error range of 4.7 to $12.3 \%$. 
Table 5.27: Power consumption calculated from on the experimental data and predicted values for various membranes at different operating conditions

\begin{tabular}{|c|c|c|c|c|c|c|c|c|c|c|c|c|c|}
\hline \multirow[b]{2}{*}{$\begin{array}{l}\text { Exp } \\
\text { No. }\end{array}$} & \multirow{2}{*}{ 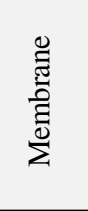 } & \multicolumn{3}{|c|}{ Operating Conditions } & \multirow[b]{2}{*}{$\zeta[\mathrm{mV}]$} & \multirow[b]{2}{*}{$\begin{array}{l}\text { Exp. } \\
P^{\prime}\end{array}$} & \multirow{2}{*}{$\begin{array}{c}\text { The specific } \\
\text { power } \\
\text { consumption } \\
{\left[\mathrm{kW} \cdot \mathrm{h} / \mathrm{m}^{3}\right]}\end{array}$} & \multicolumn{2}{|c|}{ Predective Models } & \multirow[b]{2}{*}{$\begin{array}{r}\text { Pred. } * P^{\prime} \\
(\text { Eqn } 3)\end{array}$} & \multirow[b]{2}{*}{$\begin{array}{c}\text { Error \% } \\
P^{\prime}\end{array}$} & \multirow{2}{*}{$\begin{array}{c}\text { Predicted } \\
\text { specific } \\
\text { power } \\
\text { consumption } \\
{\left[\mathrm{kW} \cdot \mathrm{h} / \mathrm{m}^{3}\right]}\end{array}$} & \multirow[b]{2}{*}{$\begin{array}{c}\text { Error } \\
\%\end{array}$} \\
\hline & & $\begin{array}{l}\text { TMP } \\
\text { [psi] }\end{array}$ & $\begin{array}{c}\mathrm{Q} \\
{[\mathrm{LPM}]}\end{array}$ & $\begin{array}{c}C_{f} \\
{\left[\mathrm{~kg} / \mathrm{m}^{3}\right]}\end{array}$ & & & & Eqn (7) & Eqn $(8)$ & & & & \\
\hline 1 & UF & 35.00 & 7.00 & 1.82 & -41.50 & 8.50 & 7.19 & 0.82 & 0.84 & 8.10 & -4.7 & 8.46 & 17.7 \\
\hline 2 & UF & 25.00 & 4.50 & 2.34 & -41.50 & 10.00 & 8.92 & 0.98 & 0.99 & 10.78 & 7.8 & 7.22 & -19.1 \\
\hline 3 & UF & 15.00 & 7.00 & 1.30 & \begin{tabular}{|l|}
-41.50 \\
\end{tabular} & 2.00 & 3.22 & 0.19 & 0.29 & 2.20 & 10.0 & 3.42 & 6.0 \\
\hline 4 & $\mathrm{CA}$ & 25.00 & 4.00 & 1.30 & -33.90 & 1.50 & 5.84 & 0.81 & 0.76 & 1.33 & -11.3 & 4.92 & -15.8 \\
\hline 5 & $\mathrm{CA}$ & 35.00 & 7.00 & 1.82 & -33.90 & 2.00 & 9.11 & 0.88 & 0.84 & 2.12 & 6.0 & 7.99 & -12.2 \\
\hline 6 & PVDF & 15.00 & 7.00 & 0.78 & -2.50 & 4.50 & 4.36 & 0.92 & 0.24 & 4.10 & -8.9 & 3.63 & -16.8 \\
\hline 7 & PVDF & 15.00 & 7.00 & 1.30 & -2.50 & 5.50 & 6.08 & 0.98 & 0.30 & 4.98 & -9.5 & 5.01 & -17.5 \\
\hline 8 & PVDF & 20.00 & 4.00 & 0.26 & -2.50 & 4.00 & 4.39 & 0.99 & 0.57 & 3.51 & -12.3 & 3.85 & \begin{tabular}{|l|}
-12.4 \\
\end{tabular} \\
\hline
\end{tabular}

As shown in Table 5.27, for run number 4 with Cellulose Acetate at a transmembrane pressure of $25.00 \mathrm{psi}$, feed flow rate of $4.00 \mathrm{LPM}$ and feed concentration $1.30 \mathrm{~kg} / \mathrm{m}^{3}$, the increase in transmembrane pressure was $1.50 \mathrm{psi}$ while the power consumption was $5.84 \mathrm{~kW} . \mathrm{h} / \mathrm{m}^{3}$. At the same operating conditions with Polysulfone membrane (Table 5.22, run 15), the increase in transmembrane pressure was $5.00 \mathrm{psi}$ and the specific power consumption was $2.04 \mathrm{~kW} \cdot \mathrm{h} / \mathrm{m}^{3}$. Notably, the surface charge of Polysulfone and Cellulose acetate membranes are relatively close to each other at $-42.40 \mathrm{mV}$ and $-33.90 \mathrm{mV}$, respectively. However, Cellulose acetate membranes with a MWCO of 20,000 had $80 \%$ of the pore size distribution at 0.01 microns, as presented in Figure 5.41 (a), which resulted in the lower experimental mass of fouling and smaller increase in transmembrane pressure. Increasing the pore size in case of Polysulfone membranes with MWCO of 60,000, as shown in Figure 5.41 (b), caused more flow through the membrane pores, thus raising the chances for the particle-to-particle and particle-to-membrane collision and attachment in the pores, hence, there would be more pore blocking. As a consequence, the mass of fouling and the increase in transmembrane pressure by the filtration time increased. However, the permeate volume was higher with Polysulfone membrane, resulting in a lower specific power consumption. Figure 5.42 shows the SEM images after the ultrafiltration process at a transmembrane pressure of $25.00 \mathrm{psi}$, feed flow rate of 4.00 LPM, and feed concentration of 1.30 $\mathrm{kg} / \mathrm{m}^{3}$ using Cellulose acetate and Polysulfone membranes. Latex particles appeared to penetrate deeper inside the pores of Polysulfone membrane, as compared to the case for Cellulose acetate membrane. These results again emphasize the effects of the morphological characterization of the membrane on the specific power consumption. 


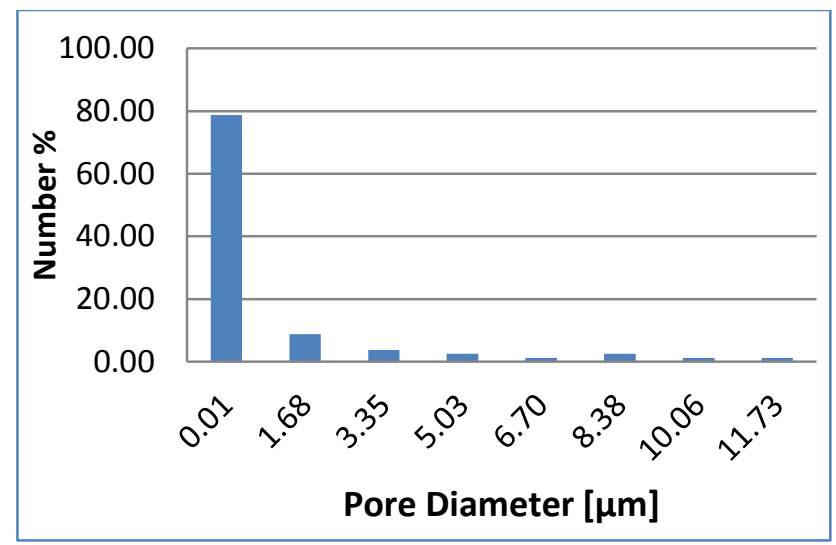

(a)

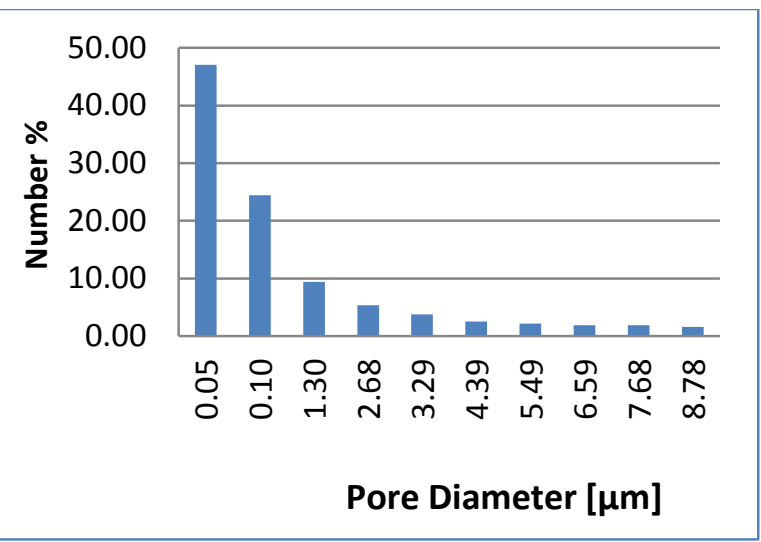

(b)

Figure 5.41: The pore size distribution (a) Cellulose Acetate (b) Polysulfone membrane

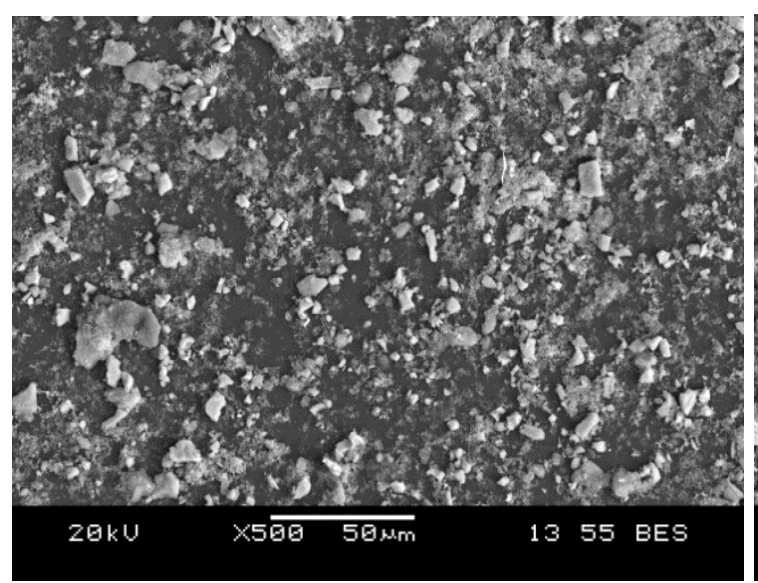

(a)

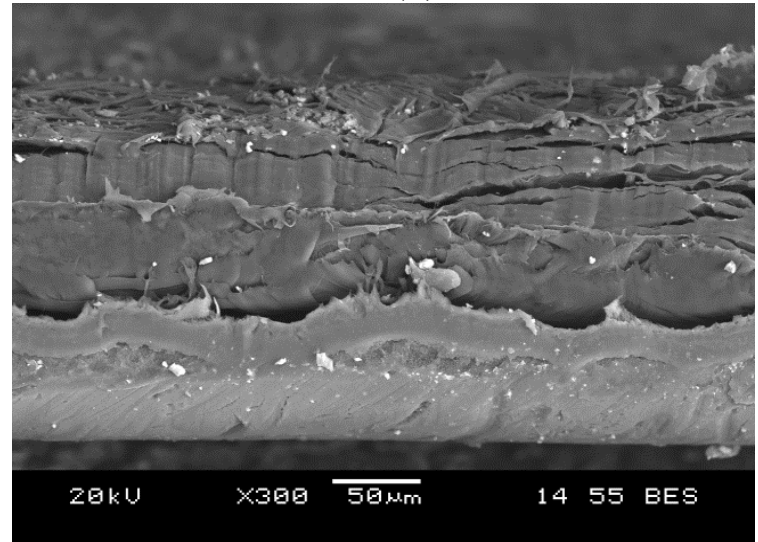

(c)

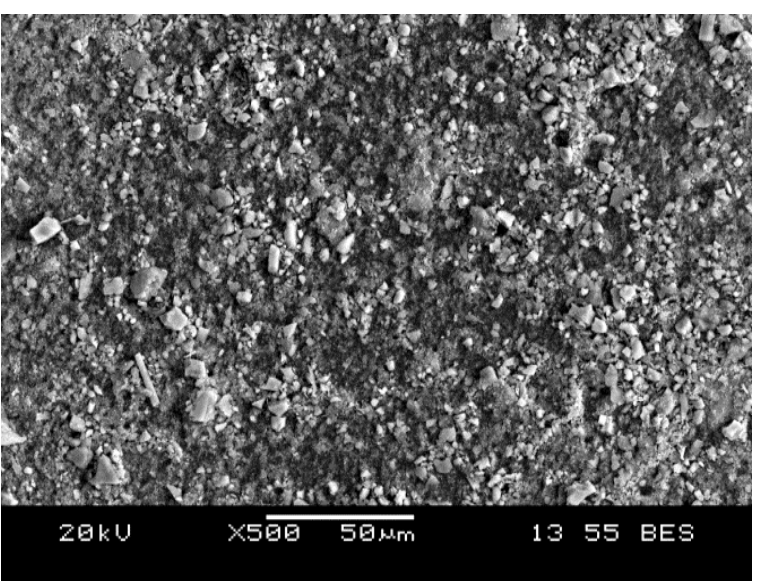

(b)

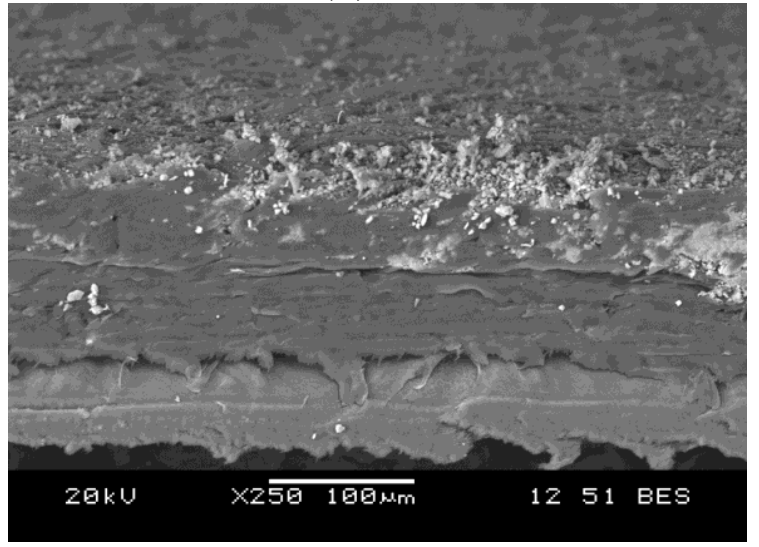

(d)

Figure 5.42: $S E M$ images after ultrafiltration at $[P=25.00 \mathrm{psi}],[Q=4.00 \mathrm{LPM}],\left[\mathrm{C}_{\mathrm{f}}=1.30\right.$ $\mathrm{kg} / \mathrm{m}^{3}$ ] using (a) Membrane surface of Cellulose Acetate membrane with MWCO of 20,000; (b) Membrane surface of Polysulfone membrane with MWCO of 60,000; (c) Side view of the cake height using Cellulose Acetate membrane with MWCO of 20,000; (d) Side view of the cake height of Polysulfone membrane with MWCO of 60,000 
Run 3 in Table 5.24 and run 6 in Table 5.27 show the results obtained using Polysulfone membrane and PVDF membrane at the transmembrane pressure of $15.00 \mathrm{psi}$, the feed flow rate of $7.00 \mathrm{LPM}$, and the feed concentration of $0.78 \mathrm{~kg} / \mathrm{m}^{3}$. The increase in transmembrane pressure was 0.50 psi and 4.50 psi for Polysulfone and PVDF membranes, respectively. Similarly, the specific power consumption was $1.92 \mathrm{~kW} \cdot \mathrm{h} / \mathrm{m}^{3}$ and $4.36 \mathrm{~kW} . \mathrm{h} / \mathrm{m}^{3}$ for Polysulfone and PVDF membranes, respectively. A PVDF membrane with MWCO of 100,000 has a larger portion of larger pore sizes as compared to those for a Polysulfone membrane with MWCO of 60,000 . The pore size distribution had a significant effect on the mass of fouling retained by the membrane and caused the increase in transmembrane pressure, resulting in the differences in the specific power consumption and the transmembrane pressure rise of the two membranes. Moreover, the higher negative charge of Polysulfone membranes of $-42.40 \mathrm{mV}$ generated a higher level of repulsion between the particles and the membrane surface, compared to PVDF membrane with surface charge of $-2.50 \mathrm{mV}$. As a consequence, the depositional attachment was 0.35 and 0.92 for Polysulfone and PVDF membrane respectively. Consequently, the total mass of fouling and the average transmembrane pressure were higher for PVDF at the same operating conditions.

On the other hand, while both Ultrafilica and PVDF membranes have the same MWCO of 100,000 with similar pore size distribution (Figure 5.43), the surface charge of each membrane played a critical role in the fouling attachments and the total mass of fouling, resulting in a higher increase in transmembrane pressure and lower cumulative permeate volume. For example, at the transmembrane pressure of 15.00 pisa, the feed flow rate of 7.00 LPM, and feed concentration of $1.30 \mathrm{~kg} / \mathrm{m}^{3}$ (Table 5.27 run 3 and 7), the increase in transmembrane pressure was $2.00 \mathrm{psi}$ and $5.50 \mathrm{psi}$ for Ultrafilic and PVDF membranes, respectively. This can be attributed to the higher negative surface charge of $-41.50 \mathrm{mV}$ for Ultrafilic membranes compared to $2.50 \mathrm{mV}$ for hydrophobic PVDF membrane. The depositional attachment values were thus 0.19 and 0.98 for Ultrafilic and PVDF membrane, respectively. As a consequence, the total mass of fouling was $0.014 \mathrm{~kg} / \mathrm{m}^{2}$ for PVDF and $0.0092 \mathrm{~kg} / \mathrm{m}^{2}$ for Ultrafilic membrane. Visual observation of the deposit on the membranes can be found in Figure 5.44. Also, the cumulative permeate volume was $0.07 \mathrm{~m}^{3} / \mathrm{m}^{2}$ and $0.04 \mathrm{~m}^{3} / \mathrm{m}^{2}$ for Ultrafilic and PVDF membranes, respectively. The specific power consumption for Ultrafilic $\left(3.22 \mathrm{~kW} \cdot \mathrm{h} / \mathrm{m}^{3}\right)$ was lower than that of PVDF $\left(6.08 \mathrm{~kW} \cdot \mathrm{h} / \mathrm{m}^{3}\right)$ as expected. In addition, it should be noted that the predicted transmembrane pressure was 2.20 and 4.10 psi using Ultrafilic and PVDF, respectively. This 
difference stems from various reasons, including the surface hydrophilic, which had a significant impact on the depositional attachment and the cumulative permeate flux, both of which significantly affected the predicted increase in transmembrane pressure. This difference can also be linked to the fact that although both membranes have MWCO of 100,000, they have different pore size distributions, as presented in Figure 5.43, and the model considers the attachment analyses of each particle size with each pore size. As a consequence, these prediction results of the transmembrane pressure enhanced the model accuracy with the variation of the morphological characterization of each membrane. Thus the prediction of the increase in transmembrane pressure using this model is accurate and highly practical. Consequently, the model showed good agreement for heterogeneous membranes featuring different materials, MWCO values, and surface charges.

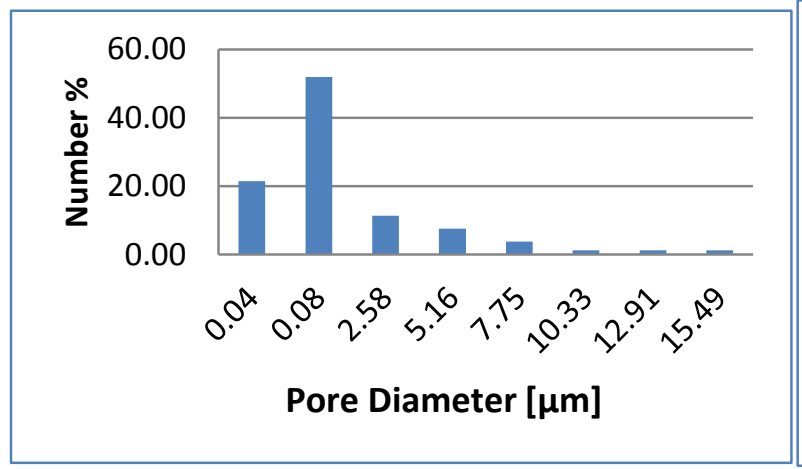

(a)

Figure 5,43:

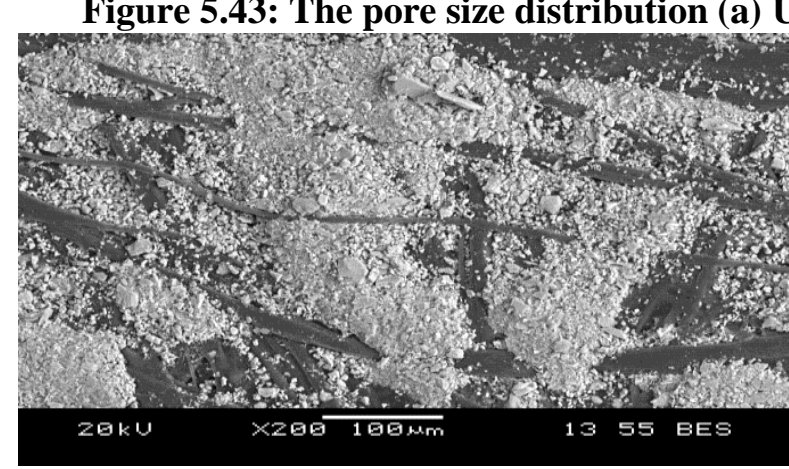

(a)

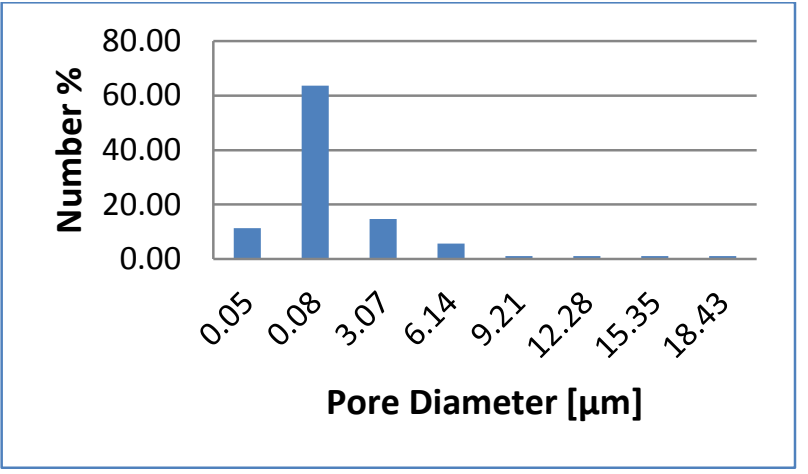

(b)

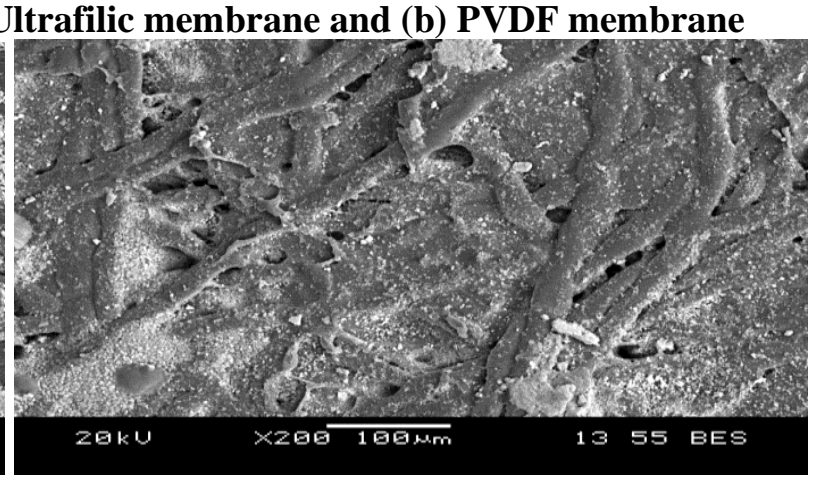

(b)

Figure 5.44: $S E M$ images after ultrafiltration at $[P=15.00 \mathrm{psi}],[Q=7.00 \mathrm{LPM}],\left[\mathrm{C}_{\mathrm{f}}=1.30 \mathrm{~kg} / \mathrm{m}^{3}\right]$ using (a) PVDF membrane with zeta potential of $-2.50 \mathrm{mV}$; (b) Ultrafilic membrane with zeta potential of $-41.50 \mathrm{mV}$ 


\subsubsection{Power consumption prediction for practical use in an industrial setting}

Table 5.28 shows the experimental runs performed to comprehensively test and validate the ability of the complete set of the predictive models to accurately estimate the power consumption at a required cumulative permeate volume. In the previous sections, the models were validated using the cumulative permeate volume obtained experimentally. On the other hand, Table 5.28 presents the predicted power consumption based on an arbitrarily required cumulative permeate volume $\mathrm{V}_{\mathrm{s}}$ for the untreated Polysulfone membrane with surface charge of $42.40 \mathrm{mV}$. The predicted values obtained agree with the power consumptions calculated from the experimental data of the cumulative filtrate volume within an error range of \pm 7.5 to $17.1 \%$. Likewise, the predicted increase in transmembrane pressure agrees with the experimental value with an error ranging from \pm 4.3 to $11.7 \%$. Therefore, the models can be considered as fairly accurate in predicting the membrane performance.

Table 5.28: Predicted power consumption using the arbitrarily input cumulative permeate volume $V_{s}$ and the power consumption calculated from the experimental cumulative permeate volume for Polysulfone membranes

\begin{tabular}{|c|c|c|c|c|c|c|c|c|c|c|c|c|}
\hline \multirow[b]{2}{*}{$\begin{array}{l}\text { Exp } \\
\text { No. }\end{array}$} & \multicolumn{3}{|c|}{ Operating Conditions } & \multirow[b]{2}{*}{ Vs [L] } & \multirow[b]{2}{*}{$\begin{array}{c}\text { Exp. } \\
P^{\prime}\end{array}$} & \multirow{2}{*}{$\begin{array}{l}\text { The specific } \\
\text { power } \\
\text { consumption } \\
{\left[\mathrm{kW} \cdot \mathrm{h} / \mathrm{m}^{3}\right]}\end{array}$} & \multicolumn{2}{|c|}{ Predective Models } & \multirow[b]{2}{*}{$\begin{array}{r}\text { Pred. }{ }^{*} P^{\prime} \\
\text { (Eqn 3) }\end{array}$} & \multirow[b]{2}{*}{$\begin{array}{c}\text { Error \% } \\
P^{\prime}\end{array}$} & \multirow{2}{*}{$\begin{array}{c}\text { Predicted } \\
\text { specific } \\
\text { power } \\
\text { consumption } \\
{\left[\mathrm{kW} \cdot \mathrm{h} / \mathrm{m}^{3}\right]}\end{array}$} & \multirow[b]{2}{*}{ Error \% } \\
\hline & $\begin{array}{l}\text { TMP } \\
\text { [psi] }\end{array}$ & $\begin{array}{c}\mathrm{Q} \\
\text { [LPM] }\end{array}$ & $\begin{array}{c}C_{f} \\
{\left[\mathrm{~kg} / \mathrm{m}^{3}\right]}\end{array}$ & & & & Eqn (7) & Eqn (8) & & & & \\
\hline 1 & 30.00 & 2.00 & 1.30 & 0.50 & 5.00 & 5.89 & 0.89 & 0.88 & 4.65 & -7.0 & 5.30 & -10.0 \\
\hline 2 & 25.00 & 7.00 & 1.82 & 2.00 & 5.00 & 4.58 & 0.84 & & 5.55 & 11.0 & & 13.0 \\
\hline 3 & 35.0 & 2.0 & & 0.50 & 3.00 & & & & 2.6 & -11.7 & & -7.5 \\
\hline 4 & 15.00 & 4.00 & 1.30 & 1.50 & 3.00 & 1.99 & 0.66 & 0.55 & 2.87 & -4.3 & & 15.2 \\
\hline 5 & 20.00 & 4.00 & 0.78 & 1.50 & 3.00 & 2.78 & 0.80 & 0.33 & 3.28 & 9.3 & 3.26 & 17.1 \\
\hline
\end{tabular}

For the practical use in an industrial setting, the specific power consumption can be predicted for a membrane filtration process, using the operating conditions, membrane surface charge, and the morphological characterization of the heterogeneous membrane. The depositional attachment and the coagulation attachment can be estimated from Equation 5.7 and Equation 5.8. The fouling attachments in addition to the morphological characterization of the membrane can be, in turn, employed to estimate the increase in the transmembrane pressure at a required cumulative permeate volume per unit area. 


\subsection{Membrane Fouling remediation}

Following previous results, the fouling remediation can be considered critical in reducing membrane fouling, increasing the permeate flux and reducing the power consumption per unit volume of filtrate at given operating conditions.

\subsubsection{Feed pre-treatment by changing the $\mathrm{pH}$ of latex solution}

The effects of the solution $\mathrm{pH}$ over a range from 3-12 on particle-particle attachment and particle-membrane were investigated since those attachment potentials strongly affect the volumetric permeate flux, the total mass of fouling, and the specific power consumption.

\subsubsection{Effect of $\mathrm{pH}$ on ionic strength of latex solution and membrane surface hydrophilicity of homogeneous Polycarbonate membrane}

The ionic strength is directly proportional to the solution conductivity. Therefore, the effect of the solution $\mathrm{pH}$ on the ionic strength of the solution is evaluated based on the change in the solution conductivity with $\mathrm{pH}$. Figure 5.45 (a) illustrates the effect of $\mathrm{pH}$ on the conductivity of the latex solution. At a solid concentration of $1.3 \mathrm{~kg} / \mathrm{m}^{3}$, the $\mathrm{pH}$ of the latex solution was 7 . The solution conductivity increased from 0.094 to $38.8 \mathrm{mS} / \mathrm{cm}$ when the solution $\mathrm{pH}$ was increased from 7 to 14 . On the other hand, decreasing $\mathrm{pH}$ from 7 to 2 using $\mathrm{HCl}$ and $\mathrm{H}_{2} \mathrm{SO}_{4}$ only resulted in a slight increase in the conductivity to 2.57 and $5.5 \mathrm{~m} \mathrm{~S} / \mathrm{cm}$, respectively. Figure 5.45 (b) depicts the zeta potential values of the latex particles and membrane surface. Zeta potential of latex particles at $\mathrm{pH} 7$ is approximately $-26.61 \mathrm{mV}$. For the $\mathrm{pH}$ values greater than 7 , the zeta potential becomes more negative as the ionic strength increases. The zeta potential of latex particles achieved $-42.66 \mathrm{mV}$ at $\mathrm{pH} 12$. The zeta potential of membrane surface is negative at all $\mathrm{pH}$ values investigated. As the $\mathrm{pH}$ is increased from 3 to 12 , the zeta potential of membrane surface becomes increasingly negative from -18.11 to $-46.77 \mathrm{mV}$, respectively. This indicates that the hydrophilicty of the membrane surface increased with the rise of $\mathrm{pH}$ value.

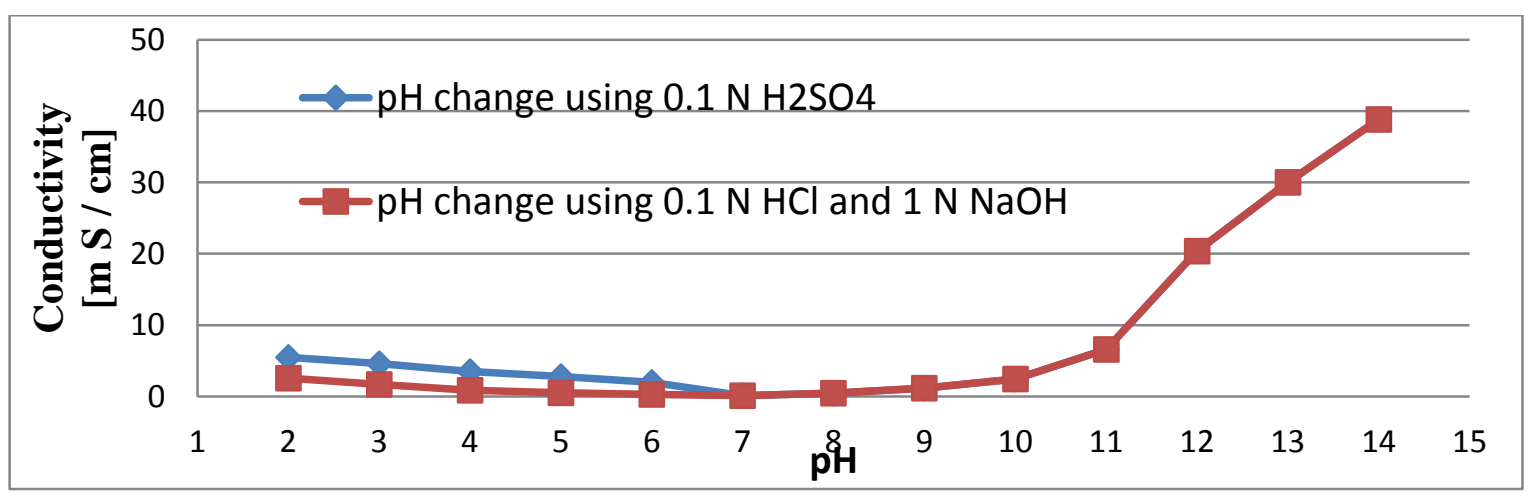

(a) 


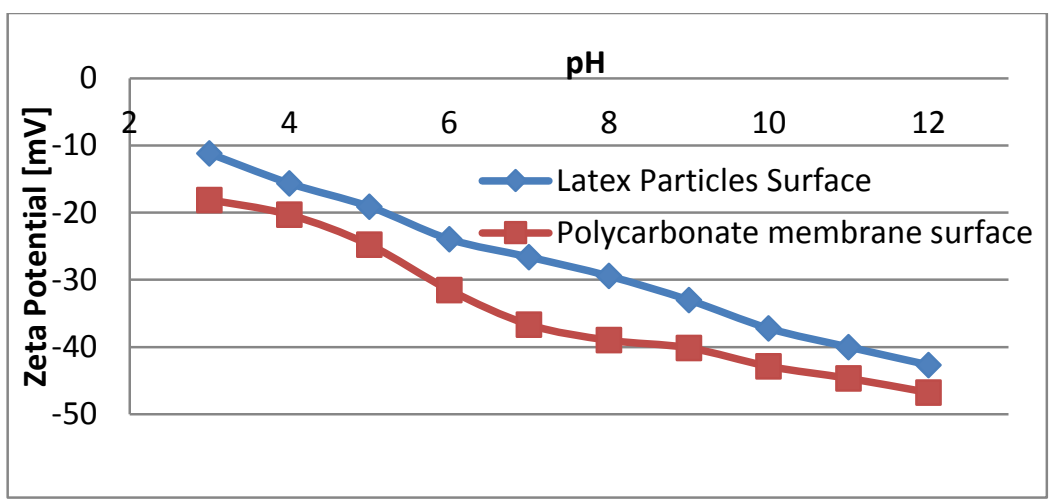

(b)

Figure 5.45: The effect of $\mathrm{pH}$ on (a) Conductivity of latex solution \& (b) Zeta potential of latex particles and membrane surface

\subsubsection{Effect of $\mathrm{pH}$ on membrane fouling and power consumption using a homogeneous Polycarbonate membrane}

For Polycarbonate membrane, at the initial transmembrane pressure of $15 \mathrm{psi}$, the feed flow rate of $4 \mathrm{LPM}$, and the feed solid concentration of $1.3 \mathrm{~kg} / \mathrm{m}^{3}$, the power consumption per unit volume of filtrate was $10.17 \mathrm{kWh} / \mathrm{m}^{3}$; and the volumetric permeate flux and the total mass of fouling were 0.0125 and 0.0104 , respectively. Under the same operating conditions, increasing the solution $\mathrm{pH}$ from 7 to 12 resulted in a significant reduction in the particle-toparticle attachment from 0.4 to 0.19 , as shown in Figure 5.46 (a). This indicates that the ionic strength of the latex solution increased with $\mathrm{pH}$, which in turn caused an increased negative charge on the latex particles due to the $\mathrm{OH}^{-}$group added to the solution. Raising the $\mathrm{pH}$ from 7 to 12 resulted in an increase of the zeta potential of the latex particles from $-26.61-42.66 \mathrm{mV}$, respectively. As a consequence, the electrostatic repulsive forces between the latex particles were increased, while the particle-to-particle attachment decreased significantly. Also, the depositional attachment decreased from 0.55 to 0.26 . This could be attributed to the enhancement of the hydrophilicty of the membrane and the increase in the negative charge on the membrane surface with increases in the solution $\mathrm{pH}$. As the $\mathrm{pH}$ is increased from 7 to 12 , the zeta potential of the membrane surface became increasingly negative from -36.67 to $-46.77 \mathrm{mV}$, respectively. Therefore, the electrostatic attraction force between latex particles and the membrane surface decreased. Consequently, the particle-to-membrane attachment was significantly reduced. The noticeable reduction of the fouling attachments caused a considerable decrease in the total mass of fouling from 0.0104 to $0.007 \mathrm{~kg} / \mathrm{m}^{2}$, as can be seen in Figure 5.46 (b). This indicates that an increase in the ionic strength via an increase in $\mathrm{pH}$ resulted in some enhancement of the anti- 
fouling property of the feed and the membrane. The decrease in the total mass of fouling caused a reduction in the resistance to the flow. Therefore, the increase in the transmembrane pressure over the duration of the filtration process was reduced, and hence, the specific power consumption decreased from 10.17 to $6.9 \mathrm{kWh} / \mathrm{m}^{3}$. In addition, decreasing of both attachments resulted in increasing permeate flux from 0.0125 to $0.018 \mathrm{~m}^{3} / \mathrm{m}^{2}$, as shown in Figure 5.46 (a).

On the other hand, in acidic conditions the hydrophilic membrane became less negatively charged (more hydrophobic). This can be attributed to the more solubility of $\mathrm{H}^{+}$functional group. As the $\mathrm{pH}$ decreased from 7 to 3 , the zeta potential of the membrane surface became significantly less negative, decreasing from -36.67 to $-18.11 \mathrm{mV}$, respectively. This in turn results in a stronger electrostatic attractive force between the latex particles and the membrane surface. As a consequence, more particle-to-membrane attachment would occur. As illustrated in Figure 5.46 (a), when $\mathrm{pH}$ was decreased from 7 to 3 , a considerable increase in the depositional attachment from 0.55 to 0.82 was observed. Moreover, the lowering of the $\mathrm{pH}$ reduced the negative charge on the particles, thus causing a stronger electrostatic attraction force between particles and encouraging particle aggregation. As the $\mathrm{pH}$ decreased from 7 to 3 , the zeta potential of latex particles became significantly less negative, decreasing from -26.61 to $11.2 \mathrm{mV}$, respectively.A stronger electrostatic attraction and particle aggregation resulted in an increased coagulation attachment from 0.4 to 0.59 . Moreover, SEM images obtained after the ultrafiltration provided further evidence in support of the results acquired previously. Particularly, at $\mathrm{pH}=7$ the cake thickness was $5.05 \mu \mathrm{m}$, as shown in Figure 5.47 (a). The cake height decreased to $3.6 \mu \mathrm{m}$ at $\mathrm{pH}=10$, as can be seen in Figure 5.47 (b).The cake thickness further diminished to $1.85 \mu \mathrm{m}$ at $\mathrm{pH}=12$, as illustrated in Figure 5.47 (c). This was due to the significant reduction in the particle-to-particle attachment, which was the predominant factor responsible for the cake formation. 


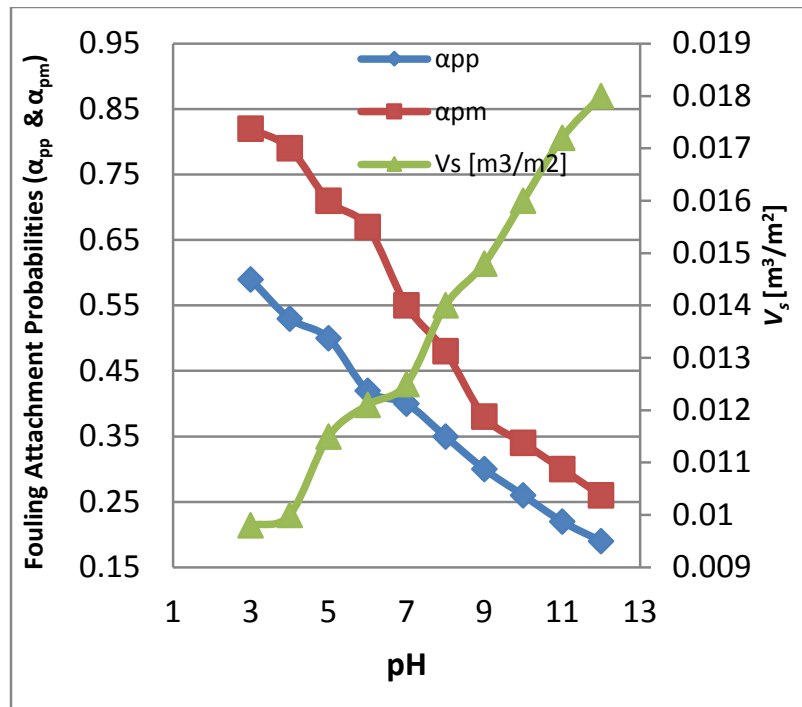

(a)

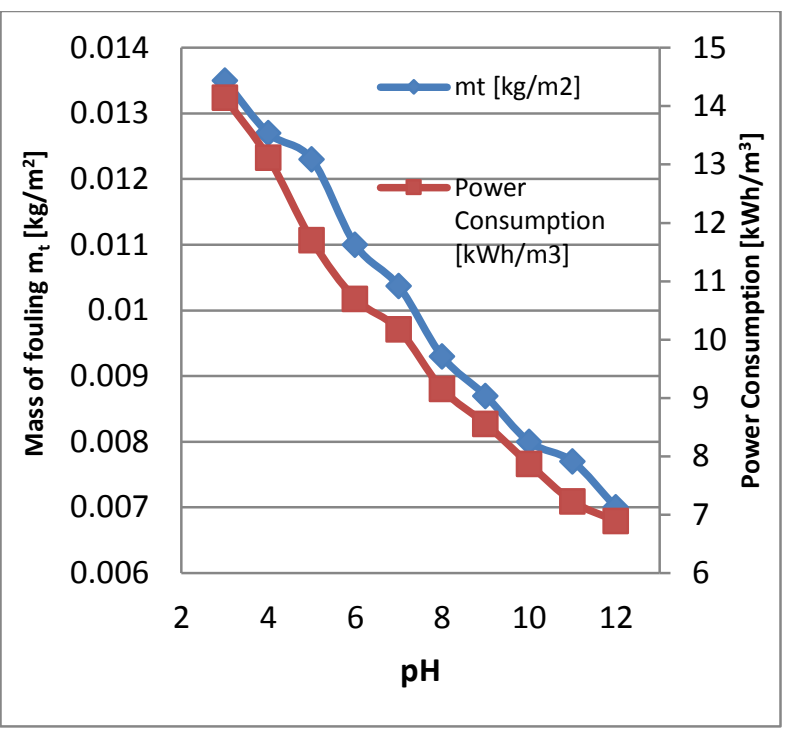

(b)

Figure 5.46: Effect of $\mathrm{pH}$ value at $[\mathrm{TMP}=15 \mathrm{psi}],\left[\mathrm{C}_{\mathrm{f}}=1.3 \mathrm{~kg} / \mathrm{m}^{3}\right] \&[\mathrm{Q}=4 \mathrm{LPM}]$ (Using $1 \mathrm{~N}$

$\left.\mathrm{NaOH} \& 0.1 \mathrm{~N} \mathrm{H}_{2} \mathrm{SO}_{4}\right)$ on (a) Fouling attachment probabilities $\left(\alpha_{\mathrm{pp}}, \alpha_{\mathrm{pm}}\right)$ and the volumetric permeate flux $\left(V_{s}\right)(b)$ Mass of fouling and power consumption $\left[\mathrm{kWh} / \mathrm{m}^{3}\right]$

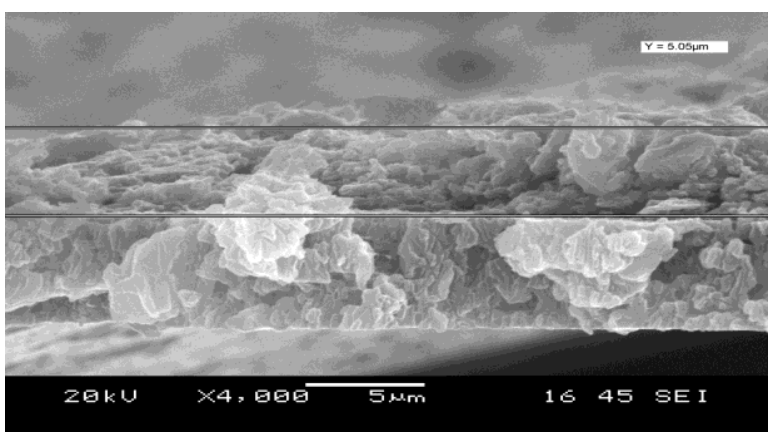

(a)

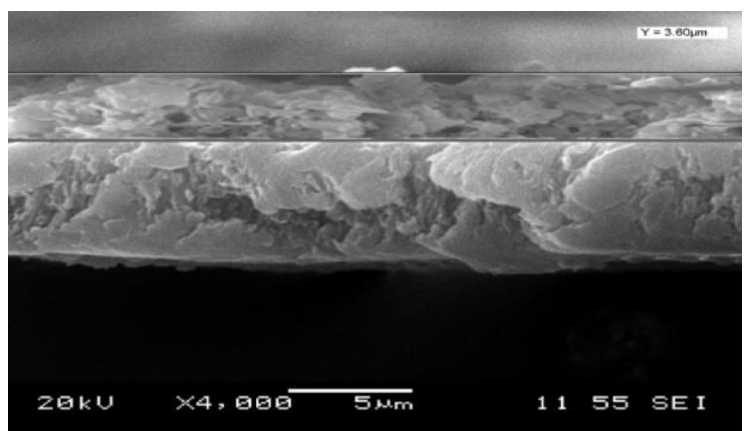

(b)

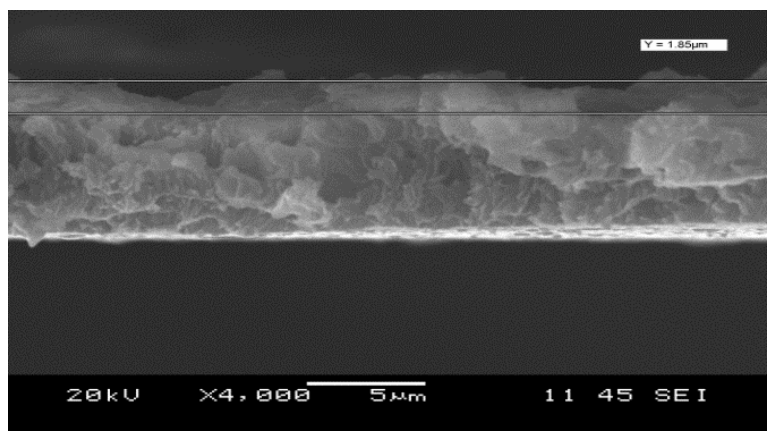

(c)

Figure 5.47: SEM images of membrane after ultrafiltration $[Q=4 \mathrm{LPM}],\left[\mathrm{C}_{\mathrm{f}}=1.3 \mathrm{~kg} / \mathrm{m}^{3}\right]$, $[\mathrm{TMP}=15 \mathrm{psi}]$ (a) Cake height $=5.05 \mu \mathrm{m}$ at $\mathrm{pH}=7$, (b) Cake height $=3.6 \mu \mathrm{m}$ at $\mathrm{pH}=10$, (c) Cake height $=1.85 \mu \mathrm{m}$ at $\mathrm{pH}=12$ 
In the previous section, the minimum specific power consumption occurred at the lowest flow rate of 1 LPM. On the other hand, at the lowest flow rate the total mass of fouling and the cake layer thickness were highest. Therefore, the effect of $\mathrm{pH}$ on the membrane fouling and the specific power consumption at a low feed flow rate of 1 LPM was further investigated. It was observed that at a feed flow rate of 1 LPM, the transmembrane pressure of 15 psi and the feed solid concentration of $1.3 \mathrm{~kg} / \mathrm{m}^{3}$, when the solution $\mathrm{pH}$ was increased from 7 to 12 , the total mass of fouling decreased from 0.0162 to $0.0081 \mathrm{~kg} / \mathrm{m}^{2}$, as can be seen in Figure 5.48 (b). This contributed to the considerable reduction in both attachment probabilities $\alpha_{\mathrm{pp}}$ and $\alpha_{\mathrm{pm}}$, from 0.86 to 0.40 and from 0.82 to 0.37 , respectively, as shown in Figure 5.48 (a). Therefore, the membrane fouling was lessened, leading to a decrease in the transmembrane pressure elevation over the duration of the experiment from 6 psi to 1 psi. Consequently, the specific power consumption decreased from 4.62 to $2.06 \mathrm{kWh} / \mathrm{m}^{3}$, as presented in Figure 5.48 (b). Moreover, at the solution $\mathrm{pH}$ of 12 , a volumetric permeate flux of $0.015 \mathrm{~m}^{3} / \mathrm{m}^{2}$ was obtained, which is higher than the permeate flux at a higher feed flow rate of 6 LPM with the solution $\mathrm{pH}$ of 7 and the same other operating conditions.

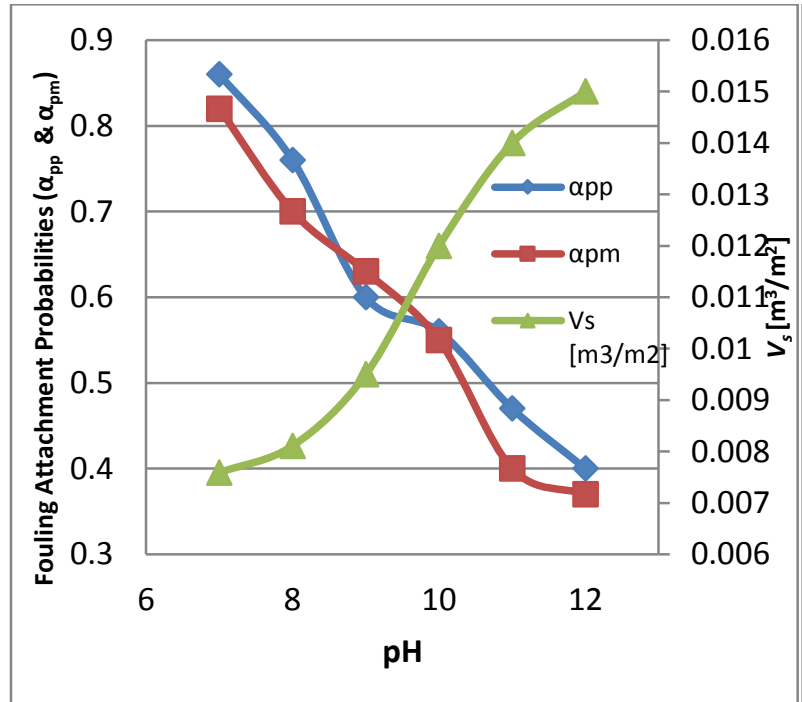

(a)

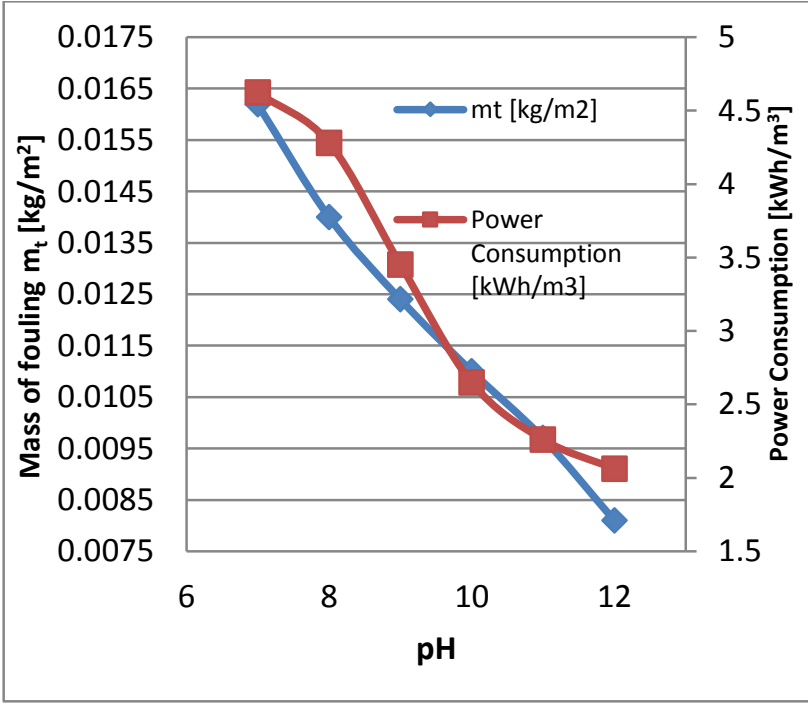

(b)

Figure 5.48: Effect of $\mathrm{pH}$ value at $[\mathrm{TMP}=15 \mathrm{psi}],\left[\mathrm{C}=1.3 \mathrm{~kg} / \mathrm{m}^{3}\right] \&[\mathrm{Q}=1 \mathrm{LPM}]$ (Using $1 \mathrm{~N}$ $\left.\mathrm{NaOH} \& 0.1 \mathrm{~N} \mathrm{H}_{2} \mathrm{SO}_{4}\right)$ on $(\mathrm{a})$ Fouling attachment probabilities $\left(\alpha_{\mathrm{pp}}, \alpha_{\mathrm{pm}}\right)$ and the volumetric permeate flux $\left(V_{s}\right)(b)$ Mass of fouling and power consumption $\left[\mathrm{kWh} / \mathrm{m}^{3}\right]$

Furthermore, the cake height at $\mathrm{Q}=1 \mathrm{LPM}, \mathrm{TMP}=15 \mathrm{psi}, \mathrm{C}_{\mathrm{f}}=1.3 \mathrm{~kg} / \mathrm{m}^{3}$, and $\mathrm{pH}=7$ was $13.8 \mu \mathrm{m}$ as shown in Figure 5.49 (a). Increasing $\mathrm{pH}$ value to 10 resulted in a significant 
reduction in the cake thickness to $6.1 \mu \mathrm{m}$. At $\mathrm{pH}=12$ the cake thickness was further reduced to $2.3 \mu \mathrm{m}$, which is very close to the cake thickness of $2.4 \mu \mathrm{m}$ at $\mathrm{Q}=6 \mathrm{LPM}, \mathrm{TMP}=15 \mathrm{psi}, \mathrm{C}_{\mathrm{f}}=1.3$ $\mathrm{kg} / \mathrm{m}^{3}$ and $\mathrm{pH}=7$. However, at the lower feed flow rate of $1 \mathrm{LPM}, \mathrm{TMP}=15 \mathrm{psi}, \mathrm{C}_{\mathrm{f}}=1.3 \mathrm{~kg} / \mathrm{m}^{3}$ and $\mathrm{pH}=12$, the specific power consumption was only $2.06 \mathrm{kWh} / \mathrm{m}^{3}$ (Figure 5.49 (b)), compared with $13.1 \mathrm{kWh} / \mathrm{m}^{3}$ at $\mathrm{Q}=6 \mathrm{LPM}, \mathrm{TMP}=15 \mathrm{psi}, \mathrm{C}_{\mathrm{f}}=1.3 \mathrm{~kg} / \mathrm{m}^{3}$ and $\mathrm{pH}=7$ (Figure 5.19 (b)).

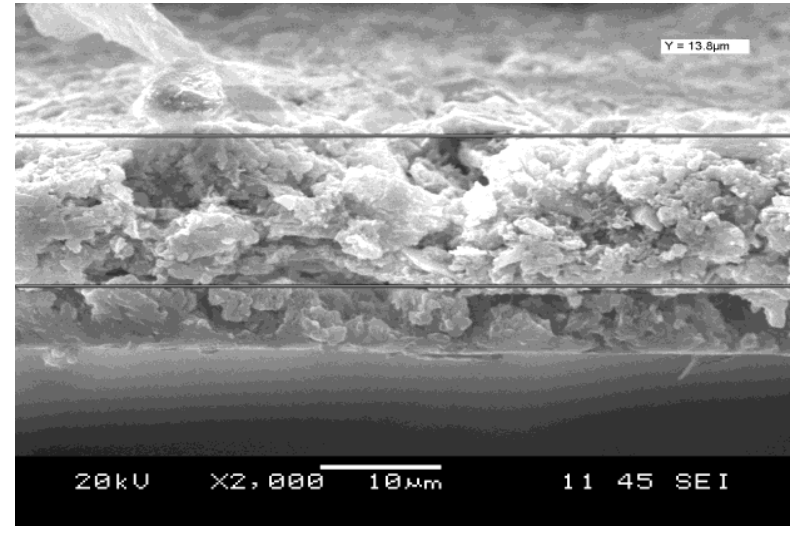

(a)

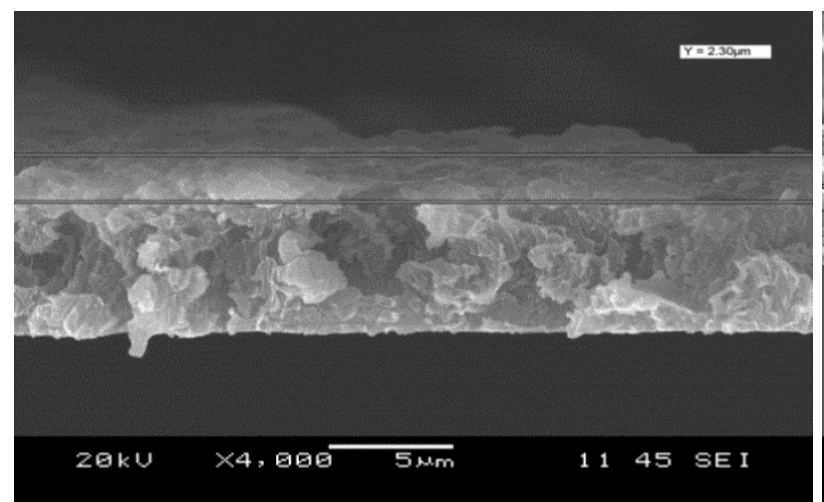

(c)

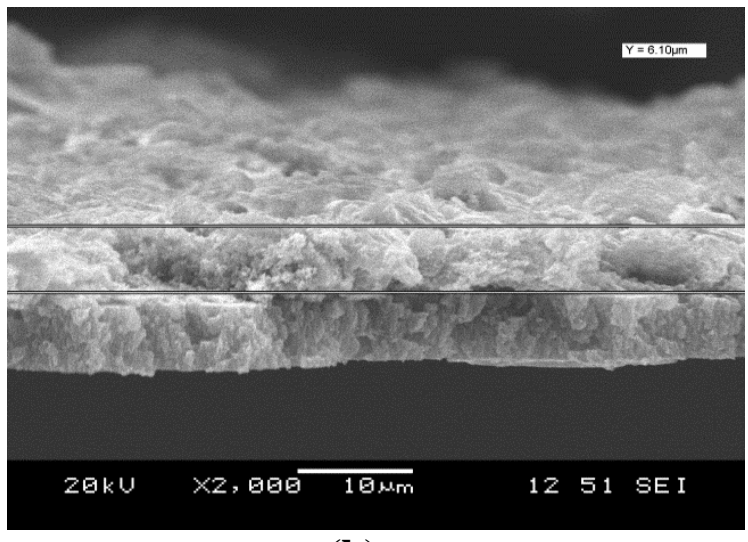

(b)

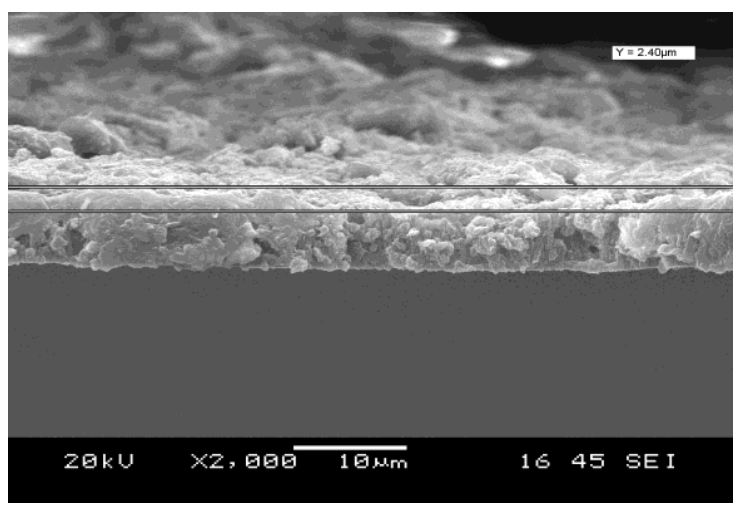

(d)

Figure 5.49: SEM images of membrane after ultrafiltration

(a) Cake height $13.8 \mu \mathrm{m}$ at $[\mathrm{TMP}=15 \mathrm{psi}],\left[\mathrm{C}_{\mathrm{f}}=1.3 \mathrm{~kg} / \mathrm{m}^{3}\right],[\mathrm{Q}=1 \mathrm{LPM}] \& \mathrm{pH}=7$

(b) Cake height $6.1 \mu \mathrm{m}$ at $[\mathrm{TMP}=15 \mathrm{psi}],\left[\mathrm{C}_{\mathrm{f}}=1.3 \mathrm{~kg} / \mathrm{m}^{3}\right],[\mathrm{Q}=1 \mathrm{LPM}] \& \mathrm{pH}=10$

(c) Cake height $2.3 \mu \mathrm{m}$ at $[\mathrm{TMP}=15 \mathrm{psi}],\left[\mathrm{C}_{\mathrm{f}}=1.3 \mathrm{~kg} / \mathrm{m}^{3}\right],[\mathrm{Q}=1 \mathrm{LPM}] \& \mathrm{pH}=12$

(d) Cake height $2.4 \mu \mathrm{m}$ at $[\mathrm{TMP}=15 \mathrm{psi}],\left[\mathrm{C}_{\mathrm{f}}=1.3 \mathrm{~kg} / \mathrm{m}^{3}\right],[\mathrm{Q}=6 \mathrm{LPM}] \& \mathrm{pH}=7$

Table 5.29 summarizes the difference between the effects achieved by either increasing the feed flow rate or by raising the $\mathrm{pH}$ value with respect to the fouling attachment, the total mass of fouling, the volumetric permeate flux, and the specific power consumption at transmembrane pressure of $15 \mathrm{psi}$ and $1.3 \mathrm{~kg} / \mathrm{m}^{3}$. A sole increase of the feed flow rate reduced membrane fouling but accompanied by high power consumption. On the other hand, an increased feed flow rate accompanied by an augmented $\mathrm{pH}$ value had a noticeable improvement 
in the specific power consumption. On the overall, a reduced flow rate in combination with an increased $\mathrm{pH}$ had best effects on both the membrane fouling and the specific power consumption.

Table 5.29: Comparison of total mass of fouling, volumetric permeate flux, cake height, and the power consumption at different $\mathrm{pH}$. [TMP=15 psi], [Cf=1.3 kg/m $\mathrm{m}^{3}$, and $25 \mathrm{~min}$

\begin{tabular}{|c|c|c|c|c|c|c|c|}
\hline $\begin{array}{c}\mathbf{Q} \\
{[\mathbf{L P M}]}\end{array}$ & $\mathbf{p H}$ & $\boldsymbol{\alpha}_{\mathbf{p p}}$ & $\boldsymbol{\alpha}_{\mathbf{p m}}$ & $\boldsymbol{m}_{t}\left[\mathbf{k g} / \mathbf{m}^{2}\right]$ & $\boldsymbol{V}_{\boldsymbol{s}}\left[\mathbf{m}^{\left.\mathbf{3} / \mathbf{m}^{2}\right]}\right.$ & $\begin{array}{c}\text { Specific Power } \\
\text { Consumption } \\
{\left[\mathbf{k W h} / \mathbf{m}^{3}\right]}\end{array}$ & $\begin{array}{c}\text { Cake } \\
\text { Height } \\
{[\boldsymbol{\mu \mathbf { m } ]}]}\end{array}$ \\
\hline 1 & 7 & 0.86 & 0.82 & 0.0162 & 0.0076 & 4.47 & 13.8 \\
\hline 1 & 10 & 0.56 & 0.55 & 0.011 & 0.012 & 2.65 & 6.1 \\
\hline 1 & 12 & 0.4 & 0.37 & 0.0081 & 0.015 & 2.06 & 2.3 \\
\hline 4 & 7 & 0.4 & 0.55 & 0.0104 & 0.0125 & 10.17 & 5.05 \\
\hline 4 & 10 & 0.26 & 0.34 & 0.008 & 0.016 & 7.87 & 3.6 \\
\hline 4 & 12 & 0.19 & 0.26 & 0.007 & 0.018 & 6.89 & 1.85 \\
\hline
\end{tabular}

The effects of ionic strength on the membrane fouling and the power consumption were also studied at a higher TMP of $25 \mathrm{psi}, \mathrm{Q}=4 \mathrm{LPM}$, and $\mathrm{C}_{\mathrm{f}}=1.3 \mathrm{~kg} / \mathrm{m}^{3}$. The solution $\mathrm{pH}$ was varied within a range from 3 to 12 . Figure 5.50 shows similar trends for the fouling attachments, the volumetric permeate flux, the total mass of fouling, and the specific power consumption as those at $\mathrm{TMP}=15$ psi shown Figure 5.45. However, ultrafiltration at TMP of 25 psi resulted in higher values for the particle-to-particle and particle-to-membrane attachments. For instance, at $\mathrm{pH}=10$, the particle-to-particle attachment was 0.40 and 0.26 , at TMP of $25 \mathrm{psi}$ and $15 \mathrm{psi}$, respectively. At a higher TMP, the permeate flux was higher. More particles were thus brought to the membrane surface; hence, more chances for the particle-to-particle and particle-to-membrane collision and attachment occurred. Consequently, the particle-to-particle and particle-tomembrane attachment increased. At $\mathrm{TMP}=25 \mathrm{psi}$ and $\mathrm{Q}=4 \mathrm{LPM}$, increases in $\mathrm{pH}$ from 7 to 12 resulted in a significant reduction in the total mass of fouling from $0.012 \mathrm{~kg} / \mathrm{m}^{2}$ to $0.0077 \mathrm{~kg} / \mathrm{m}^{2}$. Consequently, the specific power consumption was reduced from $14.0 \mathrm{kWh} / \mathrm{m}^{3}$ to $10.1 \mathrm{kWh} / \mathrm{m}^{3}$, as shown in Figure 5.50 (b). Figure 5.51 (a) and (b) presents SEM images of the cake height after ultrafiltration at the solution $\mathrm{pH}$ of 7 and 10, respectively. The cake thickness decreased from 6.65 to $5.30 \mu \mathrm{m}$ when the $\mathrm{pH}$ was raised from 7 to 10. SEM images in Figure 5.51 and Figure 5.47 provide a confirmation of the effect of the transmembrane pressure on the cake height. 


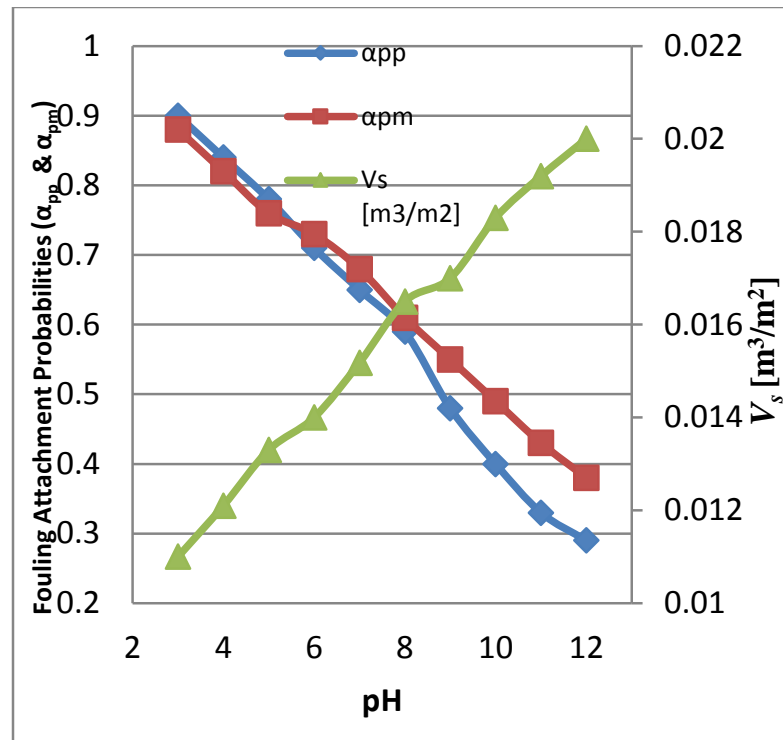

(a)

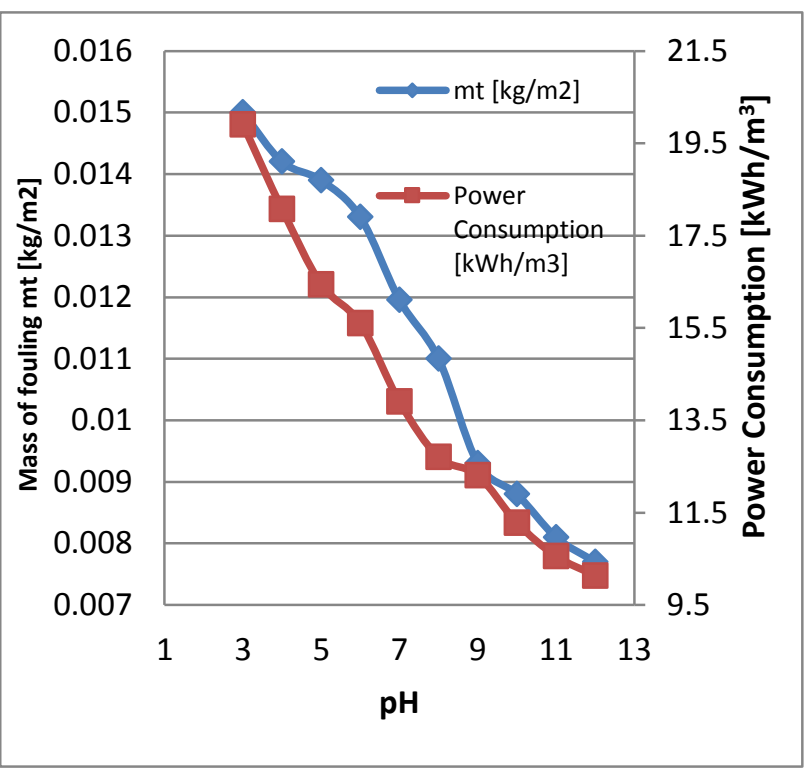

(b)

Figure 5.50: Effect of $\mathrm{pH}$ value at $[\mathrm{TMP}=25 \mathrm{psi}],\left[\mathrm{C}_{\mathrm{f}}=1.3 \mathrm{~kg} / \mathrm{m}^{3}\right] \&[\mathrm{Q}=4 \mathrm{LPM}]$ (Using $1 \mathrm{~N}$

$\left.\mathrm{NaOH} \& \mathrm{O}_{1} \mathrm{~N} \mathrm{H}_{2} \mathrm{SO}_{4}\right)$ on (a) Fouling attachment probabilities $\left(\alpha_{\mathrm{pp}}, \alpha_{\mathrm{pm}}\right)$ and the volumetric permeate flux $\left(V_{s}\right)(b)$ Mass of fouling and power consumption $\left[\mathrm{kWh} / \mathrm{m}^{3}\right]$

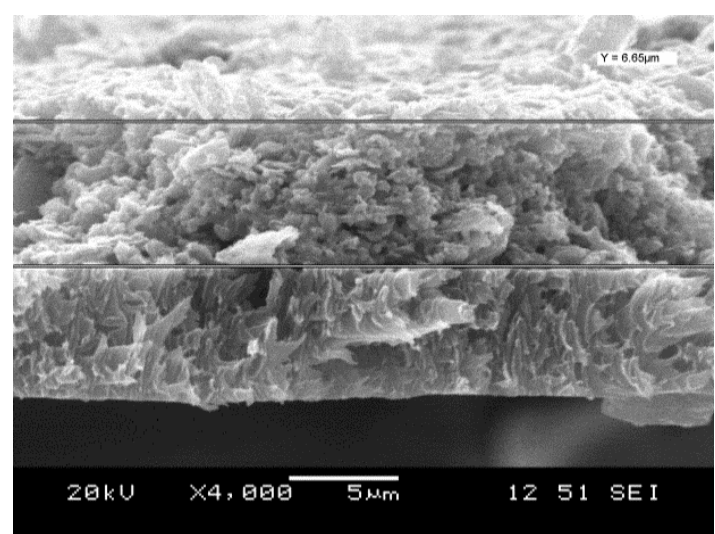

(a)

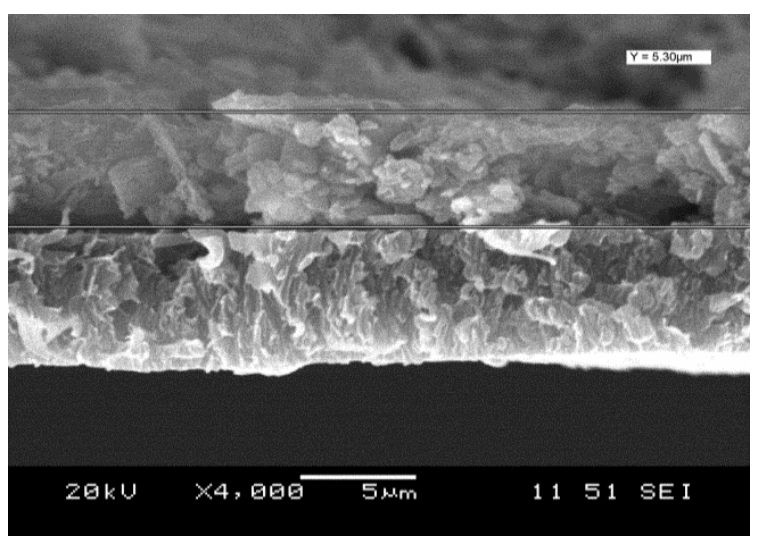

(b)

Figure 5.51: SEM images of membrane after ultrafiltration $[Q=4 \mathrm{LPM}],\left[\mathrm{C}_{\mathrm{f}}=1.3 \mathrm{~kg} / \mathrm{m}^{3}\right]$, [ TMP= 25 psi] (a) Cake height $6.65 \mu \mathrm{m}$ at $\mathrm{pH}=7$, (b) Cake height $5.30 \mu \mathrm{m}$ at $\mathrm{pH}=10$

\subsubsection{Effect of ionic valence on membrane fouling remediation using Polycarbonate membrane}

The effect of the ionic valance on fouling attachments, total mass of fouling, and specific power consumption was also investigated using sulfuric acid and hydrochloric acid. As shown in Table 5.30 at $\mathrm{pH}$ of 3 and 5, lower fouling attachment probabilities, lower total total mass of fouling, higher volumetric permeate flux and lower power consumption were achieved with sulfuric acid. This can be attributed to the more negative charge sulphate ion, $\mathrm{SO}_{4}{ }^{2-}$, of sulfuric 
acid, which makes the membrane less hydrophobic in comparison to the chlorine ion, $\mathrm{Cl}^{-}$, of hypochloric acid. It is relevant to note that the zeta potential of the membrane surface at $\mathrm{pH}=3$ was $-18.11 \mathrm{mV}$ and $-16.31 \mathrm{mV}$ with sulfuric acid and hydrochloric acid, respectively. When $\mathrm{pH}$ was increased to 5 , the zeta potential of the membrane surface increased to $-24.78 \mathrm{mV}$ using sulfuric acid, in comparison to $-20.55 \mathrm{mV}$ using hydrochloric acid. This again reconfirms the advantage of sulfuric acid over hydrochloric acid in fouling mediation. Figure 5.52 presents the SEM images of the cake thickness at $\mathrm{pH}=3$ using sulfuric acid and hypochloric acid. The cake thickness increased to $6.35 \mu \mathrm{m}$ for $0.1 \mathrm{~N} \mathrm{H}_{2} \mathrm{SO}_{4}$ to $7.65 \mu \mathrm{m}$ for $0.1 \mathrm{~N} \mathrm{HCl}$.

Table 5.30: Comparison of the effect of the monovalent acid ( $\mathrm{HCl})$ and the divalent acid $\left(\mathrm{H}_{2} \mathrm{SO}_{4}\right)$ at $\mathrm{pH} 3$ and 5 at transmembrane pressure $15 \mathrm{psi}, 4 \mathrm{LPM}$ and $1.3 \mathrm{~kg} / \mathrm{m}^{3}$

\begin{tabular}{|c|c|c|c|}
\hline \multicolumn{2}{|c|}{ 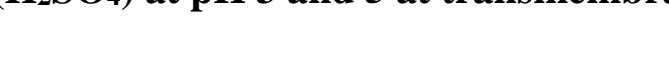 } & Using $0.1 \mathrm{~N} \mathrm{H}_{2} \mathrm{SO}_{4}$ & Using $0.1 \mathrm{~N} \mathrm{HCl}$ \\
\hline \multirow{5}{*}{$\frac{\pi}{\mathbb{I}}$} & $\alpha_{\mathrm{pp}}$ & 0.59 & 0.62 \\
\hline & $\alpha_{\mathrm{pm}}$ & 0.82 & 0.97 \\
\hline & $\mathrm{m}_{\mathrm{t}}[\mathrm{kg} / \mathrm{m} 2]$ & 0.0135 & 0.0145 \\
\hline & $V_{s}\left[\mathrm{~m}^{3} / \mathrm{m}^{2}\right]$ & 0.0098 & 0.0088 \\
\hline & Power Consumption $[\mathrm{kWh} / \mathrm{m} 3]$ & 14.14 & 15.94 \\
\hline \multirow{5}{*}{$\begin{array}{l}\frac{\pi}{I} \\
\frac{\pi}{2}\end{array}$} & $\alpha_{\mathrm{pp}}$ & 0.5 & 0.54 \\
\hline & $\alpha_{\mathrm{pm}}$ & 0.71 & 0.8 \\
\hline & $\mathrm{m}_{\mathrm{t}}[\mathrm{kg} / \mathrm{m} 2]$ & 0.0123 & 0.013 \\
\hline & $V_{s}\left[\mathrm{~m}^{3} / \mathrm{m}^{2}\right]$ & 0.0115 & 0.01 \\
\hline & Power Consumption $[\mathrm{kWh} / \mathrm{m} 3]$ & 11.7 & 13.86 \\
\hline
\end{tabular}

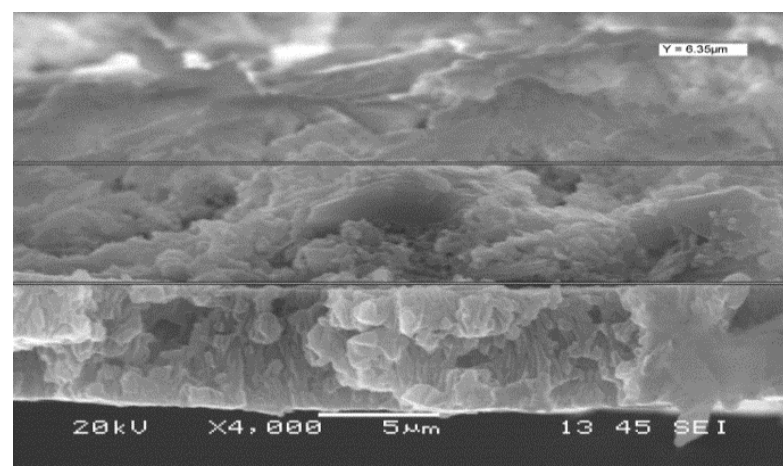

(a)

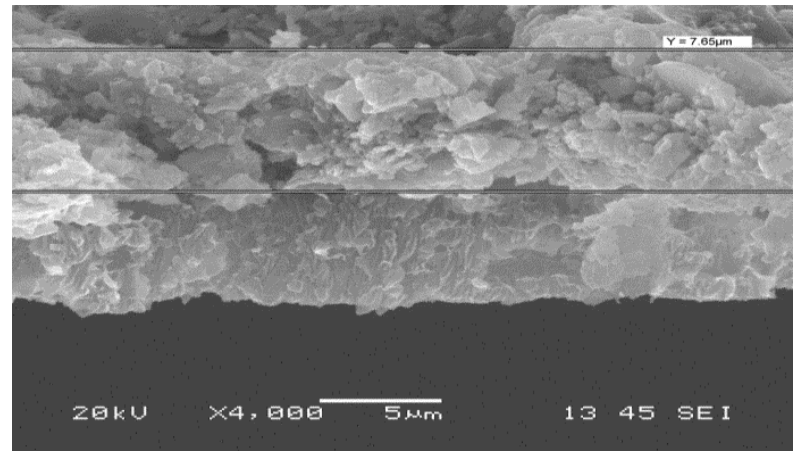

(b)

Figure 5.52: $S E M$ images of membrane after ultrafiltration $[Q=4 \mathrm{LPM}],\left[\mathrm{C}_{\mathrm{f}}=1.3 \mathrm{~kg} / \mathrm{m}^{3}\right],[\mathrm{TMP}=$ $15 \mathrm{psi}$, pH=3 (a) Cake height $=6.35 \mu \mathrm{m}$ using $0.1 \mathrm{~N} \mathrm{H}_{2} \mathrm{SO}_{4}$ (b) Cake height=7.65 $\mu \mathrm{m}$ using $0.1 \mathrm{~N}$ $\mathrm{HCl}$ 


\subsubsection{Effect of pre-treatment of simulated latex effluent by $\mathrm{pH}$ change on filtration using heterogeneous membranes}

The simulated latex effluent with a solid concentration of $1.30 \mathrm{~kg} / \mathrm{m}^{3}$ has a $\mathrm{pH}$ of 7 . The zeta potential of latex particles at $\mathrm{pH} 7$ is approximately $-26.61 \mathrm{mV}$. As the $\mathrm{pH}$ increased from 7 to 11 the zeta potential negativity of latex particles had increased significantly from $-26.61 \mathrm{mV}$ to $-40.00 \mathrm{mV}$, as shown in Figure 5.53. The adsorption of $\mathrm{OH}^{-}$group on the particle surface at higher $\mathrm{pH}$ values in turn caused the negative charge on the latex particle surfaces to increase until it achieved $-42.66 \mathrm{mV}$ at $\mathrm{pH}$ of 12 . Furthermore, the solution conductivity increased from 0.094 to $20.4 \mathrm{mS} / \mathrm{cm}$ when the solution $\mathrm{pH}$ was increased from 7 to 11 . Notably, the ionic strength is directly proportional to the solution conductivity. On the other hand, decreasing $\mathrm{pH}$ from 7 to 3 using sulfuric acid resulted in a substantial decrease in the zeta potential value from $26.61 \mathrm{mV}$ to $-11.20 \mathrm{mV}$. It is relevant to note that the zeta potential of the latex particles was $4.83 \mathrm{mV}$ at $\mathrm{pH}$ of 3 using hydrochloric acid $(\mathrm{HCl})$. This can be attributed to the more negative charge of sulphate ion, $\mathrm{SO}_{4}{ }^{2-}$, of sulfuric acid in comparison to the chlorine ion, $\mathrm{Cl}^{-}$, of hydrochloric acid.

In addition, the zeta potential of each membrane surface was investigated at each $\mathrm{pH}$ value so as to simulate the effects of $\mathrm{pH}$ of the latex solution through the ultrafiltration process. As the $\mathrm{pH}$ of the simulated latex effluent was increased from 3 to 11, the zeta potential of PVDF, Ultrafilic, and Polysulfone membrane surfaces became increasingly negative: from -2.01 to $32.62 \mathrm{mV},-18.99$ to $-43.00 \mathrm{mV}$, and -5.67 to $-41.98 \mathrm{mV}$, respectively, as shown in Figure 5.52. Notably, the hydrophilicity of the hydrophobic PVDF membrane surface was enhanced from -2.5 to $-32.62 \mathrm{mV}$ when the latex solution $\mathrm{pH}$ was increased from the original value of 7 to 11 . While it resulted in an insignificant change in the surface of the Ultrafilic membrane from -41.5 to $43.00 \mathrm{mV}$. On the other hand, increasing the $\mathrm{pH}$ value from 7 to 11 resulted in a slight decrease in the membrane surface negativity of the Polysulfone membrane from -42.40 to $-41.98 \mathrm{mV}$. This may be attributed to the fact that 25 minutes of the ultrafiltration process were not sufficient enough to change the zeta potential of Polysulfone membrane, of the unique chemical structure with the sulfone group, especially if compared to the two hour treatment of the surface soaked in alkaline as a membrane surface treatment. 


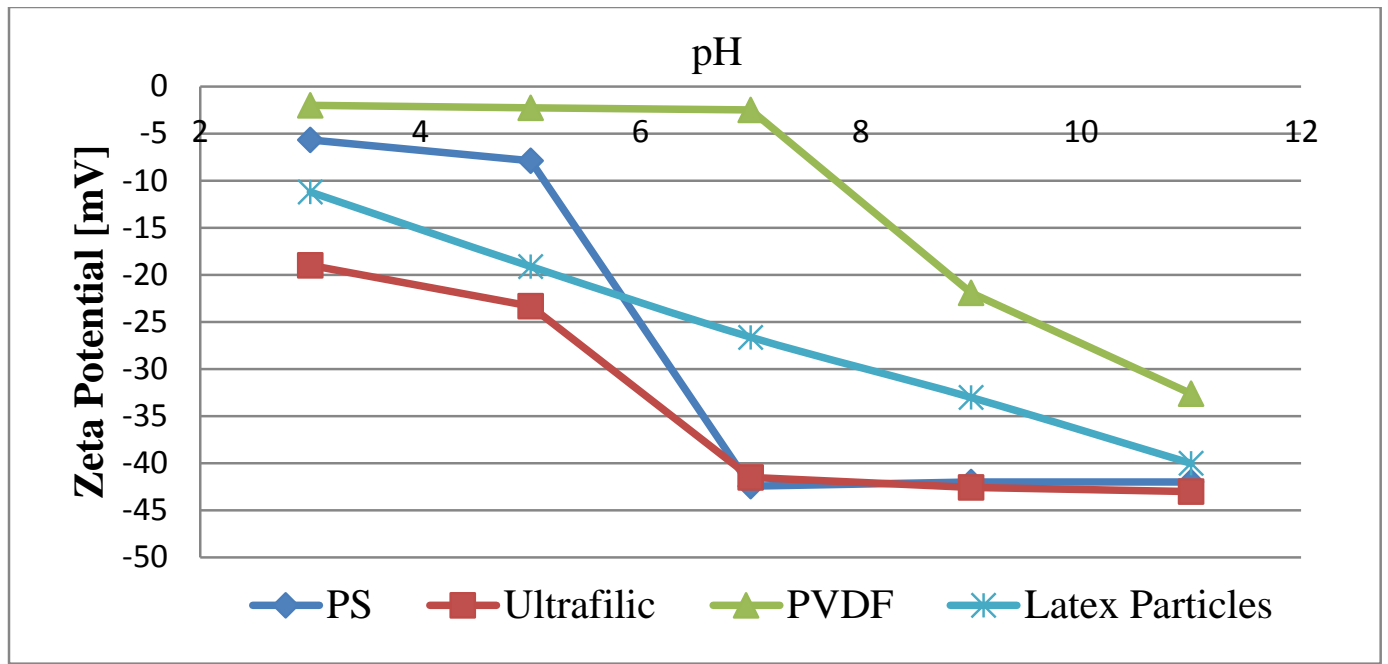

Figure 5.53: Effect of $\mathrm{pH}$ change of latex effluent on the zeta potential of latex particles and the membrane surface through the ultrafiltration process

The results obtained indicated that the most significant influence of increasing the $\mathrm{pH}$ of simulated latex effluent through the ultrafiltration process occurred with the use of hydrophobic PVDF membrane surface, as presented in Figure 5.54. Due to the high adsorption of $\mathrm{OH}^{-}$group on the hydrophobic membrane surface. At the feed flow rate of 4 LPM, feed concentration of $0.78 \mathrm{~kg} / \mathrm{m}^{3}$, and transmembrane pressure of $15 \mathrm{psi}$, using a PVDF membrane and increasing the $\mathrm{pH}$ value from 7 to 11 resulted in an increase in the zeta potential negativity from $-2.5 \mathrm{mV}$ to $32.62 \mathrm{mV}$. In addition to, the zeta potential negativity of latex particles had a significant increase from $26.61 \mathrm{mV}$ to $-40.00 \mathrm{mV}$. As a consequence, the repulsion force between the latex particles and the membrane surface increased, causing the depositional attachment to decrease from 0.97 to 0.21 . Hence, the total mass of fouling significantly decreased by $29.60 \%$ from 0.0125 to $0.0088 \mathrm{~kg} / \mathrm{m}^{2}$, and the specific power consumption experienced a substantial decrease by 88.12 $\%$ from 15.4 to $1.83 \mathrm{~kW} . \mathrm{h} / \mathrm{m}^{3}$, while the permeate flux experiences a noticeable 7 time increase from 0.01 to $0.07 \mathrm{~m}^{3} / \mathrm{m}^{2}$. Figure 5.54 (a) and Figure 5.54(b) present the respective SEM images of PVDF membrane after ultrafiltration of simulated latex effluent at $\mathrm{pH} 7$ and 11 at feed flow rate of $4 \mathrm{LPM}$, feed concentration of $0.78 \mathrm{~kg} / \mathrm{m}^{3}$, and transmembrane pressure of 15 psi. As shown in Figure 5.54 (a), at $\mathrm{pH}$ of 7 the higher depositional attachment resulted in a greater number of latex particles deposited on the membrane surface, more blocked membrane pores, and a higher number of particles accumulated at the surface, due to the higher attraction force between PVDF membrane with the zeta potential of $-2.50 \mathrm{mV}$ and the latex particles with the 
zeta potential of -26.61 . On the other hand at Figure 5.54 (b), at $\mathrm{pH}$ of 11 the higher repulsion force between the PVDF membrane of higher zeta potential negativity of $-32.62 \mathrm{mV}$ and the latex particles of higher negativity of $-40.00 \mathrm{mV}$ resulted in less particles deposited on the membrane surface and a presence of unrestricted membrane pores.

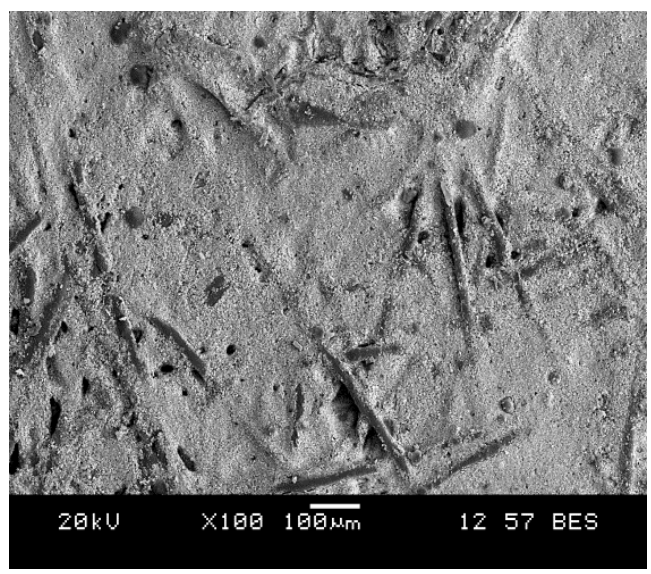

(a)

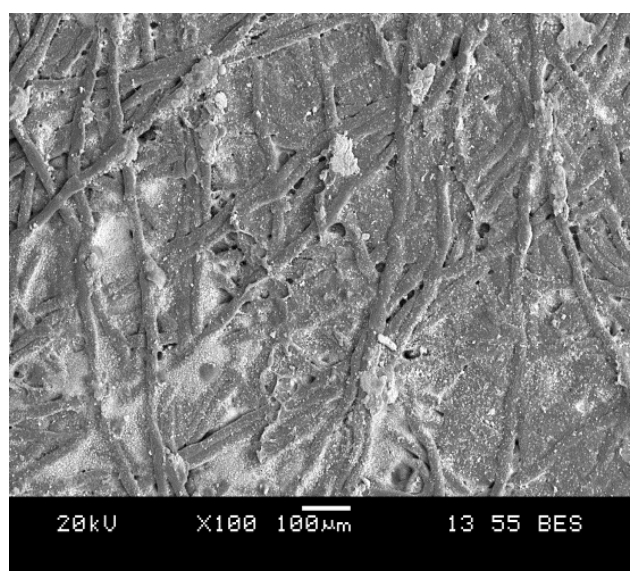

(b)

Figure 5.54: $S E M$ images of $P V D F$ membrane surfaces after ultrafiltration at $[Q=4 \mathrm{LPM}],\left[\mathrm{C}_{\mathrm{f}}=0.78\right.$ $\left.\mathrm{kg} / \mathrm{m}^{3}\right]$, [15 psi] using latex solution (a) at $\mathrm{pH}$ of 7 (b) at $\mathrm{pH}$ of 11

Although increasing the $\mathrm{pH}$ of latex solution from 7 to 11 had an insignificant effect on the surface charges hydrophilicty improvement of Polysulfone and Ultrafilic membranes. As the zeta potential negativity of Polysulfone decreased from -42.40 to $-41.98 \mathrm{mV}$, while the the zeta potential negativity slightly increased from -41.50 to $-43.00 \mathrm{mV}$. However, the increase of the solution $\mathrm{pH}$ had a significant effect on the latex particles surface charge negativity, as it increased from $-26.61 \mathrm{mV}$ to $-40.00 \mathrm{mV}$. Thus, ultrafilitation process using latex solution at $\mathrm{pH}$ of 11 and using Polysulfone and Ultrafilic membranes were performed in order to investigate the effect of foulants surface charge on the membrane fouling, cumulative permeate flux, and the specific power consumption. At the feed flow rate of $4 \mathrm{LPM}$, feed concentration of $1.30 \mathrm{~kg} / \mathrm{m}^{3}$, and transmembrane pressure of $25 \mathrm{psi}$, the total mass of fouling decreased by $11.11 \%$ from $0.0135 \mathrm{~kg} / \mathrm{m}^{2}$ to $0.012 \mathrm{~kg} / \mathrm{m}^{2}$, while the cumulative filtration volume increased by $10.43 \%$ from 0.115 to $0.127 \mathrm{~m}^{3} / \mathrm{m}^{2}$ using Polyulfone membrane. Consequently, the specific power consumption was lowered by $20.56 \%$ from $2.14 \mathrm{~kW} . \mathrm{h} / \mathrm{m}^{3}$ to $1.7 \mathrm{~kW} \cdot \mathrm{h} / \mathrm{m}^{3}$. Similarly, at the same operating conditions the total mass of fouling decreased by $24 \%$ from $0.025 \mathrm{~kg} / \mathrm{m}^{2}$ to 0.019 $\mathrm{kg} / \mathrm{m}^{2}$, while the cumulative filtration volume was increased by $38.21 \%$ from 0.123 to 0.17 $\mathrm{m}^{3} / \mathrm{m}^{2}$. The decrease in total mass of fouling resulted in a decrease in the specific power 
consumption by $28.02 \%$ from $1.82 \mathrm{~kW} \cdot \mathrm{h} / \mathrm{m}^{3}$ to $1.31 \mathrm{~kW} \cdot \mathrm{h} / \mathrm{m}^{3}$. As a result, the latex particles charge was found to have a significant effect when it came to increasing the repulsion forces between latex particles and membrane surfaces.

\subsection{2. pH treatment for membrane surface}

The effect of the surface hydrophilicity after the $\mathrm{pH}$ treatment of the membrane surface on fouling attachments, the total mass of fouling, permeate flux- and specific power consumption was also investigated. Polysulfone membrane surface charges from $-10 \mathrm{mV}$ to $-50 \mathrm{mV}$ were obtained by soaking the membrane for 2 hours in solutions at varied $\mathrm{pH}$ from 2.4 to 10.9. Under the operating conditions of $25 \mathrm{psi}, 4.5 \mathrm{LPM}, 1.30 \mathrm{~kg} / \mathrm{m}^{3}$, increasing the zeta potential of the membrane surface from -10.00 to $-50.00 \mathrm{mV}$, resulted in a substantial reduction of depositional attachment $\left(\alpha_{\mathrm{pm}}\right)$ by $65 \%$, from 0.99 to 0.35 , as shown in Figure 5.55 (a). This could be attributed to the increased hydrophilicity of the membrane, which was created upon introducing more negative charges on the membrane surface. As a result, the electrostatic attraction force between the latex particles and the higher negatively charged membrane surface was significantly decreased. The particle-to-membrane attachment was thus notably reduced. On the other hand, increasing the zeta potential negativity of the membrane surface caused an insignificant decrease in the coagulation attachment $\left(\alpha_{\mathrm{pp}}\right)$ by $5.3 \%$, from 0.75 to 0.71 , as shown in Figure $5.55(\mathrm{a})$. The decrease in the depositional attachment resulted in a significant increase in the cumulative filtration volume per unit area $(V S)$ from 0.015 to $0.123 \mathrm{~m}^{3} / \mathrm{m}^{2}$, an augmentation of about 10 folds, as shown in Figure 5.55 (a). This could be attributed to the significant reduction in the depositional attachment that resulted in a lower frequency of particle attached to the membrane pores, i.e. less pore blockage for the filtrate passage through the membrane. As a consequence, the total mass of fouling diminished by $61 \%$, from 0.018 to $0.007 \mathrm{~kg} / \mathrm{m}^{2}$, as indicated in Figure 5.55 (b). Decreasing the total mass of fouling resulted in a lower rate of the transmembrane pressure increase during the filtration process. Accordingly, the specific power consumption was dramatically decreased by $92.5 \%$, from 24.83 to $1.86 \mathrm{~kW} . \mathrm{h} / \mathrm{m}^{3}$, as presented in Figure 5.55 (b). From these observations a conclusion can be drawn that the depositional attachment is the predominant factor in membrane fouling. In addition, altering the particle-to-membrane attachment $\left(\alpha_{\mathrm{pm}}\right)$ by manipulating the zeta potential of the membrane surface could be an essential process in fouling remediation. Figure 5.56 (a) presents SEM image of Polysulfone 
membrane with the zeta potential of $-50.00 \mathrm{mV}$ after ultrafiltration at a transmembrane pressure of $25 \mathrm{psi}$, a feed flow rate of 4.5 LPM, and a feed concentration of $1.30 \mathrm{~kg} / \mathrm{m}^{3}$. Alternatively, Figure 5.56 (b) presents an SEM image of Polysulfone membrane with the zeta potential of $10.00 \mathrm{mV}$ after ultrafiltration at the same operating conditions. As shown in Figure 5.56 (a), the lower depositional attachment caused a decrease in the total mass of fouling, due to the reduced chances for particles to participate in particle-to-membrane attachment.

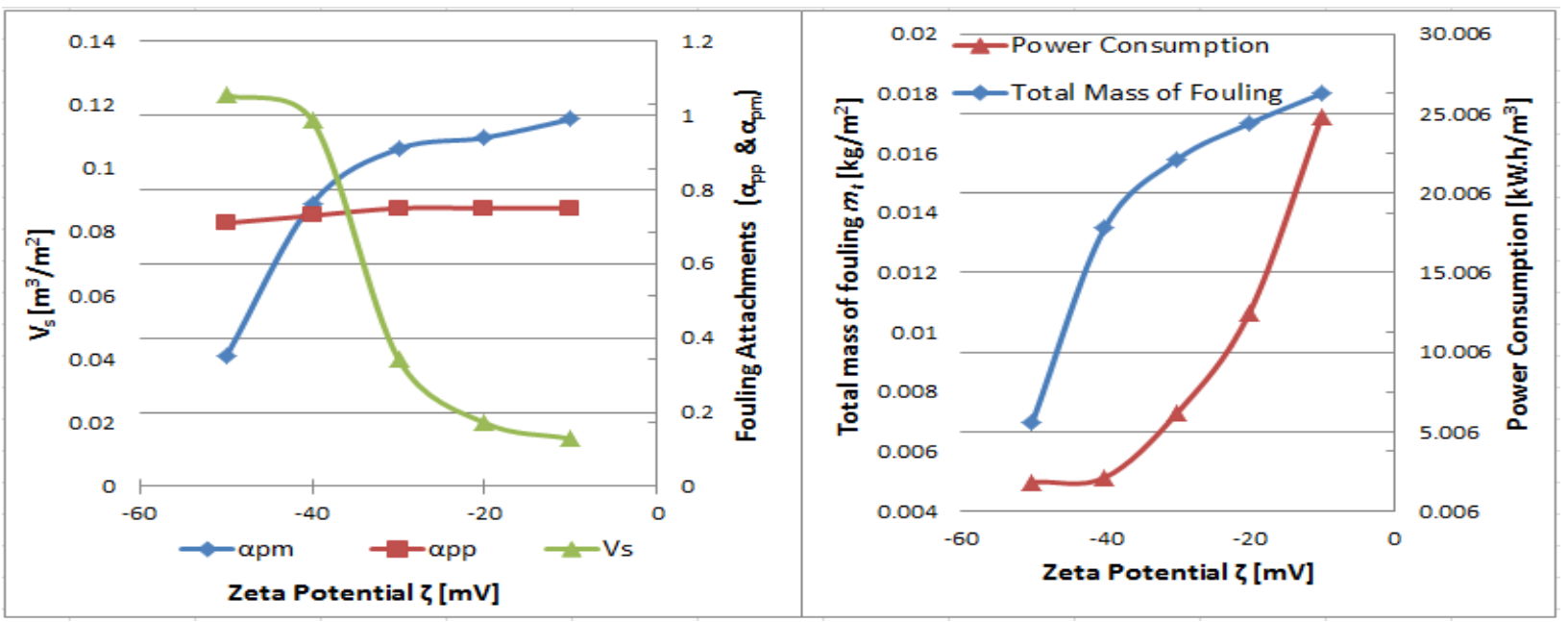

(a)

(b)

Figure 5.55: Effect of the zeta potential of Polysulfone membrane surface at [25 psi], $[Q=4.5 \mathrm{LPM}]$, $\left[C_{\mathrm{f}}=1.3 \mathrm{~kg} / \mathrm{m}^{3}\right]$ on (a) Fouling attachment probabilities $\left(\alpha_{\mathrm{pp}}, \alpha_{\mathrm{pm}}\right)$; and cumulative filtration volume per unit area $\left(V_{s}\right)\left[\mathrm{m}^{3} / \mathrm{m}^{2}\right]$; (b) Total mass of fouling $\left(m_{t}\right)\left[\mathrm{kg} / \mathrm{m}^{2}\right]$; and the specific power

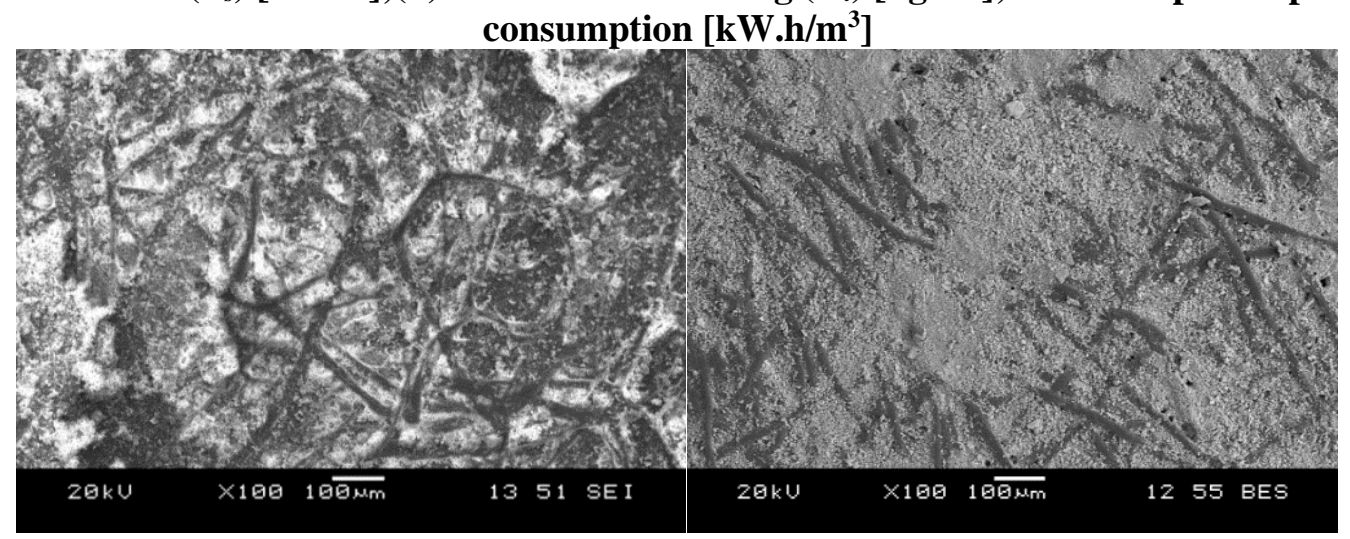

(a)

(b)

Figure 5.56: SEM images of Polysulfone membranes after ultrafiltration at [25 psi], [Q= 4.5 LPM], $\left[C_{f}=1.3 \mathrm{~kg} / \mathrm{m}^{3}\right]$ at the zeta potential of $(\mathrm{a})-50.00 \mathrm{mV} ;(\mathrm{b})-10.00 \mathrm{mV}$

When using the same operating conditions, the reduction of the negativity of the surface charge of Ultrafilic membrane, from the original zeta potential value of $-41.50 \mathrm{mV}$ to -30.00 $\mathrm{mV}$, caused a noticeable decrease in repulsion force between the membrane surface and latex particles. This in turn caused the depositional attachment $\left(\alpha_{\mathrm{pm}}\right)$ to increase from 0.70 to 0.85 . A 
significantly higher $\alpha_{\mathrm{pm}}$ facilitated a larger number of particle attachments to the membrane surface, thus resulting in a greater pore blockage, a lowered cumulative filtration volume per unit area from 0.123 to $0.115 \mathrm{~m}^{3} / \mathrm{m}^{2}$, power consumption upsurge from 1.82 to $1.93 \mathrm{~kW} . \mathrm{h} / \mathrm{m}^{3}$, and an overall increase in the mass of fouling from 0.025 to $0.03 \mathrm{~kg} / \mathrm{m}^{2}$. A continued decrease in the surface negativity, from $-30.00 \mathrm{mV}$ to $-15.00 \mathrm{mV}$, resulted in an additional increase in the depositional attachment, from 0.85 to 0.96 . As a consequence, the cumulative filtration volume per unit area lowered from 0.115 to $0.03 \mathrm{~m}^{3} / \mathrm{m}^{2}$, and the mass of fouling was augmented from 0.03 to $0.05 \mathrm{~kg} / \mathrm{m}^{2}$. The increase in the total mass of fouling resulted in the increase in the transmembrane pressure, which in turn caused a higher rate through the filtration process, allowing the power consumption to increase from 1.93 to $7.5 \mathrm{~kW} \cdot \mathrm{h} / \mathrm{m}^{3}$. Notably, when using an Ultrafilic membrane with the zeta potentials of $-41.50 \mathrm{mV},-30.00 \mathrm{mV}$, and $-15.00 \mathrm{mV}$, the coagulation attachment $\left(\alpha_{\mathrm{pp}}\right)$ was 0.76, 0.76, and 0.77, respectively. Figure 5.57 (a), Figure 5.57 (b), and Figure 5.57 (c) feature the SEM images for Ultrafilic membrane after ultrafiltration at a transmembrane pressure of $25 \mathrm{psi}$, a feed flow rate of 4 LPM, and a feed concentration of 1.3 $\mathrm{kg} / \mathrm{m}^{3}$, at the zeta potentials of $-41.50 \mathrm{mV},-30.00 \mathrm{mV}$, and $-15.00 \mathrm{mV}$, respectively. Figure 5.57 (b) showcases the fact that decreasing the negativity of the surface charge of the Ultrafilic membrane caused a smaller number of clean pores, the greater number of particle attachments to the membrane surface, and a higher chance of particle-to-particle collisions and attachments, if compared to Figure 5.57 (a). An extensive particle deposition on the membrane surface was caused by a further decrease in the surface negativity, which ensured an even higher chance for the particles to contribute to the coagulation attachment and cake formation, as shown in Figure $5.57(\mathrm{c})$.

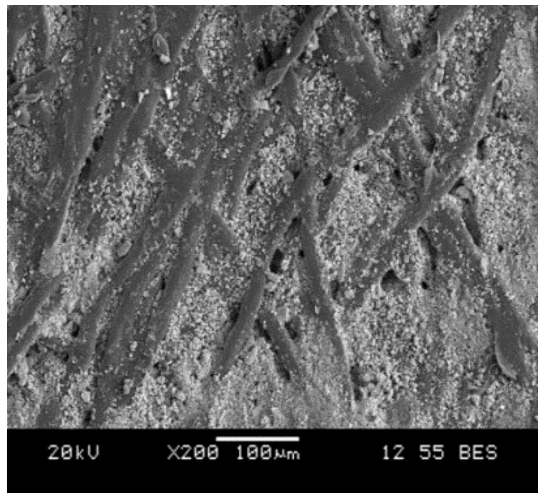

(a)

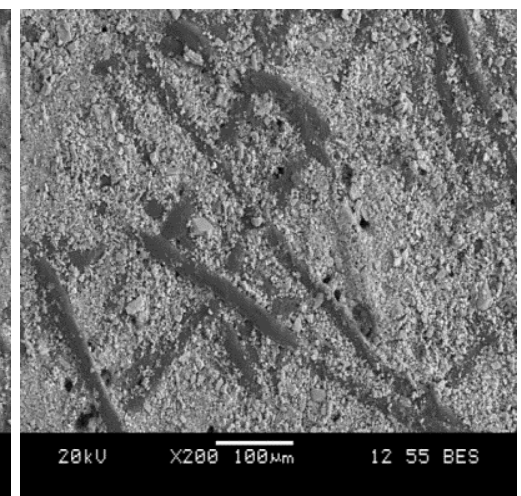

(b)

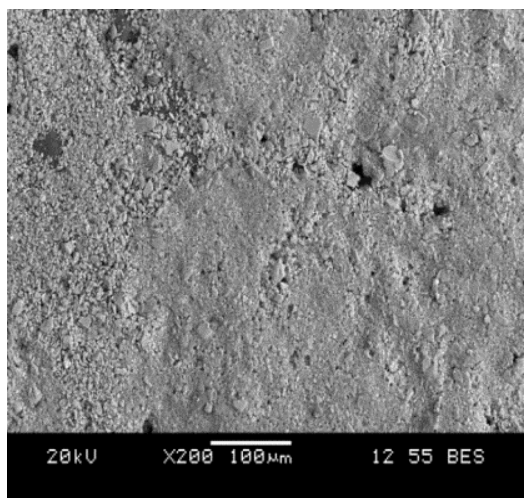

(c)

Figure 5.57: SEM images of Ultrafilic membranes after ultrafiltration at [25 psi], $[Q=4 \mathrm{LPM}]$, $\left[\mathrm{C}_{\mathrm{f}}\right.$ $=1.30 \mathrm{~kg} / \mathrm{m}^{3}$ ] at zeta potential of (a) $-41.50 \mathrm{mV}$; (b) $-30.00 \mathrm{mV}$; (c) $-15.00 \mathrm{mV}$ 


\subsubsection{Simulated latex effluent treatment using anionic surfactant}

As the anionic surfactant concentration increased from $0.0001 \mathrm{~g} / \mathrm{L}$ to $0.1 \mathrm{~g} / \mathrm{L}$, the ionic strength of the latex solution increased, and the solution conductivity increased from 0.0944 to $6.5210 \mathrm{mS} / \mathrm{cm}$. However, the zeta potential negativity decreased from $-26.61 \mathrm{mV}$ to $-4.86 \mathrm{mV}$, as shown in Table 5.31. This can be attributed to the electrostatic repulsions between the highly charged latex surface and the anionic head groups. As a consequence, the anionic surfactant stayed in the latex solution, which resulted in the low electrical stability of colloids, and a significant decrease in the potential difference between the bulk liquid and the stationary layer of fluid attached to the dispersed latex particles. The zeta potential negativity of the latex particles was thus reduced. Furthermore, Table 5.31 illustrates the effects of LAS additions to the latex solution on the zeta potential of the membrane surface through the ultrafiltration process. The LAS concentration of $0.0001 \mathrm{~g} / \mathrm{L}$ was an optimum concentration for the enhancement of hydrophobic PVDF surface charge, while it had an insignificant effect on Ultrafilic membrane at this concentration. However, the addition of LAS had an opposite effect on the Polysulfone membrane, as presented in Table 5.31. This may attributed to the unique chemical structure of the Polysulfone membrane with the sulfone group. The repulsion between the functional group of anionic surfactant and the functional group of Polysulfone explain the unchanged hydrophilicity of the membrane surface after treatment with LAS.

The results in Table 5.31 also indicate that increasing the LAS concentration to more than $0.0001 \mathrm{~g} / \mathrm{L}$ resulted in a decreased zeta potential negativity of PVDF and Ultrafilic membrane surface. The increase in the concentration of the anionic surfactants in latex solution caused a reduction in the potential difference between the latex solution and the membrane surface. It should also be mentioned that the micellar ulfiltration at the CMC of LAS of $0.1 \mathrm{~g} / \mathrm{L}$ had the least favorable results for the zeta potential negativity of latex particles and featured a decrease from -26.61 to $-4.86 \mathrm{mV}$. Furthermore, the zeta potential negativity of Polysulfone, Ultrafilic, and PVDF changed from -42.40 to $0.96 \mathrm{mV},-41.50$ to $3.58 \mathrm{mV}$, and -2.5 to $-0.26 \mathrm{mV}$, respectively. The reason for this behavior stems from the fact that when the micelles were formed, as shown in Figure 5.58, they reduced the interfacial tension between a latex solution and the membrane surface or the latex particle surface. In addition, the electrostatic repulsions between the highly charged membrane surfaces or the latex particles and the micelles increased, which resulted in the presence of the micelle in the solution. Hence, a substantial decrease in the 
potential difference between the liquid and the surfaces can occur. Moreover, the maximum allowable concentration of LAS in wastewater discharged to the environment is $1 \mathrm{ppm}(1 \mathrm{mg} / \mathrm{L})$, because LAS was found to be fully biodegradable. Hence, the toxicity of LAS at this concentration of $1 \times 10^{-4} \mathrm{~g} / \mathrm{L}$ was found to be safe for marine, freshwater, and estuarine environments (Morrow and Piwoni, 1993).

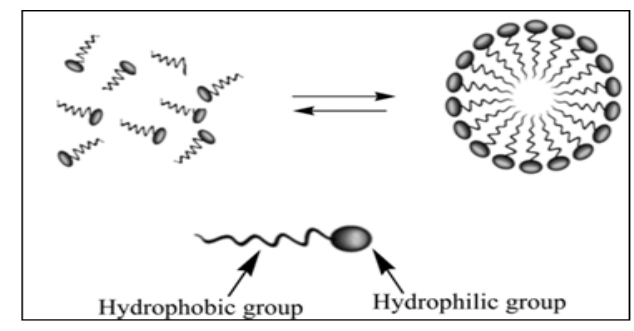

Figure 5.58: Micelle formation of anionic surfactant

Table 5.31: Zeta potential of latex particles and latex solution conductivity at different LAS concentrations, and the zeta potential of membrane surfaces after the ultrafiltration process (after 15 minutes of LAS addition).

\begin{tabular}{|c|c|c|c|c|c|}
\hline \multirow{2}{*}{$\begin{array}{c}\text { LAS } \\
\text { Concentration } \\
{[\mathrm{g} / \mathrm{L}]}\end{array}$} & $\begin{array}{c}\text { Zeta } \\
\text { Potential } \\
\text { of Latex } \\
\text { Particles } \\
{[\mathrm{mV}]}\end{array}$ & $\begin{array}{c}\text { Latex } \\
\text { Colution } \\
\text { Conductivity } \\
{[\mathrm{mS} / \mathrm{cm}]}\end{array}$ & \multicolumn{3}{|c|}{$\begin{array}{c}\text { Zeta Potential of membrane } \\
\text { surface after ultrafiltration } \\
\text { process [mV] }\end{array}$} \\
\cline { 4 - 6 } & -26.61 & 0.0944 & -42.4 & -41.5 & -2.5 \\
\hline 0 & -24.05 & 0.3601 & -25.22 & -41.97 & -28.66 \\
\hline 0.0001 & -16.3 & 1.102 & -18.43 & -27.51 & -17.18 \\
\hline 0.001 & -10.02 & 2.403 & -8.09 & -18.77 & -11.67 \\
\hline 0.01 & -4.86 & 6.521 & 0.96 & 3.58 & -0.26 \\
\hline 0.1 & & & & & \\
\hline
\end{tabular}

Furthermore, the effect of LAS at various time treatments was investigated at a concentration of $0.0001 \mathrm{~g} / \mathrm{L}$ and the CMC concentration of $0.1 \mathrm{~g} / \mathrm{L}$. At a zero concentration of LAS, the zeta potential of latex particles and the conductivity of simulated latex effluent are $26.61 \mathrm{mV}$ and $0.0944 \mathrm{mS} / \mathrm{cm}$, respectively. As presented in Table 5.32, right after the addition of LAS, the zeta potential of latex particles was dropped to $-0.94 \mathrm{mV}$ and $-2.13 \mathrm{mV}$, at the concentration of $0.0001 \mathrm{~g} / \mathrm{L}$ and $0.1 \mathrm{~g} / \mathrm{L}$, respectively. Due to the increase of anionic heads in the latex solutions, there was a significant change in charge of the dispersion medium with respect to the dispersed particle, which in turn resulted in a significant decrease in the potential difference between the bulk liquid and the dispersed latex particles. Consequently, the zeta potential negativity was significantly decreased. The latex solution ionic strength increased through the 
addition of the anionic surfactant due to the presence of the negative charge hydrophilic head of the anionic surfactant. Hence, the latex solution conductivity was increased to $0.3070 \mathrm{mS} / \mathrm{cm}$ and $6.4411 \mathrm{mS} / \mathrm{cm}$, as LAS was added at the concentration of $0.0001 \mathrm{~g} / \mathrm{L}$ and $0.1 \mathrm{~g} / \mathrm{L}$, respectively. The optimum time was determined to be 15 minutes for both concentrations for the addition of LAS as feed pretreatment. The zeta potential measurements of latex particles indicated that the treatment time was ineffective as a method of increasing the zeta potential negativity of latex particles, as presented in Table 5.32. Furthermore, the zeta potential of latex particles had very low negative values at the CMC of LAS, as depicted in Table 5.32. Due to the negative influence of micelles formation on the reduction of zeta potential negativity as previously discussed. Moreover, the treatment time had an insignificant effect on the solution ionic strength at both concentrations.

Table 5.32: Zeta potential of latex particles and latex solution conductivity at various time treatments at LAS concentration of $0.0001 \mathrm{~g} / \mathrm{L}$ and $0.1 \mathrm{~g} / \mathrm{L}$.

\begin{tabular}{|c|c|c|c|c|}
\hline \multirow[b]{2}{*}{$\begin{array}{l}\text { Time } \\
\text { [min] }\end{array}$} & \multicolumn{2}{|c|}{ LAS Concentration $0.0001 \mathrm{~g} / \mathrm{L}$} & \multicolumn{2}{|c|}{ LAS Concentration $0.1 \mathrm{~g} / \mathrm{L}$ (CMC) } \\
\hline & $\begin{array}{c}\text { Zeta Potential of } \\
\text { Latex Particles } \\
{[\mathrm{mV}]}\end{array}$ & $\begin{array}{c}\text { Latex } \\
\text { Solution } \\
\text { Conductivity } \\
{[\mathrm{mS} / \mathrm{cm}]}\end{array}$ & $\begin{array}{l}\text { Zeta Potential } \\
\text { of Latex } \\
\text { Particles [mV] }\end{array}$ & $\begin{array}{c}\text { Latex Solution } \\
\text { Conductivity } \\
{[\mathrm{mS} / \mathrm{cm}]}\end{array}$ \\
\hline $0+$ & -0.94 & 0.307 & -2.13 & 6.4411 \\
\hline 15 & -24.05 & 0.3601 & -4.86 & 6.521 \\
\hline 30 & -22.3 & 0.387 & -1.84 & 6.5401 \\
\hline 60 & -19.2 & 0.387 & -1.58 & 5.9806 \\
\hline 90 & -19.76 & 0.3865 & -1.64 & 6.011 \\
\hline
\end{tabular}

Note: 0+: right after the addition of LA

The influence of adding LAS at a concentration of $0.0001 \mathrm{~g} / \mathrm{L}$ to the latex solution 15 minutes before the ultrafiltration process using hydrophilic membranes was investigated. At the feed flow rate of $4 \mathrm{LPM}$, feed concentration of $1.30 \mathrm{~kg} / \mathrm{m}^{3}$, and transmembrane pressure of 25 psi, the total mass of fouling substantially increased from $0.0135 \mathrm{~kg} / \mathrm{m}^{2}$ to $0.0931 \mathrm{~kg} / \mathrm{m}^{2}$, while the cumulative filtration volume significantly decreased from 0.115 to $0.078 \mathrm{~m}^{3} / \mathrm{m}^{2}$ using the Polyulfone membrane. Due to the decrease of the zeta potential negativity of latex particles from $-26.61 \mathrm{mV}$ to $-24.05 \mathrm{mV}$, in addition to the substantial decrease of Polysulfone surface charge negativity from $-42.40 \mathrm{mV}$ to $-25.22 \mathrm{mV}$, there was a higher attraction force between foulants and the membrane surface. As a consequence, the depositional attachment increased from 0.76 to 
0.91. The increase in the total mass of fouling caused an increase in the specific power consumption from $2.14 \mathrm{~kW} \cdot \mathrm{h} / \mathrm{m}^{3}$ to $4.14 \mathrm{~kW} \cdot \mathrm{h} / \mathrm{m}^{3}$. At the same operating conditions, Ultrafilic membrane showed a slight increase in the total mass of fouling and a slight decrease in the cumulative permeate volume, from 0.025 to $0.0261 \mathrm{~kg} / \mathrm{m}^{2}$ and from 0.123 to $0.119 \mathrm{~m}^{3} / \mathrm{m}^{2}$ respectively. While the specific power consumption slightly increased from 1.82 to 1.86 $\mathrm{kW} . \mathrm{h} / \mathrm{m}^{3}$. The reason for this slight changes can be found in the decrease in the zeta potential negativity of latex particles from $-26.61 \mathrm{mV}$ to $-24.05 \mathrm{mV}$ was slight more than the enhancement of Ultrafilic surface hydrophilicity from $-41.50 \mathrm{mV}$ to $-41.97 \mathrm{mV}$. In this case the deposition attachment was slightly increased from 0.7 to 0.72 . Thus, the results indicate that the LAS addition can be considered an ineffective pre-treatment for limiting the fouling propensity of the latex solution when using hydrophilic membranes.

On the other hand, the addition of LAS to the latex solution had a definitively positive effect on the enhancement of the surface charge of the PVDF hydrophobic membrane from -2.5 to $-28.66 \mathrm{mV}$. Thus, the repulsion force between the latex particles and the membrane surface increased even though the zeta potential negativity of the latex particles was decreased from 26.61 to $-24.05 \mathrm{mV}$. As a result, the depositional attachment decreased from 0.97 to 0.54 , the total mass of fouling significantly lowered by $12.80 \%$ from 0.0125 to $0.0109 \mathrm{~kg} / \mathrm{m}^{2}$, and the specific power consumption experienced a substantial decrease by $34.15 \%$ from 15.4 to 10.14 $\mathrm{kW} \cdot \mathrm{h} / \mathrm{m}^{3}$. Nevertheless, the feed pretreatment, that includes the increasing of the solution alkalinity to $\mathrm{pH}$ of 11 , was found to enhance the PVDF surface charge more than the addition of $0.0001 \mathrm{~g} / \mathrm{L}$ of LAS, in addition to the significant effect of higher $\mathrm{pH}$ on the latex particle negativity enhancement. The results obtained indicate that the total mass of fouling was decreased by $29.60 \%$, in case of the feed pretreatment where the $\mathrm{pH}$ was increased to the value of 11 , and decreased to $12.80 \%$, with the addition of $0.0001 \mathrm{~g} / \mathrm{L} \mathrm{LAS}$. While the specific power consumption was decreased by $88.12 \%$ in case of the feed pretreatment by $\mathrm{pH}$ change, and decreased by $34.15 \%$ in the instance where LAS was added.

\subsubsection{Membrane surface treatment using anionic surfactant}

This study investigated the effect of the surface hydrophilicity of the membrane surface using anionic surfactant, on fouling attachments, the total mass of fouling, permeate flux, and specific power consumption. As shown in Figure 5.59 (a), the LAS treatment had a noticeable effect on hydrophobic PVDF and hydrophilic Ultrafilic membranes at low concentration of 
$0.0001 \mathrm{~g} / \mathrm{L}$. Alternatively, LAS treatment was ineffective in the case of the Polysulfone membrane. Notably, the results suggested that LAS treatment was ineffective for Polysulfone membranes even in the instances where soaking was implemented for long periods of time. This is may be attributed to the repulsion between the functional group of LAS and the functional group of Polysulfone membrane. The original zeta potential value of each membrane is highlighted at $\mathrm{Y}$-axis in Figure 5.59 (a). The optimum enhancement of membrane surface hydrophilicity occurred during the LAS treatments at a concentration of $0.0001 \mathrm{~g} / \mathrm{L}$. The optimum time for LAS treatment was 15 and 20 minutes, for Ultrafilic and PVDF membranes, respectively. However, zeta potential negativity of PVDF and Ultrafilic membranes had an opposite trend after the optimum time, as shown in Figure 5.59 (a). At the CMC, LAS treatment had an opposite effect on the zeta potential of membrane surfaces due to the micelles formation, as shown in Figure 5.59(b). The surface charge negativity was turned into positive charge from 42.40 to $1.62 \mathrm{mV},-41.50$ to $4.07 \mathrm{mV},-2.50$ to $0.26 \mathrm{mV}$, for the Polysulfone, Ultrafilic, and PVDF membranes, respectively. Figure 5.60 (a) and Figure 5.60 (b) simulate the attraction between anionic surfactant hydrophilic head and hydrophilic surfaces, as well as, between anionic surfactant hydrophilic head and hydrophobic membrane surfaces. It should be mentioned that the LAS treatment for the membrane surface had a more noticeable effect than the addition of LAS to the latex solution as a feed pretreatment before the ultrafiltration process. This can be attributed to the fact that the soaking time for the membranes in LAS is more effective than the ultrafiltration process duration. For instance, the zeta potential negativity of PVDF membrane was enhanced from -2.50 to $-28.66 \mathrm{mV}$, and from -2.50 to -40.90 using LAS as feed pretreatment, and for membrane surface treatment, respectively. Furthermore, in the mentioned cases the negative effects of LAS addition to latex solution on the zeta potential of latex particles was avoided. 


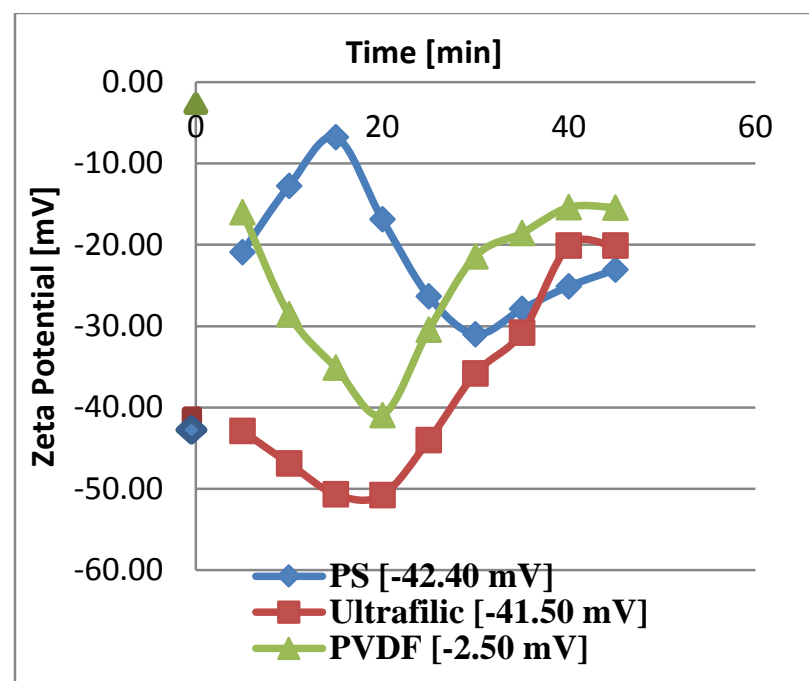

(a)

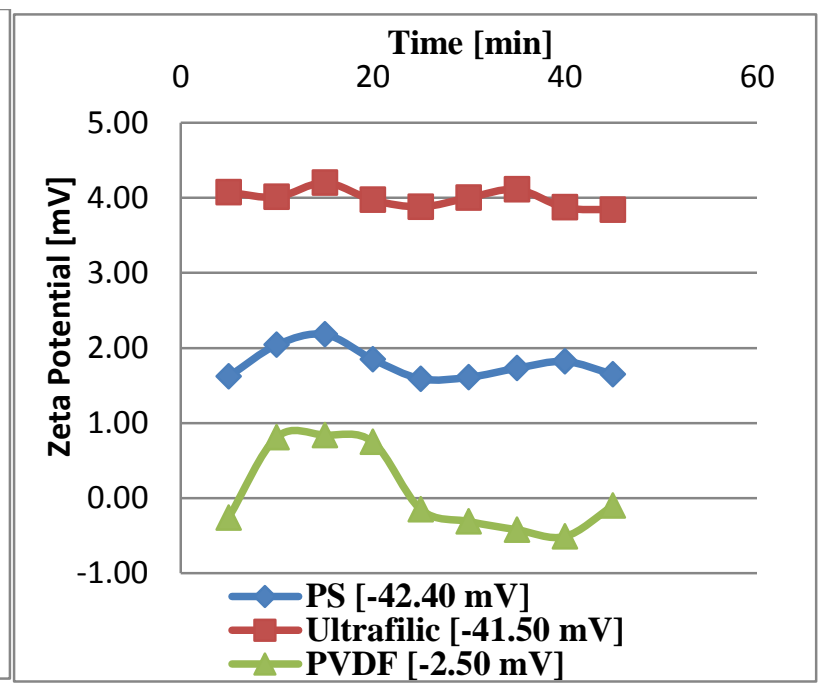

(b)

Figure 5.59: Zeta potential of membrane surfaces after LAS treatment at a concentration of (a) $1 \times 10^{-4} \mathrm{~g} / \mathrm{L}(\mathrm{b}) 0.1 \mathrm{~g} / \mathrm{L}$

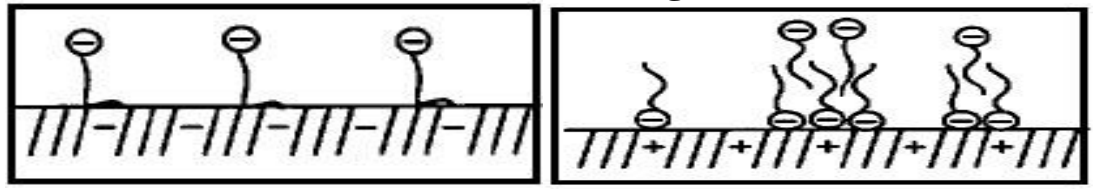

(a)

(b)

Figure 5.60: Schematic of adsorption of Linear Alkyl Benzene Sulfonate (LAS) into the membrane surface (a) hydrophilic membranes (b) hydrophobic membranes

As shown in Figure 5.59, the results obtained indicated that the most significant effect of LAS, at a low concentration of $1 \times 10^{-4} \mathrm{~g} / \mathrm{L}$, was on the hydrophobic PVDF membrane by increasing the membrane surface charge from $-2.50 \mathrm{mV}$ to $-40.90 \mathrm{mV}$ after 20 minutes of membrane treatment. This increase was due to the high electrostatic attraction between the anionic heads of LAS and the PVDF membrane surface, as shown in Figure 5.60 (b). At the feed flow rate of $4 \mathrm{LPM}$, feed concentration of $0.78 \mathrm{~kg} / \mathrm{m}^{3}$, and transmembrane pressure of $15 \mathrm{psi}$, the repulsion force between the latex particles of untreated latex effluent and the membrane surface was increased. As a consequence, the depositional attachment $\left(\alpha_{\mathrm{pm}}\right)$ decreased from 0.97 to 0.1. Hence, the total mass of fouling experienced a substantial decrease by $44.0 \%$, from 0.0125 $\mathrm{kg} / \mathrm{m}^{2}$ to $0.007 \mathrm{~kg} / \mathrm{m}^{2}$, the specific power consumption significantly decreased by $92.1 \%$, from $15.4 \mathrm{~kW} . \mathrm{h} / \mathrm{m}^{3}$ to $1.21 \mathrm{~kW} \cdot \mathrm{h} / \mathrm{m}^{3}$, while the permeate flux perceptibly increased from 0.01 to 0.124 $\mathrm{m}^{3} / \mathrm{m}^{2}$. Figure 5.61 (a) and Figure 5.61 (b) present the SEM images of PVDF membrane after ultrafiltration at the mentioned operating conditions using untreated and treated PVDF 
membrane surfaces, respectively. Figure 5.61 (b), indicates less attachment and deposition of latex particles on the PVDF membrane surface.

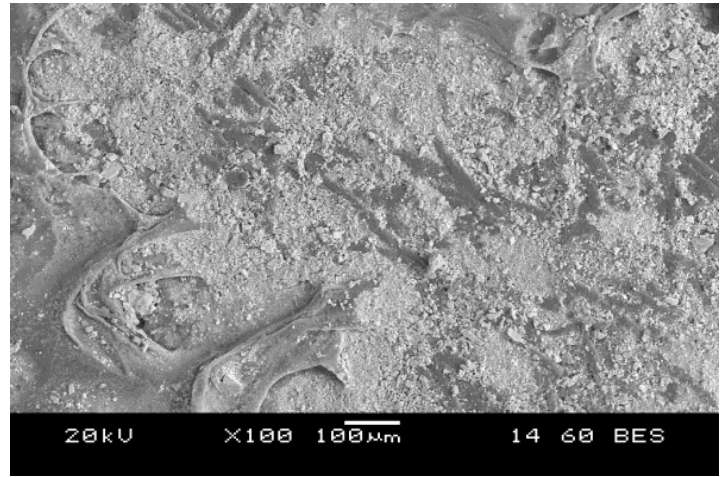

(a)

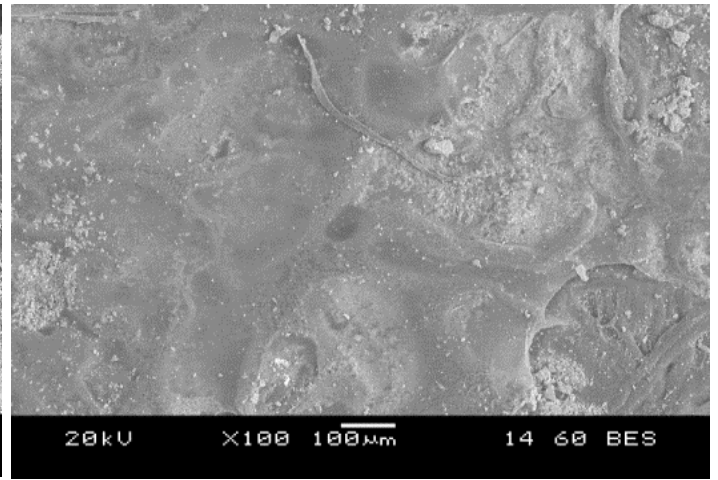

(b)

Figure 5.61: SEM images of PVDF membrane surfaces after ultrafiltration at $[Q=4 \mathrm{LPM}]$, $\left[\mathrm{C}_{\mathrm{f}}=0.78 \mathrm{~kg} / \mathrm{m}^{3}\right]$, [15 psi]: (a) at original zeta potential of $-2.50 \mathrm{mV}$ (b) at zeta potential of $-40.91 \mathrm{mV}$ after 20 minutes treatment for the surface charge using LAS with concentration of $0.0001 \mathrm{~g} / \mathrm{L}$

It should be also mentioned that in the case of treated PVDF membrane surface, using anionic surfactants at a low concentration of $0.0001 \mathrm{~g} / \mathrm{L}$, had more favorable results than the best results obtained by feed pre-treatment occurring due to the $\mathrm{pH}$ change. As such, the total mass of fouling decreased by $44.0 \%$ and $29.6 \%$, in case of treated membrane surface with anionic surfactant, and treated latex solution feed at $\mathrm{pH}$ of 11, respectively. Moreover, the specific power consumption was substantially decreased by $92.1 \%$ and $88.1 \%$, in case of the treated membrane surface with anionic surfactant, and in the instance of the treated latex solution feed at $\mathrm{pH}$ of 11 , respectively. Although when the $\mathrm{pH}$ of latex solution was increased to 11 the membrane surface charge was changed from $-2.50 \mathrm{mV}$ to $-32.62 \mathrm{mV}$, in addition to the significant increase of the latex particles surface charge from $-26.61 \mathrm{mV}$ to $-40.00 \mathrm{mV}$. As a consequence, the depositional attachment, $\alpha_{\mathrm{pm}}$, decreased from 0.97 to 0.21 . However, when the ultrafiltration process was performed with the PVDF treated surface using anionic surfactants of the zeta potential of $-40.90 \mathrm{mV}$ with untreated simulated latex effluent with the particle zeta potential of $-26.61 \mathrm{mV}$, the depositional attachment was 0.1 . This gives a strong indication of the significant impact that membrane surface charge has when it comes to contributing to the attachment force between the membrane surface and the foulants, in comparison to the potential effects of the latex particle's charge.

Moreover, the ultrafiltration process was performed using treated Ultrafilic membranes using LAS with concentration of $0.0001 \mathrm{~g} / \mathrm{L}$ for 15 minutes. At feed flow rate of 1 LPM, 
transmembrane pressure of $35 \mathrm{psi}$, and feed concentration of $1.3 \mathrm{~kg} / \mathrm{m}^{3}$, the total mass of fouling was decreased by $28.0 \%$ from $0.0278 \mathrm{~kg} / \mathrm{m}^{2}$ to $0.02 \mathrm{~kg} / \mathrm{m}^{2}$, due to the increase of surface charge negativity from $-41.50 \mathrm{mV}$ to $-50.67 \mathrm{mV}$ which caused a significant decrease in the attraction force between latex particles and Ultrafilic membrane surface. Hence, the depositional attachment was decreased from 0.98 to 0.84 . Figure 5.62 presents SEM images of the Ultrafilic membranes after ultrafiltration process using treated and untreated membranes. As shown in Figure 5.62(b), the latex particle depositions was decreased at the same operating conditions when Ultrafilic membrane was soaked for 15 minutes using $0.0001 \mathrm{~g} / \mathrm{L}$ LAS.

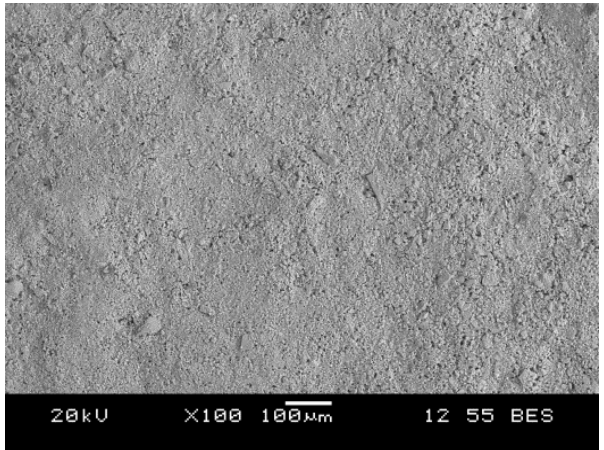

(a)

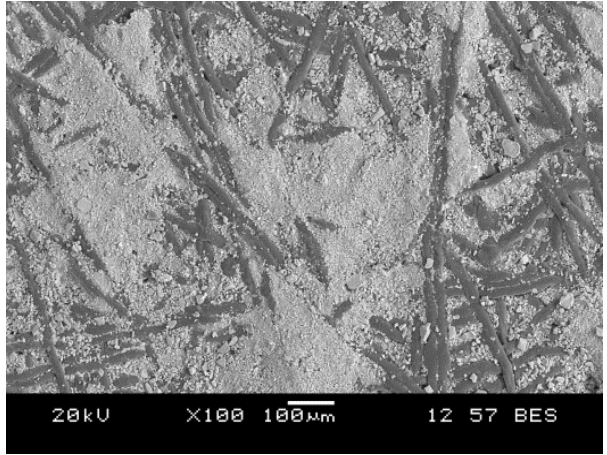

(b)

Figure 5.62: SEM images of Ultrafilic membrane surfaces after ultrafiltration at $[Q=1 \mathrm{LPM}]$, $\left[\mathrm{C}_{\mathrm{f}}=1.3 \mathrm{~kg} / \mathrm{m}^{3}\right.$ ], [35 psi]: (a) at original zeta potential of $-41.50 \mathrm{mV}$ (b) at zeta potential of -50.67 after 15 minutes treatment for the surface charge using LAS with concentration of $0.0001 \mathrm{~g} / \mathrm{L}$

A comparative analysis was conducted on the effect of enhancing the PVDF membrane's surface hydrophilicty on the membrane's performance, with the effects of increasing the ionic strength of the latex solution either by $\mathrm{pH}$ or LAS. Figure 5.63 illustrates that the best membrane performance and cumumlative permeate volume per unit area was obtained when the PVDF membrane surface was treated with LAS. The second best PVDF performance results were obtained in the case of untreated PVDF membrane and treated simulated latex solution at $\mathrm{pH}$ of 11, followed by trated latex solution with LAS and featuring untreated PVDF. 


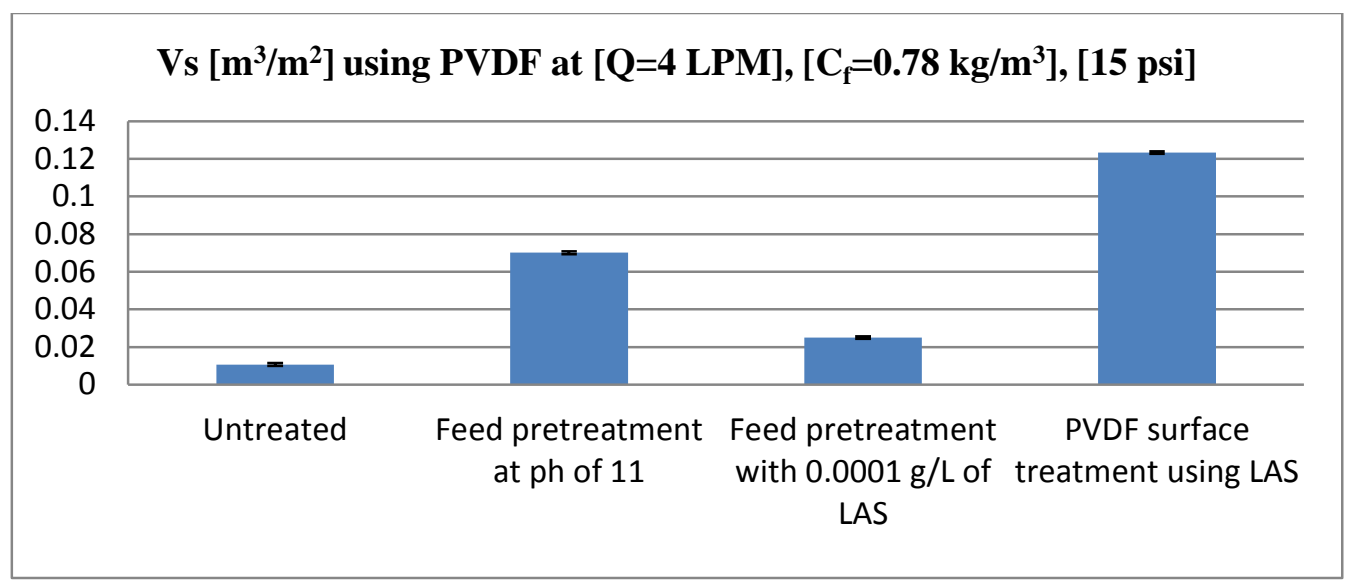

\section{Figure 5.63: PVDF membrane performance using different remediation techniques}

Furthermore, a comparative analysis was conducted as a way of assessing the effects of enhancing Polysulfone membrane surface hydrophilicty on the membrane's performance, with the effects of increasing the latex solution ionic strength by either $\mathrm{pH}$ or LAS. Figure 5.64 showcases that the best membrane performance and cumulative permeate volume per unit area were obtained when the Polysulfone membrane was treated with the $\mathrm{pH}$ membrane treatment method. The second best results of Polysulfone performance were obtained in the case of the untreated Polysulfone membrane and treated simulated latex solution at $\mathrm{pH}$ of 11. As illustrated in Figure 5.63, the LAS treated latex solution featuring untreated Polysulfone membranes had the worst Polysulfone membrane performance, even if compared to the untreated ultrafiltation process.

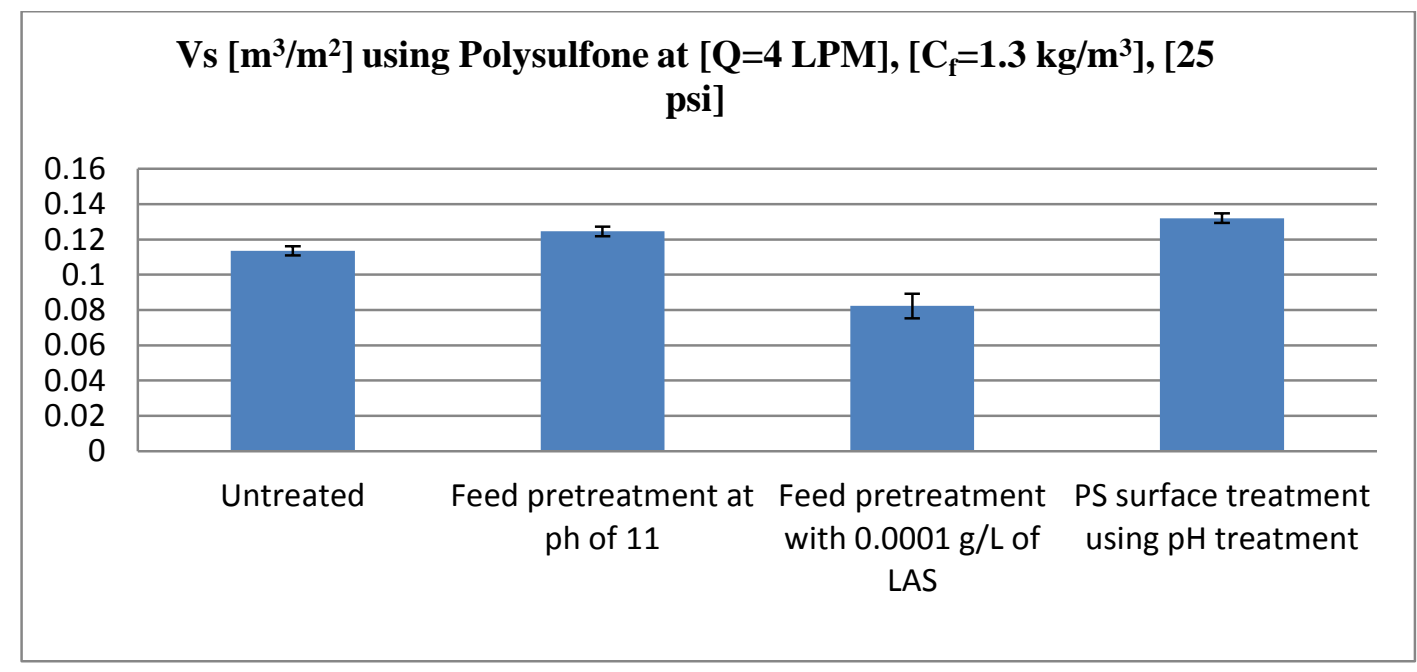

Figure 5.64 : Polysulfone membrane performance using different remediation techniques 


\subsubsection{Simulated latex effluent treatment using cationic surfactant}

The effect of the cationic surfactant, $\mathrm{CTAB}$, on the latex particle size distribution was also studied. Figure 5.65 (a), Figure 5.65 (b), and Figure 5.65 (c) depict the particle size (diameter) distribution of the latex solution with a solid concentration of $0.78 \mathrm{~kg} / \mathrm{m}^{3}, 1.30 \mathrm{~kg} / \mathrm{m}^{3}$, $1.82 \mathrm{~kg} / \mathrm{m}^{3}$, respectively, at different CTAB concentrations. As shown in Figure 5.65, the particle size distribution of the treated latex solution featured noticeable shifts in the peaks toward larger size ranges due to the aggregation of latex particles. At the CMC concentration of CTAB of $0.36 \mathrm{~g} / \mathrm{L}$ or the lower concentration of $0.18 \mathrm{~g} / \mathrm{L}$, latex particle sizes smaller than 1 microns were by the most part eliminated. The treated latex solution at the CMC of CTAB had the largest particle sizes. This can be attributed to the fact that at the critical micelles concentration (CMC) the micelles formed, as illustrated in Figure 5.66. At this point, the positively charged hydrophilic heads were attracted and clustered around the negatively charged latex paint solids. Figure 5.67 presented the SEM images of the latex particles after the ultrafiltration process, both, with and without the addition of CTAB to the latex solution and featuring the concentration of $1.3 \mathrm{~kg} / \mathrm{m}^{3}$ as feed pre-treatment. As shown in Figure 5.67 (b), which offers a lower magnification of 300 , the aggregated latex particles were almost the same size, if compared to the particles at 3 times higher magnification of 1000 , without the CTAB addition presented in Figure 5.67 (a).

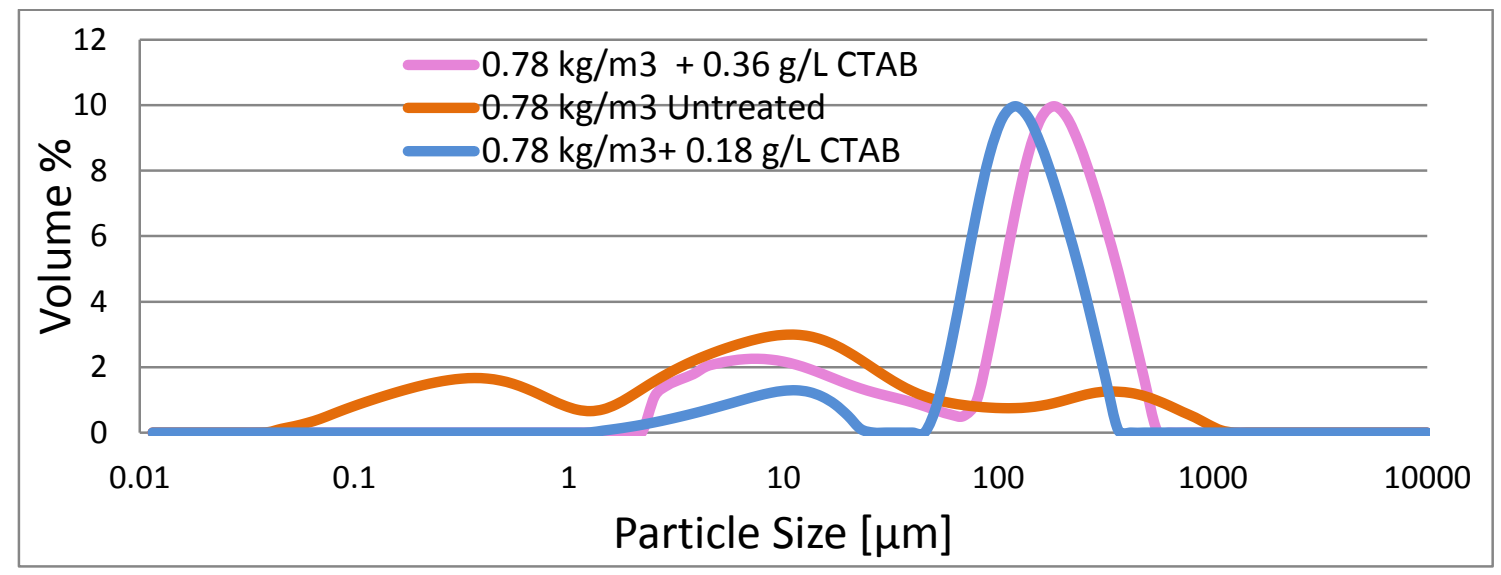

(a) 


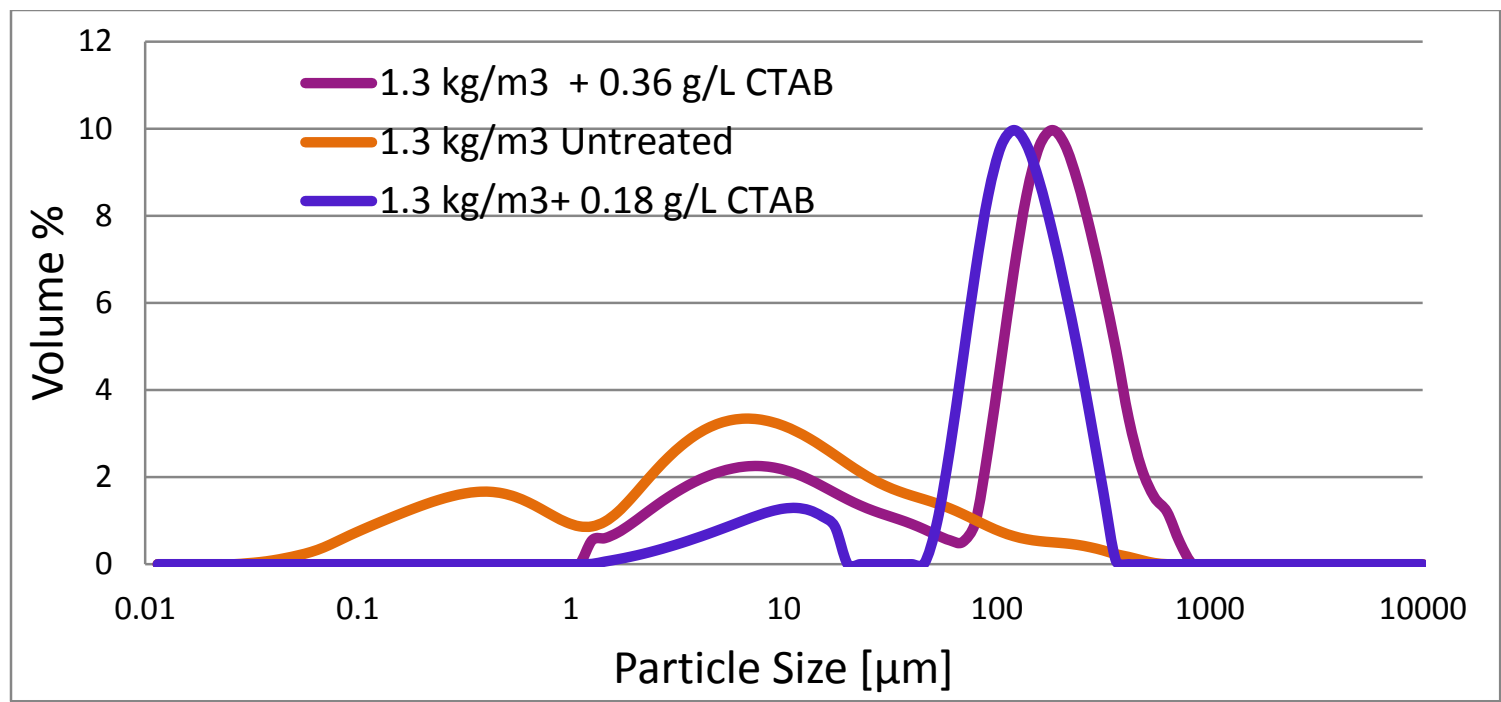

(b)

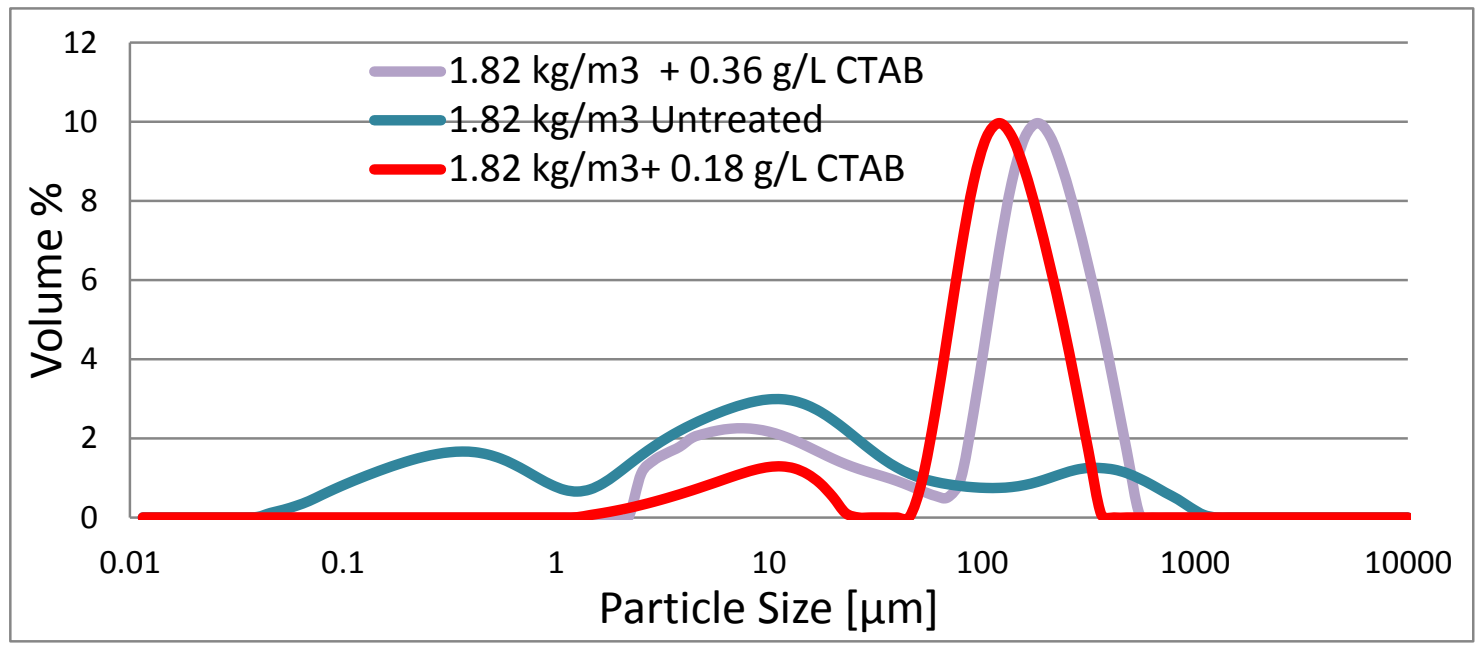

(c)

Figure 5.65: The particle size (diameter) distribution of the treated latex solution with the concentration of (a) $0.78 \mathrm{~kg} / \mathrm{m}^{3}$, (b) $1.3 \mathrm{~kg} / \mathrm{m}^{3}$, (c) $1.82 \mathrm{~kg} / \mathrm{m}^{3}$

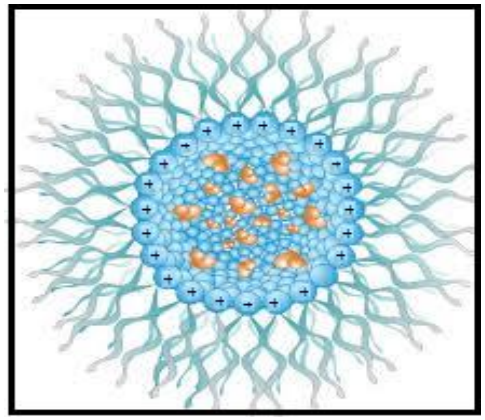

Figure 5.66: Micelles formed around negatively charged latex particles using cationic surfactant 


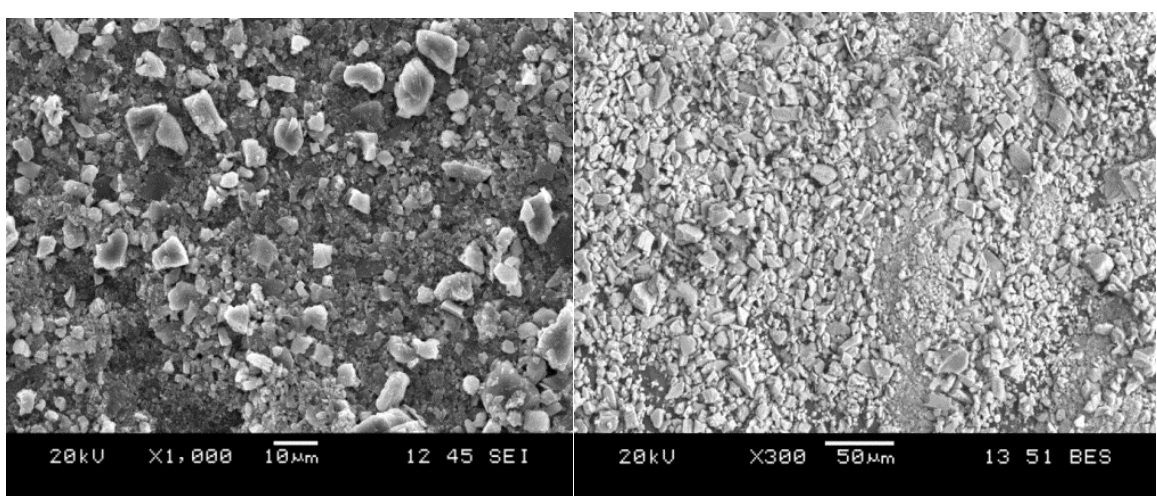

(a) (b)

\section{Figure 5.67: SEM of latex particles after the ultrafiltration process (a) without CTAB addition at magnification of 1000 , (b) with CTAB pre-treatment at magnification of 300}

Figure 5.68 shows the particle size distribution of untreated and treated simulated latex effluent at the $\mathrm{CMC}$ of $\mathrm{CTAB}$ at different concentrations of the latex solution. The latex particles had the largest sizes at the solution concentration of $1.82 \mathrm{~kg} / \mathrm{m}^{3}$, followed by $1.3 \mathrm{~kg} / \mathrm{m}^{3}$, and finally $0.78 \mathrm{~kg} / \mathrm{m}^{3}$. For CTAB at the CMC concentration of $0.36 \mathrm{~g} / \mathrm{L}$, the treatment duration was found to have no effect on the particle size distribution, as can be seen in Figure 5.69. The particle size distributions of the latex solutions treated for 5, 10, and 15 minutes were almost identical. This indicates that particles aggregated together, and then formed clusters of particles within a matter of a few seconds or minutes. The particles dispersed in the liquid phase stuck to each other, growing in size and then forming irregular particle clusters or aggregates. Because of this observation, the 10 minutes duration was selected within this study as the feed pre-treatment time for the $\mathrm{CTAB}$ addition to the simulated latex effluent. It should be also noted that the particle size distribution could not be measured in a period less than 5 minutes, due to the time necessary for the sample preparation and the calibration of the particle size analyzer.

Figure 5.70 illustrates the effect of CTAB addition to the latex solution on the cake formation on the membrane surface. The images clearly indicate that the cake layer was less compact in Figure 5.70 (b), as compared to the sample without the cationic surfactant in Figure 5.70 (a). This may be attributed to the presence of newly formed coarse particles by agglomeration of fine latex particles with $\mathrm{CTAB}$, in the cake layer, resulting in larger lumps as can be seen in Figure 5.70 (b). 


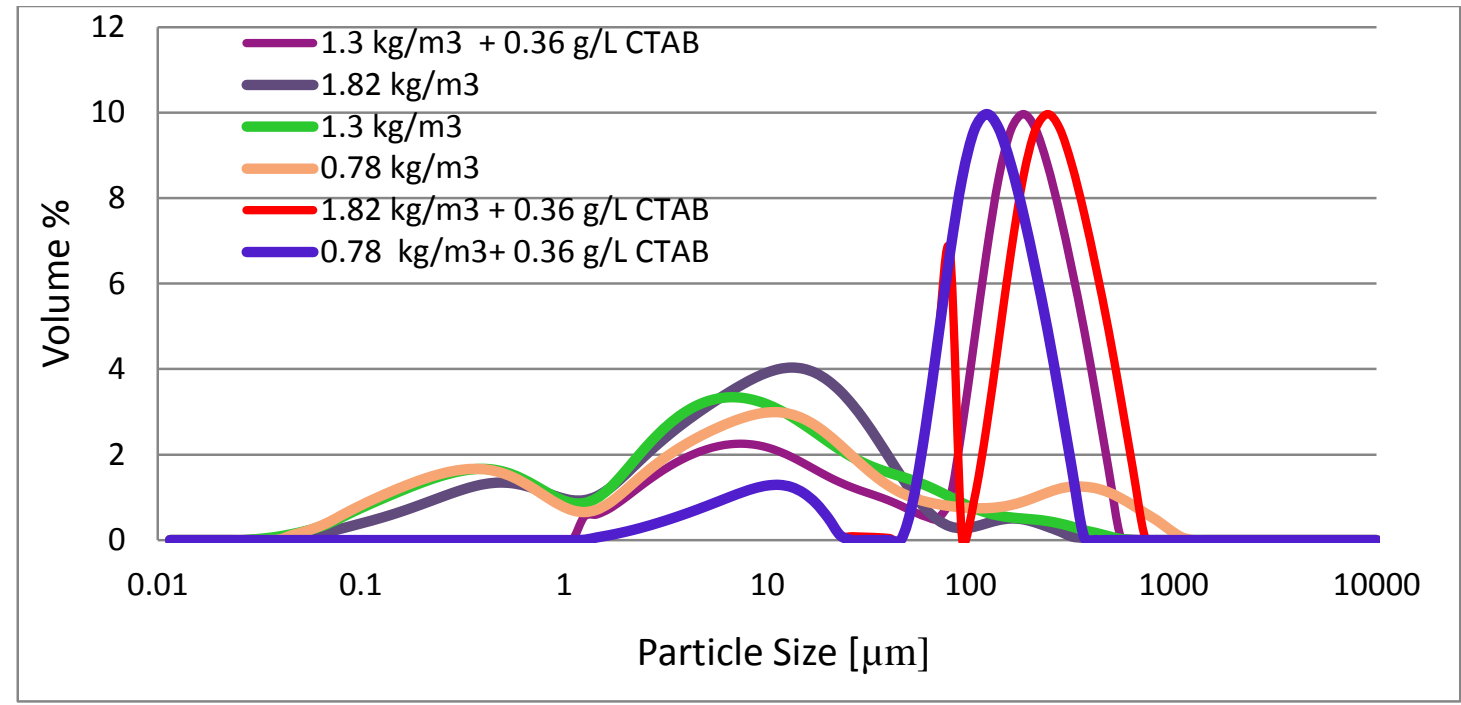

Figure 5.68: Particle size distribution of untreated and treated latex solutions at different solid concentrations, using CTAB at its CMC

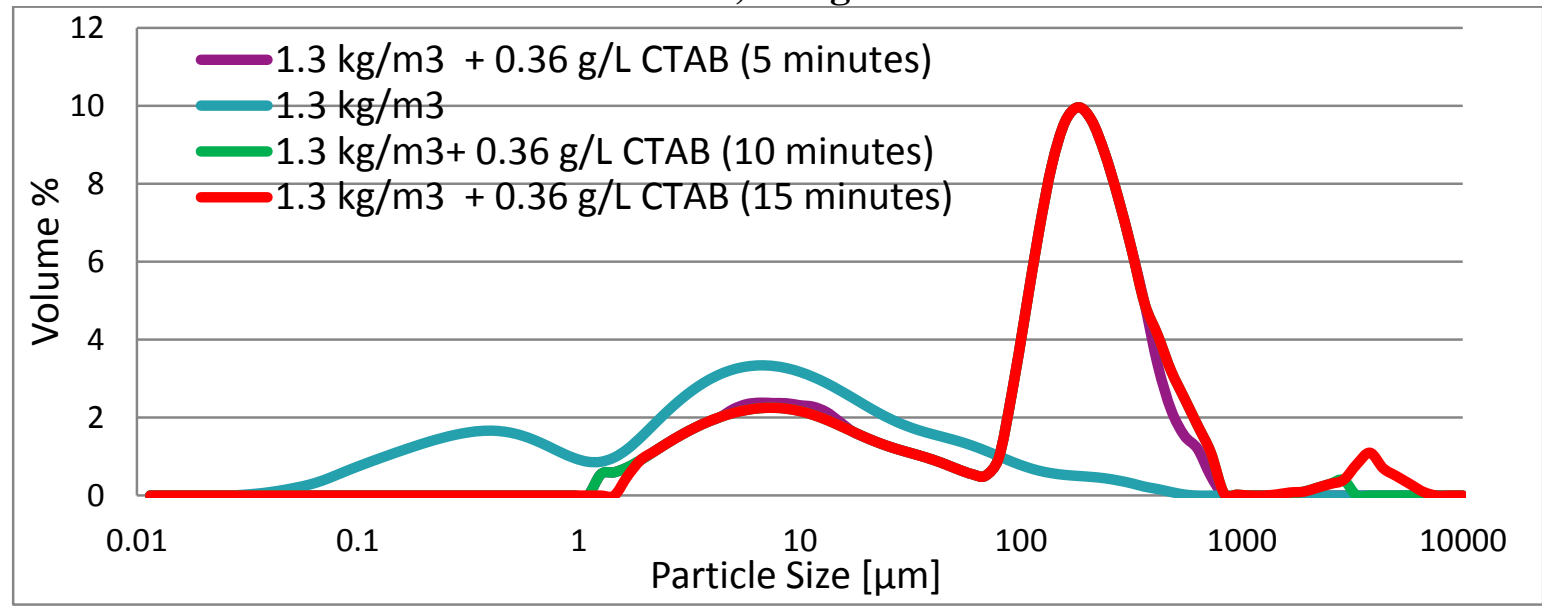

Figure 5.69: Particle size distribution of untreated and treated latex solutions, using CTAB at its $\mathrm{CMC}$ at different treating times

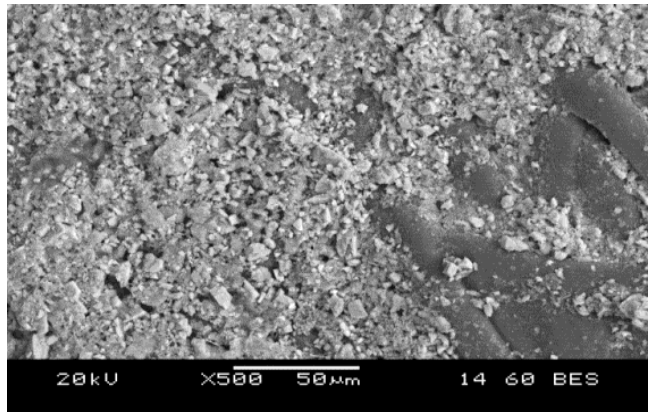

(a)

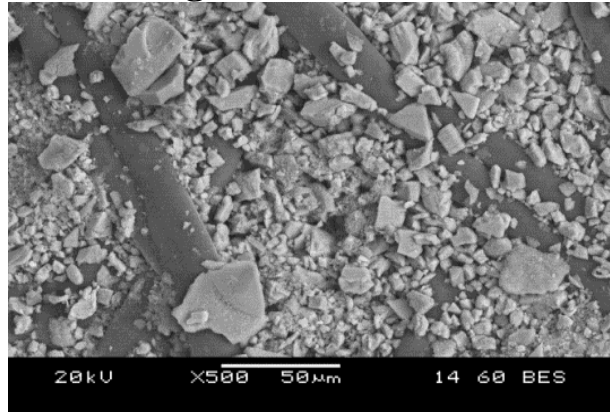

(b)

Figure 5.70: SEM images of latex particles after ultrafiltration process at the feed solid concentration of $1.3 \mathrm{~kg} / \mathrm{m}^{3}$, feed flow rate of $1 \mathrm{LPM}$, and transmembrane pressure of 35 psi; using (a) untreated simulated latex effluent (b) pretreated feed with CTAB at CMC concentration for 10 minutes 
Particle aggregation is normally an irreversible process. However, particle aggregates can be disrupted and dispersed if stirring is applied. As shown in Figure 5.71, the minimal agitation, 2-3 seconds, during the addition of $\mathrm{CTAB}$ to the latex solution featured the largest size particles. A large portion of the particle size distribution peaks between 100 to 1000 microns, as compared to the range of 1 to 100 microns for longer stirring time. This might be due to agitation's high shear capable of effectively breaking down aggregated particles. In fact, Figure 5.72 provides additional evidence of the dispersion of the aggregated particles from small-angle scattering of X-rays (SAXS). The scattering patterns in the small-angle regime reflect a decay of scattered intensity due to decreasing the particle size, which reduces the number of electrons in a given volume (Svergun and Koch, 2003). The scattered intensity is a proportional relationship of the particle size as a function of the interparticle interactions (Kotlarchyk M, Chen, 1983; Liu et al., 2005). As shown in Figure 5.72 (a), the intensity of the waves reaches 2700 because of the aggregated particles occurring once $\mathrm{CTAB}$ was added to the latex solution with minimal stirring, while the maximum wave intensity was around 600 after 1 minute stirring, as presented in Figure 5.72 (b). Figure 5.73 (b) presents an SEM image of the aggregated latex particles with the concentration of $1.82 \mathrm{~kg} / \mathrm{m}^{3}$ after the addition of $\mathrm{CTAB}$ at $\mathrm{CMC}$ concentration for the duration of 10 minutes as feed pre-treatment with minimal agitation. Figure 5.73 (a) features the SEM image of latex particles after 2 minutes of continuous stirring during the CTAB addition at the same operating conditions. Figure 5.73 (b) offers evidence to support data in Figure 5.68 that at a higher concentration of $1.82 \mathrm{~kg} / \mathrm{m}^{3}$ the latex particles grew larger in size.

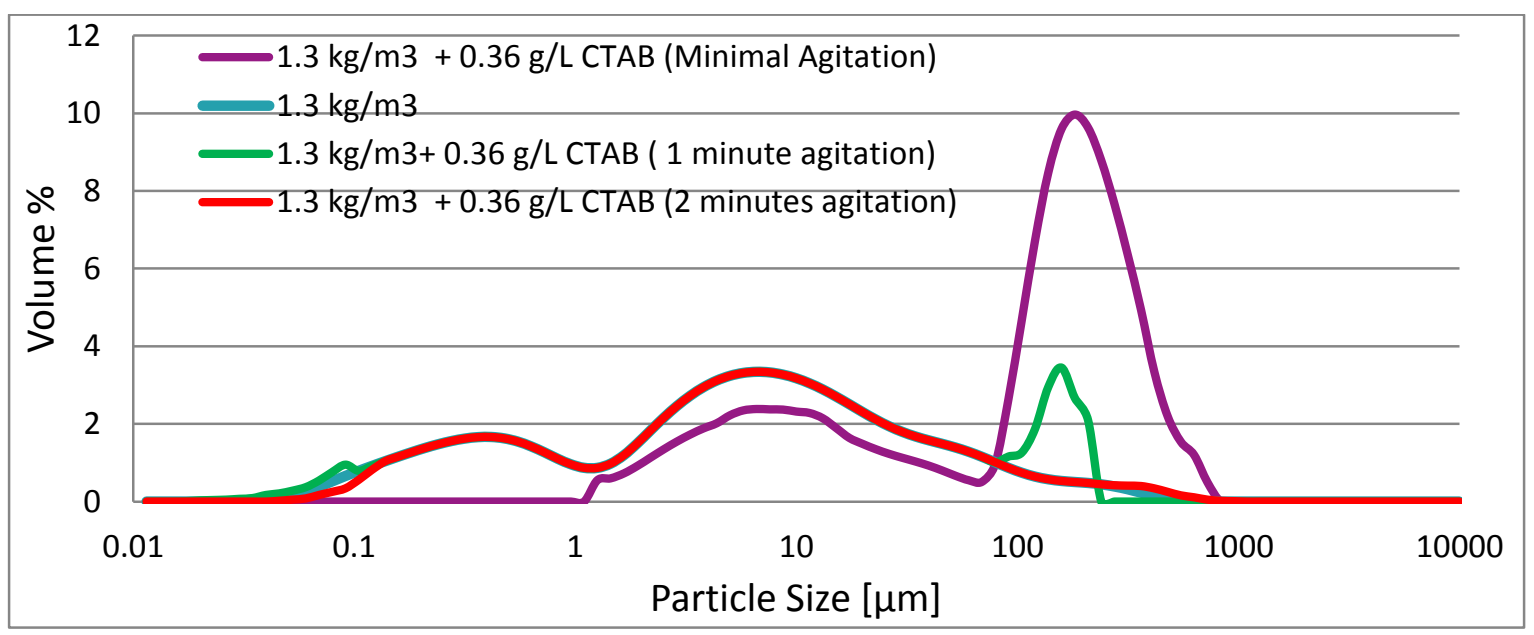

Figure 5.71 Particle size distribution of untreated and treated latex solutions, using CTAB at its $\mathrm{CMC}$ at different agitation durations 


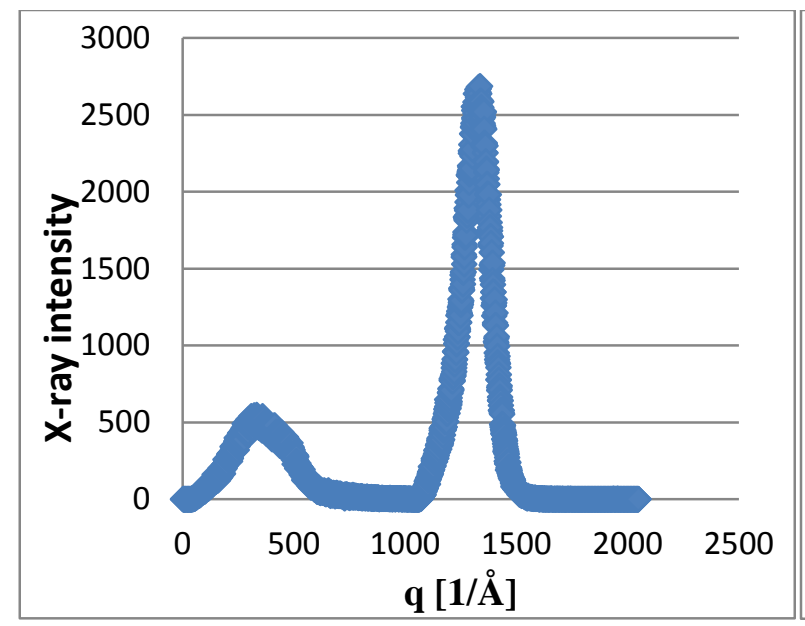

(a)

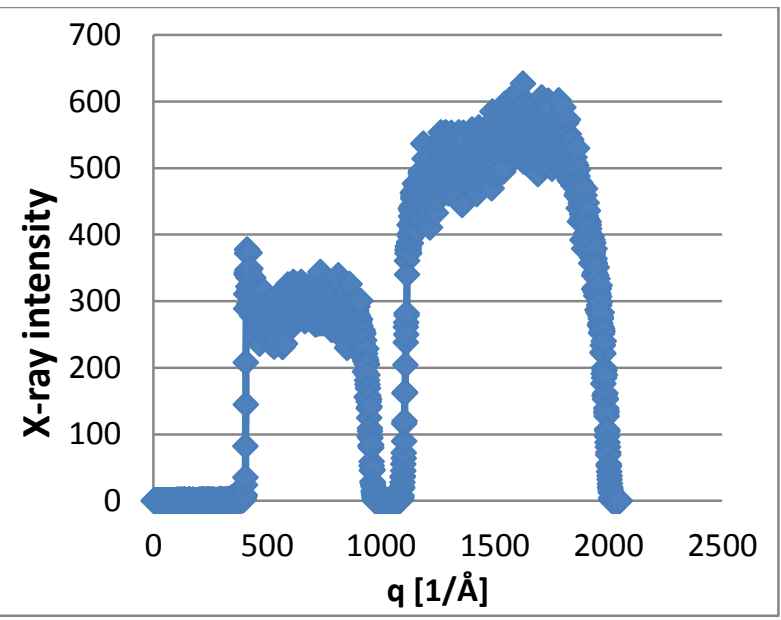

(b)

Figure 5.72: Small angle scattering data for a latex solution at the concentration of $1.3 \mathrm{~kg} / \mathrm{m}^{3} \mathrm{after}$ the addition of $0.36 \mathrm{~g} / \mathrm{L}$ CTAB (a) At minimal stirring (b) After 1 minutes stirring
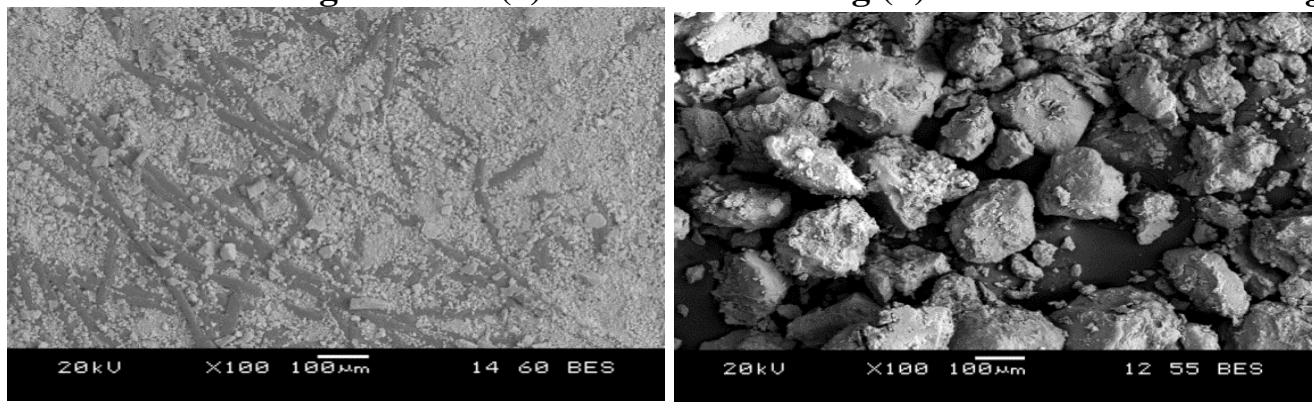

Figure 5.73: SEM images of latex particles after ultrafiltration process at the feed concentration of $1.82 \mathrm{~kg} / \mathrm{m}^{3}$, feed flow rate of $1 \mathrm{LPM}$, and transmembrane pressure of $25 \mathrm{psi}$ using pretreated feed with CTAB at CMC concentration for 10 minutes (a) 2 minutes continuous stirring during the CTAB addition (b) minimal agitation

The addition of CTAB to the latex solution as a feed pre-treatment prior to the ultrafiltration process caused a decrease in the negative charge of the latex particles and the membrane surfaces throughout the duration of the ultrafiltration process. The zero concentration of $\mathrm{CTAB}$ represents the original zeta potential values of latex particles and the membrane surfaces on the Y-axis, as shown in Figure 5.74. Increasing the concentration of CTAB resulted in a continuous decrease of the negative charge until reaching the $\mathrm{CMC}$ of $\mathrm{CTAB}$, at which point it started to level off. This is an effectual consequence of the electrostatic attractions that exist between the negatively charged membrane surface and the cationic head groups, which caused an increase in the membrane surface's positive charge. As a consequence, the zeta potential negativity of the membrane surface was significantly reduced. Similarly, the charge positivity of latex particles increased from $-26.61 \mathrm{mV}$ to $+20.30 \mathrm{mV}$ due to the micelles formation with CTAB at its CMC. It should be noted that the treatment time was ineffective on the zeta potential 
of latex particles, or the membrane surfaces at CMC, as shown in Figure 5.75. However, decreasing the surface negativity of the latex particles and the membrane surfaces at a similar trend and magnitude would result in a similar repulsion between them during the ultrafiltration process, as compared to the untreated latex solution.

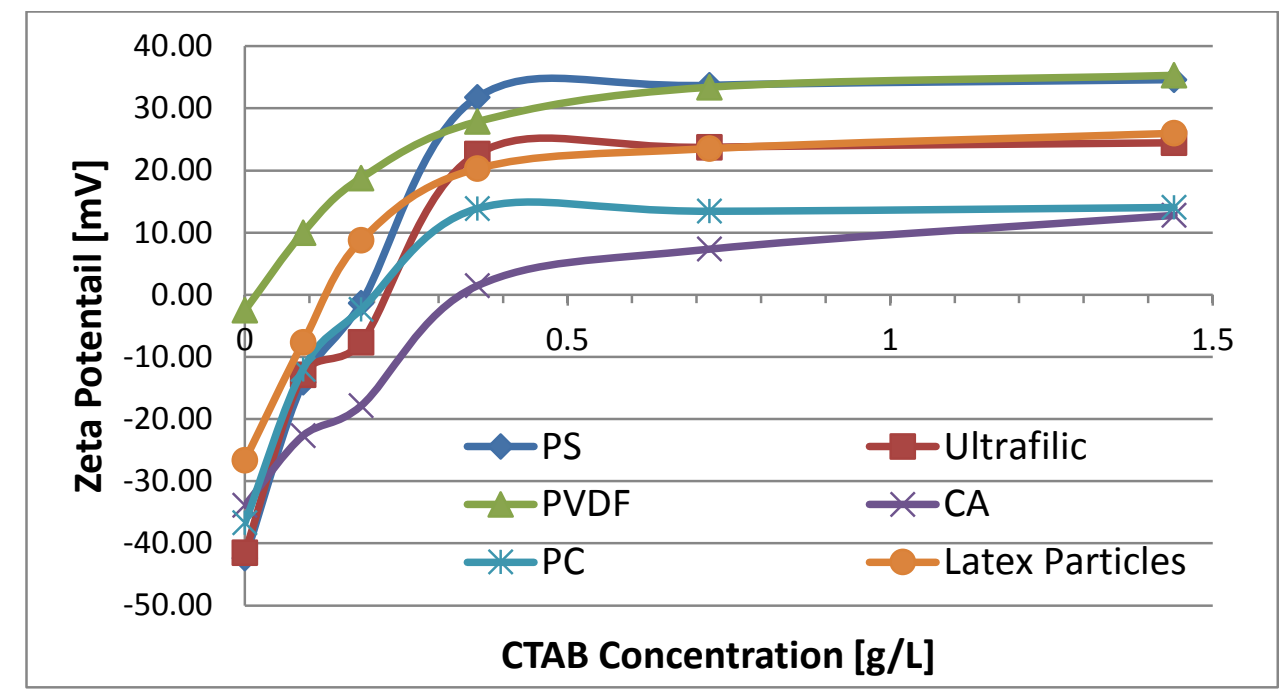

Figure 5.74 : Zeta potential of latex particles and various membrane surfaces at different CTAB concentrations $f$ or 10 minutes

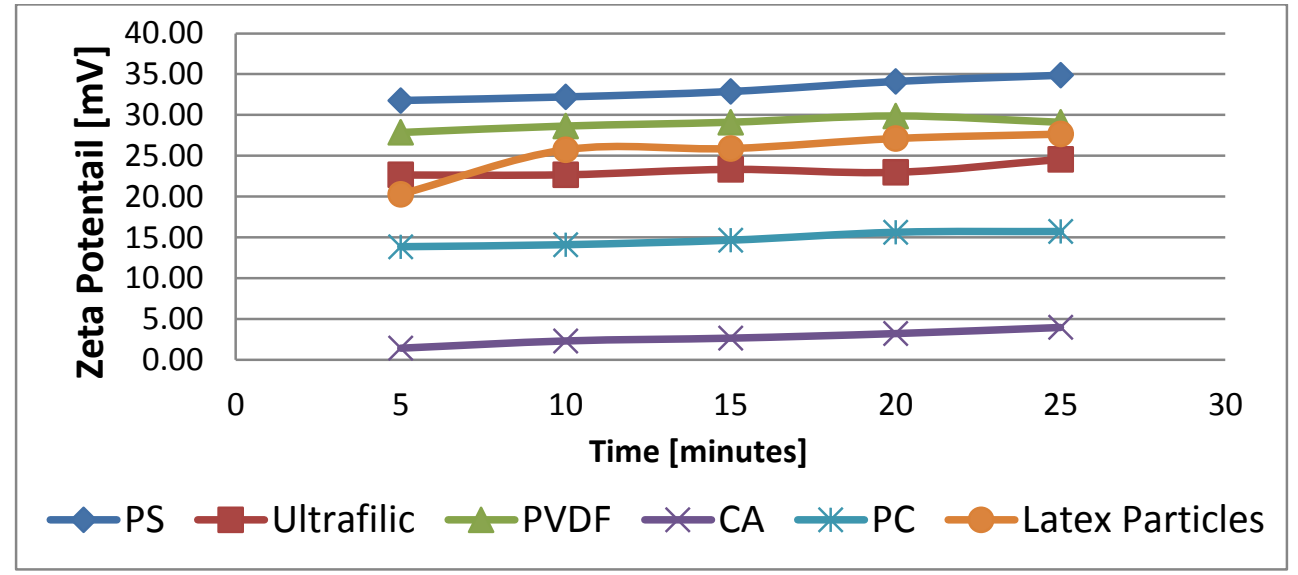

Figure 5.75: Zeta potential of latex particles and various membrane surfaces at CMC of CTAB at different treatment durations

\subsubsection{CTAB influence on membrane fouling using a homogeneous polycarbonate membrane}

Table 5.33 and Table 5.34 showcases the results obtained through the ultrafiltration process at different operating conditions using Polycarbonate homogeneous membranes with pore sizes of 0.1 and $0.05 \mu \mathrm{m}$, while utilizing untreated simulated latex effluent, and treated latex solution with CTAB at CMC, respectively. As indicated in Table 5.34, the total mass of particles 
contributing to pore blocking was diminished for each of the experimental runs. The reason for these results can be allocated to the aggregation of very small particles, less than 0.1 and 0.05 microns in size, and the fact that this size range was eliminated from the particle size distribution which is what generally contributes to pore blocking. The mass of particles contributed to pore blocking was attributed to the traces of small contaminated particles in the simulated latex effluent. Therefore, the depositional attachment, which represents the attachment of particles to the membrane's surface or membrane pores, was calculated based on the experimental values and was shown to be reduced. Each experimental run within this study was repeated 4 times so as to ensure the accuracy of the results with $95 \%$ of confidence intervals. As depicted in Figure 5.76 (a), for each experimental run the depositional attachment was reduced by $6.1 \%$, to $11.7 \%$. While in Figure 5.76 (b), the mass of particles contributing to pore blocking was reduced up to $97 \%$.

Although there was a significant reduction in the mass of particles contributing to pore blocking, the total mass of fouling was only decreased by up to $35.0 \%$. The reason for this limited result was that the mass of particles contributing to pore blocking accounts for only $5.0 \%$ of the total mass of fouling, in cases with homogeneous Polycarbonate membranes of uniform pore size of $0.05 \mu \mathrm{m}$ or $0.1 \mu \mathrm{m}$, and due to the original latex particle size distribution of simulated latex effluent. On the other hand, the aggregated large particles contributing to the cake build up were also reduced by up to $35.0 \%$, as shown in Table 5.34. The reduction of cake layer was caused by the ability of large aggregated particles to go through the cross ultrafiltration to the permeate stream, instead of engaging in collision and deposition between other particles and allowing for the coagulation attachment. Thus, the coagulation attachment, which represents particle-to-particle attachment, was reduced by up to $14.0 \%$. In addition to the aggregation of the particles eliminated from the deposition there were changes with respect to the smaller particles in the cake. In particular, the presence of the larger sizes of the micelles, if compared to the original particles, resulted in a less dense cake layer, allowing more water molecules to pass freely into the permeate stream. Furthermore, after the initial layer of micelles was built onto the surface of the membranes, the similar surface charge of the approaching micelles would cause a repulsion force, essentially increasing the diffusion of particles away from the membrane's surface. As a result, the cumulative permeate volume was significantly increased up to $21.8 \%$ with the addition of $\mathrm{CTAB}$ at $\mathrm{CMC}$ which improved the ultrafiltration process, as shown in 
Figure 5.77(a). The transmembrane pressure was likewise significantly reduced by $12.5 \%$, to $25.0 \%$, due to the less condensed cake layer of the small particles as in the case of untreated latex solution. Decreasing the average transmembrane pressure through the ultrafiltration process and increasing the permeate results in a substantial overall decrease of specific power consumption. Thus, the specific power consumption is directly proportional to the average transmembrane pressure within the ultrafiltration process and is inversely proportional to the cumulative permeate volume.

Table 5.33: Fouling attachments, membrane fouling, increase in transmembrane pressure, and irreversible fouling at different operating conditions using the untreated latex solution and Polycarbonate membrane

\begin{tabular}{|c|c|c|c|c|c|c|c|c|c|c|c|c|c|}
\hline \multirow[b]{2}{*}{$\begin{array}{c}\text { Exp } \\
\text { Run \# }\end{array}$} & \multirow{2}{*}{$\begin{array}{c}\text { PC } \\
\text { uniform } \\
\text { Pore size } \\
{[\mu \mathrm{m}]}\end{array}$} & \multirow[b]{2}{*}{$\begin{array}{c}\text { Initial } \\
\text { TMP } \\
\text { [psi] }\end{array}$} & \multirow[b]{2}{*}{$\begin{array}{c}\mathrm{C}_{\mathrm{f}} \\
{\left[\mathrm{kg} / \mathrm{m}^{3}\right]}\end{array}$} & \multirow[b]{2}{*}{$\begin{array}{c}\mathbf{Q} \\
{\left[\begin{array}{l}\mathbf{L P M}]\end{array}\right.}\end{array}$} & \multicolumn{9}{|c|}{ Untreated Latex Solution } \\
\hline & & & & & $\begin{array}{c}V s \\
{\left[\mathrm{~m}^{3} / \mathrm{m}^{2}\right]}\end{array}$ & $\begin{array}{c}m_{p} \operatorname{Exp} \\
{[g]}\end{array}$ & $\begin{array}{c}m_{c} \operatorname{Exp} \\
{[\mathrm{g}]}\end{array}$ & $\begin{array}{c}m_{t} \operatorname{Exp} \\
{[\mathrm{g}]}\end{array}$ & $\begin{array}{c}\mathbf{m}_{\mathrm{t}} \\
{\left[\mathrm{kg} / \mathrm{m}^{2}\right]}\end{array}$ & $\boldsymbol{\alpha}_{\mathrm{pp}}$ & $\boldsymbol{\alpha}_{\mathrm{pm}}$ & TMP $^{*}$ & $\begin{array}{c}m_{I R R} \\
{\left[\mathrm{~kg} / \mathrm{m}^{2}\right]}\end{array}$ \\
\hline 1 & 0.1 & 4 & 1.3 & 2 & 0.04 & 0.0162 & 0.6420 & 0.6582 & 0.0294 & 0.80 & 0.77 & 20 & 0.0118 \\
\hline 2 & 0.1 & 5 & 1.3 & 3 & 0.064 & 0.0274 & 1.0820 & 1.1094 & 0.0495 & 0.70 & 0.82 & 29 & 0.0198 \\
\hline 3 & 0.1 & 4 & 1.82 & 1 & 0.007 & 0.0040 & 0.1710 & 0.1750 & 0.0078 & 0.90 & 0.90 & 8 & 0.0031 \\
\hline 4 & 0.1 & 2 & 0.78 & 1 & 0.007 & 0.0018 & 0.0750 & 0.0768 & 0.0034 & 0.50 & 0.85 & 6 & 0.0014 \\
\hline 5 & 0.05 & 11 & 1.3 & 4 & 0.007 & 0.0012 & 0.1190 & 0.1202 & 0.0054 & 0.60 & 0.30 & 5 & 0.0021 \\
\hline 6 & 0.05 & 4 & 1.3 & 2 & 0.0189 & 0.0029 & 0.3750 & 0.3779 & 0.0169 & 0.50 & 0.72 & 10 & 0.0067 \\
\hline
\end{tabular}

Note: TMP ${ }^{*}$ is the experimental increase in transmembrane pressure.

Table 5.34: Fouling attachments, membrane fouling, increase in transmembrane pressure, and irreversible fouling at different operating conditions using the treated latex solution with CTAB at CMC and Polycarbonate membrane

\begin{tabular}{|c|c|c|c|c|c|c|c|c|c|c|c|c|c|}
\hline \multirow[b]{2}{*}{$\begin{array}{c}\text { Exp } \\
\text { Run \# }\end{array}$} & \multirow{2}{*}{$\begin{array}{c}\text { PC } \\
\text { uniform } \\
\text { Pore size } \\
{[\mu \mathrm{m}]} \\
\end{array}$} & \multirow{2}{*}{$\begin{array}{c}\text { Initial } \\
\text { TMP } \\
\text { [psi] }\end{array}$} & \multirow[b]{2}{*}{$\begin{array}{c}C_{f} \\
{\left[\mathrm{~kg} / \mathrm{m}^{3}\right]}\end{array}$} & \multirow[b]{2}{*}{$\begin{array}{c}\mathbf{Q} \\
{\left[\begin{array}{l}\mathbf{L P M} \\
0\end{array}\right.}\end{array}$} & \multicolumn{9}{|c|}{ Latex Solution + 0.36 CTAB } \\
\hline & & & & & $\begin{array}{c}V s \\
{\left[\mathrm{~m}^{3} / \mathrm{m}^{2}\right]}\end{array}$ & $\begin{array}{c}m_{p} \operatorname{Exp} \\
{[\mathrm{g}]} \\
\end{array}$ & $\begin{array}{c}m_{c} \operatorname{Exp} \\
{[g]}\end{array}$ & $\begin{array}{c}m_{t} \operatorname{Exp} \\
{[\mathrm{g}]} \\
\end{array}$ & $\begin{array}{c}m_{t} \\
{\left[\mathrm{~kg} / \mathrm{m}^{2}\right]}\end{array}$ & $\boldsymbol{\alpha}_{\mathrm{pp}}$ & $\boldsymbol{\alpha}_{\mathrm{pm}}$ & TMP $^{*}$ & $\begin{array}{c}m_{I R R} \\
{\left[\mathrm{~kg} / \mathrm{m}^{2}\right]}\end{array}$ \\
\hline 1 & 0.1 & 4 & 1.3 & 2 & 0.0487 & 0.0005 & 0.5387 & 0.5392 & 0.0241 & 0.76 & 0.68 & 17.0 & 0.0072 \\
\hline 2 & 0.1 & 5 & 1.3 & 3 & 0.0695 & 0.0008 & 1.0514 & 1.0522 & 0.0470 & 0.68 & 0.77 & 25.0 & 0.0141 \\
\hline 3 & 0.1 & 4 & 1.82 & 1 & 0.0075 & 0.0011 & 0.1377 & 0.1388 & 0.0062 & 0.87 & 0.81 & 7.0 & 0.0019 \\
\hline 4 & 0.1 & 2 & 0.78 & 1 & 0.0082 & 0.0007 & 0.0611 & 0.0618 & 0.0028 & 0.47 & 0.76 & 4.5 & 0.0008 \\
\hline 5 & 0.05 & 11 & 1.3 & 4 & 0.0078 & 0.0008 & 0.1088 & 0.1096 & 0.0049 & 0.54 & 0.22 & 4.0 & 0.0015 \\
\hline 6 & 0.05 & 4 & 1.3 & 2 & 0.0225 & 0.0001 & 0.2441 & 0.2442 & 0.0109 & 0.43 & 0.66 & 7.5 & 0.0033 \\
\hline
\end{tabular}

Note: TMP* is the experimental increase in transmembrane pressure. 


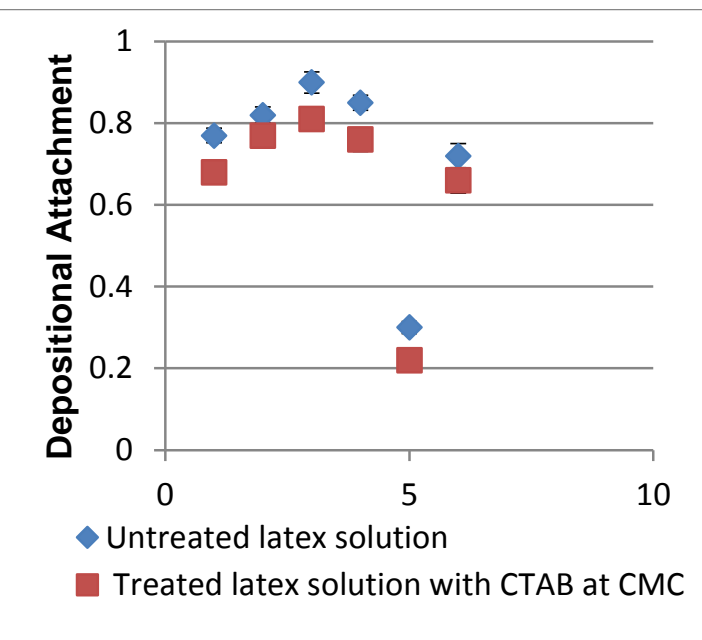

(a)

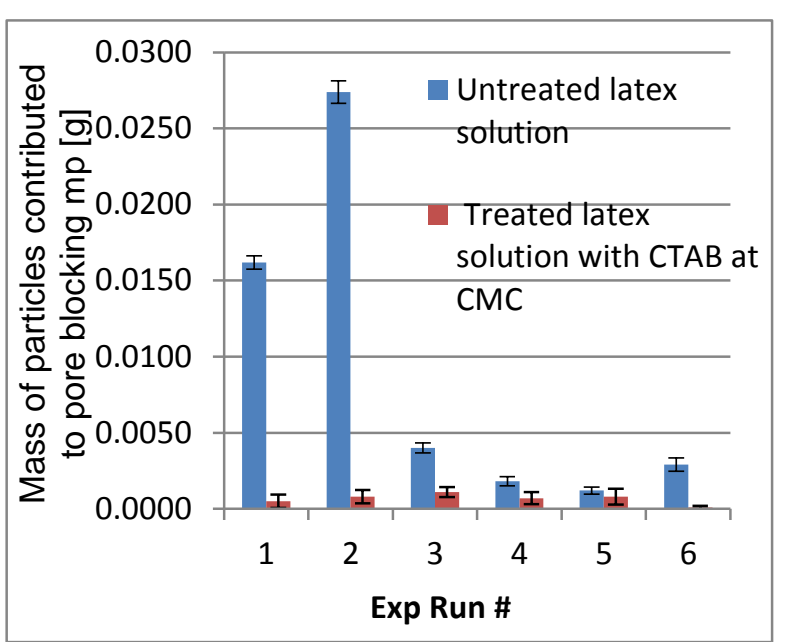

(b)

Figure 5.76: Effects of CTAB addition at the concentration of CMC of $0.36 \mathrm{~g} / \mathrm{L}$ for each experimental run using PC (a) The depositional attachment ( $\left.\alpha_{\mathrm{pm}}\right)$; (b) mass of fouling contributed to pore blocking $\left(m_{p}\right)$

Figure 5.77 (b) reveals a significant reduction in irreversible fouling, ranging from $28.9 \%$ to $51.5 \%$ decrease in the mass of fouling. This significant reduction of irreversible fouling is directly related to the elimination of the very small particles that are less than the pore diameter and do not get attached to the membrane wall which generally contributes to irreversible fouling. In addition, the bigger particles that are attached to the membrane's surface are less dense and can thus be easily washed away through the backwash process.

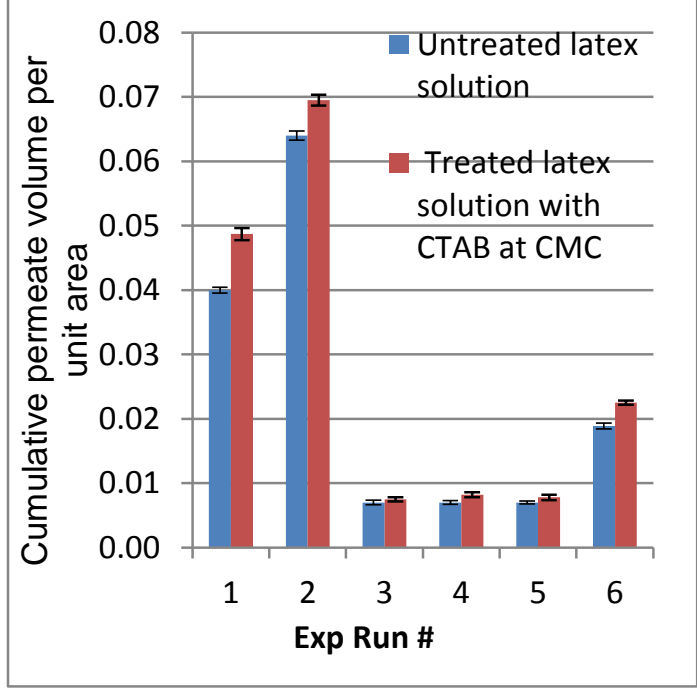

(a)

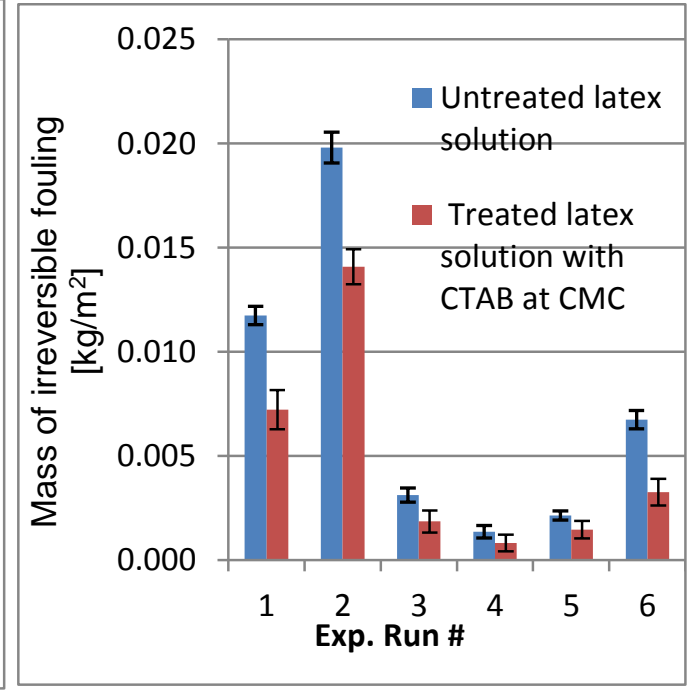

(b)

Figure 5.77: Effects of CTAB addition at the concentration of CMC of $0.36 \mathrm{~g} / \mathrm{L}$ for each experimental run using PC (a) Cumulative permeate volume per unit area ; (b) mass of irreversible fouling per unit area 


\subsubsection{CTAB influence on membrane fouling using a heterogeneous PS membrane}

The results obtained after the ultrafiltration process using heterogeneous Polysulfone membranes with untreated and treated simulated latex effluent, and utilizing CTAB at CMC concentration for 10 minutes feed pretreatment at minimal agitation, are presented in Table 5.35. The addition of CTAB at CMC caused a significant reduction in the total mass of fouling by up to $27.0 \%$, as shown in Figure 5.78 (a). The percentage of reduction in the cases with Polysulfone membranes was less than the percentage of reduction using homogeneous membranes, due to the matrix nature of Polysulfone heterogeneous membrane featuring different pore sizes, which constrict the continuous washing of aggregated particles through the cross ultrafiltration, if compared to homogeneous membranes. In addition, the mass of particles contributing to pore blocking was significantly reduced from $32.6 \%$ to $55.5 \%$, but not diminished to $97.0 \%$ as in the case of homogeneous Polycarbonate membranes. This is due to the fact that in the case of Polycarbonate membranes with small uniform pore size the large particles could not pass through the membrane's pores, which effectually eliminated the chances of collisions and attachments of particles and membrane pore. Nevertheless, the chances of collision and attachments between a wide range of aggregated particle, sizes 1 to 1000 microns with Polysulfone membrane surface and its non-uniform pore size ranging up to $8.78 \mu \mathrm{m}$, was increased. Furthermore, the particle-to-membrane attachment was reduced by $8.8 \%$, to $25.3 \%$. It should be noted that in case of Polysulfone membrane with non-uniform pore size membrane, the mass of particles contributing to the cake layer was increased. In the case with non-uniform pore size this may be a result of the aggregated large particles which settled onto the matrix tissue of the membrane's surface and contributed to cake formation, instead of being washed away through the cross flow ultrafiltration process. Alternatively, the larger sized micelles aggregated particles permitted the formation of a less dense cake layer, which in turn allowed more water molecules to pass freely into the permeate stream. Therefore, the increase in transmembrane pressure was significantly decreased by $20.0 \%$, to $42.8 \%$. Also, after the initial layer of micelles built onto the membrane's surface, the similar surface charges of the approaching micelles cause a repulsion force that essentially increased the diffusion of water through the particles. As a consequence, similar to the results obtained using homogeneous Polycarbonate membranes, the less dens cake layer allowed for $10.0 \%$ to $26.9 \%$ improvement in the ultrafiltration process of cumulative permeate volume per unit, as presented in Figure 5.78 
(b). Each experimental run during this study was repeated 4 times so as to ensure the accuracy of the results with $95 \%$ of confidence intervals.

Table 5.35: Fouling attachments, membrane fouling, increase in transmembrane pressure, and irreversible fouling at different operating conditions using Polysulfone membrane and untreated and treated latex solutions

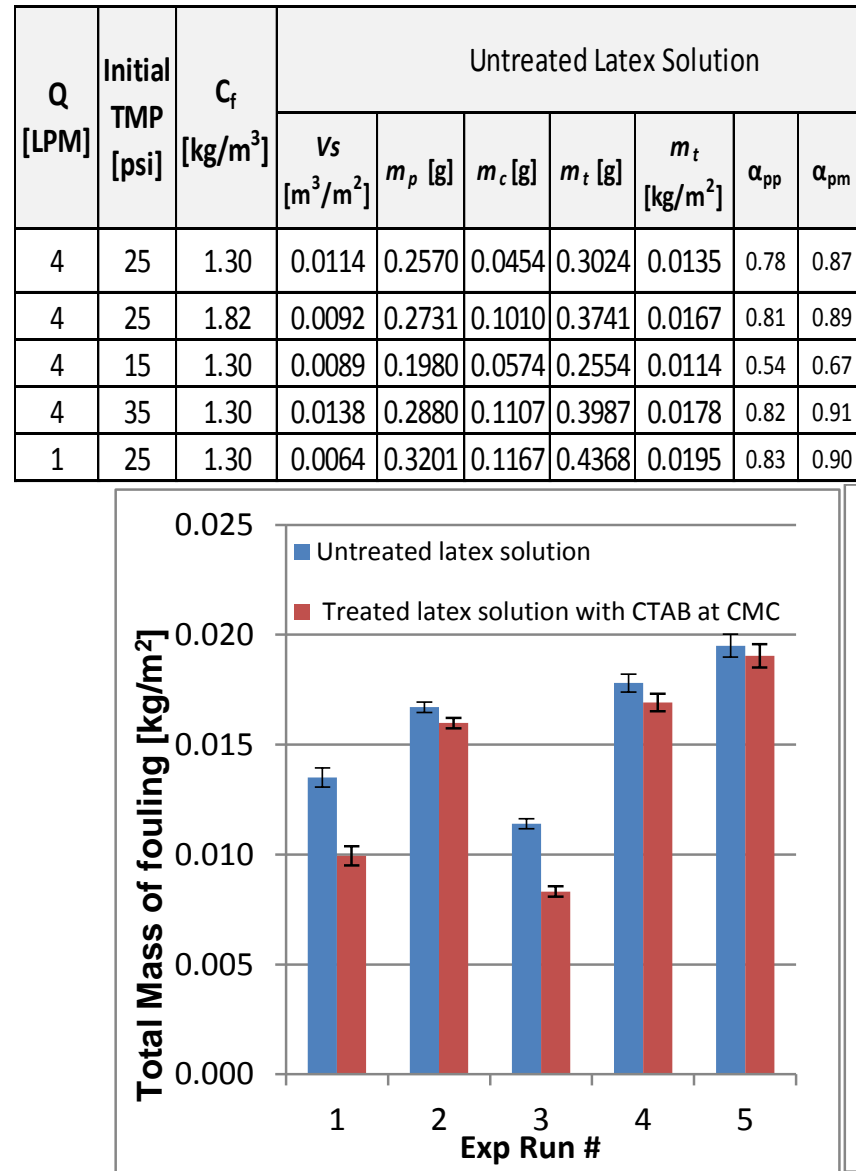

(a)

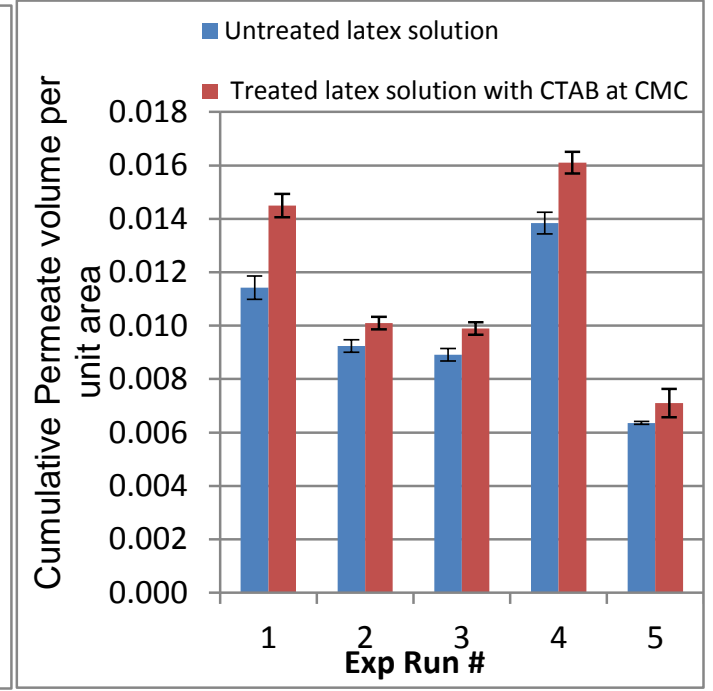

(b)

Figure 5.78: Effect of CTAB addition at the concentration of CMC of $0.36 \mathrm{~g} / \mathrm{L}$ for each experimental run using Polysulfone membrane (a) Total mass of fouling, (b) Cumulative permeate volume per unit area

\subsubsection{Effect of combined pretreatment of latex solution and membrane surface on ultrafiltration performance}

For the purposes of the current research study it was likewise necessary to compare the effects of cationic surfactant as feed pretreatment, the effects of anionic surfactant on membrane surface treatment, and the combined effects of using cationic surfactant together with treated surface charges of different membranes. This comparative analysis is essential for attaining better fouling remediation results, and completing a comprehensive investigation of its impact on 
the depositional attachment, the mass of fouling and the power consumption, all primary concern of this study. Table 5.36 presents a comparison of different remediation techniques and their effects on ultrafiltrattion using PVDF hydrophobic membrane at a feed flow rate of 4 LPM, feed concentration of $0.78 \mathrm{~kg} / \mathrm{m}^{3}$, and transmembrane pressure of $15 \mathrm{psi}$.

Table 5.36: Results obtained from different remediation techniques using PVDF membranes at the feed flow rate of $4 \mathrm{LPM}$, feed concentration of $0.78 \mathrm{~kg} / \mathrm{m}^{3}$, and transmembrane pressure of 15 psi

\begin{tabular}{|l|c|c|c|c|c|}
\hline \multicolumn{1}{|c|}{ Fouling Remediation Technique } & $\begin{array}{c}\zeta[\mathrm{mV}] \\
\text { of } \\
\text { PVDF } \\
\text { after } \\
\text { UF }\end{array}$ & $\begin{array}{c}\zeta[\mathrm{mV}] \\
\text { of Latex } \\
\text { Particles }\end{array}$ & $\alpha_{\mathrm{pm}}$ & $\begin{array}{c}m_{t} \\
{\left[\mathrm{~kg} / \mathrm{m}^{2}\right]}\end{array}$ & $\begin{array}{c}\text { Power } \\
{\left[\mathrm{kW} . \mathrm{h} / \mathrm{m}^{3}\right]}\end{array}$ \\
\hline $\begin{array}{l}\text { 1. Untreated PVDF + Untreated Latex } \\
\text { Solution }\end{array}$ & -2.50 & -26.61 & 0.97 & 0.0125 & 15.4 \\
\hline $\begin{array}{l}\text { 2. Treated PVDF using LAS with } \\
\text { concentration of 0.0001 g/L + } \\
\text { Untreated Latex Solution }\end{array}$ & -40.90 & -26.61 & 0.10 & 0.0070 & 1.2 \\
\hline $\begin{array}{l}\text { 3. Untreated PVDF + Treated latex } \\
\text { solution using 0.036 g/L of CTAB at } \\
\text { minimal agitation }\end{array}$ & 27.86 & 20.30 & 0.43 & 0.0094 & 4.4 \\
\hline $\begin{array}{l}\text { 4. Untreated PVDF + Treated latex } \\
\text { solution using 0.0001 g/L of LAS }\end{array}$ & -28.66 & -24.05 & 0.54 & 0.0109 & 10.1 \\
\hline $\begin{array}{l}\text { 5. Combined treated PVDF membrane } \\
\text { surface + Treated latex feed using 0.036 } \\
\text { g/L CTAB }\end{array}$ & -10.33 & 20.30 & 0.84 & 0.0113 & 13.5 \\
\hline
\end{tabular}

As indicated in Table 5.36, the repulsion forces between the latex particles and the membrane surface was increased using the treated PVDF membranes featuring the zeta potential of $-40.9 \mathrm{mV}$, in comparison to the untreated PVDF of $-2.50 \mathrm{mV}$. Due to increase in the repulsion force, the depositional attachment $\left(\alpha_{\mathrm{pm}}\right)$ decreased from 0.97 to 0.1 . The total mass of fouling also experienced a substantial decrease by $44.0 \%$, from $0.0125 \mathrm{~kg} / \mathrm{m}^{2}$ to $0.007 \mathrm{~kg} / \mathrm{m}^{2}$, while the specific power consumption significantly decreased by $92.1 \%$, from $15.4 \mathrm{~kW} \cdot \mathrm{h} / \mathrm{m}^{3}$ to 1.21 $\mathrm{kW} \cdot \mathrm{h} / \mathrm{m}^{3}$, and the permeate flux increased from 0.01 to $0.124 \mathrm{~m}^{3} / \mathrm{m}^{2}$. Using the untreated PVDF membrane at the same operating conditions and treated latex solution with $0.36 \mathrm{~g} / \mathrm{L} \mathrm{CTAB}$ caused a substantial decrease in the original latex particles negativity of $-26.61 \mathrm{mV}$ and the PVDF membrane surface negativity of $-2.5 \mathrm{mV}$, to $20.30 \mathrm{mV}$ and $27.86 \mathrm{mV}$, respectively. Notably, this positive charge surrounding the latex particles and membrane surface resulted in 
further repulsion force between latex particles and PVDF surface, when compared to the original case of the untreated ultrafiltration process. Hence, the depositional attachment decreased by $55.7 \%$, from 0.97 to 0.43 . The total mass of fouling was further decreased by $24.8 \%$, from $0.0125 \mathrm{~kg} / \mathrm{m}^{2}$ to $0.0094 \mathrm{~kg} / \mathrm{m}^{2}$, while the power consumption was lowered by $71.8 \%$, from 15.4 $\mathrm{kW} \cdot \mathrm{h} / \mathrm{m}^{3}$ to $4.4 \mathrm{~kW} \cdot \mathrm{h} / \mathrm{m}^{3}$. The results presented in Table 4 highlights that the cationic surfactant $\mathrm{CTAB}$ at $\mathrm{CMC}$ as a feed pretreatment was a more effective treatment for latex solution than the anionic surfactant LAS when improving ultrafiltration performance and minimizing membrane fouling are considered. On the other hand, using the cationic surfactant had an opposite effect when the treated PVDF membrane surface was used. This was due to the opposite effect of the cationic surfactant on decreasing the surface negativity of treated membrane surfaces and latex particles from $-40.90 \mathrm{mV}$ to $-10.33 \mathrm{mV}$ and from -26.61 to 20.30 , respectively. Hence, the attraction force between latex particles with zeta potential of $20.30 \mathrm{mV}$ and the treated membrane surface was increased, if compared to untreated feed. As a consequence, the depositional attachment was significantly increased from 0.1 to 0.84 . Therefore, the total mass of fouling was obviously increased by $162 \%$, from $0.0070 \mathrm{~kg} / \mathrm{m}^{2}$ to $0.0113 \mathrm{~kg} / \mathrm{m}^{2}$, and the specific power consumption was noticeably increased more than 10 times, from $1.2 \mathrm{~kW} \cdot \mathrm{h} / \mathrm{m}^{3}$ to 13.5 $\mathrm{kW} \cdot \mathrm{h} / \mathrm{m}^{3}$, when the treated membrane surface was combined with the pretreated latex solution with CTAB at CMC. Therefore, it can be concluded that ultrafiltration process using treated PVDF membrane with LAS at a concentration of $0.0001 \mathrm{~g} / \mathrm{L}$ had the best performance, followed by the case with untreated membrane and pretreated feed using CTAB at CMC for 10 minutes with minimal agitation. 


\section{CHAPTER 6 CONCLUSIONS AND FUTURE WORK}

\subsection{Conclusions}

The results of this study showed that:

- Fouling could be primarily attributed to the attachments among foulant entities (coagulation attachment) and between foulants and membrane surfaces (depositional attachment). The fouling attachments are dependent not only on the properties of the foulants and the membranes but also on the solution chemistry. The reduction of membrane permeability caused by particles larger than the pore size was mainly by the pore blocking or the cake layer formation while the fouling by smaller particles was predominantly the internal fouling or the standard pore blocking.

- The fouling attachment mechanistic model developed in this study could accurately and effectively incorporate the coupled effects of the chemical and physical factors involved in the membrane fouling, thus allowing for a comprehensive understanding of the fouling phenomenon. The transmembrane pressure estimated from the model agreed with the experimentally measured values, mostly within 5.0 - $8.0 \%$ error, and up to $13.0 \%$ error for the uniform, and non-uniform pore size membranes, respectively.

- The mechanistic mathematical model and the fouling attachment correlations, taking into account the effect of the zeta potential on fouling, developed in the present study form a comprehensive set of predictive models in ultrafiltration of latex paint effluent under a constant feed flow rate and a cross-flow model, applicable to both hydrophilic and hydrophobic membranes of a variety of materials with different molecular weight cut-off (MWCO) values. The masses of fouling experimentally measured agreed with the predicted values from the models, within the error ranges of $2.5-9.1 \%$, and $4.0-14.3 \%$ for hydrophilic and hydrophobic membranes, respectively. The sphericity of the particles had a noticeable effect on the attachment model using homogeneous membranes. The systematic overestimation of the model acquired using the latex solution or the monodisperse particles can be attributed to the complexity of the model's calculation, which treats the average of 
each particle size range as a matrix with each pore size range. Admittedly, the model's calculation is a dynamic somewhat different from the real fouling phenomenon.

- The particle-to-membrane attachment is primarily responsible for reversible and irreversible membrane fouling. On the other hand, the particle-to-particle attachment probability was the predominant factor responsible for the cake formation, even though the particle-to-membrane attachment $\left(\alpha_{\mathrm{pm}}\right)$ decreased with the increase in the solid feed concentration. Higher fouling probabilities caused an increase in the total mass of fouling retained by the membrane and the cake thickness, which in turn resulted in an increased resistance to the permeate flux.

- The zeta potential of the membrane surface has a predominant effect on the fouling attachment. The total mass of fouling and the power consumption could be reduced by manipulating the depositional attachment between latex particles and the membrane surface. However, the hydrophilicity of the membrane did not have a noticeable effect on the particle-to-particle attachment. For a PVDF membrane, the mass of fouling calculated using the correlations incorporating the zeta potential effect had a much lower error of 7.8 to $14.3 \%$ , as compared to the error of 26.7 to $43.3 \%$ using the correlations without the effect of the zeta potential of the membrane surface. Likewise, for the increase in the transmebrane pressure, the error range was 8.9 to $12.3 \%$, as compared to 25 to $41.8 \%$ using the models without the effect of the zeta potential.

- The numerical model of specific power consumption based on the fouling attachment model of the increase in transmembrane pressure agreed quite well with the power consumption calculated from the experimental values for both hydrophilic and hydrophobic membranes of various materials, surface charges, and different MWCO with an error range of $6.0 \%$ up to $19.1 \%$.

- The morphological characteristics of the membrane, operating conditions, and membrane surface charge had a significant effect on the specific power consumption, and have a critical role that justifies their inclusion into the complete set of the predictive models. Increasing the zeta potential negativity of the latex particles or enhancing the membrane surface hydrophilicity resulted in a significant increase in the cumulative permeate flux, a substantial decrease in the total mass of fouling, and a noticeable decrease in the specific power consumption. Also, lower membrane fouling, higher volumetric permeate flux and lower specific power consumption were obtained by increasing the solution $\mathrm{pH}$. At given 
transmembrane pressure, feed solid concentration and $\mathrm{pH}$, increasing the feed flow rate resulted in a reduced total mass of fouling while the specific power consumption increased. On the other hand, increase in the $\mathrm{pH}$ from 7 to 12 lead to a decrease in the total mass of fouling and the specific power consumption. A combination of an increased feed flow rate and a higher solution $\mathrm{pH}$ was shown to enhance both the permeate flux and the specific power consumption with less membrane fouling.

- The LAS, an anionic surfactant, was found to be an ineffective pre-treatment for fouling remediation of latex solution using hydrophilic membranes even at high concentrations and long treatment times. Nevertheless, the LAS addition to the latex solution had an overall positive effect on the enhancement of the surface charge of the PVDF hydrophobic membrane from -2.50 to $-28.66 \mathrm{mV}$ through the ultrafiltration process. The optimum time was determined as 15 minutes of LAS addition at the concentration of $0.0001 \mathrm{~g} / \mathrm{L}$ as a feed pretreatment. The feed pretreatment based on increasing the solution alkalinity to $\mathrm{pH}$ of 11 enhanced the PVDF surface charge more than the addition of $0.0001 \mathrm{~g} / \mathrm{L}$ of LAS, in addition to a noticeable effect of higher $\mathrm{pH}$ on the latex particle negativity enhancement. The total mass of fouling was decreased by $29.6 \%$ and $12.8 \%$, in the case of the feed pretreatment by $\mathrm{pH}$ increase to value of 11 , and the addition of $0.0001 \mathrm{~g} / \mathrm{L}$ LAS, respectively. While the specific power consumption was decreased by $88.1 \%$ and $34.2 \%$, in case of the feed pretreatment by $\mathrm{pH}$ change, and in the instance of LAS addition, respectively.

- The optimum enhancement of Ultrafilic and PVDF membrane surface hydrophilicity was achieved with the LAS treatments at a concentration of $1 \times 10^{-4} \mathrm{~g} / \mathrm{L}$. The optimal time for LAS treatment was 15 and 20 minutes for Ultrafilic and PVDF membranes, respectively. The treated PVDF membrane surface with anionic surfactants at a concentration of $0.0001 \mathrm{~g} / \mathrm{L}$, yielded better performance than that obtained from feed pre-treatment by $\mathrm{pH}$ change. As such, the total mass of fouling decreased by $44.0 \%$ and $29.6 \%$, in case of treated membrane surface with anionic surfactant, and treated the latex solution feed at $\mathrm{pH}$ of 11, respectively. Moreover, the specific power consumption was substantially decreased by $92.1 \%$ and 88.1 $\%$, in case of treated membrane surface with anionic surfactant, and treated latex solution feed at $\mathrm{pH}$ of 11 , respectively. Moreover, the LAS treatment of the membrane surface at a concentration of $0.0001 \mathrm{~g} / \mathrm{L}$ had much more desirable effect than the addition of LAS to the latex solution as a feed pretreatment before ultrafiltration using PVDF and Ultrafilic 
membranes. However, the LAS was found to be an ineffective treatment either for latex solution treatment or enhancement of the surface hydrophilicity for Polysulfone membranes.

- CTAB, a cationic surfactant, played a critical role in enhancing the latex particles aggregation, which resulted in elimination of the particles of the fine size range. As a consequence, the mass of fouling contributing to pore blocking and the irreversible fouling were significantly reduced. The optimum results occurred with the addition of CTAB at the critical micelle concentration of $0.36 \mathrm{~g} / \mathrm{L}$ for 10 minutes with minimal agitation. Also, CTAB was found to be an effective pretreatment of latex solution using untreated homogeneous and heterogeneous membranes.

- For Polysulfone membrane, CTAB at CMC concentration with minimal agitation to the simulated latex effluent was the best treatment for minimizing membrane fouling and enhancing ultrafiltration performance. For hydrophobic PVDF membrane, CTAB at CMC concentration of $0.36 \mathrm{~g} / \mathrm{L}$ with minimal agitation had an overall favorable effect as feed pretreatment, as compared to the anionic surfactant LAS. However, enhancing the PVDF membrane surface hydrophilicty using LAS concentration of $0.0001 \mathrm{~g} / \mathrm{L}$ for two hours facilitated a significant reduction in membrane fouling and power consumption, in comparison to the addition of CTAB to latex solution.

\subsection{Future work}

Based on the finding from this study some investigations are recommended as follows:

\subsubsection{Membrane Fouling Remediation Using Ozonated Membrane Surfaces in Ultrafiltration Processes}

The modification and post-treatment of membranes have become popular subjects for discussion among researchers. In comparison to other surface modification techniques, such as plasma treatment, irradiation with gamma-rays, corona discharge, ion beam treatment, or UV radiation, ozonation is a much more inexpensive and simpler to operate. Moreover, the ozonation method can modify membrane surfaces uniformly even in the cases with complicated shapes. In fact, when polymers are exposed to ozone active peroxide groups are introduced onto the surface. Therefore, membrane fouling remediation using ozonated membrane surfaces in ultrafiltration of latex effluent is recommended. The influences of ozonated membrane surfaces on the total mass of fouling, cake height, cumulative permeate flux, and the specific power consumption should be investigated. The effects of different parameters should be examined, 
such as: ozone weight percentage and/or the gas flow rate, application duration, and $\mathrm{pH}$ to obtain the optimum condition of membrane surface ozonation. The effects of ozonation in either gaseous phase or aqueous phase on membrane surface charge and the surface hydrophilicity should be also investigated. Furthermore, the effects of temperature on aqueous ozonation technique for hydrophilicty enhancement should be considered. Nevertheless, the mechanical properties of the membranes should be examined with the aid of tensile strength and elongation tests. In that case, the impact of micellar-enhanced filtration combined with membrane surface ozonation should be investigated for further membrane fouling remediation.

\subsubsection{Morphology Control Influences on Membrane Fouling and Fouling Attachments}

The key factor in the development and application of polymeric membranes is the control of its polymeric morphology. As a result, many of the researchers have recently investigated the influence of membrane morphology control on the membranes' performance. Findings from these studies reported that there were effects of morphology control on pore sizes and surface porosity. However, the reported studies only examined the methods used for the preparation of polymeric membranes as a way of controlling its morphology. The heat treatment was the only technique applied to the Polysulfone membrane flat sheets for morphology control purpose and enhancement of the pore size. These studies did not provide a comprehensive understanding of the influence of morphology control on the membrane fouling phenomenon. Therefore, the effects of heat treatment of different membrane surfaces on the morphological characterization, including, membrane thickness, pore size distribution, and surface porosity should be investigated. The aim would be to obtain the optimum condition of the heat treatment of different membranes so as to attain the optimum required morphology with improved mechanical properties for optimum performance with minimum fouling. The effects of heat treatment on the membrane surface charge should likewise be investigated. The influence of morphology control on the fouling attachment, permeate flux, the total mass of fouling and its irreversibility should be examined.

\subsubsection{Influence of Combination of Ozonation with Ultrafiltration Process on Membrane Fouling and Water Quality}

The objective can be to further investigate the feasibility of combining ozonation as the feed treatment and the ultrafiltration process in order to achieve and maintain a high and stable permeate flux, decrease membrane fouling, and lower the formation of disinfection by-products. 
The ozone will be helpful in reducing the fouling of microbiological organisms associated with latex effluent, as well as enhancing the latex particle surface charge. Furthermore, the combined effects of ozone and ultrafiltration on the total mass of fouling, cake height, cumulative permeate flux, irreversible fouling, and specific power consumption should be investigated. Different parameters, such as ozone concentration and treatment duration, should be examined in order to obtain the optimum condition for the most favorable results with regards to the permeate flux, membrane fouling, and power consumption. The influence of ozone at different concentrations and various treatment times on the zeta potential of latex particles and membrane surface charges should likewise be analyzed. Notably, different membranes would be used for optimum results.

\subsubsection{Air and Ozone Backwashing for Flux Restoration in Ultrafiltration of Wastewater Treatment}

Recently, air and ozone backwash have been introduced into membrane filtration in wastewater treatment. The ozone backwashing could effectively recover the permeation flux in the ultrafiltration process, and prolong the period that it takes to re-reach the membrane fouling if compared to air backwashing. This may be ascribed to the decomposition of organic foulants in the membrane pore structure due to the strong oxidation of ozone and the exfoliation of cake layer by physical force of backwashing on the membrane surface. The air backwashing method for membrane fouling reduction is believed to be relatively inefficient in the case of long-term operation because it acts solely through the physical exfoliating effect. However, both research directions did not provide a conclusive analysis of the irreversible fouling for scale up purpose. Therefore, it's essential to develop numerical models of irreversible membrane fouling including the backwash parameters that would allow for an accurate prediction and scale up purposes. Furthermore, the process parameters such as ozone gas flow rate and injection time would be optimized so as to enhance fouling reduction, increase membrane life time, and minimize consumed power and the total cost. The optimum condition would be obtained in order to enhance the membrane life time.

\subsubsection{Spacer Geometry Influence on Membrane Fouling and Modelling of Feed Flow in Ultrafiltration Process using Computational Fluids Dynamics CFD}

The presence of spacers, which are the spaces for feed flow in rectangular filtration units, leads to increased pressure drop, and improved permeate flux. The hydrodynamics allow for the increase of shear stress near the membrane surface, which in turn improves the filtration process. 
However, larger spacers lead to the formation of localized stagnation or dead zones, where the membrane fouling phenomena may be increased. As a consequence, it's essential to investigate the influences of the feed spacer geometry on filtration performance and fouling, with the aim to determine the flow pattern and turbulence distribution using computational fluid dynamics (CFD). Furthermore, optimum spacer geometry and optimum conditions would be determined for best performance, minimum membrane fouling, and minimum power consumption.

\subsubsection{Gas Injection Technique for Flux Enhancement}

Recent studies indicate that gas injection enhances the shear rate and reduces the concentration polarization in filtration processes. The formation of bubbles through gas injection has a positive effect and increases turbulence leading to flux enhancement. However, none of these research studies give a comprehensive understanding of gas injection's influence on fouling phenomenon. Therefore, gas injection would be introduced into the cross-flow filtration unit and investigate the influence of gas injection rate on the attachment of foulants to the membrane surface, flux improvement, total fouling, and cake height. Moreover, the attachment models will be developed to include the gas flow rate in addition to the feed flow rate, feed concentration, transmembrane pressure, and surface charge for a more accurate prediction of fouling attachments. 


\section{LIST OF APPENDICES}

APPENDIX A

\section{HERMia MODEL FOR CONSTANT FLUX}

Hermia (1982) developed four empirical models that correspond to four basic types of fouling: complete blocking, intermediate blocking, standard blocking and cake layer formation. The mode of fouling depends on the size of particles either larger or smaller than the pore size of the membrane used. In the complete blocking mode, the particles are larger than the pore size of the membrane used. These particles adsorbed onto the membrane surface. In the intermediate blocking mode, the particles are of similar size to the pore size of the membrane, causing obstruction of the pores. There is also a reduction of the pore size of the pores where there is a buildup of particles near the pore entrance. Typically, it is assumed that the particles are chemically adsorbed to the surface, and particles arriving to the membrane were blocked by already adsorbed particles. Standard blocking involves particles smaller than the membrane pore size. Here, the particles adsorb onto the walls of pores, essentially, restricting the flow through them. These modes of fouling are considered pore-blocking and are usually irreversible. The final mode of fouling considered by Hermia's models is the formation of a cake layer. Particles involved in the cake layer may be larger or smaller than the membrane pore size, and is due to a buildup of particles on the surface.

The consecutive steps in the membrane fouling process entail the following:

- Blockage of the smallest pores by particles arriving at the membrane (complete blocking)

- Coverage of the inner surfaces of larger pores (standard blocking)

- Particles arriving to the membrane block some of the remaining pores, while other particles cover particles already blocking pores (intermediate blocking)

- Build up of a cake layer (cake formation)

The parameters considered by these models have a physical meaning and contribute to the comprehension of the mechanisms of membrane fouling. These models were developed for deadend filtration and are based on constant pressure filtration laws

$$
\frac{d^{2} t}{d V^{2}}=\mathrm{K}\left(\frac{d t}{d V}\right)^{\mathrm{n}}
$$


where $t$ [second] and $V\left[\mathrm{~m}^{3}\right]$ are the filtration time and cumulative permeate volume, respectively, and $k$ and $n$ are two model parameters with varying values or dimensions. $n$ is a dimensionless number that is related to the fouling mechanism as introduced later; $t$ and $V$ are obtained from constant pressure filtration experiments. Schematic diagrams of the four fouling modes proposed by Hermia are presented in Figure (2.4). However, most low pressure membrane filtration systems nowadays are designed and operated in the constant flow mode, which considered a limitation of the original model developed by Hermia. In this case, $(d t / d V)$ is constant, and the secondary derivative $d^{2} t / d V^{2}$ becomes zero. Therefore, the abov ementioned original form of Hermia model becomes invalid. In order to apply the model to constant flow filtration, the basic expressions of the model has to be revised by integrating the constant flow condition (Huang et al., 20008).

\section{A.1. Complete Pore Blocking:}

Complete pore blocking occurs when all particles reaching the membrane only participate in the sealing of membrane pores as illustrated in Figure (2.4 a). This idealized condition assumes that none of the particles are situated on top of other particles (i.e., no cake layer formation) or on the solid area of the membrane surface between pores. Therefore, the area of membrane surfaces with open pores $\left(\mathrm{A}_{\mathrm{t}}, \mathrm{m}^{2}\right)$ decreases linearly with the number of particles reaching the membrane with the projected area of the particles on the membrane surface $\left(A_{p}\right.$, $\mathrm{m}^{2}$ ). For a given particle suspension, the latter can be expressed as

$A_{p}=\sigma m_{f}$

Equation (A.2)

where $\mathrm{mf}[\mathrm{kg}]$ is the mass of particles that attach to membrane surfaces and cause fouling, and $\sigma$ $\left[\mathrm{m}^{2} / \mathrm{kg}\right]$ is the projected area of these particles on the membrane surface normalized to a unit mass of particles . $A_{t}$ can be expressed as:

$$
A_{t}=A_{o}-A_{p}=A_{o}-\sigma m_{f}
$$

Equation (A.3)

where $A_{o}$ is the initial pore area of the membrane. Hence,

$\frac{d A_{t}}{d m_{f}}=-\sigma$

Equation (A.4)

The transmembrane pressure required to drive the permeate through the membrane $(\mathrm{P}, \mathrm{Pa})$ is related to the permeate flowrate $\left(\mathrm{Q}, \mathrm{m}^{3} / \mathrm{s}\right)$ and $\mathrm{A}_{\mathrm{t}}$.It can be written following Darcy's law: $\mathrm{Q}=\frac{P \mathrm{~A}_{t}}{\mu R_{m}}$

Equation (A.5) 
where $\mathrm{R}_{\mathrm{m}}\left[\mathrm{m}^{-1}\right]$ is the hydraulic resistance of the membrane. For constant flow membrane filtration, Q remains constant during filtration and $\mathrm{P}$ increases as a result of membrane fouling. The characteristic rate of fouling in constant flow membrane filtration is $\mathrm{dP} / \mathrm{dm}_{\mathrm{f}}$ which describes the rate at which the transmembrane pressure would increase per unit mass of aquatic materials being filtered. It is related to the decrease of open membrane pore area as follows

$\frac{d P}{d m_{f}}=\frac{d}{d m_{f}}\left(\frac{\mu Q R_{m}}{\mathrm{~A}_{\mathrm{t}}}\right)=-\left(\frac{\mu Q R_{m}}{A_{t}^{2}}\right) \frac{d \mathrm{~A}_{\mathrm{t}}}{d m_{f}}=-\left(\frac{P^{2}}{P_{o} A_{o}}\right) \frac{d \mathrm{~A}_{\mathrm{t}}}{d m_{f}}$

Equation (A.6)

By inserting equation (A.4) into equation (A.6), we have:

$\frac{d P}{d m_{f}}=\left(\frac{\sigma}{P_{o} A_{o}}\right) P^{2}$

Equation (A.7)

Equation (A.7) can be further simplified by introducing two normalized parameters, $P^{\prime}$ and $\mathrm{m}_{\mathrm{f}}^{\prime}$

$\frac{d P^{\prime}}{d m_{f}^{\prime}}=\sigma P^{\prime 2}$

Equation (A.8)

where $P^{\prime}$ and $\mathrm{m}_{\mathrm{f}}^{\prime}$; are defined as follows:

$P^{\prime}=\frac{P}{P_{o}}$ and $m_{f}^{\prime}=\frac{m_{f}}{A_{o}}$

Equation (A.9)

\section{A.2. Intermediate Pore Blocking Model}

In the case of intermediate pore blocking (see Figure $2.4 \mathrm{c}$ ), each particle reaching the membrane may not only block membrane pores as in the case of complete pore blocking, but also attach to other particles that have already been on the membrane surface. It is assumed, however, that the fouling is only contributed by particles blocking membrane pores. This means that the existing particles on the membrane surface serve as competitors to membrane pores and reduce the actual number of approaching particles that can indeed block pores. Therefore, we only need to incorporate an analysis of pore blocking probability into the previous discussion of complete pore blocking. The probability for a particle to block membrane pores at any time is equivalent to the ratio of the remaining open area, $A_{t}$, to the initial total open area, $\mathrm{A}_{\mathrm{o}}$. Therefore, the decrease of the membrane open area as a unit mass of particles being retained can be expressed as (Huang et al., 2008):

$\Delta A_{t}=-\sigma \Delta m_{f}\left(\frac{\mathrm{A}_{\mathrm{t}}}{\mathrm{A}_{\mathrm{o}}}\right)$

Equation (A.10) can be written in a differential form: 
$\frac{d A_{t}}{\mathrm{dm}_{\mathrm{f}}}=-\sigma\left(\frac{\mathrm{A}_{\mathrm{t}}}{\mathrm{A}_{\mathrm{o}}}\right)$

Equation (A.11)

Solving Equation (A.11) with a boundary condition of $A_{t}=A o$ at $V$ (cumulative filtrate volume) $=0$, we have:

$A_{t}=\mathrm{A}_{\mathrm{o}} \exp \left(-\frac{\sigma m_{f}}{\mathrm{~A}_{\mathrm{o}}}\right)$

By inserting Equation (A.12) into Equation (A.6):

$\frac{P_{o}}{P}=\frac{\mathrm{A}_{\mathrm{t}}}{\mathrm{A}_{\mathrm{o}}}=\exp \left(-\frac{\sigma m_{f}}{\mathrm{~A}_{\mathrm{o}}}\right)$

Equation (A.13)

The fouling rate in the case of intermediate blocking is thus obtained:

$\frac{\mathrm{dP}}{\mathrm{dm}_{\mathrm{f}}}=\left(\frac{\sigma}{\mathrm{A}_{\mathrm{o}}}\right) \mathrm{P}$

Equation (A.14)

Or

$\frac{\mathrm{dP}^{\prime}}{\mathrm{dm}_{\mathrm{f}}^{\prime}}=\sigma \mathrm{P}^{\prime}$

Equation (A.15)

Where $\sigma\left[\mathrm{m}^{2} / \mathrm{kg}\right]$ is the projected area of these particles on the membrane surface normalized to a unit mass of particles.

\section{A.3. Standard Pore Blocking}

As shown in the Figure $(2.4 \mathrm{~b})$, standard pore blocking results in the shrinkage of membrane pores by particles attached to the pore walls. It's first assumed that the membrane consists of $N$ uniform cylindrical pores with a radius of $r_{o}$ and a length of L. Next, it is also assumed that the radius of the pores decreases at the same rate as particles attach to their walls. Then, the following mass balance relationship is established to determine the effective pore radius after fouling $(r)$ :

$\mathrm{N} \pi\left(r_{o}^{2}-r^{2}\right) L_{m}=\frac{m_{f}}{\rho}$

Equation (A.16)

With aforementioned assumptions, the transmembrane pressure of the membrane is invertly proportional to the radius of the pores following Poiseuille's equation:

$\mathrm{P}=\frac{8 \mu L_{m} Q}{N \pi} \cdot \frac{1}{r^{4}}$

Equation (A.17)

Consequently, the normalized transmembrane pressure is simply:

$P^{\prime}=\frac{P}{P_{o}}=\frac{r_{o}^{4}}{r^{4}}$

Equation (A.18)

By combining Equation (A.16)-Equation (A.18), we obtain: 
$\frac{\mathrm{dP}^{\prime}}{\mathrm{dm}_{\mathrm{f}}^{\prime}}=\left(\frac{2}{L_{m} \rho}\right) P^{3 / 2}$

Where $\mathrm{L}$ is cylindrical pores length and $\rho$ is the particle density $\left[\mathrm{kg} / \mathrm{m}^{3}\right]$.

\section{A.4. Cake Filtration Model}

The most widely used empirical model is the cake filtration model that focuses on the role of materials larger than membrane pore size. Unlike pore blocking, the cake filtration type of fouling does not involve any changes to the pore structure of membranes. Instead, the increase of hydraulic resistance encountered during membrane filtration is caused by the formation of a cake layer on top of the membrane surface (see Figure $2.4 \mathrm{~d}$ ).

The cake layer resistance, $R_{c}$, is usually expressed as (Huang et al., 2008):

$R_{c}=\hat{\mathrm{R}}_{\mathrm{c}} \frac{m_{f}}{A_{o}}$

Equation (A.20)

Where $\hat{\mathrm{R}}_{\mathrm{c}}[\mathrm{m} / \mathrm{kg}]$ is the specific resistance of cake layers. Again, by applying Darcy's law, we have:

$\mathrm{P}=\frac{Q \mu\left(R_{m}+R_{C}\right)}{A_{o}}$ and $\mathrm{P}_{\mathrm{o}}=\frac{Q \mu R_{m}}{A_{o}}$

Since $R_{m}$ remains constant, it is easy to obtain fouling rate by combination Equation (A.20) and Equation (A.21)

$\frac{d P}{d m_{f}}=\frac{Q \mu \hat{\mathrm{R}} \mathrm{c}}{A_{o}^{2}}$

Equation (A.22)

or the normalized form:

$\frac{d P^{\prime}}{d m_{f}^{\prime}}=\frac{\hat{R}_{c}}{R_{m}}$

Equation (A.23)

\section{The Unified Expression}

Eqns (A.8), (A.15), (A.19), and (A.23) can be written into a unified simple expression as follows:

$\frac{d P^{\prime}}{d m_{f}^{\prime}}=\mathrm{k} P^{\prime n}$

Equation (A.24)

The meanings of $k$ and $n$ in different types of fouling are presented in Table A.1. It is noteworthy that the $n$ values are the same as those found in the constant pressure model developed by Hermia for all types of membrane fouling. This indicates that the operating 
conditions (constant pressure versus constant flow) do not affect the way in which membranes are fouled as long as the assumed conditions used to obtain the model are met.

Table A.1 Values of $\mathbf{k}$ and $\mathbf{n}$ in the generalized Hermia model for constant flux

\begin{tabular}{|c|c|c|}
\hline Fouling Mechanism & $\mathbf{K}$ & $\mathbf{n}$ \\
\hline Cake formation & $\frac{\hat{R}_{c}}{R_{m}}$ & 0 \\
\hline Intermediate Blocking & $\sigma$ & 1 \\
\hline Standard Blocking & $2 / L_{m} \rho$ & $3 / 2$ \\
\hline Complete Blocking & $\sigma$ & 2 \\
\hline
\end{tabular}

Where $\hat{R}_{c}$ is the cake resistance $\left[\mathrm{m}^{-1}\right], R_{m}$ is the membrane resistance $\left[\mathrm{m}^{-1}\right], \sigma$ is the projected area of these particles on the membrane surface normalized to a unit mass of particles $\left[\mathrm{m}^{2} / \mathrm{kg}\right]$, $L_{m}$ is cylindrical pores length and $\rho$ is the particle density $\left[\mathrm{kg} / \mathrm{m}^{3}\right]$. 


\section{APPENDIX B \\ MODEl DERIVATIONS For MEMBRANe FOULING}

In this section the contribution of the model development for membrane fouling will be illustrated in details.

For projected area of particles on membrane surface per unit mass

$\sigma=\frac{\pi \mathrm{a}^{2}}{\rho \frac{4 \pi \mathrm{a}^{3}}{3}}=\frac{3}{4 \rho a}$

Equation (B.1)

$\sigma=\frac{0.75}{\rho a}$

Equation (B.2)

B.1. Mass of particles retained by the membrane due to Large Particle:

$$
\begin{aligned}
& \beta_{s}+\beta_{p}+\beta_{p p}=1 \\
& A_{t}=\frac{\mathrm{A}_{o}-\mathrm{A}_{\text {covered }}}{\mathrm{A}_{o}}=\frac{\mathrm{A}_{\text {uncovered }}}{\mathrm{A}_{o}} \\
& d A_{t}=-4^{\alpha \mathrm{pp}} \sigma A_{t} d m_{t} \\
& \frac{d A_{t}}{A_{t}}=-4^{\alpha} \alpha_{p p} \sigma d m_{t} \\
& \int_{1}^{A_{t}} \frac{d A_{t}}{A_{t}}=-4^{\alpha} \alpha_{p p} \sigma \int_{0}^{m_{t}} d m_{t} \\
& \ln A_{t}=-4^{\alpha_{p p}} \sigma m_{t} \\
& A_{t}=\exp \left(-4^{\alpha \mathrm{pp}} \sigma m_{t}\right) \\
& \beta_{p p}=1-A_{t} \\
& \beta_{p p}=1-\exp \left(-4^{\mathrm{\alpha pp}} \sigma m_{t}\right) \\
& \beta_{p}=\varepsilon_{\mathrm{s}} \exp \left(-4^{\alpha \mathrm{pp}} \sigma m_{t}\right) \\
& \beta_{s}=1-\left(\beta_{p}+\beta_{p p}\right) \\
& \beta_{s}=\left(1-\varepsilon_{\mathrm{s}}\right) \exp \left(-4^{\alpha \mathrm{pp}} \sigma m_{t}\right)
\end{aligned}
$$

Equation (B.3)

Equation (B.7)

Equation (B.8)

Equation (B.9)

Equation (B.10)

Equation (B.11)

Equation (B.12)

Equation (B.13)

Equation (B.14)

\section{B.1.1. Mass of large particles contributes to pore blocking $\boldsymbol{m}_{p L}$}

$d m_{p}=\alpha_{\mathrm{pm}} \beta_{p} d m_{t}$

Equation (B.15)

Insert equation (B.12) into equation (B.15)

$d m_{p L}=\alpha_{\mathrm{pm}} \varepsilon_{\mathrm{s}} \exp \left(-4^{\alpha \mathrm{pp}} \sigma_{\mathrm{L}} m_{t}\right) d m_{t}$
Equation (B.16) 
$\int_{0}^{m_{p L}} d m_{p L}=\alpha_{\mathrm{pm}} \varepsilon_{\mathrm{s}} \int_{0}^{m_{t}} \exp \left(-4^{\alpha \mathrm{pp}} \sigma_{\mathrm{L}} m_{t}\right) d m_{t}$

Equation (B.17)

$m_{p L}=\frac{-\alpha_{\mathrm{pm}} \varepsilon_{\mathrm{S}}}{4^{\alpha \mathrm{pp}} \sigma_{\mathrm{L}}}\left[\exp \left(-4^{\alpha \mathrm{pp}} \sigma_{\mathrm{L}} m_{t}\right)-1\right]$

Equation (B.18)

$m_{p L}=\frac{\alpha_{\mathrm{pm}} \varepsilon_{\mathrm{S}}}{4^{\alpha_{\mathrm{pp}}} \sigma_{\mathrm{L}}}\left[1-\exp \left(-4^{\alpha \mathrm{pp}} \sigma_{\mathrm{L}} m_{t}\right)\right]$

Equation (B.19)

Equation (B.19) represent the mass of large particles retained by the membrane contributes to pore blocking.

\section{B.1.2. Mass of large particles contributes to irreversible cake $\mathbf{m}_{\mathbf{c} \text { IRRL }}$}

$m_{C I R R L}=m_{s L}+m_{p p L}$

Equation (B.20)

$d m_{s}=\alpha_{\mathrm{pm}} \beta_{s} d m_{t}$

Equation (B.21)

Insert equation (B.14) into equation (B.21)

$d m_{s L}=\alpha_{\mathrm{pm}}\left(1-\varepsilon_{\mathrm{s}}\right) \exp \left(-4^{\alpha \mathrm{pp}} \sigma_{\mathrm{L}} m_{t}\right) d m_{t}$

Equation (B.22)

$\int_{0}^{m_{s L}} m_{s L}=\alpha_{\mathrm{pm}}\left(1-\varepsilon_{\mathrm{s}}\right) \int_{0}^{m_{t}} \exp \left(-4^{\alpha \mathrm{pp}} \sigma_{\mathrm{L}} m_{t}\right) d m_{t}$

Equation (B.23)

$m_{s L}=\frac{-\alpha_{\mathrm{pm}}\left(1-\varepsilon_{\mathrm{s}}\right)}{4^{\alpha \mathrm{pp}} \sigma_{\mathrm{L}}}\left[\exp \left(-4^{\alpha \mathrm{pp}} \sigma_{\mathrm{L}} m_{t}\right)-1\right]$

Equation (B.24)

$m_{s L}=\frac{\alpha_{\mathrm{pm}}\left(1-\varepsilon_{\mathrm{s}}\right)}{4^{\alpha \mathrm{pp}} \sigma_{\mathrm{L}}}\left[1-\exp \left(-4^{\alpha \mathrm{pp}} \sigma_{\mathrm{L}} m_{t}\right)\right]$

Equation (B.25)

Equation (B.25) represents the mass of large particles attached to the membrane surface after back-washing.

$d m_{p p}=\alpha_{p p} \beta_{p p} d m_{t}$

Equation (B.26)

Insert equation (B.11) into equation (B.26)

$d m_{p p L}=\alpha_{\mathrm{pp}}\left[1-\exp \left(-4^{\alpha_{p p}} \sigma_{\mathrm{L}} m t\right)\right] d m_{t}$

Equation (B.27)

$d m_{p p L}=\alpha_{\mathrm{pp}} d m_{t}-\alpha_{\mathrm{pp}} \exp \left(-4^{\alpha_{p p}} \sigma_{\mathrm{L}} m t\right) d m_{t}$

Equation (B.28)

$\int_{0}^{m_{p p L}} d m_{p p L}=\int_{0}^{m_{t}} \alpha_{\mathrm{pp}} d m_{t}-\alpha_{\mathrm{pp}} \int_{0}^{\mathrm{m}_{\mathrm{t}}} \exp \left(-4^{\alpha_{p p}} \sigma_{\mathrm{L}} m t\right) d m_{t}$

Equation (B.29)

$m_{p p L}=\alpha_{\mathrm{pp}} m_{t}+\frac{\alpha_{p p}}{4^{\alpha p p} \sigma_{\mathrm{L}}}\left[\exp \left(-4^{\alpha}{ }^{\alpha p} \sigma_{\mathrm{L}} m_{t}\right)-1\right]$

Equation (B.30)

$m_{p p L}=\alpha_{\mathrm{pp}} m_{t}-\frac{\alpha_{p p}}{4^{\alpha p p} \sigma_{\mathrm{L}}}\left[1-\exp \left(-4^{\alpha}{ }^{p p} \sigma_{\mathrm{L}} m_{t}\right)\right]$

Equation (B.31)

Equation (B.31) represents the mass of large particles contributes to cake layer after backwashing

$m_{C I R R L}=m_{s L}+m_{p p L}$

Equation (B.32)

So the total mass of large particles contributes to irreversible cake can be represented as: 
$m_{C I R R L}=\alpha_{\mathrm{pp}} m_{t}+\frac{\alpha_{\mathrm{pm}}\left(1-\varepsilon_{\mathrm{s}}\right)-\alpha_{\mathrm{pp}}}{4^{\alpha \mathrm{pp}} \sigma_{\mathrm{L}}}\left[1-\exp \left(-4^{\alpha}{ }_{\mathrm{pp}} \sigma_{\mathrm{L}} m_{t}\right)\right]$

Equation (B.33)

\section{B.2. Mass of particles retained by the membrane due to Small Particle:}

\section{B.2.1. Small Particles $\left(a<D_{m} / 6\right.$ or $\left.D_{p} / D_{m}<1 / 3\right)$ attached to membrane wall}

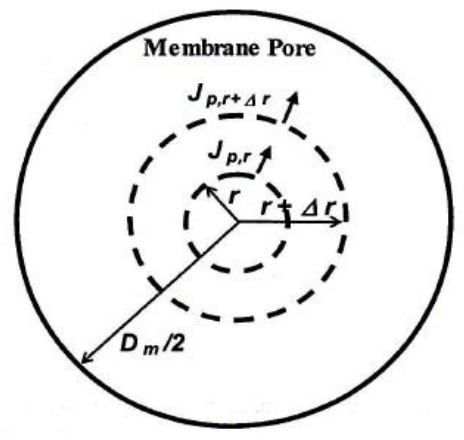

Steady state mass balance equation in a cylindrical coordinate system in radial direction as shown in Figure (3.4 a)

The ring-like space is between $r$ and $r+\Delta r, J_{p, r+\Delta r}$ and $J_{p, r}$ represent the particle flux at $r$ and $r+\Delta r$, respectively.

$\mathrm{J}_{\mathrm{p}, \mathrm{r}+\Delta \mathrm{r}}\left[2 \pi(\mathrm{r}+\Delta \mathrm{r}) L_{m}\right]-\mathrm{J}_{\mathrm{p}, \mathrm{r}}\left(2 \pi \mathrm{r} L_{m}\right)=0$

Equation (B.34)

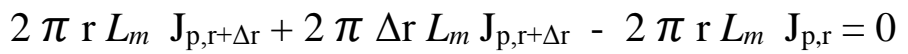

Equation (B.35)

$2 \pi \mathrm{r} L_{m} \mathrm{~J}_{\mathrm{p}, \mathrm{r}+\Delta \mathrm{r}}-2 \pi \mathrm{r} L_{m} \mathrm{~J}_{\mathrm{p}, \mathrm{r}}=-2 \pi \Delta \mathrm{r} L_{m} \mathrm{~J}_{\mathrm{p}, \mathrm{r}+\Delta \mathrm{r}}$

Equation (B.36)

$\mathrm{r}\left(\mathrm{J}_{\mathrm{p}, \mathrm{r}+\Delta \mathrm{r}}-\mathrm{J}_{\mathrm{p}, \mathrm{r}}\right)=-\Delta \mathrm{r} \mathrm{J}_{\mathrm{p}, \mathrm{r}+\Delta \mathrm{r}}$

Equation (B.37)

$\frac{J p, r+\Delta r-J p, r}{\Delta r}=-\frac{J p, r+\Delta r}{r}$

Equation (B.38)

Let $\Delta r \rightarrow 0$

$\frac{\mathrm{dJ}_{\mathrm{p}}}{\mathrm{dr}}=-\frac{\mathrm{Jp}_{\mathrm{p}}}{\mathrm{r}}$

Equation (B.39)

$\frac{\mathrm{dJ}_{\mathrm{p}}}{\mathrm{J}_{\mathrm{p}}}=-\frac{\mathrm{dr}}{\mathrm{r}}$

Equation (B.40)

$\ln J_{p}=-\ln r$

Equation (B.41)

$J_{p}=\frac{K}{r}$

Equation (B.42)

By combining Equation (B.42) with fick's law to get Equation (B.44)

$J_{p}=-\mathrm{D} \frac{d C_{p}}{d r} \quad$ Fick's Law

Equation (B.43)

$\frac{\mathrm{K}}{\mathrm{r}}=-\mathrm{D} \frac{d C_{p}}{d r}$

Equation (B.44) 
$\mathrm{K}=-\mathrm{D} \frac{r d c_{p}}{d r}$

Equation (B.45)

$\mathrm{K} \frac{d r}{r}=-\mathrm{D} d c_{p}$

Equation (B.46)

$\mathrm{K} \int_{D m / 2}^{a} \frac{d r}{r}=-\mathrm{D} \int_{0}^{c_{a}} d c_{p}$

Equation (B.47)

where $c_{a}$ is the concentration of solid particle in permeate stream in the pore at $\mathrm{r}=\mathrm{a}$

$\mathrm{K}\left[\ln \mathrm{a}-\ln \frac{D_{m}}{2}\right]=-\mathrm{D} \mathrm{c}_{\mathrm{a}}$

Equation (B.48)

$\mathrm{K}\left[\ln \frac{D_{m}}{2 \mathrm{a}}\right]=\mathrm{D}_{\mathrm{p}} \mathrm{C}_{\mathrm{a}}$

Equation (B.49)

$\mathrm{K}=\frac{\mathrm{D} \mathrm{c} \mathrm{a}}{\left[\ln \frac{D_{m}}{2 \mathrm{a}}\right]}$

Equation (B.50)

By inserting $\mathrm{K}$ value in $J_{p}$ in Equation (B.42)

$J_{p}=\frac{\mathrm{D} \mathrm{c} c}{\mathrm{r}\left[\ln \frac{D_{m}}{2 \mathrm{a}}\right]}$

Equation (B.51)

$J_{p, D m / 2}=\frac{2 C_{a} \mathrm{D}}{D_{m} \ln \left(\frac{D_{m}}{2 a}\right)}$

Equation (B.52)

Equation (B.52) represents the flux of particles in radial direction at $\mathrm{D}_{\mathrm{m}} / 2$

The change in concentration along the axial direction of the pore as illustrated in Figure $3.4 \mathrm{~b}$. For a slice of disk-like space inside the pore with diameter $\mathrm{D}_{\mathrm{m}}$ and thickness of $\mathrm{dl}$

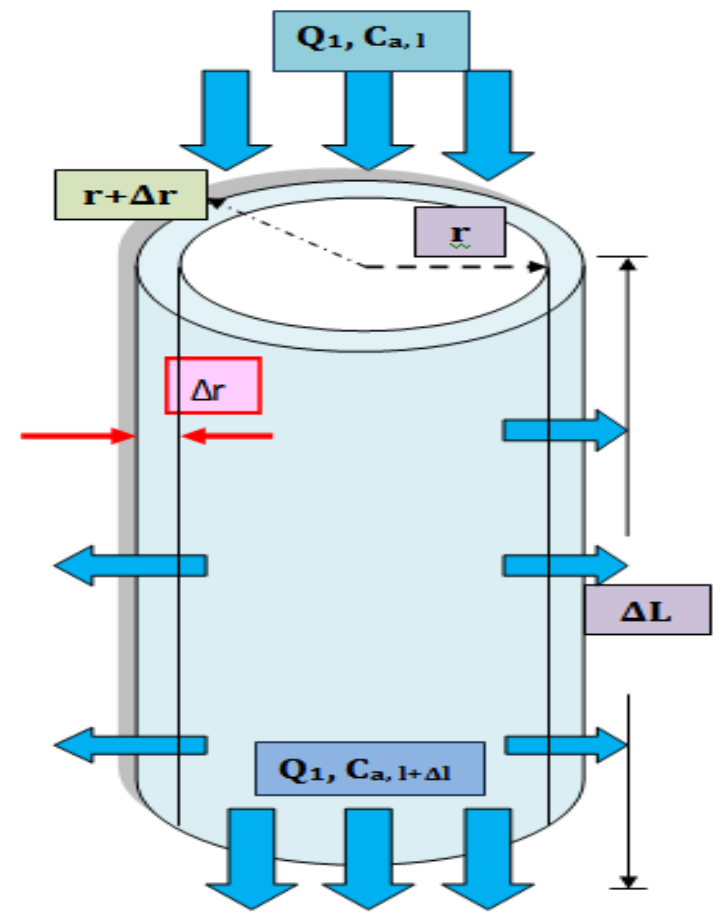


Shell mass balance under steady state

$C_{a, l} Q_{l}=C_{a, l+\Delta l} Q_{l}+\alpha_{p m} J_{p, D m / 2}\left(\pi D_{m} \Delta l\right)$

Equation (B.53)

$Q_{l}$ is the permeate flow rate in one membrane pore and is related to the total permeate flow rate with the following equation

Where $\mathrm{Q}_{1}=\frac{Q}{A_{m} N_{m}}=\frac{J}{N_{m}}$

Equation (B.54)

$C_{a, l+\Delta l} Q_{l}-C_{a, l} Q_{l}=-\alpha_{p m} J_{p, D m / 2}\left(\pi D_{m} \Delta l\right)$

Equation (B.55)

$\frac{\mathrm{dC}_{\mathrm{a}, 1}}{\mathrm{dl}}=\frac{-\alpha_{\mathrm{pm}} \mathrm{J}_{\mathrm{p}, \mathrm{Dm} / 2}(\pi \mathrm{Dm})}{\mathrm{Q}_{1}}$

Equation (B.56)

By inserting Equation (B.52) for $J_{p, \frac{D m}{2}}$ in Equation (B.56)

$\frac{\mathrm{dC}_{\mathrm{a}, 1}}{\mathrm{dl}}=\frac{-\alpha_{\mathrm{pm}}(\pi \mathrm{Dm})}{\mathrm{Q}_{1}} \frac{2 C_{a} \mathrm{D}}{D_{m} \ln \left(\frac{D_{m}}{2 a}\right)}$

Equation (B.57)

$\frac{\mathrm{dC}_{\mathrm{a}, 1}}{\mathrm{dl}}=\frac{-2 \Pi \alpha_{\mathrm{pm}} C_{a} \mathrm{D}}{\mathrm{Q}_{1} \ln \left(\frac{D_{m}}{2 a}\right)}$

Equation (B.58)

$\frac{\mathrm{dC}_{\mathrm{a}, \mathrm{l}}}{C_{a}}=\frac{-2 \pi \alpha_{\mathrm{pm}} \mathrm{D}}{\mathrm{Q}_{1} \ln \left(\frac{D_{m}}{2 a}\right)} \mathrm{dl}$

Equation (B.59)

$\int_{C_{0}}^{c_{l}} \frac{\mathrm{dC}_{\mathrm{a}, \mathrm{l}}}{C_{a}}=\frac{-2 \pi \alpha_{\mathrm{pm}} \mathrm{D}}{\mathrm{Q}_{1} \ln \left(\frac{D_{m}}{2 a}\right)} \int_{0}^{l} d l$

Equation (B.60)

$\ln \frac{C_{a, l}}{C_{a, o}}=\frac{-2 \pi \alpha_{\mathrm{pm}} \mathrm{D}}{\mathrm{Q}_{1} \ln \left(\frac{D_{m}}{2 a}\right)} l$

Equation (B.61)

$\frac{\mathrm{C}_{\mathrm{a}, \mathrm{l}}}{\mathrm{C}_{\mathrm{a}, \mathrm{o}}}=\exp \left[\frac{-2 \pi \alpha_{\mathrm{pm}} \mathrm{D}}{\mathrm{Q}_{1} \ln \left(\frac{D_{m}}{2 a}\right)} l\right]$

Equation (B.62)

$\frac{\mathrm{C}_{\text {out }}}{\mathrm{C}_{\text {in }}}=\exp \left[\frac{-2 \pi \alpha_{\mathrm{pm}} \mathrm{D}}{\mathrm{Q}_{1} \ln \left(\frac{D_{m}}{2 a}\right)} l\right]$

Equation (B.63)

$\frac{C_{\text {out }}}{C_{\text {in }}}=\exp \left[\frac{-2 \pi \mathrm{D}_{\mathrm{m}} \alpha_{\mathrm{pm}} \mathrm{D}}{\mathrm{Q}_{1} D_{m} \ln \left(\frac{D_{m}}{2 a}\right)} l\right]$

Equation (B.64)

$\frac{\mathrm{C}_{\text {out }}}{\mathrm{C}_{\text {in }}}=\exp \left[-\frac{2 \alpha_{\mathrm{pm}} \mathrm{D}}{\mathrm{Q}_{1} D_{m} \ln \left(\frac{\mathrm{Dm}_{\mathrm{m}}}{2 \mathrm{a}}\right)}\left(\pi D_{m} L_{m}\right)\right]$

Equation (B.65)

If the membrane pore is partially fouled due to particle attachment onto the pore wall, Equation (B.65) need to be modified

$\frac{C_{\text {out }}}{C_{\text {in }}}=\exp \left[-\frac{2 \alpha_{\mathrm{pm}} D A w, 1}{D_{m} Q_{1} \ln \left(\frac{D_{m}}{2 \mathrm{a}}\right)}\right]=\exp \left(-\alpha_{\mathrm{pm}} B A_{\mathrm{w}, 1}\right)$

Where $A_{w, 1}\left[\mathrm{~m}^{2}\right]$ is total open area on the wall of one membrane pore after partially fouled. 
$\mathrm{B}=\frac{2 \mathrm{D}}{D_{m} \mathrm{Q}_{1} \ln \left(\frac{D_{m}}{2 \mathrm{a}}\right)}$

Equation (B.67)

Where $\mathrm{B}\left[\mathrm{m}^{-2}\right]$ is a mass transfer coefficient clustering all parameters in the exponential term on the RHS of the Equation (B.65) except $\alpha_{\mathrm{pm}}$ and the variable $\mathrm{A}_{\mathrm{w}, 1}$

To get $A_{w, 1}$ (total open area on the wall of one membrane pore after partially fouled), so the mass of particles attaching to the wall of one membrane pore $d m_{w, 1}[\mathrm{~kg}]$ should be also calculated.

$$
\begin{aligned}
& d m_{w, 1}=\mathrm{C}_{\mathrm{in}} Q_{1}\left(1-\frac{\mathrm{C}_{\text {out }}}{\mathrm{C}_{\mathrm{in}}}\right) d t_{1} \\
& d m_{w, 1}=\mathrm{C}_{\mathrm{in}}\left(1-\frac{\mathrm{C}_{\text {out }}}{\mathrm{C}_{\mathrm{in}}}\right) d V_{1} \\
& d A_{w, 1}=-\sigma_{\mathrm{xs}} d m_{w, 1} \\
& d A_{w, 1}=-\sigma_{\mathrm{xs}} \mathrm{C}_{\mathrm{in}}\left(1-\frac{\mathrm{C}_{\text {out }}}{\mathrm{C}_{\mathrm{in}}}\right) d V_{1}
\end{aligned}
$$

Then insert Equation (B. 66) of $\frac{\mathrm{C}_{\text {out }}}{\mathrm{C}_{\mathrm{in}}}$ into Equation (B.71)

$d A_{w, 1}=-\sigma_{\mathrm{xs}} \mathrm{C}_{\mathrm{in}}\left(1-\exp \left(-\alpha_{\mathrm{pm}} \mathrm{BA}_{\mathrm{w}, 1}\right)\right) d V_{1}$

Equation (B.72)

$d A_{w, 1}=-\sigma_{\mathrm{xs}} \mathrm{C}_{\mathrm{in}} d V_{1}+\sigma_{\mathrm{xs}} \mathrm{C}_{\mathrm{in}} \exp \left(-\alpha_{\mathrm{pm}} \mathrm{BA}_{\mathrm{w}, 1}\right) d V_{1}$

Solving for $A_{w, 1}$

$\mathrm{A}_{\mathrm{w}, 1}=\frac{1}{\alpha_{\mathrm{pm}} \mathrm{B}} \ln \left\{1+\left[\exp \left(\pi D_{m} L_{m} \mathrm{~B} \alpha_{\mathrm{pm}}-1\right] \exp \left(-\sigma_{\mathrm{xs}} \alpha_{\mathrm{pm}} \mathrm{B} \mathrm{C}_{\mathrm{in}} \mathrm{V}_{1}\right)\right\}\right.$

Equation (B.74)

$$
\pi \mathrm{D}_{\mathrm{m}} \mathrm{L}_{\mathrm{m}} \mathrm{B} \alpha_{\mathrm{pm}} \gg 1
$$

$$
\mathrm{A}_{\mathrm{w}, 1}=\frac{1}{\alpha_{\mathrm{pm}} \mathrm{B}} \ln \left\{1+\exp \left(\pi D_{m} L_{m} \mathrm{~B} \alpha_{\mathrm{pm}}\right) \exp \left(-\sigma_{\mathrm{xs}} \alpha_{\mathrm{pm}} \mathrm{B} \mathrm{C}_{\mathrm{in}} \mathrm{V}_{1}\right)\right\}
$$

$\mathrm{A}_{\mathrm{w}, 1}=\frac{1}{\alpha_{\mathrm{pm}} \mathrm{B}} \ln \left[1+\exp \left(\pi D_{m} L_{m} \mathrm{~B} \alpha_{\mathrm{pm}}-\sigma_{\mathrm{xs}} \alpha_{\mathrm{pm}} \mathrm{B} \mathrm{C}_{\mathrm{in}} \mathrm{V}_{1}\right)\right]$

Where $\mathrm{V}_{1}=\frac{\mathrm{V}_{\mathrm{s}}}{\mathrm{N}_{\mathrm{m}}}$

$\mathrm{m}_{\mathrm{w}, 1} \cong \frac{\pi D_{m} L_{m}-\mathrm{A}_{\mathrm{w}, 1}}{\sigma}$

$m_{w, 1}=\frac{1}{\sigma_{\mathrm{xs}} \alpha_{p m} B}\left\{\pi D_{m} L_{m} B \alpha_{p m^{-}} \ln \left[1+\exp \left(\pi D_{m} L_{m} B \alpha_{p m^{-}} \sigma_{\mathrm{xs}} \alpha_{p m} \mathrm{~B} C_{i n} V_{1}\right)\right]\right\}$

$\mathrm{m}_{\mathrm{w}, 1}=\frac{\mathrm{m}_{\mathrm{w}}}{\mathrm{N}_{\mathrm{m}}}$

Equation (B.79)

Equation (B.80) 
$m_{w}=\frac{N_{m}}{\sigma_{\mathrm{xs}} \alpha_{p m} B}\left\{\pi D_{m} L_{m} B \alpha_{\mathrm{pm}}-\ln \left[1+\exp \left(\pi D_{m} L_{m} B \alpha_{p m}-\frac{\sigma_{\mathrm{xs}} \alpha_{\mathrm{pm}} \mathrm{B}}{N_{m}} \mathrm{C}_{\mathrm{in}} V_{s}\right)\right]\right.$

Equation (B.81)

The mean particle concentrations at the inlet $\mathrm{C}_{\text {in }}$ is the concentration of solid particles in the feed water $\left[\mathrm{Kg} / \mathrm{m}^{3}\right]\left(C_{f}\right)$

$m_{w}=\frac{N_{m}}{\sigma_{\mathrm{xs}} \alpha_{p m} B}\left\{\pi D_{m} L_{m} B \alpha_{\mathrm{pm}}-\ln \left[1+\exp \left(\pi D_{m} L_{m} B \alpha_{p m}-\frac{\sigma_{\mathrm{xs}} \alpha_{\mathrm{pm}} \mathrm{B}}{N_{m}} \mathrm{C}_{\mathrm{f}} V_{s}\right)\right]\right.$

Equation (B.82)

This Equation (B.82) represents the mass of particles retained by the membrane due to small particle with radius less than pore diameter over six, these particles attached to the membrane pore wall.

B.2.2. For mass of small particles $\left(\frac{D m}{6}<\mathbf{a}<\frac{D m}{2}\right)$ contributes to pore blocking $\mathrm{m}_{\mathrm{pS}}$

$d m_{p}=\alpha_{\mathrm{pm}} \varepsilon_{\mathrm{s}} \exp \left(-4^{\alpha \mathrm{pp}} \sigma m_{t}\right) d m_{t}$

Equation (B.83)

$\int_{0}^{m_{p}} d m_{p}=\alpha_{\mathrm{pm}} \varepsilon_{\mathrm{s}} \int_{0}^{m_{t}} \exp \left(-4^{\alpha \mathrm{pp}} \sigma m_{t}\right) d m_{t}$

$m_{p}=\frac{-\alpha_{\mathrm{pm}} \varepsilon_{\mathrm{s}}}{4^{\alpha_{\mathrm{pp}}}}\left[\exp \left(-4^{\alpha \mathrm{pp}} \sigma m_{t}\right)-1\right]$

$m_{p}=\frac{\alpha_{\mathrm{pm}} \varepsilon_{\mathrm{s}}}{4^{\alpha \mathrm{pp}_{\sigma}}}\left[1-\exp \left(-4^{\alpha \mathrm{pp}} \sigma m_{t}\right)\right]$

For small particle inside the pore $\alpha_{p p}=0$

$m_{p S}=\frac{\alpha_{\mathrm{pm}} \varepsilon_{\mathrm{s}}}{\sigma_{\mathrm{S}}}\left[1-\exp \left(-\sigma_{\mathrm{S}} m_{\mathrm{t}}\right)\right]$

Equation (B.87)

Equation (B.87) represent the mass of small particles contributes to pore blocking.

B.2.3. Mass of small particles $\left(\frac{D m}{6}<\mathbf{a}<\frac{D m}{2}\right)$ contributes to irreversible cake $\boldsymbol{m}_{c \text { IRR } S}$

Similarly to large particles approach, small particles contribute to irreversible fouling.

$$
\begin{aligned}
& d m_{s}=\alpha_{\mathrm{pm}} \beta_{s} d m_{t} \\
& d m_{s}=\alpha_{\mathrm{pm}}\left(1-\varepsilon_{\mathrm{s}}\right) \exp \left(-4^{\alpha \mathrm{pp}} \sigma m_{t}\right) d m_{t} \\
& \int_{0}^{m_{s}} m_{s}=\alpha_{\mathrm{pm}}\left(1-\varepsilon_{\mathrm{s}}\right) \int_{0}^{m_{t}} \exp \left(-4^{\alpha \mathrm{pp}} \sigma m_{t}\right) d m_{t} \\
& m_{s}=\frac{-\alpha_{\mathrm{pm}}\left(1-\varepsilon_{\mathrm{s}}\right)}{4^{\alpha \mathrm{pp}} \sigma}\left[\exp \left(-4^{\alpha \mathrm{pp}} \sigma m_{t}\right)-1\right] \\
& m_{s}=\frac{\alpha_{\mathrm{pm}}\left(1-\varepsilon_{\mathrm{s}}\right)}{4^{\alpha \mathrm{pp}} \sigma}\left[1-\exp \left(-4^{\alpha \mathrm{pp}} \sigma m_{t}\right)\right] \\
& m_{s S}=\frac{\alpha_{\mathrm{pm}}\left(1-\varepsilon_{\mathrm{s}}\right)}{4^{\alpha \mathrm{pp}} \sigma_{\mathrm{s}}}\left[1-\exp \left(-4^{\alpha \mathrm{pp}} \sigma_{\mathrm{s}} m_{t}\right)\right]
\end{aligned}
$$

Similarly

$d m_{p p}=\alpha_{p p} \beta_{p p} d m_{t}$

Equation (B.94) 
Insert equation (B.11)

$$
\begin{aligned}
& d m_{p p S}=\alpha_{\mathrm{pp}}\left[1-\exp \left(-4^{\alpha_{p p}} \sigma_{\mathrm{S}} m t\right)\right] d m_{t} \\
& d m_{p p S}=\alpha_{\mathrm{pp}} d m_{t}-\alpha_{\mathrm{pp}} \exp \left(-4^{\alpha_{p p}} \sigma_{\mathrm{S}} m t\right) d m_{t} \\
& \int_{0}^{m_{p p S}} d m_{p p L}=\int_{0}^{m_{t}} \alpha_{\mathrm{pp}} d m_{t}-\alpha_{\mathrm{pp}} \int_{0}^{\mathrm{m}_{\mathrm{t}}} \exp \left(-4^{\alpha}{ }_{p p} \sigma_{\mathrm{S}} m t\right) d m_{t} \\
& m_{p p S}=\alpha_{\mathrm{pp}} m_{t}+\frac{\alpha_{p p}}{4^{\alpha p p} \sigma_{\mathrm{S}}}\left[\exp \left(-4^{\alpha_{p p}} \sigma_{\mathrm{S}} m_{t}\right)-1\right] \\
& m_{p p s}=\alpha_{\mathrm{pp}} m_{t}-\frac{\alpha_{\mathrm{pp}}}{4^{\alpha \mathrm{pp}} \sigma_{\mathrm{S}}}\left[1-\exp \left(-4^{\alpha_{\mathrm{pp}}} \sigma_{\mathrm{S}} m_{t}\right)\right]
\end{aligned}
$$

Equation (B.99) represents the mass of small particles contributes to cake layer after backwashing

$$
m_{C \text { IRR } S}=m_{S S}+m_{p p S}=\alpha_{\mathrm{pp}} m_{t}+\frac{\alpha_{\mathrm{pm}}\left(1-\varepsilon_{\mathrm{S}}\right)-\alpha_{\mathrm{pp}}}{4^{\alpha_{\mathrm{pp}}} \sigma_{\mathrm{S}}}\left[1-\exp \left(-4^{\alpha_{\mathrm{pp}}} \sigma_{\mathrm{S}} m_{t}\right)\right] \quad \text { Equation (B.100) }
$$

Equation (B.100) represent the mass of small particles contributes to irreversible cake by attached on the membrane surface.

\section{B.3.Cake layer fouling}

For mass of particles contributes to the total cake layer $m_{\mathrm{c}}\left[\mathrm{kg} / \mathrm{m}^{2}\right]$,

$m_{c}=\alpha_{p p} m_{t}-m_{p L}-m_{p S}-m_{w}$

Equation (B.101)

$m_{c}=\alpha_{p p} m_{t}-\frac{\alpha_{\mathrm{pm}} \varepsilon_{\mathrm{s}}}{4^{\alpha \mathrm{pp}} \sigma_{\mathrm{L}}}\left[1-\exp \left(-4^{\alpha \mathrm{pp}} \sigma_{\mathrm{L}} \mathrm{m}_{\mathrm{t}}\right)\right]-\frac{\alpha_{\mathrm{pm}} \varepsilon_{\mathrm{s}}}{\sigma_{\mathrm{s}}}\left[1-\exp \left(-\sigma_{\mathrm{s}} m_{t}\right)\right]-\frac{N_{m}}{\sigma_{\mathrm{xs}} \alpha_{\mathrm{pm}} B}\left\{\pi D_{m} L_{m} B\right.$

$\alpha_{\mathrm{pm}}-\ln \left[1+\exp \left(\pi D_{m} L_{m} B \alpha_{\mathrm{pm}}-\frac{\sigma_{\mathrm{xs}} \alpha_{\mathrm{pm}} B}{N_{m}} C_{f} V_{s}\right)\right]$

Moreover, the mass of fouling contributed to cake layer formation resulted from the particles attached to the membrane surface, and the particles contributed to cake build up due to particleto-particle attachment.

$$
m_{c}=\alpha_{\mathrm{pp}} C f V S+\left\{\frac{\alpha_{\mathrm{pm}}\left(1-\varepsilon_{\mathrm{s}}\right)-\alpha_{\mathrm{pp}}}{4^{\alpha} \mathrm{pp}}\left[\frac{\left[1-\exp \left(-4^{\alpha} \mathrm{pp}_{\sigma_{\mathrm{L}}} m_{t}\right)\right.}{\sigma_{\mathrm{L}}}+\frac{\left[1-\exp \left(-4^{\alpha} \mathrm{pp}_{\sigma_{\mathrm{S}}} \mathrm{m}_{\mathrm{t}}\right)\right.}{\sigma_{\mathrm{s}}}\right]\right\}
$$

Equation (B.103)

\section{B.4. Transmembrane Pressure}

Transmembrane pressure $\left(P^{\prime}\right)$ is a function of the mass of particles retained by the membrane based on Hermia model for constant flux (Huang et al.,2008) 
$\frac{d P^{\prime}}{d m_{f}^{\prime}}=\mathrm{k} P^{\prime n}$

Equation (B.104)

where $\mathrm{P}^{\prime}$ is the increase in TMP, $m_{f}^{\prime}$ is the mass of particles that attach to the membrane surface and cause fouling and $\mathrm{k}, \mathrm{n}$ are constants depending on the type of fouling as illustrated in table (A.1)

For pore blocking and cake formation, the equation can be rewritten as:

$\frac{d P^{\prime}}{d m_{f}^{\prime}}=\sigma P^{\prime 2}$

Equation (B.105)

$P^{\prime}=\frac{P}{P_{o}}=1$ to $P^{\prime}$

Equation (B.106)

$m_{f}^{\prime}=\frac{\mathrm{m}_{\mathrm{f}}}{\mathrm{A}_{\mathrm{o}}}$

Equation (B.107)

By replacing $m_{f}^{\prime}\left[\mathrm{kg} / \mathrm{m}^{2}\right]$ with $\mathrm{m}_{\mathrm{p}}\left[\mathrm{kg} / \mathrm{m}^{2}\right]$

$\frac{d P^{\prime}}{d m_{p}}=\sigma P^{\prime 2} \quad$ (Complete pore blocking)

Equation (B.108)

$\int_{1}^{P^{\prime}} \frac{d P^{\prime}}{P^{\prime 2}}=\int_{0}^{m_{p}} \sigma d m_{p}$

Equation (B.109)

$\int_{1}^{P_{p L}^{\prime}} \frac{d p_{p L}^{\prime}}{P_{p L}^{\prime 2}}=\int_{0}^{m_{p L}} \sigma_{\mathrm{L}} d m_{p L}$

Equation (B.110)

$\frac{1}{P_{p L}^{\prime}}-1=-\sigma_{\mathrm{L}} m_{p L}$

Equation (B.111)

$\frac{1}{P_{p L}^{\prime}}=1-\sigma_{\mathrm{L}} m_{p L}$

Equation (B.112)

$P_{p L}^{\prime}=\frac{1}{1-\sigma_{\mathrm{L}} m_{p L}}$

Equation (B.113)

Insert Equation (B.19) for $m_{p L}$

$P_{p L}^{\prime}=\frac{1}{1-\frac{\alpha_{p m} \varepsilon_{\mathrm{S}}}{4^{\alpha p p}}\left[1-\exp \left(-4^{\alpha p p} \sigma_{\mathrm{L}} \mathrm{C}_{\mathrm{f}} \mathrm{V}_{\mathrm{S}}\right)\right]}$

Equation (B.114)

Equation (B.114) represents the increase in transmembrane pressure due to large particles contributes to pore blocking.

Similarly for small particles contributes to pore blocking, insert equation (B.87) for $m_{p S}$

$P_{p s}^{\prime}=\frac{1}{1-\alpha_{p m} \varepsilon_{s}\left[1-\exp \left(-\sigma_{\mathrm{s}} \mathrm{C}_{\mathrm{f}} V_{s}\right)\right]}$

Equation (B.115)

Increasing in transmembrane pressure due to small particles $\mathrm{a}<\mathrm{Dm} / 6$ : 


$$
\begin{aligned}
& \frac{d P^{\prime}}{d m_{f}^{\prime}}=\left(\frac{2}{L_{m} \rho}\right) P^{\prime 3 / 2} \\
& \frac{d P^{\prime}}{d m_{w}}=\left(\frac{2}{L_{m} \rho}\right) P^{\prime 3 / 2} \quad \text { (standard pore blocking) } \\
& \frac{d P^{\prime}}{P^{\prime 3 / 2}}=\left(\frac{2}{L_{m} \rho}\right) d m_{w} \\
& \int_{1}^{P_{w}^{\prime}} \frac{d P_{w}^{\prime}}{P_{w}^{\prime 3 / 2}}=\left(\frac{2}{L_{m} \rho}\right) \int_{0}^{m_{w}} d m_{w} \\
& -2\left[\frac{1}{P_{w}^{\prime 1 / 2}}-1\right]=\left(\frac{2}{L_{m} \rho}\right) m_{w} \\
& \frac{1}{P_{w}^{\prime 1 / 2}}=1-\frac{m_{w}}{L_{m} \rho} \\
& P_{w}^{\prime 1 / 2}=\frac{1}{1-\frac{m_{w}}{\rho L_{m}}} \\
& P_{w}^{\prime}=\frac{1}{\left(1-\frac{m_{w}}{\rho L_{m}}\right) 2} \\
& P_{w}^{\prime}=\frac{1}{\left\{1-\frac{N_{m}}{\sigma_{\mathrm{xs}} \rho \alpha_{\mathrm{pm}} B L_{m}}\left\{\pi D m L m B \alpha_{\mathrm{pm}}-\ln \left[1+\exp \left(\pi D m L m B \alpha_{\mathrm{pm}}-\frac{\sigma_{\mathrm{xs}} \alpha_{\mathrm{pm}} B}{N_{m}} C f V s\right)\right\}\right\}^{2}\right.}
\end{aligned}
$$

Equation (B.124)

Equation (B.124) represents the increase in transmembrane pressure due to small particles with radius less than pore diameter over six, these particles attached to the membrane pore wall.

For the increase of transmembrane pressure due to cake layer formation

$$
\frac{d P^{\prime}}{d m_{f}^{\prime}}=\frac{\hat{\mathrm{R}}_{\hat{R} c}}{R_{m}}
$$

$d P^{\prime}=\frac{\hat{\mathrm{R}}_{\hat{R} c}}{R_{m}} d m_{f}^{\prime}$

$m_{f}^{\prime}=\frac{\mathrm{m}_{\mathrm{f}}}{\mathrm{A}_{\mathrm{o}}}$

By replacing $m_{f}^{\prime}\left[\mathrm{kg} / \mathrm{m}^{2}\right]$ with $\mathrm{m}_{\mathrm{c}}\left[\mathrm{kg} / \mathrm{m}^{2}\right]$

$\frac{d P^{\prime}}{d m_{c}}=\frac{\hat{R}_{c}}{R_{m}} \quad$ (cake layer formation)

Equation (B.128)

$\int_{1}^{P_{c}^{\prime}} d P_{c}^{\prime}=\frac{\hat{\mathrm{R}}_{\hat{R} c}}{R_{m}} \int_{0}^{m_{c}} m_{c}$

Equation (B.129) 
$\int_{1}^{P_{c}^{\prime}} d P_{c}^{\prime}=\frac{\hat{\mathrm{R}}_{\hat{R} c}}{R_{m}} \int_{0}^{m_{c}} m_{c}$

Equation (B.130)

$P_{c}^{\prime}-1=\frac{\hat{\mathrm{R}}_{\hat{R} c}}{R_{m}} m_{c}$

Equation (B.131)

$P_{c}^{\prime}=1+\frac{\hat{\mathrm{R}}_{\hat{R} c}}{R_{m}} m_{c}$

Equation (B.132)

Insert Equation (B.102) for $m_{c}$

$P_{c}^{\prime}=1+\frac{\hat{R}_{C}}{R_{m}}\left\{\alpha_{\mathrm{pp}} \mathrm{C}_{\mathrm{f}} V_{s}-\frac{\alpha_{\mathrm{pm}} \varepsilon_{\mathrm{s}}}{4^{\alpha_{\mathrm{pp}}} \sigma_{\mathrm{L}}}\left[1-\exp \left(-4^{\alpha \mathrm{pp}} \sigma_{\mathrm{L}} \mathrm{m}_{\mathrm{t}}\right]-\frac{\alpha_{\mathrm{pm}} \varepsilon_{\mathrm{s}}}{\sigma_{\mathrm{s}}}\left[1-\exp \left(-\sigma_{\mathrm{s}} m_{\mathrm{t}}\right)\right]-\frac{N_{m}}{\sigma_{\mathrm{xs}} \alpha_{\mathrm{pm}} B}\left\{\pi D_{m}\right.\right.\right.$

$\left.L_{m} B \alpha_{\mathrm{pm}}-\ln \left[1+\exp \left(\pi D_{m} L_{m} B \alpha_{\mathrm{pm}}-\frac{\sigma_{\mathrm{xs}} \alpha_{\mathrm{pm}} \mathrm{B}}{N_{m}} C_{f} V_{s}\right)\right]\right\}$

Equation (B.133)

Equation (B.133) represents the increase in transmembrane pressure due to cake formatio

The total mass of particles contributes to irreversible fouling can be calculated from the following equation.

$m_{I R R}=m_{c I R R L}+m_{c I R R S}+m w$

Equation (B.134)

$m_{I R R}=\alpha_{\mathrm{pp}} m_{t}+\left\{\frac{\alpha_{\mathrm{pm}}\left(1-\varepsilon_{\mathrm{s}}\right)-\alpha_{\mathrm{pp}}}{4^{\alpha \mathrm{pp}}}\left[\frac{\left[1-\exp \left(-4^{\alpha} \mathrm{pp}_{\sigma_{\mathrm{L}}} m_{t}\right)\right.}{\sigma_{\mathrm{L}}}+\frac{\left[1-\exp \left(-4^{\alpha} \mathrm{pp}_{\sigma_{\mathrm{s}}} \mathrm{m}_{\mathrm{t}}\right)\right.}{\sigma_{\mathrm{s}}}\right]\right\}+\frac{N_{m}}{\sigma_{\mathrm{xs}} \alpha_{\mathrm{pm}} B}\{\pi$

$\left.D_{m} L_{m} B \alpha_{\mathrm{pm}^{-}}-\ln \left[1+\exp \left(\pi D_{m} L_{m} B \alpha_{\mathrm{pm}}-\frac{\sigma_{\mathrm{xs}} \alpha_{\mathrm{pm}} B}{N_{m}} C_{f} V_{s}\right)\right]\right\}$

Equation (B.135)

Total increase in trasmembrane pressure due to irreversible fouling can be calculated from equation

$P_{\text {IRR }}=P^{\prime} c_{I R R L}+P^{\prime} c_{I R R S}+P_{w}^{\prime}$

Equation (B.136)

$\dot{P}_{I R R}=1+\frac{\hat{R} c}{R_{m}}\left\{\alpha_{\mathrm{pp}} m_{t}+\left(\frac{\alpha_{\mathrm{pm}}\left(1-\varepsilon_{\mathrm{s}}\right)-\alpha_{\mathrm{pp}}}{4^{\alpha \mathrm{pp}}}\left[\frac{\left[1-\exp \left(-4^{\alpha_{\mathrm{pp}}} \sigma_{\mathrm{L}} m_{t}\right)\right.}{\sigma_{\mathrm{L}}}+\frac{\left[1-\exp \left(-4^{\alpha} \mathrm{pp}_{\sigma_{\mathrm{s}}} \mathrm{m}_{\mathrm{t}}\right)\right.}{\sigma_{\mathrm{s}}}\right]\right)\right\}$

$+\frac{1}{\left\{1-\frac{N_{m}}{\sigma_{\mathrm{Xs}} \rho \alpha_{\mathrm{pm}} B L_{m}}\left\{\pi D m L m B \alpha_{\mathrm{pm}}-\ln \left[1+\exp \left(\pi D m L m B \alpha_{\mathrm{pm}}-\frac{\sigma_{\mathrm{Xs}}{ }^{\alpha} \mathrm{pm}^{B}}{N_{m}} \operatorname{Cin} V s\right)\right]\right\}\right\}^{2}}$

Equation (B.137) 


\section{APPENDIX C \\ MODEL DEVELOPMENT FOR NON-UNIFORM PORE SIZE MEMBRANES}

In this study, a mechanistic model was developed and generalized for the applications with non-uniform pore size membranes, based on the fouling potential of the particles of different sizes with different pore sizes. The heterogeneous membranes have pore size distribution of $(N)$ non-uniform pore sizes, as shown in Figure (C.1). Notably, the individual pores are not aligned in a straight manner, and thus cause the flow to take a non-linear path with the length of the path greater than the path equal to the membrane thickness, as shown in Figure (C.2). Consequently, the tortuosity of the membrane will be included in the model expressions. All possible mechanisms involved in particle attachments with non-homogenous pore membrane using ImageJ software [ImageJ 1.46r, National Institutes Of Health, USA]. All possible attachments of each particle size are applied in the mathematical model for each pore size $(i)$. Eventually, the average percentage $\left(x_{i}\right)$ of each pore size $(i)$ estimated by the software will be used in the model's calculations.

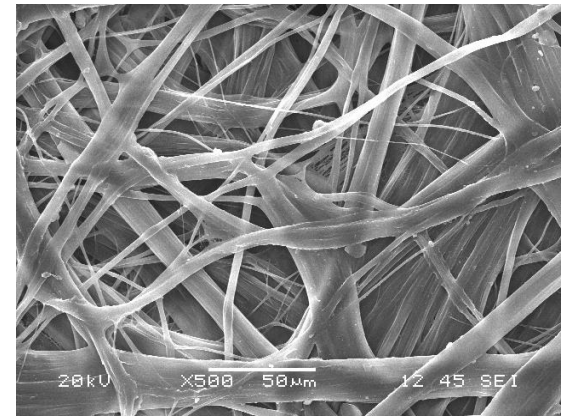

Figure C.1. SEM of Polysulfone non-uniform pore size membrane

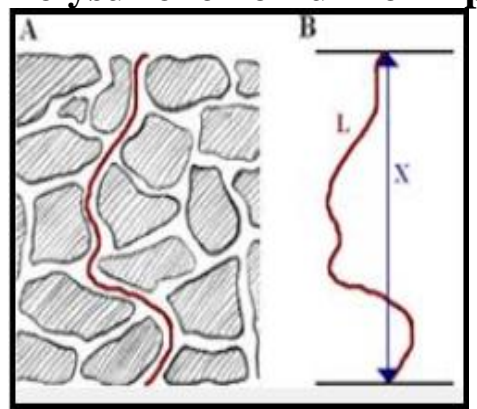

Figure C.2. Effective pore length of the heterogeneous membrane

As discussed in the model simulation in Section 3.3.1, the particles size will be classified for each pore size $(i)$. 


\section{C.1. Large particles (particle size $\geq$ pore diameter) $\left(a \geq D_{m} / 2\right)$}

Based on the equation derived for the uniform pore size membrane and intended for calculating the mass of fouling contributed to pore blocking by larger sized particle, the equation was developed for non-uniform pore size membranes. For each pore size ( $i$ to $N$ ).

The mass of the particles larger than the pore of size $i$ contributes to the pore blocking $\left(m_{p L_{i}}\right)$ $\left[\mathrm{kg} / \mathrm{m}^{2}\right]$ calculated using Equation (C.1)

$m_{p L_{i}}=\frac{\alpha_{p m} \varepsilon_{\mathrm{S}}}{4^{\alpha} p p_{\sigma_{\mathrm{L}}}}\left[1-\exp \left(-4^{\alpha}{ }^{\alpha p p} \sigma_{\mathrm{L}} C_{f} V_{S}\right)\right]$

Equation (C.1)

For the total mass of large particles contributed to pore blocking using heterogeneous membranes have pore size distribution of $(N)$ non-uniform pore sizes.

$m_{p L}=\sum_{i=1}^{N} x_{i} m_{p L_{i}}$

Equation (C.2)

\section{C.2. Small particles $\left(\mathrm{a}<D_{m} / 2\right)$}

\section{C.2.1. Very small particles $\left(a<D_{m} / 6\right)$ (standard pore blocking)}

Equation (B.81) for uniform pore size membrane will be developed for non-uniform pore size membranes for each pore size. In addition the tortuosity will be included for the effective length of the membrane pore.

$m_{w_{i}}=\frac{N_{m}}{\sigma_{\mathrm{xS}} \alpha_{\mathrm{pm}} B_{i}}\left\{\frac{\pi D_{m_{i}} L_{m} B_{i} \alpha_{\mathrm{pm}}}{\tau}-\ln \left[1+\exp \left(\frac{\pi D_{m_{i}} L_{m} B_{i} \alpha_{\mathrm{pm}}}{\tau}-\frac{\sigma_{\mathrm{xs}} \alpha_{\mathrm{pm}} B_{i}}{N_{m}} C_{f} V_{s}\right)\right]\right\}$

Equation (C.3)

$\tau$ is the tortuosity of the membrane (defined as ratio between the membrane thickness $\left(L_{m}\right)$ and the actual path that the small particles follows through the membrane pore The tortuosity in our study was estimated using Hagen Poiseuille Equation (Cuperus, 1991) and using the experimental data of the permeate flux of water collected at different transmembrane pressures. Besides, $B_{i}\left[\mathrm{~m}^{-2}\right]$ is a mass transfer coefficient will be defined for each pore size.

$B_{i}=\frac{2 \mathrm{D}}{D_{m_{i}} Q_{i} \ln \left(\frac{D_{m_{i}}}{2 \mathrm{a}}\right)}$

Equation (C.4)

The effective diffusion coefficient describes diffusion through the pore space of porous media (Grathwohl, 1998). The effective diffusion coefficient for transport through the pores, $\mathrm{D}_{\mathrm{e}}$, is estimated as follows:

$\mathrm{D}_{\mathrm{e}}=\frac{D \varepsilon_{S} \delta_{c}}{\tau}$

Equation (C.5) 
$D\left[\mathrm{~m}^{2} / \mathrm{s}\right]$ is the diffusion coefficient in the pores, $\varepsilon_{s}$ [dimensionless] is the porosity available for the transport, $\tau$ [dimensionless] is the tortuosity, and $\delta_{c}$ [dimensionless] is the constrictivity which is the ratio of the diameter of the diffusing particle to the pore diameter.

Consequently, the total mass of small particles attached to the pore wall of heterogeneous membranes of $(N)$ non-uniform pore sizes.

$m_{w}=\sum_{i=1}^{N} x_{i} m_{w_{i}}$

Equation (C.6)

\section{C.2.2. Models for small particles $\left(D_{m} / 6<a<D_{m} / 2\right)$}

The mass of the small particles contributing to the blocking of the pores of size $i\left(m_{p s_{i}}\right)\left[\mathrm{kg} / \mathrm{m}^{2}\right]$ is calculated from Equation (C.7), while the total mass of small particles contributing to pore blocking $m_{p S}\left[\mathrm{~kg} / \mathrm{m}^{2}\right]$ is calculated from Equation (C.8), as the model was developed for non-uniform pore size membrane.

$m_{p S_{i}}=\frac{\alpha_{\mathrm{pm}} \varepsilon_{\mathrm{s}}}{\sigma_{\mathrm{s}}}\left[1-\exp \left(-\sigma_{\mathrm{s}} C_{f} V_{s}\right)\right]$

Equation (C.7)

$m_{p S}=\sum_{i=1}^{N} x_{i} m_{p s_{i}}$

Equation (C.8)

The total mass of particles contributed to pore blocking

$m_{p}=\sum_{i=1}^{N} x_{i}\left\{\frac{\alpha_{p m} \varepsilon_{\mathrm{s}}}{4^{a} p \sigma_{\sigma_{\mathrm{L}}}}\left[1-\exp \left(-4^{\alpha_{p p}} \sigma_{\mathrm{L}} C_{f} V_{s}\right)\right]\right\}+\sum_{i=1}^{N} x_{i}\left\{\frac{N_{m}}{\sigma_{\mathrm{xs}} \alpha_{\mathrm{pm}} B_{i}}\left\{\frac{\pi D_{m_{i}} L_{m} B_{i} \alpha_{\mathrm{pm}}}{\tau}-\ln [1+\exp \right.\right.$

$\left.\left.\left.\left(\frac{\pi D_{m_{i}} L_{m} B_{i} \alpha_{\mathrm{pm}}}{\tau}-\frac{\sigma_{\mathrm{xs}} \alpha_{\mathrm{pm}} B_{i}}{N_{m}} C_{f} V_{s}\right)\right]\right\}\right\}+\sum_{i=1}^{N} x_{i}\left\{\frac{\alpha_{\mathrm{pm}} \varepsilon_{\mathrm{s}}}{\sigma_{\mathrm{s}}}\left[1-\exp \left(-\sigma_{\mathrm{s}} C_{f} V_{s}\right)\right]\right\}$

Equation (C.9)

\section{C.3. Mathematical expression for cake layer}

The mass of the particles participating in the cake layer formation, $m_{\mathrm{c}}\left[\mathrm{kg} / \mathrm{m}^{2}\right]$, can be expressed as:

$$
\begin{aligned}
& m_{c}=\alpha_{\mathrm{pp}} C_{f} V_{s^{-}}\left\{\sum_{i=1}^{N} x_{i} m_{p L_{i}}-\sum_{i=1}^{N} x_{i} m_{p S_{i}}-\sum_{i=1}^{N} x_{i} m_{w_{i}}\right\} \\
& m_{c}=\alpha_{\mathrm{pp}} C_{f} V_{s^{-}}\left\{\sum_{i=1}^{N} x_{i}\left\{\frac{\alpha_{p m} \varepsilon_{s}}{4^{\alpha} p \sigma_{\sigma_{\mathrm{L}}}}\left[1-\exp \left(-4^{\alpha_{p p}} \sigma_{\mathrm{L}} C_{f} V_{s}\right)\right]\right\}+\sum_{i=1}^{N} x_{i}\left\{\frac{N_{m}}{\sigma_{\mathrm{xs}} \alpha_{\mathrm{pm}} B_{i}}\right.\right. \\
& \left.\left\{\frac{\pi D_{m_{i}} L_{m} B_{i} \alpha_{\mathrm{pm}}}{\tau}-\ln \left[1+\exp \left(\frac{\pi D_{m_{i}} L_{m} B_{i} \alpha_{\mathrm{pm}}}{\tau}-\frac{\sigma_{\mathrm{xs}} \alpha_{\mathrm{pm}} B_{i}}{N_{m}} C_{f} V s\right)\right]\right\}\right\}+\sum_{i=1}^{N} x_{i}\left\{\frac{\alpha_{\mathrm{pm}} \varepsilon_{\mathrm{s}}}{\sigma_{\mathrm{s}}}[1-\right.
\end{aligned}
$$$$
\left.\left.\left.\exp \left(-\sigma_{s} C_{f} V_{s}\right)\right]\right\}\right\}
$$

The mass of particles contributed to cake layer formation can be also expressed as the mass of particles attached to membrane surface in addition to the mass of particles contributed to cake build up, as presented in Equation (C.12). 
$m_{c}=\alpha_{\mathrm{pp}} C_{f} V_{s}+\left\{\frac{\alpha_{\mathrm{pm}}\left(1-\varepsilon_{\mathrm{s}}\right)-\alpha_{\mathrm{pp}}}{4^{\alpha \mathrm{pp}}}\left[\frac{\left[1-\exp \left(-4^{\alpha}{ }^{\alpha} \sigma_{\sigma_{\mathrm{L}}} C_{f} V_{S}\right)\right.}{\sigma_{\mathrm{L}}}+\frac{\left[1-\exp \left(-4^{\alpha} \mathrm{pp}_{\sigma_{\mathrm{s}}} C_{f} V_{S}\right)\right.}{\sigma_{\mathrm{s}}}\right]\right\}$

Equation (C.12)

\section{C.4. Modeling of irreversible fouling}

Similarly, Equations (C.13) and (C.14) presented the irreversible cake fouling.

$m_{s}=\frac{\alpha_{\mathrm{pm}}\left(1-\varepsilon_{\mathrm{s}}\right)}{4^{\alpha} p p_{\sigma}}\left[1-\exp \left(-4^{\alpha} p p \sigma C_{f} V_{s}\right)\right]$

Equation (C.13)

$m_{p p}=\alpha_{\mathrm{pp}} C_{f} V_{s}-\frac{\alpha_{p p}}{4^{\alpha p p} \sigma}\left[1-\exp \left(-4^{\alpha}{ }^{\alpha p} \sigma C_{f} V_{s}\right)\right]$

Equation (C.14)

As a consequence, the total mass of irreversible fouling can be calculated using the following equations:

$m_{I R R}=m_{s}+m_{p p}+m_{w}$

$m_{I R R}=\alpha_{\mathrm{pp}} C_{f} V_{s}+\left\{\left[1-\exp \left(-4^{\alpha_{p p}} \sigma C_{f} V_{S}\right)\right]\left(\frac{\alpha_{\mathrm{pm}}\left(1-\varepsilon_{\mathrm{s}}\right)-\alpha_{p p}}{4^{\alpha p p} \sigma}\right)\right\}+\sum_{i=1}^{N} x_{i} m_{w_{i}}$

Equation (C.16)

\section{C.5. Mathematical model for transmembrane pressure}

Equation (C.17) presented the increase in TMP due to large particles contributed to pore blocking developed from Equation (B.113) for uniform pore size membrane.

$P_{p L}^{\prime}=\frac{1}{1-\sigma_{\mathrm{L}} \sum_{i=1}^{N} x_{i} m_{p L_{i}}}$

Equation (C.17)

Equation (C.18) presented the increase in TMP due to small particles contributed to pore blocking.

$P_{p S}^{\prime}=\frac{1}{1-\sigma_{\mathrm{S}} \sum_{i=1}^{N} x_{i} m_{p S_{i}}}$

The change of transmembrane pressure, due to very small particles getting attached to the membrane pore wall, can be expressed as:

$P_{w}^{\prime}=\frac{1}{\left(1-\frac{\sum_{i=1}^{N} x_{i} m_{w_{i}}}{\rho L_{m}}\right)^{2}}$

Equation (C.19)

The increase of transmembrane pressure due to the cake layer formation can be written as:

$P_{c}^{\prime}=1+\frac{\hat{\mathrm{R}}_{C}}{R_{m}}\left[\alpha_{\mathrm{pp}} C_{f} V_{s}-\left(\sum_{i=1}^{N} x_{i} m_{p L_{i}}-\sum_{i=1}^{N} x_{i} m_{p S_{i}}-\sum_{i=1}^{N} x_{i} m_{w_{i}}\right)\right]$

Equation (C.20)

Accordingly, the increase of total transmembrane membrane pressure during a filtration process can be calculated from Equation (C.21) 
$P^{\prime}=1+\frac{1}{1-\sigma_{\mathrm{L}} \sum_{i=1}^{N} x_{i} m_{p L_{i}}}+\frac{1}{1-\sigma_{\mathrm{S}} \sum_{i=1}^{N} x_{i} m_{p S_{i}}}+\frac{1}{\left(1-\frac{\sum_{i=1}^{N} x_{i} m_{w_{i}}}{\rho L_{m}}\right) 2}+\frac{\hat{\mathrm{R}}_{\mathrm{\textrm {R }} c}}{R_{m}}\left[\alpha_{\mathrm{pp}} C_{f} V_{s}-\left(\sum_{i=1}^{N} x_{i} m_{p L_{i}}-\right.\right.$

$\left.\left.\sum_{i=1}^{N} x_{i} m_{p S_{i}}-\sum_{i=1}^{N} x_{i} m_{w_{i}}\right)\right]$

Equation (C.21)

The increase of transmembrane pressure after backwash $\left(P_{\text {IRR }}\right)$ can be calculated from Equation (C.23)

$\dot{P}_{\text {IRR }}=P^{\prime} c_{I R R}+P_{w}^{\prime}$

Equation (C.22)

$P_{I R R}^{\prime}=1+\frac{\hat{\mathrm{R}} c}{R_{m}}\left\{\alpha_{\mathrm{pp}} C_{f} V_{s}+\left(\left[1-\exp \left(-4^{\alpha} p p \sigma C_{f} V_{s}\right)\right]\left(\frac{\alpha_{\mathrm{pm}}\left(1-\varepsilon_{\mathrm{s}}\right)-\alpha_{p p}}{4^{\alpha p p} \sigma}\right)\right)\right\}+\frac{1}{\left(1-\frac{\sum_{i=1}^{N} x_{i} m_{w_{i}}}{\rho L_{m}}\right)^{2}}$

Equation (C.23) 


\section{APPENDIX D \\ CHEMICAL STRUCTURE OF MEMBRANES}

- $\mathrm{PC}$

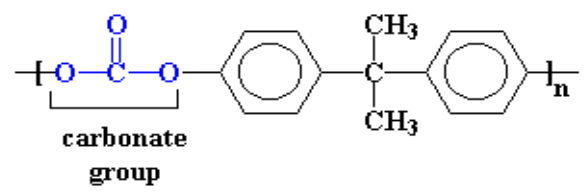

- PS $\left[\mathrm{OC}_{6} \mathrm{H}_{4} \mathrm{OC}_{6} \mathrm{H}_{4} \mathrm{SO}_{2} \mathrm{C}_{6} \mathrm{H}_{4}\right]_{\mathrm{n}}$

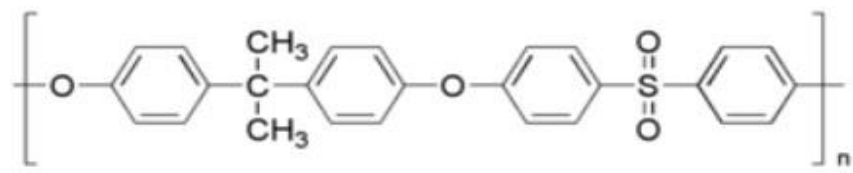

- $\mathrm{CA} \mathrm{C}_{6} \mathrm{H}_{7} \mathrm{O}_{2}(\mathrm{OH})_{3}$

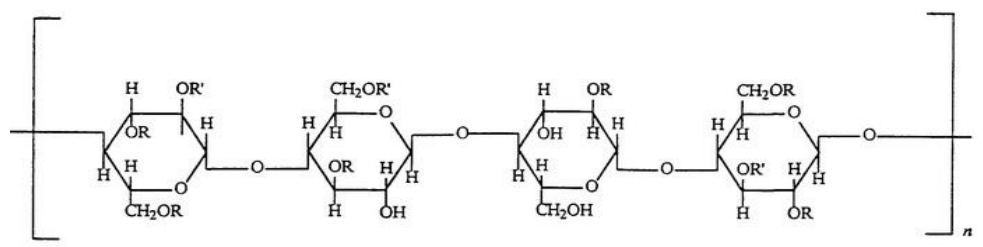

- PVDF $-\left(\mathrm{C}_{2} \mathrm{H}_{2} \mathrm{~F}_{2}\right)_{\mathrm{n}}$<smiles>CC(C)C(F)(F)C(C)C</smiles>

- Ultrafilic Polyacrylonitrile $\left(\mathrm{C}_{3} \mathrm{H}_{3} \mathrm{~N}\right)_{\mathrm{n}}$<smiles>CC(C)(C)CC(C#N)C(C)(C)C</smiles> 


\section{APPENDIX E \\ SURFACTANTS}

The surfactants used for membrane fouling remediation (Fainerman, 2001)

Table E.1. Surfactants tested for fouling remediation in ultrafiltration of latex solution

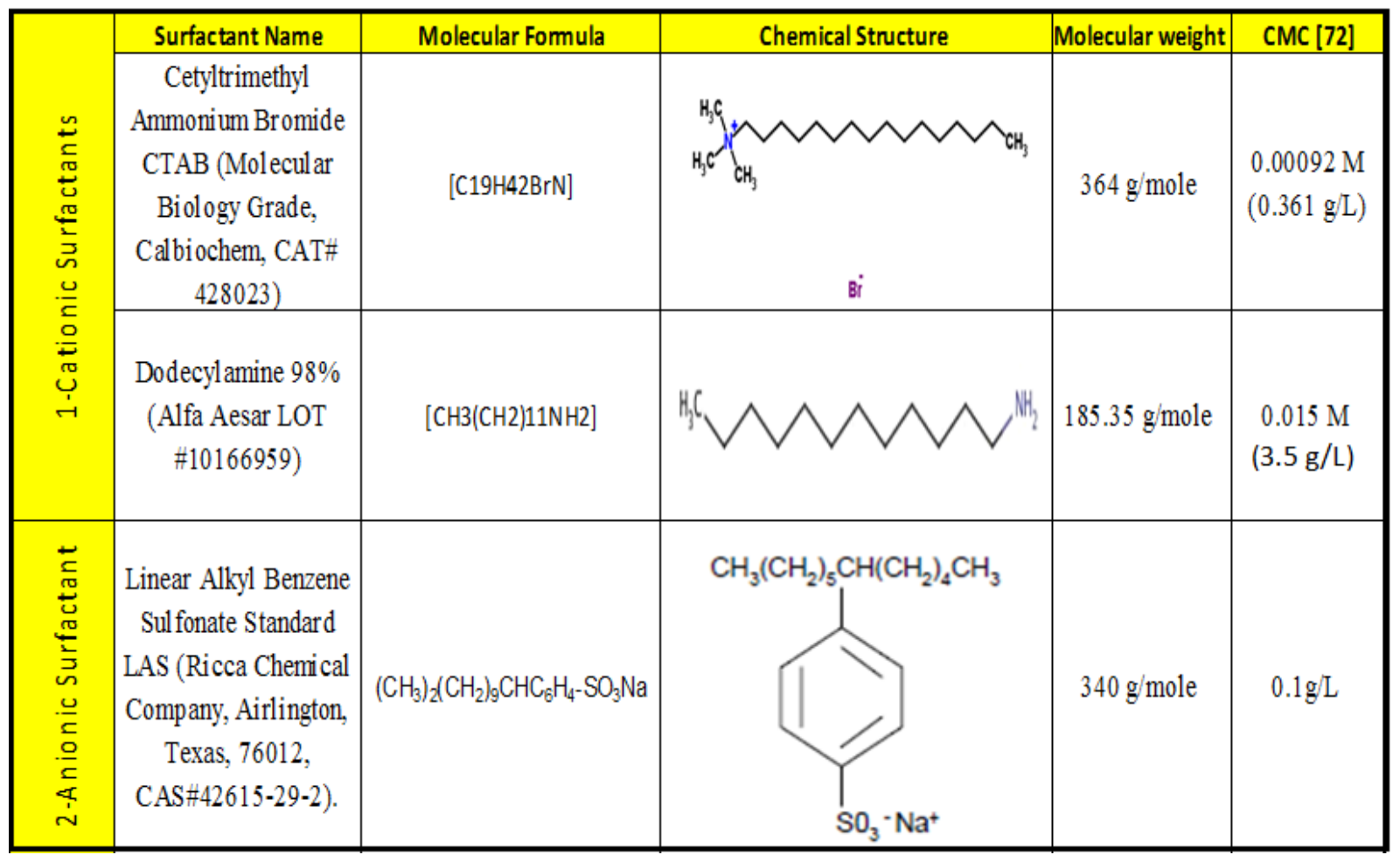




\section{APPENDIX F SPECIFIC POWER CONSUMPTION}

$\begin{aligned} \text { Specific power consumption }\left[\frac{k W h}{m^{3}}\right] & =\frac{\overline{\mathrm{TMP}}_{A V G}[\mathrm{psi} . \mathrm{min}] * \mathrm{Q}[\mathrm{LPM}] * 0.264 \frac{[\mathrm{GPM}]}{[\mathrm{LPM}]}}{\overline{\mathrm{V}}_{\mathrm{s}}\left[\mathrm{m}^{3}\right] * 1714 \frac{[\mathrm{psi} . \mathrm{GPM}]}{[\mathrm{HP}]}} \\ & =1.54 \times 10^{-4} \frac{[\mathrm{HP} . \mathrm{min}] * 746 \frac{[\mathrm{W} . \mathrm{min}]}{[\mathrm{HP} . \mathrm{min}]}}{\left[\mathrm{m}^{3}\right]} \\ & =0.115 \frac{[\mathrm{W} \cdot \mathrm{min}]}{\left[\mathrm{m}^{3}\right] * 60 * 1000 \frac{[\mathrm{W} . \mathrm{min}]}{[\mathrm{kW} . \mathrm{hr}]}} \\ & =1.916 \times 10^{-6} \times \frac{\overline{\mathrm{TMP}}_{A V G}[\mathrm{psi.min}] * \mathrm{Q}[\mathrm{LPM}]}{\overline{\mathrm{V}}_{S}\left[\mathrm{~m}^{3}\right]}\end{aligned}$ 


\section{APPENDIX G \\ PORE SIZE DISTRIBUTION OF DIFFERENT NON-UNIFORM PORE SIZE MEMBRANES}

The non-uniform pore size distribution of the heterogeneous membranes was estimated using the ImageJ software. The membranes consist of multilayers featuring pores in a non-linear alignment. The SEM images with higher magnification and set at random positions along the membrane's surface were used to ascertain the accuracy of the obtained pore size distribution. Figure G.1 presented SEM images of the heterogeneous membrane surfaces applied to the software. On the other hand Figure G.2 presented SEM image of the exact pores obtained using the software for the estimation of the pore size distribution. The pore size distribution of Ultrafilic, cellulose acetate, and PVDF membranes, are presented in Figure G.3. (a), (b), and (c), respectively. The Polysulfone membrane had ten non-uniform pore sizes, i.e. $N=10$, while the Ultrafilic, cellulose acetate, and PVDF had eight non-uniform pore sizes, i.e. $N=8$.

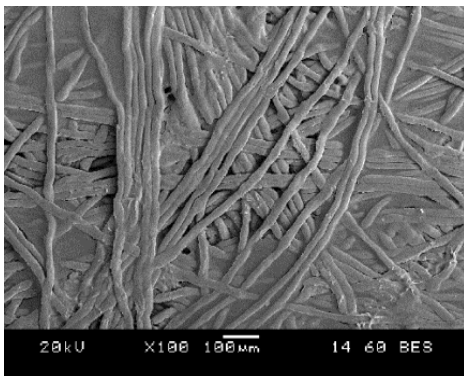

(a)

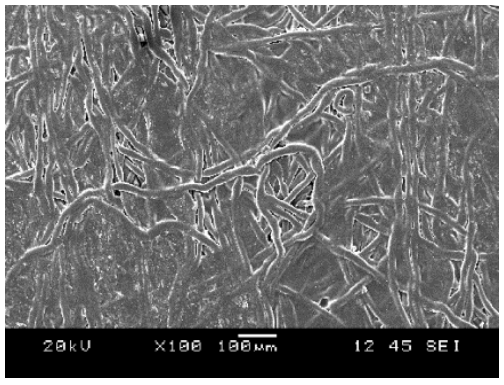

(b)

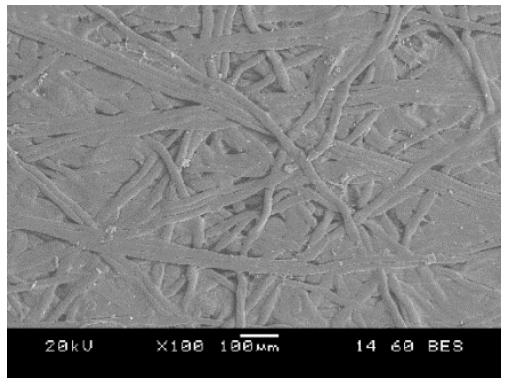

(c)

Figure G.1. SEM images of the membrane used for the validation of the models of fouling attachments (a) Ultrafilic membrane; (b) Cellulose Acetate membrane; and (c) PVDF membrane

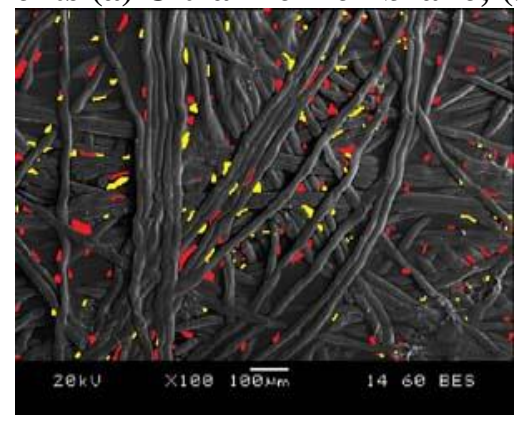

(a)

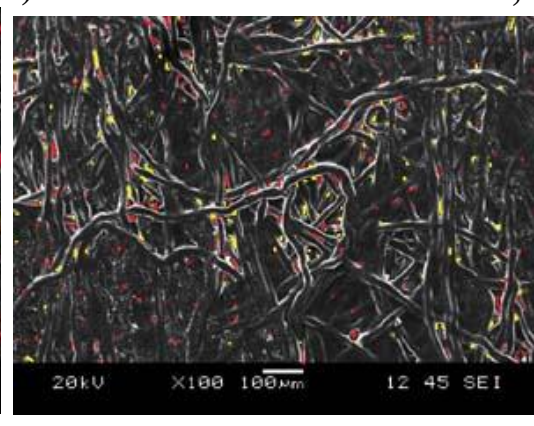

(b)

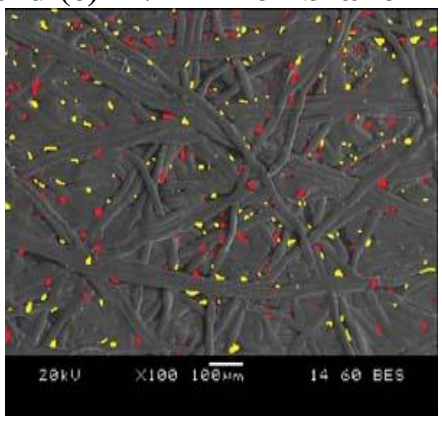

(c)

Figure G.2. SEM image of the exact pores obtained using the software for the estimation of the pore size distribution (a) Ultrafilic membrane; (b) Cellulose Acetate membrane; and (c) PVDF membrane 


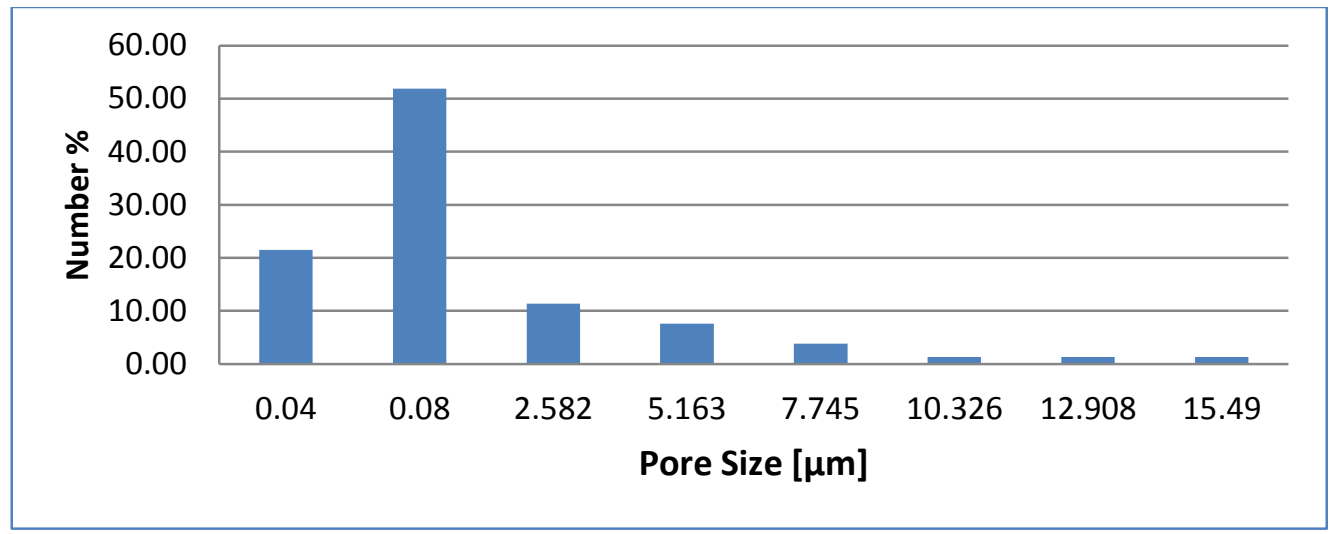

(a)

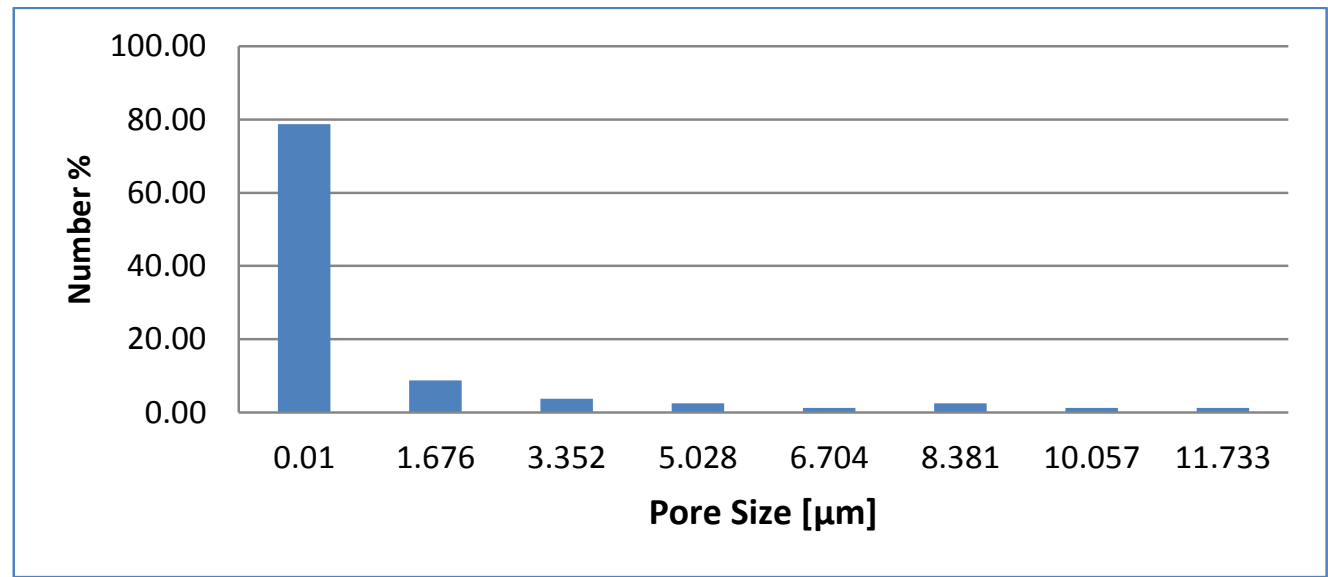

(b)

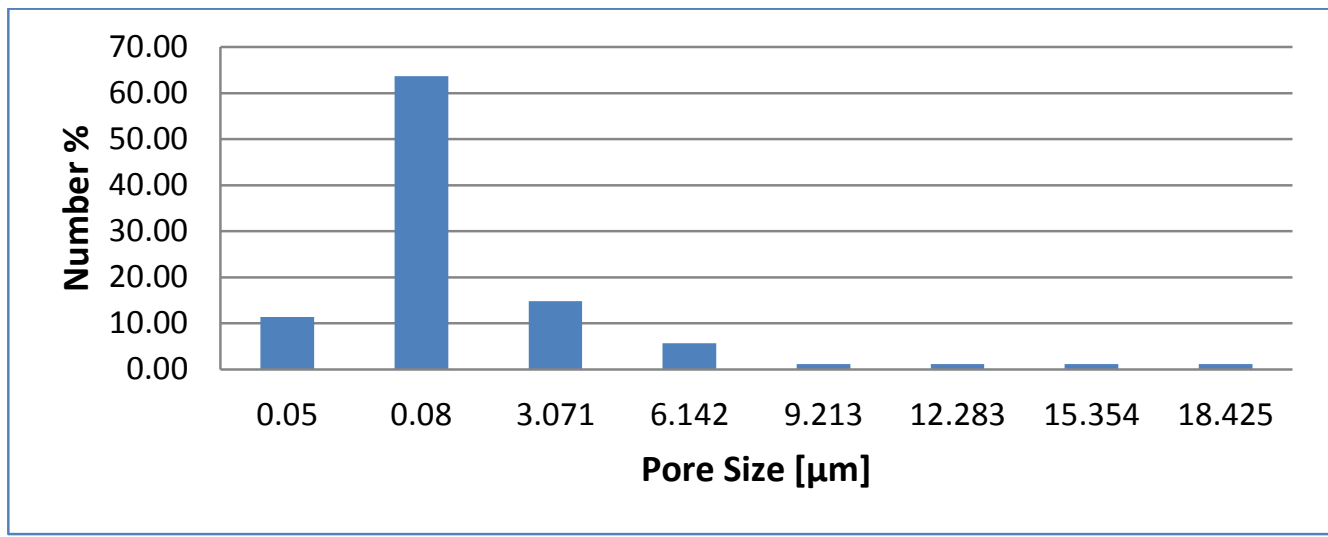

(c)

Figure G.3. The pore size distribution (a) Ultrafilic membrane, (b) cellulose acetate membrane, and (c) PVDF membrane 


\section{APPENDIX H Cross Flow Velocity \& REYNOLDS Number}

Reynolds Number of the flow can be calculated from equation (H.1) .Values of Reynolds number at different flow rate shown in Table (H.1) which all represents laminar flow.

$\operatorname{Re}=\frac{\rho \vee L}{\mu}=\frac{\rho Q L}{A \mu}$

Equation (H.1)

Where $\rho$ is the fluid, density $=1000 \mathrm{~kg} / \mathrm{m}^{3}, \mathrm{~V}$ is the fluid velocity, Q is the feed flow rate, $\mathrm{A}$ is the cross sectional area, $\mu$ is the fluid viscosity $=0.001 \mathrm{Ns} / \mathrm{m}^{2}, \mathrm{~L}$ is characteristic length which can be calculated from equation (H.2)

$\mathrm{L}=\frac{4 \mathrm{~A}}{\mathrm{P}}$

Equation (H.2)

Where $\mathrm{P}$ is the wetted perimeter

Table H.1. Cross flow velocity \& Reynolds Number of various feed flow rates

\begin{tabular}{|c|c|c|}
\hline Q [LPM] & $\begin{array}{c}\text { Cross Flow } \\
\text { Velocity }(v) \\
{[\mathrm{cm} / \mathrm{s}]}\end{array}$ & $\operatorname{Re}$ \\
\hline 1 & 10.42 & 23.02 \\
\hline 2 & 20.83 & 46.04 \\
\hline 3 & 31.25 & 69.06 \\
\hline 4 & 41.67 & 92.08 \\
\hline 5 & 52.08 & 115.1 \\
\hline 6 & 62.50 & 138.12 \\
\hline
\end{tabular}




\section{APPENDIX I \\ STABILITY OF TREATED MEMBRANE SURFACES AFTER THE ULTRAFILTRATION PROCESS}

\section{I.1. Stability of the treated membrane surface using pH treatment after the UF process}

Polysulfone membrane has an original zeta potential of $-42.40 \mathrm{mV}$. In part of this study, thirty experimental runs of CCC experimental design were performed at different zeta potential values of the membrane surface. It was necessary to check the zeta potential of the treated membrane after the ultrafiltration process in order to ensure the stability of the surface charge throughout the filtration process, as depicted in Figure I.1.

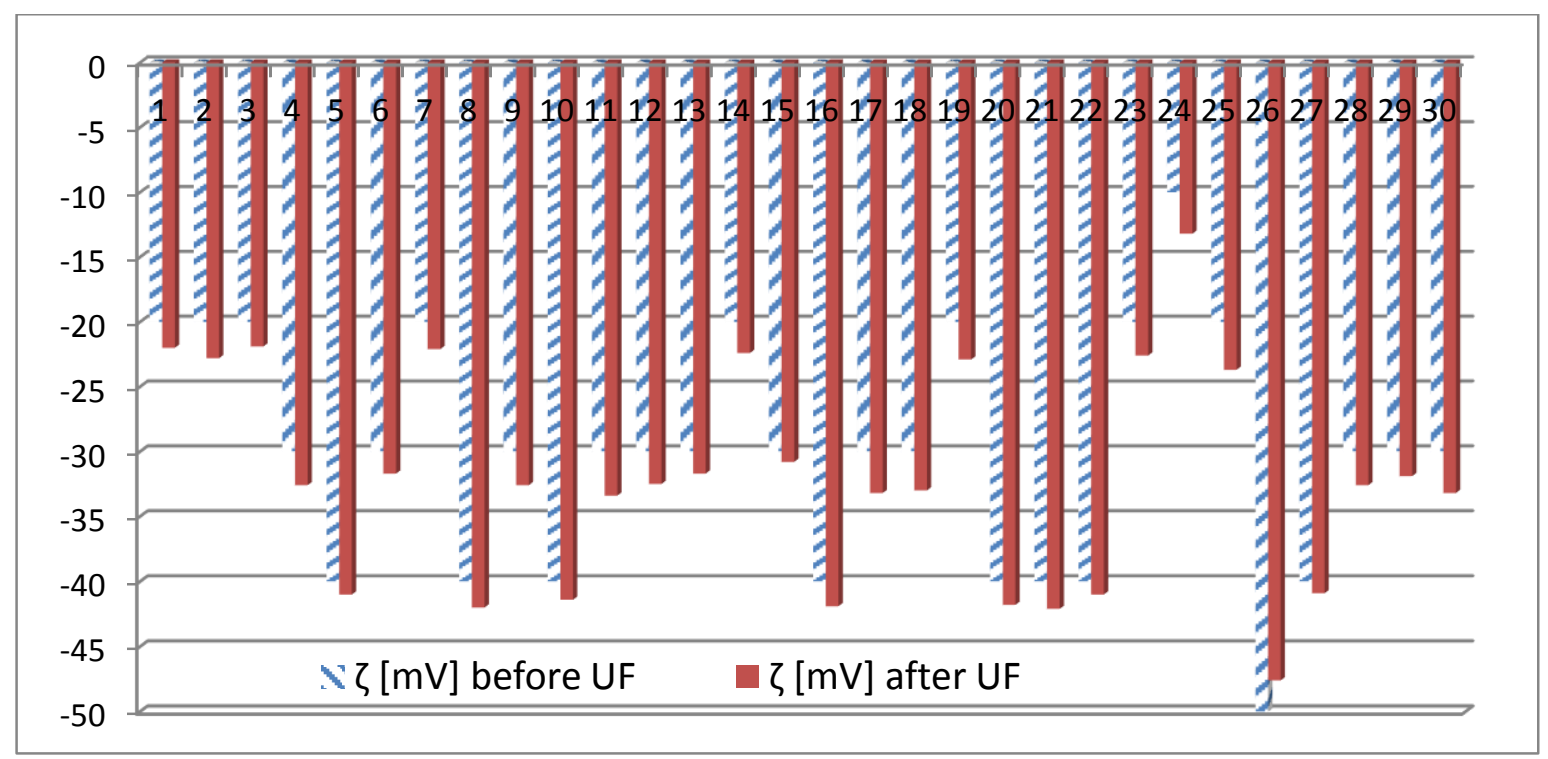

Figure I.1: The zeta potential of Polysulfone membrane surface before and after ultrafiltration process

Polysulfone membrane zeta potentials of $-10.00 \mathrm{mV},-20.00 \mathrm{mV},-30.00 \mathrm{mV},-40.00 \mathrm{mV}$, and $-50.00 \mathrm{mV}$, were respectively changed to the average zeta potentials of $-13.20 \mathrm{mV},-22.50$ $\mathrm{mV},-32.40 \mathrm{mV},-41.50 \mathrm{mV}$, and $-47.60 \mathrm{mV}$ after the ultrafiltration process. The simulated latex effluent had a $\mathrm{pH}$ of 7 , which would affect the membrane surface charge during filtration. The zeta potential of Polysulfone membrane was $-42.40 \mathrm{mV}$ at $\mathrm{pH}$ of 7 . It was observed that in the case of the treated Polysulfone membrane with a lower negativity, whenever the latex solution was allowed to go through the membrane for 25 minutes, the negativity of the zeta potential of 
membrane surface increased by 2.00 to $3.00 \mathrm{mV}$. On the other hand, for the treated Polysulfone membranes with a negativity charge higher than the original zeta potential value, ultrafiltration of latex solution caused a reduction of the negative charge on the membrane surface from -50 $\mathrm{mV}$ to $-47.6 \mathrm{mV}$. This can be attributed to the influence of the ionic strength of simulated latex effluent at $\mathrm{pH}$ of 7 on the zeta potential of the treated membrane surfaces at higher $\mathrm{pH}$ values. Similarly, Ultrafilic membrane with zeta potentials of $-15.00 \mathrm{mV}$ and $-30.00 \mathrm{mV}$ were also changed to $-16.50 \mathrm{mV}$ and $-31.20 \mathrm{mV}$, respectively, after 25 minute of ultrafiltration with latex solution.

\section{I .2. Stability of the treated membrane surface using anionic surfactant treatment after the UF process}

On the other hand, the surface charge of the treated membranes using anionic surfactant was stable enough after the ultrafiltration of simulated latex effluent of $\mathrm{pH}$ of 7 . As such, the surface charge negativity of the treated PVDF membrane was decreased only by $18.00 \%$ from 40.90 to -33.27 after 25 minutes of filtration time, if compared to the significant enhancement of the surface charge negativity of around 16 times from $-2.50 \mathrm{mV}$ to $-40.90 \mathrm{mV}$ after the 20 minutes of membrane treatment. Moreover, the surface charge negativity of treated ultrafilic membrane was decreased by $4.60 \%$ from $-50.67-48.34$ after 25 minutes of filtration time, if compared to the increased surface charge negativity by $22.10 \%$ from $-41.50 \mathrm{mV}$ to $-50.67 \mathrm{mV}$ after 15 minutes of membrane treatment. 


\section{APPENDIX J EXPERIMENTAL REPRODUCIBILITY}

The Standard deviation can be calculated as the square root of the mean of the squared variance, $\sigma_{S d}^{2}$ (Douglas et al., 2007; Sheskin, 2011), as shown in Equation J.1

$S T D E V=\sqrt{\frac{\sum_{i=1}^{N_{s d}\left(x_{i}-\mu_{s d}\right)^{2}}}{N_{s d}-1}}$ Equation (J.1)

Where $\sigma_{s d}$ is the standard deviation, $N_{s d}$ is the number of repeated data, $x_{i}$ is the individual value of each repeated experiment, and $\mu_{s d}$ is the number mean value of the results obtained.

The confidence interval used to express the degree of uncertainty associated with the data. The experimental run was repeated in order to verify the precision of the results with $95 \%$ of confidence level of the normal distribution curve, as shown in Figure (J.1) (Douglas et al., 2007; Sheskin, 2011). Hence, the probability of observing values outside of this area is less than 0.05 . The confidence can be calculated using Equation (J.2)

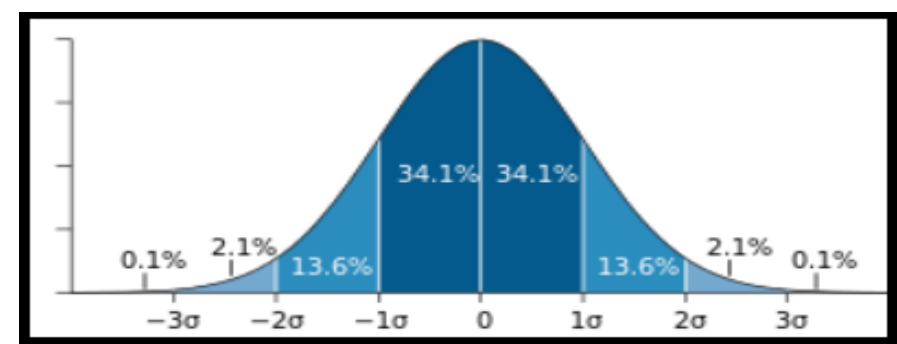

Figure J.1: Normal distribution curve

Confidence $(C F)=\mu_{s d} \pm Z_{c}\left(\frac{S T D E V}{\sqrt{N_{S d}}}\right)$

Equation (J.2)

where $Z_{c}$ is a constant equal 1.96 in case of $95 \%$ confidence level. 
Table J.1. Model validation errors for the Polycarbonate membrane at different operating conditions using simulated latex effluent

\begin{tabular}{|c|c|c|c|c|c|c|c|c|c|c|c|}
\hline $\begin{array}{c}\text { Pore } \\
\text { Size } \\
{[\mu \mathrm{m}]}\end{array}$ & $\begin{array}{l}\text { Initial } \\
\text { TMP } \\
\text { [psi] }\end{array}$ & $\begin{array}{c}C_{f} \\
{\left[\mathrm{~kg} / \mathrm{m}^{3}\right]}\end{array}$ & $\begin{array}{c}\mathbf{Q} \\
{[\mathrm{LPM}]}\end{array}$ & $\begin{array}{c}V_{s 1} \\
{\left[\mathrm{~m}^{3} / \mathrm{m}^{2}\right]}\end{array}$ & $\begin{array}{c}V_{s 2} \\
{\left[\mathrm{~m}^{3} / \mathrm{m}^{2}\right]}\end{array}$ & $\begin{array}{c}V_{s 3} \\
{\left[\mathrm{~m}^{3} / \mathrm{m}^{2}\right]}\end{array}$ & $\begin{array}{c}V_{s 4} \\
{\left[m^{3} / m^{2}\right]}\end{array}$ & $\begin{array}{c}V_{s \text { mean }} \\
{\left[\mathrm{m}^{3} / \mathrm{m}^{2}\right]}\end{array}$ & STDEV & CF & $\begin{array}{c}V_{s} \\
{\left[\mathrm{~m}^{3} / \mathrm{m}^{2}\right]}\end{array}$ \\
\hline 0.1 & 3 & 1.3 & 1 & 0.007 & 0.0071 & 0.0073 & 0.0068 & 0.007 & 0.0002 & 0.0002 & $0.007 \pm 0.0002$ \\
\hline 0.1 & 4 & 1.3 & 2 & 0.04 & 0.042 & 0.041 & 0.038 & 0.040 & 0.0015 & 0.0014 & $0.04 \pm 0.0014$ \\
\hline 0.1 & 5 & 1.3 & 3 & 0.064 & 0.062 & 0.0635 & 0.065 & 0.064 & 0.0011 & 0.0011 & $0.064 \pm 0.0011$ \\
\hline 0.1 & 4 & 1.82 & 1 & 0.007 & 0.008 & 0.007 & 0.006 & 0.007 & 0.0007 & 0.0007 & $0.007 \pm 0.0007$ \\
\hline 0.1 & 3 & 1.3 & 1 & 0.007 & 0.0085 & 0.0065 & 0.007 & 0.007 & 0.0008 & 0.0007 & $0.007 \pm 0.0007$ \\
\hline 0.1 & 2 & 0.78 & 1 & 0.007 & 0.0075 & 0.0085 & 0.0065 & 0.007 & 0.0007 & 0.0007 & $0.007 \pm 0.0007$ \\
\hline 0.05 & 11 & 1.3 & 4 & 0.007 & 0.007 & 0.008 & 0.006 & 0.007 & 0.0007 & 0.0007 & $0.007 \pm 0.0007$ \\
\hline 0.05 & 4 & 1.3 & 2 & 0.0189 & 0.019 & 0.0188 & 0.0189 & 0.019 & 0.0001 & 0.0001 & $0.0189 \pm 0.0001$ \\
\hline
\end{tabular}

\begin{tabular}{|c|c|c|c|c|c|c|c|c|c|c|c|c|c|c|}
\hline $\begin{array}{c}\text { Pore } \\
\text { Size } \\
{[\mu \mathrm{m}]}\end{array}$ & $\begin{array}{c}\text { Initial } \\
\text { TMP } \\
\text { [psi] }\end{array}$ & $\begin{array}{c}C_{f} \\
{\left[\mathrm{~kg} / \mathrm{m}^{3}\right]}\end{array}$ & $\begin{array}{c}Q \\
\text { [LPM] }\end{array}$ & $\begin{array}{c}\text { Exp } \\
\text { Increase } \\
\text { in TMP } \\
1 \\
\end{array}$ & $\begin{array}{c}\text { Exp } \\
\text { Increase } \\
\text { in TMP } \\
2 \\
\end{array}$ & $\begin{array}{c}\text { Exp } \\
\text { Increase } \\
\text { in TMP } \\
\mathbf{3} \\
\end{array}$ & $\begin{array}{c}\text { Exp } \\
\text { Increase } \\
\text { in TMP } \\
4 \\
\end{array}$ & $\begin{array}{c}\text { Exp } \\
\text { Increase } \\
\text { in TMP } \\
\text { Mean } \\
\end{array}$ & STDEV & CF & $\begin{array}{c}\text { Exp } \\
\text { Increase } \\
\text { in TMP }\end{array}$ & $\begin{array}{l}\text { Increase } \\
\text { in TMP } \\
\text { Predicted }\end{array}$ & $\begin{array}{c}\text { Error } \\
\%\end{array}$ & Error \% \\
\hline 0.1 & 3 & 1.3 & 1 & 7 & 7.3 & 7.1 & 6.6 & 7 & 0.2550 & 0.2 & $7 \pm 0.2$ & 6.63 & -5.3 & $-5.3 \pm 0.2$ \\
\hline 0.1 & 4 & 1.3 & 2 & 20 & 21 & 22 & 17 & 20 & 1.8708 & 1.8 & $20 \pm 1.8$ & 18.69 & -6.5 & $-6.5 \pm 1.8$ \\
\hline 0.1 & 5 & 1.3 & 3 & 29 & 27 & 30 & 30 & 29 & 1.2247 & 1.2 & $29 \pm 1.2$ & 27.47 & -5.3 & $-5.3 \pm 1.2$ \\
\hline 0.1 & 4 & 1.82 & 1 & 8 & 8 & 10 & 6 & 8 & 1.4142 & 1.4 & $8 \pm 1.4$ & 7.58 & -5.3 & $-5.3 \pm 1.4$ \\
\hline 0.1 & 3 & 1.3 & 1 & 7 & 7 & 8 & 6 & 7 & 0.7071 & 0.7 & $7 \pm 0.7$ & 6.63 & -5.3 & $-5.3 \pm 0.7$ \\
\hline 0.1 & 2 & 0.78 & 1 & 6 & 7 & 6 & 5 & 6 & 0.7071 & 0.7 & $6 \pm 0.7$ & 5.54 & -7.7 & $-7.7 \pm 0.7$ \\
\hline 0.05 & 11 & 1.3 & 4 & 5 & 6 & 4 & 5 & 5 & 0.7071 & 0.7 & $5 \pm 0.7$ & 4.7 & -6.0 & $-6.0 \pm 0.7$ \\
\hline 0.05 & 4 & 1.3 & 2 & 10 & 9 & 10 & 11 & 10 & 0.7071 & 0.7 & $10 \pm 0.7$ & 7.38 & -7.7 & $-7.7 \pm 0.7$ \\
\hline
\end{tabular}

The increase in transmembrane pressure throughout the filtration time of 25 minutes. 
Table J.2. Model validation errors using Polysulfone heterogeneous membrane at different operating conditions using latex effluent.

\begin{tabular}{|c|c|c|c|c|c|c|c|c|c|c|c|c|c|c|c|c|}
\hline $\begin{array}{c}\text { Initial } \\
\text { TMP } \\
\text { [psi] }\end{array}$ & $\begin{array}{c}\mathrm{C}_{\mathrm{f}} \\
{\left[\mathrm{kg} / \mathrm{m}^{3}\right]}\end{array}$ & $\begin{array}{c}\mathbf{Q} \\
\text { [LPM] }\end{array}$ & $\begin{array}{c}V_{s 1} \\
{\left[\mathrm{~m}^{3} / \mathrm{m}^{2}\right]}\end{array}$ & $\begin{array}{c}V_{\mathrm{s} 2} \\
{\left[\mathrm{~m}^{3} / \mathrm{m}^{2}\right]}\end{array}$ & $\begin{array}{c}V_{\mathrm{s3}} \\
{\left[\mathrm{m}^{3} / \mathrm{m}^{2}\right]}\end{array}$ & $\begin{array}{c}V_{s 4} \\
{\left[\mathrm{~m}^{3} / \mathrm{m}^{2}\right]}\end{array}$ & $\begin{array}{c}V_{s \text { mean }} \\
{\left[\mathrm{m}^{3} / \mathrm{m}^{2}\right]}\end{array}$ & STDEV & CF & $\begin{array}{c}m_{t} 1 \\
{[g]}\end{array}$ & $\begin{array}{c}m_{t} 2 \\
{[g]}\end{array}$ & $\begin{array}{c}m_{t} 3 \\
{[g]}\end{array}$ & $\begin{array}{c}m_{t} 4 \\
{[g]}\end{array}$ & $\begin{array}{c}\mathrm{m}_{\mathrm{t}} \\
\text { mean } \\
{[\mathrm{g}]}\end{array}$ & STDEV & CF \\
\hline 25 & 0.78 & 4 & 0.0142 & 0.0144 & 0.0142 & 0.014 & 0.0142 & 0.0001 & 0.0001 & 0.2464 & 0.2464 & 0.2466 & 0.2462 & 0.2464 & 0.0001 & 0.0001 \\
\hline 25 & 1.3 & 4 & 0.0114 & 0.0115 & 0.0113 & 0.0114 & 0.0114 & 0.0001 & 0.0001 & 0.3024 & 0.3022 & 0.3024 & 0.3026 & 0.3024 & 0.0001 & 0.0001 \\
\hline 25 & 1.82 & 4 & 0.0092 & 0.0092 & 0.0095 & 0.009 & 0.0092 & 0.0002 & 0.0002 & 0.3741 & 0.3744 & 0.3738 & 0.3741 & 0.3741 & 0.0002 & 0.0002 \\
\hline 15 & 1.3 & 4 & 0.0089 & 0.0091 & 0.0089 & 0.0087 & 0.0089 & 0.0001 & 0.0001 & 0.2554 & 0.2554 & 0.2557 & 0.2551 & 0.2554 & 0.0002 & 0.0002 \\
\hline 35 & 1.3 & 4 & 0.0138 & 0.0138 & 0.0139 & 0.00137 & 0.0107 & 0.0054 & 0.0053 & 0.3987 & 0.399 & 0.3987 & 0.3984 & 0.3987 & 0.0002 & 0.0002 \\
\hline 25 & 1.3 & 1 & 0.0064 & 0.0067 & 0.0061 & 0.0064 & 0.0064 & 0.0002 & 0.0002 & 0.4368 & 0.4369 & 0.4367 & 0.4368 & 0.4368 & 0.0001 & 0.0001 \\
\hline
\end{tabular}

\begin{tabular}{|c|c|c|c|c|c|c|c|c|c|c|c|c|c|}
\hline $\begin{array}{l}\text { Initial } \\
\text { TMP } \\
\text { [psi] }\end{array}$ & $\begin{array}{c}C_{f} \\
{\left[\mathrm{~kg} / \mathrm{m}^{3}\right]}\end{array}$ & $\underset{[\mathrm{LPM}]}{\mathbf{Q}}$ & $\begin{array}{c}\text { Exp } \\
\text { Increase } \\
\text { in TMP } \\
1\end{array}$ & $\begin{array}{c}\text { Exp } \\
\text { Increase } \\
\text { in TMP } \\
2\end{array}$ & $\begin{array}{c}\text { Exp } \\
\text { Increase } \\
\text { in TMP } \\
3\end{array}$ & $\begin{array}{c}\text { Exp } \\
\text { Increase } \\
\text { in TMP } \\
4\end{array}$ & $\begin{array}{c}\text { Exp } \\
\text { Increase } \\
\text { in TMP } \\
\text { Mean }\end{array}$ & STDEV & CF & $\begin{array}{c}\text { Exp } \\
\text { Increase } \\
\text { in TMP }\end{array}$ & $\begin{array}{c}\text { Increase } \\
\text { in TMP } \\
\text { Predicted }\end{array}$ & $\begin{array}{c}\text { Erro } \\
r \%\end{array}$ & Error \% \\
\hline 25 & 0.78 & 4 & 3 & 3.2 & 2.8 & 3 & 3 & 0.1414 & 0.1 & $3 \pm 0.1$ & 3.32 & 10.7 & $10.7 \pm 0.1$ \\
\hline 25 & 1.3 & 4 & 5.5 & 5.6 & 5.5 & 5.4 & 5.5 & 0.0707 & 0.1 & $5.5 \pm 0.1$ & 6.14 & 11.6 & $11.6 \pm 0.1$ \\
\hline 25 & 1.82 & 4 & 7 & 7 & 6.8 & 7.2 & 7 & 0.1414 & 0.1 & $7 \pm 0.1$ & 7.77 & 11.0 & $11.0 \pm 0.1$ \\
\hline 15 & 1.3 & 4 & 3.5 & 3.3 & 3.5 & 3.7 & 3.5 & 0.1414 & 0.1 & $3.5 \pm 0.1$ & 3.88 & 10.9 & $10.9 \pm 0.1$ \\
\hline 35 & 1.3 & 4 & 7.5 & 7.7 & 7.3 & 7.5 & 7.5 & 0.1414 & 0.1 & $7.5 \pm 0.1$ & 8.23 & 9.7 & $9.7 \pm 0.1$ \\
\hline 25 & 1.3 & 1 & 8 & 8 & 8.2 & 7.8 & 8 & 0.1414 & 0.1 & $8 \pm 0.1$ & 8.99 & 12.4 & $12.4 \pm 0.1$ \\
\hline
\end{tabular}


Table J.3. Validation errors of the Attachment Models with different Heterogeneous Membranes

\begin{tabular}{|c|c|c|c|c|c|c|c|c|c|c|c|c|c|c|}
\hline $\begin{array}{c}\text { Membrane } \\
\text { Material }\end{array}$ & $\begin{array}{l}\text { TMP } \\
{[\mathrm{psi}]}\end{array}$ & $\begin{array}{c}\mathrm{Q} \\
\text { [LPM] }\end{array}$ & $\begin{array}{c}\mathrm{C}_{\mathrm{f}} \\
{\left[\mathrm{kg} / \mathrm{m}^{3}\right]}\end{array}$ & $\stackrel{\zeta}{[\mathrm{mV}]}$ & $\begin{array}{c}\text { Pred. }^{*} m_{t} \\
{[\mathrm{~kg} / \mathrm{m} 2]}\end{array}$ & $\begin{array}{l}\operatorname{Exp} m_{t} \\
{[\mathrm{~kg} / \mathrm{m} 2]}\end{array}$ & $\begin{array}{c}\operatorname{Exp} m_{t} 2 \\
{[\mathrm{~kg} / \mathrm{m} 2]}\end{array}$ & $\begin{array}{l}\operatorname{Exp} m_{t} 3 \\
{[\mathrm{~kg} / \mathrm{m} 2]}\end{array}$ & $\begin{array}{l}\text { Exp } m_{t} 4 \\
{[\mathrm{~kg} / \mathrm{m} 2]}\end{array}$ & $\begin{array}{l}\text { Exp } m_{t} \\
\text { Mean } \\
{[\mathrm{kg} / \mathrm{m} 2]}\end{array}$ & STDEV & $\mathrm{CF}$ & $\begin{array}{c}\text { Error } \\
\%\end{array}$ & Error \% \\
\hline Polysulfone & 25 & 7.5 & 1.30 & $\begin{array}{c}- \\
25.00\end{array}$ & 0.0123 & 0.0120 & 0.0122 & 0.0120 & 0.0118 & 0.0120 & 0.0001 & 0.0001 & 2.5 & $2.5 \pm 0.0001$ \\
\hline Polysulfone & 15 & 4.0 & 1.30 & 10.00 & 0.0155 & 0.0167 & 0.0170 & 0.0164 & 0.0167 & 0.0167 & 0.0002 & 0.0002 & -7.2 & $-7.2 \pm 0.0002$ \\
\hline Polysulfone & 25 & 4.0 & 0.78 & $\begin{array}{c}- \\
42.40 \\
\end{array}$ & 0.0120 & 0.0110 & 0.0110 & 0.0130 & 0.0090 & 0.0110 & 0.0014 & 0.0014 & 9.1 & $9.1 \pm 0.0014$ \\
\hline Polysulfone & 15 & 6.0 & 1.82 & 15.00 & 0.0143 & 0.0155 & 0.0155 & 0.0156 & 0.0154 & 0.0155 & 0.0001 & 0.0001 & -7.7 & $-7.7 \pm 0.0001$ \\
\hline Polysulfone & 25 & 4.5 & 1.30 & 28.00 & 0.0155 & 0.0158 & 0.0160 & 0.0158 & 0.0156 & 0.0158 & 0.0001 & 0.0001 & -1.6 & $-1.6 \pm 0.0001$ \\
\hline $\begin{array}{l}\text { cellulose } \\
\text { acetate }\end{array}$ & 25 & 4.5 & 1.30 & $\begin{array}{c}- \\
33.90 \\
\end{array}$ & 0.0064 & 0.0061 & 0.0062 & 0.0060 & 0.0061 & 0.0061 & 0.0001 & 0.0001 & 4.9 & $4.9 \pm 0.0001$ \\
\hline Ultrafilic & 25 & 4.5 & 2.34 & $\begin{array}{c}- \\
41.50 \\
\end{array}$ & 0.0294 & 0.0285 & 0.0285 & 0.0284 & 0.0286 & 0.0285 & 0.0001 & 0.0001 & 3.2 & $3.2 \pm 0.0001$ \\
\hline Ultrafilic & 15 & 7.0 & 1.30 & $\begin{array}{c}- \\
41.50 \\
\end{array}$ & 0.0080 & 0.0086 & 0.0088 & 0.0086 & 0.0084 & 0.0086 & 0.0001 & 0.0001 & -7.0 & $-7.0 \pm 0.0001$ \\
\hline PVDF & 15 & 4.0 & 0.78 & -2.50 & 0.0120 & 0.0125 & 0.0123 & 0.0127 & 0.0125 & 0.0125 & 0.0001 & 0.0001 & -4.0 & $-4.0 \pm 0.0001$ \\
\hline PVDF & 15 & 7.0 & 1.30 & -2.50 & 0.0123 & 0.0134 & 0.0134 & 0.0135 & 0.0133 & 0.0134 & 0.0001 & 0.0001 & -8.2 & $-8.2 \pm 0.0001$ \\
\hline PVDF & 20 & 4.0 & 0.26 & -2.50 & 0.09 & 0.105 & 0.107 & 0.105 & 0.103 & 0.1050 & 0.0014 & 0.0014 & -14.3 & $-14.3 \pm 0.0014$ \\
\hline
\end{tabular}




\begin{tabular}{|c|c|c|c|c|c|c|c|c|c|c|c|c|c|c|}
\hline $\begin{array}{l}\text { Membrane } \\
\text { Material }\end{array}$ & $\begin{array}{l}\text { TMP } \\
\text { [psi] }\end{array}$ & $\begin{array}{c}\mathrm{Q} \\
\text { [LPM] }\end{array}$ & $\begin{array}{c}\mathrm{C}_{\mathrm{f}} \\
{\left[\mathrm{kg} / \mathrm{m}^{3}\right]}\end{array}$ & $\stackrel{\zeta}{[\mathrm{mV}]}$ & $\begin{array}{l}\text { Pred.* } \\
\text { Increase } \\
\text { in TMP }\end{array}$ & $\begin{array}{l}\text { Exp. } \\
\text { Increase in } \\
\text { TMP }\end{array}$ & $\begin{array}{c}\text { Exp. } \\
\text { Increase } \\
\text { in TMP } 2\end{array}$ & $\begin{array}{c}\text { Exp. } \\
\text { Increase } \\
\text { in TMP } 3\end{array}$ & $\begin{array}{c}\text { Exp. } \\
\text { Increase } \\
\text { in TMP } 4\end{array}$ & $\begin{array}{c}\text { Exp. } \\
\text { Increase } \\
\text { in TMP } \\
\text { Mean }\end{array}$ & STDEV & CF & $\begin{array}{c}\text { Error } \\
\%\end{array}$ & Error \% \\
\hline Polysulfone & 25 & 7.5 & 1.30 & $\begin{array}{c}- \\
25.00 \\
\end{array}$ & 3.70 & 4.0 & 3.8 & 4.0 & 4.2 & 4.0 & 0.1414 & 0.14 & -7.5 & $-7.5 \pm 0.14$ \\
\hline Polysulfone & 15 & 4.0 & 1.30 & 10.00 & 5.95 & 6.5 & 6.5 & 6.3 & 6.7 & 6.5 & 0.1414 & 0.14 & -8.5 & $-8.5 \pm 0.14$ \\
\hline Polysulfone & 25 & 4.0 & 0.78 & $\begin{array}{c}- \\
42.40\end{array}$ & 3.77 & 3.5 & 4.5 & 2.5 & 3.5 & 3.5 & 0.7071 & 0.69 & 7.7 & $7.7 \pm 0.69$ \\
\hline Polysulfone & 15 & 6.0 & 1.82 & $\begin{array}{c}- \\
15.00 \\
\end{array}$ & 6.45 & 6.0 & 6.2 & 6.0 & 5.8 & 6.0 & 0.1414 & 0.14 & 7.5 & $7.5 \pm 0.14$ \\
\hline Polysulfone & 25 & 4.5 & 1.30 & $\begin{array}{c}- \\
28.00 \\
\end{array}$ & 5.46 & 6.0 & 6.1 & 5.9 & 6.0 & 6.0 & 0.0707 & 0.07 & -9.0 & $-9.0 \pm 0.07$ \\
\hline $\begin{array}{c}\text { cellulose } \\
\text { acetate }\end{array}$ & 25 & 4.5 & 1.30 & $\begin{array}{c}- \\
33.90 \\
\end{array}$ & 1.62 & 1.5 & 1.5 & 1.7 & 1.3 & 1.5 & 0.1414 & 0.14 & 8.0 & $8.0 \pm 0.14$ \\
\hline Ultrafilic & 25 & 4.5 & 2.34 & $\begin{array}{c}- \\
41.50 \\
\end{array}$ & 10.78 & 10.0 & 11.0 & 10.0 & 9.0 & 10.0 & 0.7071 & 0.69 & 7.8 & $7.8 \pm 0.69$ \\
\hline Ultrafilic & 15 & 7.0 & 1.30 & $\begin{array}{c}- \\
41.50 \\
\end{array}$ & 2.20 & 2.0 & 3.0 & 1.0 & 2.0 & 2.0 & 0.7071 & 0.69 & 10.0 & $10.0 \pm 0.69$ \\
\hline PVDF & 15 & 4.0 & 0.78 & -2.50 & 4.37 & 4.0 & 3.5 & 4.5 & 4.0 & 4.0 & 0.3536 & 0.35 & 9.3 & $9.3 \pm 0.35$ \\
\hline PVDF & 15 & 7.0 & 1.30 & -2.50 & 4.83 & 5.0 & 5.0 & 4.0 & 6.0 & 5.0 & 0.7071 & 0.69 & -3.4 & $-3.4 \pm 0.69$ \\
\hline PVDF & 20 & 4.0 & 0.26 & -2.50 & 3.51 & 4.0 & 4.0 & 3.0 & 5.0 & 4.0 & 0.7071 & 0.69 & -12.3 & $-12.3 \pm 0.69$ \\
\hline
\end{tabular}


Table J.4. Validation errors of the attachment model, incorporating the particles sphericity, applied to the homogeneous Polycarbonate membrane a) The model did not include the particles sphericity

\begin{tabular}{|c|c|c|c|c|c|c|c|c|c|c|c|c|c|c|}
\hline $\begin{array}{c}\text { Pore } \\
\text { size } \\
{[\mu \mathrm{m}]}\end{array}$ & $\begin{array}{l}\text { Initial } \\
\text { TMP } \\
\text { [Psi] }\end{array}$ & $\begin{array}{c}\mathrm{C}_{\mathrm{f}} \\
{\left[\mathrm{kg} / \mathrm{m}^{3}\right]}\end{array}$ & $\begin{array}{c}\mathrm{Q} \\
{[\mathrm{LPM}]}\end{array}$ & $\begin{array}{c}\mathrm{m}_{\mathrm{t}} \operatorname{Exp} \\
1 \\
{\left[\mathrm{~kg} / \mathrm{m}^{2}\right]}\end{array}$ & $\begin{array}{c}\mathrm{m}_{\mathrm{t}} \operatorname{Exp} \\
2 \\
{\left[\mathrm{~kg} / \mathrm{m}^{2}\right]}\end{array}$ & $\begin{array}{l}\mathrm{m}_{\mathrm{t}} \operatorname{Exp} 3 \\
{\left[\mathrm{~kg} / \mathrm{m}^{2}\right]}\end{array}$ & $\begin{array}{c}\mathrm{m}_{\mathrm{t}} \operatorname{Exp} \\
4 \\
{\left[\mathrm{~kg} / \mathrm{m}^{2}\right]}\end{array}$ & $\begin{array}{l}\mathrm{m}_{\mathrm{t}} \operatorname{Exp} \\
\text { Mean } \\
{\left[\mathrm{kg} / \mathrm{m}^{2}\right]}\end{array}$ & STDEV & $\mathrm{CF}$ & $\begin{array}{l}\mathrm{m}_{\mathrm{t}} \operatorname{Exp} \\
{\left[\mathrm{kg} / \mathrm{m}^{2}\right]}\end{array}$ & $\begin{array}{c}\mathrm{m}_{\mathrm{t}} \\
{\left[\mathrm{kg} / \mathrm{m}^{2}\right]} \\
\text { Predicted }\end{array}$ & $\begin{array}{c}\text { Error } \\
\%\end{array}$ & Error \% \\
\hline 0.1 & 3 & 1.3 & 1 & 0.1206 & 0.1200 & 0.1206 & 0.1212 & 0.1206 & 0.0004 & 0.0004 & $\begin{array}{c}0.1206 \pm \\
0.0004\end{array}$ & 0.109 & -9.6 & $-9.6 \pm 0.0004$ \\
\hline 0.1 & 4 & 1.3 & 2 & 0.0294 & 0.0291 & 0.0297 & 0.0294 & 0.0294 & 0.0002 & 0.0002 & $\begin{array}{c}0.0294 \pm \\
0.0002 \\
\end{array}$ & 0.026 & -11.5 & $-11.5 \pm 0.0002$ \\
\hline 0.1 & 5 & 1.3 & 3 & 0.0495 & 0.0495 & 0.0491 & 0.0499 & 0.0495 & 0.0003 & 0.0003 & $\begin{array}{c}0.0495 \pm \\
0.0003\end{array}$ & 0.055 & 11.1 & $11.1 \pm 0.0003$ \\
\hline 0.1 & 4 & 1.82 & 1 & 0.0078 & 0.0078 & 0.0074 & 0.0082 & 0.0078 & 0.0003 & 0.0003 & $\begin{array}{c}0.0078 \pm \\
0.0003 \\
\end{array}$ & 0.0069 & -11.7 & $-11.7 \pm 0.0003$ \\
\hline 0.1 & 2 & 0.78 & 1 & 0.0034 & 0.0034 & 0.0034 & 0.0034 & 0.0034 & 0.0000 & 0.0000 & $\begin{array}{c}0.0034 \pm \\
0.0000\end{array}$ & 0.0029 & -15.4 & $-15.4 \pm 0.0000$ \\
\hline 0.05 & 11 & 1.3 & 4 & 0.0054 & 0.0053 & 0.0053 & 0.0054 & 0.0054 & 0.0000 & 0.0000 & $\begin{array}{c}0.0054 \pm \\
0.0000\end{array}$ & 0.006 & 11.8 & $11.8 \pm 0.0000$ \\
\hline 0.05 & 4 & 1.3 & 2 & 0.0169 & 0.0168 & 0.0170 & 0.0169 & 0.0169 & 0.0001 & 0.0001 & $\begin{array}{c}0.0169 \pm \\
0.0001\end{array}$ & 0.0149 & -11.7 & $-11.7 \pm 0.0001$ \\
\hline
\end{tabular}

\begin{tabular}{|c|c|c|c|c|c|c|c|c|c|c|c|c|c|c|}
\hline $\begin{array}{l}\text { Pore } \\
\text { size } \\
{[\mu \mathrm{m}]}\end{array}$ & $\begin{array}{l}\text { Initial } \\
\text { TMP } \\
\text { [Psi] }\end{array}$ & $\begin{array}{c}\mathrm{C}_{\mathrm{f}} \\
{\left[\mathrm{kg} / \mathrm{m}^{3}\right]}\end{array}$ & $\begin{array}{c}\mathrm{Q} \\
{[\mathrm{LPM}]}\end{array}$ & $\begin{array}{c}\text { Exp } \\
\text { Increase } \\
\text { in TMP } \\
1 \\
\end{array}$ & $\begin{array}{c}\text { Exp } \\
\text { Increase } \\
\text { in TMP } \\
2 \\
\end{array}$ & $\begin{array}{c}\text { Exp } \\
\text { Increase } \\
\text { in TMP } \\
3 \\
\end{array}$ & $\begin{array}{c}\text { Exp } \\
\text { Increase } \\
\text { in TMP } \\
4 \\
\end{array}$ & $\begin{array}{c}\text { Exp } \\
\text { Increase } \\
\text { in TMP } \\
\text { Mean } \\
\end{array}$ & STDEV & $\mathrm{CF}$ & $\begin{array}{l}\text { Exp Increase } \\
\text { in TMP }\end{array}$ & $\begin{array}{c}\text { Increase } \\
\text { in } T M P \\
\text { Predicted }\end{array}$ & $\begin{array}{c}\text { Error } \\
\%\end{array}$ & Error \% \\
\hline 0.1 & 3 & 1.3 & 1 & 7 & 7.30 & 7.10 & 6.60 & 7 & 0.2550 & 0.2 & $7 \pm 0.2$ & 6.63 & -5.3 & $-5.3 \pm 0.2$ \\
\hline 0.1 & 4 & 1.3 & 2 & 20 & 21.00 & 22.00 & 17.00 & 20 & 1.8708 & 1.8 & $20 \pm 1.8$ & 18.69 & -6.6 & $-6.6 \pm 1.8$ \\
\hline 0.1 & 5 & 1.3 & 3 & 29 & 27.00 & 30.00 & 30.00 & 29 & 1.2247 & 1.2 & $29 \pm 1.2$ & 27.47 & -5.3 & $-5.3 \pm 1.2$ \\
\hline 0.1 & 4 & 1.82 & 1 & 8 & 8.00 & 10.00 & 6.00 & 8 & 1.4142 & 1.4 & $8 \pm 1.4$ & 7.58 & -5.2 & $-5.2 \pm 1.4$ \\
\hline 0.1 & 2 & 0.78 & 1 & 6 & 7.00 & 6.00 & 5.00 & 6 & 0.7071 & 0.7 & $6 \pm 0.7$ & 5.54 & -7.7 & $-7.7 \pm 0.7$ \\
\hline 0.05 & 11 & 1.3 & 4 & 5 & 6.00 & 4.00 & 5.00 & 5 & 0.7071 & 0.7 & $5 \pm 0.7$ & 4.7 & -6 & $-6 \pm 0.7$ \\
\hline 0.05 & 4 & 1.3 & 2 & 10 & 9.00 & 10.00 & 11.00 & 10 & 0.7071 & 0.7 & $10 \pm 0.7$ & 9.23 & -7.7 & $-7.7 \pm 0.7$ \\
\hline
\end{tabular}




\section{b) The model, including the particles sphericity}

\begin{tabular}{|c|c|c|c|c|c|c|c|c|c|c|c|c|c|c|}
\hline $\begin{array}{l}\text { Pore } \\
\text { size } \\
{[\mu \mathrm{m}]}\end{array}$ & $\begin{array}{l}\text { Initial } \\
\text { TMP } \\
{[\mathrm{Psi}]}\end{array}$ & $\begin{array}{c}\mathrm{C}_{\mathrm{f}} \\
{\left[\mathrm{kg} / \mathrm{m}^{3}\right]}\end{array}$ & $\begin{array}{c}\mathrm{Q} \\
{[\mathrm{LPM}]}\end{array}$ & $\begin{array}{c}\mathrm{m}_{\mathrm{t}} \operatorname{Exp} \\
1 \\
{\left[\mathrm{~kg} / \mathrm{m}^{2}\right]}\end{array}$ & $\begin{array}{c}\mathrm{m}_{\mathrm{t}} \operatorname{Exp} \\
2 \\
{\left[\mathrm{~kg} / \mathrm{m}^{2}\right]}\end{array}$ & $\begin{array}{c}\mathrm{m}_{\mathrm{t}} \operatorname{Exp} 3 \\
{\left[\mathrm{~kg} / \mathrm{m}^{2}\right]}\end{array}$ & $\begin{array}{c}\mathrm{m}_{\mathrm{t}} \operatorname{Exp} \\
4 \\
{\left[\mathrm{~kg} / \mathrm{m}^{2}\right]}\end{array}$ & $\begin{array}{l}\mathrm{m}_{\mathrm{t}} \operatorname{Exp} \\
\text { Mean } \\
{\left[\mathrm{kg} / \mathrm{m}^{2}\right]}\end{array}$ & STDEV & CF & $\begin{array}{l}\mathrm{m}_{\mathrm{t}} \operatorname{Exp} \\
{\left[\mathrm{kg} / \mathrm{m}^{2}\right]}\end{array}$ & $\begin{array}{c}\mathrm{m}_{\mathrm{t}} \\
{\left[\mathrm{kg} / \mathrm{m}^{2}\right]} \\
\text { Predicted }\end{array}$ & $\begin{array}{c}\text { Error } \\
\%\end{array}$ & Error \% \\
\hline 0.1 & 3 & 1.3 & 1 & 0.1206 & 0.1200 & 0.1206 & 0.1212 & 0.1206 & 0.0004 & 0.0004 & $\begin{array}{c}0.1206 \pm \\
0.0004\end{array}$ & 0.112 & -7.1 & $-7.1 \pm 0.0004$ \\
\hline 0.1 & 4 & 1.3 & 2 & 0.0294 & 0.0291 & 0.0297 & 0.0294 & 0.0294 & 0.0002 & 0.0002 & $\begin{array}{c}0.0294 \pm \\
0.0002\end{array}$ & 0.027 & -8.1 & $-8.1 \pm 0.0002$ \\
\hline 0.1 & 5 & 1.3 & 3 & 0.0495 & 0.0495 & 0.0491 & 0.0499 & 0.0495 & 0.0003 & 0.0003 & $\begin{array}{c}0.0495 \pm \\
0.0003\end{array}$ & 0.052 & 5.0 & $5.0 \pm 0.0003$ \\
\hline 0.1 & 4 & 1.82 & 1 & 0.0078 & 0.0078 & 0.0074 & 0.0082 & 0.0078 & 0.0003 & 0.0003 & $\begin{array}{c}0.0078 \pm \\
0.0003\end{array}$ & 0.0071 & -9.1 & $-9.1 \pm 0.0003$ \\
\hline 0.1 & 2 & 0.78 & 1 & 0.0034 & 0.0034 & 0.0034 & 0.0034 & 0.0034 & 0.0000 & 0.0000 & $\begin{array}{c}0.0034 \pm \\
0.0000\end{array}$ & 0.003 & -12.5 & $-12.5 \pm 0.0000$ \\
\hline 0.05 & 11 & 1.3 & 4 & 0.0054 & 0.0053 & 0.0053 & 0.0054 & 0.0054 & 0.0000 & 0.0000 & $\begin{array}{c}0.0054 \pm \\
0.0000\end{array}$ & 0.0057 & 6.2 & $6.2 \pm 0.0000$ \\
\hline 0.05 & 4 & 1.3 & 2 & 0.0169 & 0.0168 & 0.0170 & 0.0169 & 0.0169 & 0.0001 & 0.0001 & $\begin{array}{c}0.0169 \pm \\
0.0001\end{array}$ & 0.0154 & -8.7 & $-8.7 \pm 0.0001$ \\
\hline
\end{tabular}

\begin{tabular}{|c|c|c|c|c|c|c|c|c|c|c|c|c|c|c|}
\hline $\begin{array}{l}\text { Pore } \\
\text { size } \\
{[\mu \mathrm{m}]}\end{array}$ & $\begin{array}{l}\text { Initial } \\
\text { TMP } \\
\text { [Psi] }\end{array}$ & $\begin{array}{c}\mathrm{C}_{\mathrm{f}} \\
{\left[\mathrm{kg} / \mathrm{m}^{3}\right]}\end{array}$ & $\begin{array}{c}\mathrm{Q} \\
{[\mathrm{LPM}]}\end{array}$ & $\begin{array}{c}\text { Exp } \\
\text { Increase } \\
\text { in TMP } \\
1\end{array}$ & $\begin{array}{c}\text { Exp } \\
\text { Increase } \\
\text { in TMP } \\
2\end{array}$ & $\begin{array}{c}\text { Exp } \\
\text { Increase } \\
\text { in TMP } \\
3\end{array}$ & $\begin{array}{c}\text { Exp } \\
\text { Increase } \\
\text { in TMP } \\
4\end{array}$ & $\begin{array}{c}\text { Exp } \\
\text { Increase } \\
\text { in TMP } \\
\text { Mean }\end{array}$ & STDEV & $\mathrm{CF}$ & $\begin{array}{c}\text { Exp Increase } \\
\text { in TMP }\end{array}$ & $\begin{array}{l}\text { Increase } \\
\text { in } T M P \\
\text { Predicted }\end{array}$ & $\begin{array}{c}\text { Error } \\
\%\end{array}$ & Error \% \\
\hline 0.1 & 3 & 1.3 & 1 & 7 & 7.30 & 7.10 & 6.60 & 7 & 0.2550 & 0.2 & $7 \pm 0.2$ & 6.73 & -3.9 & $-3.9 \pm 0.2$ \\
\hline 0.1 & 4 & 1.3 & 2 & 20 & 21.00 & 22.00 & 17.00 & 20 & 1.8708 & 1.8 & $20 \pm 1.8$ & 18.99 & -5.1 & $-5.1 \pm 1.8$ \\
\hline 0.1 & 5 & 1.3 & 3 & 29 & 27.00 & 30.00 & 30.00 & 29 & 1.2247 & 1.2 & $29 \pm 1.2$ & 27.97 & -3.6 & $-3.6 \pm 1.2$ \\
\hline 0.1 & 4 & 1.82 & 1 & 8 & 8.00 & 10.00 & 6.00 & 8 & 1.4142 & 1.4 & $8 \pm 1.4$ & 7.68 & -4.0 & $-4.0 \pm 1.4$ \\
\hline 0.1 & 2 & 0.78 & 1 & 6 & 7.00 & 6.00 & 5.00 & 6 & 0.7071 & 0.7 & $6 \pm 0.7$ & 5.66 & -5.7 & $-5.7 \pm 0.7$ \\
\hline 0.05 & 11 & 1.3 & 4 & 5 & 6.00 & 4.00 & 5.00 & 5 & 0.7071 & 0.7 & $5 \pm 0.7$ & 4.81 & -3.8 & $-3.8 \pm 0.7$ \\
\hline 0.05 & 4 & 1.3 & 2 & 10 & 9.00 & 10.00 & 11.00 & 10 & 0.7071 & 0.7 & $10 \pm 0.7$ & 9.55 & -4.5 & $-4.5 \pm 0.7$ \\
\hline
\end{tabular}


Table J.5. Validation errors of the attachment model, incorporating the particles sphericity, applied to the heterogeneous Polysulfone membrane

a. The model did not include the particles sphericity

\begin{tabular}{|c|c|c|c|c|c|c|c|c|c|c|c|c|c|}
\hline $\begin{array}{c}\text { Initial } \\
\text { TMP } \\
{[\text { Psi] }}\end{array}$ & $\begin{array}{c}\mathrm{C}_{\mathrm{f}} \\
{\left[\mathrm{kg} / \mathrm{m}^{3}\right]}\end{array}$ & $\begin{array}{c}\mathrm{Q} \\
{[\mathrm{LPM}]}\end{array}$ & $\begin{array}{c}\mathrm{m}_{\mathrm{t}} \operatorname{Exp} \\
1 \\
{\left[\mathrm{~kg} / \mathrm{m}^{2}\right]}\end{array}$ & $\begin{array}{c}\mathrm{m}_{\mathrm{t}} \operatorname{Exp} \\
2 \\
{\left[\mathrm{~kg} / \mathrm{m}^{2}\right]}\end{array}$ & $\begin{array}{l}\mathrm{m}_{\mathrm{t}} \operatorname{Exp} 3 \\
{\left[\mathrm{~kg} / \mathrm{m}^{2}\right]}\end{array}$ & $\begin{array}{c}\mathrm{m}_{\mathrm{t}} \operatorname{Exp} \\
4 \\
{\left[\mathrm{~kg} / \mathrm{m}^{2}\right]}\end{array}$ & $\begin{array}{l}\mathrm{m}_{\mathrm{t}} \operatorname{Exp} \\
\text { Mean } \\
{\left[\mathrm{kg} / \mathrm{m}^{2}\right]}\end{array}$ & STDEV & CF & $\begin{array}{l}\mathrm{m}_{\mathrm{t}} \operatorname{Exp} \\
{\left[\mathrm{kg} / \mathrm{m}^{2}\right]}\end{array}$ & $\begin{array}{c}\mathrm{m}_{\mathrm{t}} \\
{\left[\mathrm{kg} / \mathrm{m}^{2}\right]} \\
\text { Predicted }\end{array}$ & $\begin{array}{c}\text { Error } \\
\%\end{array}$ & Error \% \\
\hline 25 & 0.78 & 4 & 0.0110 & 0.0112 & 0.0110 & 0.0108 & 0.0110 & 0.0001 & 0.0001 & $\begin{array}{c}0.0110 \\
\pm 0.0001\end{array}$ & 0.0096 & -12.7 & $-12.7 \pm 0.0001$ \\
\hline 25 & 1.30 & 4 & 0.0135 & 0.0135 & 0.0137 & 0.0131 & 0.0135 & 0.0002 & 0.0002 & $\begin{array}{c}0.0135 \\
\pm 0.0002\end{array}$ & 0.0146 & 8.1 & $8.1 \pm 0.0002$ \\
\hline 25 & 1.82 & 4 & 0.0167 & 0.0166 & 0.0167 & 0.0168 & 0.0167 & 0.0001 & 0.0001 & $\begin{array}{c}0.0167 \\
\pm 0.0001\end{array}$ & 0.0187 & 12.0 & $12.0 \pm 0.0001$ \\
\hline 15 & 1.30 & 4 & 0.0114 & 0.0117 & 0.0112 & 0.0114 & 0.0114 & 0.0002 & 0.0002 & $\begin{array}{c}0.0114 \\
\pm 0.0002\end{array}$ & 0.0103 & -9.7 & $-9.7 \pm 0.0002$ \\
\hline 35 & 1.30 & 4 & 0.0178 & 0.0180 & 0.0178 & 0.0176 & 0.0178 & 0.0001 & 0.0001 & $\begin{array}{c}0.0178 \\
\pm 0.0001 \\
\end{array}$ & 0.0195 & 9.6 & $9.6 \pm 0.0001$ \\
\hline 25 & 1.30 & 1 & 0.0195 & 0.0195 & 0.0190 & 0.0110 & 0.0195 & 0.0036 & 0.0035 & $\begin{array}{c}0.0195 \\
\pm 0.0035\end{array}$ & 0.0177 & -9.2 & $-9.2 \pm 0.0035$ \\
\hline
\end{tabular}

\begin{tabular}{|c|c|c|c|c|c|c|c|c|c|c|c|c|c|}
\hline $\begin{array}{l}\text { Initial } \\
\text { TMP } \\
\text { [Psi] }\end{array}$ & $\begin{array}{c}\mathrm{C}_{\mathrm{f}} \\
{\left[\mathrm{kg} / \mathrm{m}^{3}\right]}\end{array}$ & $\begin{array}{c}\mathrm{Q} \\
{[\mathrm{LPM}]}\end{array}$ & $\begin{array}{c}\text { Exp } \\
\text { Increase } \\
\text { in TMP } \\
1\end{array}$ & $\begin{array}{c}\text { Exp } \\
\text { Increase } \\
\text { in TMP } \\
2\end{array}$ & $\begin{array}{c}\text { Exp } \\
\text { Increase } \\
\text { in TMP } \\
3\end{array}$ & $\begin{array}{c}\text { Exp } \\
\text { Increase } \\
\text { in TMP } \\
4\end{array}$ & $\begin{array}{c}\text { Exp } \\
\text { Increase } \\
\text { in TMP } \\
\text { Mean }\end{array}$ & STDEV & CF & $\begin{array}{c}\text { Exp } \\
\text { Increase } \\
\text { in TMP }\end{array}$ & $\begin{array}{c}\text { Increase } \\
\text { in } T M P \\
\text { Predicted }\end{array}$ & $\begin{array}{c}\text { Error } \\
\%\end{array}$ & Error \% \\
\hline 25 & 0.78 & 4 & 3 & 3.2 & 2.8 & 3 & 3 & 0.1414 & 0.1 & $3 \pm 0.1$ & 3.32 & 10.7 & $10.7 \pm 0.1$ \\
\hline 25 & 1.30 & 4 & 5.5 & 5.6 & 5.5 & 5.4 & 5.5 & 0.0707 & 0.1 & $5.5 \pm 0.1$ & 6.14 & 11.6 & $11.6 \pm 0.1$ \\
\hline 25 & 1.82 & 4 & 7 & 7 & 6.8 & 7.2 & 7 & 0.1414 & 0.1 & $7 \pm 0.1$ & 7.77 & 11.0 & $11.0 \pm 0.1$ \\
\hline 15 & 1.30 & 4 & 3.5 & 3.3 & 3.5 & 3.7 & 3.5 & 0.1414 & 0.1 & $3.5 \pm 0.1$ & 3.18 & -9.1 & $-9.1 \pm 0.1$ \\
\hline 35 & 1.30 & 4 & 7.5 & 7.7 & 7.3 & 7.5 & 7.5 & 0.1414 & 0.1 & $7.5 \pm 0.1$ & 8.23 & 9.7 & $9.7 \pm 0.1$ \\
\hline 25 & 1.30 & 1 & 8 & 8 & 8.2 & 7.8 & 8 & 0.1414 & 0.1 & $8 \pm 0.1$ & 7.35 & -8.1 & $-8.1 \pm 0.1$ \\
\hline
\end{tabular}




\section{b. The model, including the particles sphericity}

\begin{tabular}{|c|c|c|c|c|c|c|c|c|c|c|c|c|c|}
\hline $\begin{array}{l}\text { Initial } \\
\text { TMP } \\
\text { [Psi] }\end{array}$ & $\begin{array}{c}\mathrm{C}_{\mathrm{f}} \\
{\left[\mathrm{kg} / \mathrm{m}^{3}\right]}\end{array}$ & $\begin{array}{c}\mathrm{Q} \\
{[\mathrm{LPM}]}\end{array}$ & $\begin{array}{c}\mathrm{m}_{\mathrm{t}} \operatorname{Exp} \\
1 \\
{\left[\mathrm{~kg} / \mathrm{m}^{2}\right]}\end{array}$ & $\begin{array}{c}\mathrm{m}_{\mathrm{t}} \operatorname{Exp} \\
2 \\
{\left[\mathrm{~kg} / \mathrm{m}^{2}\right]}\end{array}$ & $\begin{array}{l}\mathrm{m}_{\mathrm{t}} \operatorname{Exp} 3 \\
{\left[\mathrm{~kg} / \mathrm{m}^{2}\right]}\end{array}$ & $\begin{array}{c}\mathrm{m}_{\mathrm{t}} \operatorname{Exp} \\
4 \\
{\left[\mathrm{~kg} / \mathrm{m}^{2}\right]}\end{array}$ & $\begin{array}{c}\mathrm{m}_{\mathrm{t}} \operatorname{Exp} \\
\text { Mean } \\
{\left[\mathrm{kg} / \mathrm{m}^{2}\right]}\end{array}$ & STDEV & $\mathrm{CF}$ & $\begin{array}{l}\mathrm{m}_{\mathrm{t}} \operatorname{Exp} \\
{\left[\mathrm{kg} / \mathrm{m}^{2}\right]}\end{array}$ & $\begin{array}{c}\mathrm{m}_{\mathrm{t}} \\
{\left[\mathrm{kg} / \mathrm{m}^{2}\right]} \\
\text { Predicted }\end{array}$ & $\begin{array}{c}* \text { Error } \\
\%\end{array}$ & *Error \% \\
\hline 25 & 0.78 & 4 & 0.0110 & 0.0112 & 0.0110 & 0.0108 & 0.0110 & 0.0001 & 0.0001 & $\begin{array}{c}0.0110 \\
\pm 0.0001 \\
\end{array}$ & 0.0095 & -13.6 & $-13.6 \pm 0.0001$ \\
\hline 25 & 1.30 & 4 & 0.0135 & 0.0135 & 0.0137 & 0.0131 & 0.0135 & 0.0002 & 0.0002 & $\begin{array}{c}0.0135 \\
\pm 0.0002 \\
\end{array}$ & 0.0145 & 7.4 & $7.4 \pm 0.0002$ \\
\hline 15 & 1.30 & 4 & 0.0114 & 0.0117 & 0.0112 & 0.0114 & 0.0114 & 0.0002 & 0.0002 & $\begin{array}{c}0.0114 \\
\pm 0.0002\end{array}$ & 0.0104 & -8.8 & $-8.8 \pm 0.0002$ \\
\hline 35 & 1.30 & 4 & 0.0178 & 0.0180 & 0.0178 & 0.0176 & 0.0178 & 0.0001 & 0.0001 & $\begin{array}{c}0.0178 \\
\pm 0.0001 \\
\end{array}$ & 0.0197 & 10.7 & $10.7 \pm 0.0001$ \\
\hline 25 & 1.30 & 1 & 0.0195 & 0.0195 & 0.0190 & 0.0110 & 0.0195 & 0.0036 & 0.0035 & $\begin{array}{c}0.0195 \\
\pm 0.0035 \\
\end{array}$ & 0.0176 & -9.7 & $-9.7 \pm 0.0035$ \\
\hline
\end{tabular}

\begin{tabular}{|c|c|c|c|c|c|c|c|c|c|c|c|c|c|}
\hline $\begin{array}{l}\text { Initial } \\
\text { TMP } \\
\text { [Psi] }\end{array}$ & $\begin{array}{c}\mathrm{C}_{\mathrm{f}} \\
{\left[\mathrm{kg} / \mathrm{m}^{3}\right]}\end{array}$ & $\begin{array}{c}\mathrm{Q} \\
{[\mathrm{LPM}]}\end{array}$ & $\begin{array}{c}\text { Exp } \\
\text { Increase } \\
\text { in TMP } \\
1\end{array}$ & $\begin{array}{c}\text { Exp } \\
\text { Increase } \\
\text { in TMP } \\
2\end{array}$ & $\begin{array}{c}\text { Exp } \\
\text { Increase } \\
\text { in TMP } \\
3\end{array}$ & $\begin{array}{c}\text { Exp } \\
\text { Increase } \\
\text { in TMP } \\
4\end{array}$ & $\begin{array}{c}\text { Exp } \\
\text { Increase } \\
\text { in TMP } \\
\text { Mean }\end{array}$ & STDEV & $\mathrm{CF}$ & $\begin{array}{c}\text { Exp } \\
\text { Increase } \\
\text { in TMP }\end{array}$ & $\begin{array}{c}\text { Increase } \\
\text { in } T M P \\
\text { Predicted }\end{array}$ & $\begin{array}{c}* \text { Error } \\
\%\end{array}$ & *Error \% \\
\hline 25 & 0.78 & 4 & 3 & 3.2 & 2.8 & 3 & 3 & 0.1414 & 0.1 & $3 \pm 0.1$ & 3.29 & 9.7 & $9.7 \pm 0.1$ \\
\hline 25 & 1.30 & 4 & 5.5 & 5.6 & 5.5 & 5.4 & 5.5 & 0.0707 & 0.1 & $5.5 \pm 0.1$ & 6.15 & 11.8 & $11.8 \pm 0.1$ \\
\hline 25 & 1.82 & 4 & 7 & 7 & 6.8 & 7.2 & 7 & 0.1414 & 0.1 & $7 \pm 0.1$ & 7.75 & 10.7 & $10.7 \pm 0.1$ \\
\hline 15 & 1.30 & 4 & 3.5 & 3.3 & 3.5 & 3.7 & 3.5 & 0.1414 & 0.1 & $3.5 \pm 0.1$ & 3.18 & -9.1 & $-9.1 \pm 0.1$ \\
\hline 35 & 1.30 & 4 & 7.5 & 7.7 & 7.3 & 7.5 & 7.5 & 0.1414 & 0.1 & $7.5 \pm 0.1$ & 8.25 & 10.0 & $10.0 \pm 0.1$ \\
\hline 25 & 1.30 & 1 & 8 & 8 & 8.2 & 7.8 & 8 & 0.1414 & 0.1 & $8 \pm 0.1$ & 7.34 & -8.3 & $-8.3 \pm 0.1$ \\
\hline
\end{tabular}




\section{REFERENCES}

Abulencia, J.P., Theodore, L. (2009) Fluid flow for practicing chemical engineering. John Wiley\& sons,Inc.

Ahmad, A.L., Chong, M., Bhatia, S. (2006) Ultrafiltration modeling of multiple solutes system for continuous cross-flowprocess. Chemical Engineering Science. 61 (15), 5057-5069.

Akbari, B., Tavandashti, M., Zandrahimi, M. (2011) Particle Size Characterization Of Nanoparticles - A PRACTICAL APPROACH, Iranian Journal of Materials Science \& Engineering. 8, , 48-56

Al-Amoudi,A., Lovitt, R.W. (2007) Fouling strategies and the cleaning system of NF membranes and factors affecting cleaning efficiency. Journal of Membrane Science. 303, 4-28

Avlonitis, S.A. , Kouroumbas, K., Vlachakis, N. (2003) Energy consumption and membrane replacement cost for seawater RO desalination plant. Desalination. 157,151-158.

Bahnasawy, A. H., Shenana, M. E. (2010) Flux behavior and energy consumption of Ultrafiltration (UF) Process of milk. Australian Journal of Agriculture Engineering. 15, 54-65.

Bedasie, R., Doan, H., Lohi, A. (2010) An investigation into the fouling phenomena of polycarbonate membranes used in the treatment of latex paint wastewater. M. Sc. Thesis.

Belfort, G.R.H. , Zydney, A.L. (1994) The behavior of suspensions and macromolecular solutions in crossflow microfiltration. Journal of Membrane Science, 96, 1-58.

Benitez, F., Acero, J., Leal, A., Gonzalez, M. (2009) The use of ultrafiltration and nanofiltration membranes for the purification of cork processing wastewater. Journal of Hazardous materials. $162,1438-1445$.

Bhattacharjee, C., Datta, S. (2003) Analysis of polarized layer resistance during ultrafiltration of PEG-6000: an approach based on filtration theory. Separation and Purification Technology. 33 (2) ,115-126.

Binks, B.P. , Horozov, T.S. (2006) Colloidal particles at liquid interfaces, Cambridge University Press, Cambridge.

Bowen, W. , Calvo, J., Hernández, A. (1995) Steps of membrane blocking in flux decline during protein microfiltration. Journal of Membrane Science. 101 (1-2) ,153-165.

Bruijn, J.P.F. , Salazar, F.N. , Borquez, R. (2005) Membrane blocking in ultrafiltration, a new approach to fouling. Institution of Chemica. Engineering. 83, 211-219.

Byhlin, H. A., Jonsson, A. S. (2002). Influence of adsorption and concentration polarisation on membrane performance during ultrafiltration of a non-ionic surfactant. Desalination.151 , 21-31 
Calatayud, M. , Vela, M. , Blanco, S. , García, J. , Rodríguez, E. (2010) Analysis and optimization of the influence of operating conditions in the ultrafiltration of macromolecules using a response surface methodological Approach. Chemical Engineering Journal. 156, 337346.

Caothien , S., O’Connell , P. (2002).Reducing Fouling and the Cost of Membrane Systems.

Carroll, T., Booker, N.A. \& Meier-Haack, J. (2002) Polyelectrolyte-grafted microfiltration membranes to control fouling by natural organic matter in drinking water. Journal of Membrane Science. 203(1-2), 3-13.

Chang, Y., Shih, Y., Ruaan, R., Higuchi, A., Chenb, W. \& Lai, J. (2008) Biofouling-resistance expanded poly(tetrafluoroethylene) membrane with a hydrogel-like layer of surface-immobilized poly(ethylene glycol) methacrylate for human plasma protein repulsions. Journal of Membrane Science. 309, 165-174.

Chellam, S., Jacangelo, J.G., Bonacquisti, T.P. (1998) Modeling and experimental verification of pilot-scale hollow fiber, direct flow microfiltration with periodic backwashing. Environmental Science \& Technology. 32(1), 75-81.

Childress, A.E. , Elimelesh, M. (1996) Effect of solution chemistry on the surface charge of polymeric reverse osmosis and nanofiltration membranes. Journal of membrane science. 119, 253-268.

Childress, A.E., Elimelech, M., (2000). Relating nanofiltration membrane performance to membrane charge (electrokinetic) characteristics. Environmental Science and Technology. 34, 3710 .

Chun, M. , Cho, H., Song, I. K. (2002) Electrokinetic behavior of membrane zeta potential during the filtration of colloidal suspensions. Desalination. 148, 363-368.

Colic, M., Morse, W., Hicks,J. (2007) Reuse of California brine olive oil processing wastewater to meet zero discharge goal. Clean Water Technology, Inc. WEFTEC 2007, San Diego, CA; October 17, 2007.

Cuperus, F. P., Smolders, C. A. (1991) Characterization of Ultrafiltration. Advances in colloid \& interface science. $34,135-173$.

Davis, R.H. (1992) Modelling of fouling of crossflow microfiltration membranes. Separation and Purification Reviews. 21(2), 75-126.

Dey, B.K. „Hashim, M.A., Hasan, S., Gupta, B. S. (2004) Microfiltration of water-based paint effluents. Advances in Environmental Research. 8 (3-4) , 455-466. 
Deshrnukh , S. S., Childress, A. E. (2001) Zeta potential of commercial RO membranes:influence of source water type and chemistry. Desalination. 140, 87-95.

Douglas, A., Skoog, F., James, H., Stanley R. C. (2007) Principles of instrumental analysis, Belmont, CA, Thomson Brooks, $6^{\text {th }}$ ed.

Endo, Y., Alonso, M. (2001) Physical meaning of specific cake resistance and effects of cake properties in compressible cake filtration. Filtration and Separation. (9), 43-46.

Elimelech, M., Chen, W., Waypa, J. (2010) Measuring zeta (electrokinetic) potential of reserve osmosis membrane. Desalination. 95, 269-286.

Faibish, R., Elimelech, M., Cohen, Y. (1998) Effect of interparticle electrostatic double layer interactiosn on permeate flux decline in cross flow membrane filtration of colloidal suspension. Journal of Colloid and interface science. 204, 77-86.

Fainerman, V.B.,Mobius, D., Miller, R. (2001) Surfactants: Chemistry, Interfacial, properties, applications. Elsevier Science B.V.

Foley, G. (2006).A review of factors affecting filter cake properties in dead-end microfiltration of microbial suspensions. Journal of Membrane Science, 274, 38-46.

Gatenholm, P., Ashida, Y., Hoffman, A.S. (1997) Hydrid biomaterials prepared by ozoneinduced polymerization Ozonization of microporous polypropylene. Journal of Polymer Science. 35, 1461-1467.

Granger, J., Leclerc, D., Dodds, J.A. (1985) Filtration of dilute suspensions of latexes. Filtration and Separation. 22, 58-60.

Grathwohl, P. (1998) Diffusion in Natural Porous Media : Contaminant transport, sorption / desorption and dissolution kinetics. Kluwer Academic Publisher.

Gregory, J. (2005) Particles in Water: Properties and Processes, Taylor \& Francis Group, CRC Press, UK, p.63-70.

Gu, H., Wu,J., Chan, P., Turcotte, G., Ye, T. (2012) Hydrophilicity modification of polypropylene microfiltration membrane by ozonation. Chemical Engineering Research and Design. 90, 229-237.

Gu,H., Wu,J. \& Doan, H. (2009) Hydrophilicity enhancement of high denisity polyethylene film by ozonation. Chemical Engineering Technology. 32, 5,726-731.

Gullinkala, T., Escobar, I. (2008) Study of the hydrophilic-enhanced ultrafiltration membrane. Environmental Program . 27, 210-217. 
Hamachi, M., Peuchot, M. (1999) Experimental investigations of cake characteristics in cross flow microfiltration. Chemical Engineering Science. 54 , 4023- 4030.

Hermia, J. (1982) Constant pressure blocking filtration laws: application to power-law nonnewtonian fluids. Chemical Engineering Research and Design. 60, 183-186.

Hester, J.F., Mayes, A.M. (2002) Design and performance of foul-resistant poly (vinylidene fluoride) membranes prepared in a single-step by surface segregation. Journal of Membrane Science. 202(1-2), 119-135.

Ho, C.C., Zydney, A.L.(2002) Transmembrane pressure profiles during constant flux microfiltration of bovine serum albumin. Journal of Membrane Science. 209(2) , 363-377.

Hoigne, J. ,Bader, H., (1976). The role of hydroxyl radical reactions in ozonation processes in aqueous solutions. Water Research. 10, 377-386.

Hu, A., Stuckey, D. (2006) Treatment of Dilute Wastewaters Using a Novel Submerged Anaerobic Membrane Bioreactor. Journal of Environmental Engineering.132 (2), 190-198

Hua, H., Li, N., Wu, L., Zhong, H. \& Tang, L. (2008) Anti-fouling ultrafiltration membrane prepared from polysulfone-graft-methyl acrylate copolymers by UV-induced grafting method. Journal of Environmental Science. 20, 565-570.

Huang, H., Young, T.A., Jacangelo, J. G. (2008) Unified membrane fouling index for low pressure membrane filtration of natural waters: principles and methodology. Environmental Science and Technology. $42,714-720$.

Huanga, J., Guoa, S., Zenga, G., Xionga, Y., Zhanga, D., Tanga, X., Xiea, G. (2012) Prediction of fouling resistance and permeate flux in cross-flow micellar-enhanced ultrafiltration (MEUF). Colloids and Surfaces A: Physicochem. Eng. Aspects. 401,81- 89.

Hwang, K.J., Liao, C.Y. , Tung, K.L. (2007) Analysis of particle fouling during microfiltration by use of blocking models. Journal of Membrane Science. 287 , 287-293.

Hwang, K., Lin, T. (2002) Effect of morphology of polymeric membrane on the performance of cross-flow microfiltration. Journal of Membrane Science. 199 (1-2),41-52.

Israelachvili, J. (1992) Intermolecular \& surface forces. 2nd ed., Academic Press Inc., San Diego, CA 92101, USA 450.

Javacek, M. H., Bouchet, F. (1993) Constant flow rate blocking laws and an example of their application to dead-end microfiltration of protein solutions. Journal of Membrane Science. 82, 285-295.

Jones, K. L., O’Melia, C.R. (2000) Protein and humic acid adsorption onto hydrophilic membrane surfaces: effects of $\mathrm{pH}$ and ionic strength. Journal of Membrane Science. 165 , 31-46 
Jurado, J., Bellhouse, B.J. (1994) Application of electrical fields and vortex mixing for enhanced ultrafiltration. Filtration and Separation. 268, 273-280

Keesom, W.H., Zelenka, R.L., Radke, C. J. (1988) A Zeta-Potential Model for Ionic Surfactant Adsorption on an Ionogenic Hydrophobic Surface. Journal of Colloid and Interface Science. 125 (2), 575-585.

Kennedy, M., Kamanyi, J., Rodriguez, S., Lee, N., Schippers, J. , Amy, G. (2008) Water Treatment by microfiltration and ultrafiltration. Advanced Membrane Technology and Applications. 131-170.

Kim, A.S., Hoek, E.M.V. (2002) Cake structure in dead-end membrane filtration: Monte Carlo simulations. Environmental Engineering Science. 19(6), 373-386.

Knops, F. , Futselaar, H. (1992) The transversal flow microfiltration module. Theory, design, realization and experiments. Journal of Membrane Sctence. 73, 153-161

Körbahti,B., Aktaş, N. , Tanyolaç, A. (2007) Optimization of electrochemical treatment of industrial paint wastewater with response surface methodology. Journal of Hazardous Materials. $148(1-2), 83-90$.

Kosvintsev, S. , Cumming, I.W. , Holdich, R.G. , Lloyd D., Starov, V.M. (2004) Sieve mechanism of microfiltration separation. Colloids and Surfaces: Physicochemical and Engineering Aspects. 230, 167-182.

Kosvintsev, S., Holdich, R.G., Cumming, I.W. , Starov, V.M. (2002) Modelling of dead-end microfiltration with pore blocking and cake formation. Journal of Membrane Science. 208, 181192.

Kotlarchyk, M. , Chen, S. -H., (1983) Analysis of small angle neutron scattering spectra from polydisperse interacting colloids. Jouranl of Chemical Physics. 79,2461-2469.

Kurt, U., Avsar, Y., Gonullu, M. T. (2006) Treatability of water-based paint wastewater with Fenton process in different reactor types. Chemosphere. 64 (9) , 1536-1540.

Lambert, J. B., Shurvell, H. F., Verbit, L. , Cooks, R. G. , Stout, G. H. ( 1967) Organic Structural Analysis, Macmillan Publishing Co. Inc. , New York, USA.

Li, N., Fane, A.G., Winston, W.S., Matsuura, T. (2008) Advanced Membrane Technology and applications, John Wiley\& sons Inc.

Liu, Y., Chen, W.-R. , Chen, S.-H., (2005) Cluster formation in two-Yukawa fluids. Journal of Chemical Physics. 122,044507. 
Liu, Z.M., Xu, Z.K., Wang, J.Q., Yang, Q., Wu, J. , Seta, P. (2003) Surface modification of microporous polypropylene membranes by the grafting of poly(gamma-stearyl- L-glutamate). European Polymer Journal. 39(12), 2291-2299.

Lozier, J., Jacangelo, A. (2002) Where we are head ? - the future of membrane treatement, in Proceedings of Water Quality Rechnology Conference, November 10-14, 2002, Seattle, WA

Mendret J, Guigui C, Cabassud C. (2010) Numerical investigation of the effect of non-uniform membrane permeability on the deposit formation and filtration process. Desalination. 263, 122132.

Mika, M., Arto, P. Marianne, N. (2006) Effect of $\mathrm{pH}$ on hydrophilicity and charge and their effect on the filtration efficiency of NF membranes at different $\mathrm{pH}$. Journal of membrane science. 280, 311-320.

Mikultiek, P. , Cakl, J. (1994) Removal of industrial latex dispersions from waste waters using microporous alumina membranes. Desalination. 95, 211-220

Mohanty,K., Purkait,M.K. (2012) Membrane Technology and applications. Taylor \& Francis group, ISBN 978-1-4398-0526-8.

Montgomery, D.C. (1997) Design and Analysis of Experiment, fifth edition, Wiley, Inc., New York, USA.

Morrow, D., Piwoni, M. (1993) LAS aquatic toxicity and biodegradation. Waste Management and Research Centre Reports, TN93-029.

Mukerjee, P., Mysels, K. (1971).Critical Micelle Concentration of Aqueous Surfactant Systems. Washington, D.C.: US. Government Printing Office.

Nal, J., Yonggang, Z. (2012) The Effect of Humic Acid on Ultrafiltration Membrane Fouling, International Conference on Computer Technology and Science (ICCTS2012), IPCSIT 47, IACSIT Press, Singapore.

Nikkola J., Sievänen J., Raulio M., Wei J., Vuorinen J., and Tang, C. (2014) Surface modification of thin film composite polyamide membrane using atomic layer deposition method. Journal of Membrane Science. 450,174-180.

Noble, R.D. \& Stern, S. A. (1995) Membrane separation technology principles and applications .Elsevier Science B.V., 46-83.

Paris, J., Guichardon, P. , Charbit, F. (2002) Transport phenomena in ultrafiltration: a new twodimensional model compared with classical models. Journal of Membrane Science. 207, 43-58. 
Patel, D., Wu, J., Chan, P., Upreti, S., Turcotte, G., Ye,T. (2012) Surface modification of low density polyethylene films by homogeneous catalytic ozonation. Chemical Engineering Research and Design.90(11), 1800-1806.

Polyakov, Y.S., Zydney, A.L. (2013) Ultrafiltration membrane performance: Effects of pore blockage/constriction. Journal of Membrane Science. 434, 106-120.

Rodriguez, J.M., Johansson, J.M.A., Edeskär, T. (2012) Particle Shape Determination by TwoDimensional Image Analysis in Geotechnical Engineering, Site investigation and laboratory testing - Particle Shape Determination by Two-Dimensional Image Analysis in Geotechnical Engineering.

Romero, C., Davis, R. (1999) Transient model of cross flow microfiltration. Chemical Engineering Science. 45(1), 13-25.

Russell, D. (2006) Practical Wastewater Treatment. John Wiley \& Sons Inc.

Salahi, A., Abassi, M. , Mohammadi, T. (2010) Permeate flux decline during UF of oily wastewater: experimental and modelling. Desalination. 251 , 153-160.

Salahi, A., Mohammedi, T., Pour, A. \& Rekabdar, F. (2000) Oily wastewater treatment using ultrafiltration. Desalination. 6,289-298.

Schmid, B., Schindelin, J., Cardona, A., Longair, M., Heisenberg, M. (2010) A high level 3D visualization API for Java and ImageJ, BMC Bioinformatics. 11,274.

Sheskin, D. J. (2011) Handbook of Parametric and Nonparametric Statistical Procedures, Fourth Edition, ISBN:1584888148.

Singh, G. , Song, L. (2005) Quantifying the effect of ionic strength on colloidal fouling potential in membrane filtration. Journal of Colloid and Interface Science. 284, 630-638.

Song, L. (1998) Flux decline in crossflow microfiltration and ultrafiltration: mechanism and modellingof membrane fouling. Journal of Membrane Science. 139, 183-200.

Song, L., Elimelech, M. (1995) Theory of concentration polarization in cross flow filtration. Journal of the Chemical Society. 91(19), 3389-3398.

Spinette, R., Charles, C. (2008) Impact of particle stabilities and size. Journal of Membrane Science. 31490-100.

Srebnik, S. (2003) Polymer adsorption on multi component surfaces with relevance to membrane fouling. Chemical Engineering Science. 58(23-24), 5291-5298.

Sui Y., Wang, Z., Gao, C., Wan, Q., Zhu, L. (2012) An investigation on the antifouling ability of PVDF membranes by polyDOPA coating. Desalination and Water Treatment. 50,22-33. 
Suman, D., Projjwal, S., Chiranjib, B., Siddhartha, D. (2012) Performance comparison of rotating disk ultrafiltration membrane module, a high shear device with cross-flow module International. Journal of Environment and Pollution. 49( 3-4), 197-209

Svergun, D.I., Koch, M.H.J. (2003) Small-angle scattering studies of biological macromolecules in solution. Reports on Progress in Physics. 66,1735-1782

Taniguchi, M., Kilduff, J.E., Belfort, G. (2003) Low fouling synthetic membranes by UVassisted graft polymerization: monomer selection to mitigate fouling by natural organic matter. Journal of Membrane Science. 222, 59-70.

Tchobanoglous, G., Burton, F.,Stensel, H. (2003) Wastewater engineering:Treatment and Reuse., McGraw-Hill.

Teuler, A.K., Glucina, J.M. (2003) Assessment of UF pre-treatment prior RO membranes for seawater desalination. Desalination. 125, 89-96.

Um, M., Yoon, S., Lee, C., Chung, K. \& Kim, J. (2001) Flux enhancement with gas injection in crossflow ultrafiltration of oily wastewater. Water Research. 35(17), 4095-4101.

Vela, M.C.V., Blanco, S.A., Garcia, J.L. , Rodríguez, E.B. (2008) Analysis of membrane pore blocking models applied to the ultrafiltration of PEG. Separation and Prurification Technology. $62(3), 489-498$.

Viadero, R.C., Vaughan R.L., Reed, B.E. (1999) Study of series resistances in high-shear rotary ultrafiltration. Journal of Membrane Science. 162, 199-211.

Vyas, H.K., Bennett, R.J. ,Marshall, A.D. (2000) Influence of feed properties on membrane fouling in crossflow microfiltration of particulate suspension. International Dairy Journal. 10, $855-861$

Wang, Y., Kim, J., Choo, K., Lee, Y. , Lee, C. (2000) Ozone-induced graft polymerization onto polymer surface. Journal of Membrane Science.169, 269-276.

Wang, F., Tarabara, V.V. (2008) Pore blocking mechanisms during early stages of membrane fouling by colloids.Journal of Colloid and Interface Science. 328 (2), 464-469.

Wavhal, D.S., Fisher, E.R. (2003) Membrane surface modification by plasma induced polymerization of acrylamide for improved surface properties and reduced protein fouling. Langmuir. 19(1), 79-85.

Wang, L.K., Chen, J.P., Hung, Y.-T., Shammas, N.K. (2011) Membrane and Desalination Technologies, Springer, DOI. 10.1007/978-1-59745-278-6.

Winzeler, H. B., Belfort, G. (1993) Enhanced performance for pressure-driven membrane processes: the argument for fluid instabilities. Journal of Membrane Science. 80, 35-47. 
Xiao, K. , Wang, X. , Huang, X., Waite, T. D., Wen, X. (2011) Combined effect of membrane and foulant hydrophobicity and surface charge on adsorptive fouling during microfiltration. Journal of Membrane Science. 373, 140-151.

Yu, H.Y., Xie, Y.J., Hu, M.X., Wang, J.L., Wang, S.Y., Xu, Z.K. (2005) Surface modification of polypropylene microporous membranes to improve its antifouling property in MBR: CO2 plasma treatment. Journal of Membrane Science. 254(1-2), 219-227.

Yuan, W., Kocic, A., Zydney, A.L. (2002) Analysis of humic acid fouling during microfiltration using a pore blockage-cake filtration model. Journal of Membrane Science. 198(1), 51-62.

Yuan, Y., Ai, F., Zhang, J., Zhang, X., Shen, J. , Lin, S. (2002) Grafting sulfobetaine monomer onto the segmented poly(ether-urethane) surface to improve hemocompatibility. Journal Of Biomaterials Science Polymer Edition. 13, 1081-1092.

Yuliwati, E.,Ismail, A.F. , Lau, W.J., Ng, B.C., Mataram, A.,Kassim, M.A. (2012) Effects of process conditions in submerged ultrafiltration for refinery wastewater treatment: Optimization of operating process by response surface methodology. Desalination. 287 , 350-361.

Zhang, M., Song, L. (2000) Mechanisms and parameters affecting flux decline in cross-flow microfiltration and ultrafiltration of colloids. Environmental Science \& Technology. 34(17), 3767-3773.

Zuo, G., Wan, R. (2013) Novel membrane surface modification to enhance anti-oil fouling property for membrane distillation application. Journal of Membrane Science. 447, 26-35. 